\title{
Poeira e Campo Magnético em Regiões Densas do Meio Interestelar
}

\author{
Antonio Armstrong Pereyra Quirós
}

Tese de doutorado, sob orientação de:

Prof. Dr. Antônio Mário Magalhães

Instituto Astronômico e Geofísico

Universidade de São Paulo

Abril de 2000 

A mis padres. 



\section{Tabela de Conteúdos}

Agradecimentos

Sumário

Abstract

\section{Introdução}

\subsection{Resumo}

1.2 Polarização Interestelar

1.2.1 Grãos não-esféricos

1.2.2 Dependência da polarização com o avermelhamento

1.2.3 Dependência espectral da Polarização Interestelar

1.2.4 Alinhamento de grãos

1.2.5 Campo Magnético e Dispersão do Ângulo de Polarização

1.2.6 Campo Magnético e Nuvens Escuras

\section{Polarimetria de Imagem com CCD}

2.1 Resumo

2.2 Análise da luz polarizada linearmente

2.3 A Gaveta Polarimétrica IAGUSP

2.3.1 Descrição da Gaveta Polarimétrica IAGUSP 19

2.3.2 Programa de controle $\quad 21$

2.4 Pacote de redução de Imagens Polarimétricas - PCCDPACK 23

2.4.1 Criando uma arquivo de coordenadas ordenado - ORDEM 24

2.4.2 Corrigindo os deslocamentos entre imagens - COORSHIFT 25

2.4.3 Fotometria das Imagens 26

2.4.4 Calculando os parâmetros polarimétricos - PCCD 26

2.4.5 Escolhendo a abertura com menor erro - MACROL 26

2.4.6 Análise dos dados polarimétricos - SELECT

2.4.7 Graficando a modulação da polarização - GRAF

2.4.8 Calculando magnitudes da polarimetria - MAGNIT 30

2.4.9 Criando um mapa de polarização - REFER e VECPLOT 31

2.4.10 Criando um catálogo polarimétrico - FINTAB 32

\section{Polarimetria, Extinção e Campo Magnético na Nuvem Escura de Musca}

3.1 Resumo 233

$\begin{array}{ll}3.2 & \text { Introdução } \\ 3.3 & \text { Polation }\end{array}$

3.3 Polarimetria Óptica $\quad 36$

3.3.1 Observações $\quad 36$

3.3.2 Dados Polarimétricos

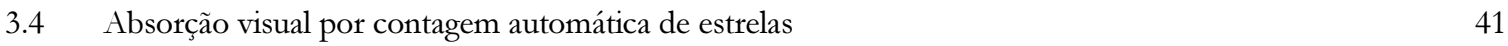

3.4.1 A Técnica

3.4.2 Análise da extinção e massas

3.5 Discussão 48

3.5.1 Análise da Polarização ao longo da nuvem 48

3.5.2 Análise do ângulo médio da polarização ao longo da NEM 51

3.5.3 Sobre o Campo Magnético e razão de energias cinética e magnética

3.5.4 Eficiência da polarização na NEM

3.6 Conclusões 
4. Polarimetria, Extinção e Campo Magnético na direção de HD62542

4.1 Resumo $\quad 65$

4.2 Introdução $\quad 66$

4.2.1 A região de Puppis e Vela 66

4.2.2 A linha de visada a HD62542

$\begin{array}{lll}4.2 .3 & \text { Este Trabalho } & 73\end{array}$

4.3 Polarimetría Óptica $\quad 73$

4.3.1 Observações $\quad 73$

4.3.2 Dados Polarimétricos

4.4 Absorção visual por contagem automática de estrelas $\quad 89$

$\begin{array}{llr}4.5 & \text { Discussão }\end{array}$

4.5.1 Polarização e extinção 92

4.5.2 Campo Magnético $\quad 95$

4.5.3 Eficiência da polarização 96

4.6 Conclusões

5. Conclusões

5.1 Sumário dos Resultados $\quad 101$

$\begin{array}{ll}5.2 & \text { Perspectivas } \\ \end{array}$

Apêndice A. Programa de Aquisição de Dados da Gaveta Polarimétrica IAGUSP 105

Apêndice B. Pacote PCCDPACK 111

$\begin{array}{lr}\text { B.1 Rotina ORDEM } & 111\end{array}$

B.2 Rotina COORSHIFT 112

B.3 Criando arquivo de informação $\quad 113$

B.4 Rotina PCCD 113

$\begin{array}{lr}\text { B.5 Rotina MACROL } & 114\end{array}$

B.6 Rotina SELECT 116

B.7 Rotina GRAF 117

B.8 Rotina MAGNIT 117

B.9 Rotina REFER 119

B.10 Rotina VECPLOT 120

$\begin{array}{lr}\text { B.11 Rotina FINTAB } & 121\end{array}$

Apêndice C. Catálogo polarimétrico da Nuvem Escura de Musca 123

Apêndice D. Análise da polarimetria na Nuvem Escura de Musca 189

Apêndice E. Catálogo polarimétrico da região IRAS Vela Shell/Gum 209

Apêndice F. Análise da polarimetria na região IRAS Vela Shell/Gum 239

$\begin{array}{lr}\text { Referências } & 249\end{array}$ 


\section{Agradecimentos}

Gostaria de agradecer em primeiro lugar às agencias de fomento CAPES e FAPESP pela bolsas concedidas durante o tempo do doutorado.

Sou grato ao Dr. Antônio Mário Magalhães pela orientação durante todos esses anos, nos quais o respeito foi mútuo.

Não posso deixar de agradecer aos membros do Grupo de Polarimetria do IAG, e os seminários nos quais a discussão foi ampla.

A meus pais e irmãos pelo apoio e ajuda contínua apesar da distancia.

A Aline pela sua compreensão e amor durante todos esses anos (e é claro pelas correções ao texto). 



\section{Sumário}

Neste trabalho estudamos a geometria do campo magnético e algumas propriedades da poeira interestelar em duas regiões do Meio Interestelar da Galáxia: a Nuvem Escura de Musca e uma parte da IRAS Vela Shell, na direção de HD62542. Empregamos a técnica da polarimetria de imagem CCD.

$\mathrm{Na}$ primeira parte desta tese mostramos nosso aporte no aprimoramento do bardware e software do Grupo de Polarimetria do IAGUSP. Basicamente, um código de controle da gaveta polarimétrica do IAG foi desenvolvido e explicamos em detalhe um pacote (PCCDPACK) de redução semi-automática e análise de imagens polarimétricas para objetos pontuais criado especificamente para este fim.

$\mathrm{Na}$ segunda parte desta tese aplicamos a técnica de polarimetria de imagem CCD para um estudo observacional em duas regiões selecionadas: a Nuvem Escura de Musca (NEM) e a região IRAS Vela Shell (IVS) / Nebulosa de Gum (NG) na direção de HD62542. Nosso interesse foi explorar a técnica polarimétrica desenvolvida para a redução e análise de campos estelares densos. O produto deste estudo foi a construção de dois catálogos polarimétricos, um para cada região, de ao redor de 2500 objetos para a NEM e quase 900 objetos para a região IVS/NG. Mostramos também como tais medidas podem ser utilizadas para mapear o campo magnético em regiões densas do meio interestelar, especificamente em nuvens escuras e frentes de ionização/shocks onde a presença de grãos de poeira é prevista. Informação sobre a intensidade do campo magnético e das razões de energia cinética turbulenta a magnética é obtida do estudo das dispersões do ângulo de polarização dos vetores de polarização em cada uma das regiões. Paralelamente, um estudo de extinção utilizando a técnica de contagem automática de estrelas foi feito em cada uma das regiões e suas correlações com os dados polarimétricos são exploradas. Combinando as medidas polarimétricas com as de extinção, a eficiência da polarização é investigada assim como suas implicâncias na determinação do tipo de grãos presentes ao serem comparados com aqueles próprios do meio interestelar difuso.

A análise da polarimetria na NEM mostra um limite inferior de polarização de $\sim 2 \%$ ao longo da estrutura filamentar da nuvem, com picos de polarização de 6-7\% na região central. A geometria do campo magnético, como é inferida do mapa de polarização, é quase 
perpendicular ao filamento, sugerindo um colapso ao longo das linhas do campo. No entanto, uma análise em pequena escala angular mostra variações no ângulo de polarização de $\sim 30^{\circ}$ ao redor do valor médio de $110^{\circ}$. O campo magnético estimado ao longo da nuvem se encontra dentro de uma faixa de 0.05 mgauss a 0.30 mgauss. Um limite inferior para a massa da nuvem de $139 \mathrm{M} \odot$ é encontrado e um grande número de condensações foram detectadas na estrutura filamentar com uma escala típica de tamanho $L \sim 0.26 \mathrm{pc}$. As correlações entre polarização e extinção sugerem que a poeira na NEM possui diferentes propriedades que as do meio interestelar difuso e que uma privilegiada visão geométrica do campo magnético pode estar presente ao longo na nuvem.

O estudo da região IVS/NG permitiu estabelecer uma geometria do campo magnético que parece acompanhar, em algumas regiões, a borda da parede de emissão $\mathrm{H}_{\alpha}$. No entanto, em outras regiões, parece evidente uma tendência perpendicular à parede. O campo magnético estimado ao longo da frente de ionização está na faixa de 0.02 mgauss a 0.11 mgauss e a pressão magnética parece dominar a pressão turbulenta do gás em algumas regiões. Uma evidencia de estruturas tipo clumpy foi detectada com limites inferiores típicos de (1-4) $\mathrm{M} \odot$ e uma escala de tamanho de $L \sim 0.47$ pc. A eficiência da polarização muda ao longo da frente de ionização e parece claro que em algumas regiões as propriedades da poeira diferem daquelas observadas no meio interestelar difuso. Um ótimo alinhamento é observado em algumas regiões o que sugere uma ótima visão geométrica do campo magnético com respeito à frente de ionização vista edge on. 


\begin{abstract}
We have used CCD imaging polarimetry to study the geometry of the magnetic field and some properties of the interstellar dust in two regions of the Interstellar Medium of the Galaxy: the Musca Dark Cloud and a section of the IRAS Vela Shell towards HD62542.

We initially describe the instrument employed with the Musca cloud, the IAG polarimeter, for which we developed control software. A very similar instrument was used at CTIO for the Vela Shell. We have also developed an IRAF software package to reduce and analyze polarimetric images in crowded fields (PCCDPACK). We next apply the technique to study two selected regions: the Musca Dark Cloud (MDC) and a section of IRAS Vela Shell (IVS). The end product is the construction of two catalogues, of approximately 2500 objects for MDC and 900 objects for IVS.
\end{abstract}

For MDC, the analyses of the polarimetric data show a polarization lower limit of $\sim 2 \%$ along the filamentary structure of the cloud, with peaks of 6-7\% in the central regions. The geometry of the magnetic field is approximately perpendicular to filament, suggesting collapse along the field lines. However, when looked in detail, we detect variations in the polarization angle of $\sim 30^{\circ}$ respect to the mean value of $110^{\circ}$. The estimated strength of the magnetic field is in a range of 0.05-0.30 mgauss. The star count technique yields a lower limit of the total mass of the cloud of $139 \mathrm{M}_{\odot}$. A large number of condensations are found, with a typical length scale $L \sim 0.26$ pc. The observed correlation between polarization and extinction suggests that the dust in MDC have different properties with respect to the dust in the diffuse Interstellar Medium. It also appears that the magnetic field along the cloud is viewed favorably so as to produce the observed polarization.

The study in the section of the IVS towards HD 62542 allows us to detect a magnetic field parallel to the ionization front in sections of the cloud. However, in others regions, a perpendicular geometry is also evident. The estimated magnetic field is in the range of 0.020.11 mgauss and the magnetic pressure may dominate the turbulent pressure of gas in some regions. Evidence of clumpy structure is found with typical masses (1-4) $\mathrm{M}_{\odot}$ and a length scale $L \sim 0.47$ pc. The polarization efficiency changes along the ionization front. It is clear that the properties of the dust are different of the interstellar medium in some regions. An optimum alignment of the polarization vectors is seen in some regions and it may reflect a 
favorable viewing geometry of the magnetic field with respect of the ionization front seeing edge on. 


\section{Lista de Figuras}

Figura 1.1 Fatores de eficiência da extinção $Q_{||}$e $Q_{\perp}$ da teoria de Mie ................................................................................2

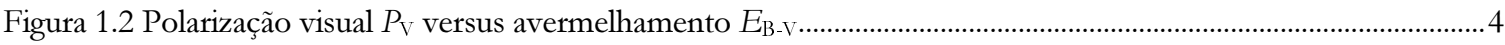

Figura 1.3 Curvas de polarização linear interestelar normalizadas .....................................................................................

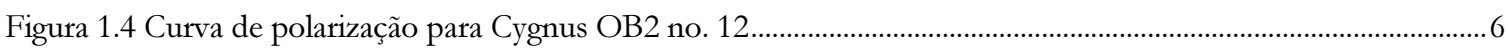

Figura 1.5 Modelo para polarização linear intelestelar $(0.3-2.2 \mu \mathrm{m})$...........................................................................

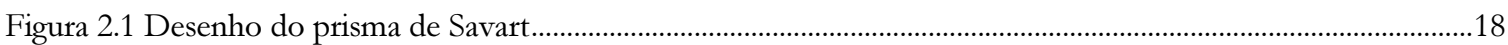

Figura 2.2 Diagrama esquemático da Gaveta Polarimétrica do IAG ..............................................................................20

Figura 2.3 Disenho esquemático do sistema óptico da gaveta polarimétrica do IAG...................................................21

Figura 2.4 Exemplo de um campo estelar denso típico obtido com a gaveta polarimétrica do IAG..........................24

Figura 2.5 Exemplo da saída gráfica da rotina SELECT. ……………………..............................................................28

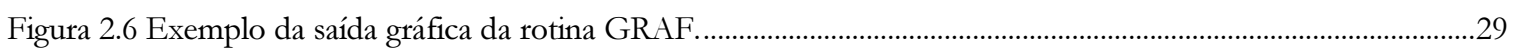

Figura 2.7 Exemplo da saída gráfica da rotina MAGNIT . ................................................................................................

Figura 2.8 Exemplo de um mapa de polarização típico elaborado utilizando a rotina VECPLOT..............................31

Figura 2.9 Exemplo de um catálogo polarimétrico construído utilizando a rotina FINTAB.......................................32

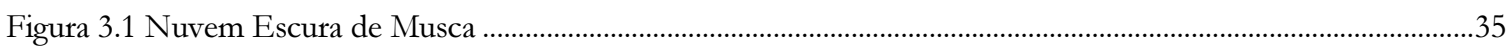

Figura 3.2 Mapa de nuvens escuras do Catálogo de Feitzinger e Stüve (1984) - Nuvem Escura de Musca ................35

Figura 3.3 Regiões Norte, Centro e Sul em que foi dividida a NEM no nosso estudo ...................................................39

Figura 3.4 Mapas de polarização para as três regiões na NEM ..........................................................................................40

Figura 3.5 Ajuste da curva de extinção normalizada e cálculo de $n(1)=0$. ..................................................................42

Figura 3.6 Mosaico das imagens de extinção das três regiões em que foi dividida a NEM neste trabalho ..................43

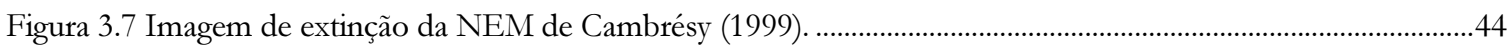

Figura 3.8 Comparação ponto a ponto entre nosso mapa de extinção e Cambrésy (1999) .............................................45

Figura 3.9 Variação do valor médio da polarização $<P>$ para os 35 campos observados ao longo da NEM ............49

Figura 3.10 Análise em detalhe da polarimetria da NEM na faixa de declinação $\mathrm{DEC}_{1950}=-70^{\circ} 44^{\prime}$..........................53

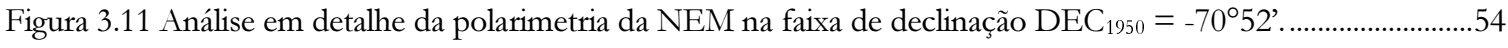

Figura 3.12 Análise em detalhe da polarimetria da NEM na faixa de declinação $\mathrm{DEC}_{1950}=-71^{\circ} 08^{\prime}$..........................55

Figura 3.13 Análise em detalhe da polarimetria da NEM na faixa de declinação $\mathrm{DEC}_{1950}=-71^{\circ} 52^{\prime}$..........................56

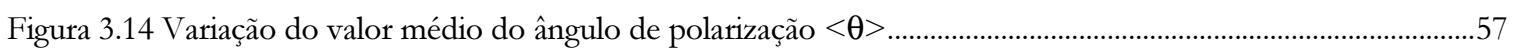

Figura 3.15 Razão de densidades de energia cinética e magnética $\left(<\Delta \theta^{2}>\right)$..................................................................58

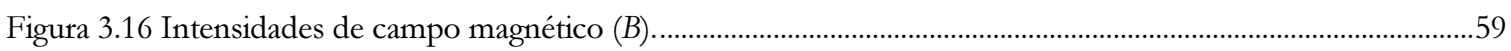

Figura 3.17 Porcentagem de polarização na banda V versus extinção visual para estrelas de backeground na NEM

e eficiência da polarização ................................................................................................................................62

Figura 3.18 Igual à Figura 3.17 mas utilizando a extinção de Cambrésy (1999)) ..............................................................62

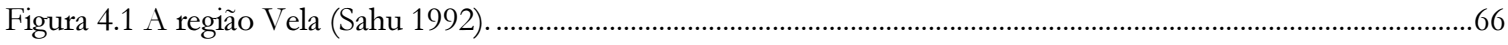

Figura 4.2 Região da IRAS Vela Shell/ Nebulosa de GUM na direção da HD62542 ................................................69

Figura 4.3 Mapa de Feitinger \& Stüwe (1984) mostrando a localização da Iras Vela Shell e HD62542 ......................70

Figura 4.4 Imagem IRAS em $100 \mu \mathrm{m}$ da parede oeste da IVS na direção da HD62542. ...........................................70

Figura 4.5 Posições dos 16 campos observados na região IVS/NG. .................................................................................75

Figura 4.6 Mapa de polarização para a região IVS/NG na direção de HD62542 ..........................................................76 
Figura 4.7 Mapas de polarização para os campos 06, 07 e 05 . . .81

Figura 4.8 Mapas de polarização para os campos 07, 08 e 09.......................................................................................... 82

Figura 4.9 Mapas de polarização para os campos 10 e 11 ...........................................................................................8

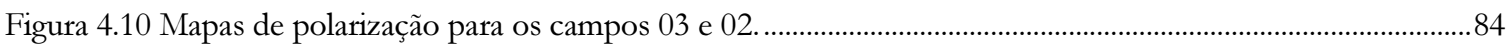

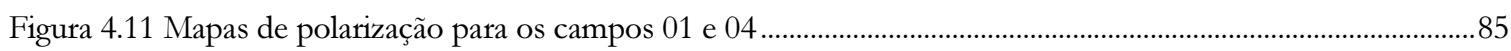

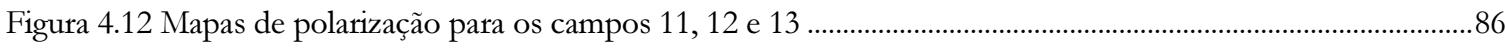

Figura 4.13 Mapas de polarização para os campos 13 e 14 .................................................................................................8

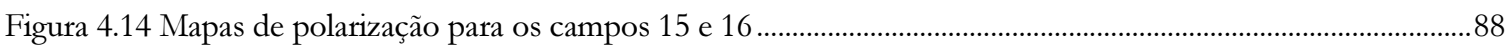

Figura 4.15 Ajuste dos resíduos de passos consecutivos de extinção para achar $n(1)=0$.........................................89

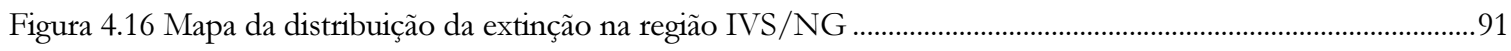

Figura 4.17 Estruturas em extinção com $A_{\mathrm{V}} \geq 1$ na direção a HD62542 …………………….....................................92

Figura 4.18 Mapa de polarização superposto ao mapa de extinção da região IVS/NG.................................................99

Figura 4.19 Porcentagem de polarização na banda V versus extinção visual para estrelas de background na região Iras Vela Shell/Nebulosa de Gum na direção de HD62542 e eficiência da polarização. 


\section{Lista de Tabelas}

Tabela 3.1 Características dos CCDs utilizados no mapeamento da NEM......................................................................36

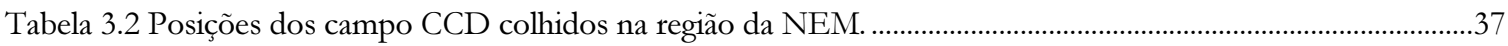

Tabela 3.3 Comparação entre polarimetria de Arnal et al. (1993) e nosso trabalho..........................................................39

Tabela 3.4 Análise da polarimetria dos 35 campos da NEM. ………..............................................................................41

Tabela 3.5 Comparação entre extinção na NEM de Gregorio-Hetem et al . (1988) e nosso trabalho.........................46

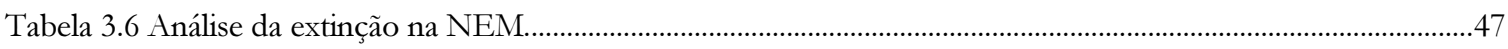

Tabela 4.1 Posições dos campos CCD colhidos na região estudada.................................................................................74

Tabela 4.2 Análise da polarimetria dos 16 campos da região em estudo..........................................................................79

Tabela 4.3 Análise das estruturas de extinção na região de IVS na direção de HD62542 com $A_{\mathrm{V}} \geq 1$ mag...............91 



\section{Capítulo 1}

\section{Introdução}

\subsection{Resumo}

Neste capítulo analisaremos algumas noções básicas no referente à extinção e polarização que serão utilizadas nos estudos observacionais dos capítulos subseguintes. Abordaremos o tópico da polarização interestelar por grãos de poeira não esféricos e sua dependência com o avermelhamento. A dependência espectral da polarização também será analisada junto aos modelos existentes. Os mecanismos de alinhamento de grãos pelo campo magnético são discutidos e são demonstradas as relações entre a dispersão do ângulo de polarização e a intensidade do campo, assim como a informação que pode ser obtida acerca da razão das densidades de energia cinética e magnética. 


\subsection{Polarização Interestelar}

A polarização da luz estelar fornece evidência de que pelo menos um componente dos grãos responsável pela extinção tem propriedades ópticas anisotrópicas. Extinção preferencial por grãos não-esféricos alinhados pelo campo magnético galáctico pode explicar a polarização linear interestelar observada. Polarização circular é também possível de ser observada se o alinhamento muda ao longo da linha de visada (birefringência linear do meio interestelar, MI). Assim, medidas de polarização permitem obter informações adicionais sobre as propriedades dos grãos (tamanho, índice de refração) como também do campo magnético galáctico.

\subsubsection{Grãos não-esféricos}

Consideremos uma partícula alongada, com simetria axial (por ex., esferóides prolatos, cilindros infinitos). O fator de eficiência da extinção dependerá da orientação da partícula com respeito à direção do vetor elétrico $\boldsymbol{E}$ e da direção de propagação da radiação. Para uma partícula orientada com seu eixo maior (eixo de simetria) perpendicular à direção da radiação incidente, $Q_{||}$e $Q_{\perp}$ são, respectivamente, as eficiências da extinção quando o eixo maior é paralelo e perpendicular ao vetor elétrico $\boldsymbol{E}$. Isto resulta numa anisotropia na extinção produzida. Para um tipo de grão dado, as eficiências podem ser calculadas. Um exemplo é mostrado na Figura 1.1 (Greenberg 1968), onde $Q_{||}$e $Q_{\perp}$ são expressados em função do parâmetro adimensional $x=2 \pi a / \lambda$, com $a$ sendo o tamanho característico da partícula e $\lambda$ o comprimento de onda.

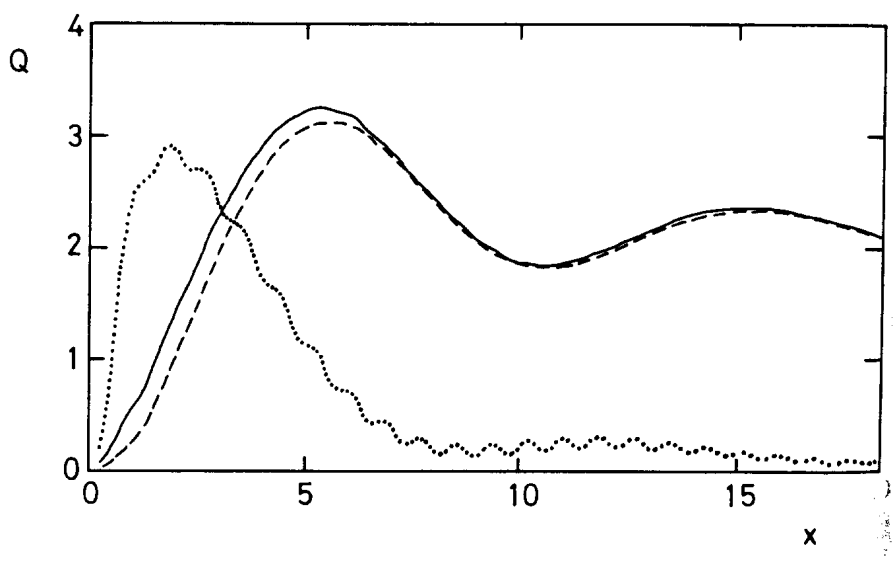

Figura 1.1 Fatores de eficiência da extinção $Q_{\|}$(contínua) e $Q_{\perp}$ (tracejada) da teoria de Mie em função do parâmetro $x=2 \pi a / \lambda$. O cálculo é feito para cilindros infinitos de raio $a$ e índice de refração complexo $m=1.33-0.05 i$. A diferença $8 \mathrm{x}\left(Q_{\|}-Q_{\perp}\right)$ também é mostrada (pontilhada) (Greenberg 1968). 
Para um meio de partículas idênticas, perfeitamente alinhadas e de densidade colunar $N_{\mathrm{d}}$, as extinções paralelas e perpendiculares ao eixo de simetria são

$$
\begin{aligned}
A_{||} & =1.086 N_{\mathrm{d}} \sigma Q_{||} \\
A_{\perp} & =1.086 \mathrm{~N}_{\mathrm{d}} \sigma Q_{\perp}
\end{aligned}
$$

onde $\sigma$ é a seção transversal da partícula. $O$ grão da polarização linear $p$ em magnitudes fica definido por

$$
p=A_{\|}-A_{\perp}=1.086 N_{\mathrm{d}} \sigma\left(Q_{\|}-Q_{\perp}\right)
$$

O comportamento de $p$ (Figura 1.1) mostra que a polarização é desprezível para $\lambda>>a$, (em concordância com a extinção) assim como também para $\lambda<a$ (em contraste com a extinção). O pico na polarização observado acontece em $x(n-1) \sim 1$, valor obtido por comparação de resultados para diferentes dielétricos. Em geral, $p$ é pequeno comparado à extinção $A=\left(A_{\|}+A_{\perp}\right) / 2$, e pode ser quantificado mediante a eficiência do alinhamento,

$$
p / A=2\left\{\left(Q_{\|}-Q_{\perp}\right) /\left(Q_{\|}+Q_{\perp}\right)\right\} .
$$

A polarização $p$ é dependente da natureza dos grãos considerados e da geometria (meio/campo magnético) local. O limite superior para a eficiência da polarização pode ser calculado se consideramos cilindros infinitos $\operatorname{com} a \sim \lambda$ perfeitamente alinhados $\mathrm{e}$ perpendiculares à linha de visada. No visível a teoria de Mie para grãos dielétricos fornece o valor de

$$
p_{\mathrm{V}} / A_{\mathrm{V}} \leq 0.3
$$

\subsubsection{Dependência da polarização com o avermelhamento}

O grau de polarização linear de uma estrela poderia, em princípio, ser determinado usando um analisador que filtra a radiação com seu vetor- $E$ vibrando num sentido determinado. $O$ analisador é girado e máximos e mínimos de intensidade são registrados de modo que o grau de polarização, em porcentagem, é expressado por

$$
P=100\left\{\left(I_{\max }-I_{\min }\right) /\left(I_{\max }+I_{\min }\right)\right\}
$$

Se expressamos a polarização observada em magnitudes é possível compará-la com a equação (1.2), assim,

$$
p=2.5 \log I_{\max } / I_{\min }
$$


Para valores de $p$ pequenos (típicos do MI) pode-se relacionar $p$ com $P$ através da seguinte relação $\left(\operatorname{com} I_{\max } \sim I_{\min }\right)$,

$$
P \sim 50\left\{\left(I_{\max } / I_{\min }\right)-1\right\}=46.05 p
$$

O ângulo de polarização é o segundo parâmetro mensurável, determinado pela orientação do analisador para o máximo de intensidade com respeito ao meridiano que passa pela estrela no sistema de coordenadas utilizado (galáctico, equatorial).

A relação entre o grau de polarização visual e o avermelhamento (Figura 1.2) mostra que a eficiência da polarização no MI não é uniforme. No entanto, um limite máximo parece evidente para um ótimo alinhamento (Serkowsky et al. 1975),

$$
P_{\mathrm{V}} / E_{\mathrm{B}-\mathrm{V}}=9 \% \mathrm{mag}^{-1}
$$

que, da equação (1.7) e considerando $R_{V} \sim 3.05 \pm 0.15$, resulta em

$$
p_{\mathrm{V}} / A_{\mathrm{V}} \leq 0.064 \quad \text { ou equivalentemente } \quad P_{\mathrm{V}} / A_{\mathrm{V}} \leq 2.95
$$

Este valor é consistente com o limite superior teórico da equação (1.4). É claro que os grãos do MI não são cilindros infinitos; partículas irregulares ou moderadamente alongadas podem dar conta do limite superior (mais moderado) observado para um ótimo alinhamento.

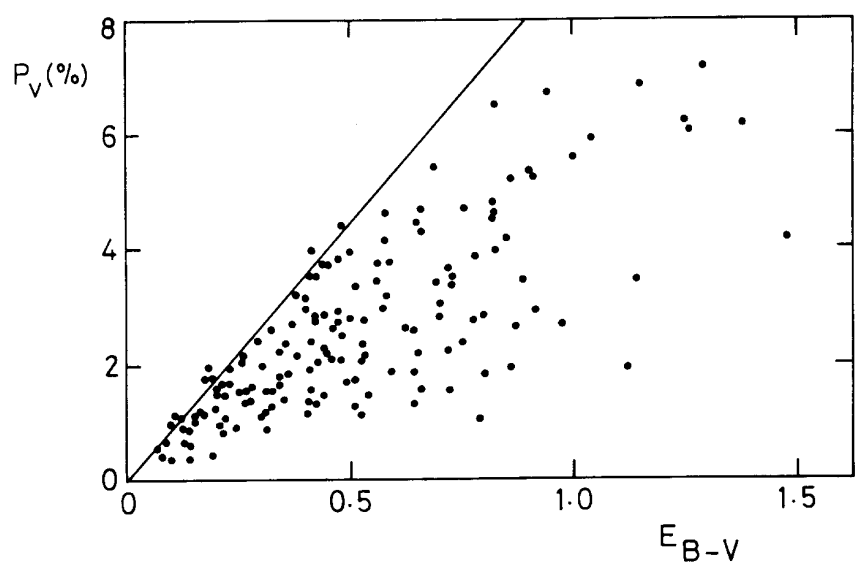

Figura 1.2 Gráfico da polarização visual $P_{\mathrm{V}}$ versus avermelhamento $E_{\mathrm{B}-\mathrm{V}}$ para uma amostra de estrelas do campo da Galáxia. A linha reta representa o ótimo alinhamento - equação (1.8). (Serkowsky et al. 1975).

Variações regionais observadas na eficiência do alinhamento devem se originar em variações na intensidade do campo magnético ou em propriedades diferentes dos grãos submetidos a diferentes condições físicas. Processos físicos como o crescimento de mantos (por acreção do gás) e taxas de colisão grão-grão otimizadas devem tender a diminuir a eficiência da polarização. No entanto, efeitos geométricos devem ser também importantes. Assim, a luz de estrelas de fundo que atravessa mais de uma nuvem (cada uma delas com 
um alinhamento particular) deve resultar em luz elípticamente polarizada, convertendo parte da polarização linear incidente em polarização circular. No caso extremo de eixos de alinhamento ortogonais de duas nuvens de populações de grãos semelhantes, a extinção deve ser acompamhada de polarização nula. Nuvens interestelares mostram estruturas de campo magnético complexas, de forma que mudanças no alinhamento numa linha de visada numa mesma nuvem também são possíveis. Isto resulta numa aparente diminuição na eficiência da polarização $P_{\mathrm{V}} / A_{\mathrm{V}}$. Todos estes fatores têm que ser levados em conta ao analisar dependências da polarização com o avermelhamento, de forma que dispersões como a mostrada na Figura 1.2 para amostras heterogêneas de estrelas são esperadas.

\subsubsection{Dependência espectral da Polarização Interestelar}

A dependência espectral da polarização linear no visível e IR próximo apresenta na maioria das estrelas estudadas um pico alargado e assimétrico no visível. O comprimento de onda $\lambda_{\max }$ para a máxima polarização $P_{\max }$ está tipicamente na faixa $(0.4-0.8 \mu \mathrm{m})$ com uma média em $0.55 \mu \mathrm{m}$. $P_{\lambda}$ e $\lambda$ são normalizadas com respeito a $P_{\max }$ e $\lambda_{\max }$ para efeitos de comparação entre diferentes estrelas. Com isto, uma fórmula empírica é utilizada para descrever a curva de polarização (Serkowsky 1973),

$$
P_{\lambda} / P_{\max }=\exp \left\{-K \ln ^{2}\left(\lambda_{\max } / \lambda\right)\right\} .
$$

O parâmetro $K$, que determina a largura do pico, historicamente foi inicialmente assumido constante $(K=1.15)$ e a equação (1.10) denomina-se a lei de Serkowsky. Posteriormente, Codina-Landberry \& Magalhães (1976) melhoraram os ajustes permitindo o $K$ variar. Refinamentos na lei empírica, levaram a encontrar uma relação entre $K$ e $\lambda_{\max }$ (Wilking et al. 1980, 1982; Whittet et al. 1992a),

$$
K=(0.01 \pm 0.05)+(1.66 \pm 0.09) \lambda_{\max }
$$

com a equação (1.10) e o vínculo da equação (1.11) conhecida como a lei de Wilking, implicando uma diminuição da largura da curva de polarização com um incremento de $\lambda_{\max }$ (Figura 1.3).

Numa determinada linha de visada o valor de $\lambda_{\max }$ pode estar relacionado com o tamanho médio dos grãos polarizantes e o comportamento de $K \operatorname{com} \lambda_{\max }$ pode indicar as mudanças 
na esfericidade dos grãos ou uma distribuição mais estreita dos tamanhos dos grãos, ao incrementar-se o tamanho como resposta a fatores locais.

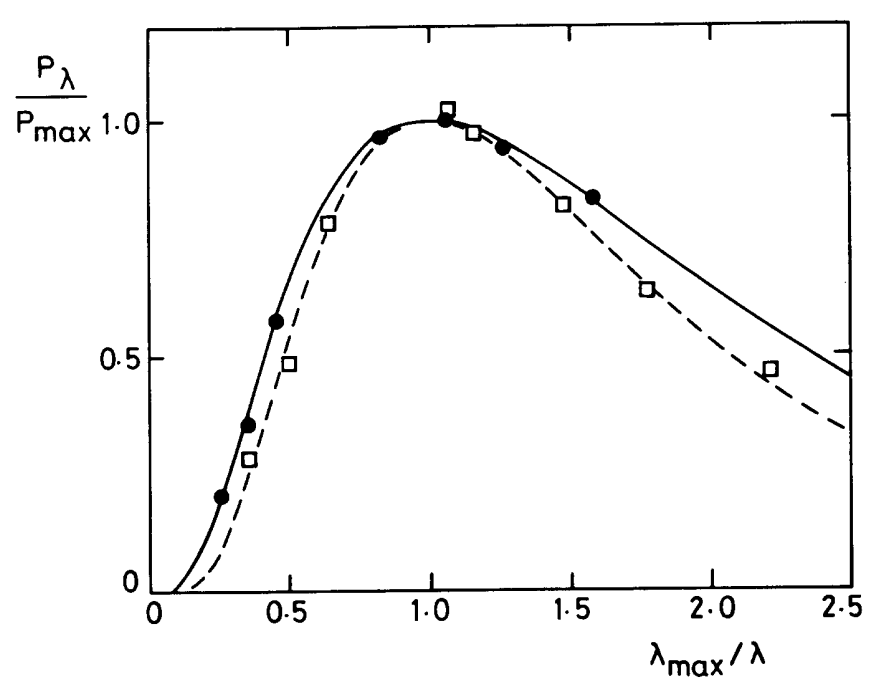

Figura 1.3 Curvas de polarização linear interestelar normalizadas para duas estrelas com valores diferentes de $\lambda_{\max }$. HD42087 $\left(\lambda_{\max }=0.57 \mu \mathrm{m}\right.$, pontos $)$, $\operatorname{HD} 147889\left(\lambda_{\max }=0.80 \mu \mathrm{m}\right.$, quadrados $)$. Ajustes da lei de Wilking são mostrados. (Whittet 1992b, pp 94).

No entanto, estas interpretações devem ser tomadas com cuidado. As leis de Serkowski e Wilkings fornecem bons ajustes dentro das faixas espectrais dos dados disponíveis no tempo em que foram formuladas $(0.35-1.0 \mu \mathrm{m}$ e $0.35-2.2 \mu \mathrm{m}$, respectivamente). Para $\lambda$ $>3 \mu \mathrm{m}$, extrapolações das leis empíricas não fornecem bons ajustes e a curva de polarização IR é melhor descrita por uma lei de potência, $P_{\lambda}=P_{1} \lambda^{-\alpha}$ (Figura 1.4). Whittet (1990) encontrou evidência para um índice $\alpha=1.8 \pm 0.2$ comum a observações em nuvens difusas e nuvens densas.

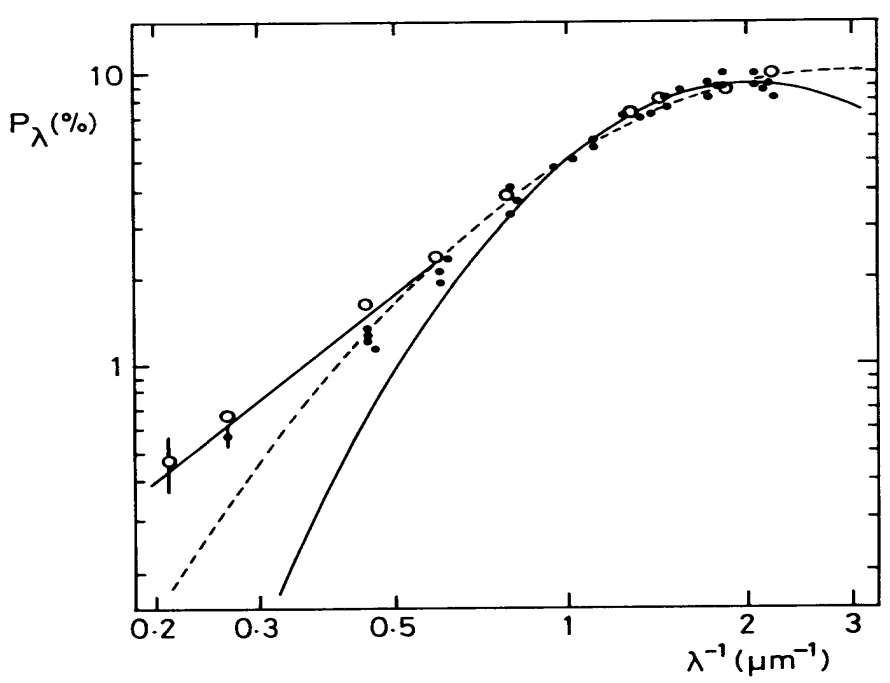

Figura 1.4 Curva de polarização para Cygnus OB2 no. 12, comparada a ajustes empíricos. Dados Nagata (1990) e Martin (1992). Ajustes: Lei de Serkowsky (contínua, $P_{\max }=9.2 \%$, $\left.\lambda_{\max }=0.49 \mu \mathrm{m}, K=1.15\right)$; Lei de Wilking (tracejada, $P_{\max }=10.2 \%, \lambda_{\max }$ $=0.33 \mu \mathrm{m}, K=0.57$ ); lei de potência (linha reta, $P_{1}=5.06, \alpha=1.6$ ). (Whittet 1992b, pp 96) 
Modelagem da curva de polarização interestelar a partir de cálculos usando a teoria de Mie é consistente com grãos esferoidais dielétricos alinhados e excluem materiais com um $m$ que mude fortemente $\operatorname{com} \lambda$, como metais e outros absorvedores fortes (grafite, magnetita). Isto, junto à informação do albedo $(\gamma \sim 0.6-0.7)$, típicos de dielétricos, obtida para luz galáctica difusa (Lillie e Witt 1976, Toller 1981), parece concluir que ao menos uma componente da poeira é dielétrica no visível. Isto é corroborado pela presença de uma eficiência na polarização na característica de $9.7 \mu \mathrm{m}$ identificada com silicatos (Capps e Knacke 1976; Aitken et al. 1986, 1988, 1989; Dyck e Lonsdale 1981). Se materiais absorventes contribuem à extinção no visível, eles não devem produzir polarização líquida devido a sua esfericidade ou a uma falência no alinhamento.

Mathis et al. (1986) extendeu o modelo de grãos MRN (Mathis et al. 1977) para levar em conta a curva de polarização observada. Assumindo que polarização é produzida somente por silicatos com uma distribuição de tamanhos $n(\mathrm{a}) \propto \mathrm{a}^{-3.5}$, um bom ajuste para cilindros infinitos se consegue sempre que partículas com raios maiores que certo patamar estejam alinhadas (Mathis 1979). A probabilidade de alinhamento se incrementaria com o volume do grão (devido a uma maior presença de inclusões ferromagnéticas); dessa forma, somente grãos grandes tendem a ser alinhados (Mathis 1986, Figura 1.5).

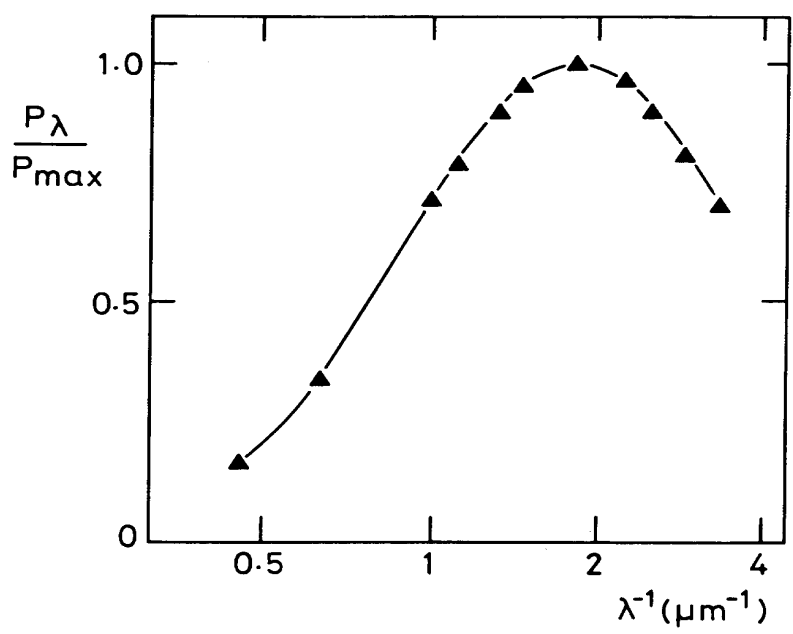

Figura 1.5 Modelo para polarização linear intelestelar $(0.3-2.2 \mu \mathrm{m})$. Lei de Wilking $\left(\lambda_{\max }=0.55 \mu \mathrm{m}\right.$, contínuo). Modelo (Mathis 1986, triângulos)

Outro resultado importante de modelos de polarização utilizando a teoria de Mie é que o comprimento de onda de máxima polarização $\lambda_{\max }$ está relacionado às dimensões dos grãos. Cilindros dielétricos de raios $a$ e índice de refração $n$ polarizam mais eficientemente quando $2 \pi a(n-1) / \lambda \sim 1$, assim (Whittet 1992b, pp 98),

$$
\lambda_{\max } \sim 2 \pi a(n-1) .
$$


No MI difuso $\lambda_{\max } \sim 0.55 \mu \mathrm{m}$ (Vrba, Coyne e Tapia 1981), portanto $<a>\sim 0.15 \mu \mathrm{m}$ para $n=1.6$ (típico de silicatos). Incrementos no $\lambda_{\max }$ em nuvens escuras são interpretados, usualmente, como simples crescimento de grãos (Whittet e Blades 1980). No entanto, se o processo de crescimento involucra acreção de mantos devido ao gás, mudanças no índice de refração devem também acontecer.

\subsubsection{Alinhamento de grãos}

Evidência observacional sugere que a polarização do MI é devida a grãos que em parte são responsáveis também pela extinção no visível. Os grãos devem ser opticamente anisotrópicos para ter a dependência direcional requerida da eficiência da extinção (grãos alongados) e deve existir um alinhamento dos eixos de anisotropia.

Modelos de alinhamento de grãos dependem da interação entre o spin do grão e o campo magnético local. Um grão de poeira imerso num meio gasoso de temperatura $T_{\mathrm{g}}$ será submetido a colisões aleatórias com os átomos e moléculas do gás, o que incrementará a energia rotacional do grão. Em equilíbrio colisional, as energias associadas com o spin com relação aos três eixos principais de inércia são iguais e o momemto angular será maior ao longo do eixo de máxima inércia; assim, grãos alongados tenderão a girar ao redor do seu eixo menor. O alinhamento do grão ficará então determinado pelo alinhamento do momento angular com respeito ao campo magnético presente. No plano galáctico, o campo magnético e a polarização observada é paralela ao plano (Mathewson e Ford 1970; Axon e Ellis 1976) o que indicaria que o momento angular do grãos é também paralelo ao campo magnético para grãos alongados (com seus eixos maiores preferentemente perpendiculares ao campo magnético).

\subsubsection{Alinhamento Davis-Greenstein}

O primeiro mecanismo magnético de alinhamento de grãos foi proposto por Davis \& Greenstein (DG, 1951). Ele se baseia na relaxação paramagnética de grãos girando termicamente. Supondo colisões elásticas, velocidades típicas de rotação de um grão são de ordem $\omega \sim 10^{5} \mathrm{rad} \mathrm{s}^{-1}$. A presença de um campo magnético externo de densidade de fluxo 
$B$ induz um campo interno na partícula sólida que dependerá da suscetibilidade magnética $\left(\chi=\chi^{\prime}+i \chi^{\prime \prime}\right)$ do material do grão. Num caso estático, os campos externo e interno são alinhados. No entanto, para uma partícula girando, existirá sempre um pequeno desalinhamento entre o campo externo e o campo induzido. Isto resulta num torque dissipativo com respeito a um eixo perpendicular a $B$ e a tendência é que o momemto angular seja alinhado a $B$, com o grão precessando ao redor de $B$. Colisões gás-grão podem trabalhar contra o mecanismo tentando restaurar as orientações aleatórias. Um alinhamento líquido será conseguido se a escala de tempo para relaxação paramagnética, $t_{\mathrm{r}} \propto \omega \chi \chi^{\prime-1} B^{-2}$ (Spitzer 1978, pp 187-189), for menor que aquela para colisões, $t_{\mathrm{c}} \propto T_{\mathrm{g}}^{-1 / 2}$ (Whittet 1992b, pp 109). A condição $\left(t_{\mathrm{c}} / t_{\mathrm{r}}\right) \geq 1$ leva a colocar um limite inferior sobre a densidade de fluxo magnético para alinhamento DG, que para condições típicas do MI resulta em,

$$
B \geq 3 \times 10^{-5} \text { gauss }
$$

O valor médio do campo magnético interestelar na vizinhança solar é $B \sim 4 \times 10^{-6}$ gauss (Heiles 1987), que é um fator 10 menor que o mínimo fluxo requerido para alinhamento DG. Apesar deste mecanismo não dar uma resposta satisfatória para o alinhamento observado, serviu de partida para modelos melhorados que sugerem um incremento na velocidade do spin ou na susceptibilidade magnética da partícula.

\subsubsection{Rotação Supratérmica}

Numa visão mais realista, grãos devem estar longe de ser superfícies uniformes e estar sujeitos a colisões elásticas. Átomos, como o de hidrogênio, colidindo com o grão poderão ser aderidos à sua superfície. Posterior combinação com outro átomo de $H$, preferentemente em sítios ativos (defeitos ou centros de impurezas, Hollenbach e Salpeter 1971) na superfície levará à formação de $\mathrm{H}_{2}$ com a subseguinte liberação da energia de ligação. Neste processo, a molécula ejetada da superfície impartirá momemto angular adicional ao grão. $O$ número e distribuição de sítios ativos na superfície do grão determinarão as propriedades do spin do grão (Purcell 1975). Sob condições favoráveis, este mecanismo levará a velocidades angulares bem mais altas $\left(\omega \sim 10^{9} \mathrm{rad} \mathrm{s}^{-1}\right)$ que as assumidas por colisões elásticas. $O$ efeito de rotação supratérmica sobre o alinhamento de grãos é obter escalas de tempo mais curtas para o alinhamento perante ao efeito em contra colisional (Purcell 1979). 
Este mecanismo fornece uma via adequada para alinhamento de grãos em nuvens difusas de HI. No entanto, em nuvens moleculares densas o hidrogênio já está em forma molecular e os grãos devem estar cobertos por mantos de $\mathrm{H}_{2} \mathrm{O}$ que tem pouca probabilidade de ser ejetados da superfície. Por isto, é difícil que rotação supratérmica dê conta das altas polarizações observadas em nuvens moleculares densas.

\subsubsection{Alinhamento Superparamagnético}

Para um grão paramagnético, o valor da parte imaginária da susceptibilidade magnética ( $\chi$ ”) pode incrementar-se num fator $\sim 10^{6}$ se o material do grão apresenta inclusões ferromagnéticas (Fe metálico, $\mathrm{Fe}_{3} \mathrm{O}_{4}$, etc). Por conseguinte, o alinhamento de grãos devido ao campo magnético seria muito mais eficiente pois $t_{\mathrm{r}}<<t_{\mathrm{c}}$. Modelos desenvolvidos por Mathis (1986) que incluem silicatos alinhados, sob a condição em que os grãos apresentam tais inclusões, dão conta da eficiência da polarização observada ( $\not / A$, ver seção 1.2.3). Adicionalmente, grãos carbonados são necessários para dar conta da extinção, mas sem a capacidade de ser alinhados pela carência das inclusões ou pela forma não alongada. Um ponto a favor deste mecanismo é que ele consegue ser insensível às mudanças no meio, tais como o crescimento de mantos em nuvens densas. Pode ser o caso que uma mistura de mecanismos, como uma leve rotação supratérmica associada com alguns sítios ativos nos mantos junto a superparamagnetismo nos núcleos dos grãos possam explicar também o alinhamento em nuvens densas. $O$ fato de considerar silicatos com inclusões ferromagnéticas é viável pois há evidência destes em estudos de meteoritos e poeira interplanetária ademais de considerar o fato da importante diminuição de $\mathrm{Fe}$ nas abundâncias do MI.

\subsubsection{Campo Magnético e Dispersão do Angulo de Polarização}

Chandrasekhar e Fermi (1953), analisando os dados de polarimetria de Hiltner (1949), notaram que a direção da polarização de estrelas distantes era somente aproximadamente paralela ao braço espiral da Galáxia. Flutuações notórias e aparentemente irregulares na direção de polarização eram evidentes no padrão de polarização. Eles sugeriram que isto era uma indicação que as linhas de força do campo magnético não eram estritamente retas e 
poderiam ser melhor descritas por linhas ondulatórias (wavy lines). O desvio angular médio $(\Delta \theta)$ do plano de polarização da direção do braço espiral foi estimado em 0.2 radianos ( $\left.10^{\circ}\right)$. Uma relação entre $\Delta \theta$ e a intensidade do campo magnético $B$ foi sugerida notando que se o campo magnético fosse o suficientemente forte as linhas de força deveriam ser bastante retas e $\Delta \theta$ teria que ser pequeno; por outro lado, se o campo magnético fosse suficientemente fraco, as linhas de força seriam dragadas em várias direções pelos movimentos turbulentos das massas de gás no braço em espiral e $\Delta \theta$ seria grande. A relação geral entre $\Delta \theta$ e $B$ foi obtida considerando a velocidade de uma onda magnetohydrodinâmica tranversal (velocidade Alfven) dado por:

$$
V=\frac{B}{\sqrt{4 \pi \rho}}
$$

onde $\rho$ é a densidade da matéria difusiva. No cômputo de $V$ não deve incluir-se em $\rho$ a densidade média devido às estrelas, pois o movimento delas através das linhas de força não deve ter apreciável interação com as linhas. No entanto, a matéria difusiva na forma de gás e poeira deve ter uma suficientemente alta conductividade elétrica para ser efetivamente ligada às linhas de força magnéticas de modo que unicamente deslocamentos longitudinais relativos podem ser possíveis.

Usando a equação (1.14), as oscilações transversais de uma linha de força em particular podem ser descritas pela equação da forma

$$
y=a \cos k(x-V t)
$$

onde $x$ é a coordenada longitudinal e $y$ representa o deslocamento lateral. Das derivadas de $y$ a respeito de $x$ e $t$ temos

$$
\begin{aligned}
& y^{\prime}=-a k \sin k(x-V t) \\
& \dot{y}=-a k V \sin k(x-V t)
\end{aligned}
$$

logo podemos concluir que

$$
V^{2} \overline{y^{\prime 2}}=\overline{\dot{y}^{2}}
$$

A velocidade lateral das linhas de força deve ser igual à velocidade lateral do gás turbulento. Se $v$ é a raíz-quadrática-média da velocidade do movimento turbulento, devemos ter a seguinte relação

$$
\overline{\dot{y}^{2}}=\frac{1}{3} v^{2}
$$


O fator $\frac{1}{3}$ vem do fato que unicamente uma componente da velocidade é efetiva em deslocar as linhas de força na direção $y$. Do outro lado, a quantidade $y^{\prime}$ representa o desvio da linha de força de uma linha reta projetada no plano de visão. Portanto,

$$
\overline{y^{\prime 2}}=\Delta \theta^{2}
$$

Logo, combinando as equações (1.14), (1.17), (1.18) e (1.19) obtemos

$$
B=\left(\frac{4}{3} \pi \rho\right)^{1 / 2} \frac{v}{\Delta \theta}
$$

O valor calculado do campo magnético no formalismo de Chandrasekhar e Fermi (1953) para o braço espiral da Galáxia foi $B=7.2 \times 10^{-6}$ gauss utilizando os valores de $\rho=2 \times 10^{-}$ ${ }^{24} \mathrm{~g} \mathrm{~cm}^{-3}, v=5 \times 10^{5} \mathrm{~cm} \mathrm{~s}^{-1}$ e $\Delta \theta=0.2$ radianos. Este procedimento foi utilizado em trabalhos prévios em outras regiões para medir o campo magnético projetado no céu (Gonatas et al. 1990; Morris et al. 1992; Chrysostomou et al. 1994; Itoh et al. 1999).

Considerando que a densidade de energia cinética (ou pressão cinética) do gás turbulento é dado por

$$
\rho_{\text {cin }}=\frac{1}{3} \rho v^{2}
$$

e a densidade de energia magnética (ou pressão magnética) é dada por

$$
\rho_{\text {mag }}=\frac{B^{2}}{8 \pi}
$$

e utilizando a equação (1.20), podemos notar que o desvio angular médio quadrado $\left(\Delta \theta^{2}\right)$ é proporcional à razão das densidades de energia cinética à magnética (Zweibel 1990), isto é

$$
\Delta \theta^{2} \propto \frac{\rho_{\text {cin }}}{\rho_{\text {mag }}}
$$

Rigorosamente,

$$
\rho_{\text {cin }} / \rho_{\text {mag }}=2 \Delta \theta^{2}
$$

mas para efeitos dos estudos observacionais dos seguintes capítulos e para ser coerentes com a literatura existente (Zweibel 1990) manteremos $\left(\Delta \theta^{2}\right)$ como nosso indicador da razão entre as densidades de energia cinética a magnética. 


\subsubsection{Campo Magnético e Nuvens Escuras}

A taxa de formação estelar observada em nuvens moleculares não é tão alta quanto como se a nuvem estivesse em colapso gravitacional (Zuckerman e Palmer 1974). A ação de outros mecanismos, tais como campos magnéticos e movimento turbulento, deve certamente também influenciar a evolução de uma dada nuvem. O campo magnético pode amortecer o colapso gravitacional em uma nuvem gerando estruturas alongadas e no regime subcrítico, (i.e. quando as forças magnéticas excedem as gravitacionais), formação estelar de baixa-massa deve ser favorecida (Shu et al. 1987). Assim, a determinação da estrutura do campo magnético interno a uma nuvem escura é crucial para compreender sua estrutura e evolução.

Campos magnéticos podem alinhar grãos de poeira no meio interestelar (DG; § 1.2.4). Grãos de poeira alinhados e assimétricos polarizam a luz de estrelas de fundo e podem revelar a estrutura do campo magnético entre o observador e as estrelas de fundo. Neste caso, a direção (projetada no céu) do campo magnético interestelar é paralela à direção da polarização observada. Vrba et al. (1976) utilizaram polarimetria óptica de estrelas de fundo para mapear a geometria do campo magnético nas regiões externas a cinco complexos de nuvens escuras (Barnard 42, Lynds 1630, Lynds 1450, Corona Austrina e Lynds 1551). Esse estudo visava estabelecer uma relação entre a geometria do campo magnético e a morfologia de complexos de nuvens de ativa formação estelar.

Trabalhos posteriores ampliaram os mapas de polarização a outras nuvens escuras alongadas mostrando que, em algumas regiões, os vectores de polarização são rigorosamente perpendiculares aos contornos alongados das nuvens projetados no céu (por exemplo, Barnard 216/217 [Heyer et al. 1987], Lupus 1 [Strom et al. 1988], Lynds 204 [McCutcheon et al. 1986], Lynds 1755 [Goodman et al. 1990], Musca [Arnal et al. 1993], Lupus 4 [Rizzo et al. 1998]). No entanto, em outros casos, o campo magnético parece ser paralelo às nuvens alongadas (por exemplo, Barnard 42 [Vrba, Strom e Strom 1976], lado leste de RcrA [Vrba et al. 1981], Lynds 1641 [Vrba et al. 1988]). Em alguns casos, não é possível definir uma direção preferencial com respeito do eixo projetado da nuvem (por exemplo, Barnard 18 [Heyer et. al 1987], Lynds 1506 e Perseus [Goodman et al. 1990], Lupus 1 [Rizzo et al. 1998]). 
A questão de se polarimetria de estrelas de fundo mapea realmente as regiões densas em nuvens escuras tem sido explorada por Goodman et. al 1995 e Goodman 1996. Esses autores consideram três fatos observacionais que levariam a concluir que nuvens escuras frias são ineficientes polarizadores da luz de estrelas de fundo. Primeiro, observações no infravermelho-próximo das regiões mais extintas nas nuvens escuras frias $\left(A_{\mathrm{V}} \sim 10 \mathrm{mag}\right.$ ) mostram um padrão de vetores de polarização idêntico àquele obtido de simples extrapolação das observações ópticas feitas nas periferias das nuvens $\left(A_{\mathrm{V}} \sim 1 \mathrm{mag}\right)$ (Figura 4 de Goodman 1996). Segundo, o valor médio e a dispersão na distribuição do ângulo de polarização para os dados ópticos e infravermelhos são idênticos (Figura 2 de Goodman et al. 1992). Ambos fatos implicariam que: (a) o notório incremento na densidade nas nuvens escuras não tem efeito sobre o campo magnético local; (b) a dispersão do campo magnético se incrementa nas nuvens escuras de tal forma que enmascara as mudanças do próprio campo; ou (c) a polarimetria infravermelha-próxima não é sensível ao campo magnético dentro das nuvens escuras. A conclusão (c) é considerada a correta, em vista do terceiro fato observacional de que a polarização não se incrementa com a extinção dentro das nuvens escuras (Figura 5 de Goodman 1996). Ou seja, esse autores concluem que as nuvens escuras são invisíveis desde o ponto de vista da polarimetria de estrelas de fundo.

Nosso ponto de vista sobre esta última questão é que a conclusão de Goodman et al. (1996) baseia-se numa amostra limitada de objetos de fundo. Por exemplo, as relações entre polarização e extinção, que são a base da argumentação anterior, apresentam medidas de somente algumas dezenas de objetos espalhados numa área de alguns graus quadrados ao redor das nuvens escuras B216-217 (Goodman et al. 1992), L1755 (Goodman et al. 1995), L1688 (Wilking et al. 1979), H Cl 2 (Tamura et al. 1987) e NGC 1333 (Tamura et al. 1988). Acreditamos que uma amostra mais completa e com maior resolução angular nos mapas de polarização é necessária para validar este resultado. Outro ponto a favor deste tipo de mapeamentos propostos é que permitiram detectar mudançãs no campo magnético não vistos por mapas a grande escala. 


\section{Capítulo 2}

\section{Polarimetria de Imagem com CCD}

\subsection{Resumo}

Neste capítulo descreveremos o hardware e software desenvolvido no IAG para a colheita e redução de imagens polarimétricas. Nossa contribuição foi a elaboração de um programa de controle da gaveta polarimétrica do IAG. Desenvolvemos ainda rotinas dentro do ambiente IRAF (pacote PCCDPACK) para a redução semi-automática de imagens polarimétricas de objetos pontuais. 


\subsection{Análise da luz polarizada}

Nesta seção, descreveremos brevemente o formalismo da análise a luz linearmente polarizada. Para uma explicação mais completa, o leitor pode remeter-se a Serkowsky 1974, Magalhães 1979 e Magalhães et al. 1984.

A luz, em geral, pode ser assumida como parcialmente elipticamente polarizada. Deste modo, a luz pode ser descrita pelos parâmetros de Stokes $I, Q, U$ e $V$ e decomposta em dois feixes: um deles natural, composto de luz não polarizada de intensidade $I \cdot\left(1-P_{E}\right)$; e o outro, completamente elipticamente polarizado de intensidade $I=\sqrt{Q^{2}+U^{2}+V^{2}}$, onde $P_{E}$ é o grau de polarização.

O vetor de uma onda luminosa associado ao feixe polarizado descreve uma elipse sobre a esfera celeste. $O$ ângulo de posição $\theta$ do plano de vibração é definido, em Astronomia, como o ângulo medido entre a direção do pólo norte celeste e o eixo maior da elipse de polarização no sentido anti-horário (isto é, medido do Norte para o Leste). Se a razão do eixo menor ao eixo maior da elipse é denotado por $\tan \beta$ os parâmetros de Stokes são:

$$
\begin{aligned}
& Q=I P_{E} \cos 2 \beta \cos 2 \theta=I P \cos 2 \theta \\
& U=I P_{E} \cos 2 \beta \sin 2 \theta=I P \sin 2 \theta \\
& V=I P_{E} \sin 2 \beta
\end{aligned}
$$

onde $P=P_{E} \cos 2 \beta$ é o grau de polarização linear, e $P_{V}=P_{E} \sin 2 \beta$ é o grau de elipticidade. Se $P_{V}$ é positivo teremos polarização elíptica à esquerda (right-handed), caso contrário $\left(P_{V}<0\right)$ teremos polarização elíptica à direita (left-handed). Assim, o grau de polarização linear e seu ângulo ficam definidos por:

$$
\begin{aligned}
& P=\sqrt{Q^{2}+U^{2}} / I \\
& \theta=1 / 2 \tan ^{-1}(U / Q)
\end{aligned}
$$

Para a análise da luz linearmente polarizada geralmente uma combinação de elementos ópticos: analisador e retardador é necessária na construção de um polarímetro. $O$ analisador subdivide a luz incidente em dois feixes, um deles linearmente polarizado em um plano paralelo ao plano principal do analisador, e o outro perpendicular a este. Dependendo da estratégia observacional, a escolha do analisador adequado pode ficar entre um típico divisor de feixe (beam-splitting analyzer) que maximiza a economia de luz ao medir 
ambos planos de polarização simultaneamente (tipo prisma Savart de calcita), ou um analisador com um dos planos de polarização extinto (tipo Polaróide). O primeiro preferentemente é usado em medidas de objetos pontuais e o segundo para objetos extensos.

O segundo componente óptico do polarímetro, o retardador, no seu caso mais simples, é uma placa plano-paralela cortada com o eixo óptico paralelo às faces da placa. Ele introduz uma diferença de fase (retardância, $\tau$ ) entre os feixes polarizados paralelo (feixe extraordinário) e perpendicular (feixe ordinário) ao eixo óptico. A retardância depende dos índices de refração ordinário e extraordinário do retardador, da espessura da placa, assim como do comprimento de onda. O retardador é colocado na frente do analisador fixo e é girado evitando assim a necessidade de rotar o mesmo analisador e/ou o detetor (isto é, a câmara CCD) ao registrar a modulação da luz polarizada. Para a análise da luz linearmente polarizada é utilizado um retardador com $\tau=\pi$, chamado 'lâmina de meia-onda', que muda luz polarizada a um ângulo $\theta$ em luz polarizada em $2 \psi-\theta$, onde $\psi$ é a orientação do eixo óptico da lâmina (que para nossos propósitos, é o ângulo de posição do retardador).

O polarímetro do IAG, quando utilizado no seu modo linear, apresenta uma combinação retardador-analisador composta de uma lâmina meia-onda giratória seguida por um prisma Savart de calcita.

O prisma de Savart (ver Figura 2.1) é composto por dois prismas de calcita cimentados com seus eixos ópticos perpendiculares um ao outro. Cada prisma de calcita, por sua vez, é construído de tal forma que seu eixo óptico faz $45^{\circ} \mathrm{com}$ as faces de entrada e saída. A combinação do prisma de Savart faz que o feixe ordinário do primeiro prisma se comporte como um feixe extraordinário no segundo prisma. Por sua vez, o feixe extraordinário do primeiro prisma se comportará como um feixe ordinário no segundo. Isto faz que não tenha sentido definir um raio ordinário e extraordinário para o sistema composto do prisma de Savart. O resultado são dois feixes emergentes deslocados ao longo de uma diagonal com respeito à direção inicial incidente. A distancia entre os feixes é $\sqrt{ } 2$ vezes o deslocamento devido somente a um dos prismas. 


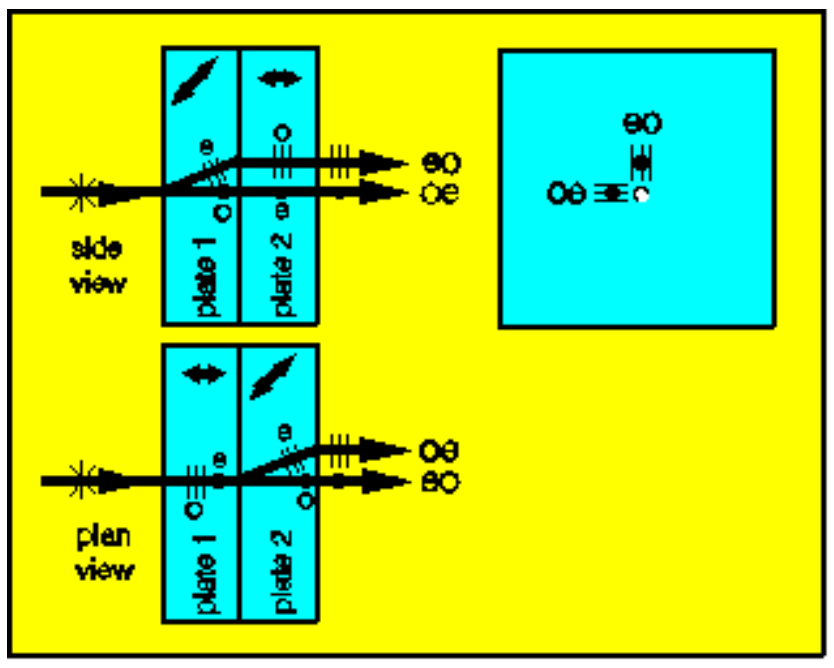

Figura 2.1 Desenho do prisma de Savart (figura obtida do site da Halbo Optics Company, http://www.halbo.com).

A intensidade da luz transmitida ( $\left.I^{\prime}\right)$ por uma lâmina de meia-onda na posição $\psi$, seguida de um prisma de Savart fixo, é (Serkowsky 1974a)

$$
I^{\prime}(\psi)=1 / 2(I \pm Q \cos 4 \psi \pm U \sin 4 \psi)
$$

onde o sinal superior (+) refere-se a um dos feixes e o sinal inferior (-) ao outro. Se $N_{i}^{+}$e $N_{i}^{-}$são o número de contagens para o primeiro e segundo feixe, respectivamente, na posição $i$-ésima da lâmina retardadora, podemos escrever a modulação da intensidade no ângulo $\psi_{i}$ assim:

$$
\begin{aligned}
& \frac{N_{i}^{+}}{\overline{N^{+}}}=1+\left(Q^{\prime} \cos 4 \psi_{i}+U^{\prime} \sin 4 \psi_{i}\right) \\
& \frac{N_{i}^{-}}{\overline{N^{-}}}=1-\left(Q^{\prime} \cos 4 \psi_{i}+U^{\prime} \sin 4 \psi_{i}\right)
\end{aligned}
$$

onde, $\overline{N^{+}}=(1 / n) \sum_{i}^{n} N_{i}^{+}, \overline{N^{-}}=(1 / n) \sum_{i}^{n} N_{i}^{-}, \psi_{i}=(i-1) 22.5^{\circ}$, para $i=1, . ., n$; e $Q$ 'e $U$, são os parâmetros de Stokes normalizados $\left(0 \leq Q^{\prime}, U^{\prime} \leq 1\right)$. Um número $(n)$ mínimo de quatro posições da lâmina retardadora são necessárias. No entanto, oito, doze ou dezesseis posições podem ser usadas para melhorar o erro da medida, que diminui com $\sqrt{ } n$. A combinação lâmina meia-onda/prisma Savart modula a polarização de entrada com uma freqüência de quatro vezes a rotação física da lâmina, de modo que quatro posições cobrem um ciclo de modulação e posições com $90^{\circ}$ de diferença são opticamente equivalentes. 
Para obter os parâmetros de Stokes, basta resolver por uma técnica numérica (usualmente mínimos quadrados) a seguinte equação derivada das equações (2.7):

$$
Q^{\prime} \cos 4 \psi_{i}+U^{\prime} \sin 4 \psi_{i}=\frac{N_{i}^{+}-N_{i}^{-} \cdot k}{N_{i}^{+}+N_{i}^{-} \cdot k}=z_{i}
$$

onde o termo $z_{i}$ é construído das medidas para cada posição da lâmina e $k=\overline{N^{+}} / \overline{N^{-}}$. A solução usando mínimos quadrados é:

$$
\begin{aligned}
Q^{\prime} & =\frac{2}{n} \sum_{i}^{n} z_{i} \cos 4 \psi_{i} \\
U^{\prime} & =\frac{2}{n} \sum_{i}^{n} z_{i} \sin 4 \psi_{i}
\end{aligned}
$$

O erro médio de cada parâmetro pode ser obtido de:

$$
\sigma_{Q}=\sigma_{U}=\frac{1}{\sqrt{n} / 2} \sqrt{\frac{1}{n-2}\left[\sum_{i}^{n} z_{i}^{2}-\frac{n Q^{2}}{2}-\frac{n U^{2}}{2}\right]}
$$

A polarização linear em porcentagem fica definida por:

$$
P=100 \sqrt{Q^{2}+U^{2}}
$$

e seu erro é $\sigma_{P}=\sigma_{U}=\sigma_{Q}$. O ângulo de posição da polarização estará dado por

$$
\theta=1 / 2 \tan ^{-1}\left(U^{\prime} / Q^{\prime}\right)
$$

e seu erro é $\sigma_{\theta}=28.65^{\circ} \sigma_{P} / P$ (Serkowsky 1974b).

\subsection{A Gaveta Polarimétrica do IAG}

\subsubsection{Descrição da Gaveta Polarimétrica do IAG}

O Departamento de Mecânica e a Seção Técnica de Eletrónica do IAG-USP desenvolveram e construíram a Gaveta Polarimétrica sob a supervisão do Dr. Antônio Mário Magalhães, e os testes inicias de funcionamento foram feitos no começo de 1996.

O instrumento (ver Figura 2.2) está composto basicamente da gaveta polarimétrica propriamente dita e de uma caixa de drives. A gaveta abriga os dispositivos ópticos e mecânicos e a caixa de drives está composta de uma fonte de alimentação e dos circuitos 
eletrônicos de controle dos motores de passo e sensores de posição que acionam as partes ópticas.

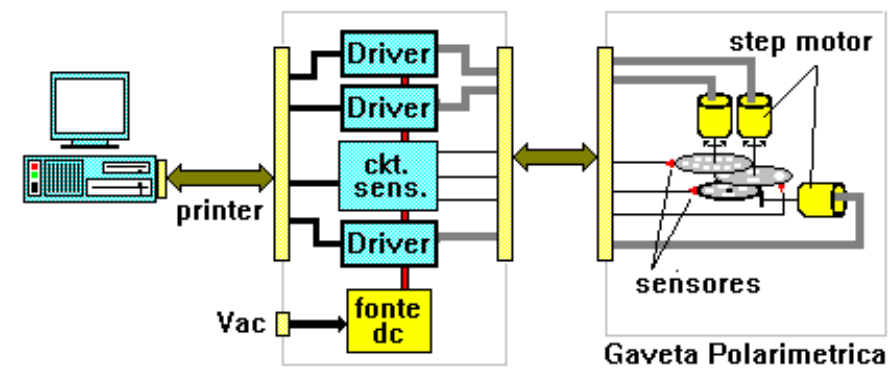

Figura 2.2 Diagrama esquemático da Gaveta Polarimétrica do IAG (figura obtida do Manual de Eletrônica de Controle da Gaveta Polarimétrica do IAG, Seção Técnica de Eletrônica do IAG-USP, responsável: Eng. Luis Galhardo Filho).

A gaveta polarimétrica está projetada para ser colocada na câmara CCD do Laboratório Nacional de Astrofísica (LNA) e consta basicamente de três dispositivos ópticos: uma lâmina retardadora, um analisador e um filtro. Tanto o analisador como o filtro possuem rodas próprias que permitem o uso de até 3 tipos diferentes de analisador e até 4 tipos de filtros. Três motores de passo controlam o giro da lâmina retardadora sobre si mesma e o posicionamento das rodas do analisador e dos filtros. A codificação das posições das peças ópticas é controlada por sensores eletro-mecânicos (micro-swithes). O processo de movimentação dos motores de passo, assim como a leitura dos micro-swithes, é controlada através da saída de uma porta paralela de um PC mediante um programa de controle (ver seção seguinte) especialmente desenvolvido para este propósito. O cabo de comunicação entre o computador e a caixa de drives tem um alcance máximo de 20 metros.

A gaveta polarimétrica aceita atualmente dois tipos de lâmina retardadora: $\lambda / 2$, para observações de polarimetria linear, e $\lambda / 4$, para observações de polarimetria circular. Dependendo do caso, o analisador também pode ser escolhido entre um prisma Savart de calcita (para objetos pontuais) ou um Polaróide (para objetos extensos). O desenho da roda do analisador possui duas posições para Polaróides, o que permite o uso conjunto de dois deles cada um centrado num comprimento de onda de interesse. Finalmente, a roda de filtros possui quatro posições para igual número de filtros. Assim, se por exemplo pretendemos operar a gaveta no seu modo linear uma combinação típica para objetos pontuais será: lâmina retardadora $\lambda / 2+$ prisma de calcita + filtros; por outro lado, se a observação priorizará objetos extensos a combinação escolhida será: lamina retardadora 
$\lambda / 2+$ Polaróide + filtros. Um disenho esquemático do sistema óptico da gaveta polarimétrica é mostrado na Figura 2.3.

A gaveta polarimétrica do IAG é altamente eficiente e é capaz de realizar observações de polarimetria linear com precisão limitada pelo ruído de fótons apenas para fontes pontuais. Da experiencia observacional acumulada, concluímos que a técnica nos permite atingir estrelas até magnitude 16 para tempos de exposição usuais de 5 minutos por posição da lâmina retardadora. Para um conjunto típico de 8 posições da lâmina, uma razão sinal-ruído de polarização maior ou igual que 5 é esperada.

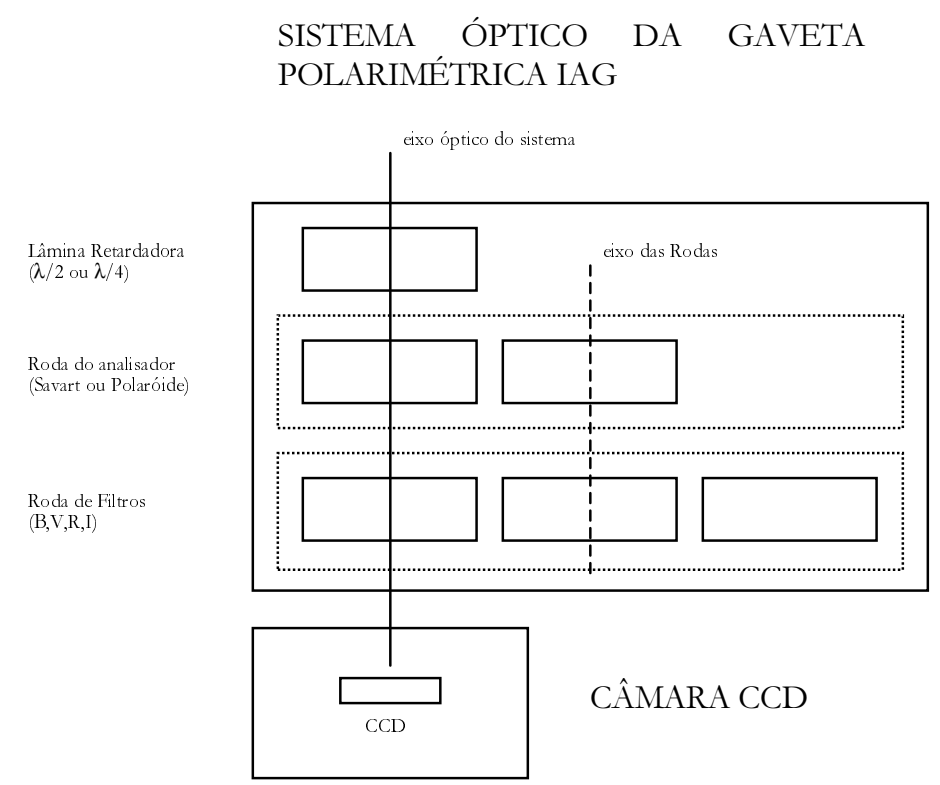

Figura 2.3 Disenho esquemático do sistema óptico da gaveta polarimétrica do IAG.

\subsubsection{Programa de controle}

Foi desenvolvido por nós um programa de controle da Gaveta Polarimétrica do IAG que basicamente permite a movimentação das peças ópticas de que está composta. O código foi desenvolvido na linguagem de programação QBASIC e pode rodar no ambiente DOS ou Windows. Uma listagem do programa é mostrada no Apêndice A. A configuração básica para que o executável rode com sucesso é um PC Pentium 100 com uma saída de porta paralela standard disponível (que conectará o PC à caixa de drives através do cabo de comunicação). 
Ao iniciar o programa de controle um ajuste de posição absoluta será requerido para cada um dos três motores que controlam a lâmina retardadora, a roda do analisador e a roda de filtros respectivamente. Esta 'zeragem' é feita digitando os comandos 'Z1', 'Z2' e 'Z3'. Por convenção as posições por default inicias são: posição 1 para a lâmina retardadora, prisma de calcita inserido no feixe para o analisador e posição do primeiro filtro (usualmente B) para a roda de filtros.

O passo seguinte é escolher quais serão o analisador e o filtro a utilizar. Atualmente duas das três posições do analisador estão disponíveis, assim digitando 'P' a roda do analisador se colocará na posição do polaróide, ou se digitar 'C', retornará à posição da calcita. No caso da roda de filtros quatro posições são disponíveis e sendo a configuração de filtros mais usada a BVRI a movimentação é feita digitando 'B', 'V', 'R', ou 'I' com o qual a roda se colocará na posição de cada um dos filtros correspondentes. Se outros filtros diferentes aos padrões são usados basta lembrar a seqüência certa.

Uma vez tendo ajustado o analisador e o filtro correspondente, o sistema está pronto para começar uma seqüência de rotação da lâmina retardadora. A lâmina retardadora gira sobre si mesma e uma rotação completa consta de 16 posições com uma separação de $22.5^{\circ}$ entre cada uma delas. O sistema "acha" cada posição quando seu número correspondente, é digitado. Assim, se por exemplo, se deseja atingir a nona posição da lâmina retardadora, basta digitar ' 9 ' seguido de $<$ return $>$.

A seqüência de posições da lâmina a utilizar dependerá do plano de observação, das condições de observação, assim como do erro esperado na medida. Em cada posição da lâmina retardadora uma imagem do objeto de interesse deve ser feito. Basta uma seqüência de 4 posições contíguas (por exemplo: pos. 1, 2, 3 e 4) para completar uma medida. O erro da medida diminui com a $\sqrt{ } N$, onde $\mathrm{N}$ é o número de posições consideradas. Assim, a seqüência básica de 4 posições geralmente é usada quando os tempos de integração são longos. Se as integrações por posição são curtas, seqüências de 8 ou 16 posições são recomendadas para melhorar o erro da medida. Uma vez completada uma seqüência de rotação da lamina retardadora, esta deve ser colocada novamente na sua posição 1 já seja digitando ' $Z 1$ ' ou '1'. 
Outros comandos incluídos no programa de controle permitem desligar os motores de passo quando for preciso (digitando 'D') e abortar a seqüência (digitando 'Q'). Cada movimentação das partes ópticas controladas pelo programa de controle é acompanhada na tela do PC de modo que uma apreciação completa do status da gaveta em cada instante pode ser obtido.

O programa de controle da gaveta polarimétrica do IAG vem funcionando satisfatoriamente desde seus teste iniciais em meados de 1996. Seu aprimoramento constante baseia-se fundamentalmente nas sugestões dos usuários que neste tempo têm utilizado o equipamento.

\subsection{Pacote de redução de Imagens Polarimétricas - PCCDPACK}

O pacote de redução de imagens polarimétricas PCCDPACK para objetos pontuais é o resultado de uma tentativa de semi-automatizar este processo. As rotinas que formam parte dele foram escritos em CL (Command Language) para serem rodados dentro do ambiente IRAF e poder utilizar algumas das livrarias e pacotes já existentes. Algumas rotinas possuem uma saída gráfica que utiliza uma interface gráfica escrita em IGI (Interactive Graphics Interpreter) do pacote STSDAS. A seguir, descreveremos um processo de redução típico onde intentaremos detalhar a seqüência de rotinas utilizadas. Para uma descrição mais detalhada de cada rotina ver o Apêndice B.

Primeiramente, assumiremos que foi observado um campo estelar denso (de algumas centenas de estrelas) com uma câmara CCD e a gaveta polarimétrica no seu modo linear para objetos pontuais (lâmina $\lambda / 2+$ prisma de calcita + filtro). Uma seqüência de quatro posições da lâmina retardadora foi feita, o que resultou em quatro imagens de nosso campo (chamaremos imagem 1 à imagem da 1a. posição da lâmina, e assim sucessivamente). Um exemplo de uma das imagens em uma das posições da lâmina para um campo típico é mostrado na Figura 2.4. A dupla imagem para cada objeto no campo é devida ao prisma de calcita. 


\subsubsection{Criando uma arquivo de coordenadas ordenado - ORDEM}

Depois de fazer as correções rotineiras de bias, flat e overscan sobre nossas imagens, precisamos obter as coordenadas (em pixels) de cada um dos objetos com perfil estelar presentes em nossos campos. Neste ponto usualmente tem que ser definida uma das quatro imagens da seqüência como a imagem de referência sobre a qual a procura de coordenadas será feita (usualmente será a imagem 1).

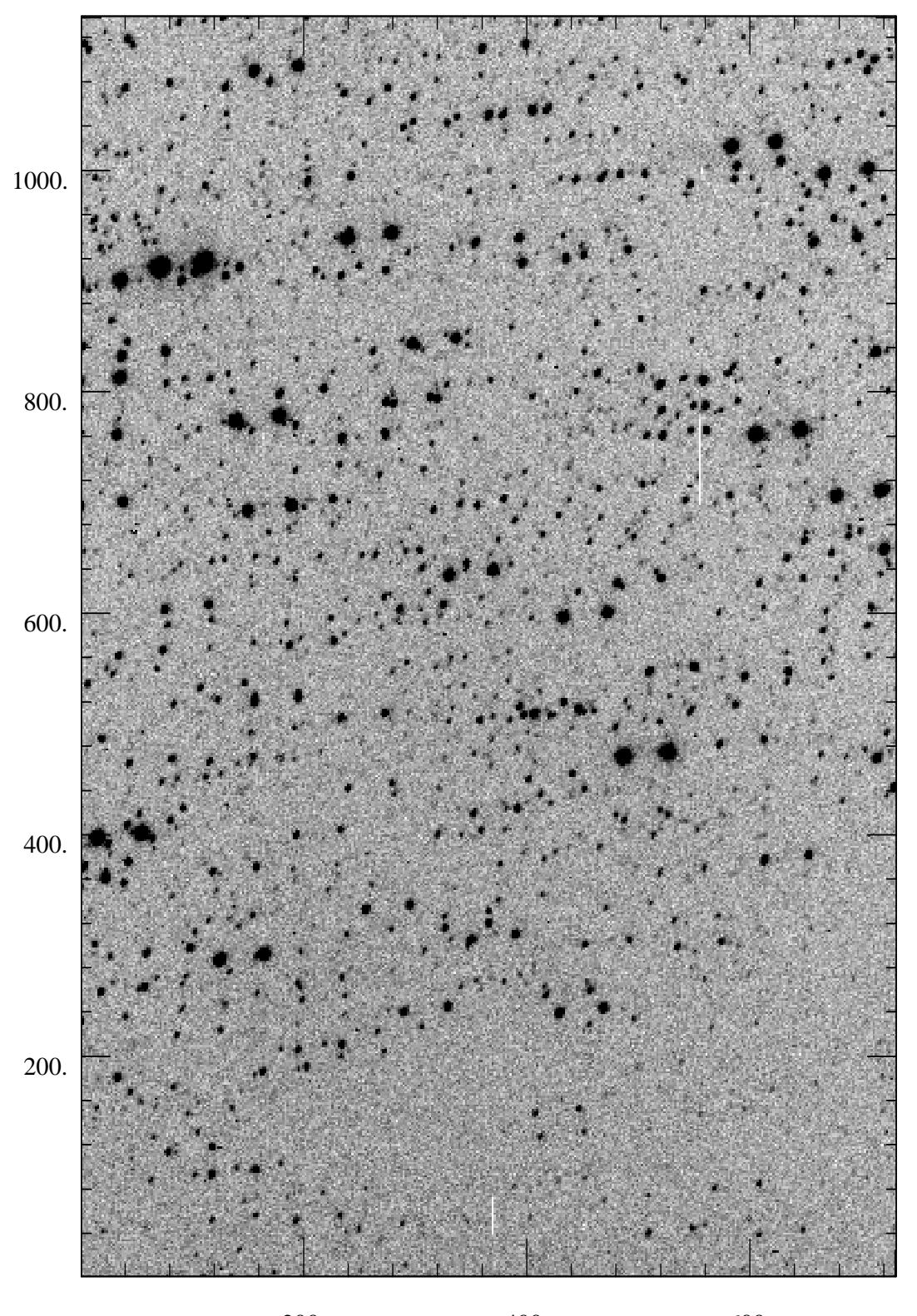

200.

400.

600.

Figura 2.4 Exemplo de um campo estelar denso típico obtido em uma das posições da lâmina retardadora com a gaveta polarimétrica do IAG. Note a imagem dupla para cada objeto devida ao prisma de calcita. Esta imagem foi obtida com o CCD048 (770x1152 pixels) e cobre uma área 8'x12'. A região mostrada corresponde ao campo 01 do estudo observacional do Capítulo 3. O Norte está a direita e o Leste para acima. 
Escolhida esta imagem de referência, utilizamos a rotina DAOFIND do pacote DAOPHOTX para criar uma lista de coordenadas das estrelas no campo. Esta rotina faz uma procura ao longo do eixo X e logo ao longo do eixo Y do campo CCD, nessa ordem. Mas como nossos campos apresentam imagens duplas para cada estrela devido ao prisma de calcita do polarímetro (para nossos propósitos, definiremos a imagem ordinária como aquela que esteja sempre na posição inferior, e a extraordinária na posição superior, ver Figura 2.4), o arquivo obtido mistura imagens ordinárias e extraordinárias de estrelas diferentes. Assim, ele deve ser ordenado de modo a apresentar a coordenada da imagem ordinária seguida da coordenada da imagem extraordinária para cada estrela do campo. Isto é feito com a rotina ORDEM do PCCDPACK que seleciona o arquivo de coordenadas obtido pelo DAOFIND, em posições pares $(\mathrm{x} 0, \mathrm{y} 0)$ inferior, e $(\mathrm{x} 1, \mathrm{y} 1)$ superior para cada estrela. Para uma descrição detalhada desta rotina ver Apêndice B.1.

\subsubsection{Corrigindo os deslocamentos entre imagens - COORSHIFT}

Geralmente a posição de um objeto na imagem de referência (1) apresenta um deslocamento com respeito à posição do mesmo objeto nas imagens restantes (2, 3 e 4). Isto pode acontecer por problemas no acompanhamento do telescopio, especialmente quando integrações longas são feitas em cada posição da lâmina. Se este for o caso, o arquivo de coordenadas para a imagem de referência deve ser corrigido pelo deslocamento de cada uma das imagens restantes.

A idéia é obter um arquivo de coordenadas por cada imagem (no nosso exemplo, seriam 4 arquivos de coordenadas), mantendo em todos eles a seqüência de objetos listada no arquivo de coordenadas da imagem de referência. Para isto, precisamos primeiro calcular o deslocamento das imagens 2, 3 e 4 com respeito à imagem de referência (1) o que pode ser feito utilizando a rotina IMALIGN do pacote PROTO. Esta rotina cria uma saída na tela com a informação dos deslocamentos calculados e deve ser direcionada a um arquivo de texto. Este arquivo será utilizado pela rotina COORSHIFT do PCCDPACK para criar os novos arquivos de coordenadas para cada uma das imagens já corrigidos. Uma descrição detalhada desta rotina é apresentada no Apêndice B.2. 


\subsubsection{Fotometria das Imagens}

Com as correções nas coordenadas feitas, estamos prontos para calcular a fotometria de cada uma das imagens utilizando a rotina PHOT do pacote DAOPHOTX. Esta rotina utiliza como entrada os arquivos de coordenadas anteriormente criados (lista 'inord'). Se as imagens não apresentam deslocamentos entre elas basta utilizar como entrada da rotina PHOT o arquivo de coordenadas da imagem 1.

\subsubsection{Calculando os parâmetros polarimétricos - PCCD}

Depois de realizar a fotometria sobre nossas imagens, a rotina PHOT terá criado um arquivo de magnitudes (com extensão 'mag') por cada imagem de cada posição da lâmina retardadora (no nosso exemplo, serão 4 arquivos de magnitudes). Nestes, está contida a informação de fotometria de abertura para todos os objetos do campo e em toda a faixa de aberturas definidas com anterioridade. Antes de calcular os parâmetros polarimétricos para todos os objetos das imagens precisamos extrair dos arquivos de magnitudes toda a informação necessária da fotometria que precisamos. Para criar o arquivo de informação ver Apêndice B.3.

Uma vez criado o arquivo de informação, a rotina PCCD do PCCDPACK pode ser executada para criar os parâmetros polarimétricos de cada um dos objetos em nosso campo. A rotina PCCD permite executar dentro do IRAF um código de cálculo de parâmetros polarimétricos escrito por o Dr. Antônio Mário Magalhães em FORTRAN que ajusta por mínimos quadrados a modulação da intensidade da luz polarizada e calcula os parâmetros de interesse. Uma descrição detalhada desta rotina é apresentada no Apêndice B.4.

\subsubsection{Escolhendo a abertura com menor erro - MACROL}

Quando várias aberturas forem utilizadas no cálculo da fotometria, é preciso escolher, entre todas elas, aquela que representa a medida polarimétrica certa para uma estrela dada. Nós definimos a abertura correta como aquela que fornece o menor erro no ajuste da 
polarização (isto é, aquela abertura que apresenta o menor $\sigma_{\mathrm{P}}$ ). Para sistematizar este passo, em um campo com centenas de estrelas, utilizamos a rotina MACROL do PCCDPACK (ver Apêndice B.5). Em geral, a abertura de erro mínimo correspode a $\sim 1$ FWHM do perfil estelar para estrelas fracas que dominam nossos campos. Neste ponto a fase propriamente dita de redução de dados polarimétricos termina. Nas seções seguintes veremos algumas rotinas criadas para a análise estatística e a checagem dos dados polarimétricos em campos estelares densos.

\subsubsection{Análise dos dados polarimétricos - SELECT}

Para uma análise detalhada da polarimetria de objetos pontuais em campos estelares densos, criamos a rotina SELECT do PCCDPACK. Esta rotina está baseada numa versão inicial de um código escrito em FORTRAN pelo Dr. Antônio Mário Magalhães para os mesmos propósitos.

Basicamente esta rotina permite a análise de um campo estelar denso filtrando a amostra de objetos para um sinal ruído de polarização $\left(P / \sigma_{P}\right)$ definido pelo usuário. Os parâmetros de controle que definem a filtragem final estão mostrados no Apêndice B.6. Um exemplo da saída gráfica desta rotina é mostrado na Figura 2.5. Neste exemplo a amostra foi filtrada para uma $\left(P / \sigma_{P}\right)>5$. Na anâlise estatística dos Apêndices D e F, esta rotina foi utilizada exaustivamente.

$\mathrm{Na}$ Figura 2.5a mostramos a distribuição dos parâmetros de Stokes $Q=P \cdot \cos (2 \theta)$ e $U=$ $P \cdot \sin (2 \theta)$ para todos os objetos da amostra já filtrados. À direita está mostrado o cálculo dos valores médios do $Q$ e $U$ ponderados pelos erros individuais respectivos, assim como o erro medio da amostra $(\sigma)$. Com eles pode-se calcular os valores representativos médios do $P$ e $\theta$ (também mostrados) para o campo analisado.

$\mathrm{Na}$ Figura 2.5b mostramos os vetores de polarização distribuídos espacialmente sobre a área coberta pelo CCD. O Norte fica para cima e o Leste para a esquerda. A escala de polarização é mostrada no canto superior direito. Para distinguir com precisão alguma tendência preferencial de orientação dos vetores de polarização, na Figura 2.5c mostramos os histogramas do ângulo de polarização. A largura do bin corresponde a $5^{\circ}$. O Norte fica 
em $\theta=0^{\circ}$ e o Leste em $\theta=90^{\circ}$. Um ajuste de gaussianas (optativo) é utilizado para calcular a dispersão dos vetores de polarização e pode ser utilizado para obter informação sobre a intensidade do campo magnético e razões de densidades de energia. Finalmente na Figura $2.5 \mathrm{~d}$ mostramos os histogramas da amostra para os valores de polarização. A largura do bin corresponde a $0.5 \%$.

Esta rotina é de especial interesse quando se trata de utilizar a técnica para obter a polarização de foreground de um objeto em particular, do qual precisa ser descontada para se obter a polarização intrínseca. Neste caso, se suficientes estrelas no campo do CCD prevalecem, basta fazer a análise anterior para todas as estrelas do campo eliminando desta análise o objeto de interesse. Assim, os valores médios do $P$ e $\theta$ assim calculados podem ser assumidos como o foreground e serem descontados do valor medido do objeto analisado.

a)
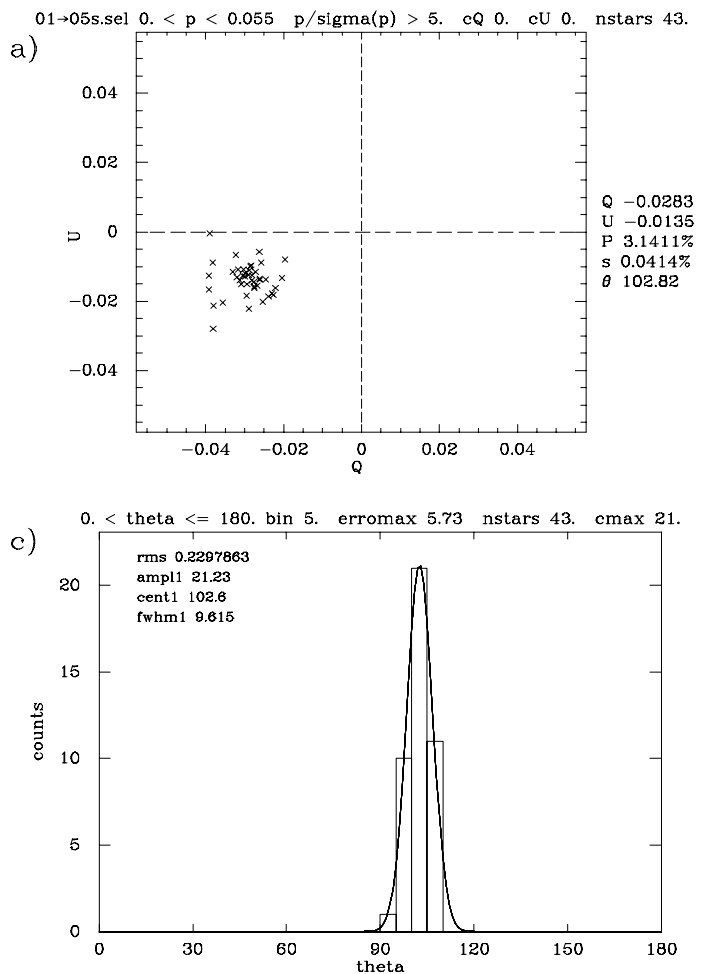

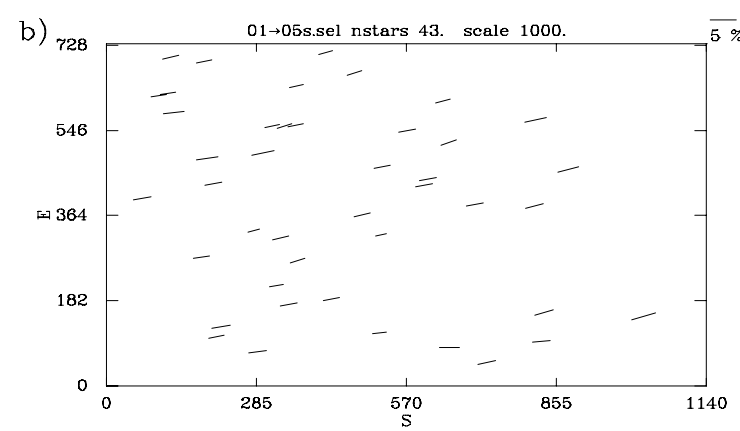

d)

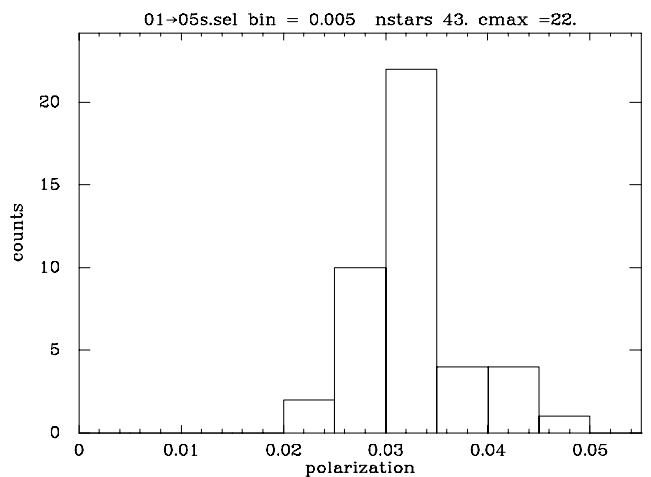

Figura 2.5 Exemplo da saída gráfica da rotina SELECT. 


\subsubsection{Graficando a modulação da polarização - GRAF}

A rotina GRAF permite verificar graficamente o ajuste da modulação da polarização para cada uma das estrelas de um campo dado feito pela rotina PCCD. Esta rotina foi inspirada numa versão semelhante escrita no SUPERMONGO pelo Dr. A. Mário Magalhães. Basicamente, a rotina permite analisar uma estrela dada que esteja contida no arquivo de saída da rotina PCCD (com extensão 'log'), e cujo ajuste para uma das aberturas utilizadas se deseja conferir. Por exemplo, pode-se utilizar esta rotina para verificar o ajuste na abertura escolhida pela rotina MACROL. Uma descrição mais detalhada é apresentada no Apêndice B.7.

Um exemplo da saída gráfica desta rotina é mostrado na Figura 2.6. Neste caso um ajuste para oito posições da lâmina foi feito. $\mathrm{Na}$ parte superior da figura estão indicados os parâmetros polarimétricos respectivos da estrela analisada para a abertura escolhida. A linha tracejada representa o ajuste de mínimos quadrados realizado e cada medida em cada posição da lâmina está indicada por um ' $x$ ' com seu erro respectivo.

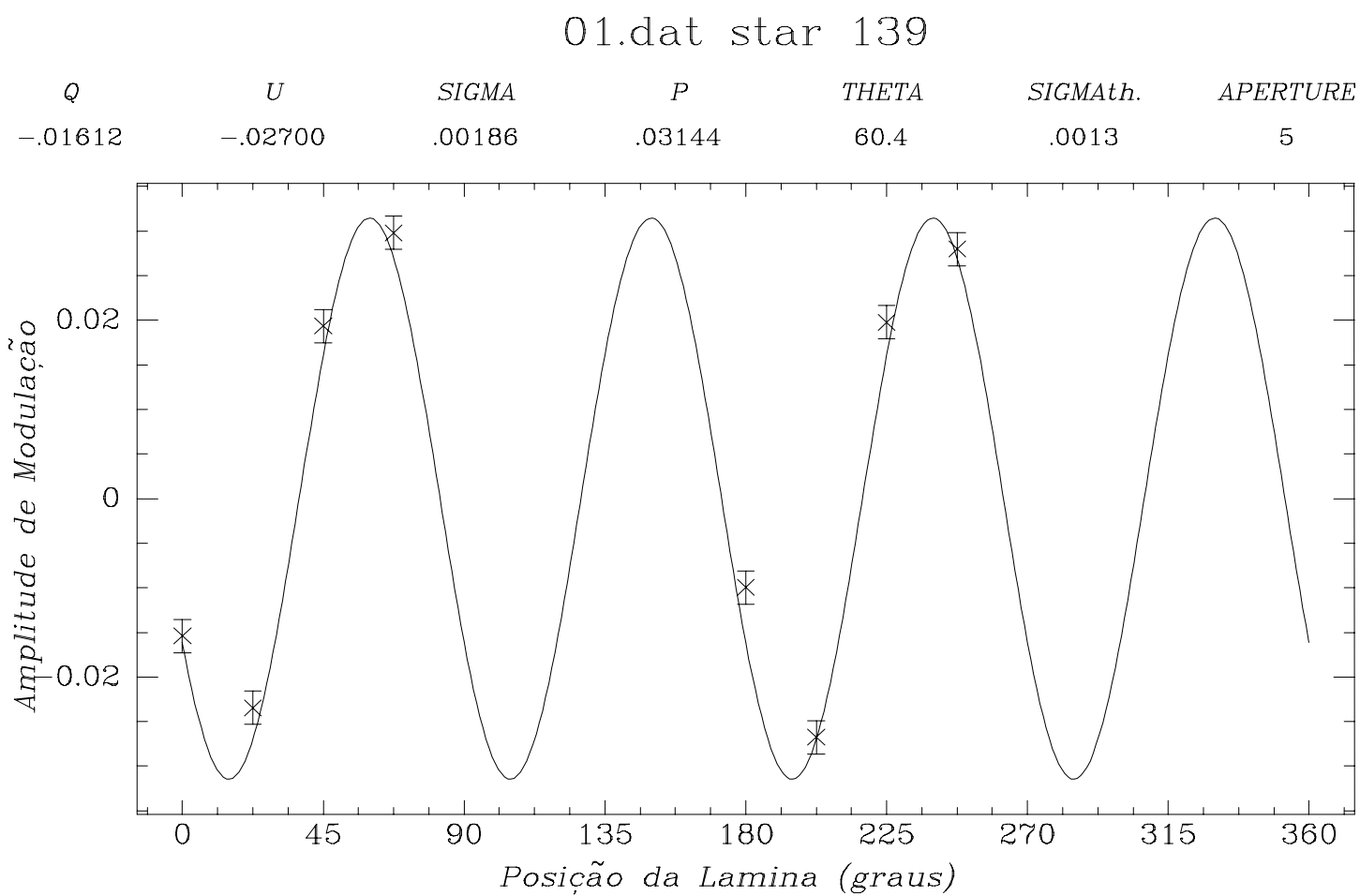

Figura 2.6 Exemplo da saída gráfica da rotina GRAF. 


\subsubsection{Calculando magnitudes da polarimetria-MAGNIT}

As mesmas imagens CCD utilizadas para o cálculo da polarização podem ser usadas numa estimativa das magnitudes. Para isto basta utilizar a imagem de uma das posições da lâmina retardadora em um campo dado. Neste caso, tanto o feixe ordinário e o extraordinário de cada objeto foram somados na mesma abertura utilizada para o cálculo da polarização. Para automatizar este processo criamos a rotina MAGNIT, no PCCDPACK, que permite o cálculo das magnitudes de imagens polarimétricas. No Apêndice B.8 é explicada em detalhe esta rotina.

A saída gráfica desta rotina é mostrada na Figura 2.7 onde podemos observar na esquerda um histograma com as magnitudes de todos os objetos presentes no campo e na direita um gráfico polarização vs. magnitude para a mesma amostra que permita detectar alguma correlação possívelmente existente.
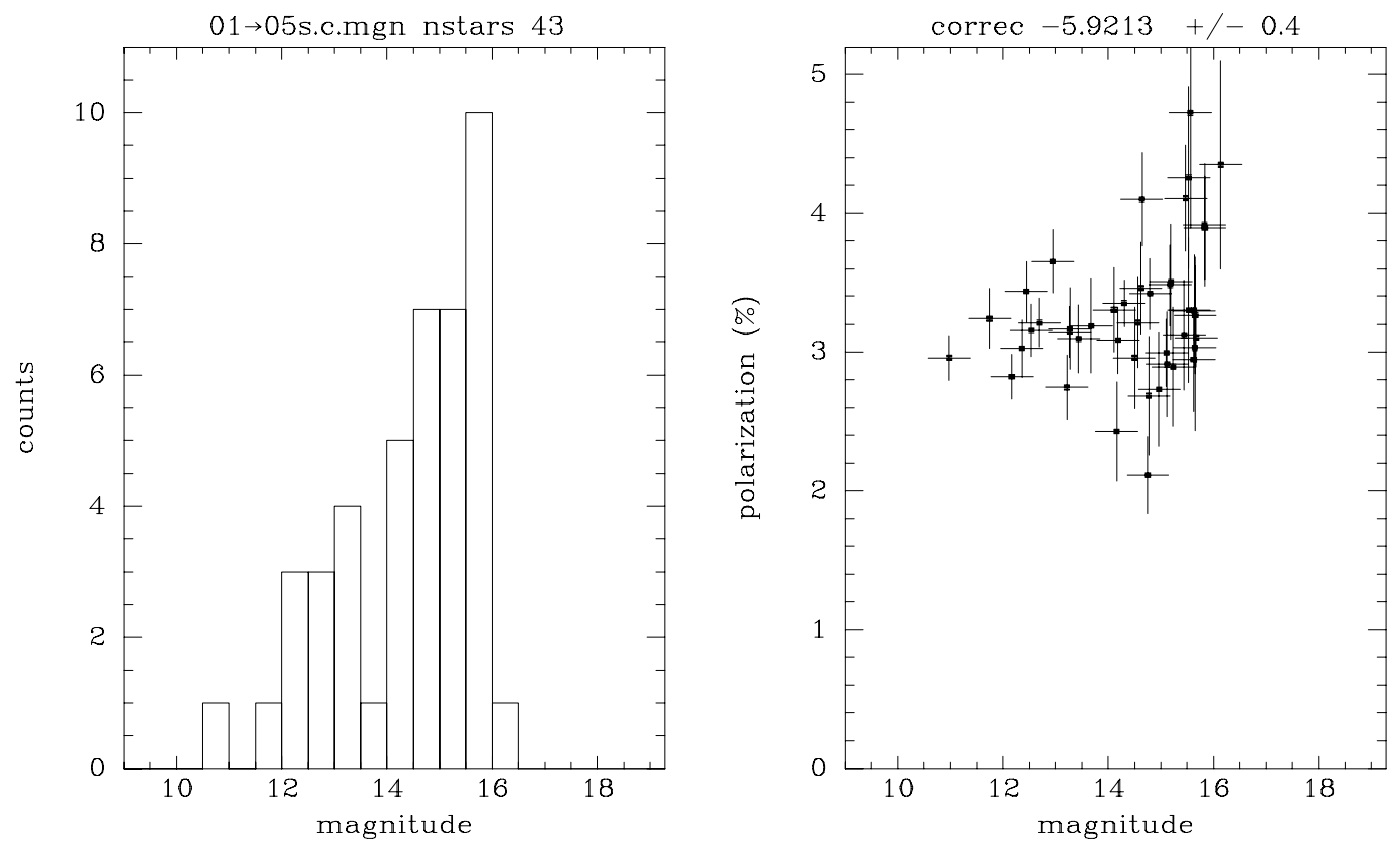

Figura 2.7 Exemplo da saída gráfica da rotina MAGNIT. 


\subsubsection{Criando um mapa de polarização - REFER e VECPLOT}

Com o objetivo de criar mapas de polarização dos objetos presentes no nossos campos CCD superpostos a imagens do Digitized Sky Survey (DSS), foi preciso registrar as posições em pixels das imagens originais com respeito a uma imagem de referência no DSS. Isto é feito utilizando a rotina REFER do PCCDPACK. Uma explicação detalhada desta rotina é apresentada no Apêndice B.9.

Para criar o mapa de polarização propriamente dito criamos a rotina VECPLOT (ver Apêndice B.10). A título de exemplo, apresentamos na Figura 2.8 uma saída gráfica desta rotina para um campo típico, onde mostramos os vetores de polarização, seus identificadores das posições dos objetos junto com a imagem DSS de fundo.

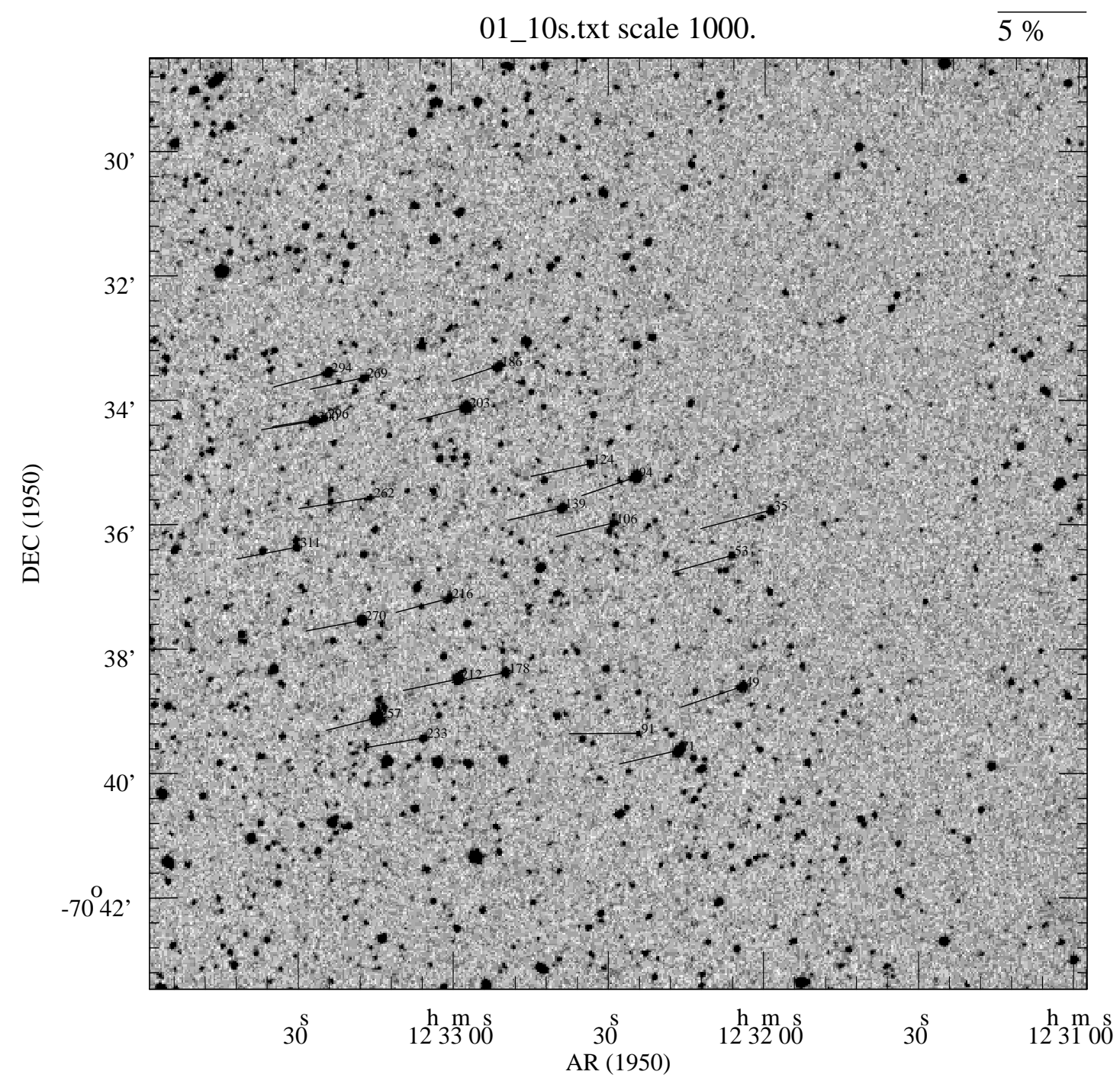

Figura 2.8 Exemplo de um mapa de polarização típico elaborado utilizando a rotina VECPLOT. 
Um catálogo polarimétrico para cada campo CCD pode ser construído utilizando a rotina FINTAB do PCCDPACK (ver Apêndice B.11, para uma explicação mais detalhada). Um exemplo de um catálogo polarimétrico construído por esta rotina é mostrado na Figura 2.9. As tabelas dos catálogos polarimétricos dos Apêndices C e E foram criados utilizando esta rotina.

$\begin{array}{lllllllr}\text { ID } & \text { AR }(1950.00) & \text { DEC }(1950.00) & \text { P() } & \text { SIGMA(\%) } & \text { THETA } & \text { MAG } & \text { EMAG } \\ 35 & 12: 31: 58.75 & -70: 35: 46.86 & 4.099 & 0.335 & 104.9 & 14.638 & 0.4 \\ 49 & 12: 32: 04.14 & -70: 38: 37.51 & 3.653 & 0.229 & 108.8 & 12.9477 & 0.4 \\ 53 & 12: 32: 06.28 & -70: 36: 30.90 & 3.481 & 0.29 & 106 . & 15.1817 & 0.4 \\ 71 & 12: 32: 16.50 & -70: 39: 39.29 & 3.434 & 0.217 & 103.1 & 12.4408 & 0.4 \\ 91 & 12: 32: 24.28 & -70: 39: 22.87 & 3.893 & 0.374 & 90.3 & 15.8349 & 0.4 \\ 94 & 12: 32: 24.70 & -70: 35: 15.09 & 3.24 & 0.215 & 109.3 & 11.746 & 0.4 \\ 106 & 12: 32: 29.07 & -70: 35: 59.61 & 3.303 & 0.306 & 103.6 & 14.1079 & 0.4 \\ 124 & 12: 32: 33.51 & -70: 35: 02.50 & 3.418 & 0.256 & 102 . & 14.7992 & 0.4 \\ 139 & 12: 32: 38.99 & -70: 35: 44.98 & 3.144 & 0.186 & 103.2 & 13.2684 & 0.4 \\ 178 & 12: 32: 49.86 & -70: 38: 24.19 & 3.092 & 0.245 & 100.6 & 13.434 & 0.4 \\ 186 & 12: 32: 51.21 & -70: 33: 27.93 & 2.745 & 0.231 & 108.2 & 13.2165 & 0.4 \\ 203 & 12: 32: 57.39 & -70: 34: 07.84 & 2.822 & 0.161 & 104.6 & 12.168 & 0.4 \\ 212 & 12: 32: 59.05 & -70: 38: 30.41 & 3.156 & 0.19 & 101.6 & 12.5344 & 0.4 \\ 216 & 12: 33: 00.76 & -70: 37: 12.29 & 3.101 & 0.209 & 105.1 & 15.6737 & 0.4 \\ 233 & 12: 33: 05.72 & -70: 39: 27.11 & 3.35 & 0.164 & 99.4 & 14.3013 & 0.4 \\ 257 & 12: 33: 14.67 & -70: 39: 07.37 & 2.957 & 0.16 & 104 . & 10.9792 & 0.4 \\ 262 & 12: 33: 15.82 & -70: 35: 34.53 & 4.108 & 0.382 & 98.9 & 15.473 & 0.4 \\ 269 & 12: 33: 17.04 & -70: 33: 38.95 & 3.082 & 0.239 & 102 . & 14.1791 & 0.4 \\ 270 & 12: 33: 17.57 & -70: 37: 33.13 & 3.212 & 0.175 & 100.9 & 12.6921 & 0.4 \\ 294 & 12: 33: 23.89 & -70: 33: 33.55 & 3.168 & 0.293 & 104.9 & 13.275 & 0.4 \\ 296 & 12: 33: 24.59 & -70: 34: 17.69 & 2.993 & 0.242 & 99.4 & 15.1112 & 0.4 \\ 300 & 12: 33: 26.58 & -70: 34: 20.39 & 3.024 & 0.207 & 99.6 & 12.3614 & 0.4 \\ 311 & 12: 33: 30.09 & -70: 36: 22.40 & 3.458 & 0.332 & 101.2 & 14.6166 & 0.4\end{array}$

Figura 2.9 Exemplo de um catálogo polarimétrico construído utilizando a rotina FINTAB. 


\section{Capítulo 3}

\section{Polarimetria, Extinção e Campo Magnético na Nuvem Escura de Musca}

\subsection{Resumo}

Utilizamos a técnica de polarimetria de imagem para obter medidas da polarização linear da Nuvem Escura de Musca (NEM). Com isto, construímos mapas de polarização que nos permitem inferir a geometria presente do campo magnético local. Um catálogo com ao redor de 2500 objetos nos permite detectar variações importantes no valor da polarização e no ângulo de polarização ao longo da nuvem.

A análise da dispersão do ângulo de polarização nos dá informação da razão da densidade de energias cinética e magnética e do valor mesmo do campo magnético. Mediante o método de contagem de estrelas calculamos abrsorções visuais $A_{\mathrm{V}}$ na nuvem que nos permitem, junto com as medidas de polarização, determinar a eficiência do mecanismo de alinhamento que opera nos grãos de poeira na nuvem. 


\subsection{Introdução}

A nuvem escura localizada em Musca (ver Figura 3.1) é extremamente interessante. Ela apresenta um aspecto filamentar, fino e alongado $\left(\sim 1 / 4^{\circ} \times 3^{\circ}\right)$. Está localizada ao sul do plano galáctico $\left(\alpha_{1950}=12^{\mathrm{h}} 20^{\mathrm{m}}, \delta_{1950}=-71.0^{\circ}, l=300.6^{\circ}, b=-8.5^{\circ}\right)$ e é muito evidente no Catálogo de nuvens escuras de Feitzinger e Stüve (1984) (ver Figura 3.2).

Franco (1991) de estudos de excesso de cor vs. distância para uma amostra de 213 estrelas na região de Musca e Chamaeleon sugeriu que o complexo de nuvens escuras ChamaeleonMusca formariam uma estrutura única (tipo sheet-likee) a uma distância de aproximadamente 140 pc do Sol. Gregório-Hetem et al. (1988) obtiveram a absorção visual ao longo da nuvem e estimaram a massa total da nuvem em $250 \mathrm{M} \odot$ e uma distância de 200-250 pc indicando também sua possível relação ao complexo Chamaeleon.

Arnal et al. (1993) realizaram observações de polarimetria fotoelétrica para 56 estrelas brilhantes (magnitude máxima 12) na região da Nuvem Escura de Musca (NEM), concluindo que a direção do campo magnético projetado é quase perpendicular ao eixo maior da nuvem. Aquele trabalho sofre de uma paucidade evidente de dados de polarimetria de estrelas ao longo da própria nuvem. Nessa amostra apenas dez estrelas estão localizadas ao longo do filamento onde alta extinção existe; as outras estrelas (algumas dezenas) são todas distantes angularmente da nuvem. Eles também observaram a nuvem em ${ }^{12} \mathrm{CO}$, estimando a massa da nuvem em $170 \mathrm{M} \odot$. Medidas adicionais em ${ }^{13} \mathrm{CO}$ na NEM foram completadas por Mizuno et al. (1998) em um survey molecular do complexo Chamaeleon-Musca.

Neste trabalho apresentamos os resultados de um estudo observacional polarimétrico e de extinção na NEM. Na seguinte seção fazemos a análise dos dados polarimétricos e nos focalizamos nas variações no valor da polarização e do seu ângulo ao longo da NEM. Mostramos também os mapas da geometria do campo magnético ao longo da nuvem. A grande quantidade de dados de polarimetria dos objetos de background da NEM é apresentada num catálogo no Apêndice C. Na seção 3.4 apresentamos a técnica de contagem de estrelas aplicada à NEM e os mapas de extinção obtidos. Calculamos as massas para o total da nuvem e para as condensações achadas nela. Discutimos também a relação entre a estrutura do campo da nuvem e sua morfologia vista através da extinção. $\mathrm{Na}$ 
seção 3.5 discutimos as relações de polarização e extinção achadas, assim como sua implicância na determinação das razões de densidade de energia cinética e magnética e da intensidade do campo magnético obtidas a partir das dispersões do ângulo de polarização dos vetores de polarização. Uma análise da eficiência da polarização também é mostrada. Finalmente, na seção 3.6 estão as conclusões.

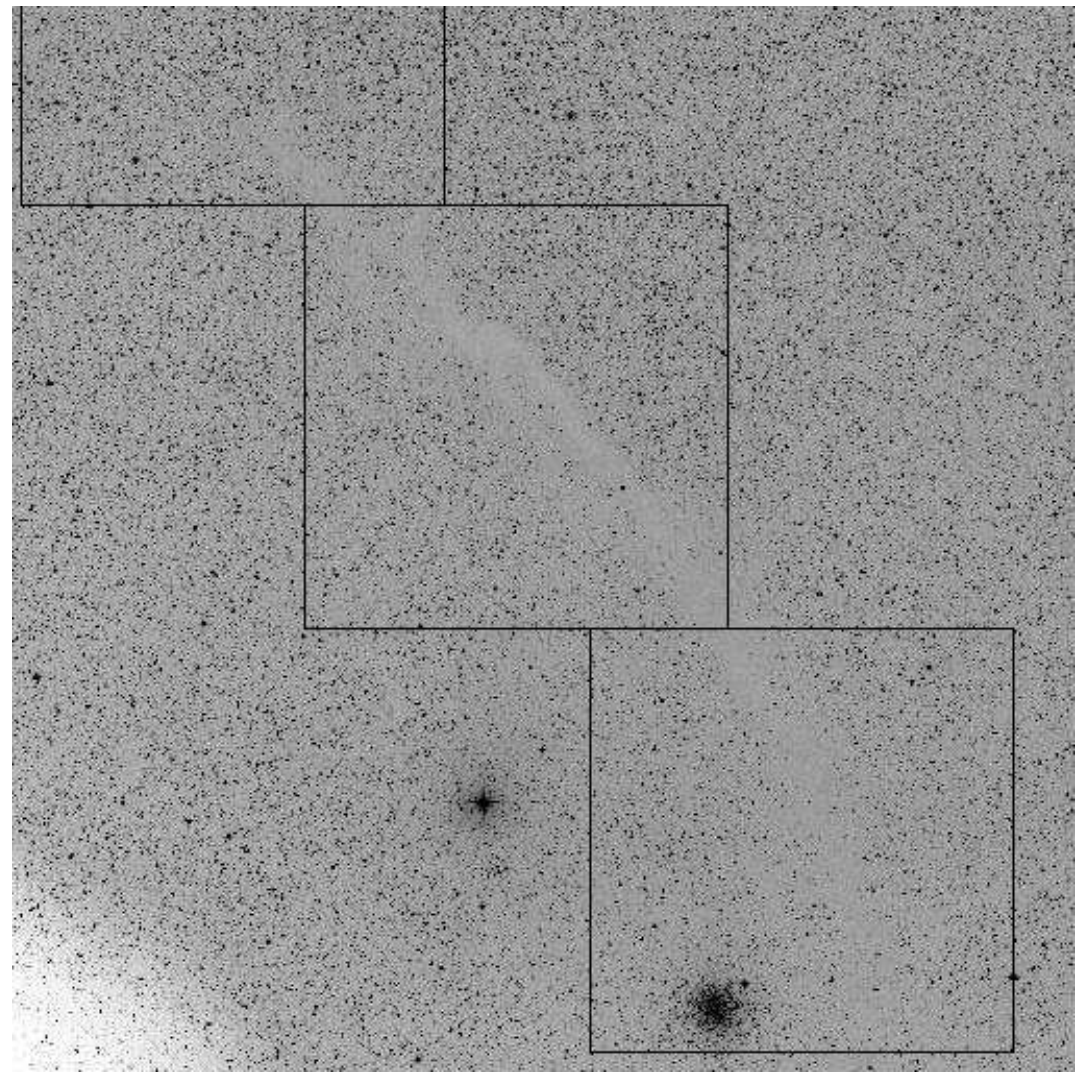

Figura 3.1 Nuvem Escura de Musca. A imagem é obtida do Digitized Sky Survey e está centrada em $\alpha_{1950}=$ $12^{\mathrm{h}} 27^{\mathrm{m}}$ e $\delta_{1950}=-71^{\circ} 15^{\prime}$. A área total é de $2.5^{\circ} \times 2.5^{\circ}$. A estrutura filamentar é bem evidente. Norte está para cima e Leste à esquerda. No canto inferior direito pode observar-se o aglomerado globular pobre en metais NGC 4372 (distancia $6.28 \mathrm{kpc}$, Alcaino 1974).

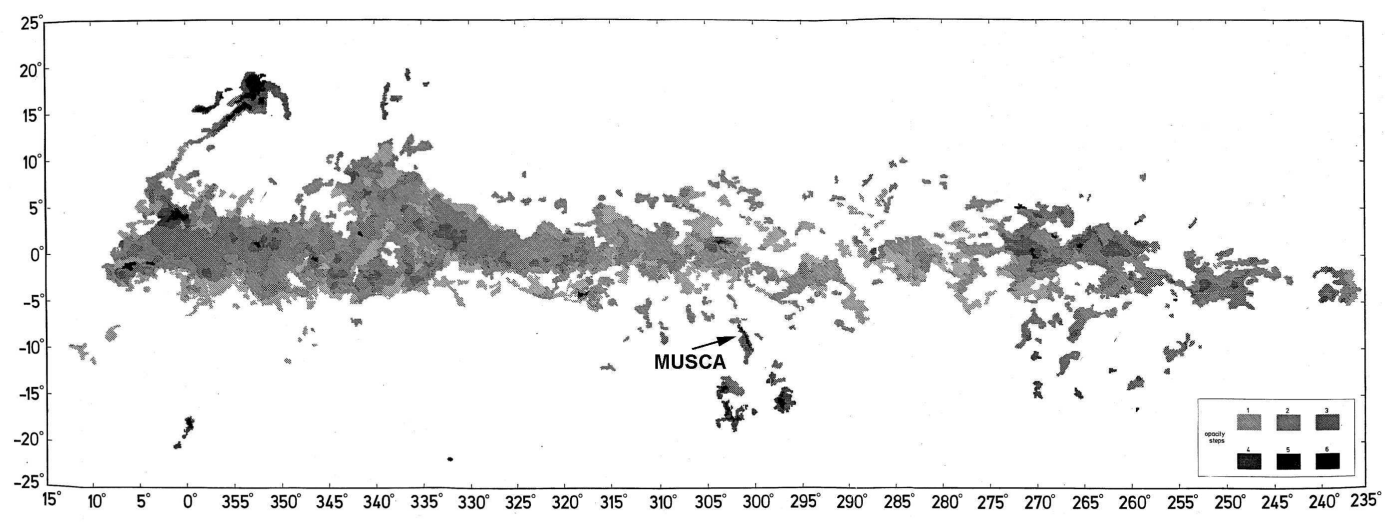

Figura 3.2 Mapa de nuvens escuras do Catálogo de Feitzinger e Stüve (1984). A posição da Nuvem Escura de Musca é mostrada. Note ao sul dela o complexo de nuvens escuras de Chamaeleon (Cha I, Cha II e Cha III). 


\subsection{Polarimetria Óptica}

\subsubsection{Observações}

As observações foram feitas usando o polarímetro de imagem IAG (Magalhães et al. 1996) no foco f/13.5 Cassegrain do telescópio de 0.6m IAGUSP no Laboratório Nacional de Astrofísica (LNA). Como vimos na seção 2.3.1, o polarímetro é altamente eficiente e é capaz de realizar observações de polarimetria linear com precisão limitada pelo ruído de fótons apenas para fontes pontuais. Quando opera no modo linear, o polarímetro está composto de uma lâmina retardadora de meia onda e um prisma Savart de calcita. A técnica nos permite atingir estrelas até magnitude 16 para uma razão sinal-ruído de polarização maior ou igual que 5. Tais estrelas estarão afetadas, em geral, por uma quantidade maior de poeira na sua linha de visada e tenderão também a ser mais polarizadas e, portanto, a mapear melhor o campo nas regiões mais internas da nuvem.

Apresentamos medidas de polarimetria linear de 35 campos CCD ao longo da NEM obtidas por nós em missões sucessivas no LNA em Abril de 1996 e Abril de 1997 através de um filtro V standard. Para cada campo, integrações de 5 minutos formas realizadas em 8 posições da lâmina retardadora de meia onda separadas por $22.5^{\circ}$. Na missão de Abril '96 foi usado o CCD048 (770 x 1152 pixels) fornecendo uma área de $\sim$ 8' x 12' por campo. Nesta missão foram colhidos um total de 19 campos. Na missão de Abril '97 foram utilizados o CCD048 e o CCD Tektronichs (1024 x 1024 pixels), este último fornecendo uma área de $\sim 10^{\prime} \times 10^{\prime}$ por campo. Um total de 16 campos foram colhidos nesta missão. Um resumo das características dos CCDs utilizados em cada missao é mostrado na Tabela 3.1. A Tabela 3.2 mostra as coordenadas equatoriais nas quais foram centrados os 35 campos, assim como as missões respectivas de cada um deles. Para uma melhor visualização, dividimos a região da NEM em três quadrantes de $1^{\circ} \times 1^{\circ}$ chamados regiões norte, central e sul (ver Figura 3.1). A Figura 3.3 mostra as posições da Tabela 3.2.

Tabela 3.1 Características dos CCDs utilizados no mapeamento da NEM.

\begin{tabular}{cccc}
\hline \hline CCD & $\begin{array}{c}\text { Tamanho } \\
\text { (pixels) }\end{array}$ & Campo & Missão \\
\hline 048 & $770 \times 1152$ & $8^{\prime} \times 12^{\prime}$ & 96,97 \\
Tektronichs & $1024 \times 1024$ & $10^{\prime} \times 10^{\prime}$ & 97 \\
\hline
\end{tabular}


Tabela 3.2 Posições dos campo CCD colhidos na região da NEM.

\begin{tabular}{|c|c|c|c|c|c|c|c|}
\hline \multicolumn{4}{|c|}{ Região Central } & \multicolumn{4}{|c|}{ Região Sul } \\
\hline Campo & $\begin{array}{c}\mathrm{AR}_{1950} \\
(\mathrm{~h}: \mathrm{m}: \mathrm{s})\end{array}$ & $\begin{array}{c}\mathrm{DEC}_{1950} \\
\left({ }^{\circ}:^{\prime}\right)\end{array}$ & Missão & Campo & $\begin{array}{c}\mathrm{AR}_{1950} \\
(\mathrm{~h}: \mathrm{m}: \mathrm{s})\end{array}$ & $\begin{array}{c}\mathrm{DEC}_{1950} \\
\left({ }^{\circ} \mathbf{y}^{\prime}\right)\end{array}$ & Missão \\
\hline 1 & $12: 32: 25.2$ & $-70: 36$ & 96 & 18 & $12: 22: 34.8$ & $-71: 36$ & 96 \\
\hline 2 & $12: 29: 57.6$ & $-70: 36$ & 96 & 19 & 12:20:00.0 & $-71: 36$ & 97 \\
\hline 3 & $12: 32: 25.2$ & $-70: 44$ & 97 & 20 & $12: 22: 34.8$ & $-71: 44$ & 97 \\
\hline 4 & $12: 29: 57.6$ & $-70: 44$ & 96 & 21 & $12: 20: 00.0$ & $-71: 44$ & 96 \\
\hline 5 & $12: 27: 30.0$ & $-70: 44$ & 97 & 22 & $12: 22: 34.8$ & $-71: 52$ & 97 \\
\hline 6 & 12:29:57.6 & $-70: 52$ & 96 & 23 & 12:20:00.0 & $-71: 52$ & 96 \\
\hline 7 & $12: 27: 30.0$ & $-70: 52$ & 96 & 24 & $12: 17: 25.2$ & $-71: 52$ & 97 \\
\hline 8 & $12: 25: 02.4$ & $-70: 52$ & 97 & 25 & 12:20:00.0 & $-72: 00$ & 96 \\
\hline 9 & $12: 27: 30.0$ & $-71: 00$ & 96 & 26 & $12: 17: 25.2$ & $-72: 00$ & 97 \\
\hline 10 & $12: 25: 02.4$ & $-71: 00$ & 96 & 27 & $12: 20: 00.0$ & $-72: 08$ & 97 \\
\hline 11 & $12: 27: 30.0$ & $-71: 08$ & 97 & 28 & $12: 17: 25.2$ & $-72: 08$ & 96 \\
\hline 12 & $12: 25: 02.4$ & $-71: 08$ & 96 & 29 & $12: 17: 25.2$ & $-72: 16$ & 97 \\
\hline 13 & $12: 22: 34.8$ & $-71: 08$ & 97 & 30 & $12: 14: 50.4$ & $-72: 16$ & 97 \\
\hline 14 & $12: 25: 02.4$ & $-71: 16$ & 97 & & & & \\
\hline 15 & $12: 22: 34.8$ & $-71: 16$ & 96 & \multicolumn{4}{|c|}{ Região Norte } \\
\hline 16 & $12: 25: 02.4$ & $-71: 24$ & 97 & 31 & $12: 35: 00.0$ & $-70: 08$ & 96 \\
\hline \multirow[t]{4}{*}{17} & $12: 22: 34.8$ & $-71: 24$ & 96 & 32 & $12: 35: 00.0$ & $-70: 16$ & 96 \\
\hline & & & & 33 & $12: 32: 39.6$ & $-70: 16$ & 96 \\
\hline & & & & 34 & $12: 35: 00.0$ & $-70: 24$ & 97 \\
\hline & & & & 35 & $12: 32: 39.6$ & $-70: 24$ & 96 \\
\hline
\end{tabular}

Correções no ângulo de posição da polarização foram feitas de medidas de estrelas padrões polarizadas em cada noite. Estrelas padrões não polarizadas foram usadas para checar a polarização instrumental que resultou desprezível. Nenhuma correção de polarização instrumental foi necessária.

\subsubsection{Dados Polarimétricos}

A grande quantidade de dados polarimétricos de objetos de background da NEM é apresentada no Apêndice $C$ em 35 tabelas com seus respectivos findings charts, um por cada campo em que foi dividida a NEM (ver Figura 3.3). Os dados polarimétricos mostrados no Apêndice $C$ apresentam uma razão sinal-ruído de polarização maior ou igual que 5. Dados com uma razão menor não são seguros, especialmente para objetos débeis (mag 15 - 16). Nestes casos, problemas de overlapping entre as imagens ordinária e extraordinária de objetos adjacentes são recorrentes. O número total de objetos é 2497.

Em cada tabela do Apêndice C (C.1 a C.35) a primeira coluna é o número de identificação para cada objeto no campo. Este número indica a posição do objeto nos findings charts. A 
segunda e terceira colunas são as coordenadas equatoriais (1950). O erro estimado na posição é menor que 1 segundo de arco. A quarta e quinta coluna são os valores da polarização observada no filtro $\mathrm{V}$ e seu erro respectivo. $\mathrm{O}$ ângulo de polarização está indicado na sexta coluna. Finalmente, a sétima e oitava coluna são a magnitude visual e seu erro. As posições dos objetos foram calculadas comparando objetos comuns presentes em nossos campos CCD e nas placas digitalizadas do Sky Survey. Deste modo, as posições (x,y) em pixels são transformadas em coordenadas equatoriais (ra,dec) usando os parâmetros de placa disponíveis nas imagens digitalizadas. As imagens usadas para esta conversão são as mesmas que aparecem nos findings charts para cada campo (Figs. B.1 a B.35), colocados cada um em seguida à tabela correspondente.

Na Figura 3.4 mostramos os mapas de polarização da NEM para os 35 campos estudados. Cada vetor representa um objeto com razão sinal-ruído de polarização $\left(P / \sigma_{P}\right)$ maior que 10 . Adotamos esta razão para incrementar a precisão da análise subseqüente. $\mathrm{O}$ número total de objetos com esta razão é 1363. Apenas quatro estrelas da amostra de Arnal et al. (1993) estão presentes em nossos dados; os resultados são coerentes, como é mostrado na Tabela 3.3.

O Apêndice D apresenta a análise estatística realizada campo a campo. Os resultados são mostrados na Tabela 3.4. O campo analisado é dado na coluna (1). O número $(N)$ de estrelas com $P / \sigma_{P}>10$ em cada campo é dado na coluna (2). Para cada campo calculamos os parâmetros de Stokes médios $\langle Q\rangle$ e $\langle U\rangle$ dos valores individuais para cada estrela $\left(q_{i}\right.$, $\left.u_{i}\right)$ pesados pelos erros respectivos $\left(\sigma_{i}\right)$ da seguinte forma:

$$
\begin{aligned}
& <Q>=\sum\left(q_{i} / \sigma_{i}^{2}\right) / \sum \sigma_{i}^{-2} \\
& <U>=\sum\left(u_{i} / \sigma_{i}^{2}\right) / \sum \sigma_{i}^{-2} .
\end{aligned}
$$

Com isto, construímos o valor médio da polarização $\langle P>$, seu erro associado $\langle\sigma\rangle$ e o ângulo médio de polarização $<\theta>$ :

$$
\begin{aligned}
& <P>=\sqrt{ }(<Q>2+<U>2) \\
& <\sigma>=\left(1 / \sum \sigma_{i}^{-2}\right)^{-1 / 2} \\
& <\theta>=(1 / 2) \tan ^{-1}(<U>/<Q>)
\end{aligned}
$$

apresentados nas colunas (3), (4) e (5) da Tabela 3.4. 

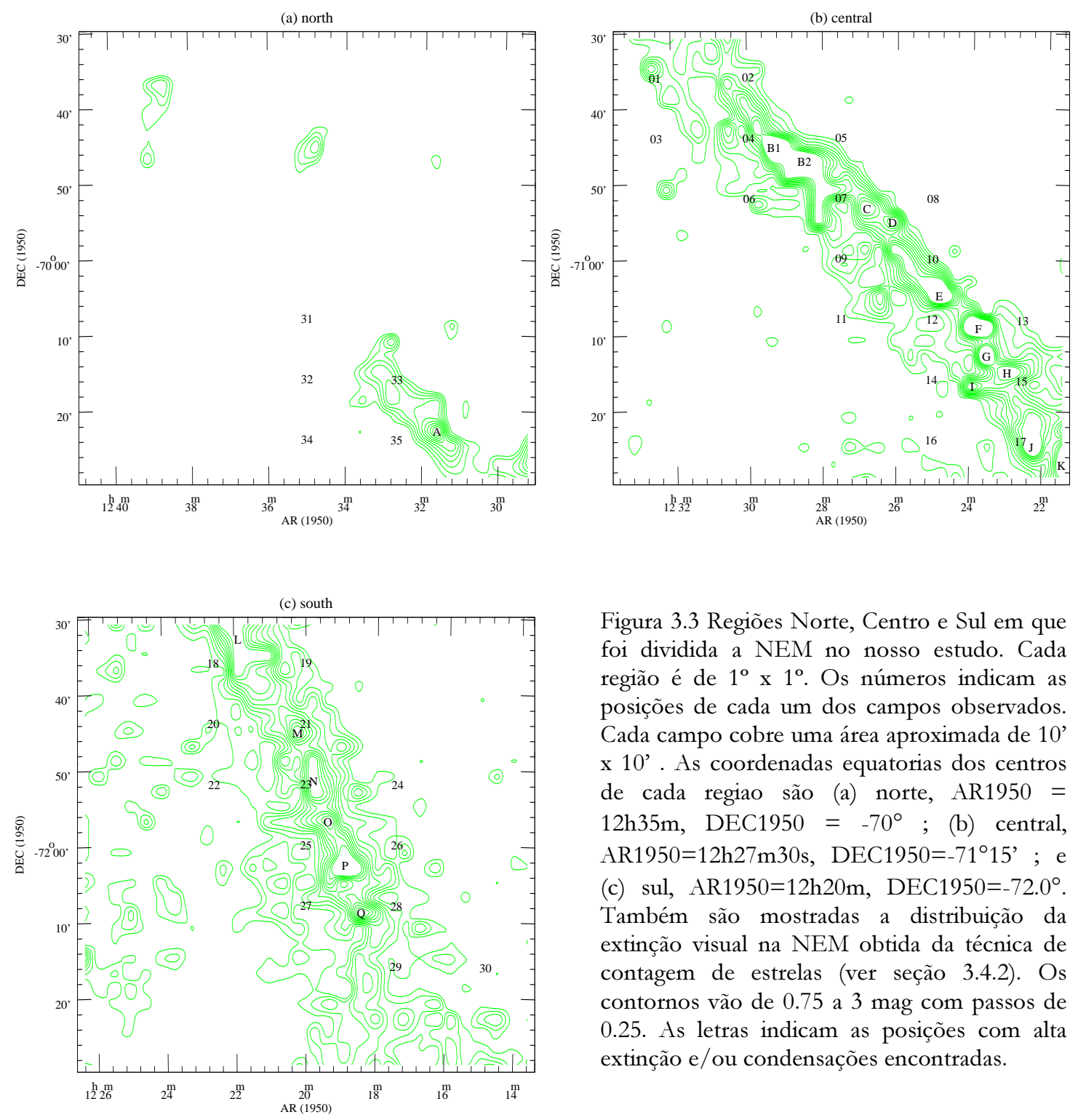

Figura 3.3 Regiões Norte, Centro e Sul em que foi dividida a NEM no nosso estudo. Cada região é de $1^{\circ} \times 1^{\circ}$. Os números indicam as posições de cada um dos campos observados. Cada campo cobre uma área aproximada de 10' x 10' . As coordenadas equatorias dos centros de cada regiao são (a) norte, AR1950 = $12 \mathrm{~h} 35 \mathrm{~m}$, DEC1950 = $-70^{\circ} ;$ (b) central, $\mathrm{AR} 1950=12 \mathrm{~h} 27 \mathrm{~m} 30 \mathrm{~s}, \mathrm{DEC} 1950=-71^{\circ} 15^{\prime} ; \mathrm{e}$ (c) sul, AR1950 $=12 \mathrm{~h} 20 \mathrm{~m}, \mathrm{DEC} 1950=-72.0^{\circ}$. Também são mostradas a distribuição da extinção visual na NEM obtida da técnica de contagem de estrelas (ver seção 3.4.2). Os contornos vão de 0.75 a 3 mag com passos de 0.25. As letras indicam as posições com alta extinção e/ou condensações encontradas.

Tabela 3.3 Comparação entre polarimetria de Arnal et al. (1993) e nosso trabalho.

\begin{tabular}{|c|c|c|c|c|c|c|c|c|}
\hline \multicolumn{4}{|c|}{ Arnal et al. (1993) } & \multicolumn{5}{|c|}{ Nosso trabalho } \\
\hline ID & $\begin{array}{c}P_{\mathrm{V}} \\
(\%)\end{array}$ & $\begin{array}{l}\sigma_{P \mathrm{v}} \\
(\%)\end{array}$ & $\begin{array}{c}\theta \\
\left({ }^{\circ}\right)\end{array}$ & Campo & ID & $\begin{array}{c}P_{\mathrm{V}} \\
(\%)\end{array}$ & $\begin{array}{l}\sigma_{P \mathrm{v}} \\
(\%)\end{array}$ & $\begin{array}{l}\theta \\
\left({ }^{\circ}\right)\end{array}$ \\
\hline 3 & 2.55 & 0.28 & 84.4 & 33 & 61 & 2.751 & 0.150 & 88.0 \\
\hline 6 & 5.29 & 0.10 & 108.8 & 10 & 46 & 5.552 & 0.084 & 113.7 \\
\hline 9 & 5.98 & 0.08 & 112.5 & 10 & 52 & 6.187 & 0.110 & 115.8 \\
\hline & 6.11 & 0.09 & 121.2 & & & & & \\
\hline 53 & 5.95 & 0.05 & 124.0 & 12 & 16 & 5.996 & 0.233 & 123.4 \\
\hline
\end{tabular}



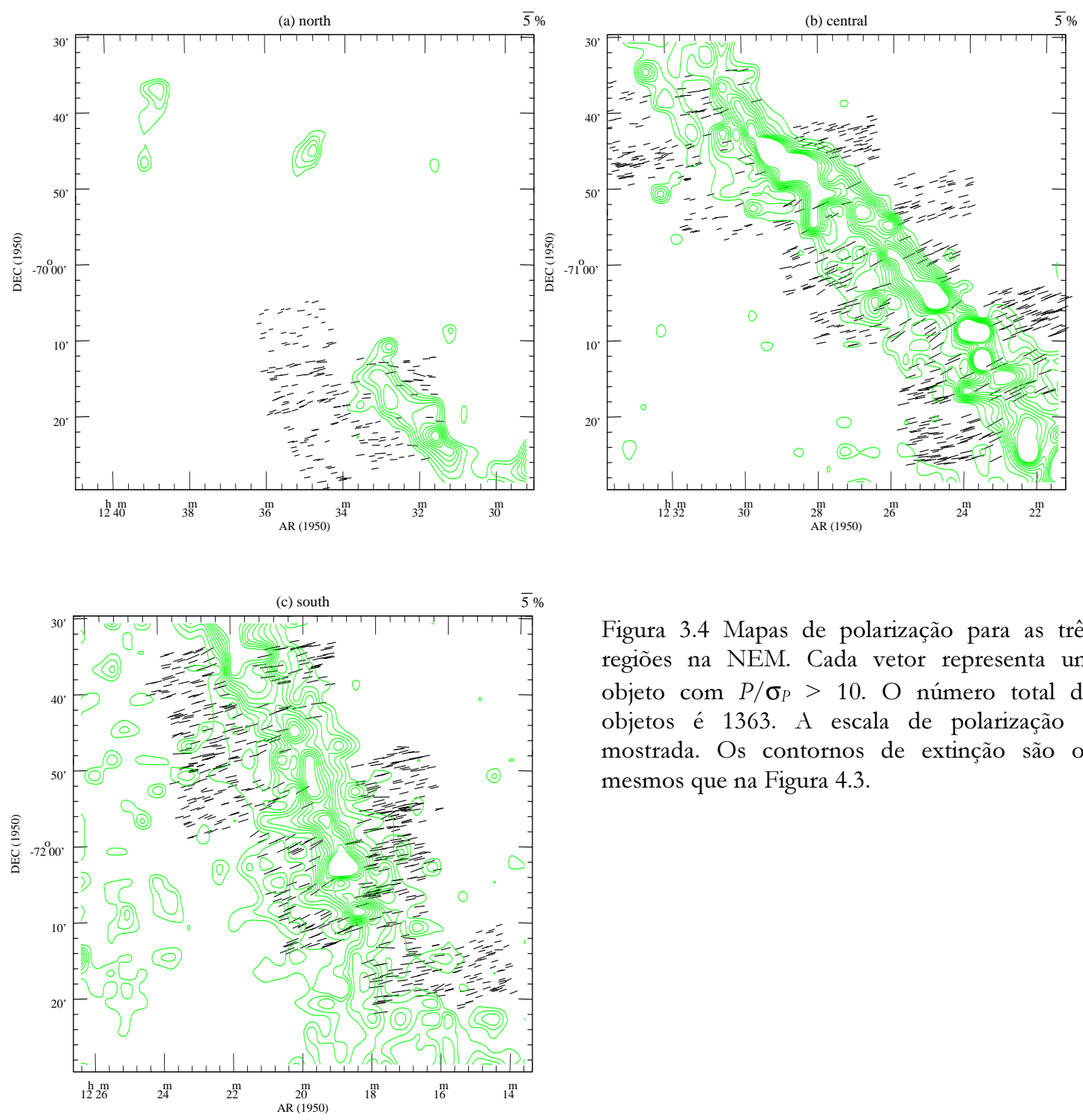

Figura 3.4 Mapas de polarização para as três regiões na NEM. Cada vetor representa um objeto com $P / \sigma_{P}>10$. O número total de objetos é 1363. A escala de polarização é mostrada. Os contornos de extinção são os mesmos que na Figura 4.3.

Para cada campo construímos histogramas do ângulo de posição e fizemos um ajuste de gaussianas (ver Figs. C.1c a C.35c) para calcular o ângulo de posição da polarização $\theta_{\text {gauss }} \mathrm{e}$ sua dispersão $\sigma_{\theta_{\text {gauks }}}$, dados nas colunas (6) e (7) da Tabela 3.4. O erro médio no ângulo de polarização é mostrado na coluna (8) e é calculado segundo $<\sigma_{\theta}>=\sum \sigma_{\theta_{i}} / N$ onde $\sigma_{\theta_{i}}=$ $28^{\circ} .65 \sigma_{\mathrm{p}_{\mathrm{i}}} / \mathrm{p}_{\mathrm{i}}$ (Serkowsky 1974) é o erro individual do ângulo de polarização. Finalmente, a coluna (9) mostra a dispersão do ângulo de polarização corrigido em quadratura pelo seu erro médio, isto é $\Delta \theta=\sqrt{ }\left(\sigma_{\text {gauss }}{ }^{2}-<\sigma_{\theta}>2\right)$. A discussão desta análise será feita na seção 3.5 . 
Tabela 3.4 Análise da polarimetria dos 35 campos da NEM.

\begin{tabular}{|c|c|c|c|c|c|c|c|c|}
\hline Campo & Objetos & $\begin{array}{c}<P> \\
(\%) \\
(3)\end{array}$ & $\begin{array}{c}<\sigma> \\
(\%) \\
(4)\end{array}$ & $\begin{array}{c}<\theta> \\
\left({ }^{\circ}\right) \\
(5)\end{array}$ & $\begin{array}{c}\theta_{\text {gaulss }} \\
\left({ }^{\circ}\right) \\
(6)\end{array}$ & $\begin{array}{c}\sigma_{\theta_{\text {gatuss }}} \\
\left(^{\circ}\right) \\
(7)\end{array}$ & $\begin{array}{c}<\sigma_{\theta}> \\
\left({ }^{\circ}\right) \\
(8)\end{array}$ & $\begin{array}{c}\Delta \theta \\
\left({ }^{\circ}\right)\end{array}$ \\
\hline 1 & 23 & 318 & & 103.93 & 10270 & 344 & 211 & 272 \\
\hline 2 & 22 & 4.30 & 0.04 & 102.17 & 101.10 & 5.63 & 1.65 & 5.39 \\
\hline 3 & 55 & 3.15 & 0.02 & 102.31 & 102.20 & 4.03 & 1.79 & 3.61 \\
\hline 4 & 15 & 3.08 & 0.03 & 105.33 & 104.50 & 3.99 & 1.72 & 3.60 \\
\hline 5 & 54 & 3.80 & 0.02 & 106.17 & 105.60 & 3.41 & 1.62 & 3.00 \\
\hline 6 & 24 & 2.96 & 0.03 & 104.32 & 104.10 & 4.12 & 1.76 & 3.72 \\
\hline 7 & 16 & 4.15 & 0.03 & 111.14 & 113.80 & 6.13 & 1.23 & 6.01 \\
\hline 8 & 48 & 3.52 & 0.03 & 107.38 & 107.60 & 3.71 & 1.97 & 3.14 \\
\hline 9 & 41 & 4.66 & 0.01 & 108.45 & 110.90 & 6.23 & 1.14 & 6.12 \\
\hline 10 & 22 & 5.15 & 0.03 & 114.17 & 114.20 & 3.41 & 1.34 & 3.14 \\
\hline 11 & 34 & 3.88 & 0.03 & 105.95 & 105.40 & 4.09 & 1.55 & 3.78 \\
\hline 12 & 13 & 6.02 & 0.10 & 122.36 & 122.90 & 3.50 & 1.90 & 2.93 \\
\hline 13 & 65 & 4.93 & 0.02 & 111.53 & 111.30 & 2.84 & 1.53 & 2.39 \\
\hline 14 & 34 & 5.01 & 0.03 & 106.96 & 106.40 & 5.43 & 1.67 & 5.17 \\
\hline 15 & 17 & 7.02 & 0.07 & 112.63 & 115.90 & 2.28 & 1.69 & 1.54 \\
\hline 16 & 62 & 4.67 & 0.03 & 102.71 & 102.30 & 5.13 & 1.70 & 4.84 \\
\hline 17 & 7 & 6.06 & 0.10 & 116.33 & 116.70 & 3.44 & 1.79 & 2.94 \\
\hline 18 & 44 & 4.42 & 0.03 & 105.31 & 106.10 & 4.68 & 1.53 & 4.43 \\
\hline 19 & 45 & 5.02 & 0.03 & 100.98 & 101.70 & 2.88 & 1.57 & 2.42 \\
\hline 20 & 64 & 4.56 & 0.03 & 105.13 & 104.80 & 3.75 & 1.71 & 3.33 \\
\hline 21 & 17 & 5.43 & 0.05 & 106.22 & 107.40 & 3.93 & 1.81 & 3.48 \\
\hline 22 & 65 & 3.92 & 0.02 & 107.74 & 106.90 & 3.93 & 1.76 & 3.52 \\
\hline 23 & 13 & 4.69 & 0.09 & 112.75 & 112.50 & 3.79 & 2.07 & 3.17 \\
\hline 24 & 78 & 4.70 & 0.02 & 102.45 & 102.00 & 2.74 & 1.57 & 2.24 \\
\hline 25 & 22 & 5.17 & 0.05 & 114.72 & 115.60 & 3.73 & 1.58 & 3.38 \\
\hline 26 & 68 & 5.03 & 0.02 & 101.81 & 102.30 & 2.67 & 1.60 & 2.14 \\
\hline 27 & 49 & 5.17 & 0.03 & 113.36 & 111.30 & 3.66 & 1.65 & 3.26 \\
\hline 28 & 36 & 4.91 & 0.03 & 100.86 & 101.50 & 3.33 & 1.56 & 2.94 \\
\hline 29 & 52 & 4.51 & 0.02 & 99.72 & 99.03 & 3.46 & 1.70 & 3.01 \\
\hline 30 & 69 & 3.25 & 0.02 & 107.20 & 107.20 & 3.15 & 1.64 & 2.69 \\
\hline 31 & 29 & 2.17 & 0.02 & 104.37 & 103.90 & 4.50 & 1.90 & 4.08 \\
\hline 32 & 55 & 3.20 & 0.02 & 103.75 & 103.70 & 5.86 & 1.73 & 5.60 \\
\hline 33 & 29 & 3.19 & 0.03 & 91.73 & 90.91 & 5.44 & 1.83 & 5.12 \\
\hline 34 & 49 & 2.67 & 0.02 & 104.24 & 103.00 & 3.87 & 1.74 & 3.45 \\
\hline 35 & 24 & 2.68 & 0.02 & 103.08 & 97.04 & 7.16 & 1.86 & 6.91 \\
\hline
\end{tabular}

\subsection{Absorção visual por contagem automática de estrelas}

\subsubsection{A Técnica}

Usamos rotinas padrões IRAF e outras desenvolvidas por nós para obter mapas de absorção visual da NEM usando a técnica de contagem automática de estrelas. Para isto, utilizamos imagens em CD ROM do Digitized Sky Survey. Foram obtidas três regiões de 
$1^{\circ} \times 1^{\circ}$ cada, tentando cobrir a NEM em toda sua extensão. Estas regiões são as mesmas em que foi dividida a NEM no estudo de polarização (ver Figura 3.1).

O primeiro passo é obter destas imagens as posições de objetos com perfil estelar mediante a tarefa DAOFIND do IRAF. Esta rotina automaticamente detecta objetos sobre uma certa intensidade limiar (threshold). Nós utilizamos um limiar de 4 vezes o ruído do céu (rms sky noise) para cada região. Nossas rotinas fazem a contagem do número de estrelas por cela de $2^{\prime}$ x 2' definida em cada imagem e calculam a absorção visual segundo:

$$
A_{\lambda}=(1 / b) \log (n(0) / n(1))
$$

onde $n(0)$ é o número médio de estrelas por cela no campo de comparação e $n(1)$ é o número total de estrelas obtido na contagem. Valores de contagens de estrelas nas celas de regiões afastadas da estrutura filamentar foram utilizados para obter um $n(0)$ médio. O valor usado foi $n(0)=25$. O parâmetro $b$ pode ser obtido das tabelas de van Rhijn (van Rhijn, 1929). Utilizamos o valor de $b=0.44$, o mesmo adotado por Gregorio-Hetem et al. (1988) no seu estudo de contagem de estrelas manual da NEM.
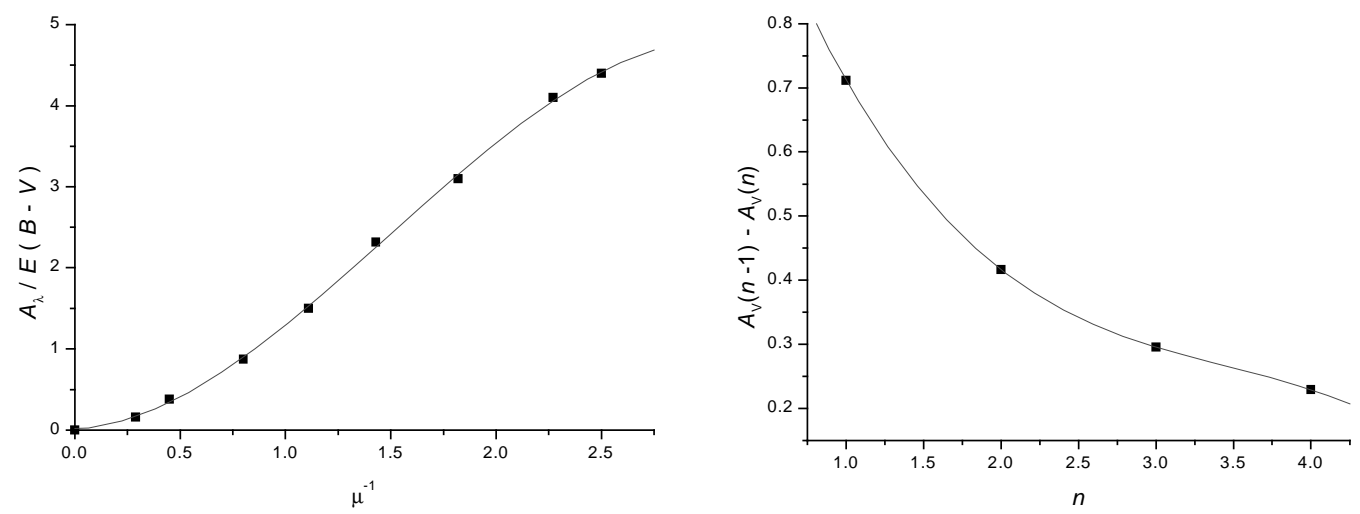

Figura 3.5 (esquerda) Ajuste da curva de extinção normalizada de Bless e Savage (1972) na faixa 0.4 - 3.4 $\mu \mathrm{m}$. (direita) Ajuste dos resíduos de passos consecutivos de extinção para achar o limite inferior de extinção para $n(1)=0$.

As extinções obtidas das placas fotográficas digitalizadas $\left(A_{\text {phot }}\right)$ podem ser transformadas em $A_{\mathrm{V}}(\lambda 5500 \AA)$ usando as curvas de extinção normalizadas de Bless e Savage (1972) da seguinte forma. As imagens digitalizadas do Sky Survey que utilizamos correspondem as placas Schmidt na combinação emulsão/filtro = IIaD/GG495, centrada em $5650 \AA$ (Lasker et al. 1990). Obtivemos a correção necessária na banda fotográfica ajustando um polinômio na faixa $0.4 \mu \mathrm{m}-3.4 \mu \mathrm{m}$ da curva de extinção normalizada de Bless e Savage 
(1972) e recalculando a extinção na banda fotográfica (Figura 3.5, esquerda). Usamos a relação:

$$
A_{\mathrm{V}}=1.04 A_{\text {phot }}
$$

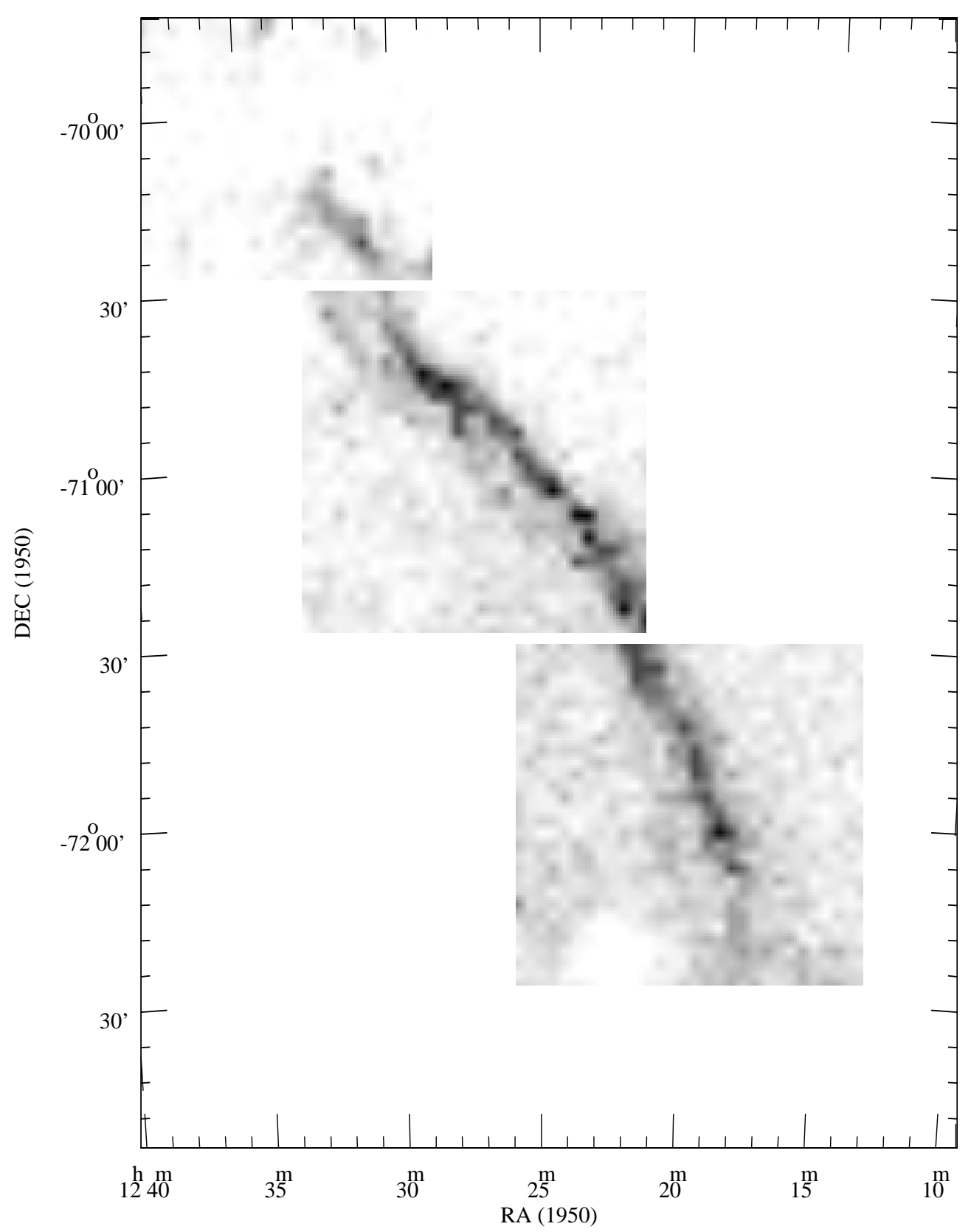

Figura 3.6 Mosaico das imagens de extinção das três regiões em que foi dividida a NEM neste trabalho. As imagens foram obtidas por contagem automática de estrelas como está explicado no texto. 


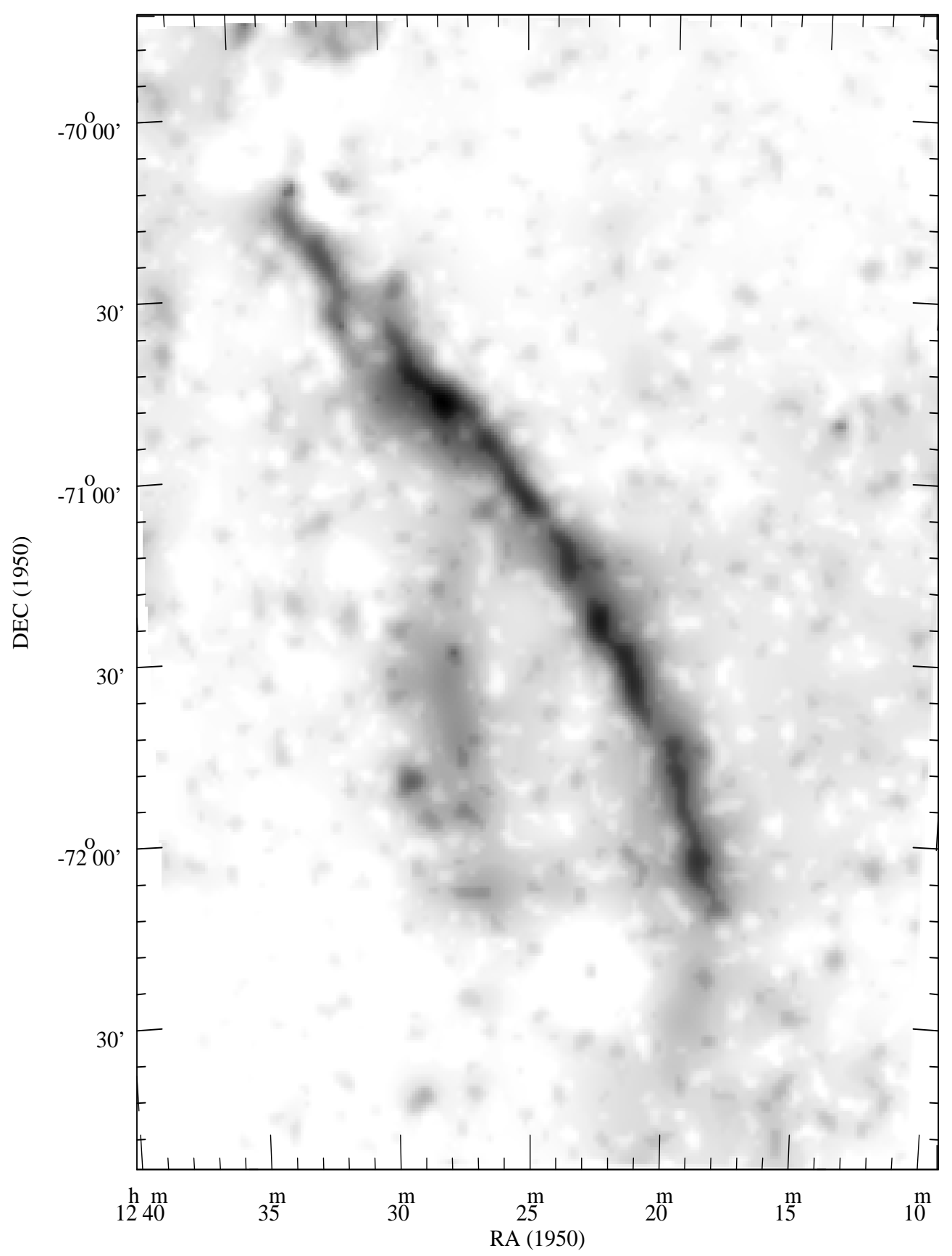

Figura 3.7 Imagem de extinção da NEM de Cambrésy (1999).

O resultado do processo é uma imagem de extinção de 30x30 pixels para cada uma das 3 regiões analisadas. A imagem é criada usando a rotina TABIM do IRAF. O erro em cada cela aumenta com o valor da extinção (Dickman 1978). Para as celas com nenhuma estrela obtivemos um limite inferior na extinção ajustando os resíduos entre passos consecutivos de extinção e extrapolando a correção para o caso $n(1)=0$ (Figura 3.5, direita). Este procedimento resultou em assumir $n(1)=0.28$ para as celas sem estrelas e o limite inferior de extinção obtido foi 4.6 mag. Este valor é coerente com o valor máximo de extinção de 4.5 mag obtido por Gregorio-Hetem et al. (1988). A Figura 3.3 mostra os mapas de 
extinção obtidos pela técnica. Os contornos mostrados vão de 0.75 a 3 mag em passos de 0.25 mag e foram criados pela tarefa NEWCOUNT no IRAF. Sua análise e discussão será feita na seção seguinte. Um mosaico das três regiões que conformam a NEM é mostrado na Figura 3.6.

Recentemente Cambrésy (1999) construiu mapas de extinção para várias nuvens moleculares na Galáxia (incluindo Musca). Nesse trabalho foi utilizada uma técnica derivada de contagens de estrelas com uma grade adaptativa e uma decomposição em wavelets que filtra o ruído nos mapas de extinção. Ela foi aplicada a dados fornecidos pelo catálogo USNO. Na Figura 3.7 Imagem de extinção da NEM de Cambrésy (1999).

mostramos o mapa de extinção para a NEM obtido por Cambrésy (1999). Valores máximos de extinção achados foram de 5.7 mag, algo maiores que no nosso trabalho (4.6 mag). De uma comparação visual entre a Figura 3.6 e a Figura 3.7 Imagem de extinção da NEM de Cambrésy (1999).

vemos que basicamente os comportamentos espaciais são coerentes entre ambos mapas. Uma tentativa de correlação ponto a ponto entres ambos mapas de extinção foi feita concentrando-nos na região central. O resultado é mostrado na Figura 3.8. Parece evidente que nossa estimativa da extinção está subestimada com respeito aquela de Cambrésy (1999) ou equivalentemente esta última superestima a extinção com respeito a nossa. Voltaremos a este ponto quando analisarmos a eficiência da polarização, $P_{\mathrm{V}} / A_{\mathrm{V}}$, na seção 3.5.4 .

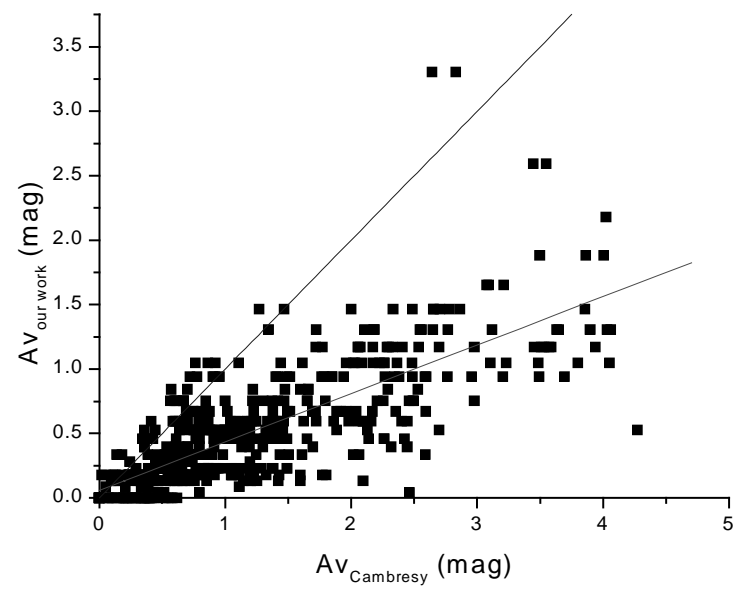

Figura 3.8 Comparação ponto a ponto entre nosso mapa de extinção e o mapa de extinção de Cambrésy (1999) para a região central da NEM. A linha reta superior indica uma pendente $45^{\circ}$. A linha reta inferior é o melhor ajuste linear: $A_{\mathrm{V} \text { nosso }}=0.06(0.02)+$ $0.38(0.01) A_{\mathrm{V}}$ Cambresy (o erro das constantes em parêntesis). 


\subsubsection{Análise da extinção e massas}

Analisando a Figura 3.3, observamos que contornos de nível maiores que 1 mag definem de maneira precisa a região de obscuração na NEM. Calculamos um limite inferior para a massa da NEM usando a relação (Dickman 1978):

$$
M=(\alpha d)^{2}\left(N_{\mathrm{H} 2} / A_{\mathrm{V}}\right) \mu \sum A_{\mathrm{V}}^{i}
$$

onde $\alpha$ é o tamanho da cela em radianos, $d$ é a distância da nuvem em centímetros, $\left(N_{\mathrm{H} 2} / A_{\mathrm{V}}\right)$ é a razão entre a densidade colunar do gás e a extinção padrão, $\sim 0.94 \times 10^{21} \mathrm{~cm}^{-}$ ${ }^{2}$ mag-1 $^{-1}$ (Bohlin et al. 1978), $\mu$ é a massa de uma partícula média que inclui uma correção de $30 \%$ devido ao peso do Hélio (Allen 1973) e $A_{\mathrm{V}}^{i}$ é a extinção visual em cada cela considerada dentro da área em que se calcula a massa. A Tabela 3.5 compara as áreas e massas calculadas por Gregorio-Hetem et al. (1988) e nosso trabalho na NEM quando a somatória é realizada sobre celas com $A_{\mathrm{V}}^{i} \geq 1,2,3$ e 4 magnitudes. Em geral, nossas áreas são maiores mas os valores das massas são consistentes. Para $A_{\mathrm{V}}^{i} \geq 1$ nosso valor da massa é praticamente o mesmo que em Gregorio-Hetem et al. (1988). Acreditamos que a diferença observada em extinções maiores é produzida pela melhor resolução da cela de extinção usada no nosso trabalho.

Tabela 3.5 Comparação entre extinção na NEM de Gregorio-Hetem et al . (1988) e nosso trabalho.

\begin{tabular}{|c|c|c|c|c|}
\hline \multicolumn{3}{|c|}{ Gregorio-Hetem et al. (1988) } & \multicolumn{2}{|c|}{ nosso trabalho } \\
\hline$A_{\mathrm{V}} \geq$ & massa & área & massa & área \\
\hline$(\operatorname{mag})$ & $\left(\mathrm{M}_{\odot}\right)$ & $\left(\circ^{2}\right)$ & $\left(\mathrm{M}_{\odot}\right)$ & $\left(0^{2}\right)$ \\
\hline 1 & 138 & 0.307 & 139.33 & 0.452 \\
\hline 2 & 75 & 0.122 & 64.04 & 0.129 \\
\hline 3 & 20 & 0.021 & 34.11 & 0.056 \\
\hline 4 & 3 & 0.003 & 8.00 & 0.010 \\
\hline
\end{tabular}

Usando os mapas de extinção (Figura 3.3), identificamos as posições de alta extinção na NEM. Elas estão listadas na Tabela 3.6, assim como suas condensações associadas. Definimos uma condensação pela área encerrada pelo contorno de extinção $A_{\mathrm{V}}=3$ mag. $\mathrm{Na}$ coluna (1) estão os identificadores para cada posição de alta extinção, também mostrados na Figura 3.3. Cada posição também define a condensação associada exceto em B onde duas posições de alta extinção foram encontradas (B1 e B2). Nas colunas (2) e (3) estão as coordenadas equatoriais; na coluna (4) está o valor do máximo de extinção na condensação em magnitudes; na coluna (5) está a densidade colunar do hidrogênio 
calculada na posição de alta extinção em cada condensação; na coluna (6) estão as áreas em minutos de arco quadrados associadas com cada condensação calculadas adicionando todas as celas com $A_{\mathrm{V}} \geq 3$ mag na condensação; na coluna (7) está a dimensão associada com a condensação em parsecs calculada segundo $\sqrt{ }(2$ area); e finalmente na coluna (8) está um limite inferior de massa de cada condensação calculada segundo a equação (3.5).

Tabela 3.6 Análise da extinção na NEM.

\begin{tabular}{|c|c|c|c|c|c|c|c|c|}
\hline ID & $\begin{array}{c}\mathrm{AR}(1950) \\
(\mathrm{h}: \mathrm{m}: \mathrm{s}) \\
(2)\end{array}$ & $\begin{array}{c}\mathrm{DEC}(1950) \\
\left({ }^{\circ}:^{\prime}:{ }^{\prime}\right) \\
(3)\end{array}$ & $\begin{array}{c}A_{\mathrm{V}} \\
(\mathrm{mag}) \\
(4)\end{array}$ & $\begin{array}{c}N\left(\mathrm{H}_{2}\right) \\
\left(10^{21} \mathrm{~cm}^{-2}\right) \\
(5)\end{array}$ & $\begin{array}{c}\text { Área } \\
(, 2) \\
(6)\end{array}$ & $\begin{array}{c}L \\
(\mathrm{pc}) \\
(7)\end{array}$ & $\begin{array}{c}\text { massa } \\
\left(\mathrm{M}_{\odot}\right) \\
(8)\end{array}$ & Obs. $^{a}$ \\
\hline$A$ & $12: 31: 36.4$ & $-70: 22: 48.6$ & 3.3 & 3.10 & 4 & 0.16 & 0.64 & Mu13 \\
\hline B1 & $12: 29: 17.4$ & $-70: 45: 20.5$ & 4.6 & 4.33 & 56 & 0.62 & 9.41 & Mu11 \\
\hline B2 & $12: 28: 29.0$ & $-70: 47: 07.5$ & 4.6 & 4.33 & & & & Mu10 \\
\hline C & $12: 26: 49.0$ & $-70: 53: 28.1$ & 3.3 & 3.10 & 4 & 0.16 & 0.64 & Mu8 \\
\hline $\mathrm{D}$ & $12: 26: 07.3$ & $-70: 55: 12.8$ & 3.3 & 3.10 & 4 & 0.16 & 0.64 & Mu9 \\
\hline $\mathrm{E}$ & $12: 24: 51.3$ & $-71: 04: 54.2$ & 4.6 & 4.33 & 20 & 0.37 & 3.43 & $\mathrm{Mu} 7$ \\
\hline $\mathrm{F}$ & $12: 23: 46.8$ & $-71: 09: 10.7$ & 4.6 & 4.33 & 8 & 0.23 & 1.78 & Mu6 \\
\hline G & $12: 23: 33.0$ & $-71: 12: 47.9$ & 4.6 & 4.33 & 4 & 0.16 & 0.89 & Mu6 \\
\hline $\mathrm{H}$ & $12: 22: 58.9$ & $-71: 14: 58.8$ & 3.3 & 3.10 & 8 & 0.23 & 1.27 & Mu6 \\
\hline I & $12: 23: 55.5$ & $-71: 16: 49.0$ & 3.3 & 3.10 & 4 & 0.16 & 0.64 & Mu6 \\
\hline J & 12:22:16.8 & $-71: 24: 46.4$ & 4.6 & 4.33 & 12 & 0.29 & 2.16 & Mu5 \\
\hline $\mathrm{K}$ & $12: 21: 26.1$ & $-71: 27: 01.6$ & 4.6 & 4.33 & 12 & 0.29 & 2.16 & Mu4 \\
\hline $\mathrm{L}$ & $12: 21: 53.3$ & $-71: 32: 53.9$ & 3.3 & 3.10 & 28 & 0.44 & 4.45 & Mu4 \\
\hline $\mathrm{M}$ & 12:20:14.1 & $-71: 45: 15.4$ & 3.3 & 3.10 & 4 & 0.16 & 0.64 & $\mathrm{Mu} 2$ \\
\hline $\mathrm{N}$ & $12: 19: 47.0$ & $-71: 51: 35.6$ & 3.3 & 3.10 & 12 & 0.29 & 1.91 & Mu3 \\
\hline $\mathrm{O}$ & $12: 19: 22.7$ & $-71: 56: 59.4$ & 3.3 & 3.10 & 4 & 0.16 & 0.64 & Mu3 \\
\hline $\mathrm{P}$ & 12:18:53.6 & $-72: 02: 43.9$ & 4.6 & 4.33 & 12 & 0.29 & 2.16 & Mu1 \\
\hline Q & $12: 18: 25.6$ & $-72: 08: 56.4$ & 3.3 & 3.10 & 4 & 0.16 & 0.64 & Mu1 \\
\hline
\end{tabular}

a identificador de Vilas-Boas et al. (1994)

Vilas-Boas, Myers e Fuller (1994, daqui em diante VMF), analisando os mapas de contagens de estrelas de Gregorio-Hetem et al. (1988) na NEM, obtiveram um valor médio para o tamanho óptico da condensação de $0.3 \pm 0.1$ pc. Este valor está em excelente concordância com nosso valor médio de $0.26 \pm 0.12$ pc para este parâmetro. VMF também calcularam o valor médio da densidade colunar do hidrogênio usando medidas de largura de linha de ${ }^{18} \mathrm{CO}$ e ${ }^{13} \mathrm{CO}$ e obtiveram um valor de $(4 \pm 1) \times 10^{21} \mathrm{~cm}^{-2}$, que é coerente com nosso valor médio de $(3.65 \pm 0.63) \times 10^{21} \mathrm{~cm}^{-2}$.

Em geral, as posições das condensações enumeradas na Tabela 3.6 são aproximadamente coincidentes com as posições identificadas por VMF (ver última coluna na Tabela 3.6). A condensação identificada como Mu13 em VMF está associada com a posição A em nosso trabalho e é coincidente com a posição da fonte IRAS 12322-7023, uma provável estrela $T$ Tauri, como notado por Gregorio-Hetem et al. (1988). A condensação identificada como 
Mu6 em VMF pode ser associada com as posições F, G, H e I em nosso trabalho. As posições $\mathrm{K}$ e L podem pertencer a uma estrutura única e é identificada como Mu4 em VMF. As posições $\mathrm{N}$ e $\mathrm{O}$ estão associadas com Mu3 e as posições $\mathrm{P}$ e Q com Mu1 em VMF.

\subsection{Discussão}

\subsubsection{Análise da Polarização ao longo da nuvem}

Para analisar o comportamento dos níveis de polarização ao longo da nuvem, graficamos (Figura 3.9a) os valores da polarização médios $\langle P\rangle$ dos 35 campos da Tabela $3.2 \mathrm{em}$ função da declinação. Dependendo da declinação, podemos ter dois ou três campos por declinação segundo nossa distribuição dos campos na NEM (ver Figura 3.3 e Tabela 3.2). O passo em declinação é de 8' de arco. Os pontos a esquerda no eixo da abcissa representam os campos mais ao norte e os da direita estão ao sul. Os pontos brancos representam posições associadas com alta extinção nas regiões mais interiores da NEM obtidas de comparação entre os mapas compostos de extinção e polarização (ver Figura 3.4). Os pontos pretos representam as posições dos campos restantes não associados, pelo menos obviamente, às regiões de maior extinção.

É interessante notar que os campos de máxima polarização coincidem com aqueles campos que estão mais próximos às partes mais densas da NEM, especialmente na região central. Isto sugere uma correlação qualitativa entre máximos de polarização e maior extinção conforme nos vamos aproximando de fora para dentro (em ascenção reta, isto é ao longo do eixo menor) da NEM. Mais adiante, nesta mesma seção, analisaremos em detalhe este aspecto.

$\mathrm{Na}$ Figura 3.9b graficamos somente os campos que apresentam picos de polarização na Figura 3.9a para indagar seu comportamento ao longo do eixo maior da NEM. Podemos notar que os valores da polarização médios $(<P>)$ apresentam variações importantes. Olhando do norte ao sul ao longo do filamento notamos que valores mínimos $(\sim 2 \%)$ são achados no norte (campo 31). A polarização aumenta na região central, sempre em direção ao sul, com picos de polarização no campos 12, 15 e $17(\sim 6-7 \%)$, para finalmente chegar 
a um valor quase constante $(\sim 5 \%)$ na região sul. A otimização da polarização na região central na faixa de declinação de $-71^{\circ} 15^{\prime}$ deve estar certamente correlacionada com as condensações $\mathrm{G}$ e H, vistas em extinção na Figura 4.3. Este fato é interessante pois, é uma evidencia que o padrão de polarização é alterado por regiões de alta extinção, que contradiz a argumentação de Goodman (1996) de que polarimetria óptica de estrelas de fundo é insensível às regiões mais densas em nuvens escuras.
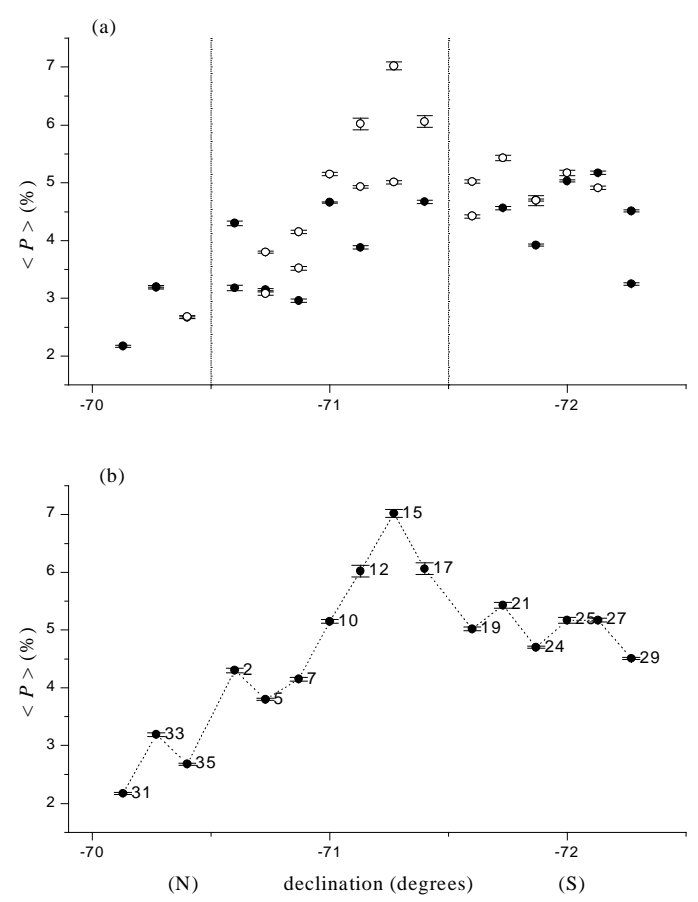

Figura 3.9 Variação do valor médio da polarização $\langle P>$ para os 35 campos observados ao longo da NEM, em função da declinação. (a) Os pontos brancos representam posições associadas com alta extinção nas regiões mais interiores da NEM obtidas de comparação entre os mapas compostos de extinção e polarização (ver Figura 3.4). Os pontos pretos representam as posições dos campos restantes não associados às regiões de maior extinção. Note a coincidência entre as posições de máxima polarização média com as de máxima extinção, especialmente na região central. As linhas verticais indicam as fronteiras entre as regiões norte e central (esquerda) e central e sul (direita). (b) Posições com máxima polarização média ao longo da NEM (uma posição por cada declinação). Os números indicam o número da posição do campo associado. Os menores valores da polarização são achados no norte $(\sim 2 \%)$ e um incremento notório é observado na região central ( $6-7 \%)$ para logo diminuir a um valor quase constante $(\sim$ $5 \%$ no sul.

Para analisar o comportamento da polarização ao longo do eixo menor da NEM (isto é, ao longo da ascenção reta), procuramos as faixas de declinação onde possuíamos maior cobertura espacial. Assim, em quatro posições de declinação $\left(-70^{\circ} 44^{\prime},-70^{\circ} 52^{\prime},-71^{\circ} 08^{\prime} \mathrm{e}-\right.$ $71^{\circ} 52^{\prime}$ ) temos três campos por posição que se prestam bem para nossa análise e cobrem razoavelmente as regiões central e sul. Nossa intenção é confirmar se existe ou não uma mudança na polarização conforme nos aproximamos das regiões com maior extinção. Isto é feito nas Figuras 3.10 - 3.13, compostas cada uma de quatro seções. Na seção (a) mostramos os mapas dos vetores de polarização superpostos às imagens respectivas obtidas do Digitized Sky Survey (DSS). Basicamente mostramos em detalhe cada uma das faixas de declinação já mostradas no mapa geral de polarização da Figura 3.4. O Norte é para cima e o Leste à esquerda. Na seção (b) apresentamos em detalhe os contornos de extinção para cada faixa de declinação superpostos à imagem DSS. A extinção foi obtida do mapa geral 
de extinção mostrado na Figura 3.3. Na seção (c) graficamos os valores individuais de polarização de cada um dos objetos presentes, na faixa de declinação respectiva, em função de sua ascenção reta. O Leste é a esquerda. Finalmente, na seção (d) graficamos os valores individuais do ângulo de polarização em função da sua ascenção reta para cada um dos objetos presentes em cada uma das faixas de declinação.

$\mathrm{Na}$ Figura 3.10a mostramos o mapa de polarização para a faixa de declinação $-70^{\circ} 44^{\prime}$ cobrindo uma área líquida de $\sim 10^{\prime}$ x 40’ (campos 03, 04 e 05). São evidentes as regiões interiores de alta extinção também mostradas na Figura 3.10b mediante os contornos de extinção. Nestes é fácil distinguir as posições B1 e B2 de alta extinção identificadas na lista de condensações da Tabela 3.6. No gráfico da Figura 3.10c mostramos a dependência da polarização observada em função de ascenção reta. O limite inferior de $\sim 2 \%$ é evidente nesta amostra e apesar da dispersão ser alta podemos notar uma ligeira tendência de incrementar-se o valor da polarização conforme nos aproximamos às partes mais interiores especialmente ao redor da posição $\mathrm{B} 1$ centrada em $\mathrm{AR}_{1950}=12^{\mathrm{h}} 29^{\mathrm{m}} 17.4^{\mathrm{s}}$.

$\mathrm{Na}$ Figura 3.11a analisamos o mapa de polarização para a faixa de declinação $-70^{\circ} 52^{\prime}$. A área mostrada cobre os campos 06, 07 e 08. Na Figura 3.11b são evidentes as posições de alta extinção identificadas como B2, C e D na Tabela 3.6. A dependência da polarização em função da ascenção reta mostrado no gráfico da Figura 3.11c indica dois picos aparentes de polarização. $\mathrm{O}$ primeiro parece coincidir com a posição $\mathrm{B} 2\left(\mathrm{AR}_{1950}=12^{\mathrm{h}} 28^{\mathrm{m}} 29^{\mathrm{s}}\right)$ e o segundo está centrado nas posições C e D $\left(\mathrm{AR}_{1950}=12^{\mathrm{h}} 26^{\mathrm{m}} 4\right)^{\mathrm{s}}$ e $12^{\mathrm{h}} 26^{\mathrm{m}} 07.3^{\mathrm{s}}$ respectivamente). O gradiente de polarização mais notório corresponde ao campo mais ao oeste.

O mapa de polarização na faixa de declinação $-71^{\circ} 08^{\prime}$ é mostrada na Figura 3.12a. A área cobre os campos 11, 12 e 13. Duas posições de alta extinção estão presentes (E e F na Tabela 3.6) como é mostrado nos contornos de extinção da Figura 3.12b. Gradientes de polarização leste e oeste são notórios e a polarização parece otimizada na região central onde as posições $\mathrm{E}$ e $\mathrm{F}\left(\mathrm{AR}_{1950}=12^{\mathrm{h}} 24^{\mathrm{m}} 51.3^{\mathrm{s}}\right.$ e $12^{\mathrm{h}} 23^{\mathrm{m}} 46.8^{\mathrm{s}}$ respectivamente $)$ se encontram como é mostrado na Figura 3.12c. É notoria também a mudança observada no $\theta$, discutida na seguinte seção. 
Finalmente, a análise do mapa de polarização para a faixa de declinação - $71^{\circ} 52^{\prime}$ é mostrado na Figura 3.13a. A área cobre 14' x 40' abarcando os campos 22, 23 e 24. Duas posições de alta extinção $\mathrm{N}$ e $\mathrm{O}$ estão presentes nesta área e são evidentes na Figura 3.13b. Novamente e ainda com mais clareza gradientes de polarização (Figura 3.13c) leste e oeste são observados centrados nestas duas posições $\left(\mathrm{AR}_{1950}=12^{\mathrm{h}} 19^{\mathrm{m}} 47^{\mathrm{s}}\right.$ e $12^{\mathrm{h}} 19^{\mathrm{m}} 22.7^{\mathrm{s}}$ respectivamente).

Apesar de nossos dados de polarimetria óptica não nos permitirem amostrar a polarização das regiões mais extintas na NEM, resulta evidente que uma otimização da polarização conforme nos aproximamos a regiões associadas às condensações existe.

\subsubsection{Análise do ângulo médio da polarização ao longo da NEM}

Da mesma maneira, podemos investigar como se comporta o ângulo médio de polarização ao longo da nuvem. Primeiramente, vemos da Tabela 3.4 que existem dois parâmetros que nos representam o ângulo médio de polarização para cada campo analisado $\left(<\theta>, \theta_{\text {gaus s }}\right)$. Uma simples inspeção destes valores indica que são praticamente coincidentes em cada campo. Assim, temos uma boa determinação do ângulo médio da polarização independente da maneira em que seja calculado. Para sermos coerentes com a análise anterior feita para os valores médios da polarização $(<P>)$, escolheremos o valor $\langle\theta>$, isto é, o valor médio do ângulo de polarização ponderado pelos erros respectivos, na nossa análise.

$\mathrm{Na}$ Figura 3.14a graficamos a variação do valor medio do ângulo de polarização, $<\theta>$ (coluna (5) na Tabela 3.4), para os 35 campos observados ao longo da NEM, em função da declinação. A figura mostra que variações importantes no $\langle\theta\rangle$ também são observadas. Novamente os campos associados às regiões mas interiores da NEM com alta extinção estão indicados com pontos brancos. É evidente que na região central e na região sul os ângulos máximos de polarização estão associados às regiões mais extintas.

$\mathrm{Na}$ Figura 3.14b mostramos apenas os ângulos médios de polarização para aqueles campos de máxima polarização observada (Figura 3.9b) e que acreditamos estar associados às regiões mais densas na NEM. Podemos notar que, em geral, valores máximos de polarização são acompanhados de ângulos de polarização também máximos na regiões 
norte e central. Ao sul esta tendência não é tão evidente exceto nos campo 21, 25 e 27 . É interessante apontar que apesar de existir uma tendência geral do ângulo de polarização centrado em $110^{\circ}$, na região norte o ângulo de polarização tem um mínimo (campo 33, $92^{\circ}$ ) para logo apresentar um máximo na região central (campos 12 e 17) e um segundo pico na região sul (campos 25 e 27). Os campos mais extremos (campo 31 no norte e campo 29 no sul) praticamente possuem o mesmo ângulo de polarização médio. Como a direção do ângulo de polarização nos dá a direção do campo magnético projetada no céu, nossa técnica é capaz de distinguir variações da quase $30^{\circ}$ na direção do campo magnético ao longo do eixo maior da NEM.

Para responder à questão de se o ângulo de polarização sofre ou não mudanças conforme nos aproximamos às condensações achadas na NEM, completamos a análise em pequena escala angular feita na seção anterior para o valor de polarização, mas agora concentrandonos no ângulo de polarização, $\theta$, de cada objeto individualmente.

A Figura $3.10 \mathrm{~d}$ mostra a dependência de $\theta$ com a ascenção reta para a faixa de declinação $70^{\circ} 44^{\prime}$. A dispersão observada é alta e nenhuma quebra aparente do valor médio de $\theta$ é observada na posição da condensação B1. A seguinte faixa de declinação estudada foi 7052'. A Figura 3.11d mostra valores maiores de $\theta$ na região central, onde estão as posições de alta extinção B2, C e D, em comparação aos valores observados nas regiões leste e oeste. A terceira faixa de declinação estudada foi $-71^{\circ} 08^{\prime}$. Uma clara quebra do padrão médio de $\theta$ é observado na região central associada as posições $E$ e F como é mostrado na Figura 3.12d. A diferença entre o $\theta$ médio da região central e o $\theta$ médio das regiões leste e oeste é de $\sim 20^{\circ}$. Finalmente, a ultima faixa de declinação estudada foi $71^{\circ} 52^{\prime}$. A Figura $3.13 \mathrm{~d}$ mostra que a região leste apresenta uma valor maior de $\theta$ que a região oeste de $\sim 10^{\circ}$. Na região central um ligeiro aumento é observado conforme nos aproximamos à posição N. Em geral podemos concluir que alguma evidência de quebra do padrão de $\theta$ é observada nas proximidades das regiões associadas a condensações, mas isto não é uma constante. Variações em pequena escala da geometria do campo magnético e/ou da eficiência de polarização certamente devem de influir nas tendências observadas. 

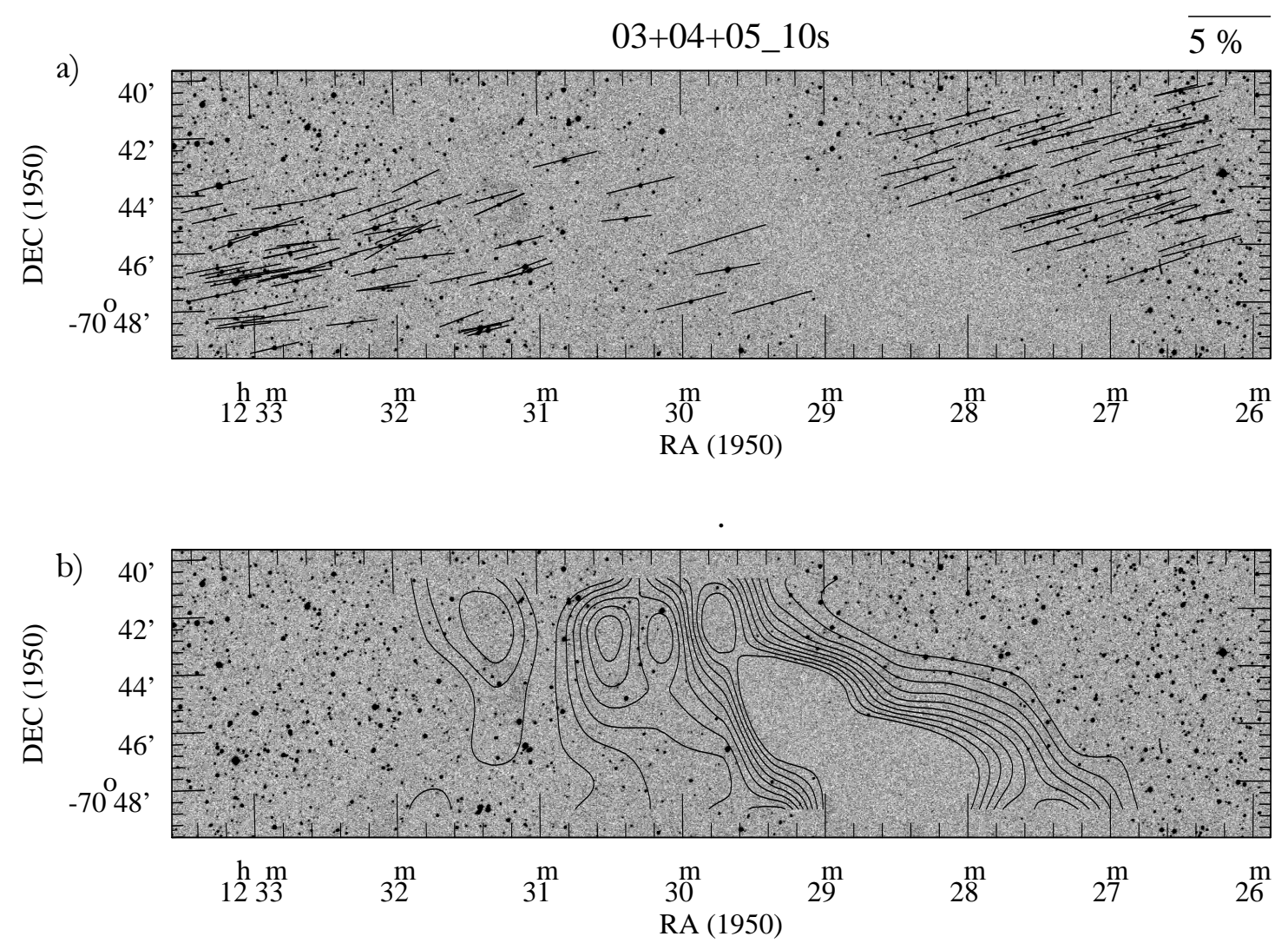

c)

d)
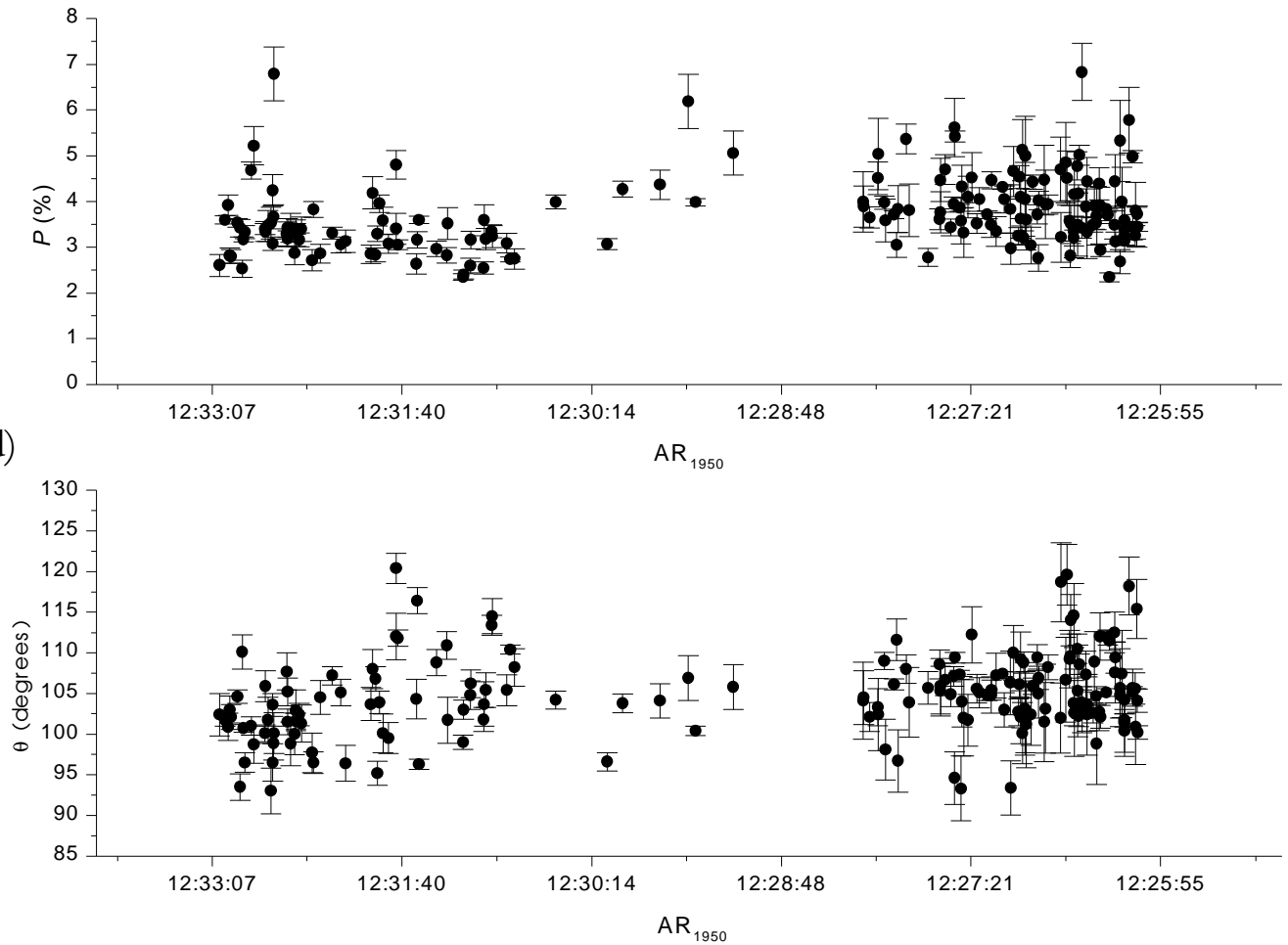

Figura 3.10 Análise em detalhe da polarimetria da NEM na faixa de declinação $\mathrm{DEC}_{1950}=-70^{\circ} 44^{\prime}$. Nesta seção estão as condensações B1 e B2 (ver Figura 3.3). (a) Mapa de polarização. A escala de polarização é mostrada no canto superior direito. (b) Mapa de extinção. Os contornos vão de 0.75 mag ate 3 mag em passos de 0.25 mag. (c) Polarização em função da ascenção reta. (d) Ângulo de polarização em função da ascenção reta. 

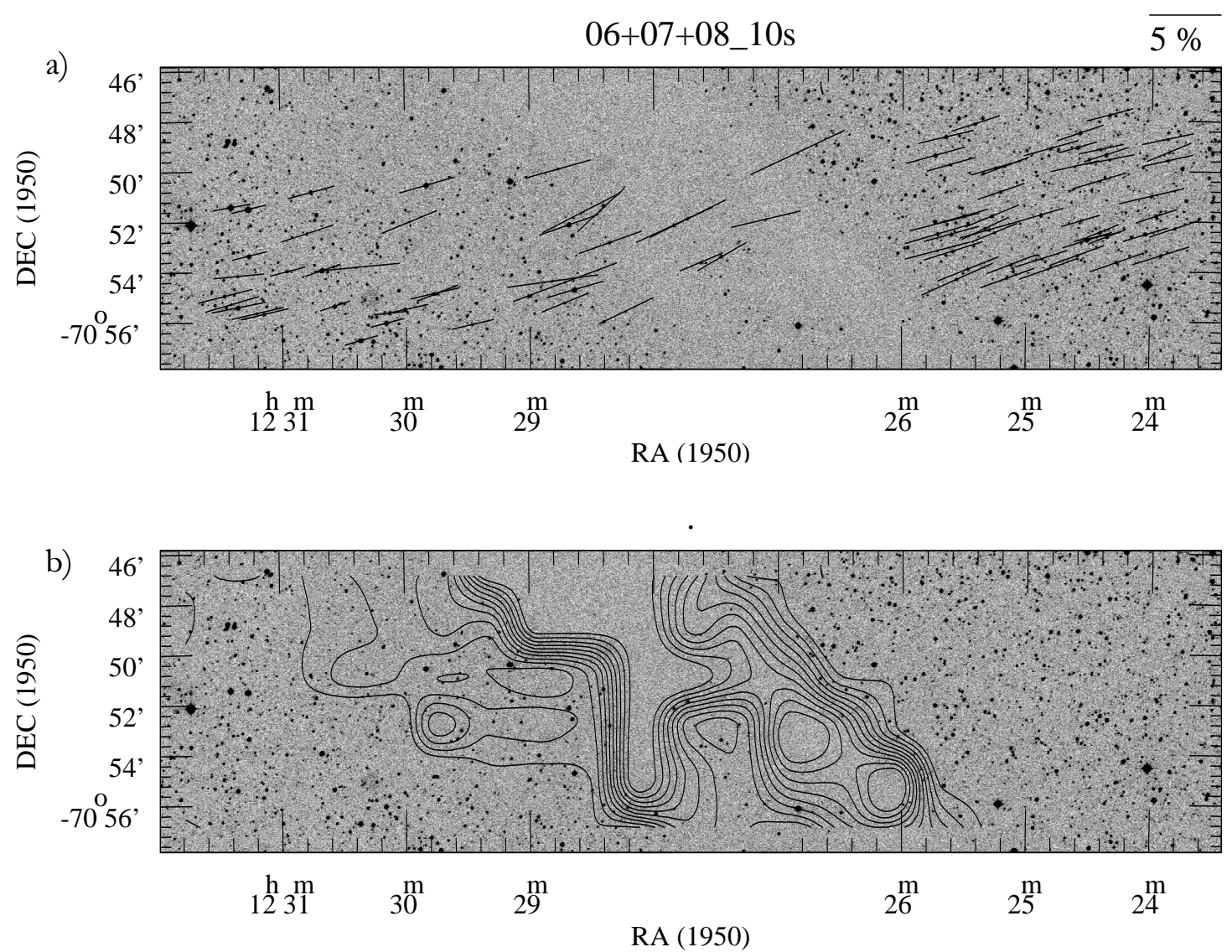

c)

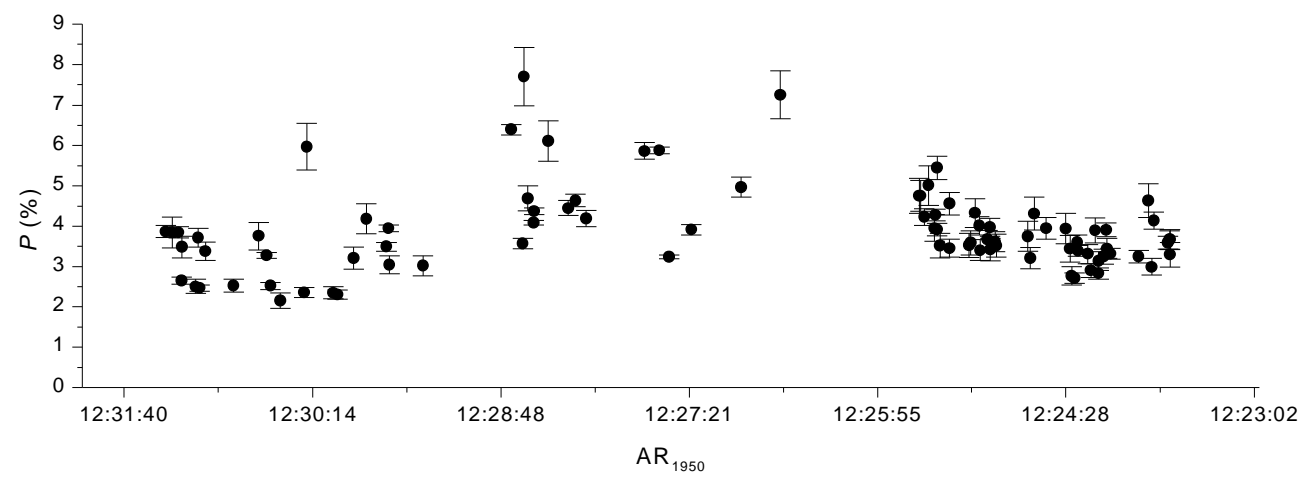

d)

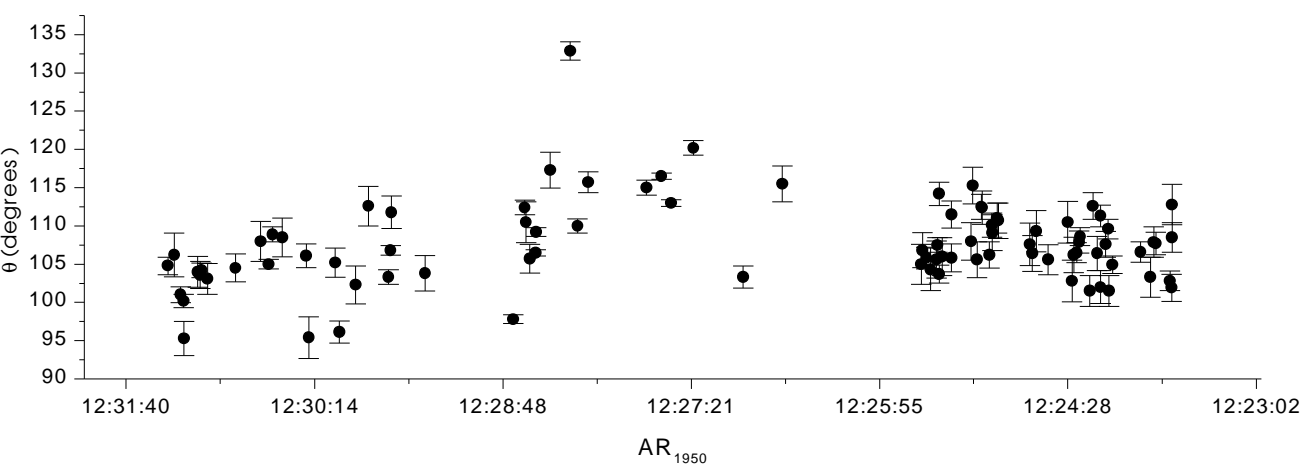

Figura 3.11 Análise em detalhe da polarimetria da NEM na faixa de declinação DEC $_{1950}=-70^{\circ} 52^{\prime}$. Nesta seção estão as condensações B2, C e D (ver Figura 3.3). Panéis como na Figura 3.10. 

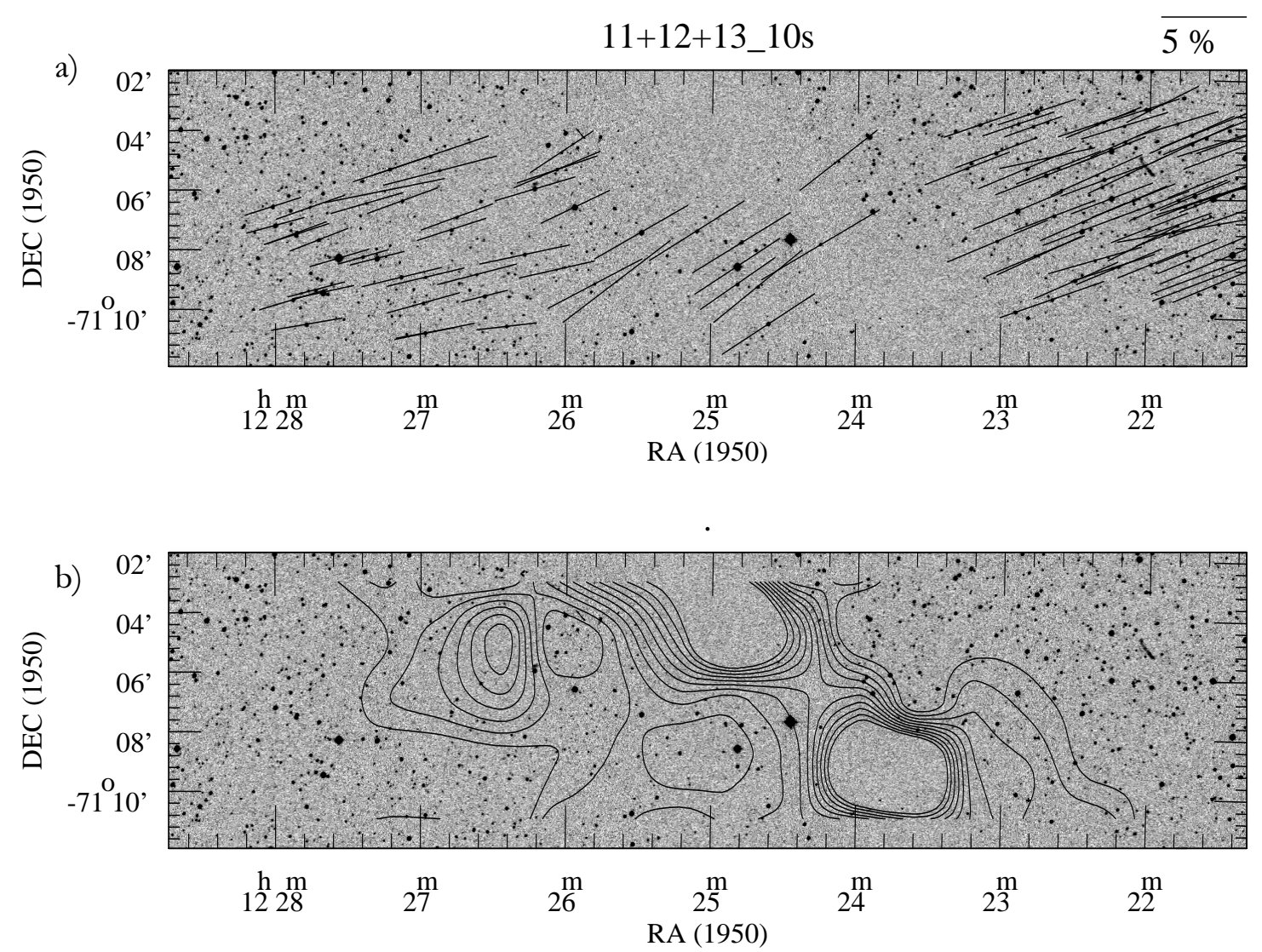

c)

d)
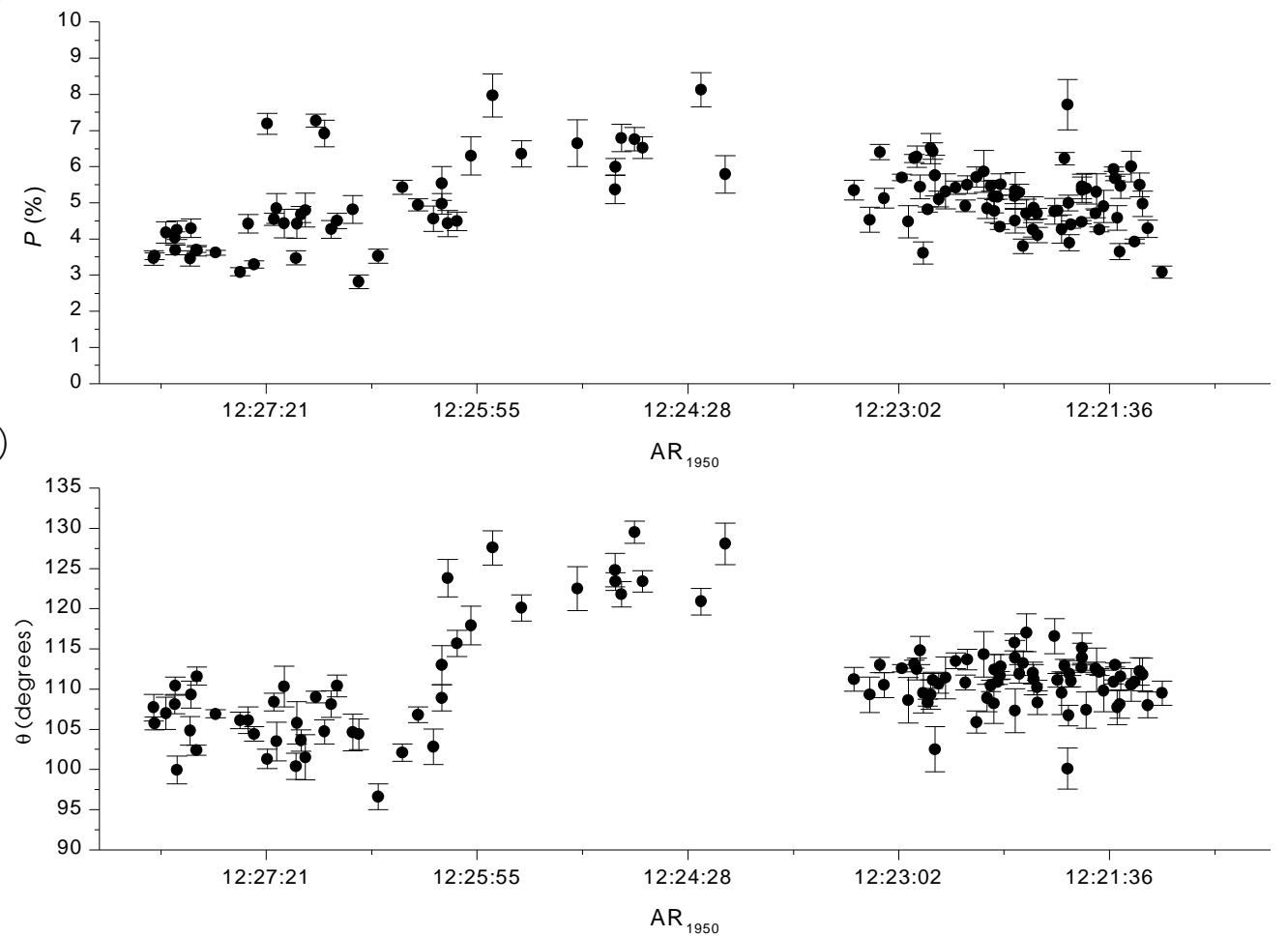

Figura 3.12 Análise em detalhe da polarimetria da NEM na faixa de declinação $\operatorname{DEC}_{1950}=-71^{\circ} 08^{\prime}$. Nesta seção estão as condensações E e F (ver Figura 3.3). Panéis como na Figura 3.10. 

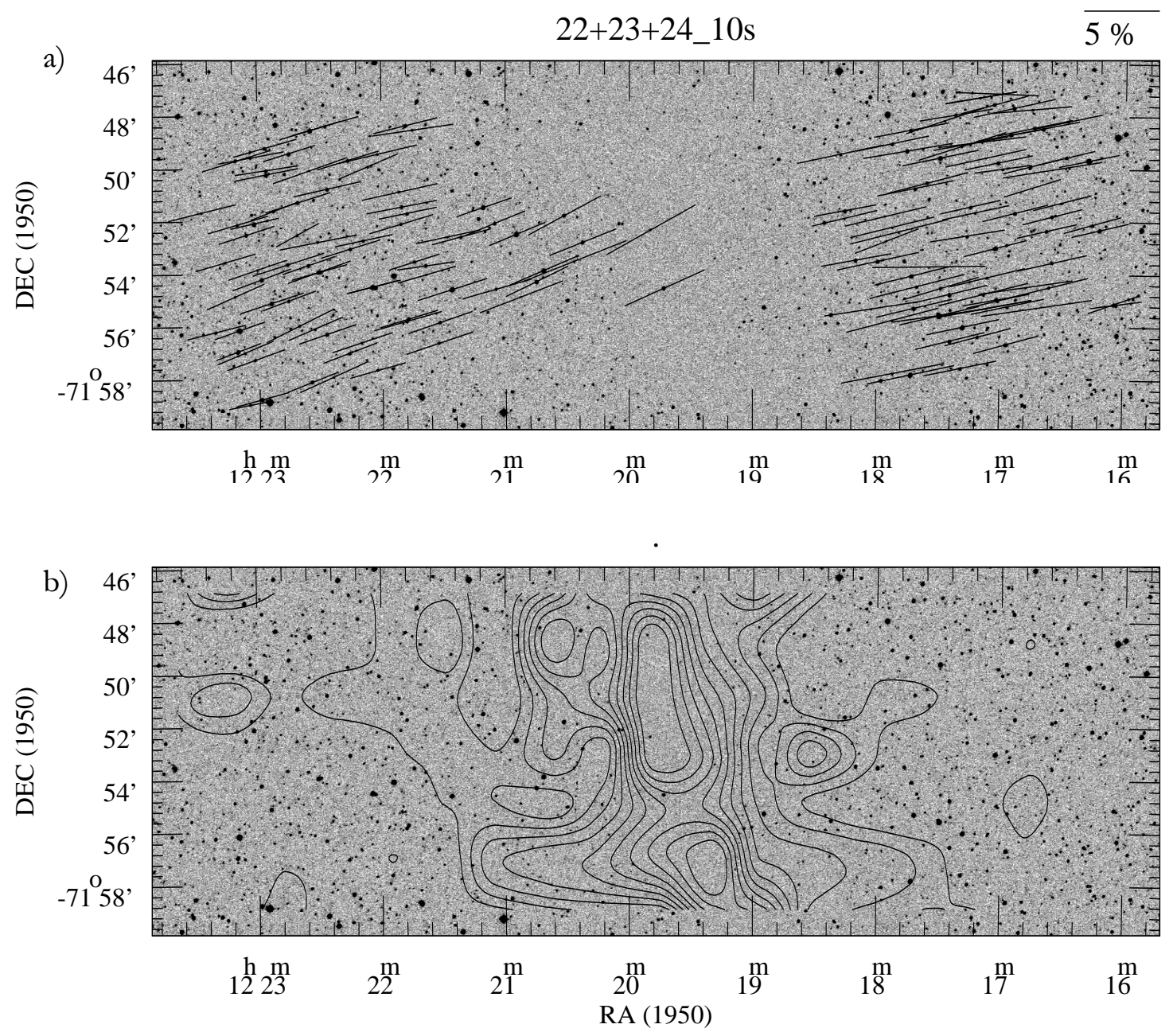

c)

d)
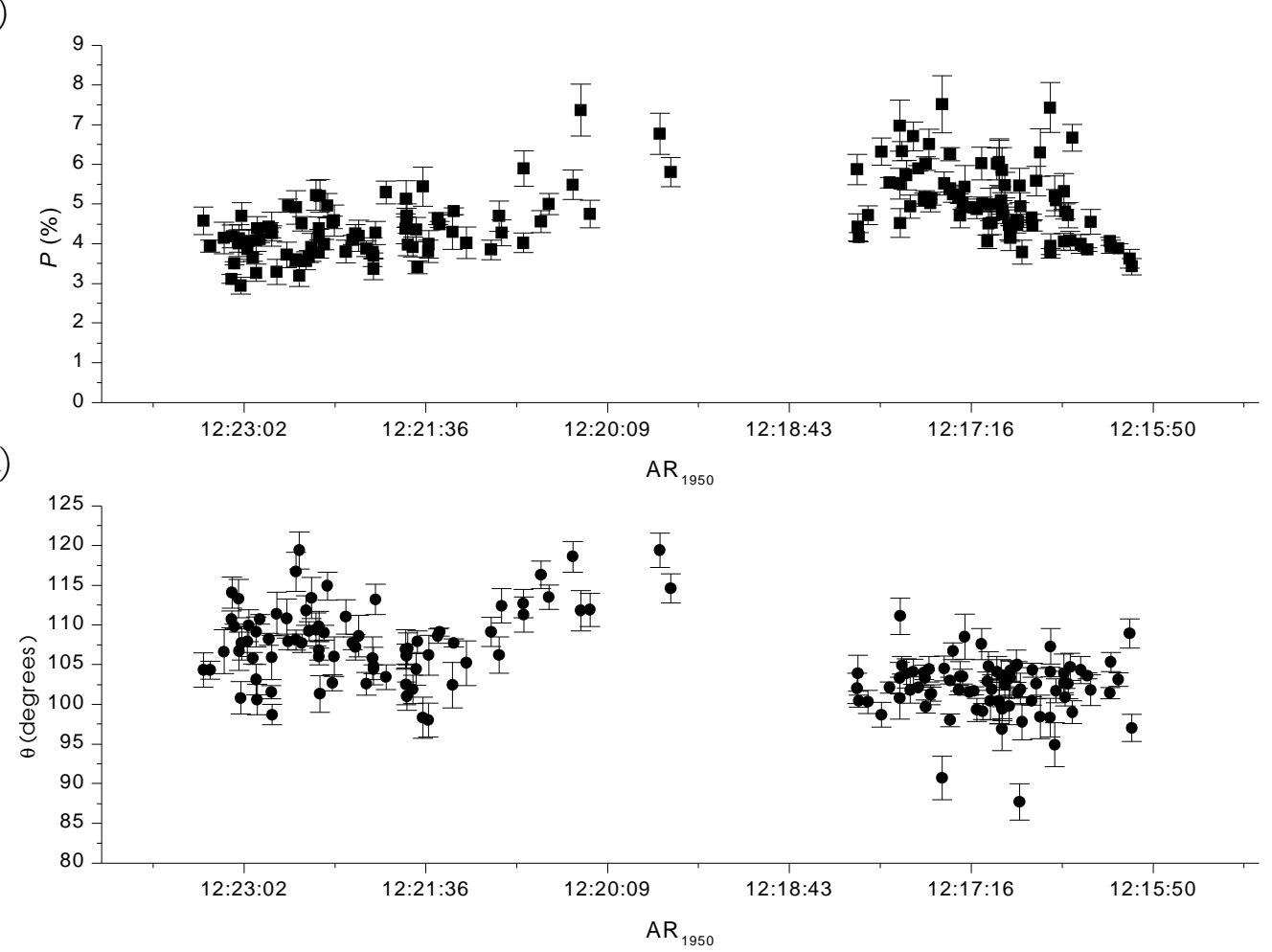

Figura 3.13 Análise em detalhe da polarimetria da NEM na faixa de declinação $\mathrm{DEC}_{1950}=-71^{\circ} 52^{\prime}$. Nesta seção estão as condensações N e O (ver Figura 3.3). Panéis como na Figura 3.10. 

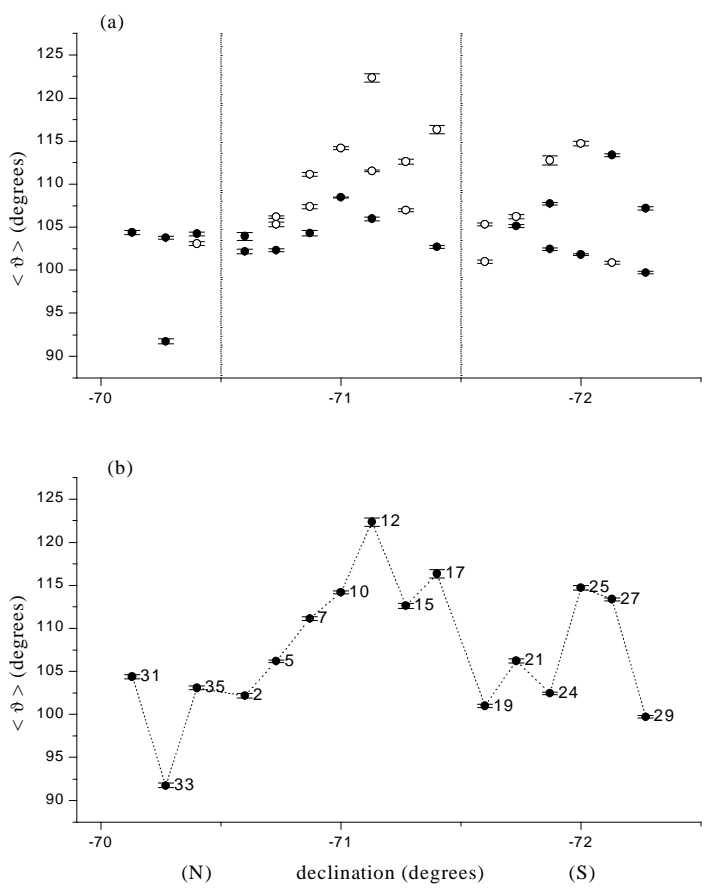

Figura 3.14 (a) Variação do valor médio do ângulo de polarização $<\boldsymbol{\theta}>$ para os 35 campos observados ao longo da NEM, em função da declinação. Os pontos brancos representam posições associadas com alta extinção nas regiões mais interiores da NEM obtidas de comparação entre os mapas compostos de extinção e polarização (ver Figura 4.4). Os pontos pretos representam as posições dos campos restantes, não associados às regiões de maior extinção. Note a coincidência entre as posições de máximo ângulo de polarização médio com as de máxima extinção, especialmente na região central. As linhas verticais indicam as fronteiras entre as regiões norte e central (esquerda) e central e sul (direita). (b) Variação do valor médio do ângulo de polarização para os campos com máxima polarização. Os números indicam os campos respectivos (ver Figura 3.3).

\subsubsection{Sobre o Campo Magnético e rąão de energias cinética e magnética}

Informação sobre a intensidade do campo magnético $(B)$ pode ser obtida a partir da dispersão do ângulo de polarização. Chandrasekhar \& Fermi (1953) demostraram que $B$ pode ser calculado de:

$$
B(\text { gauss })=(4 \pi \varrho / 3)^{1 / 2} V_{\text {turb }} / \Delta \theta
$$

onde $\varrho$ é a densidade do hidrogênio molecular $\left(\mathrm{g} \mathrm{cm}^{-3}\right), V_{\text {turb }}$ é a velocidade da turbulência $\left(\mathrm{cm} \mathrm{s}^{-1}\right)$ e $\Delta \theta$ é a flutuação do $B$ medida pela dispersão angular dos vetores de polarização (radianos). Por outro lado, em termos de densidades de energia, a razão entre a densidade

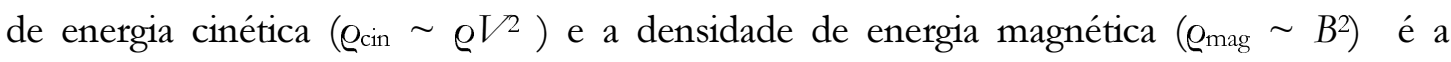
flutuação quadrada média do $B$ representada pelo $<\Delta \theta^{2}>$ (Zweibel, 1990).

Para calcular $<\Delta \theta^{2}>$ utilizamos a última coluna da Tabela 3.4 (pág. 41). A Figura 3.15a mostra a dependência da razão das densidades de energia ao longo da NEM em declinação. Variações notórias são observadas ao longo do eixo maior da NEM com @in / @mag alta no norte e baixa no sul. Para a mesma declinação, a dispersão é maior na região central onde a componente cinética parece ser mais importante nas regiões externas com baixa 
extinção. A Figura 3.15b mostra apenas os pontos com a máxima polarização em cada declinação e podemos interpretar este resultado de duas maneiras: a) um campo magnético fraco na região Norte que se incrementa notoriamente e é mantido constante na medida em que vamos para o Sul da NEM, ou b) o componente cinético turbulento é maior na região norte e é menor nas regiões central e sul da NEM. Considerando o primeiro cenário, é possível calcular a intensidade do campo magnético usando a equação (3.6). Arnal et al. (1993) concluíram que a FWHM dos perfis ${ }^{12} \mathrm{CO}$ não mudam apreciavelmente através da NEM e acharam um valor médio de $1.1 \pm 0.2 \mathrm{~km} \mathrm{~s}^{-1}$. Se assumirmos que a turbulência domina a largura de linha do $\mathrm{CO}$ e uma densidade de partícula de 300 moléculas $\mathrm{cm}^{-3}$ adotada pelos mesmos autores, podemos estimar a intensidade do campo magnético da seguinte expressão:

$$
B(\text { gauss })=7.1 \times 10^{-6} / \Delta \theta(\mathrm{rad})
$$

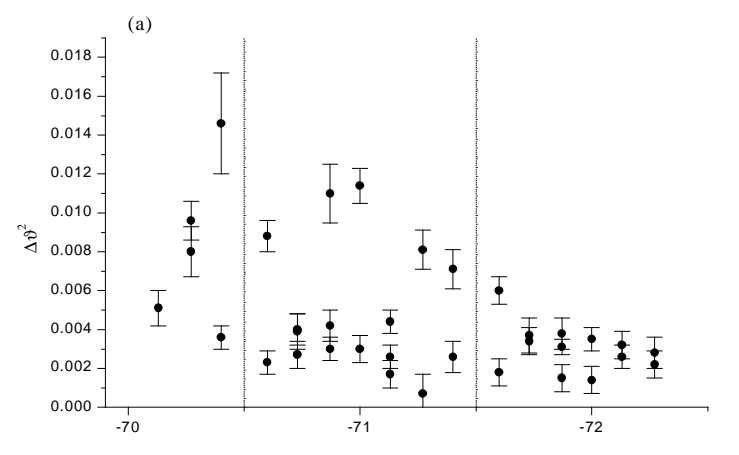

Figura 3.15 (a) Razão de densidades de energia cinética e magnética $\left.\left(<\Delta \theta^{2}\right\rangle\right)$ para os 35 campos ao longo da NEM. (b) Razão de densidades de energia cinética e magnética $\left(<\Delta \theta^{2}>\right)$ para os campos com máxima polarização. Os números indicam os campos respectivos.

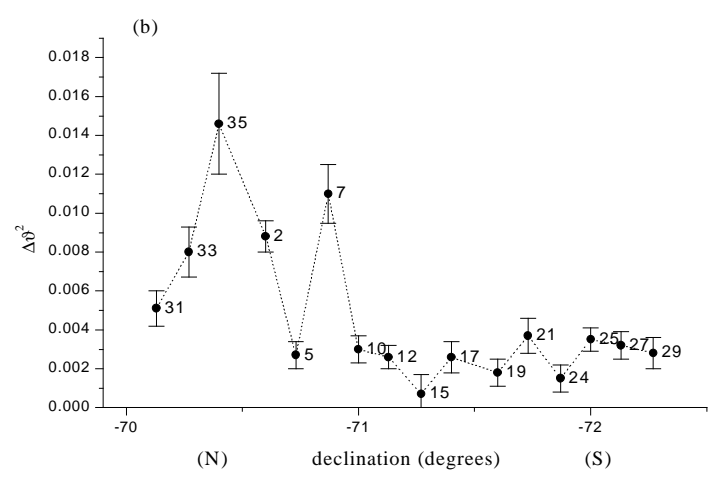

a partir da equação (3.6). A Figura 3.16a mostra $B$ através da NEM em declinação. Em geral, observamos um campo magnético que aumenta de norte ao sul com um pico na região central (campo 15). Este pico apresenta o maior erro na amostra, mas está associado com uma região de máxima polarização e extinção. Em geral, uma dispersão grande em $B$ é observada em qualquer faixa de declinação, sendo esta dispersão maior que os erros 
individuais. A Figura 3.16b mostra o campo magnético nas regiões com máxima polarização. A tendência de $B$ aumentar na direção sul é confirmada. A faixa de valores da intensidade do campo magnético ao longo da NEM é $(0.05-0.30)$ mgauss. Nossos resultados são uma ordem de magnitude maior que o cálculo de Arnal et al. (1993) (B 0.032 mgauss), obtido de considerações de equilíbro virial (McCutcheon et al. 1986). A título de comparação, Arnal et al. (1993) calcularam a faixa de variação de $B$, supondo uma amplificação do campo $\left(B \propto n^{\mathrm{k}}\right.$, com $1 / 3<k<1 / 2$, Mouschovias 1976), obtendo $B=0.02-$ 0.06 mgauss.

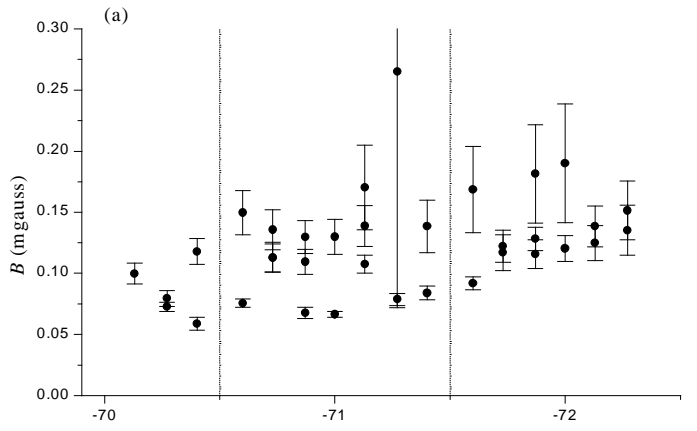

Figura 3.16 (a) Intensidades de campo magnético (B) calculadas em cada una das 35 posições dos campos ao longo da NEM da dispersão dos vetores de polarização; (b) intensidades de campo magnético nos campos com máxima polarização. Os números indicam os campos respectivos.

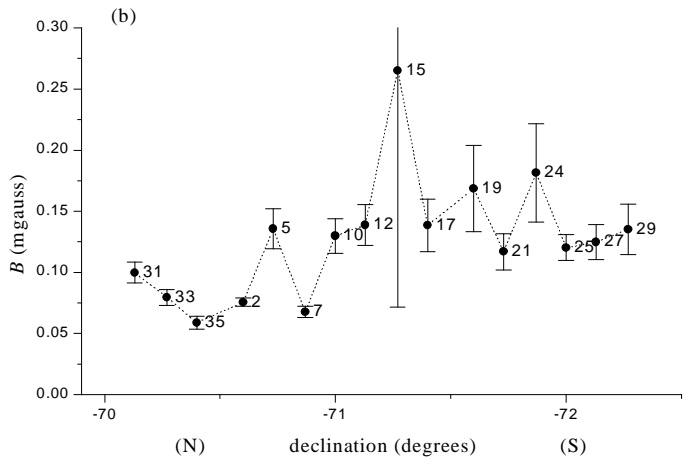

\subsubsection{Eficiência da polarização na NEM}

Para analisar a eficiência da polarização pela poeira na NEM combinamos nossos dados de polarização com os mapas de extinção obtidos de nossa técnica automática de contagem de estrelas. A posição de cada estrela em nossos dados polarimétricos está bem determinada. Assim, identificamos esta posição com relação aos mapas de extinção e atribuímos a ela o valor da cela de extinção. Devemos notar que este procedimento pode subestimar o valor 
da extinção associada a uma estrela pois a resolução de 2' x 2' dos mapas de extinção pode não resolver variações da extinção existentes dentro de uma dada cela de extinção.

A Figura 3.17a mostra a porcentagem de polarização na banda $V$ versus a extinção visual para cada estrela. Eliminamos objetos $\operatorname{com} A_{\mathrm{V}}=0$ nesta figura. $\mathrm{O}$ número total de objetos analisados foi de 1205. Podemos observar que, independente da extinção, um nível mínimo de polarização $\sim 2 \%$ prevalece ao longo da NEM. Acreditamos que isto confirma o fato de estarmos amostrando estrelas de background com relação à NEM. Apenas uma estrela em nossa amostra parece ser de foreground (estrela 13 no campo 14, Tabela C.19 no Apêndice C) e apresenta a mais baixa polarização da amostra $(0.47 \%)$. Esta estrela está localizada numa região de $A_{\mathrm{V}} \sim 1$ mag e é uma das mais brilhantes da nossa amostra (11.5 mag). Este fato parece ser consistente com a idéia que esta estrela está à frente da NEM. Infelizmente, o catálogo Hipparcos não tem informação sobre a distancia desta estrela, o que permitiria aclarar este ponto.

A linha sólida na Figura 3.17a representa o limite superior para a polarização no meio interestelar difuso ( $p_{\max }=3 A_{\mathrm{V}}$; Serkowsky et al. 1975). É evidente que nossa amostra não está bem representada por este limite superior. Apenas $2 \%$ dos dados estão abaixo deste limite. Se consideramos a possibilidade que nossa amostra esteja subestimada em extinção, acreditamos que isto não deveria mudar o fato que as propriedades dos grãos de poeira responsáveis pela extinção na NEM são diferentes daqueles no meio interestelar difuso. Isto pode ser verificado, se utilizamos, por exemplo, a extinção de Cambresy (1999) (superestimada com respeito à nossa) como veremos mais adiante (Figura 3.18a). Arnal et al. (1993) acharam evidências para a presença de grãos grandes na NEM $\left(\lambda_{\max } \sim 0.58 \mu \mathrm{m}\right)$ comparados àqueles presentes no meio interestelar difuso $\left(\lambda_{\max } \sim 0.55 \mu \mathrm{m}, \mathrm{Vrba}\right.$, Coyne $\mathrm{e}$ Tapia 1981).

Um limite maior para a polarização foi achado por Whittet et al. (1994) ( $p_{\max } / A_{\mathrm{V}} \sim 4.5 \%$ mag $^{-1}$; linha tracejada na Figura 3.17a) em algumas linhas de visada da nuvem escura Chamaeleon I e concluiu que um alto grau de alinhamento estava presente com as linhas do campo magnético essencialmente perpendiculares à linha de visada. Acreditamos que um cenário similar está presente na NEM. O alto grau de alinhamento é muito evidente nos mapas de polarização da Figura 3.4 na NEM e o alto grau de polarização $(\geq 2 \%$ ) para baixas extinções como é mostrado na Figura 3.17a sugere uma ótima visão geométrica do 
campo magnético. Ou seja, o campo magnético está a um ângulo próximo a $90^{\circ}$ da linha de visada à NEM.

A Figura 3.17b mostra a eficiência da polarização, $P_{\mathrm{V}} / A_{\mathrm{V}}$, em função da extinção visual. Observamos que as regiões exteriores com baixa extinção são mais eficientes para polarizar estrelas de background que as regiões mais interiores com alta extinção. Esta tendência de diminuição da eficiência da polarização já foi observada em outras regiões (Vrba et. al. 1994; McGregor et al. 1994; Whittet et al. 1994; Gerakines et al. 1995). A linha tracejada na Figura 3.17b mostra um ajuste de mínimos quadrados a uma lei de potência para nossa amostra. O ajuste obtido é $P_{\mathrm{V}} / A_{\mathrm{V}}=5.22(.05) A_{\mathrm{V}^{-0.84}(.01)} \% \mathrm{mag}^{-1}$. Os erros das constantes estão entre parêntesis. Gerakines et al. (1995) deduziram que $P / A \propto A^{2 k-1}$ quando é assumido uma dependência da densidade $(n)$ com o campo magnético $\left(B \propto n^{k}\right.$; Mouschovias 1978) e uma eficiência da polarização $P / A \propto B^{2} / n$ (Vrba et al. 1981). Nosso ajuste fornece um fator de escala para $B$ de $k=0.08$ para a NEM que está abaixo do limite inferior de 1/3 dado por Mouschovias (1978). Como foi notado por Gerakines et al. (1995), esta discrepância pode ser o resultado de ignorar por um lado os efeitos das inhomogeneidades em pequena escala no campo magnético e, por outro, o acoplamento das temperaturas do gás e a poeira nas regiões de alta densidade na eficiência da polarização assumida por Vrba et al. (1981).

A título de comparação, apresentamos a mesma análise anterior utilizando o mapa de extinção de Cambrésy (1999). Na Figura 3.18a podemos notar que os pontos se estendem até magnitudes maiores ( $4.4 \mathrm{mag})$ que as obtidas por nós ( $3.3 \mathrm{mag})$. O mapa de Cambrésy (1999) possui um tamanho de pixel de 0.46' mas está sobreamostrado tendo uma escala real de extinção variável. De modo geral notamos que se confirma que a maior parte de nossos dados estão acima do ótimo alinhamento do MI difuso, inclusive se consideramos o limite superior de Whittet et al. (1944). Por outro lado, a eficiência da polarização mostra o mesmo comportamento como é mostrado na Figura 3.18b com o

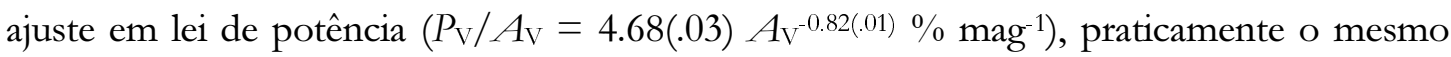
que o obtido usando nossos mapas de extinção. 

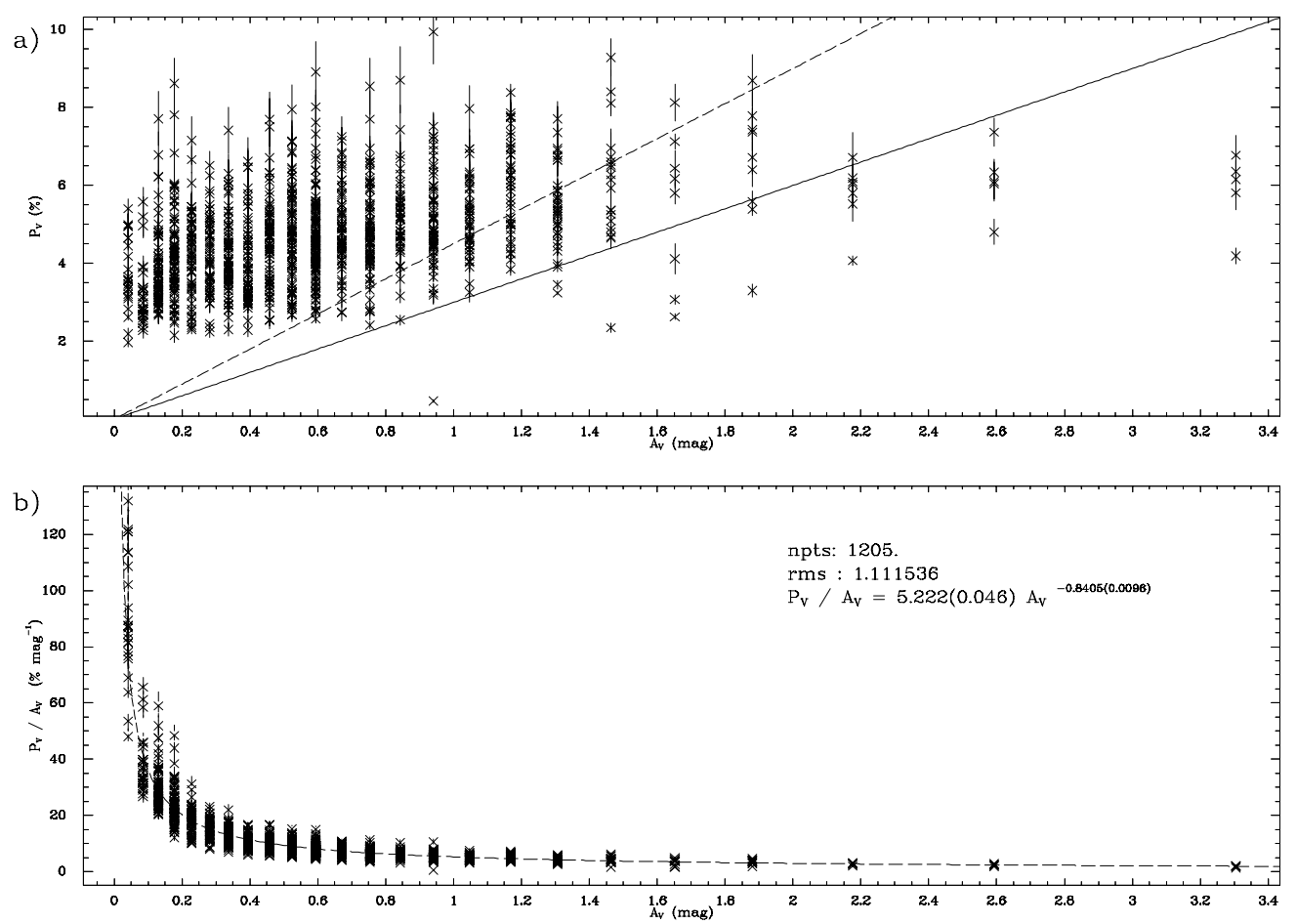

Figura 3.17 (a) Porcentagem de polarização na banda V versus extinção visual para estrelas de backeground na NEM. A linha sólida representa o limite superior para o meio interestelar difuso $\left(P_{\mathrm{V}}=3 A_{\mathrm{V}}\right.$; Serkowsky et al., 1975). A linha tracejada representa o limite superior na linha de visada de Cha I (Whittet et al., 1994). (b) Eficiência da polarização versus extinção visual para estrelas de background na NEM. A linha tracejada representa um ajuste de mínimos quadrados a uma lei de potência para a amostra $\left(P_{\mathrm{V}}=5.2 A_{\mathrm{V}}{ }^{-0.84}\right)$.
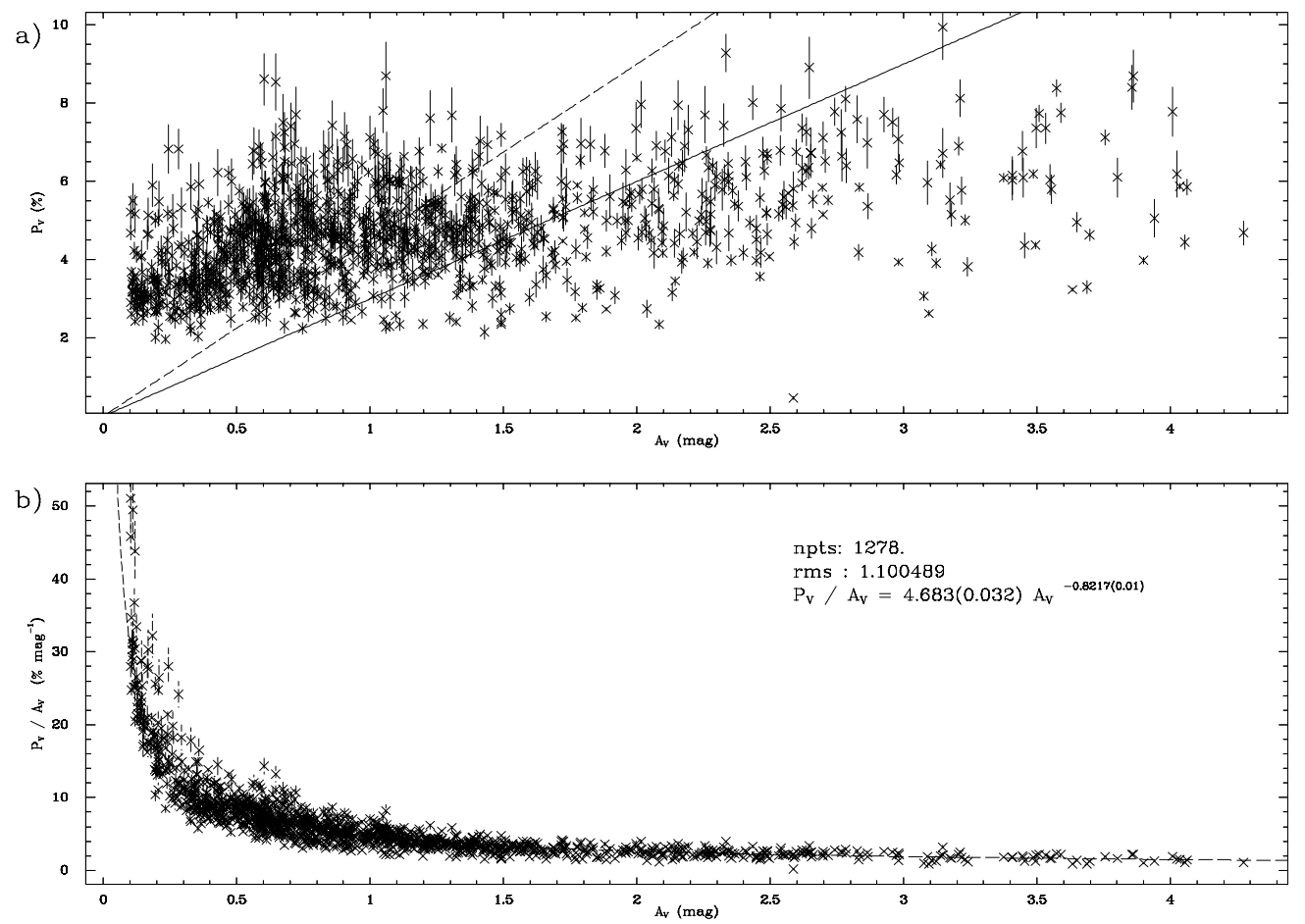

Figura 3.18 Igual à Figura 3.17 mas utilizando a extinção de Cambrésy (1999). A linha tracejada em (b) representa um ajuste de mínimos quadrados a uma lei de potência para a amostra $\left(P_{\mathrm{V}}=4.68 A_{\mathrm{V}}{ }^{-0.82}\right)$. 


\subsection{Conclusões}

- Se contornos de $A_{\mathrm{V}}=1$ são assumidos como as bordas da nuvem e uma distância de 200 pc, a contagem automática de estrelas na NEM fornece um limite inferior de 139 $\mathrm{M} \odot$ para a massa total da nuvem.

- Uma escala de tamanho $L \sim 0.26$ pc foi achada para condensações com $A_{\mathrm{V}} \geq 3$ mag.

- Um limite inferior de polarização de $2 \%$ foi detectado através da NEM com picos de polarização de $6-7 \%$ na região central. Variações de quase $30^{\circ}$ foram detectadas no ângulo de polarização ao longo da NEM, com um ângulo médio centrado em $110^{\circ}$.

- Usando a dispersão medida dos ângulos de polarização, estimamos a intensidade do campo magnético através da NEM e detectamos valores dentro de uma faixa de 0.05 mgauss a 0.30 mgauss.

- Correlações entre extinção e polarização reforçam a idéia de que a poeira na NEM possui diferentes propriedades que as do meio interestelar difuso. Uma visão geométrica em que o campo magnético é quase perpendicular à linha de visada parece estar presente ao longo da nuvem. 



\section{Capítulo 4}

\section{Polarimetria, Extinção e Campo Magnético na direção de HD62542}

\subsection{Resumo}

A região da parede oeste da Iras Vela Shell na direção da HD62542 é ionizada pelos ventos da estrela $\gamma$ Velorum e possivelmente por $\zeta$ Puppis. Aplicamos a técnica de polarimetria de imagem para mapear o campo magnético nessa direção e sua relação com a geometria da região. Um catálogo polarimétrico com quase 900 objetos foi construído. Um estudo de extinção utilizando a técnica de contagem automática de estrelas foi completado para a mesma região e é utilizado para analisar a eficiência da polarização dos grãos de poeira comparándo-los com aqueles do MI. 


\subsection{Introdução}

\subsubsection{A região de Puppis e Vela}

Sahu (1992) analisou a morfologia do MI na região de Puppis e Vela $\left(l=245^{\circ}\right.$ a $270^{\circ}$ e $|b|$ $<20^{\circ}$ ) identificando três principais estruturas dentro dos primeiros $2 \mathrm{kpc}$ de distância: o Vela Molecular Ridge (VMR, $r \sim 1 \mathrm{kpc}$ ), a Nebulosa de Gum (NG, $r \sim 800$ pc) e a IRAS Vela Shell (IVS, $r \sim 450 \mathrm{pc}$ ). A região também apresenta associações OB e R tais como Vela OB1, Vela OB2 e Vela R2. Estrelas early-type de interesse na região incluem $\zeta$ Puppis (O5 Iaf), a mais brilhante estrela tipo $\mathrm{O}$ no céu, e $\gamma^{2}$ Velorum (WC8), a mais brilhante e provavelmente mais próxima binária Wolf-Rayet. Em projeção na região estão também os remanescentes de supernova (SNRs) Vela X, Y, Z e Puppis A; assim como alguns pulsares entre eles o pulsar de Vela. A região contém numerosos glóbulos cometários (CGs) e nuvens escuras (Hawarden e Brand 1976, Sandqvist 1976, Zealey et al. 1983, Reipurth 1983). Os CGs tem núcleos densos que são completamente opacos à luz estelar de fundo e caudas tenuemente luminosas que deixam transluzir estrelas de fundo. Os núcleos destes CGs apresentam às vezes bordas brilhantes. A distribuição espacial das estruturas na região Puppis-Vela mostrada por Sahu (1992) é apresentada na Figura 4.1 (esquerda).
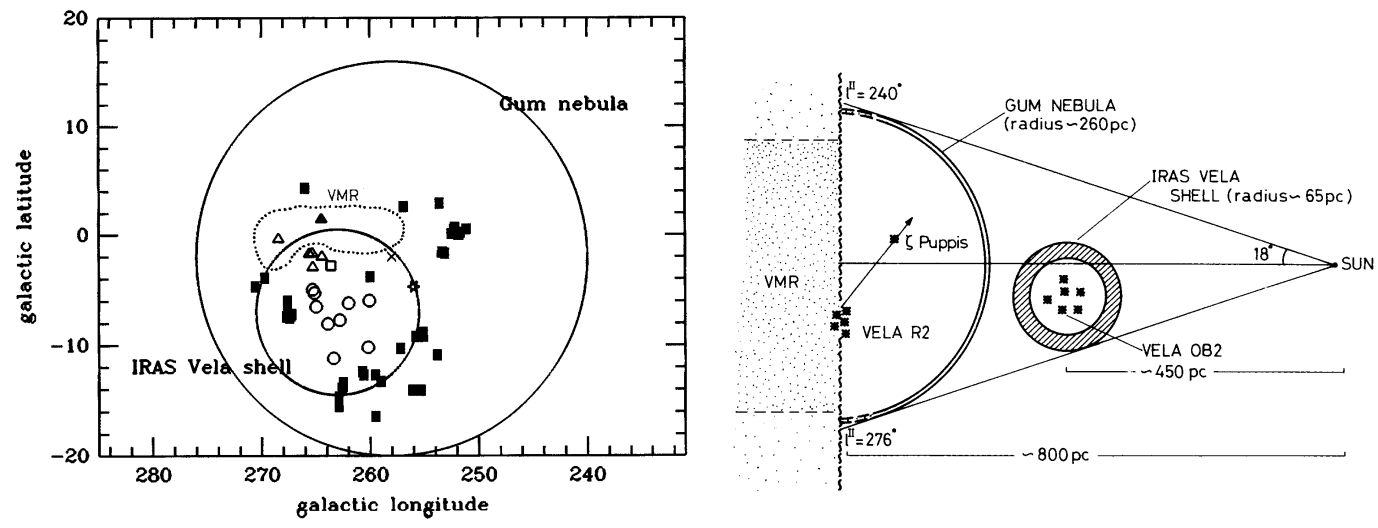

Figura 4.1 (esquerda) Figura esquemática projetada no céu mostrando as localizações da IRAS Vela Shell, a Nebulosa de Gum, a associação Vela OB2 (ćrculos abertos), a associação Vela R2 (centrada no triângulo preto), os glóbulos cometários (quadrados pretos) e o Vela Molecular Ridge. A estrela $\zeta$ Puppis está indicada por uma "estrela" e o Vela Pulsar por um quadrado aberto; (direita) Figura esquemática projetada sobre o plano galáctico mostrando as estruturas em Puppis-Vela. A trajetória passada de $\zeta$ Puppis é indicada pela seta. As distâncias à NG e à IVS estão indicadas (Sahu 1992).

A massa estimada do $\operatorname{VMR}\left(\sim 10^{6} \mathrm{M} \odot\right)$ é consistente com uma típica nuvem molecular gigante (GMC). A NG é uma enorme estrutura de emissão $\mathrm{H}_{\alpha}$ com seu diâmetro angular de $\sim 36^{\circ}$, espalhando-se por grande parte de Puppis e Vela. A uma distância de 800 pc, o 
diâmetro angular da NG corresponde a $\sim 250$ pc (Sahu, 1992). Vários cenários tem sido propostos para a origem da nebulosa. Reynolds (1976a,b) propós que a nebulosa é um velho remanescentente de supernova sendo aquecido e ionizado pelo fluxo $\mathrm{UV}$ de $\zeta$ Puppis. Weaver et al. (1977) sugeriu um modelo alternativo onde a NG é uma shell formada pelos ventos estelares de $\zeta$ Puppis e $\gamma^{2}$ Velorum. Ambos cenários predizem idades $\sim 10^{6}$ anos e velocidades de expansão de $10 \mathrm{a} 30 \mathrm{~km} \mathrm{~s}^{-1}$.

Nestes modelos, é assumido que a shell de $36^{\circ}$ de extensão junto à intensa emissão perto da região de Vela OB2 formam parte da mesma estrutura. No entanto, baseado nos mapas IRAS de emissão extensa, Sahu (1992) descobriu a existência da IVS, uma estrutura tipo anel de $\sim 7.5^{\circ}(\sim 60 \mathrm{pc})$, associada com Vela OB2 e localizada numa posição assimétrica $(l, b) \sim\left(263,-7^{\circ}\right)$ com respeito à NG. De estudos cinemáticos do gás ionizado em PuppisVela e de movimentos próprios em Vela OB2, Sahu (1992) determinou que tanto a NG como a IVS são estruturas separadas com diferentes origens e natureza (Figura 4.1, direita).

A NG foi interpretada como uma estrutura tipo shell formada pela interação da jovem associação Vela R2 com o MI circundante através da radiação ionizante, ventos estelares e supernovas. A associação Vela R2 está localizada à $\sim 800$ pc nas partes externas do VMR, no lado mais próximo a nós. Assim, a NG estaria situada na borda de uma nuvem molecular. Sahu (1992), estudando a trajetória passada projetada no céu de $\zeta$ Puppis, sugeriu que esta estrela teria sua origem em Vela R2 e não em Vela OB2 como foi apontada por trabalhos anteriores (Upton 1971, Reynold 1976a). A assimetria $\left(\sim 8^{\circ}\right)$ entre o centro $\mathrm{H}_{\alpha}$ da NG e a associação Vela R2 pode estar relacionada ao deslocamento de $\zeta$ Puppis em direção a longitudes baixas e latitudes negativas. Por outro lado, a IVS tem sido interpretada como o remanescente de uma GMC envolvendo a relativamente velha associação Vela OB2, da qual forma parte $\gamma^{2}$ Velorum. A cavidade associada à IVS estaria criada pelas estrelas da associação Vela OB2 através dos efeitos combinados de ventos estelares e supernovas. 


\subsubsection{A linha de visada a HD62542}

A linha de visada na direção da estrela HD 62542 (Figura 4.2) coincide com uma das paredes (borda oeste) da cavidade associada à IVS. Na Figura 4.3 mostramos a localização da HD62542 no contexto do mapa de nuvens escuras de Feitzinger e Stüwe (1984) onde a IVS é muito evidente. A HD62542 possui a menor extinção visual por unidade de densidade colunar molecular de qualquer linha de visada conhecida. No UV, o bump em $2175 \AA$ é fraco, largo e deslocado a $2110 \AA$ e a extinção cresce anormalmente no UV longínquo. Estas peculiaridades são compartilhadas por algumas linhas de visada que atravessam entornos densos e escuros (Cardelli e Clayton 1991).

Trabalhos prévios associaram a parede na direção a HD62542 com a NG (Cardelli e Savage 1988) mas sua distribuição espacial parece ser mais consistente com a IVS (Sahu 1992, Churchwell et al. 1996). Cardelli e Savage (1988) apontaram que a emissão $H_{\alpha}$ observada na parede parece consistente com a ionização proveniente de $\zeta$ Puppis e $\gamma^{2}$ Velorum (Reynolds 1976a, b), sugerindo também que parte da própria emissão da parede pode provir de choques produzidos pelos ventos destas duas estrelas $\left(2700 \mathrm{~km} \cdot \mathrm{s}^{-1}\right.$ para $\zeta$ Puppis, Olson e Castor 1981; e $1600 \mathrm{~km} \cdot \mathrm{s}^{-1}$ para e $\gamma^{2}$ Velorum, Abbot et al. 1986, Van der Hucht et al. 1986).

A região contém os glóbulos cometários CG 8, 9 e 10 (Hawarden e Brand 1976) e tem sido extensivamente estudada no óptico e no UV. A região analisada possui matéria escura, ou seja, poeira interestelar e a borda leste da região (voltada para dentro da cavidade) apresenta uma frente de ionização $\mathrm{H}_{\alpha}$ (I-front) bastante bem definida com curvaturas diferenciadas na seção norte e sul. Emissão térmica infravermelha longínqua da poeira está deslocada a oeste do I-front mas acompanhando o padrão desta (Sahu 1992, Gregorich e Cardelli 1992, ver Figura 4.4). A poeira é principalmente aquecida pela radiação de Vela OB2. No entanto, algum aquecimento pode ser produzido pelos shocks na shell em expansão. A região parece ser uma frente de ionização e shocks (I/S front) vista quase edge-on, onde o meio muda em uma distância muito curta de um meio que se expande de baixa densidade e completamente fotoionizado a um ambiente molecular frio, denso e neutro.

A parede sul é normal à direção do centro da IVS na associação Vela OB2 e sua morfologia sugere que a matéria foi varrida da região pelo vento dos membros desta associação $\left(\gamma^{2}\right.$ 
Velorum principalmente, ver Figura 4.4). Por outro lado, a curvatura da parede norte parece ser normal à direção de $\zeta$ Puppis o que indicaria a interação do vento desta estrela com à IVS (Cardelli e Savage 1988). Devemos apontar, no entanto, que a distância estimada de $\zeta$ Puppis apresenta uma grande incerteza (800 pc, Allen 1964; 450 pc, Brandt et al. 1971, Upton 1971, Reynolds 1976b; 700 pc, Zombeck 1980) o que pode restringir a eficácia desta possível interação. Isto é apoiado, também, pela análise de Sahu (1992), no sentido que $\zeta$ Puppis não formaria parte da associação Vela OB2.

Devemos indicar que o modelo apresentado por Sahu (1992) não é o único para a morfologia do MI na região Vela-Puppis. Franco (1990) re-estimou a distância ao centro da NG em $200 \pm 30$ pc, colocando o raio dela em $90 \pm 10$ pc. Van der Hucht et al. (1997), utilizando medidas do satélite Hipparcos, estimou a distância a $\gamma^{2}$ Velorum em $258_{-31}^{+41} \mathrm{pc}$ e a $\zeta$ Puppis em $429_{-77}^{+120}$ pc sugerindo que $\gamma^{2}$ Velorum continua sendo uma das principais fontes ionizantes da NG colocando-la quase no centro dela, no entanto $\zeta$ Puppis parece estar localizada atrás a NG segundo a distância proposta por Franco (1990).

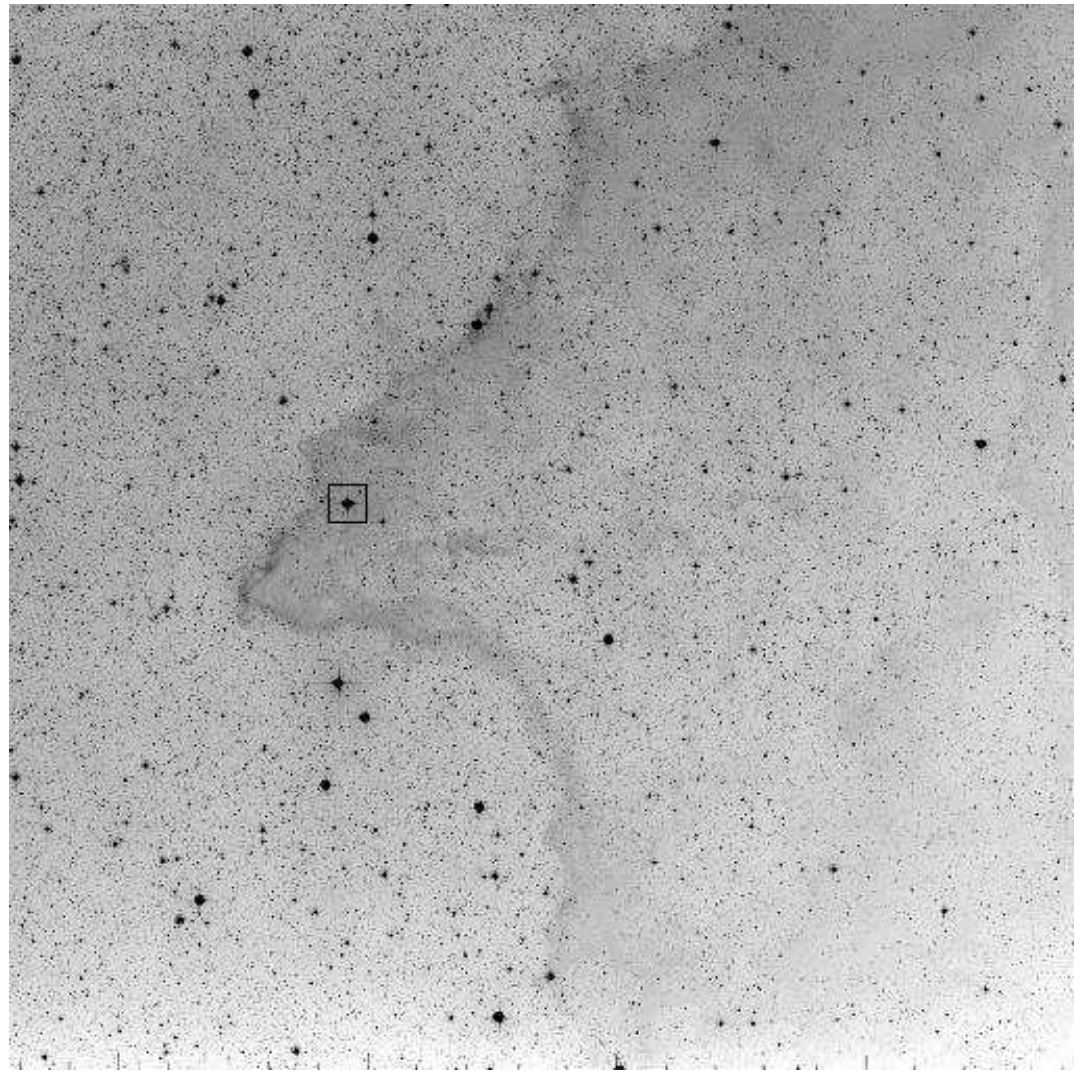

Figura 4.2 Região da IRAS Vela Shell/ Nebulosa de GUM na direção da HD62542 obtida do Digitizęed Sky Survey. A área total é de $2^{\circ} \times 2^{\circ}$ e está centrada em $\mathrm{AR}_{1950}=07^{\mathrm{h}} 39^{\mathrm{m}}$ e $\mathrm{DEC}_{1950}=-42^{\circ} 10^{\prime}$. Norte é para cima e Leste à esquerda. A estrela HD62542 está indicada com um quadrado pero da borda da parede. 


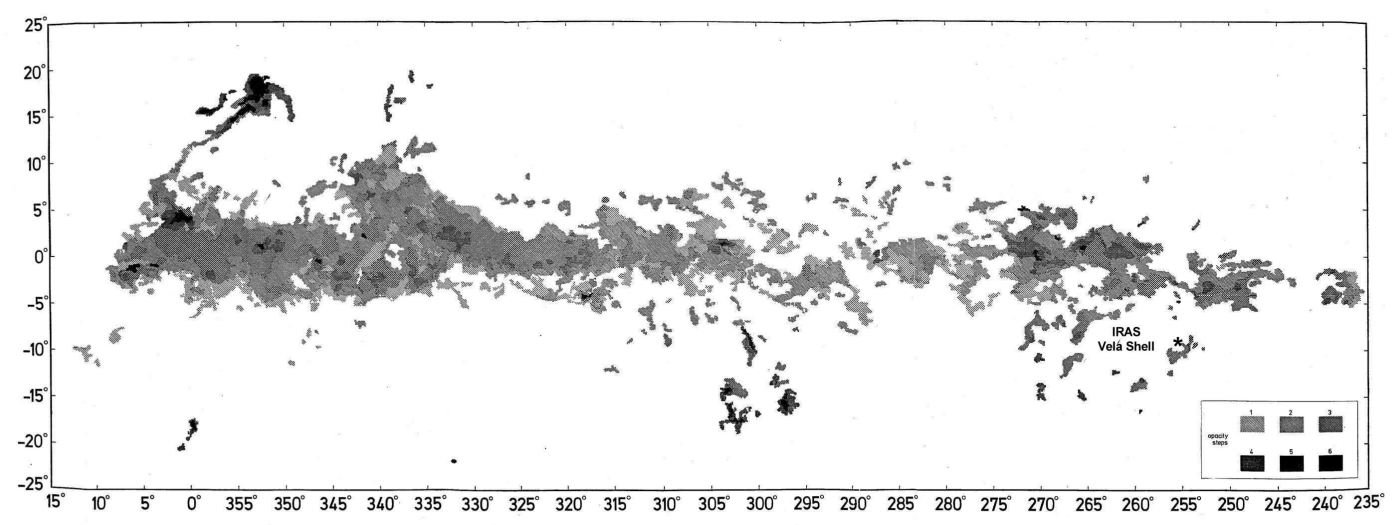

Figura 4.3 Mapa de Feitinger \& Stüwe (1984) mostrando a localização da Iras Vela Shell e a posição da estrela HD62542 (indicada com um asterisco).

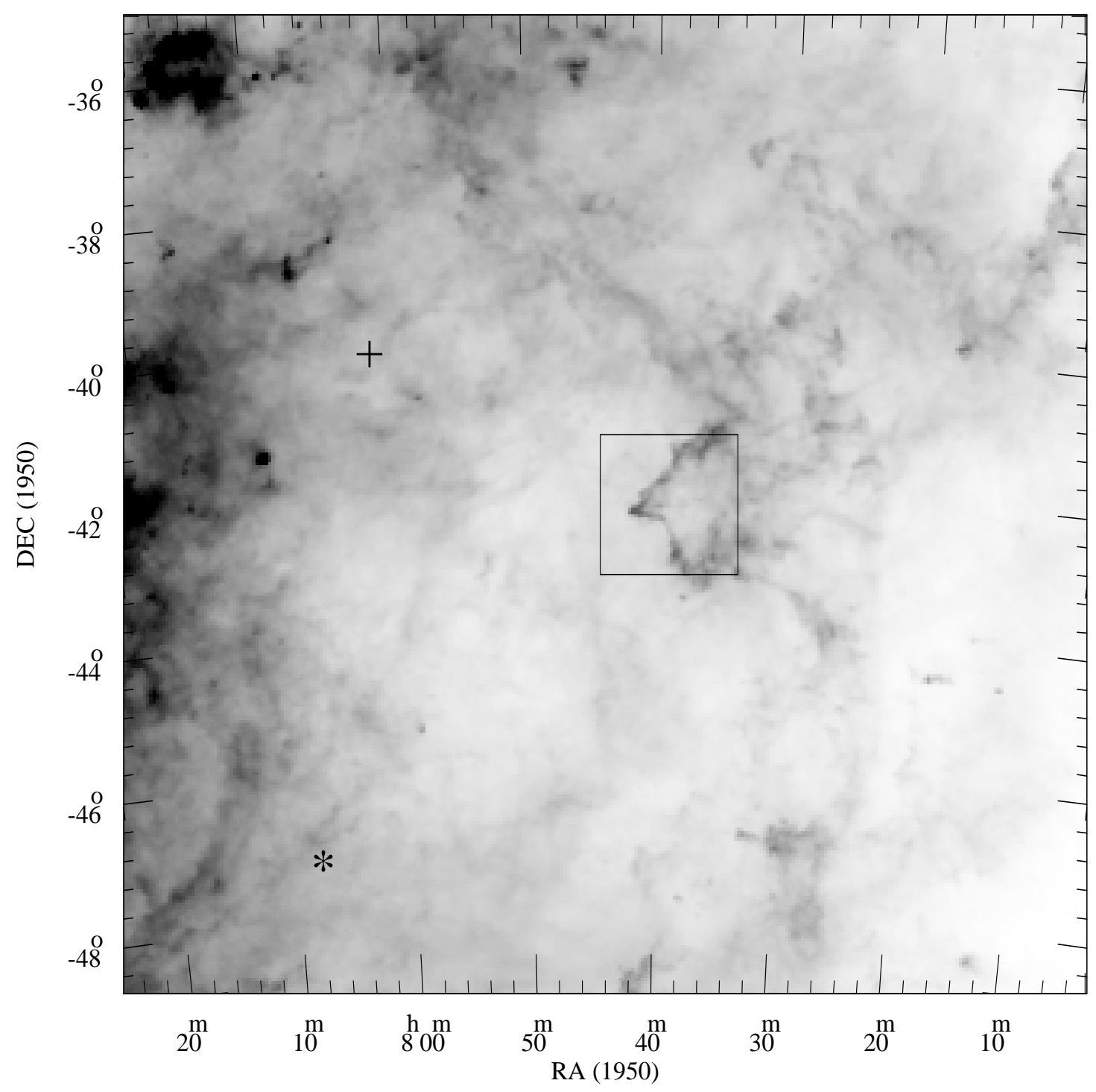

Figura 4.4 Imagem IRAS em $100 \mu \mathrm{m}$ da parede oeste da IVS na direção da HD62542 obtida do Sky View. A região de $2^{\circ} \times 2^{\circ}$ (Figura 4.2) matéria deste trabalho é bem evidente na região central desta figura e está indicada com um quadrado. A área total é de $14^{\circ} \mathrm{x} 14^{\circ}$ e está centrada em $\mathrm{AR}_{1950}=07 \mathrm{~h} 44^{\mathrm{m}}$ e $\mathrm{DEC}_{1950}=$ $42^{\circ} 10^{\prime}$. Com $(+)$ está indicada a posição de $\zeta$ Puppis e com $\left(^{*}\right)$ a posição de $\gamma$ Velorum. 
A região analisada neste trabalho não pode estar mais longe que $\sim 450$ pc (distancia estimada a IVS, Sahu 1992). A estrela HD62542 (B5 V), observada através da borda da região, foi colocada inicialmente a uma distância de 350-500 pc (Cardelli e Savage 1988; Cardelli et al. 1990). No entanto, medidas do satélite Hipparcos, fornecem uma distância menor de $\sim 250$ pc. CN, CH e Ca II (Cardelli et al. 1990) e C 2 e CO (van Dishoeck et al. 1991; Gredel et al. 1993) tem sido observados em absorção nesta estrela no óptico. As densidades colunares de CN e CH na direção de HD62542 são altas, 2.6-4.2 x $10^{13} \mathrm{~cm}^{-2} \mathrm{e}$ 3.5-3.8 x $10^{13} \mathrm{~cm}^{-2}$, respectivamente (Cardelli et al. 1990; Gredel et al. 1993), relativas à extinção visível inferida para a estrela $\left(A_{\mathrm{V}}=1 \mathrm{mag}\right)$. Ca I e Fe I não foram detectados. $\mathrm{A}$ análise de dados moleculares, incluindo a não detecção de $\mathrm{CH}^{+}$, levaram a Cardelli et al. (1990) a concluir que a densidade molecular na direção de HD62542 poderia ser tão alta quanto $10^{4} \mathrm{~cm}^{-3}$. Gredel et al. (1994) acharam uma densidade de $2000 \mathrm{~cm}^{-3}$ da análise do CO e CS em $3 \mathrm{~mm}$. A análise da excitação do $\mathrm{C}_{2}$ na direção de HD62542 por Gredel et al. (1993) indica uma temperatura cinética do gás de $\sim 40 \mathrm{~K}$. Este valor concorda com uma temperatura da poeira de 30-40 K achada por Gregorich e Cardelli (1992) da emissão em $60 \mu \mathrm{m}$.

O’ Donnell et al. (1992) reportaram detecções prováveis de CII, CIII e CIV no espectro UV obtido em várias posições ao longo da borda oeste da IVS. Eles sugeriram que CII e CIII são fotoionizados mas CIV é provavelmente produzido por shocks terminais de ventos estelares na borda interior da shell (i.e., dentro do I-front). Gredel et al. (1994) tem mapeado emissão ${ }^{12} \mathrm{CO}(\mathrm{J}=1-0)$ na região ao redor da $\mathrm{HD} 62542$ e observou ${ }^{13} \mathrm{CO}, \mathrm{C}^{18} \mathrm{O}, \mathrm{HCN}$, $\mathrm{HCO}^{+}$, CS e CH na direção desta estrela.

Churchwell et al. (1996) mapearam uma seção de $3.3 \times 1.2$ pc da borda oeste da IVS na direção da HD62542 em CS ( $J=2-1)$ encontrando densidades colunares de CS (assumido opticamente fino) moderadas, ligeiramente menores que $10^{13} \mathrm{~cm}^{-2}$. A emissão da nuvem de CS acompanha quase coincidentemente a emissão em ${ }^{12} \mathrm{CO}$ e a emissão térmica da poeira em $60 \mu \mathrm{m}$. O contorno leste da nuvem CS segue a geometria do $I / S$ front $\mathrm{H}_{\alpha}$. A energia cinética da nuvem de CS foi encontrada uma ordem de magnitude maior que a energia potencial gravitacional indicando que a parede não esta gravitacionalmente ligada e dispersaria em uma escala de tempo curta se não for pela pressão de radiação da IVS em expansão que continuamente varre novo material interestelar nela. CN $(N=1-0)$ também foi observado por Churchwell et al. (1996) nos picos de emissão CS encontrando 
temperaturas de excitação de $\sim 3 \mathrm{~K}$ e densidade colunares de $4-11 \times 10^{13} \mathrm{~cm}^{-2}$. A baixa excitação do $\mathrm{CN}$ coloca um limite inferior na densidade do gás de $\sim 10^{4} \mathrm{~cm}^{-3}$ e a emissão de CS requer densidades de algumas vezes $10^{3}-10^{4} \mathrm{~cm}^{-3}$. Somente $1-10 \%$ da linha de visada está preenchida com gás na faixa de densidade anterior do qual é inferido que a nuvem de CS é clumpy em escalas de tamanho menores que 0.11 pc. Da comparação das razões $\mathrm{CN} / \mathrm{CS}$ com os modelos químicos de Herbst e Leung, um cenário de nuvens com abundâncias pobres em metais e que não tem alcançado o equilíbrio químico é inferido o que supõe idades menores a 3 × $10^{5}$ anos.

Das considerações anteriores vemos que a região analisada é uma região de transição de um $I / S$ front e o estudo de sua estrutura é de particular interesse pois permite estabelecer vínculos observacionais para modelos de processos de aquecimento e resfriamento, estrutura de ionização, dinâmica, densidade, estrutura de temperatura e química para regiões onde as propriedades mudam sobre curtas distâncias. A borda oeste da IVS é de grande interesse porque a frente $I / S$ é vista quase edge-on à nossa linha de visada e está suficientemente próxima, o que torna possível distinguir diferentes regiões de ionização, temperatura e densidade. É também umas das poucas regiões onde é possível detectar linhas moleculares nos regimes UV, IR e radio.

O papel do campo magnético em frentes de ionização $(I / S$ front $)$ não é bem conhecido e evidências observacionais são escassas. Mapas de polarização de regiões escurecidas podem revelar a estrutura do campo magnético se mecanismos de alinhamento de grãos de poeira são invocados (ver seção 1.2.4). A direção da polarização linear das estrelas de fundo nos dá a direção do campo magnético projetada no céu da região entre o observador e as estrelas. Em particular, a borda oeste da IVS possui evidência de poeira como foi anotado linhas acima. A polarização na direção de HD62542 foi estudada por Clayton et al. (1992). Eles modelaram a dependência da polarização com o comprimento de onda para a HD62542 e obtiveram um valor máximo de polarização $p_{\max }=1.38 \%$ para o comprimento de onda máximo $\lambda_{\max }=0.59 \mu \mathrm{m}$. $\mathrm{O}$ ângulo de polarização, $\theta=30.8^{\circ}$, não muda significativamente com o comprimento de onda. 


\subsubsection{Este Trabalho}

Apresentamos os resultados de um estudo observacional polarimétrico e de extinção na região IRAS Vela Shell/Nebulosa de Gum na direção da HD62542. Na seguinte seção fazemos a análise dos dados polarimétricos e nos concentramos nas variações em pequena escala no valor da polarização e do seu ângulo ao longo da região. Mostramos também os mapas da geometria do campo magnético ao longo da região. A grande quantidade de dados de polarimetria dos objetos de background desta região é apresentada num catálogo no Apêndice E. Na seção 4.4 apresentamos a técnica de contagem de estrelas aplicada à região e os mapas de extinção obtidos. Discutimos também a relação entre a estrutura do campo na região e sua morfologia vista através da extinção. $\mathrm{Na}$ seção 4.5 discutimos as relações de polarização e extinção achadas assim como sua implicância na determinação das razões de densidade de energia cinética e magnética e da intensidade do campo magnético obtidas a partir das dispersões do ângulo de polarização dos vetores de polarização. Uma análise da eficiência da polarização também é mostrada. Finalmente, a seção 4.6 são as conclusões.

\subsection{Polarimetría Óptica}

\subsubsection{Observações}

As observações foram realizadas pelo Dr. A. Mário Magalhães usando o polarímetro de imagem IAG (Magalhães et al. 1996) adaptado ao telescópio de $1.5 \mathrm{~m}$ do Cerro Tololo Interamerican Observatory no Chile. Os dados foram colhidos em missões sucessivas em Dezembro de 1991 e Dezembro de 1992.

As medidas foram feitas usando um filtro V standard. Foi utilizado um CCD 1024x1024 pixels cobrindo um área aproximada de 8'x8' por campo. Um total de 16 campos CCD (4 em Dez91 e 12 em Dez92) foram completados. Para cada campo, integrações típicas de 5 minutos foram realizadas (exceto campo 01, 10s ; campo 02, 180s ; campos 03 e 04, 240s ) por posição para 4 posições da lâmina retardadora de meia onda separadas por $22.5^{\circ}$. Na Tabela 4.1 mostramos as coordenadas equatoriais nas quais foram centrados os 16 campos, assim como as missões respectivas de cada um deles. Na Figura 4.5 mostramos a distribuição dos campos na região. 
Correções no ângulo de posição da polarização foram feitas de medidas de estrelas padrões polarizadas em cada noite. Estrelas padrões não-polarizadas foram usadas para checar a polarização instrumental, que resultou desprezível. Nenhuma correção de polarização instrumental foi necessária.

Tabela 4.1 Posições dos campos CCD colhidos na região estudada.

\begin{tabular}{cccc}
\hline Campo & $\begin{array}{c}\mathrm{AR}_{1950} \\
(\mathrm{~h}: \mathrm{m}: \mathrm{s})\end{array}$ & $\begin{array}{c}\mathrm{DEC}_{1950} \\
\left({ }^{\circ} \mathbf{}^{\prime}:{ }^{\prime}\right)\end{array}$ & Missão \\
\hline 01 & $07: 40: 58$ & $-42: 06: 34$ & 91 \\
02 & $07: 40: 22$ & $-41: 59: 54$ & 91 \\
03 & $07: 39: 46$ & $-41: 54: 57$ & 91 \\
04 & $07: 41: 34$ & $-42: 13: 12$ & 91 \\
05 & $07: 37: 20$ & $-41: 29: 59$ & 92 \\
06 & $07: 37: 52$ & $-41: 22: 01$ & 92 \\
07 & $07: 38: 24$ & $-41: 29: 59$ & 92 \\
08 & $07: 38: 24$ & $-41: 37: 59$ & 92 \\
09 & $07: 38: 56$ & $-41: 45: 59$ & 92 \\
10 & $07: 40: 32$ & $-41: 53: 58$ & 92 \\
11 & $07: 40: 32$ & $-42: 09: 59$ & 92 \\
12 & $07: 41: 04$ & $-42: 18: 00$ & 92 \\
13 & $07: 40: 32$ & $-42: 17: 59$ & 92 \\
14 & $07: 39: 28$ & $-42: 21: 59$ & 92 \\
15 & $07: 38: 32$ & $-42: 49: 59$ & 92 \\
16 & $07: 38: 00$ & $-43: 02: 00$ & 92 \\
\hline
\end{tabular}

\subsubsection{Dados Polarimétricos}

$\mathrm{Na}$ Figura 4.6 mostramos os mapas de polarização da região em estudo para os 16 campos CCD analisados nos quais temos dados de polarimetria. Cada vetor representa um objeto com razão sinal-ruído de polarização $\left(P / \sigma_{P}\right)$ maior que 10 . O número total de objetos mostrados é 856 .

É evidente da Figura 4.6 uma múltipla estrutura de alinhamento ao longo da região estudada. Para maior clareza, mostramos pequenas seções do mapa de polarização geral da Figura 4.6 agrupando dois ou três campos superpostos a sua respectivas imagens do Digitized Sky Survey. Nesta primeira análise seguiremos a ordem de norte ao sul e nos concentraremos nos padrões qualitativos em pequena escala angular mostrados pelo alinhamento dos vetores de polarização. Alguns campos são mostrados em mais de uma seção para melhor acompanhar os padrões observados. 
$\mathrm{Na}$ Figura 4.7 mostramos o mapa de polarização composto para os campos 05, 06 e 07, junto com suas posições com relação à região total. A área mostrada é de $\sim 25^{\prime}$ x $18^{\prime}$. Notase o aparente alinhamento do padrão de polarização com a estrutura vertical da parede norte, especialmente evidente no campo 07 e com um menor grau de polarização no campo 06. O campo 05 mais afastado da borda da parede e com uma inclinação maior a respeito desta sugere uma suave continuidade com o campo 06. O padrão dos vectores de polarização aparenta ser torcido em direção à parede leste, conforme nos aproximamos dela.

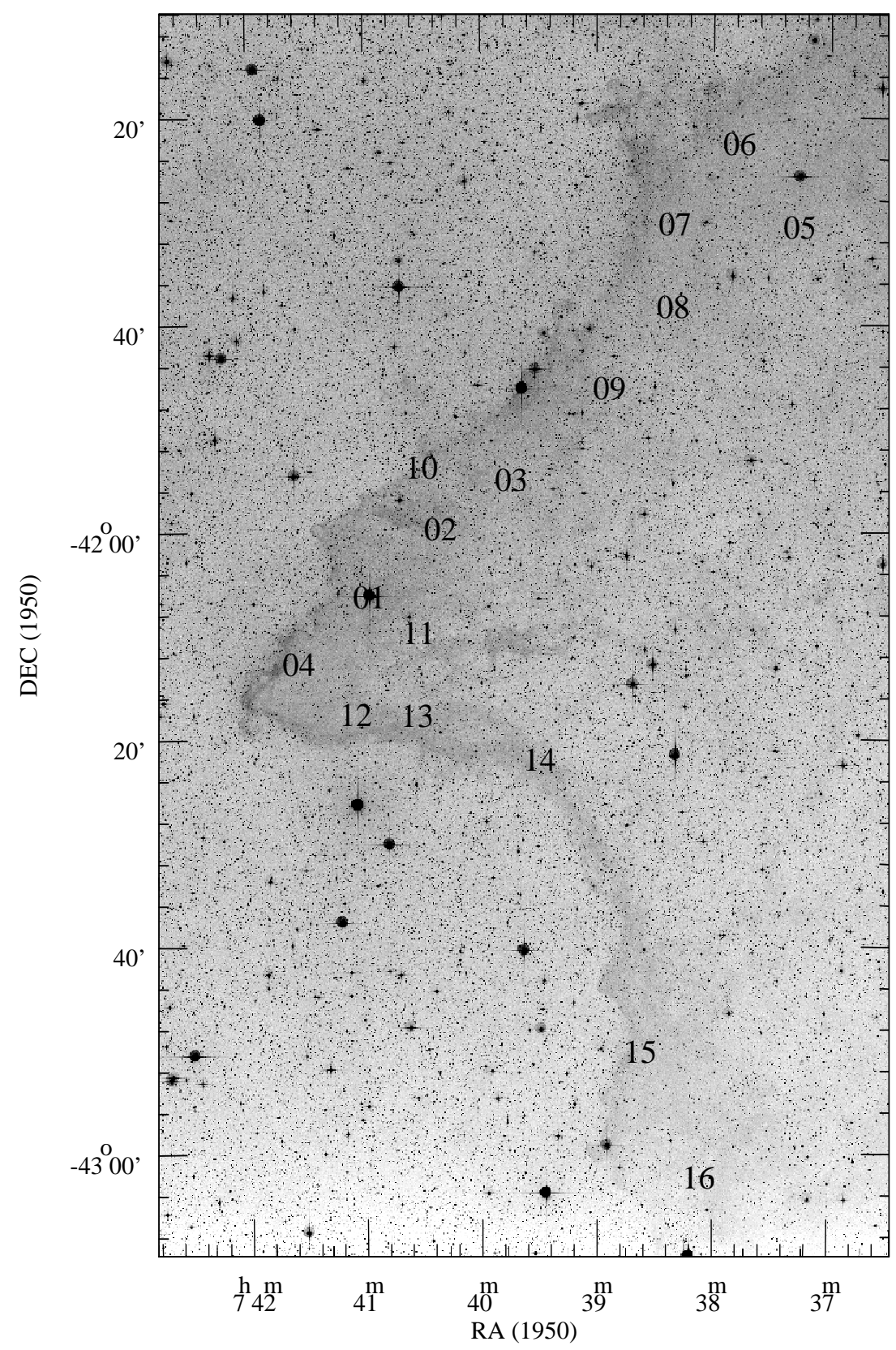

Figura 4.5 Os números indicam as posições de cada um dos 16 campos observados. Cada campo cobre uma área $\sim$ 8’x 8'. A imagem é uma seção da Figura 4.2. A posição da HD62542 é coincidente com o centro do campo 01 . 
$\mathrm{Na}$ Figura 4.8 apresentamos o mapa de polarização composto para os campos 07, 08 e 09 e suas posições com relação à região total cobrindo uma área de $\sim 18^{\prime}$ x $30^{\prime}$. O padrão de polarização observado no campo 08 parece acompanhar a borda da parede e é consistente com o campo 07 ao norte. No campo 09, no entanto, os valores de polarização são baixos e nenhuma tendência aparente de alinhamento é observada. Devemos notar que a posição do campo 09 coincide com uma quebra na estrutura de emissão da parede norte.

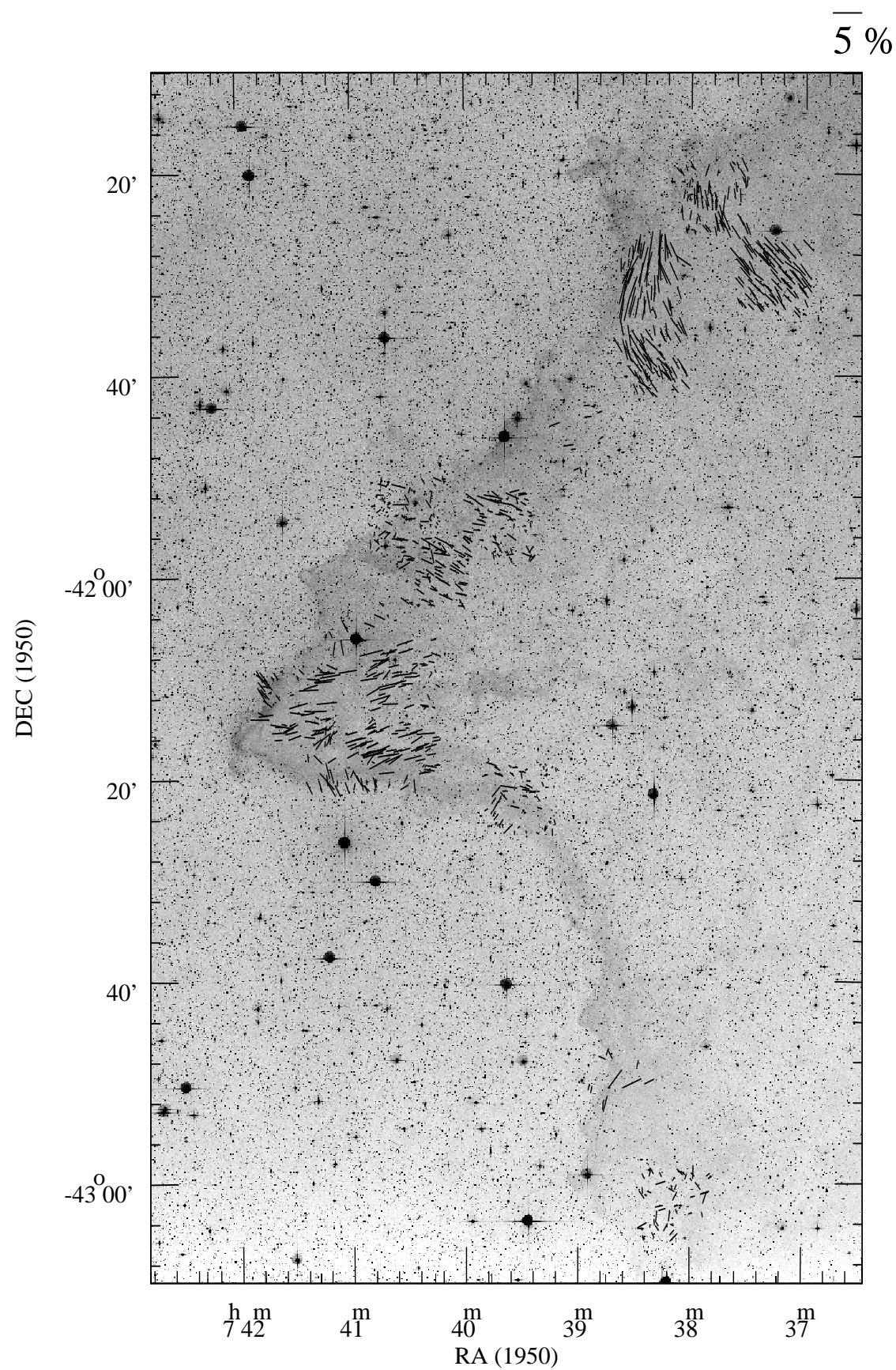

Figura 4.6 Mapa de polarização para os 16 campos CCD da região estudada superposto a uma imagem do Digitized Sky Survey. Cada vetor representa um objeto $\operatorname{com}\left(P / \sigma_{P}\right)>10$. O número total de objetos mostrados é 875. A escala de polarização é mostrada no canto superior direito. 
$\mathrm{Na}$ Figura 4.9 é mostrado o mapa de polarização composto para os campos 10 e 11. A área mostrada cobre $\sim 12^{\prime}$ x 28'. A exemplo do campo 09 , a NE, no campo 10 não é observado um padrão de alinhamento coerente e podemos notar que os vetores se encontram a ambos lados da interface bem definida da borda da parede, onde a emissão é descontínua. O campo 11 se encontra afastado da borda da parede é imerso numa região de emissão tipo cirrus que o padrão de polarização bem definido parece acompanhar. A estrela HD62542 esta localizada no canto superior esquerdo do campo 11, sendo a estrela mais brilhante nesta imagem.

Na Figura 4.10 mostramos o mapa de polarização composto para os campos 02 e 03 . A área mostrada cobre $\sim 18^{\prime}$ x 15'. Ambos campos estão inseridos na região de emissão $\mathrm{H}_{\alpha} \mathrm{e}$ um padrão quase perpendicular à direção da borda da parede (no canto superior esquerdo) parece prevalecer. No entanto, pequenas distorções desta tendência são evidentes e podem estar correlacionados com a estrutura dispersa da emissão observada.

$\mathrm{Na}$ Figura 4.11 mostramos o mapa de polarização composto para os campos 01 e 04 . A área mostrada cobre $\sim 16^{\prime}$ x 16'. O campo 01 centrado na estrela HD62542 (a estrela mais brilhante na imagem) mostra poucos objetos (o tempo de integração usado foi apenas 18 segundos por posição da lâmina) e não é evidente uma tendência de alinhamento clara. No entanto, ao analisar com cuidado esta figura e ajudados da análise do campo 01 (Figura F. 1, Apêndice F), podemos advertir que alguns objetos (ID 23, 73, 76 e 88 na Tabela E.1) perto da posição de $\operatorname{HD} 62542\left(P_{\max }=1.38 \%, \theta=30.8^{\circ}\right.$, Clayton et al. 1992) apresentam valores semelhantes a esta estrela tanto no valor de polarização como no $\theta$. No campo 04 , por outro lado, é evidente um padrão de alinhamento que quase acompanha a borda da parede na região imersa na emissão e outro praticamente perpendicular à parede localizado bem na interface desta (canto superior esquerdo do campo 04). Devemos notar que a região da Figura 4.11 apresenta valores altos de extinção, como será visto mais adiante, e o canto inferior esquerdo é o ponto de quebra da parede em duas concavidades norte (até agora analisada) e sul (analisada a seguir).

$\mathrm{Na}$ Figura 4.12 mostramos o mapa de polarização composto para os campos 11, 12 e 13. A área mostrada cobre $\sim 20^{\prime}$ x $20^{\prime}$. No campo 11, como já foi apontado na discussão da Figura 4.9, o padrão de polarização parece seguir as estruturas tipo cirrus observadas em emissão que, por sua vez, parecem acompanhar predominantente a borda norte da parede. 
No campo 13, o padrão de alinhamento está quase alinhado com a interface da borda sul e parece existir uma suave continuidade com o padrão do campo 11. O campo 12 é muito interessante (está indicado com um quadrado tracejado na Figura 4.12 para maior clareza). Ele está localizado numa região de alta extinção (condensação B, ver seção 4.4) e até três tendências diferenciadas são evidentes. No canto superior direito, o padrão segue aquele observado no campo 13 e está acompanhando a interface da borda sul. No canto superior esquerdo o padrão é quebrado e torcido, quase que envolvendo à condensação. Na região sul deste campo, é observado um padrão de alinhamento quase perpendicular à parede sul $\mathrm{e}$ localizado bem na interface desta. Este último aspecto é semelhante ao do campo 04, discutido no parágrafo anterior. Olhando em detalhe o campo 13, alguns objetos próximos à borda sul também possuem uma orientação normal à borda.

$\mathrm{Na}$ Figura 4.13 mostramos o mapa de polarização composto para os campos 13 e 14 . A área coberta é de $\sim 20^{\prime} \times 12^{\prime}$. A parede sul da região emissora é bem evidente nesta imagem. O campo 13, como já mencionado acima, apresenta um padrão principal que acompanha bem a borda da parede sul. O campo 14 apresenta duas tendências. A primeira parece acompanhar a estrutura da parede e sugere uma continuidade com o padrão principal observado no campo 13. No canto inferior esquerdo deste campo, uma ligeira tendência perpendicular à parede sul parece existir estando localizada bem na interface desta, à exemplo dos campos 04 e 12.

Na Figura 4.14 mostramos os mapas de polarização para os campos 15 e 16. Ambos campos são as regiões mais ao sul da parede onde dados de polarização foram colhidos. $O$ campo 15 apresenta uma amostra pobre (com $P / \sigma_{\mathrm{P}} \geq 10$ ), no entanto, os objetos mais próximos da borda parecem ter uma tendência de alinhamento paralela a esta. O campo 16 apresenta uma boa amostra mas o padrão é confuso e nenhuma correlação com a região emissora é evidente. Entretanto, a emissão difusa também não é regular na região.

Da análise acima, parece existir uma correlação entre o padrão de alinhamento e a emissão da parede da região estudada. No sentido que os vetores de polarização parecem acompanhar a borda da parede, tanto no norte como no sul, nas regiões imersas na emissão ao oeste da interface. Por outro lado, uma ligeira tendência de alinhamento perpendicular à parede também parece existir e coincidentemente é observada bem na interface da parede. 
Tendências de alinhamento diferenciadas associadas à presença de condensações (campo 12) ou a estruturas tipo cirrus em emissão (campo 11) são observadas.

Tabela 4.2 Análise da polarimetria dos 16 campos da região em estudo.

\begin{tabular}{|c|c|c|c|c|c|c|c|c|c|c|c|}
\hline campo & tendência & $\begin{array}{c}\theta_{\text {gauss }} \\
\left({ }^{\circ}\right) \\
(3)\end{array}$ & $\begin{array}{c}\sigma_{\theta_{\text {gauss }}} \\
\left({ }^{\circ}\right) \\
(4)\end{array}$ & objetos & $\begin{array}{c}<P> \\
(\%) \\
(6)\end{array}$ & $\begin{array}{c}<\sigma> \\
(\%) \\
(7)\end{array}$ & $\begin{array}{c}<\theta> \\
\left({ }^{\circ}\right) \\
(8)\end{array}$ & $\begin{array}{c}<\sigma_{\theta}> \\
\left({ }^{\circ}\right) \\
(9)\end{array}$ & $\begin{array}{c}\Delta \theta \\
\left({ }^{\circ}\right) \\
(10)\end{array}$ & $\begin{array}{l}\Delta \theta^{2} \\
10^{-2} \\
(11)\end{array}$ & $\begin{array}{c}B \\
\text { (mgauss) } \\
(12)\end{array}$ \\
\hline 01 & 1 & -- & -- & 14 & 1.105 & 0.005 & 32.88 & 1.22 & - & - & - \\
\hline 02 & 1 & 63.66 & 18.07 & 66 & 0.665 & 0.001 & 61.17 & 1.07 & 18.04 & 9.91 & 0.0166 \\
\hline 03 & 1 & 69.79 & 15.20 & 43 & 0.703 & 0.005 & 57.94 & 1.82 & 15.09 & 6.93 & 0.0198 \\
\hline \multirow[t]{2}{*}{04} & 1 & 96.53 & 13.20 & 35 & 1.798 & 0.003 & 104.00 & 0.70 & 13.18 & 5.29 & 0.0227 \\
\hline & 2 & 40.86 & 12.33 & 22 & 0.870 & 0.001 & 41.75 & 1.01 & 12.29 & 4.60 & 0.0243 \\
\hline 05 & 1 & 40.24 & 5.38 & 74 & 2.284 & 0.001 & 42.42 & 0.97 & 5.29 & 0.85 & 0.0566 \\
\hline 06 & 1 & 10.83 & 14.91 & 66 & 1.723 & 0.001 & 9.98 & 0.92 & 14.88 & 6.75 & 0.0201 \\
\hline \multirow[t]{2}{*}{07} & 1 & 171.58 & 10.19 & 51 & 2.529 & 0.003 & 165.45 & 0.79 & 10.16 & 3.14 & 0.0295 \\
\hline & 2 & 23.49 & 2.88 & 8 & 2.344 & 0.012 & 23.23 & 0.70 & 2.80 & 0.24 & 0.1070 \\
\hline 08 & 1 & 32.54 & 7.95 & 65 & 1.701 & 0.003 & 32.94 & 1.01 & 7.89 & 1.89 & 0.0379 \\
\hline 09 & 1 & -- & -- & 18 & 0.429 & 0.005 & 95.92 & 1.66 & -- & -- & -- \\
\hline 10 & 1 & -- & -- & 78 & 0.057 & 0.001 & 47.27 & 1.06 & -- & -- & -- \\
\hline 11 & 1 & 105.3 & 9.54 & 43 & 0.598 & 0.002 & 109.37 & 1.20 & 9.47 & 2.73 & 0.0316 \\
\hline \multirow[t]{2}{*}{12} & 1 & 15.92 & 14.29 & 29 & 1.623 & 0.001 & 16.02 & 1.04 & 14.25 & 6.19 & 0.0210 \\
\hline & 2 & 116.3 & 18.99 & 33 & 0.799 & 0.001 & 116.06 & 0.89 & 18.97 & 10.96 & 0.0158 \\
\hline 13 & 1 & 104.59 & 10.10 & 44 & 3.113 & 0.002 & 104.23 & 0.98 & 10.05 & 3.08 & 0.0298 \\
\hline \multirow[t]{3}{*}{14} & 1 & 75.58 & 8.38 & 23 & 0.435 & 0.001 & 75.63 & 0.91 & 8.33 & 2.11 & 0.0359 \\
\hline & 2 & 8.102 & 19.32 & 31 & 0.220 & 0.001 & 9.41 & 1.25 & 19.28 & 11.33 & 0.0155 \\
\hline & 3 & 143.12 & 8.93 & 9 & 0.733 & 0.004 & 133.03 & 0.84 & 8.89 & 2.41 & 0.0336 \\
\hline 15 & 1 & -- & -- & 12 & 0.218 & 0.003 & 158.39 & 0.90 & -- & -- & -- \\
\hline 16 & 1 & -- & -- & 52 & 0.251 & 0.001 & 125.05 & 1.09 & -- & -- & -- \\
\hline
\end{tabular}

Para quantificar melhor os padrões observados campo a campo, uma análise estatística foi feita (ver Apêndice F) e é apresentada na Tabela 4.2 (ver seção 3.3.2 para a definição de cada parâmetro). O campo analisado é dado na coluna (1). Em cada campo construímos histogramas do ângulo de posição e fizemos um ajuste de gaussianas para calcular o ângulo de posição da polarização $\theta_{\text {gauks }}$ e sua dispersão $\sigma_{\theta_{\text {gauks }}}$, apresentados nas colunas (3) e (4). Geralmente, uma tendência prevalece em cada campo mas alguns campos apresentam duas e até três tendências marcadas (cada uma com seu próprio $\theta_{\text {gauss }}$ e $\sigma_{\theta_{\text {gauss }}}$ ), como indicado na coluna (2). Em alguns campos a amostra foi pobre ou nenhuma tendência era evidente $\mathrm{e}$ não foi possivel fazer este ajuste. Uma posterior filtragem foi feita, em cada campo e para cada tendência achada, para determinar com precisão o valor médio de polarização $\langle P\rangle$, seu erro associado $\langle\sigma\rangle$ e ângulo médio de polarização $\langle\theta>$ representados nas colunas (6), (7) e (8). Nesta filtragem foi utilizado como critério de seleção aqueles objetos que apresentaram um ângulo de polarização entre $\left(\theta_{\text {gauss }}-2 \sigma_{\theta_{\text {gauss }}}, \theta_{\text {gauss }}+2 \sigma_{\theta_{\text {gauss }}}\right)$. O número $(N)$ 
de estrelas com $P / \sigma_{P} \geq 10$ para cada tendência em cada campo é dado na coluna (5). O erro médio no ângulo de polarização é mostrado na coluna (9). Finalmente, a coluna (10) mostra a dispersão do ângulo de polarização corrigido em quadratura pelo seu erro médio $(\Delta \theta)$; na coluna (11) temos o quadrado desta dispersão em radianos; e, na coluna (12), a intensidade do campo magnético em mgauss calculada segundo a seção 4.5.2. A discussão completa desta análise será feita na seção 4.5 . 


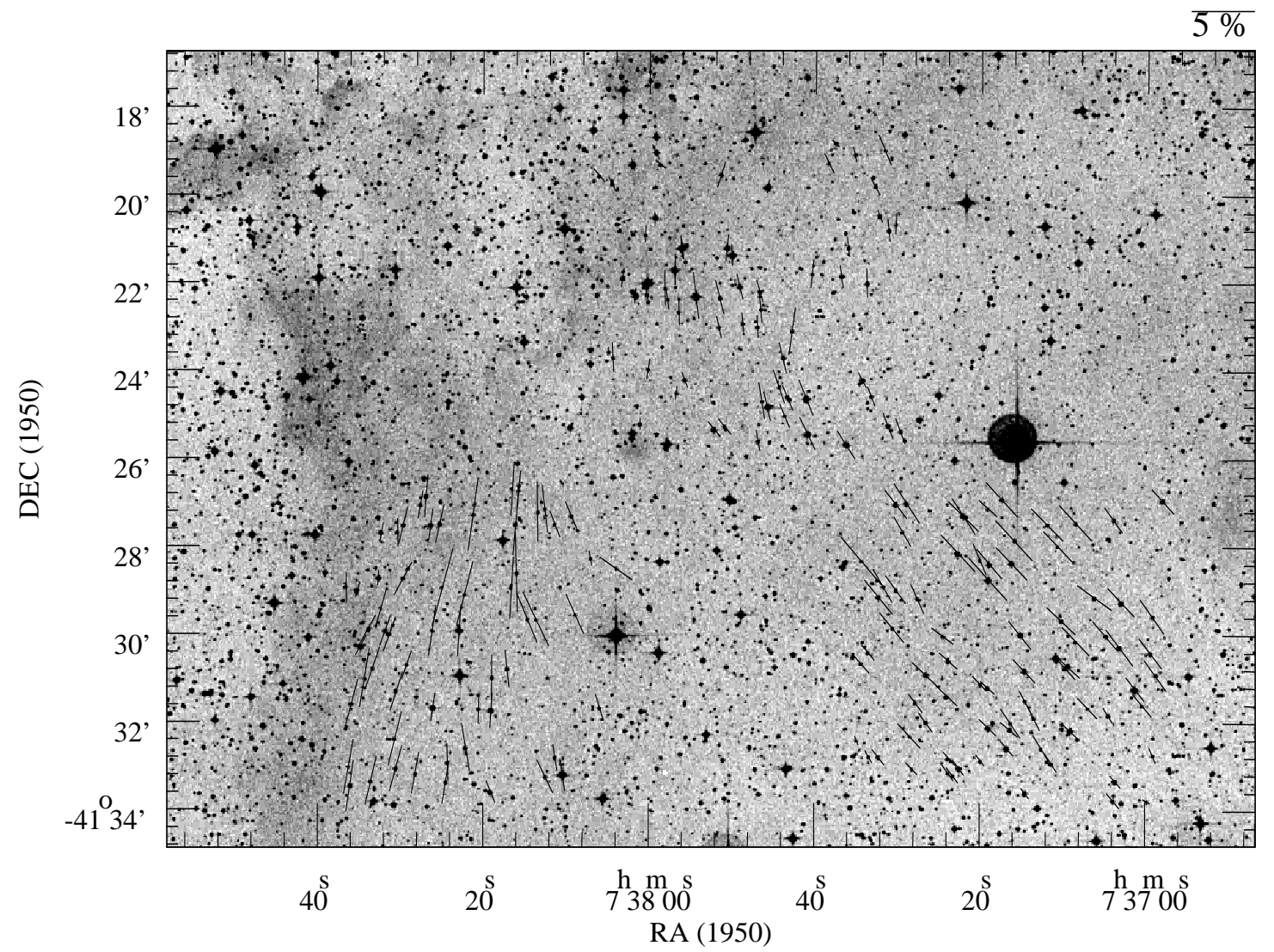

Figura 4.7 (superior) Mapas de polarização para os campos 06 (norte), 07 (sudeste) e 05 (sudoeste). A escala de polarização é mostrada no canto superior direito. (direita) Posições destes campos com respeito à região total.

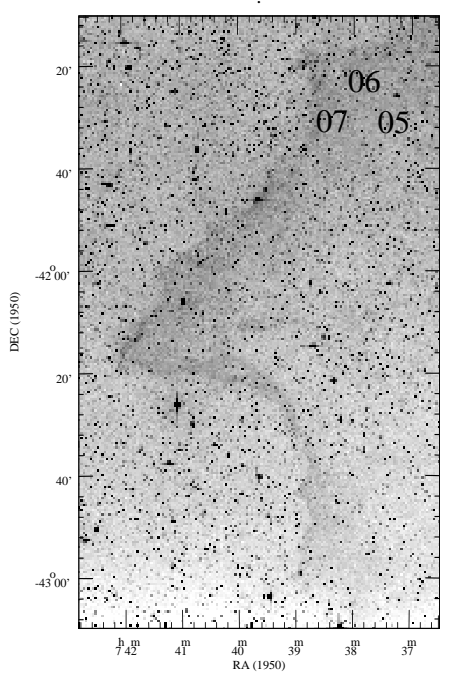



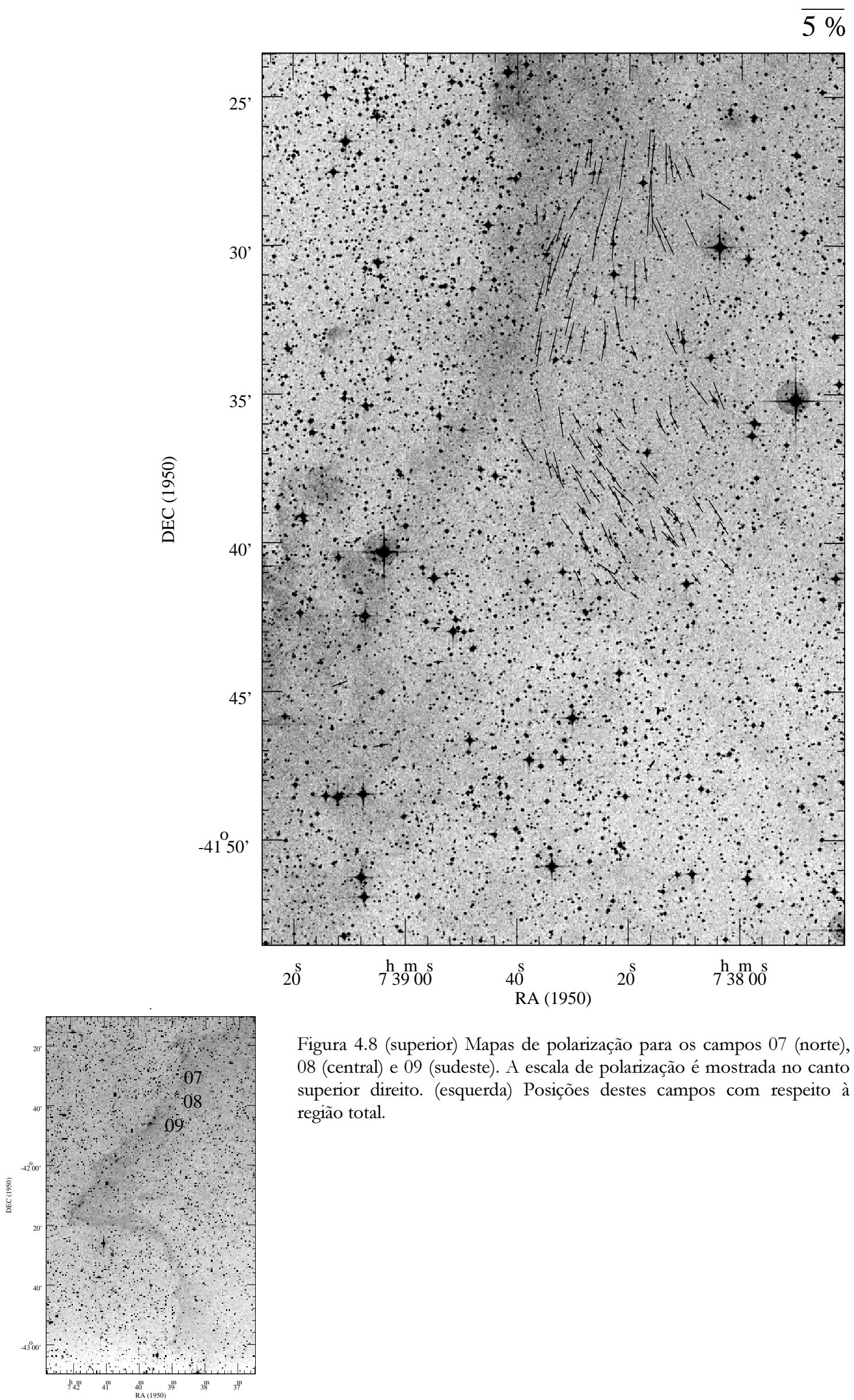

Figura 4.8 (superior) Mapas de polarização para os campos 07 (norte), 08 (central) e 09 (sudeste). A escala de polarização é mostrada no canto superior direito. (esquerda) Posições destes campos com respeito à região total. 

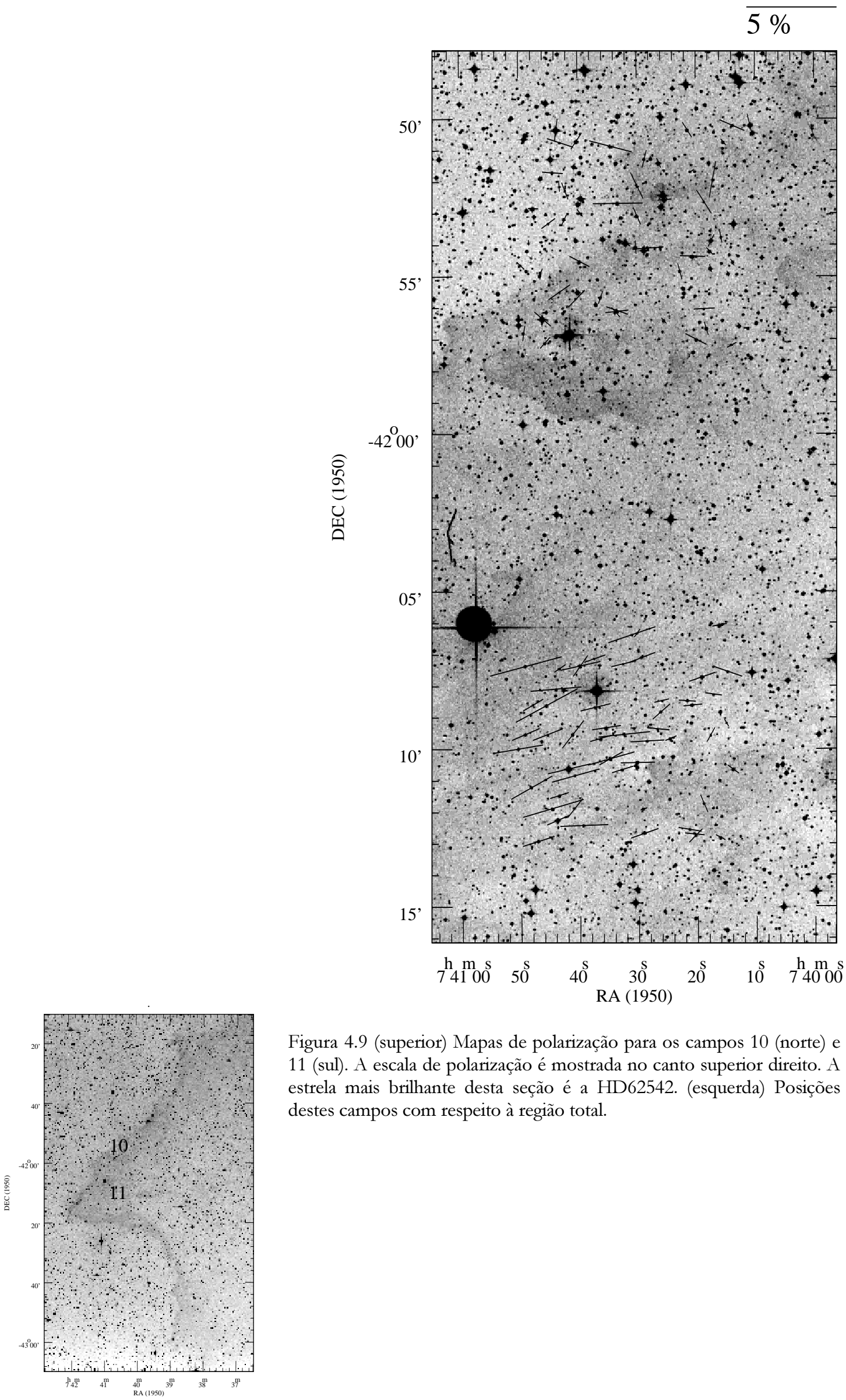

Figura 4.9 (superior) Mapas de polarização para os campos 10 (norte) e 11 (sul). A escala de polarização é mostrada no canto superior direito. A estrela mais brilhante desta seção é a HD62542. (esquerda) Posições destes campos com respeito à região total. 

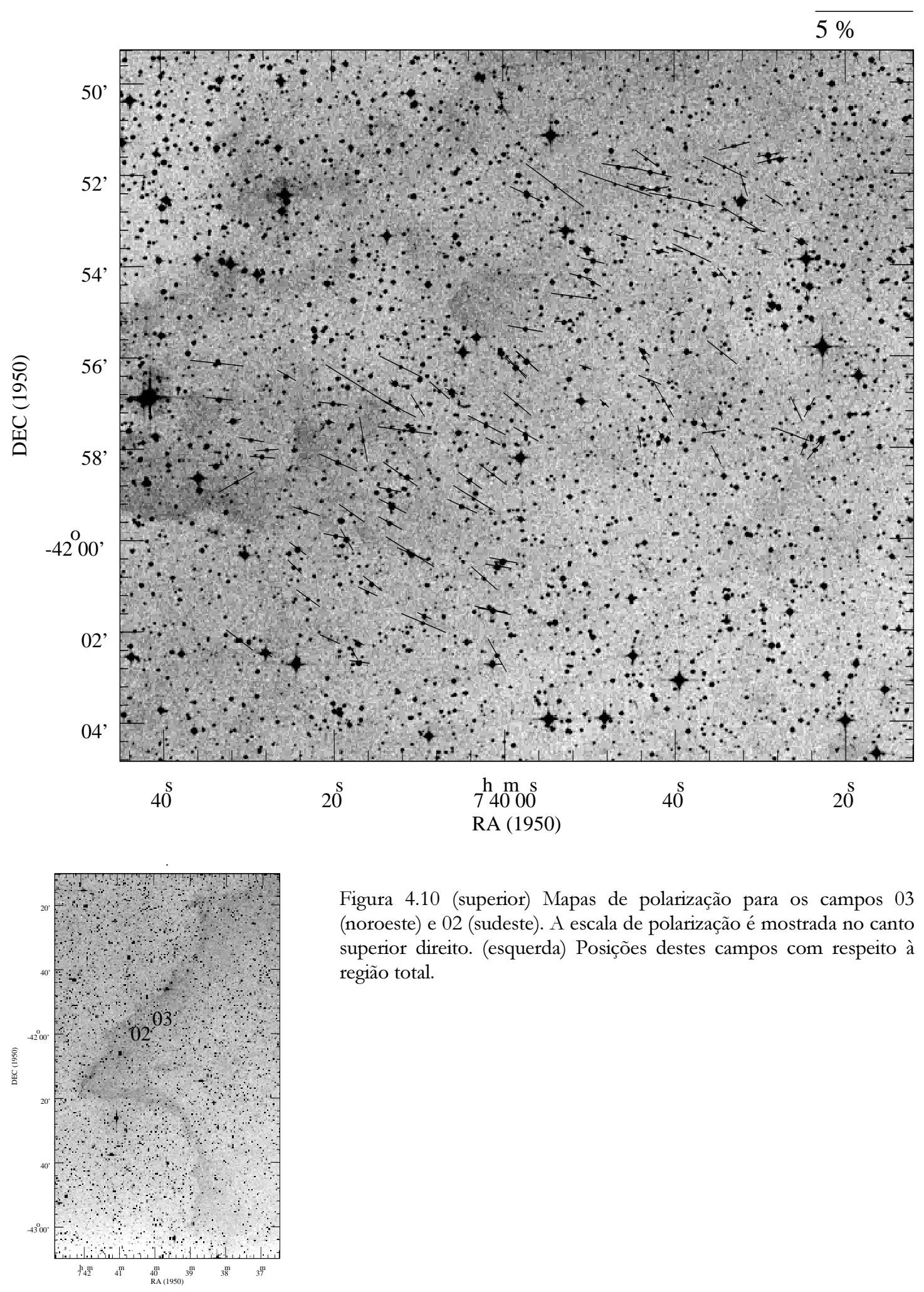

Figura 4.10 (superior) Mapas de polarização para os campos 03 (noroeste) e 02 (sudeste). A escala de polarização é mostrada no canto superior direito. (esquerda) Posições destes campos com respeito à região total. 

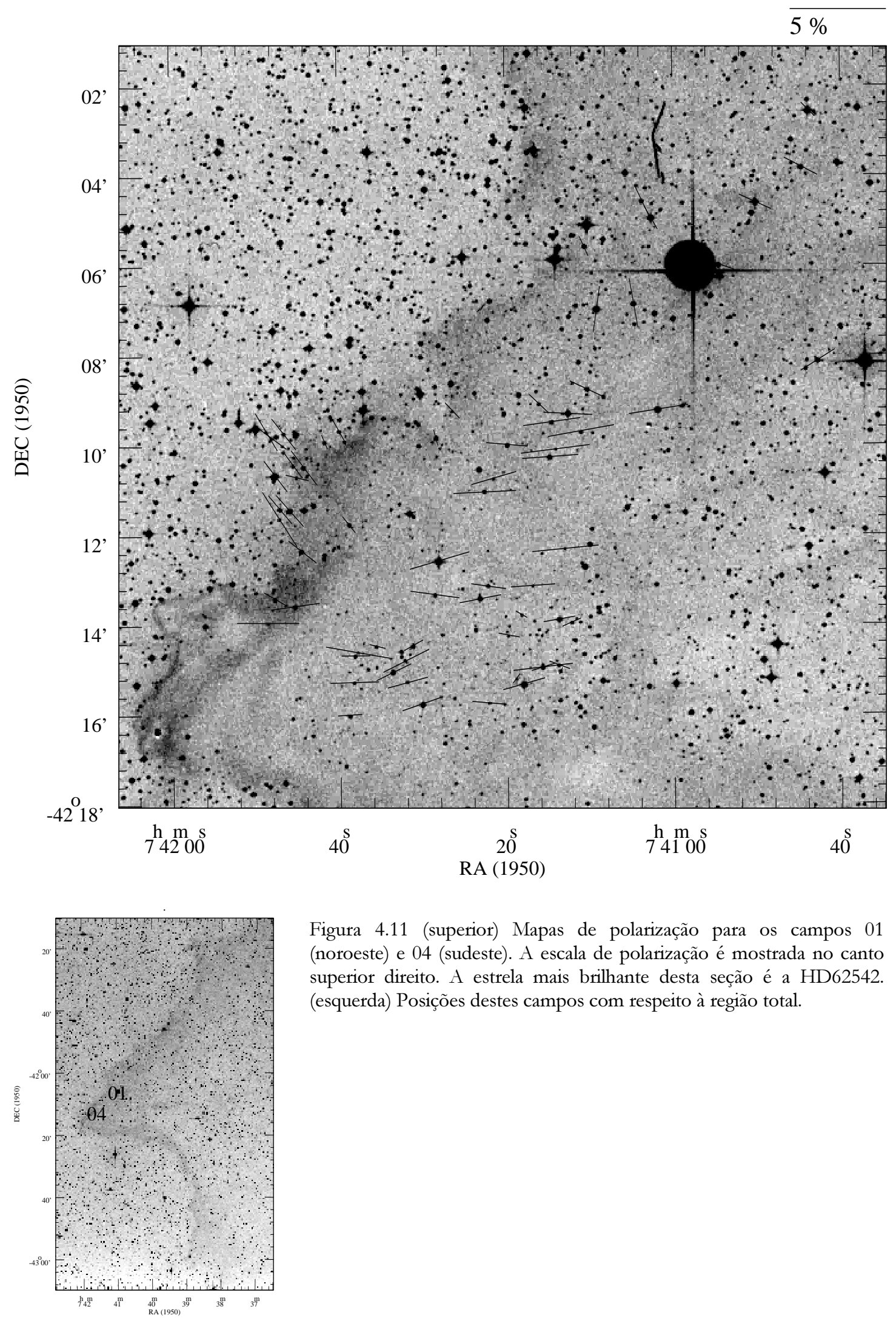

Figura 4.11 (superior) Mapas de polarização para os campos 01 (noroeste) e 04 (sudeste). A escala de polarização é mostrada no canto superior direito. A estrela mais brilhante desta seção é a HD62542. (esquerda) Posições destes campos com respeito à região total. 

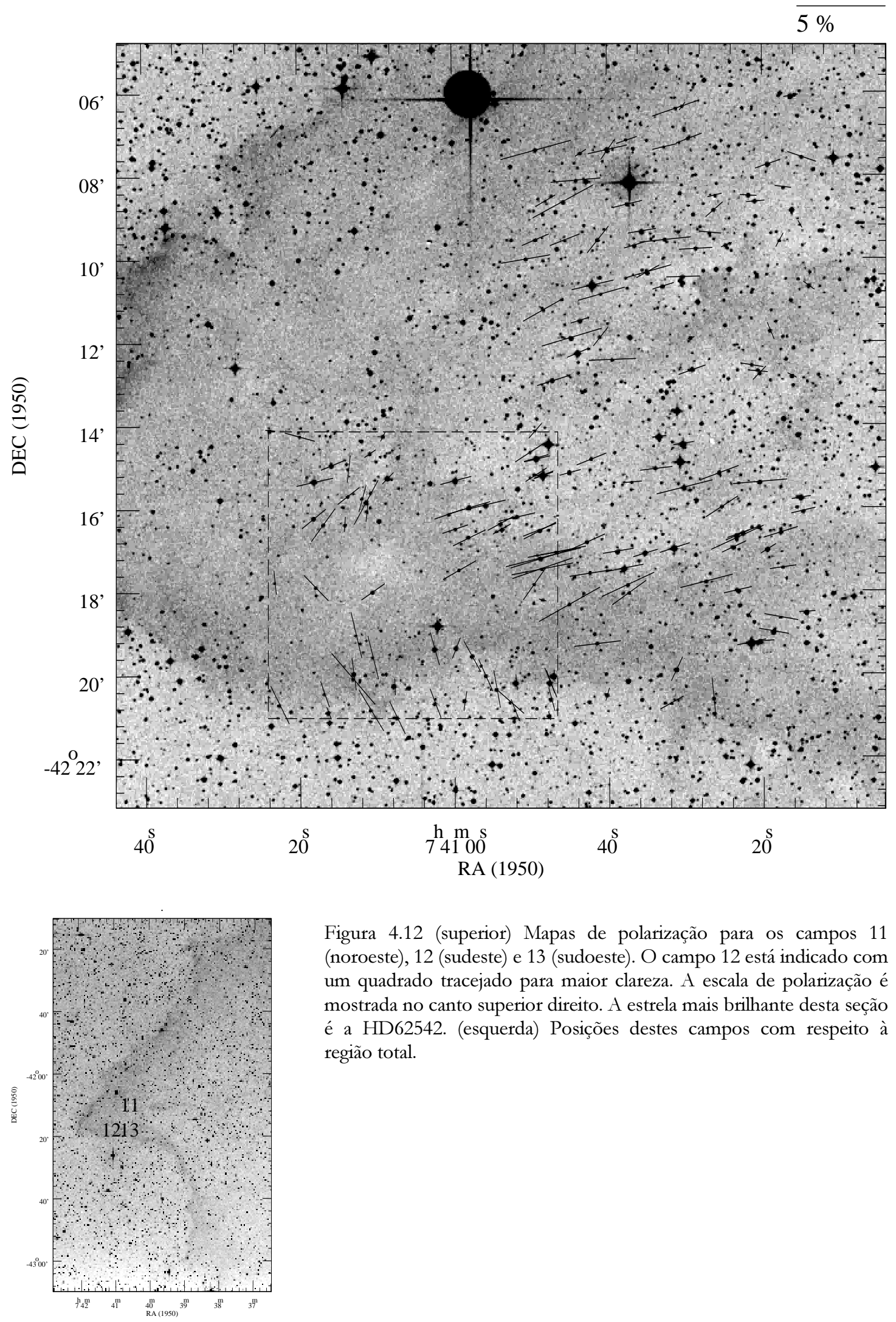

Figura 4.12 (superior) Mapas de polarização para os campos 11 (noroeste), 12 (sudeste) e 13 (sudoeste). O campo 12 está indicado com um quadrado tracejado para maior clareza. A escala de polarização é mostrada no canto superior direito. A estrela mais brilhante desta seção é a HD62542. (esquerda) Posições destes campos com respeito à região total. 

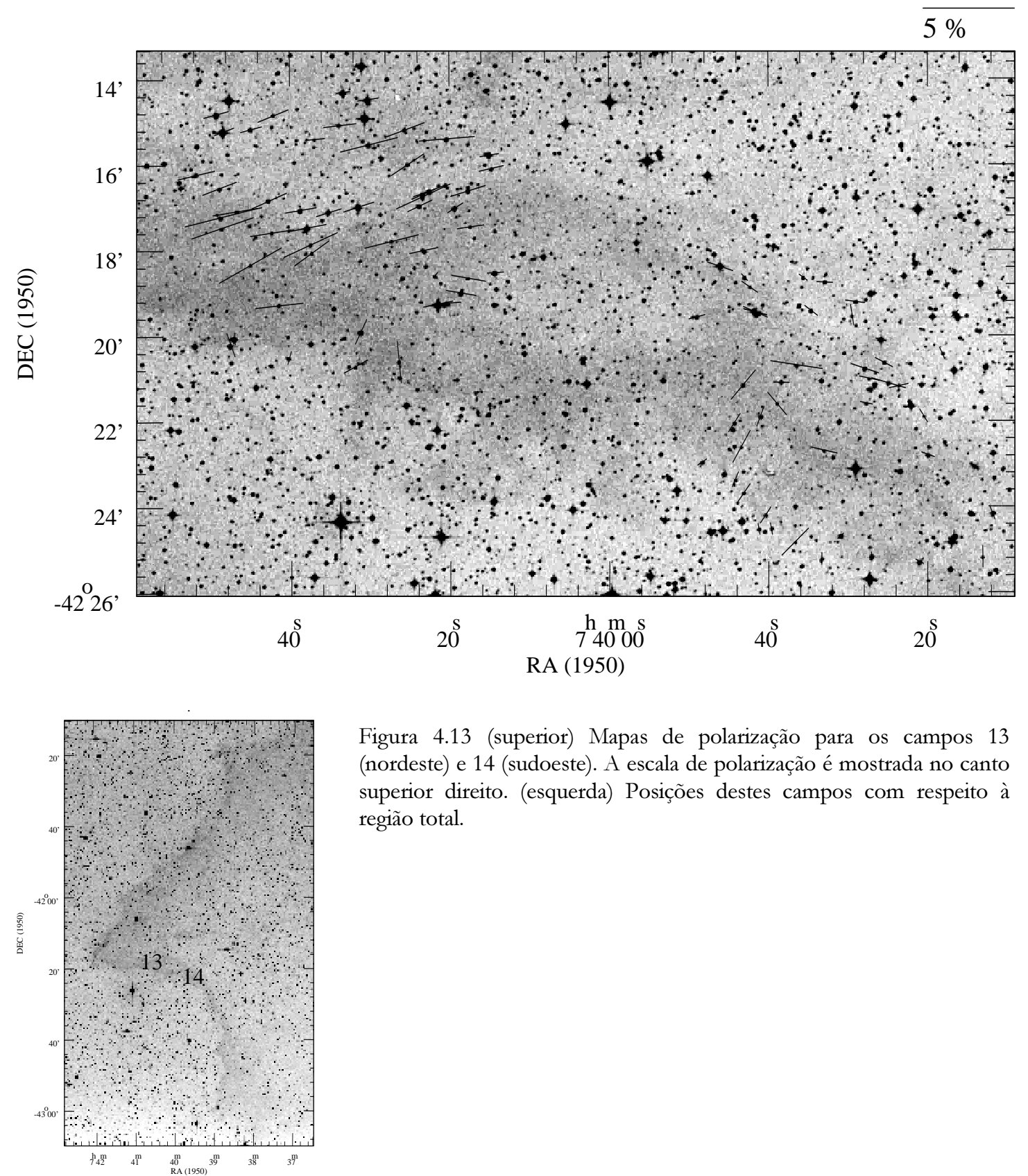

Figura 4.13 (superior) Mapas de polarização para os campos 13 (nordeste) e 14 (sudoeste). A escala de polarização é mostrada no canto superior direito. (esquerda) Posições destes campos com respeito à região total. 

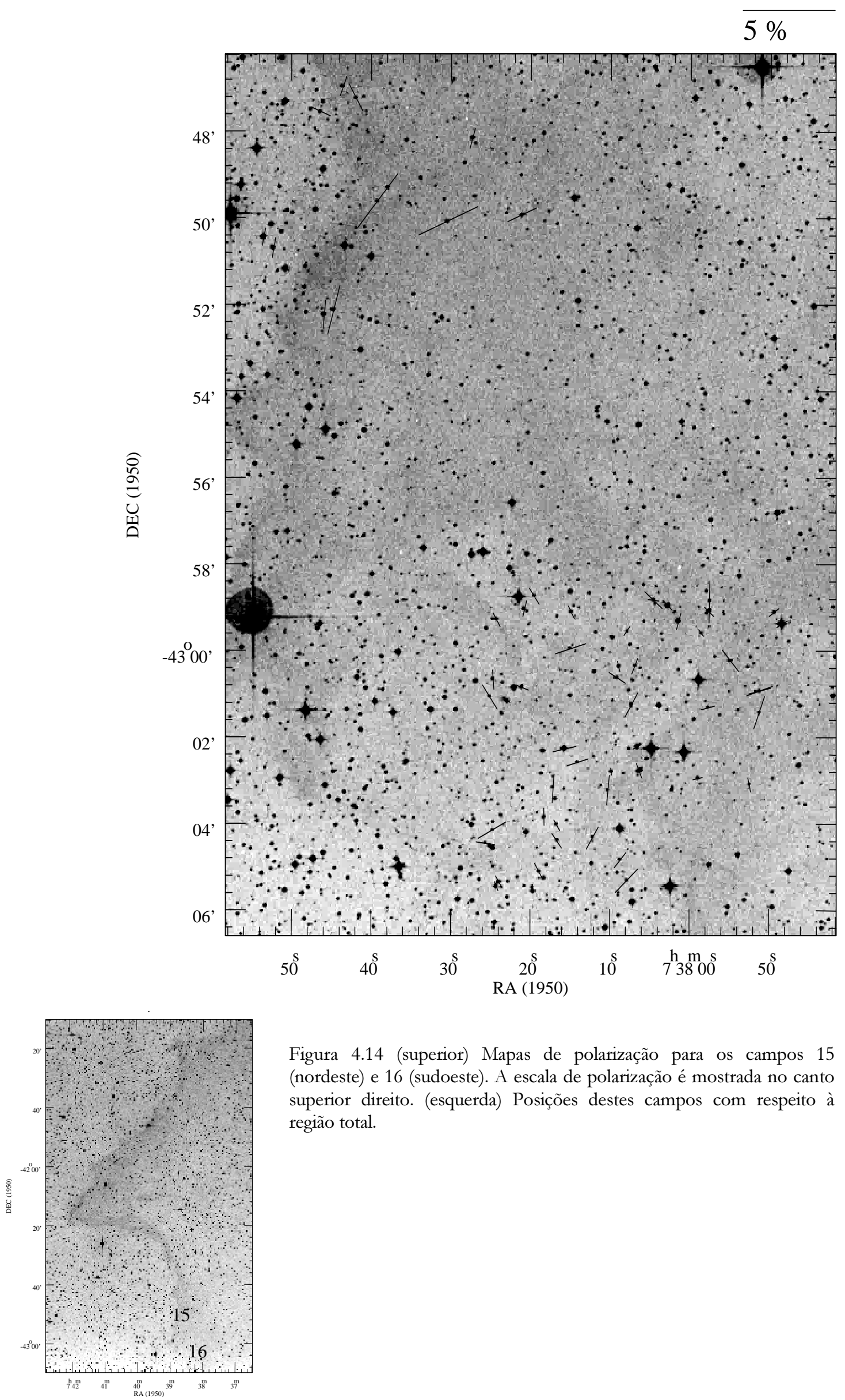

Figura 4.14 (superior) Mapas de polarização para os campos 15 (nordeste) e 16 (sudoeste). A escala de polarização é mostrada no canto superior direito. (esquerda) Posições destes campos com respeito à região total. 


\subsection{Absorção visual por contagem automática de estrelas}

A técnica de contagem automática de estrelas apresentada na seção 3.4.1 foi empregada no cálculo da absorção visual da região estudada da IVS/NG. A imagem utilizada na contagem foi obtida do Digitized Sky Survey e é a mesma mostrada na Figura 4.2. Depois de obter as posições dos objetos com perfil estelar usando a rotina DAOFIND do IRAF, a imagem de $2^{\circ} \times 2^{\circ}$ foi dividida em celas de $2^{\prime} \times 2^{\prime}$ e a contagem foi feita num total de 3600 celas. A absorção visual foi calculada segundo a equação (3.3) onde utilizamos $n(0)=62$ como o número médio de estrelas no campo de comparação e o parâmetro $b=0.44$. A imagem digitalizada empregada corresponde a uma seção de uma placa Schmidt com a combinação emulsão/filtro = IIIaJ/GG395 centrada em 4500 A (Lasker et al., 1990). Em seguida, a extinção obtida da placa fotográfica ( $A_{\text {phot }}$ ) foi transformada em $A_{\mathrm{V}}(\lambda 5500 \AA$ ) ajustando um polinômio na faixa 0.4 - $3.4 \mu \mathrm{m}$ da curva de extinção normalizada de Bless e Savage (1972) e recalculando a extinção na banda fotográfica (Figura 3.5, esquerda). A relação utilizada foi:

$$
A_{\mathrm{V}}=0.79 A_{\text {phot }}
$$

Para as celas com nenhuma estrela, obtivemos um limite inferior na extinção ajustando os resíduos entre passos consecutivos de extinção e extrapolando a correção para o caso n(1) $=0$ (Figura 4.15). O procedimento resultou em assumir $n(1)=0.28$ para as celas sem estrelas, o que equivaleria a obter um limite inferior para a máxima extinção detectável de $4.2 \mathrm{mag}$. No entanto, nas regiões de interesse (i.e., onde temos dados de polarimetria), a extinção é relativamente baixa e apresenta valores máximos de 1.5 mag. Assim, o valor do limite inferior para a máxima extinção detectável claramente não é atingido. A imagem final de 60 x 60 pixels é mostrada na Figura 4.16. Os contornos vão de 0.3 ate $1.2 \mathrm{mag} \mathrm{em}$ passos de $0.1 \mathrm{mag}$.

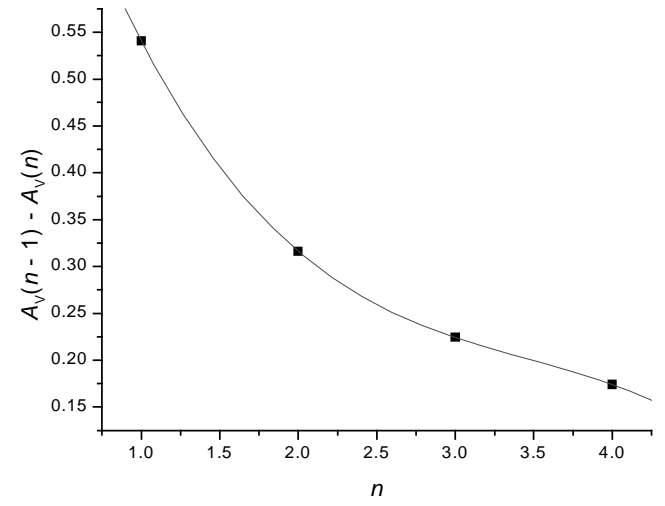

Figura 4.15 Ajuste dos resíduos de passos consecutivos de extinção para achar o limite inferior de extinção para $n(1)=0$. 
Analisando o mapa de extinção da Figura 4.16, vemos que as estruturas observadas seguem o padrão da frente de ionização $H_{\alpha}$ observado na região (Figura 4.2) e parecem correlacionar-se bem com a emissão extensa da poeira (Figura 4.4). É evidente que a poeira que origina a extinção observada foi deslocada para o oeste do I-front mas acompanhando o padrão deste, mantendo inclusive as curvaturas norte e sul observadas no I-front. Apesar de ter valores relativamente discretos de extinção, com máximos de extinção de $\sim 1.5 \mathrm{mag}$, a morfologia observada no mapa de extinção sugere uma região tipo clumpy, também sugerida pelos estudos de CS de Churchwell et al. (1996).

Para caraterizar melhor as estruturas vistas em extinção, escolhemos aquelas regiões com $A_{\mathrm{V}} \geq 1$ mag. A Figura 4.17 mostra estas regiões e procedemos a uma análise de suas principais propriedades. $\mathrm{Na}$ Tabela 4.3 estão as coordenadas equatoriais das posições da alta extinção observadas na região de interesse (colunas 2 e 3). Na coluna (4) está o valor máximo de extinção associado a cada estrutura em magnitudes; na coluna (5) está a densidade colunar do hidrogênio calculada na posição de alta extinção em cada estrutura para o qual temos usado a razão gás a extinção padrão $N_{\mathrm{H}_{2}} / A_{\mathrm{V}} \sim 0.94 \times 10^{21} \mathrm{~cm}^{-2} \mathrm{mag}^{-1}$ (Bohlin et al. 1978); na coluna (6) estão as áreas em minutos de arco quadrados associadas a cada estrutura supondo uma distância de 450 pc e onde tem sido consideradas todas as celas com $A_{\mathrm{V}} \geq 1$ mag; na coluna (7) está a dimensão associada com cada estrutura em parsecs calculada segundo $\sqrt{ }(2$ area); e finalmente na coluna (8) está um limite inferior de massa para cada estrutura calculada segundo a equação (3.5).

Das quatro estruturas (A, B C e D) mostradas na Figura 4.17, somente a estrutura A é coincidente com a condensação V12 listada em Vilas-Boas, Myers e Fuller (1994, de aqui em diante VMF) na região de Vela. O catálogo de nuvens escuras do sul de Hartley et al. (1986) coloca 6 mag de extinção para V12 e VMF calculou $A_{\mathrm{V}}=3.7$ mag usando larguras de linha de $\mathrm{C}^{18} \mathrm{O}$. Nosso valor obtido de $A_{\mathrm{V}}=1.42 \mathrm{mag}$ para esta estrutura é claramente inferior às estimativas anteriores. Como comparação, VMF também calculou a escala de tamanho, densidade colunar de hidrogênio e massa para V12 e obteve os valores de 0.15 pc, $3.4 \times 10^{21} \mathrm{~cm}^{-2}$ e $1.3 \mathrm{M}_{\odot}$ (limite inferior) respectivamente. As diferenças com nossos valores mostrados na Tabela 4.3 podem dever-se à menor distância assumida por VMF (300 pc versus 450 pc em nosso trabalho) para V12, assim como à escolha feita por VMF da escala certa de conversão da densidade colunar de $\mathrm{C}^{18} \mathrm{O}$ para extinção visual. VMF utilizou a relação $A_{\mathrm{V}}=6.4 \times 10^{-15} \mathrm{~N}\left(\mathrm{C}^{18} \mathrm{O}\right)+3.2$ mag obtida de Nozawa et al. 1991, 
enquanto nossos valores de extinção são obtidos directamente do mapa da Figura 4.16. As estruturas A e B vistas em nosso mapa de extinção também são coincidentes com o clumps A e B do estudo da distribuição da densidade colunar de CS de Churchwell et al. (1996) feito na mesma região.

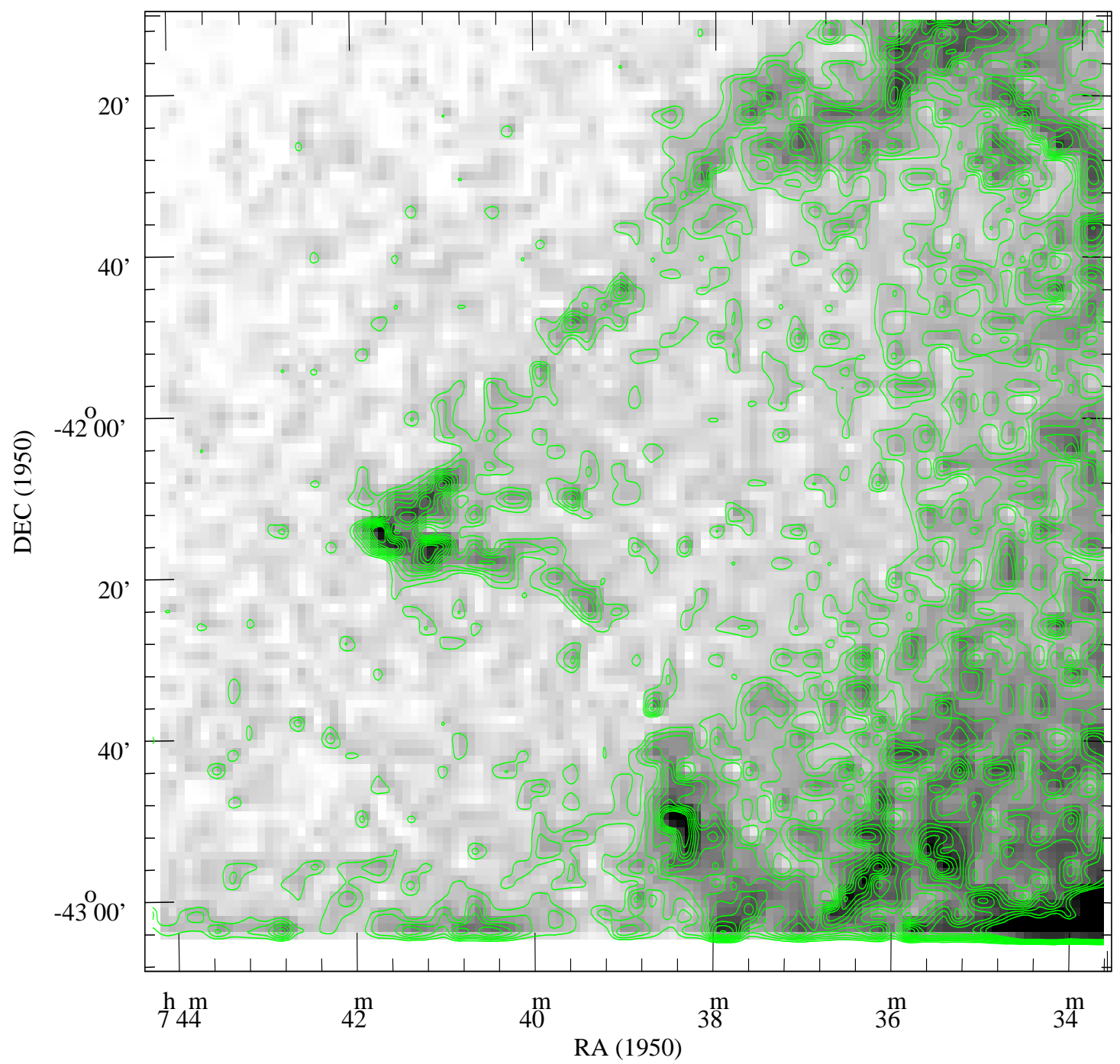

Figura 4.16 Mapa da distribuição da extinção na região estudada obtida por contagem automática de estrelas. As curvas de nível vão de 0.3 ate $1.2 \mathrm{mag}$ em passos de $0.1 \mathrm{mag}$. A área mostrada é de $2^{\circ} \times 2^{\circ} \mathrm{e}$ corresponde à mesma região mostrada na Figura 4.2. Nesta figura é evidente a ausencia de poeira no lado leste da frente de ionização (I-front). A extinção acompanha, razoavelmente, as curvaturas norte e sul já observadas no I-front.

Tabela 4.3 Análise das estruturas de extinção na região de IVS na direção de HD62542 com $A_{\mathrm{V}} \geq 1$ mag.

\begin{tabular}{ccccccccc}
\hline \hline ID & $\begin{array}{c}\text { AR }(1950) \\
(\mathrm{h}: \mathrm{m}: \mathrm{s})\end{array}$ & $\begin{array}{c}\text { DEC }(1950) \\
\left({ }^{\circ}:{ }^{\prime}: ”\right)\end{array}$ & $\begin{array}{c}A_{\mathrm{V}} \\
(\mathrm{mag})\end{array}$ & $\begin{array}{c}\mathrm{N}\left(\mathrm{H}_{2}\right) \\
\left(10^{21} \mathrm{~cm}^{-2}\right)\end{array}$ & $\begin{array}{c}\text { área } \\
(, 2)\end{array}$ & $\begin{array}{c}L \\
(\mathrm{pc})\end{array}$ & $\begin{array}{c}\text { Massa } \\
(\mathrm{M} \odot)\end{array}$ & Obs. \\
\hline A & $07: 41: 48.0$ & $-42: 15: 08.6$ & 1.42 & 1.33 & 8 & 0.52 & 2.52 & ${\mathrm{~V} 12^{\mathrm{a}}, \mathrm{A}^{\mathrm{b}}}^{\mathrm{b}}$ \\
$\mathrm{B}$ & $07: 41: 13.9$ & $-42: 17: 32.2$ & 1.16 & 1.09 & 4 & 0.37 & 1.13 & $\mathrm{~B}^{\mathrm{b}}$ \\
$\mathrm{C}$ & $07: 41: 04.7$ & $-42: 09: 05.8$ & 1.05 & 0.99 & 4 & 0.37 & 1.02 & -- \\
$\mathrm{D}$ & $07: 38: 28.5$ & $-42: 51: 11.1$ & 1.50 & 1.41 & 12 & 0.64 & 4.02 & -- \\
\hline
\end{tabular}

a Vila-Boas et al. (1994)

b Churchwell et al. (1996) 


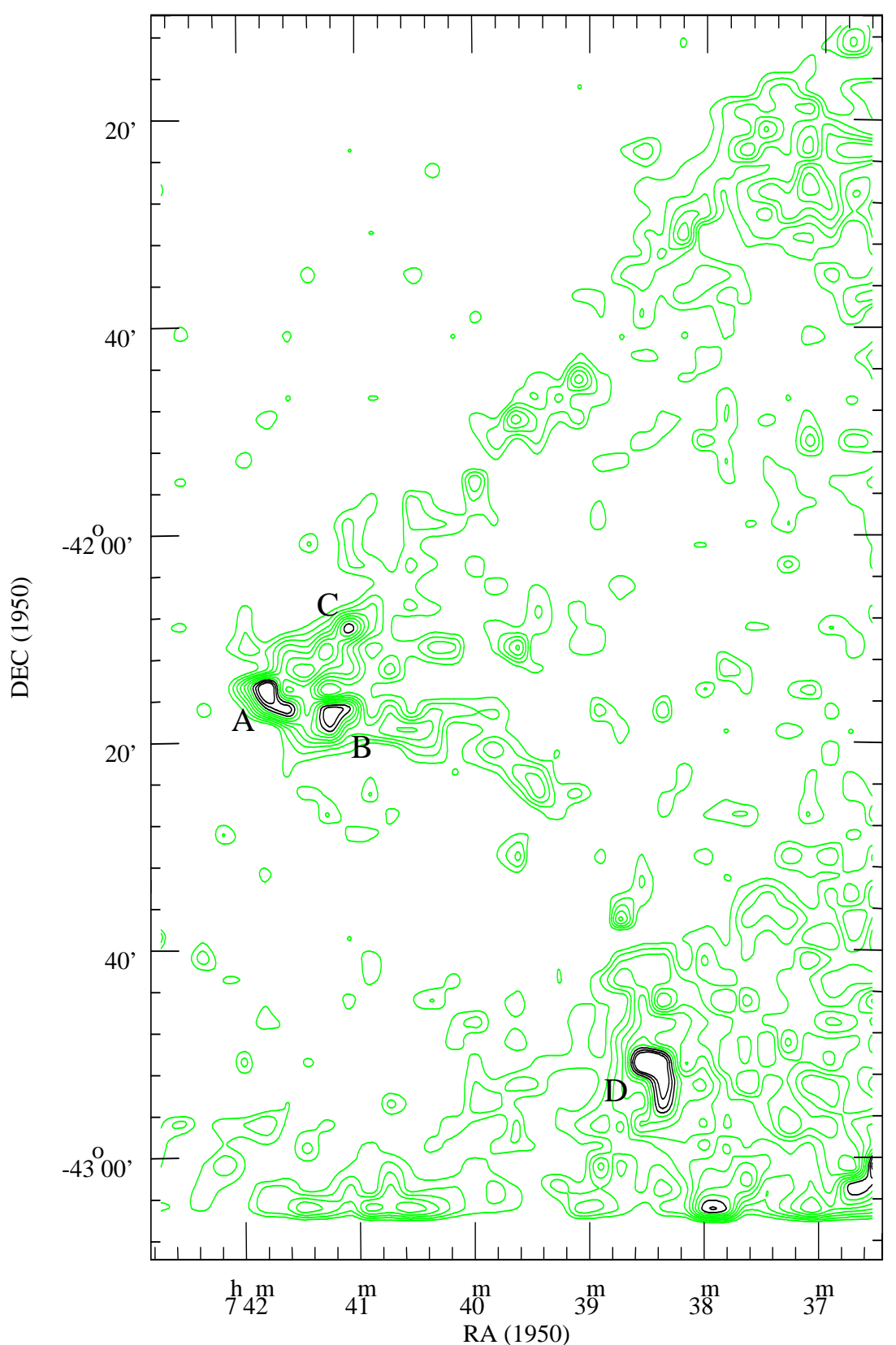

Figura 4.17 Estruturas em extinção com $A_{\mathrm{V}} \geq 1$ na direção a HD62542 na frente de ionização oeste do IRAS Vella Shell. Cada estrutura está indicada com uma letra e é definida pelos contornos em negro. Suas posições estão mostradas na Tabela 4.3. Os contornos em cinza ( $\left.0.3 \mathrm{mag} \leq A_{\mathrm{V}}<1 \mathrm{mag}\right)$ são os mesmos da Figura 4.16.

\subsection{Discussão}

\subsubsection{Polarização e extinção}

$\mathrm{Na}$ Figura 4.18 superpusemos os mapas de extinção obtidos da contagem de estrelas na seção anterior e os mapas de polarização dos 16 campos estudados na região (ver Figura 
4.6). Podemos notar que os vetores de polarização basicamente se concentram nas regiões onde extinção é detectada ao longo da frente de ionização. Os valores de extinção são baixos $\left(A_{\mathrm{V}} \leq 1.5 \mathrm{mag}\right)$ mas são suficientes para produzir a polarização observada.

Da Tabela 4.2 vemos que, ao longo da frente de ionização, o mais alto valor médio de polarização é atingido na posição do campo 13 (3.1\%), perto da estrutura B no começo da curvatura sul. $\mathrm{O}$ máximo valor de extinção para esta posição é $\sim 0.8$ mag . O $\theta$ médio observado para esta posição é $\sim 104^{\circ}$ e parece ser coerente com o $\theta$ de uma das tendências observadas no campo 12 (tendencia 2 na coluna (2) da Tabela 4.2), que é contígua ao leste $\left(\theta \sim 116^{\circ}\right)$. Esta última apresenta um valor médio de polarização menor $(\sim 0.8 \%)$, mas parece seguir o contorno da frente de ionização (ver Figura 4.12). A posição do campo 12 coincide com a estrutura $B$ vista em extinção que apresenta um máximo de $\sim 1.2$ mag. A outra tendência de polarização observada no campo 12 é quase perpendicular à frente de ionização $\left(\theta \sim 16^{\circ}\right)$ e apresenta uma polarização ainda maior $(\sim 1.6 \%)$.

Outra região com alta polarização observada é a correspondente as posições dos campos 05 e 07 na parte superior da curvatura norte (ver Figura 4.7). A posição do campo 05 apresenta um valor médio de polarização de $\sim 2.5 \%$ e $\theta \sim 42^{\circ}$, mas com apenas 0.6 mag de extinção máxima. A posição do campo 07 apresenta duas tendências de polarização sendo a primeira (aquela que apresenta o maior número de objetos) a que apresenta a maior polarização média $(\sim 2.5 \%)$ com um $\theta \sim 165^{\circ}$. A extinção máxima observada para esta posição é de apenas 0.7 mag. Um alinhamento dos padrões de polarização com a parede da frente de ionização é evidente nos campos 05 e 07.

A estrutura $\mathrm{A}$ vista em extinção $\left(A_{\mathrm{V}}=1.42 \mathrm{mag}\right)$, e que coincide com a condensação V12 de VMF, está localizada no canto inferior esquerdo do campo 04 (ver Figura 4.11). Apesar desta estrutura não ser bem amostrada polarimétricamente, parece evidente que, das duas tendências de polarização observadas para esta posição, a tendência $1(<P>\sim 1.7 \%, \theta \sim$ $104^{\circ}$ na Tabela 4.2) ao sul na Figura 4.11 parece estar associada com esta estrutura. É interessante notar que a estrutura A é o ponto de encontro das curvaturas norte e sul do frente de ionização; ela se encontra na região onde a estrutura tipo clumpy é mais evidente. Isto possivelmente pode explicar o fato que nossa estimativa de extinção, para esta estrutura, esteja subestimada frente aos valores encontrados na literatura. 
A outra estrutura nesta região $\left(\mathrm{C}, A_{\mathrm{V}}=1.05 \mathrm{mag}\right)$ está localizada no canto superior direito do campo $04 \mathrm{e}$, da mesma análise espacial, podemos concluir que a mesma tendência associada à estrutura A prevalece na estrutura $\mathrm{C}$, basicamente seguindo a parede da frente de ionização da curvatura norte.

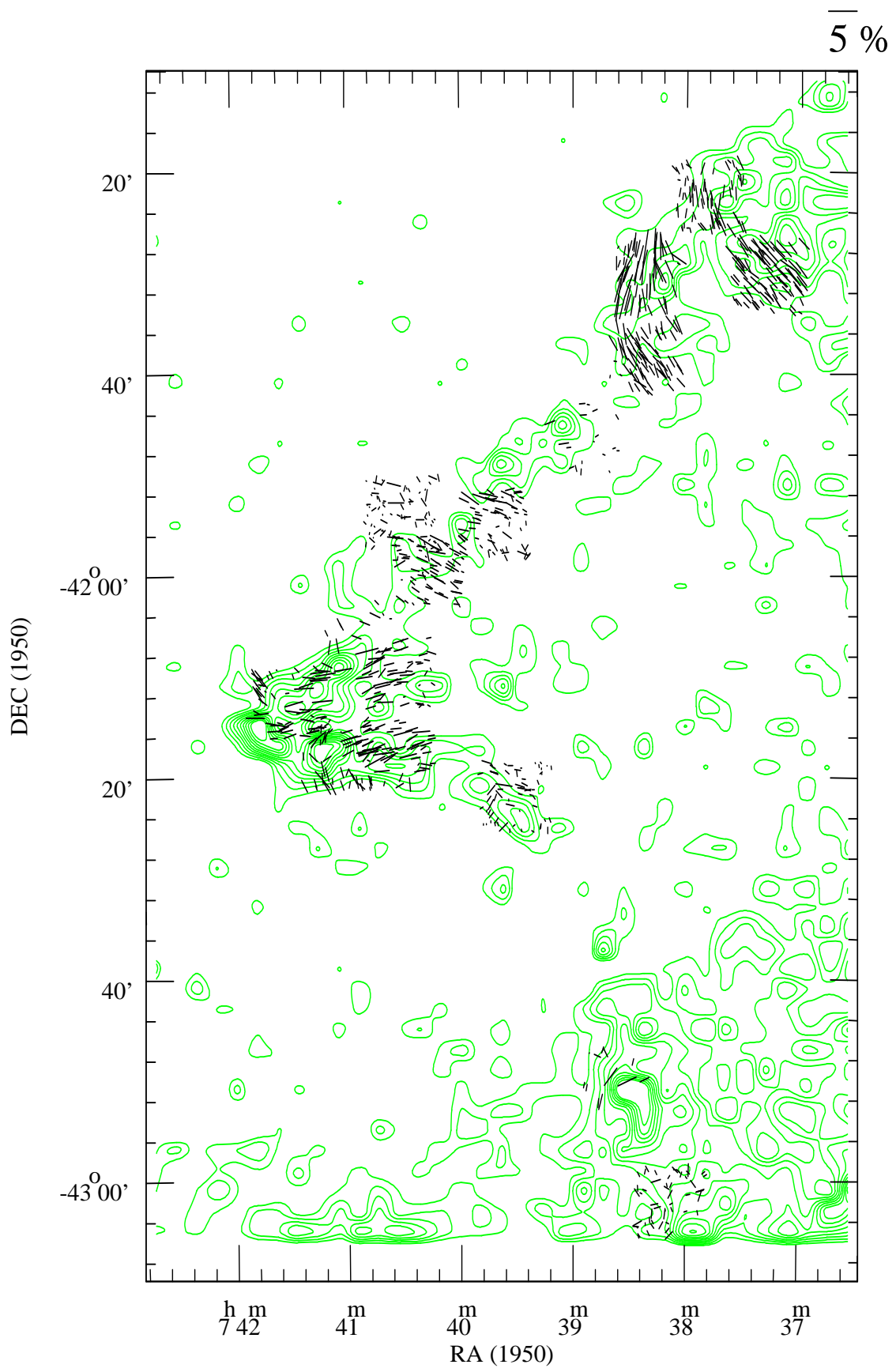

Figura 4.18 Mapa de polarização superposto ao mapa de extinção (igual à Figura 4.17, 0.3 mag $\leq A_{\mathrm{V}} \leq 1.2$ mag) da região estudada. A escala de polarização é mostrada no canto superior direito.

A última estrutura detectada em extinção $\left(\mathrm{D}, A_{\mathrm{V}}=1.5 \mathrm{mag}\right)$ está localizada no canto inferior direito da área coberta pelo campo 15. Infelizmente este campo apresentou uma 
pobre amostragem nas medidas de polarização o que impede qualquer procura de correlação espacial com a extinção.

Finalmente, devemos indicar que, em alguns campos, nossa técnica de procura de tendências de polarização via ajuste de gaussianas em $\theta$ deu resultados negativos mesmo quando se possuía uma boa amostragem. Isto é evidente no campo 09 (Figura 4.8) e no campo 10 (Figura 4.9). No entanto esta falta de um padrão de polarização parece ser consistente com regiões de pouca extinção ( $A_{\mathrm{V}} \leq 0.3 \mathrm{mag}$ ), como é verificado ao comparar as posições 09 e 10 com o mapa de extinção na Figura 4.18.

\subsubsection{Campo Magnético}

Seguindo o formalismo da seção 3.5.3, procedemos a calcular a razão das densidades de energia cinética e magnética assim como a intensidade do campo magnético da informação da dispersão do ângulo de polarização (coluna (8) na Tabela 4.2). Nas posições 01, 09, 10 , 15 e 16, não foi possível obter informação da dispersão do ângulo seja por uma pobre amostragem ou por apresentar um padrão aleatório de polarização. Para as todas as demais posições restantes, o cálculo de $\left\langle\Delta \theta^{2}>\right.$ foi feito para cada tendência e é apresentado na coluna (10) da Tabela 4.2. Podemos notar que nosso indicador da razão das densidades de energia cinética turbulenta a magnética apresenta uma faixa de variação de $\left\langle\Delta \theta^{2}\right\rangle=(0.24-$ 11.33) $\times 10^{-2}$ o que indicaria que ao longo da frente de ionização variações de quase uma ordem de magnitude entre a razão de ambas densidades prevalecem. O valor médio do indicador é $(4.90 \pm 3.51) \times 10^{-2}$ sugerindo que a pressão magnética domina à pressão do movimento turbulento em algumas regiões ao longo da frente de ionização. Por outro lado, a grande variação apresentada por $\left\langle\Delta \theta^{2}\right\rangle$ é consistente com o fato de algumas regiões apresentar uma variação totalmente aleatória do $\theta$. No caso extremo dos campos 09 e 10 , por exemplo, a impossibilidade de obter um $\Delta \theta$ mensurável pode ser atribuída a que a energia cinética prevalece sobre a magnética.

Para o cálculo da intensidade do campo magnético, utilizamos a equação (3.6) onde assumimos uma velocidade turbulenta $V_{\text {turb }}=1.4 \mathrm{~km} \mathrm{~s}^{-1}$, obtida da FWHM média da emissão de CS na região, e uma densidade de partícula $\sim 10^{4} \mathrm{~cm}^{-3}$ necessária para a excitação do CS (Churchwell et al. 1996). Como notado por estes autores, esta largura de 
linha é equivalente a uma temperatura Doppler de $\sim 1900 \mathrm{~K}$ que grandemente excede a temperatura cinética de 30 - 40 K representativa da emissão CS (Gregorich e Cardelli 1992; Gredel et al. 1993). Parece assim claro que a emissão CS é dominada por movimentos turbulentos e possivelmente fluxos em grande escala ou choques. A expressão final para o campo magnético resulta em:

$$
B(\text { gauss })=5.2 \times 10^{-5} / \Delta \theta(\text { radianos }) .
$$

O cálculo de $B$ feito em cada posição é apresentado na última coluna da Tabela 4.2. A intensidade do campo magnético promediada em todas as posições da frente de ionização é (0.0324 \pm 0.0225$)$ mgauss. No entanto a faixa extrema de variação do campo magnético é de aproximadamente uma ordem de magnitude $(0.0155$ - 0.1070) mgauss, em contraste, por exemplo, como nossas estimativas maiores de $B$ para o caso do estudo da Nuvem Escura de Musca (Figura 3.16) usando a mesma técnica.

Churchwell et al. (1996) concluíram que a energia potencial da região é unicamente $\sim 0.05$ da energia cinética total (térmica mais turbulenta) e que a dissipação da região é evitada pela pressão da shell em expansão. De nossas estimativas do campo magnético e do fato observado que a pressão magnética domina a pressão turbulenta em varias partes da shell, acreditamos que a componente magnética contribua de maneira importante ao balanço dinâmico da região.

\subsubsection{Eficiência da polarização}

Podemos analisar a eficiência da polarização da poeira na região estudada combinando nossos dados de polarização com a extinção obtida da contagem automática de estrelas. $O$ processo é o mesmo que o empregado na seção 3.5.4.

$\mathrm{Na}$ Figura 4.19a mostramos a porcentagem de polarização na banda $V$ versus a extinção visual para um total de 875 objetos nas 16 posições ao longo da frente de ionização onde temos dados colhidos. Primeiramente, vemos que a faixa de extinção de nossa amostra se extende até $\sim 1.5$ mag e os valores máximos de polarização são do ordem de $\sim 6 \%$. A linha sólida representa o limite superior para uma ótima eficiência da polarização no meio interestelar difuso ( $p_{\max }=3 A_{\mathrm{V}}$; Serkowsky et al. 1975). Observamos que apenas $31.2 \%$ da amostra está por debaixo deste limite e se considerarmos o limite superior (linea tracejada, 
$p_{\max } / A_{\mathrm{V}} \sim 4.5 \% \mathrm{mag}^{-1}$ ) de Whittet et al. (1994) a porcentagem sobe para 50.2\%. Parece evidente que parte da poeira responsável pelo alinhamento observado na região tém propriedades diferentes daquela presente no MI difuso especialmente para valores baixos de extinção $\left(A_{\mathrm{V}}<0.8 \mathrm{mag}\right.$ ), ou que, junto aos altos valores de polarização para baixas extinções, é um indicador que um ótimo alinhamento está presente em algumas regioes da frente de ionização tal vez favorecido por uma privilegiada visão geométrica do campo magnético com respeito da visão edge on da parede. A possibilidade de nosso cálculo de extinção estar subestimado, não deve ser descartado, em vista que nossa resolução (cela de 2'x2') pode estar mascarando valores maiores de extinção, favorecidos pela natureza clumpy já observada. Se este for o caso, o cenário de um ótimo alinhamento mas que uma diferença nas propriedades da poeira deveria explicar as correlações encontradas.
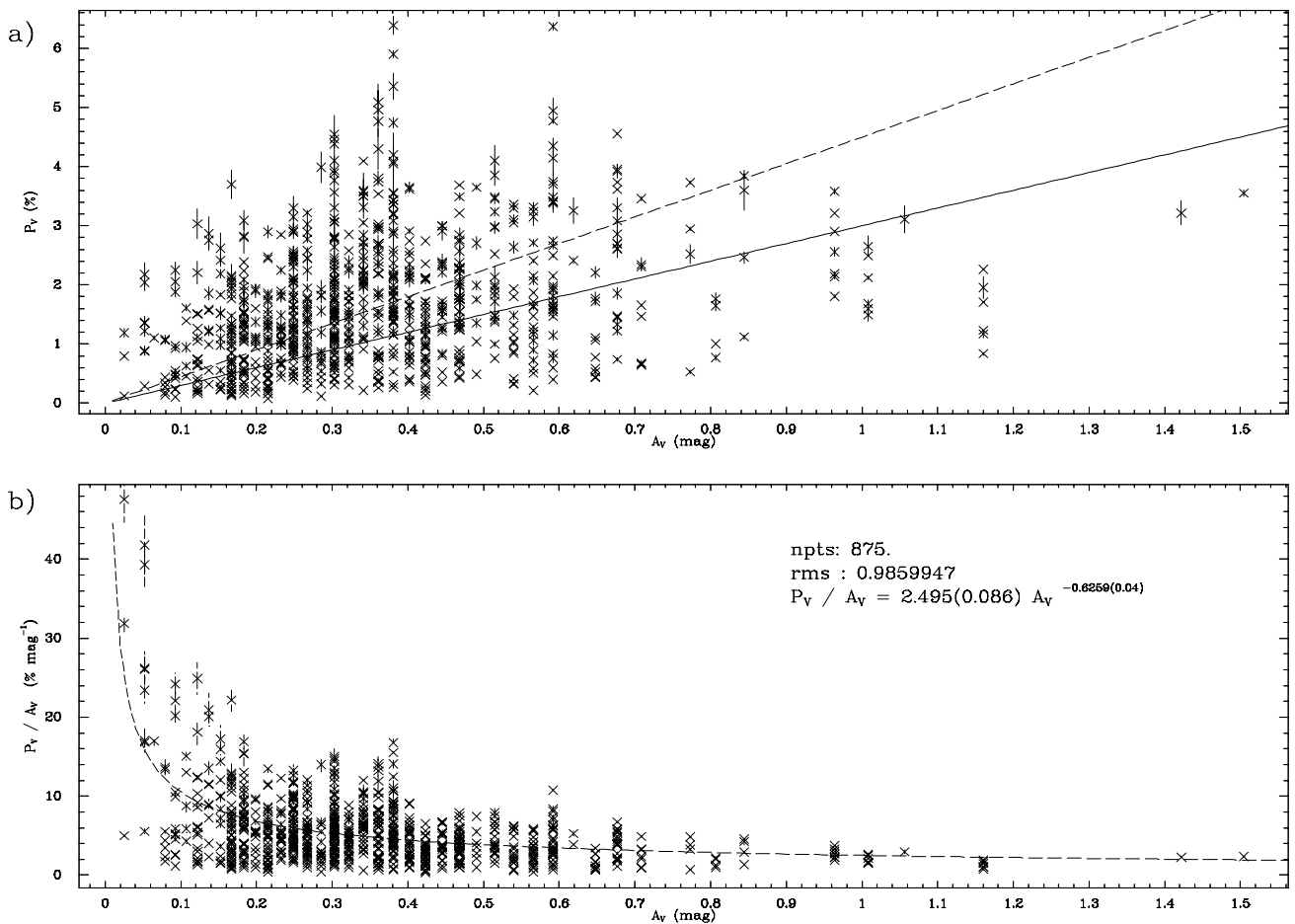

Figura 4.19 (a) Porcentagem de polarização na banda $V$ versus extinção visual para estrelas de background na na região Iras Vela Shell/Nebulosa de Gum na direção de HD62542. A linha sólida representa o limite superior para o meio interestelar difuso $\left(P_{\mathrm{V}}=3 A_{\mathrm{V}}\right.$; Serkowsky et al., 1975). A linha tracejada representa o limite superior na linha de visada de Cha I (Whittet et al., 1994). (b) Eficiência da polarização versus extinção visual para estrelas de background na região estudada. A linha tracejada representa um ajuste de mínimos quadrados a uma lei de potência para a amostra $\left(P_{\mathrm{V}}=2.50 A_{\mathrm{V}^{-0.63}}\right)$.

$\mathrm{Na}$ Figura 4.19b, graficamos a eficiência da polarização versus a extinção visual e podemos notar que as regiões com baixa extinção são mais eficientes para polarizar a luz das estrelas de background que as regiões com alta extinção. Este fato ja tem sido observado anteriormente nos entornos de nuvens escuras (Vrba et. al., 1994; Mc Gregor et al., 1994; 
Whittet et al., 1994; Gerakines et al., 1995) mas em frentes de ionização de shells em expansão como o estudado não existe evidência anterior na literatura.

A linha tracejada na Figura 4.19b representa um ajuste de mínimos quadrados a uma lei de potencia para nossa amostra. $\mathrm{O}$ ajuste obtido é $P_{\mathrm{V}} / A_{\mathrm{V}}=2.50(0.09) A_{\mathrm{V}}{ }^{-0.63(0.04)}$,com os erros das constantes em parêntesis. Se consideramos a dependência da eficiência da polarização com a extinção de Gerakines et al. (1995) $\left(P / A \propto A^{2 k-1}\right)$ onde o coeficiente $k$ representa a amplificação do campo magnético com a densidade $\left(B \propto n^{k}\right)$ de Mouschovias (1978), nosso ajuste fornece uma fator de escala para $B$ de $k=0.185$. Este valor é um tanto menor ao limite inferior $(k=0.33)$ dado por Mouschovias (1978) mas devemos ter em mente que este limite foi calculado em base a evidência observacional da época. Por outro lado, devemos considerar também que, no cálculo da eficiência da polarização de Gerakines at al. (1995), foi assumido uma relação $P / A \propto B^{2} / n$ (Vrba et al. 1981) que não leva em conta variações em pequena escala do campo magnético assim como variações no acoplamento térmico do gás e da poeira nas regiões de alta densidade.

\subsection{Conclusões}

- Contagem automática de estrelas no frente de ionização estudado fornece evidência de estruturas tipo clumpy com limites inferioes de massa típicos $(1-4) \mathrm{M}_{\odot}$ e uma escala de tamanho de $L \sim 0.47$ pc.

- A geometria do campo magnético parece acompanhar a borda da parede mas en algumas posições uma tendência perpendicular a ésta é detectada.

- A intensidade do campo magnético foi calculada ao longo do frente de ionização mediante a dispersão dos ângulos de polarização e obtivemos valores dentro de uma faixa de 0.02 mgauss a 0.11 mgauss sendo que a pressão magnética parece dominar a pressão turbulenta do gás em algumas regiões da parede.

- A eficiência da polarização muda ao longo do frente de ionização. Valores altos de polarização são observados para baixas extinções, o que pode ser explicado, ja seja por propriedades da poeira diferentes daquelas observadas no meio interestelar difuso, ou 
por um ótimo alinhamento, tal vez favorecido por uma privilegiada visão geométrica do campo magnético com respeito à frente de ionização vista edge on. 



\section{Capítulo 5}

\section{Conclusões}

\subsection{Sumário dos Resultados}

No presente trabalho, desenvolvimos e aplicamos a técnica da polarimetria de imagem CCD em campos estelares densos.

Na primeira parte desta tese, explicamos em detalhe nossa contribuição ao aprimoramento do hardware e software desenvolvido no Grupo de Polarimetria do IAG. Um programa de controle da movimentação da gaveta polarimétrica do IAG foi criado e permite uma fácil interação do usuário com o instrumento. O polarímetro do IAG junto ao seu programa de controle vem sendo usado rotineiramente por pesquisadores de diferentes grupos no LNA. Para a redução e análise semi-automática de imagens polarimétricas em campos estelares densos foi desenvolvido um pacote (PCCDPACK) dentro do ambiente IRAF. Este pacote foi o resultado de uma tentativa de sistematizar o processo de redução, toda vez que a técnica utilizada lida com campos estelares com um grande número (centenas) de objetos.

$\mathrm{Na}$ segunda parte desta tese, aplicamos a técnica descrita anteriormente em duas regiões de interesse: a Nuvem Escura de Musca (NEM) e a região IRAS Vela Shell (IVS)/Nebulosa de Gum na direção de HD62542. Para complementar a informação da polarimetria, usamos a técnica de contagem de estrelas para a estimativa da extinção em ambas regiões.

O estudo da NEM permitiu criar um catálogo polarimétrico de cerca de 2500 objetos com $P / \sigma_{P} \geq 5$. Um total de 35 campos CCD foram necessários para amostrar a nuvem em sua totalidade. A análise deste catálogo mostra um limite inferior de polarização de $\sim 2 \%$ detectado através da nuvem, com um incremento notório nos níveis de polarização de 6$7 \%$ na região central. O mapa de polarização mostra que a geometria do campo magnético é quase perpendicular a estrutura filamentar da nuvem. No entanto, quando analisamos o ângulo de polarização em detalhe detectamos variações de $\sim 30^{\circ}$ ao redor do valor médio de $110^{\circ}$. Mediante a dispersão dos ângulos de polarização, medimos a intensidade do campo magnético através da NEM e encontramos valores dentro de uma faixa de 0.05 
mgauss a 0.30 mgauss. O estudo de extinção utilizando a técnica de contagem automática de estrelas aplicado à nuvem forneceu um limite inferior de $139 \mathrm{M}_{\odot}$ para a massa total da nuvem (assumida uma distancia de 200 pc). Várias condensações foram encontradas na estrutura filamentar e uma escala típica de tamanho $L \sim 0.26 \mathrm{pc}$ foi obtida para estruturas $\operatorname{com} A_{\mathrm{V}} \geq 3$ mag. Finalmente, correlações entre extinção e polarização reforçam a idéia de que a poeira na NEM possui diferentes propriedades que as do meio interestelar difuso e que uma ótima visão geométrica do campo magnético pode estar presente ao longo da nuvem.

No estudo referente à região Iras Vela Shell/Nebulosa de Gum, na direção de HD62542 foi construído também um catálogo polarimétrico de ao redor de 900 objetos com $P / \sigma_{P} \geq 10$. Foram utilizados 16 campos CCD distribuídos ao longo da frente de ionização. Da análise dos mapas de polarização, a geometria do campo magnético parece acompanhar, em algumas posições, a borda da parede. No entanto, em outras posições uma tendência perpendicular à parede é notada. A intensidade do campo magnético foi estimada ao longo da frente de ionização mediante a dispersão dos ângulos de polarização. Os valores encontrados estão na faixa de 0.02 mgauss a 0.11 mgauss sendo que a pressão magnética parece dominar a pressão turbulenta do gás em algumas regiões da parede. A contagem automática de estrelas para o cálculo de extinção também foi aplicada nesta região. Evidência de estruturas tipo clumpy foi detectada com limites inferiores típicos de (1-4) $\mathrm{M}_{\odot}$ e uma escala de tamanho de $L \sim 0.47$ pc. Das correlações entre polarização e extinção, notamos que a eficiência da polarização muda ao longo da frente de ionização. Em algumas posições valores altos de polarização para baixas extinções são observados, o que pode ser explicado, já seja, por propriedades diferentes da poeira com respeito daquelas do meio interestelar difuso, ou, por um ótimo alinhamento tal vez favorecido por uma privilegiada visão geométrica do campo magnético com respeito à frente de ionização vista edge on.

\subsection{Perspectivas}

Temos em mente o aprimoramento do software de controle de gaveta polarimétrica do IAG. Sua conversão para a linguagem VISUAL BASIC poderá melhorar o acesso gráfico para os usuários potenciais. 
Pretendemos complementar a documentação referente ao processo de redução de imagens polarimétricas para objetos pontuais, mostrado ao longo do capítulo 2. A ampliação da semi-automatização do processo de redução para o caso de fontes extensas está prevista.

A técnica de polarimetria óptica de imagem desenvolvida no presente trabalho pode ser estendida ao infravermelho. Importante informação pode ser obtida da polarização em regiões mais profundas e de maior extinção. Nosso interesse é estudar o comportamento do campo magnético em regiões associadas a condensações e correlacioná-lo com os padrões observados no óptico. Isto é de especial interesse na NEM, onde um grande número de condensações foram detectadas.

As correlações entre polarização e extinção podem ser melhoradas se as estimativas da extinção tiveram uma melhor resolução angular. Técnicas alternativas para o cálculo de extinção devem ser exploradas e a possibilidade de usar as razões das cores IRAS (60 e 100 $\mu \mathrm{m})$ parece factível, considerando as novas imagens de alta resolução disponíveis (HIRESIPAC) que melhoram grandemente a resolução IRAS original. 



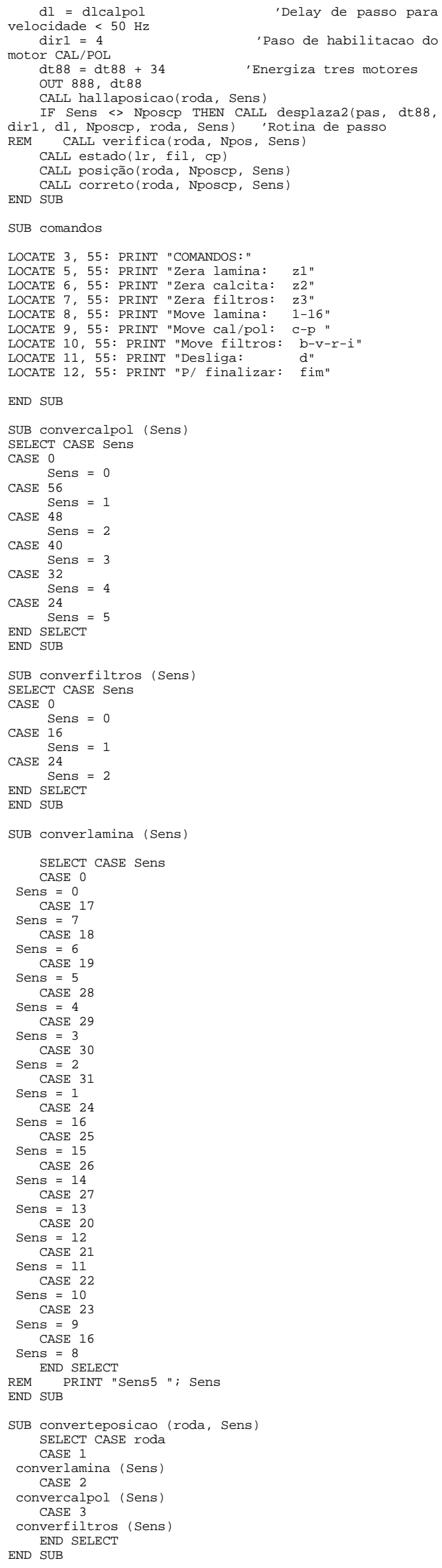

\section{'Delay de passo para \\ 'Paso de habilitacao do}


IF Nposcp $=1$ AND Sens $=2$ AND paso $>$ erroroda2 AND vez $=0$ THEN dt $88=$ dt88 - 64: paso $=0$ : OUT 888, dt 88: vez $=1$

IF Nposcp $=1$ AND Sens $=3$ AND paso $>$ erroroda2 AND vez $=0$ THEN dt $88=d t 88-64:$ paso $=0:$ OUT 888 , dt88: vez $=1$

$\mathrm{IF}$ NposcP $=4$ AND Sens $=2$ AND paso $>$ erroroda2 AND vez $=0$ THEN dt $88=$ dt $88-64:$ paso $=0$ : OUT 888 , dt $88:$ vez $=1$

IF NposcP $=4$ AND Sens $=3$ AND paso $>$ erroroda2 AND vez $=0$ THEN dt88 $=$ dt88 - 64: paso $=0$ : OUT 888 , dt88: $\operatorname{vez}=1$
LOCATE 22, 2: PRINT "van "; paso; " passos de "; pas LOCATE 23, 2: PRINT "Nposcp "; Nposcp; " Sens "; Sens; " vez "; vez

INPUT a

LOOP
IF paso > INT $(1.1$ * pas) THEN LOCATE 20, 1: PRINT "Problemas com a roda . resetear. STOP "

END SUB

SUB desplaza3 (pas, dt88, dir1, dl, Nposfil, roda, Sens, Posroda3)

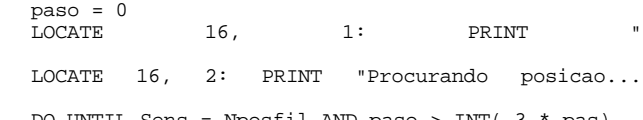
DO UNTIL Sens $=$ Nposfil AND paso $>\operatorname{INT}(.3 *$ pas $)$
dt $88=d t 88+\operatorname{dir} 1$ Motor OUT 888, dt 88 $\begin{array}{ll}\text { FOR } t=0 \text { TO dl: NEXT } t & \text { 'Loop de tempo } \\ \text { dt88 } 8 \text { dt8 } 88 \text {-dirl } & \text { 'Resetea bit de }\end{array}$

passo

OUT 888, dt 88

FOR $t=0$ TO dl: NEXT $t \quad$ 'Loop de tempo en andamento 'Calcula posicao

paso $=$ paso +1

IF paso > INT $(1.1$ * pas) THEN LOCATE 20, 1: PRINT "Problemas com a roda... resetear: STOP " END SUB

SUB estado (lr, fil, $\mathrm{cp}$ )

LOCATE 2, 2: PRINT "Lamina Ret.

LOCATE 4, 6: PRINT lr

SELECT CASE fil

SELECT 1

CASE 1 LOCATE 4, 35: PRINT "B"

CASE 2

LOCATE 4,35. PRINT "V"

CASE 3

LOCATE 4, 35: PRINT "R"

CASE 4

LOCATE 4, 35: PRINT "I"

SELECT CASE CP

CASE 1

CASE LOCATE 4, 19: PRINT "Calcita "

CATE 4, 19: PRINT "Polaroid"

END SELECT

END SUB

SUB filtros (k\$, Sens, posroda1, Posroda3, dlfiltros) roda $=3$

SELECT CASE $k$

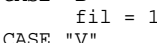

$\underset{\mathrm{fil}}{\mathrm{CASE}}=2$

CASE "I $\mathrm{fil}=3$

END SELECT

CALL hallaposicao(roda, Sens)

filactual = Posroda3

$\mathrm{mm}=\mathrm{fil}-\mathrm{filactual}$
$\mathrm{IF}$ filactual $>$ fil $\mathrm{THEN} \mathrm{mm}=(4-$ filactual $)+\mathrm{fil}$

FOR $i \mathrm{i}=1 \mathrm{TO} \mathrm{mm}$

SELECT CASE Posroda3

CASE 1

Nposfil $=2:$ Posroda $3=2:$ Sens $=0$

CASE 2

Nposfil $=2:$ Posroda $3=3:$ Sens $=0$

CASE 3

Nposfil $=2:$ Posroda $3=4:$ Sens $=0$

CASE 4

Nposfil $=1:$ Posroda $3=1:$ Sens $=0$

END SELECT

$\operatorname{dir}=64$

'Direcao prossimo filtro

dt $88=\operatorname{dir}+160$

dt $88=d t 88+10$

'Energiza tres motores $\mathrm{dl}=$ dlfiltros para velocidade $<60 \mathrm{~Hz}$ $\operatorname{dir} 1=16$

CALL desplaza3(pas, dt88, dir1, dl, Nposfil, roda, Sens, Posroda3) 'ROTINA DE PASSO

FOR tt $=1$ TO 1500: NEXT 'Loop de tempo

REM CALL verifica(roda, Npos, Sens)

CALL posicao (roda, Posroda3, Sens)

CALL estado (posroda1, Posroda3, cp)

NEXT

CALL correto(roda, Posroda3, Sens)

END SUB

SUB hallaposicao (roda, Sens)

SELECT CASE roda

M OUT 888,0

(889)

Sens $=$ Sens AND 248

CASE 2

REM OUT 888, 128

Sens $=\operatorname{INP}(889)$

Sens = Sens AND 56

CASE 3

REM ${ }^{2}$ OUT 888,128

Sens $=\operatorname{INP}(889)$

Sens $=$ Sens AND 192

END SELECT

Sens $=$ INT $($ Sens $/ 8)$

LOCATE 23, 40: PRINT "379h "; Sens

REM INPUT a

$$
\begin{aligned}
& \text { IF roda }=1 \text { THEN } \\
& \text { SELECT CASE Sens } \\
& \text { CASE IS }<16 \\
& \text { ens }=0 \\
& \begin{array}{l}
\text { CASE } 17 \\
\text { S }=7
\end{array} \\
& \text { CASE } 18
\end{aligned}
$$

SELECT CASE Sens

CASE IS $<3$

Sens $=$

CASE 7

Sens $=1$

Sens $=2$

CASE 5

Sens $=3$

Sens $=4$

CAE 3

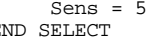

END IF

IF roda $=3$ THEN

SELECT CASE SenS

CASE 0

Sens $=0$

16
Sens $=1$

Sens $=1$
24

Sens $=2$

END SELECT 
END IF

END SUB

SUB incorreto (roda, Npos, Sens)

LOCATE 16, 1: PRINT "Posicao incorreta... corrigendo" CALL corrige(roda, Npos, Sens)

END SUB

SUB incorreto1 (roda, Npos, Sens, dllamina)

$\operatorname{dir}=64$

dt $88=$ dir +2

dt $88=d t 88+40$ 'Energiza tres motores

$\operatorname{dir} 1=$

$\mathrm{d} 1=$ dllamin

pas $=3520$

, Rotina desplazal

paso $=0$

errosensor $=600$

DO UNTIL Sens $=$ NDOS AND paso $>600$

$\begin{array}{cccc}\text { DO UNTIL Sens } & =\text { Npos AND paso }>600 \\ \text { LOCATE } & 16, & 1: & \text { PRINT }\end{array}$

LOCATE 16, 2: PRINT "Procurando posicao..

dt88 = dt88 $+\operatorname{dir} 1 \quad$ 'Anda 1 Passo Motor

OUT $888, \mathrm{dt} 88$

FOR $t=0$ TO dl: NEXT $t \quad$ 'Loop de tempo

dt $88=$ dt88 - dir1 'Resetea bit de passo

dt 88 T 888, dt 88 dir

FOR $t=0$ TO $d l:$ NEXT $t \quad$ Loop de tempo

CALL hallaposicao(roda, Sens) 'Calcula posicao en andamento$$
\text { LOCATE 22, 2: PRINT "van "; paso; " passos de "; }
$$

pas

LOCATE 23, 2: PRINT "Npos "; Npos; " Sens "; Sens

REM INPUT a

LOOP

IF paso > INT $(1.1$ * pas) THEN LOCATE 20, 1: PRINT "Problemas com a roda... resetear: STOP "

IF Sens = Npos THEN CALL correto (roda, Npos, Sens) IF Sens <> Npos THEN LOCATE 20, 1: PRINT " Problemas no Posicionamento": STOP

END SUB

SUB incorreto2 (roda, Nposcp, Sens, dlcalpol)

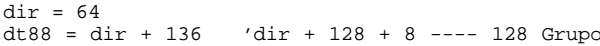

Sensores $88+34$,

$\operatorname{dir} 1=4$

dirl $=4$
$d l=$ dlcalpol

pas $=\operatorname{INT}(1.1 *$ pas $)$

, Rotina desplaza2

paso $=0$

vez $=0$
LOCATE
" 16,

LOCATE 16, 2: PRINT "Procurando posicao...

erroroda2 = 10 'Numero de pasos de erro en posicoes da roda2

UNTIL Sens $=$ Nposcp AND paso $>$ erroroda2

Motor

$\mathrm{dt} 88=\mathrm{dt} 88+\operatorname{dir} 1$ 'Anda 1 Passo

OUT $888, \mathrm{dt} 88$

FOR $t=0$ TO dl: NEXT $t \quad$ 'Loop de tempo

passo $\mathrm{dt} 88=\mathrm{dt} 88-\operatorname{dir} 1$

'Resetea bit de

OUT $888, d t 88$

FOR $t=0$ TO dl: NEXT $t \quad$ 'Loop de tempo en andamento

paso $=$ paso +1

THEN dt8 8 = dt88 -2 AND paso $>$ erroroda 2 AND vez $=$

64: paso $=0:$ OUT 888 , dt $88:$ vez $=$

IF Sens $=3$ AND paso $>$ erroroda2 AND vez $=0$ THEN dt88 $=$ dt88 $-64:$ paso $=0$ : OUT 888, dt88: vez $=$

LOCATE 22, 2: PRINT "van "; paso; " passos de

"; pas

LOCATE 23, 2: PRINT "Npos "; Nposcp; " Sens "; REM LOCATE 22, 35: INPUT a

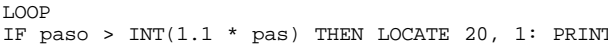
"Problemas com a roda... resetear: STOP "

REM LOCATE 10, 20: PRINT "Sens "; Sens

IF $\mathrm{Sens}=$ Nposcp THEN CALL correto(roda, Nposcp, IF Sens <> Nposcp THEN LOCATE 20, 1: PRINT " Problemas no POsicionamento": STOP
END SUB

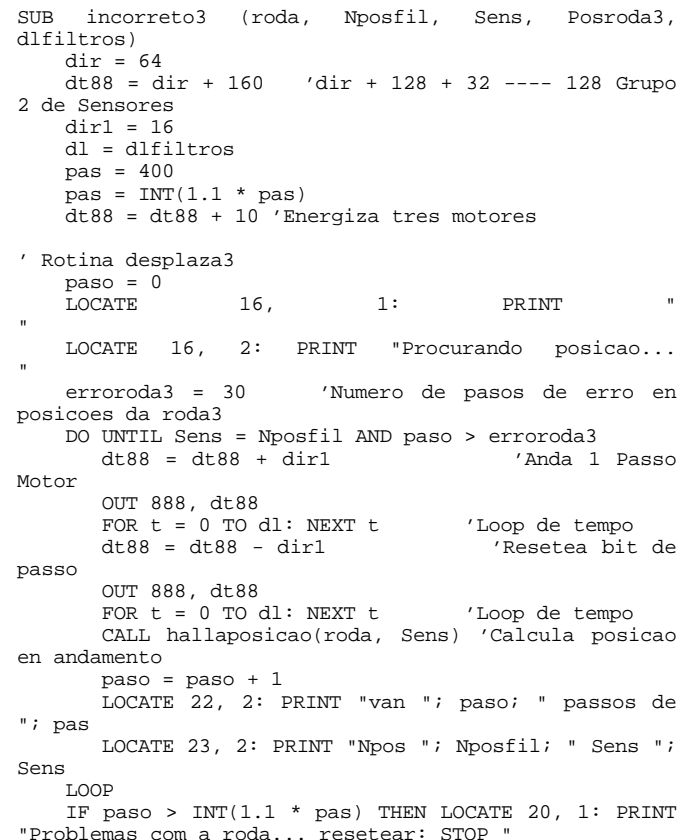
"Problemas com a roda... resetear: STOP "

REM LOCATE 10, 20: PRINT "Sens "; Sens

IF Sens = Nposfil THEN CALL correto(roda, Nposfil, ens)

IF Sens <> Nposfil THEN LOCATE 20, 1: PRINT " LOCAlemas no Posicionamento": STOP
LOCATE 1 : PRINT "

END SUB

SUB lamina (k\$, Sens, lr, dllamina)

roda $=1$

lr $=\operatorname{VAL}(\mathrm{k} \$)$

REM OUT 888, 0 'Activa lectura de sensores

da roda 1 CALL hallaposicao (roda, Sens)

REM Iractual = Sens

SHARED lractual, Npos

lractual $=$ Npos

$\mathrm{mm}=1 \mathrm{r}-$ lractua

IF lractual $>\operatorname{lr}$ THEN $\mathrm{mm}=(16-$ lractual $)+\operatorname{lr}$

FOR $\mathrm{ii}=1 \mathrm{TO} \mathrm{mm}$

Npos $=$ lractual $+i i$

$\operatorname{dir}=64$
$\operatorname{dt} 88=\operatorname{dir}+2$

$\mathrm{L}$

pas $=2200$

dt $88=\mathrm{dt} 88+40$

$\mathrm{dl}=$ dllamina

velocidade $<250 \mathrm{~Hz}$

IF Npos > 16 THEN Npos $=$ Npos -16

CALL desplaza (pas, dt88, dir1, dl, Npos, roda, Sens)

REM CALL verifica(roda, Npos, Sens)

CALL posicao(roda, Npos, Sens)

CALL posicao (roda, Npos,

$\mathrm{l} r=$ Npos $\quad$ 'Atualiza posicao lamina

NEXT ii

lractual = Npos
CALL correto (roda, Npos, Sens)

END SUB

FUNCTION nomeposicao\$ (roda, Npos)

SELECT CASE roda

CASE 2

SELECT CASE Npos

CASE 1

nomeposicao\$ = "Calcita"
CASE 4

nomeposicao\$ = "Polaroid"

CASE 3

SELECT CASE NpOS

CASE 1

omeposicao\$ $=" \mathrm{~B} "$

CASE 2

omeposicao $=" \mathrm{~V}$

CASE 3

omeposicao\$ = "R"

CASE 4

omeposicao\$ = "I"

CASE 1

'Direcao que habilita moto

\# passos / posicao

'Delay de passo para a

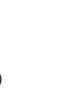


nomeposicao\$ $=$ STR $\$$ (Npos)

END SELECT

FUNCTION NOMERODA\$ (valor)

SELECT CASE valor

CASE 1

CASE NOMERODA\$ = "Lamina Retar.

CASE 2

NOMERODA\$ = "Cal/Pol "

CASE

NOMERODA $=$ "Filtros "

END SELECT

END FUNCTION

SUB posicao (roda, Nos, sens)

LOCATE $18, \quad \begin{aligned} & \text { PRINT } \\ & \text { 1: }\end{aligned}$

LOCATE 18, 2: PRINT "Roda "; NOMERODA(roda); " em "; nomeposicao (roda, Npos)

SUB tempo

CLS

LOCATE 5, 20: PRINT "Ajustando o Programa para a vel. da CPU."

LOCATE 6, 20: PRINT "

Aquarde..."

inicio $=$ TIMER

FOR $I=1$ TO 100000

NEXT

fim $=$ TIMER

delta $=($ fim - inicio $) / 100000$

SHARED dllamina, dlcalpol, dlfiltros

REM lamina

REM dllamina $=0 \quad$ Polar $1: 12$

tlam $=20.185$

temp $=$ tlam

DO UNTIL ver $=1$

dllamina $=\operatorname{INT}(($ temp $/(2200 *$ delta $)-63 !) / 2$ -

$3.89+.5)$

IF dllamina $<0$ THEN

temp $=$ temp +.5

END IF

LND

REM calcita/pol.

REM calcita/pol.
REM dlcalpol $=25 \quad$ Polar1: 200

dlcalpol $=\operatorname{INT}(($ tcal $/(100 *$ delta $)-73.6) / 2$ -

$3.89+.5)$

REM filtros

REM dlfiltros $=25$ Polar $1: 200$

tfil $=2.582$

dlfiltros $=\operatorname{INT}(($ tfil $/(100 *$ delta $)-34.1) / 2$ -

$3.89+.5)$

LOCATE 9, 25

PRINT ("POLARI

LOCATE 10,15

"; dlcalpol

LOCATE 12, 15

"; dlfiltros

PRINT "Filtros:

LOCATE 14, 25: "; 200; "
END SUB

SUB verifica (roda, Npos, Sens) SELECT CASE roda

$$
\text { CASE } 1
$$

CALL hallaposicao (roda, Sens)

FOR $t=1$ TO 1000: NEXT $t$

CASE 2

OUT 888,128

CALL hallaposicao (roda, Sens)

FOR $t=1$ TO $1000:$ NEXT $t$

OUT 888,128

CALL hallaposicao (roda, Sens)

FOR $t=1$ TO 1000: NEXT $t$

END SELECT

Npos THEN CALL correto(roda, Npos, Sens) ELSE CALL incorreto(roda, Npos, Sens)

SUB zeragemrodal (roda, Sens, lr, dllamina)

REM OUT 888,0

SHARED NPOS

,

LOCATE 15

15, 1: PRINT

LOCATE
retardadora..."
LOCATE

2 :

Zerando

18,1

PRINT

CALL hallaposicao (roda, Sens)

FOR $t=1$ TO 1000: NEXT $t$ correto(roda, Npos, Sens) ELSE CALL incorretol (roda, Npos, Sens, dllamina)

$\operatorname{lr}=1$
Npos $=1$

CALL estado(lr, fil, cp)

END SUB

SUB zeragemroda2 (roda, Sens, dlcalpol, lr)

REM OUT 888,128

SHARED NPOSCP
OUT 888,170

OUT 888,170

LOCATE 15, 2: PRINT "Zerando roda cal/pol..." "

CALI hallaposicao (roda, Sens)

CALL hallaposicao (roda, Sens)
FOR $t=1$ TO 1000: NEXT $t$

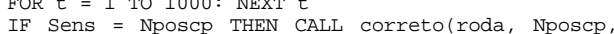

Sens) ELSE CALL incorreto2(roda, Nposcp, Sens, dlcalpol)

CALL estado(lr, fil, $\mathrm{cp}$ )

END SUB

SUB zeragemroda3 (roda, Sens, lr, Posroda3, dlfiltros) REM OUT 888,128

SHARED Nposfil

OUT $888,170 \quad 15, \quad 1: \quad$ PRINT
LOCATE

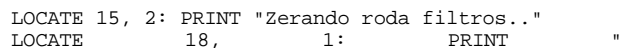

CALL hallaposicao(roda, Sens)

FOR $t=1$ TO 1000: NEXT $t$

IF Sens = Nposfil THEN CALL correto(roda, Nposfil, Sens) ELSE CALL incorreto3(roda, Nposfil, Sens, Posroda3, dlfiltros

Posroda $3=1$

END SUL estado( $(r$, Posroda3, cp) 



\section{Apêndice B. Pacote PCCDPACK}

Este apêndice contém uma descrição detalhada do pacote de redução de imagens polarimétricas PCCDPACK, desenvolvido por nós, para a redução e análise de campos estelares densos.

\section{B.1 Rotina ORDEM}

Na Figura B.1 mostramos o arquivo de parâmetros da rotina ORDEM assim como um exemplo de sua execução. $O$ arquivo de entrada (file_in) é o arquivo de coordenadas obtido pelo DAOFIND. Os parâmetros shiftx e shifty são a distância em pixels em $x$ e $y$ entre as imagens ordinária e extraordinária de uma mesma estrela. Estes valores podem ser calculados facilmente utilizando as estrelas mais brilhantes na mesma imagem que deu origem ao arquivo file_in. As posições das imagens ordinária e extraordinária podem ser obtidas utilizando, por exemplo, a rotina RIMCURSOR do pacote LISTS.

I $R$ A F

Image Reduction and Analysis Facility

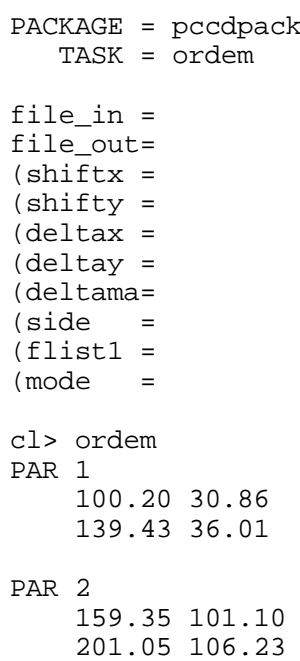

Figura B.1 O arquivo de parâmetros do rotina ORDEM e um exemplo de sua execução.

Os parâmetros deltax e deltay definem os erros em pixels nos eixos x e y onde a procura do par associado será feita (usualmente 1 ou 2 pixels serão suficientes para estes parâmetros). Ou seja, se $(\mathrm{x} 0, \mathrm{y} 0)$ é a posição da imagem ordinária, a procura da posição da imagem extraordinária será feita naquelas coordenadas que estejam entre $(\mathrm{x} 0+\operatorname{shiftx} \pm$ 
deltax, $y 0+\operatorname{shiftx} \pm$ deltay). $O$ parâmetro side define se a posição da imagem extraordinária (superior) esta à direita ou à esquerda da imagem ordinária (inferior). $\mathrm{O}$ arquivo de saída (file_out) estará composto pelas coordenadas $(\mathrm{x} 0, \mathrm{y} 0)$ da imagem ordinária seguida pela coordenada $(\mathrm{x} 1, \mathrm{y} 1)$ da imagem extraordinária para a 1a. estrela, vindo em seguida os pares respectivos da 2 a. estrela e assim sucessivamente.

\section{B.2 Rotina COORSHIFT}

$\mathrm{O}$ arquivo de parâmetros da rotina COORSHIFT é mostrado na Figura B.2, assim como um exemplo de sua execução. O parâmetro infile é o arquivo de saída da rotina IMALIGN com a informação dos deslocamentos entre as imagens. $O$ arquivo de coordenadas da imagem de referência é indicado no parâmetro coorfile. A opção cria deve estar 'yes' se se deseja proceder com a criação dos arquivos de coordenadas.

I R A F

Image Reduction and Analysis Facility

PACKAGE $=$ pccdpack

TASK $=$ coorshift

infile $=$
coorfil=
(cria =
(corrige=
(xside =
(yside =
(deltax $=$
(deltay =
(flist =
(mode =

imalign.out) file de saída do imalign

teste.ord) file de coordenadas a deslocar (.ord)

yes) cria arquivos de coordenadas?

yes) elimina estrelas das bordas?

368.) tamanho do CCD en X (pixels)?

571.) tamanho do CCD en Y (pixels)?

5.) distancia minima a borda X (em pixels)?

imalign.out)

5.) distancia minima a borda Y (em pixels)?

cl> coorshift

Analizando file...

shift $(X, Y):-7.6 \quad-23.86$

delta $(X, Y): 5.5$.

limites $(\mathrm{X}, \mathrm{Y}): 718.4 \quad 1111.14$

objetos filtrados 333

criando arquivo coordenadas para teste01.imh xshift 0 . yshift 0 .

criando arquivo coordenadas para teste02.imh xshift -2.57 yshift -5.01

criando arquivo coordenadas para teste03.imh xshift -3.93 yshift -6.88

criando arquivo coordenadas para teste04.imh xshift -4.87 yshift -10.03

Warning: Attempt to delete a nonexistent file (inord)

Figura B.2 O arquivo de parâmetros da rotina COORSHIFT e um exemplo de sua execução.

Às vezes pode acontecer que, devido ao deslocamento entre a imagem de referência e as imagens restantes, uma posição registrada na imagem de referencia cai afora dos limites das imagens restantes, o que impossibilita a medida posterior. Isto é recorrente nos objetos próximos às bordas nas imagens. Para eliminar estes objetos, a opção corrige deve estar 'yes'. Com a opção anterior ativada, somente serão incluídos na lista final aqueles objetos na 
imagem de referência que estejam afastados das bordas por uma quantidade em pixels igual ao parâmetro deltax no eixo x e deltay no eixo y. O tamanho em pixels da imagem de referencia deve ser ingressado nos parâmetros xside e yside.

A saída da tarefa consistirá em tantos arquivos de coordenadas corrigidos como imagens foram utilizadas no cálculo dos deslocamentos da rotina IMALIGN. Por definição, os nomes dos arquivos serão 'coord1', 'coord2, e assim sucessivamente. Uma lista final chamada 'inord' também será criada incluindo os nomes de todos os arquivos criados e será utilizada como entrada nas rotinas fotométricas.

\section{B.3 Criando arquivo de informação}

O arquivo de informação é criado utilizando a rotina TXDUMP do pacote DAOPHOTX sobre todos os arquivos de magnitudes ('mag') e extraindo deles os seguintes parâmetros: 'mksy', magnitude do céu em contagens; 'nsky', número de pixels utilizados no cálculo de 'msky'; 'rapert', raio da abertura utilizada em pixels; 'sum', soma das contagens dentro da abertura; e, 'area', área da abertura utilizada. Os parâmetros 'rapert', 'sum' e 'area', devem ser extraídos para cada uma das aberturas disponíveis. A saída do TXDUMP deve ser direcionada a um arquivo de texto que servirá de entrada para o cálculo dos parâmetros polarimétricos. Por exemplo, se para nossas imagens fizermos a fotometria para 10 aberturas, o comando que criará o arquivo de informação (que chamaremos 'teste.dat') será:

cl> txdump *.mag fields="image,msky,nsky, rapert[1-10], sum[1-10], área[1-10] " > teste.dat

\section{B.4 Rotina PCCD}

Na Figura B.3 mostramos o arquivo de parâmetros do PCCD. O arquivo de entrada (filename) é o arquivo de informação criado linhas acima. O parâmetro nstars é o número de estrelas contido em nossas imagens. O número de posições da lâmina retardadora utilizadas na colheita dos dados e o número de aberturas utilizadas no cálculo da fotometria são ingressados nos parâmetros nhw e nap respectivamente. 
Apêndice B

O tipo de analisador utilizado é definido pelo parâmetro calc ('c' para a calcita e 'p' para o polaróide). A informação do CCD utilizado como o ruído de leitura e o ganho é ingressado nos parâmetros readnoise e ganho. Se se deseja corrigir o ângulo de polarização (previamente calculado do estudo de estrelas padrões durante a missão), isto pode ser feito ingressando a desfasagem no parâmetro deltatheta. O caminho do executável do código FORTRAN deve ser incluído no parâmetro fileexe.

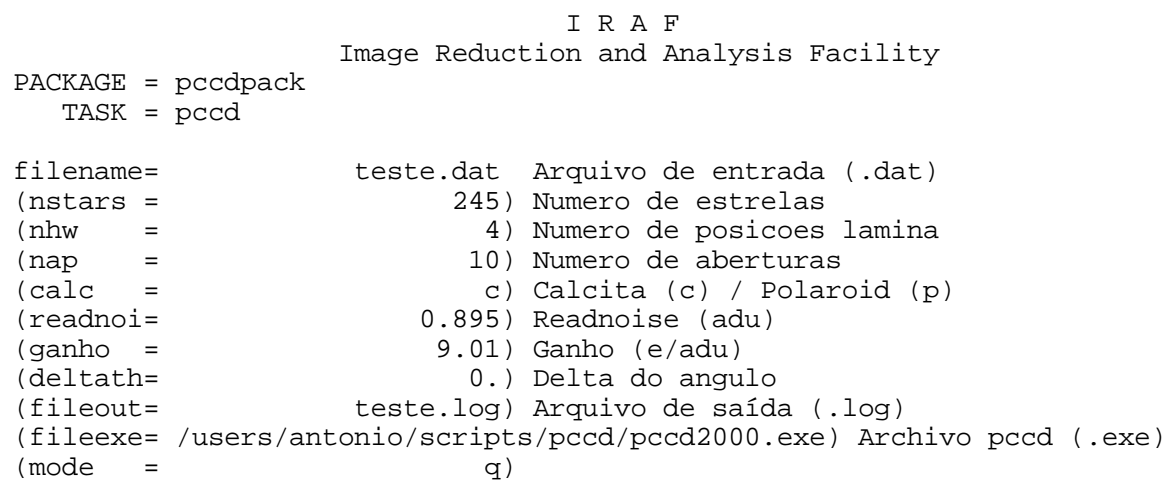

Figura B.3 O arquivo de parâmetros da rotina PCCD, baseada num código para cálculo de parâmetros polarimétricos desenvolvido pelo Dr. Antônio Mário Magalhães.

Finalmente, o parâmetro fileout (por convenção terá extensão 'log') é o nome do arquivo final com os dados polarimétricos e que irá conter os parâmetros de Stokes $(Q$ e $U$ ), o valor de polarização $(P)$, seu erro $\left(\sigma_{P}\right)$, o angulo de polarização $(\theta)$, o erro teórico assumido $\left(\sigma_{P}^{\text {teórico }}\right)$ e a modulação da intensidade $(z=\mathrm{Q} \cos (4 \psi)+U \sin (4 \psi))$ em cada posição da lâmina $(\psi)$ e para cada uma das estrelas analisadas. Um exemplo deste arquivo é dado na Figura B.4.

\section{B.5 Rotina MACROL}

Esta rotina, tendo como entrada o arquivo de saída da rotina PCCD (no nosso exemplo, 'teste.log'), criará um arquivo contendo a informação polarimétrica com a abertura certa para cada uma das estrelas no nosso campo. $\mathrm{O}$ arquivo de parâmetros desta rotina junto com um exemplo de como executá-lo é dado na Figura B.5 onde também é mostrado o acompanhamento do processo na tela. Por definição, o arquivo criado terá extensão 'out' e um exemplo é apresentado na Figura B.6. 


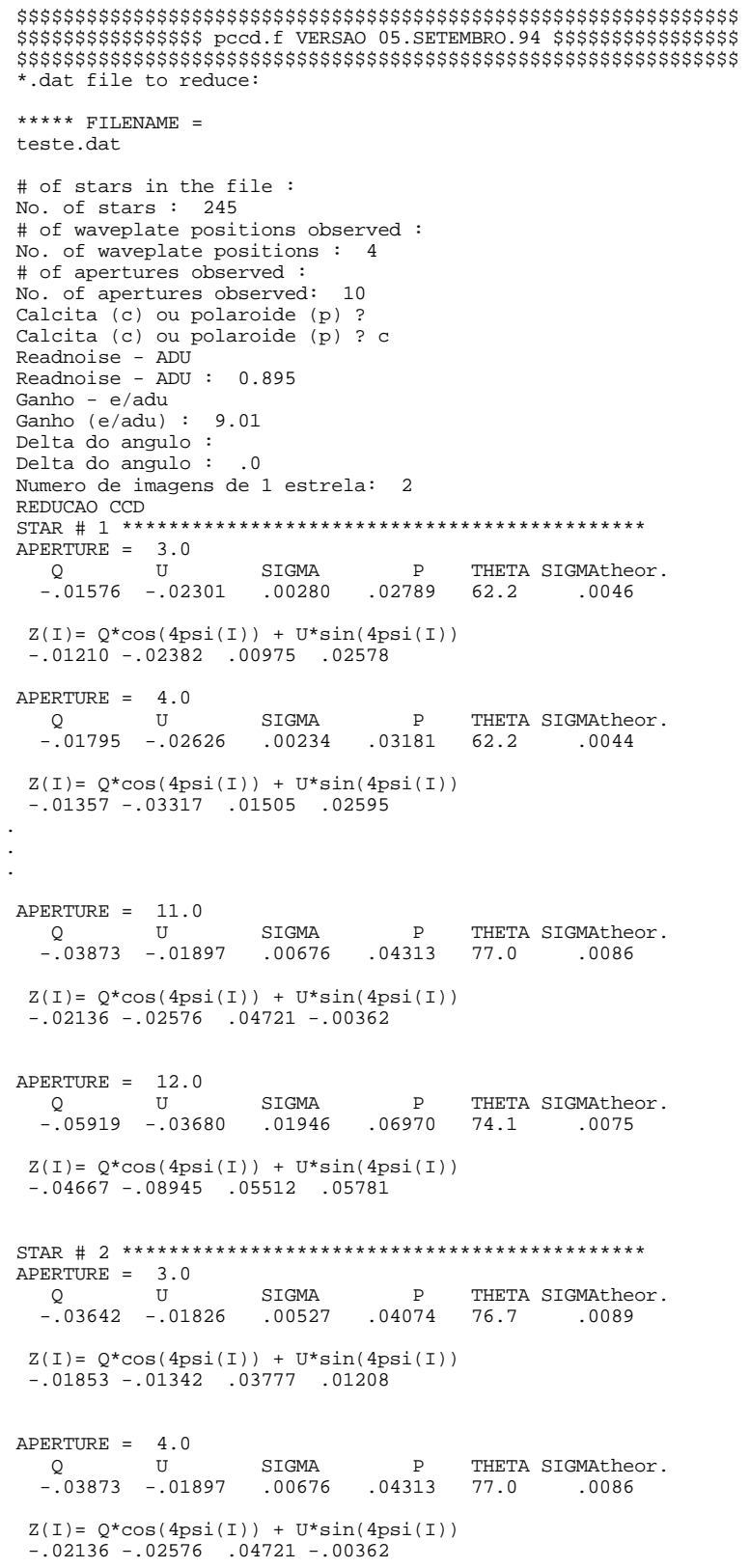

Figura B.4 Exemplo do arquivo de saída da rotina PCCD

I R A F

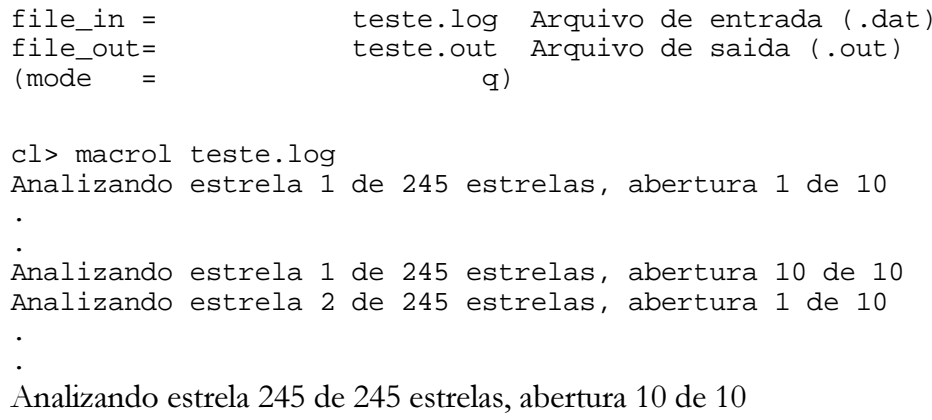

Analizando estrela 245 de 245 estrelas, abertura 10 de 10

Figura B.5 O arquivo de parâmetros da rotina MACROL junto a um exemplo de sua execução com o acompanhamento do processo na tela. 
Apêndice B

$\begin{array}{cccccccc}\mathrm{Q} & \mathrm{U} & \text { SIGMA } & \mathrm{P} & \text { THETA } & \text { SIGMAtheor. } & \text { APERTURE } & \text { STAR } \\ -.02579 & -.02131 & .00142 & .03346 & 70.2 & .0017 & 3 . & 1 \\ -.00735 & -.03124 & .00805 & .03209 & 51.6 & .0095 & 4 . & 2 \\ -.01795 & -.02626 & .00234 & .03181 & 62.2 & .0044 & 4 . & 3 \\ -.03642 & -.01826 & .00527 & .04074 & 76.7 & .0089 & 3 . & 4 \\ -.04005 & -.00376 & .00532 & .04022 & 87.3 & .0086 & 4 . & 5 \\ -.01164 & -.02264 & .00132 & .02546 & 58.6 & .0032 & 3 . & 6 \\ -.01128 & -.02271 & .00113 & .02536 & 58.2 & .0032 & 3 . & 7 \\ -.02242 & -.02674 & .00549 & .03489 & 65.0 & .0057 & 3 . & 8 \\ -.01022 & -.01998 & .00450 & .02244 & 58.5 & .0065 & 6 . & 9 \\ -.03117 & -.00503 & .01069 & .03157 & 85.4 & .0276 & 5 . & 10 \\ -.03107 & -.03220 & .01000 & .04474 & 67.0 & .0159 & 3 . & 11 \\ -.02490 & -.02337 & .00563 & .03415 & 68.4 & .0078 & 4 . & 12 \\ .02099 & -.00297 & .00856 & .02120 & 4.0 & .0224 & 4 . & 13 \\ -.01065 & -.01428 & .01473 & .01781 & 63.4 & .0148 & 3 . & 14\end{array}$

Figura B.6 Exemplo do arquivo de saída da rotina MACROL.

\section{B.6 Rotina SELECT}

O arquivo de parâmetros desta rotina é mostrado na Figura B.7. Depois da análise, a rotina cria um arquivo (file_sel) com os parâmetros polarimétricos da amostra filtrada que por definição terão extensão 'sel'.

I R A F

Image Reduction and Analysis Facility

PACKAGE $=$ pccdpack

TASK $=$ select

file_out $=$

(file_or=

(file_se=

(polmin $=$

(polinf $=$

(polmax $=$

(maiors $=$

(stheoma $=$

(thetain=

(thetasu=

(deltath $=$

(coorq $=$

(cooru $=$

(xpixmax $=$

(ypixmax $=$

(outgrap=

(veccons $=$

(norte $=$

(leste $=$

(binpol =

(thetafi=

(gausspa=

(binthet $=$

(thetami=

(thetama $=$

(stareli=

(meanval=

(flist =

(flist $1=$

(flist $2=$

(flist $3=$

(line $=$

(line1 =

(line3 =

(mode

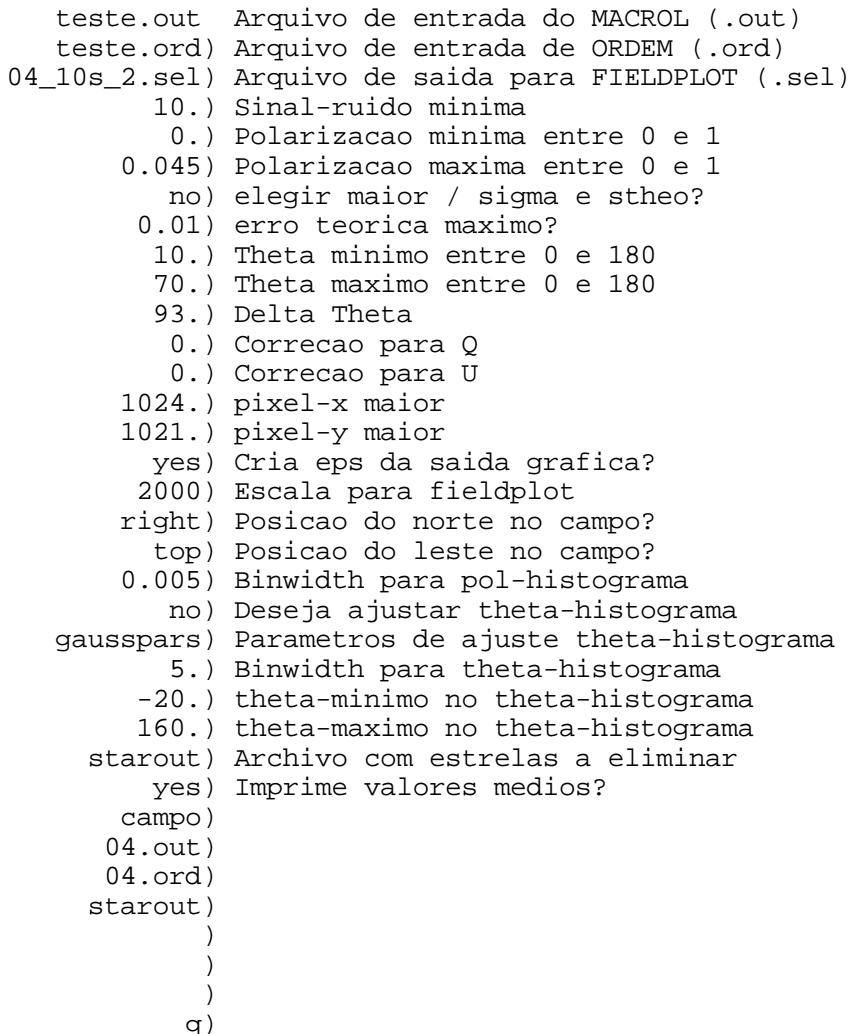

Figura B.7 O arquivo de parâmetros da rotina SELECT. 


\section{B.7 Rotina GRAF}

$\mathrm{Na}$ Figura B.8 mostramos o arquivo de parâmetros desta rotina e um exemplo de sua execução. $\mathrm{O}$ arquivo a analisar é colocado no parâmetro filein e o número da estrela a analisar é dado no parâmetro starin. O tamanho da abertura é inserido no parâmetro aperture. Se foram utilizadas posições não contíguas da lâmina retardadora (por exemplo, se se utilizou uma seqüência de 8 posições da lâmina retardadora distribuídas entre a 1a. à 4a e 9a. à 12a. posições), o parâmetro postype deve estar 'yes'. Finalmente, se se deseja criar um arquivo metacode da saída gráfica o parâmetro metafile deve estar 'yes'.

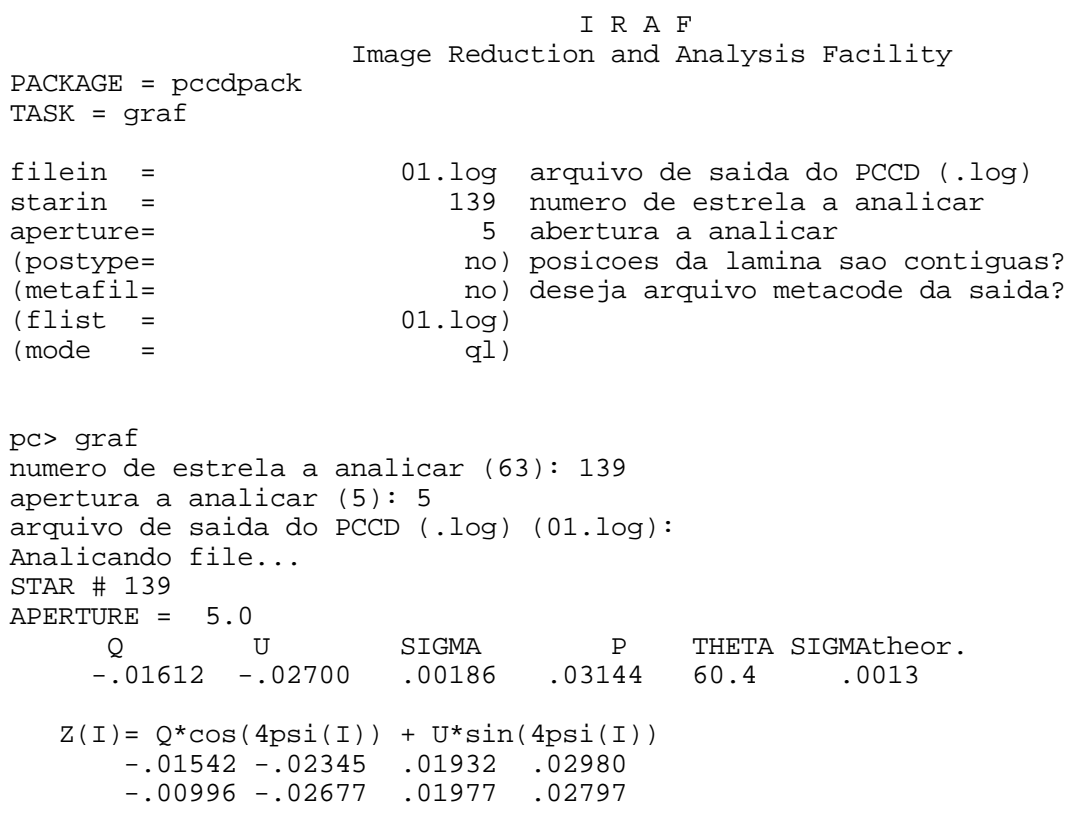

Figura B.8 O arquivo de parâmetros da rotina GRAF e um exemplo de sua execução.

\section{B.8 Rotina MAGNIT}

$\mathrm{O}$ arquivo de parâmetros desta rotina é mostrado na Figura B.9. A rotina utiliza o arquivo de saída da rotina SELECT (file_sel) onde procura as posições de cada um dos objetos no campo dado. O arquivo de saída da rotina PHOT (file_mag) para uma das posições da lâmina também é necessário (usualmente será o da 1a.). Deste arquivo de fotometria são extraídos, para cada um dos objetos da imagem, os seguintes parâmetros (o subíndice $o$ indica o feixe ordinário e $e$ o extraordinário):

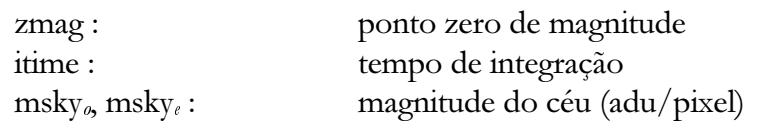




\section{B.9 Rotina REFER}

Basicamente, uma transformação de coordenadas entre a imagem CCD e a imagem DSS é feita com a rotina REFER e seu arquivo de parâmetros é mostrado na Figura B.10. Assim, para cada campo CCD (tipicamente de 8' x 12'), escolhemos no DSS uma imagem de 15' x 15' centrada na mesma posição do campo. Logo, é necessário encontrar as coordenadas (em pixels) de uma estrela de referência presente em ambas imagens, o que pode ser feito facilmente utilizando a rotina DAOEDIT do DAOPHOTX (digitando 'a' com o puntero sobre o objeto). Uma vez que as coordenadas do objeto de referência foram obtidas, devem ser inseridas nos parâmetros xo e yo, para a imagem DSS, e xoi e yoi, para o campo CCD. A lista de objetos a registrar (file_sel) deve ser o arquivo de saída da rotina SELECT.

I R A F

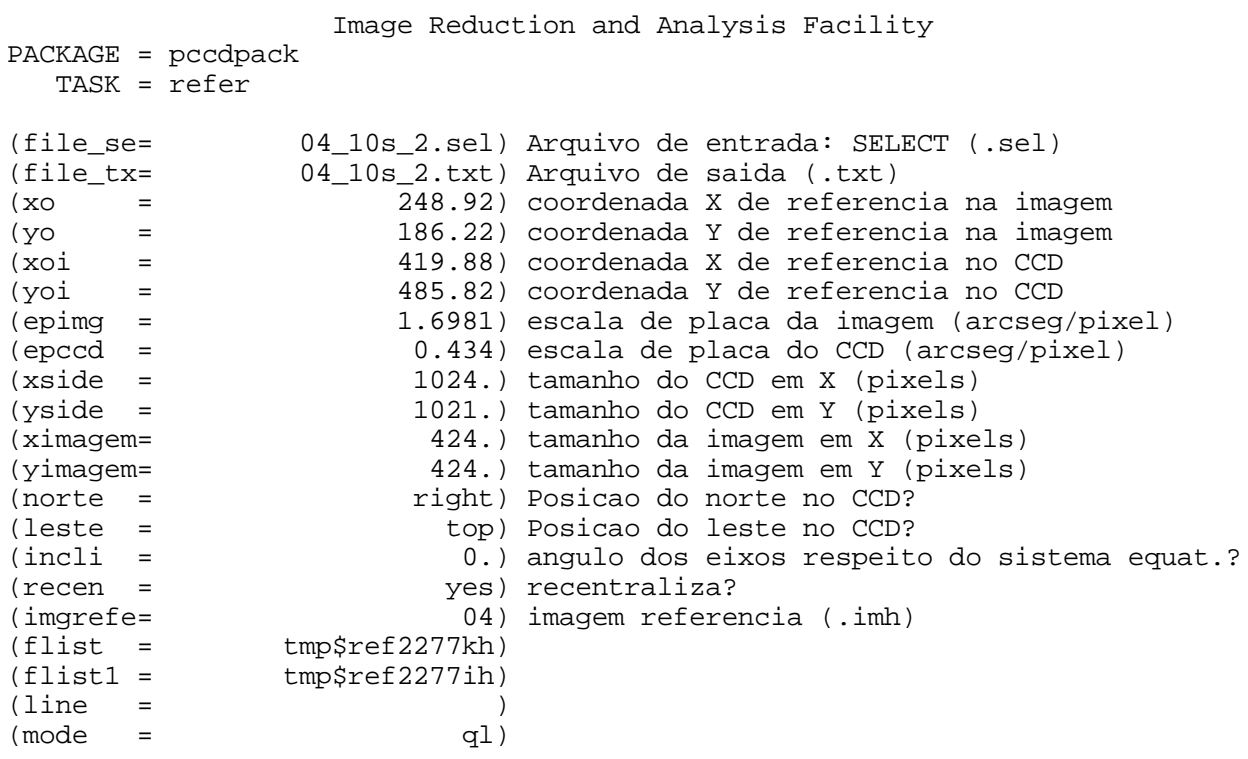

Figura B.10 O arquivo de parâmetros da rotina REFER.

A transformação de coordenadas precisa, entre outros parâmetros, da escala de placa da imagem DSS (epimg) em "/pixel, da escala de placa do campo CCD (epccd) em "/pixel, do tamanho em pixels do campo CCD (xside e yside), e do tamanho em pixels da imagem DSS (ximagem e yimagem). Para uma orientação correta dos vetores de polarização, as posições ('top', 'bottom', 'right' ou 'left') do Norte (norte) e o Leste (leste) no campo CCD (como aparece mostrada no SAOIMAGE ou XIMTOOL) devem ser inseridas. Se a orientação do campo CCD não coincide com o sistema equatorial, o ângulo de inclinação dos eixos pode ser inserido no parâmetro incli. Por outro lado, se a transformação linear apresenta desfasagens nas coordenadas criadas, as posições podem ser melhoradas ativando 
o parâmetro recen. Isto fará que sobre cada posição criada seja executada a rotina CENTER do DAOPHOTX que recalcula o centro via um algoritmo de centróide. Neste caso a imagem DSS de referência também tem que ser inserida (imgrefer). O arquivo de saída file_txt, por definição com extensão 'txt', guardará a informação das novas coordenadas junto com os parâmetros polarimétricos respectivos.

\section{B.10 Rotina VECPLOT}

$\mathrm{O}$ arquivo de parâmetros desta rotina é mostrado na Figura B.11. A rotina precisa do arquivo de saída da rotina REFER (files_txt). Se vários arquivos pretendem ser graficados no mesmo mapa, uma lista os contendo deve ser inserida precedida do prefixo '@’’

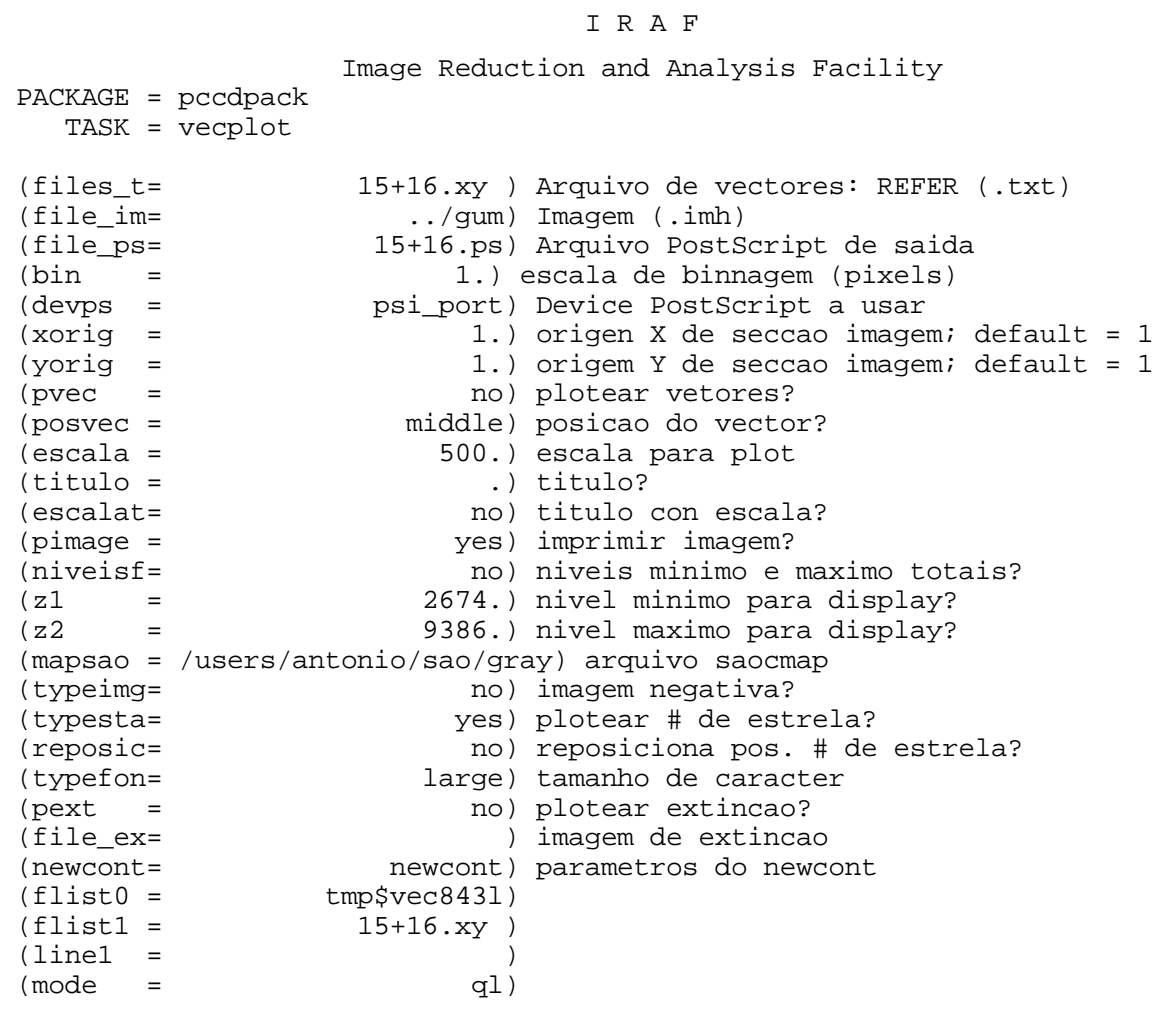

Figura B.11 O arquivo de parâmetros da rotina VECPLOT.

A imagem de referência do DSS é inserida no parâmetro file_img. O mapa final será um arquivo postscript e seu nome é dado pelo parâmetro file_ps. Varias opções podem ser definidas para o gráfico do mapa final. Por exemplo, se somente se deseja mostrar as posições dos objetos mas não graficar os vetores de polarização, o parâmetro pvect deve estar 'no' e o parâmetro typestar, 'yes'. Este é o caso dos findings charts dos catálogos 
polarimétricos mostrados nos Apêndices C e E. O parâmetro pimage deve estar 'yes' se se deseja que a imagem de referência do DSS esteja incluída no mapa final.

\section{B.11 Rotina FINTAB}

O arquivo de parâmetros desta rotina é mostrado na Figura B.12. Em um primeiro passo, a rotina calcula as coordenadas equatoriais para todos os objetos presentes no campo dado. Para isto, precisa-se do arquivo de saída da rotina REFER (file_txt) e da imagem de referência do DSS (file_img). O cálculo de coordenadas é feito automaticamente em cada posição via a rotina RIMCURSOR que utiliza os parâmetros do header da imagem de referência. Depois disto, as coordenadas encontradas são complementadas à informação polarimétrica e (se houver) com os dados de magnitudes obtidos da rotina MAGNIT (file_mg). O nome do catálogo de saída é obtido do parâmetro file_out.

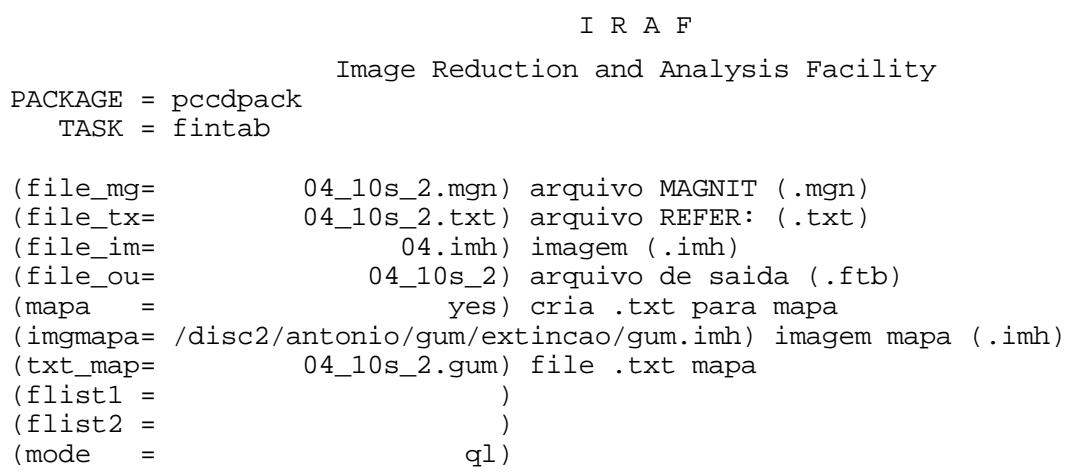

Figura B.12 O arquivo de parâmetros da rotina FINTAB. 



\section{Apêndice C. Catálogo polarimétrico da Nuvem Escura de Musca}

Este apêndice apresenta um catálogo polarimétrico da região da Nuvem Escura de Musca. Está composto de 35 tabelas e igual número de findings charts, um por cada campo em que foi dividida a região (ver Figura 3.3). Todos os objetos deste catálogo apresentam uma sinal-ruído de polarização maior ou igual que 5. O número total de objetos é 2497. Alguns objetos (58 em total) apresentam duas medidas polarimétricas independentes e estão indicados nos pé de pagina respectivos.

Em cada tabela, a primeira coluna é o número de identificação (ID) de cada objeto em cada campo. Este número indica a posição do objeto nos findings charts. A segunda e terceira colunas são as coordenadas equatoriais (1950). O erro estimado na posição é menor que 1 segundo de arco. A quarta e quinta coluna são os valores da polarização observada no filtro $\mathrm{V}\left(P_{\mathrm{V}}\right)$ e seu erro respectivo $\left(\sigma P_{\mathrm{V}}\right)$. O ângulo de polarização $(\theta)$ está na sexta coluna. Finalmente, a sétima e oitava coluna são a magnitude visual $(\mathrm{V})$ e seu erro $\left(\sigma_{\mathrm{V}}\right)$. 
Tabela C.1 Dados polarimétricos do Campo 01

\begin{tabular}{|c|c|c|c|c|c|c|c|}
\hline ID & (AR $(1950.00)$ & "DEC (1950.00) & $P_{\mathrm{V}}$ & $\sigma P_{\mathrm{V}}$ & $\theta$ & V & 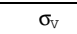 \\
\hline & $(\mathrm{h}: \mathrm{m}: \mathrm{s})$ & $\left({ }^{\circ}::^{\prime}: "\right)$ & $\left(\frac{\circ}{0}\right)$ & $\left(\frac{\circ}{0}\right)$ & $\left({ }^{\circ}\right)$ & & (mag) \\
\hline 14 & $12: 31: 42.16$ & $-70: 38: 41.96$ & 4.723 & 0.829 & 108.1 & 15.5639 & 0.4 \\
\hline 35 & $12: 31: 58.75$ & $-70: 35: 46.86$ & 4.099 & 0.335 & 104.9 & 14.638 & 0.4 \\
\hline 49 & $12: 32: 04.14$ & $-70: 38: 37.51$ & 3.653 & 0.229 & 108.8 & 12.9477 & 0.4 \\
\hline 50 & $12: 32: 04.88$ & $-70: 39: 14.52$ & 3.302 & 0.522 & 95.9 & 15.5324 & 0.4 \\
\hline 51 & $12: 32: 05.59$ & $-70: 34: 47.33$ & 4.349 & 0.749 & 104.6 & 16.1352 & 0.4001 \\
\hline 53 & $12: 32: 06.28$ & $-70: 36: 30.90$ & 3.481 & 0.29 & 106. & 15.1817 & 0.4 \\
\hline 71 & $12: 32: 16.50$ & $-70: 39: 39.29$ & 3.434 & 0.217 & 103.1 & 12.4408 & 0.4 \\
\hline 77 & $12: 32: 18.92$ & $-70: 36: 30.18$ & 3.298 & 0.402 & 101.3 & 15.6368 & 0.4 \\
\hline 91 & $12: 32: 24.28$ & $-70: 39: 22.87$ & 3.893 & 0.374 & 90.3 & 15.8349 & 0.4 \\
\hline 94 & $12: 32: 24.70$ & $-70: 35: 15.09$ & 3.24 & 0.215 & 109.3 & 11.746 & 0.4 \\
\hline 99 & $12: 32: 26.11$ & $-70: 34: 27.05$ & 2.944 & 0.375 & 103.6 & 15.6261 & 0.4 \\
\hline 106 & $12: 32: 29.07$ & $-70: 35: 59.61$ & 3.303 & 0.306 & 103.6 & 14.1079 & 0.4 \\
\hline 112 & $12: 32: 29.86$ & $-70: 36: 07.28$ & 3.265 & 0.421 & 101.7 & 15.6533 & 0.4 \\
\hline 124 & $12: 32: 33.51$ & $-70: 35: 02.50$ & 3.418 & 0.256 & 102. & 14.7992 & 0.4 \\
\hline 139 & $12: 32: 38.99$ & $-70: 35: 44.98$ & 3.144 & 0.186 & 103.2 & 13.2684 & 0.4 \\
\hline 141 & $12: 32: 39.95$ & $-70: 39: 05.57$ & 2.685 & 0.426 & 96.1 & 14.7763 & 0.4 \\
\hline 142 & $12: 32: 39.96$ & $-70: 37: 07.49$ & 2.113 & 0.276 & 101. & 14.7527 & 0.4 \\
\hline 151 & $12: 32: 43.10$ & $-70: 36: 42.48$ & 3.19 & 0.341 & 105.3 & 13.6776 & 0.4 \\
\hline 160 & $12: 32: 44.87$ & $-70: 33: 52.67$ & 3.028 & 0.593 & 109. & 15.6464 & 0.4 \\
\hline 178 & $12: 32: 49.86$ & $-70: 38: 24.19$ & 3.092 & 0.245 & 100.6 & 13.434 & 0.4 \\
\hline 186 & $12: 32: 51.21$ & $-70: 33: 27.93$ & 2.745 & 0.231 & 108.2 & 13.2165 & 0.4 \\
\hline 199 & $12: 32: 57.29$ & $-70: 37: 36.63$ & 2.911 & 0.379 & 108.8 & 15.1245 & 0.4 \\
\hline 201 & $12: 32: 57.37$ & $-70: 34: 54.99$ & 3.119 & 0.394 & 103.8 & 15.4476 & 0.4 \\
\hline 203 & $12: 32: 57.39$ & $-70: 34: 07.84$ & 2.822 & 0.161 & 104.6 & 12.168 & 0.4 \\
\hline 212 & $12: 32: 59.05$ & $-70: 38: 30.41$ & 3.156 & 0.19 & 101.6 & 12.5344 & 0.4 \\
\hline 214 & $12: 32: 59.86$ & $-70: 34: 56.46$ & 2.892 & 0.428 & 109.4 & 15.2375 & 0.4 \\
\hline 216 & $12: 33: 00.76$ & $-70: 37: 12.29$ & 3.101 & 0.209 & 105.1 & 15.6737 & 0.4 \\
\hline 221 & $12: 33: 01.87$ & $-70: 38: 08.42$ & 2.731 & 0.409 & 99.5 & 14.9701 & 0.4 \\
\hline 223 & $12: 33: 02.47$ & $-70: 34: 57.04$ & 2.957 & 0.364 & 101.5 & 14.4989 & 0.4 \\
\hline 228 & $12: 33: 03.77$ & $-70: 35: 28.67$ & 4.256 & 0.653 & 101.5 & 15.5267 & 0.4 \\
\hline 233 & $12: 33: 05.72$ & $-70: 39: 27.11$ & 3.35 & 0.164 & 99.4 & 14.3013 & 0.4 \\
\hline 239 & $12: 33: 06.94$ & $-70: 37: 01.11$ & 2.427 & 0.355 & 106.5 & 14.1608 & 0.4 \\
\hline 251 & $12: 33: 13.34$ & $-70: 38: 57.10$ & 3.505 & 0.417 & 99.6 & 15.191 & 0.4 \\
\hline 257 & $12: 33: 14.67$ & $-70: 39: 07.37$ & 2.957 & 0.16 & 104. & 10.9792 & 0.4 \\
\hline 259 & $12: 33: 14.94$ & $-70: 36: 05.12$ & 3.213 & 0.327 & 99.9 & 14.5627 & 0.4 \\
\hline 262 & $12: 33: 15.82$ & $-70: 35: 34.53$ & 4.108 & 0.382 & 98.9 & 15.473 & 0.4 \\
\hline 269 & $12: 33: 17.04$ & $-70: 33: 38.95$ & 3.082 & 0.239 & 102. & 14.1791 & 0.4 \\
\hline 270 & $12: 33: 17.57$ & $-70: 37: 33.13$ & 3.212 & 0.175 & 100.9 & 12.6921 & 0.4 \\
\hline 287 & $12: 33: 22.94$ & $-70: 34: 41.28$ & 3.915 & 0.443 & 96.5 & 15.8296 & 0.4 \\
\hline 294 & $12: 33: 23.89$ & $-70: 33: 33.55$ & 3.168 & 0.293 & 104.9 & 13.275 & 0.4 \\
\hline 296 & $12: 33: 24.59$ & $-70: 34: 17.69$ & 2.993 & 0.242 & 99.4 & 15.1112 & 0.4 \\
\hline 300 & $12: 33: 26.58$ & $-70: 34: 20.39$ & 3.024 & 0.207 & 99.6 & 12.3614 & 0.4 \\
\hline 311 & $12: 33: 30.09$ & $-70: 36: 22.40$ & 3.458 & 0.332 & 101.2 & 14.6166 & 0.4 \\
\hline
\end{tabular}




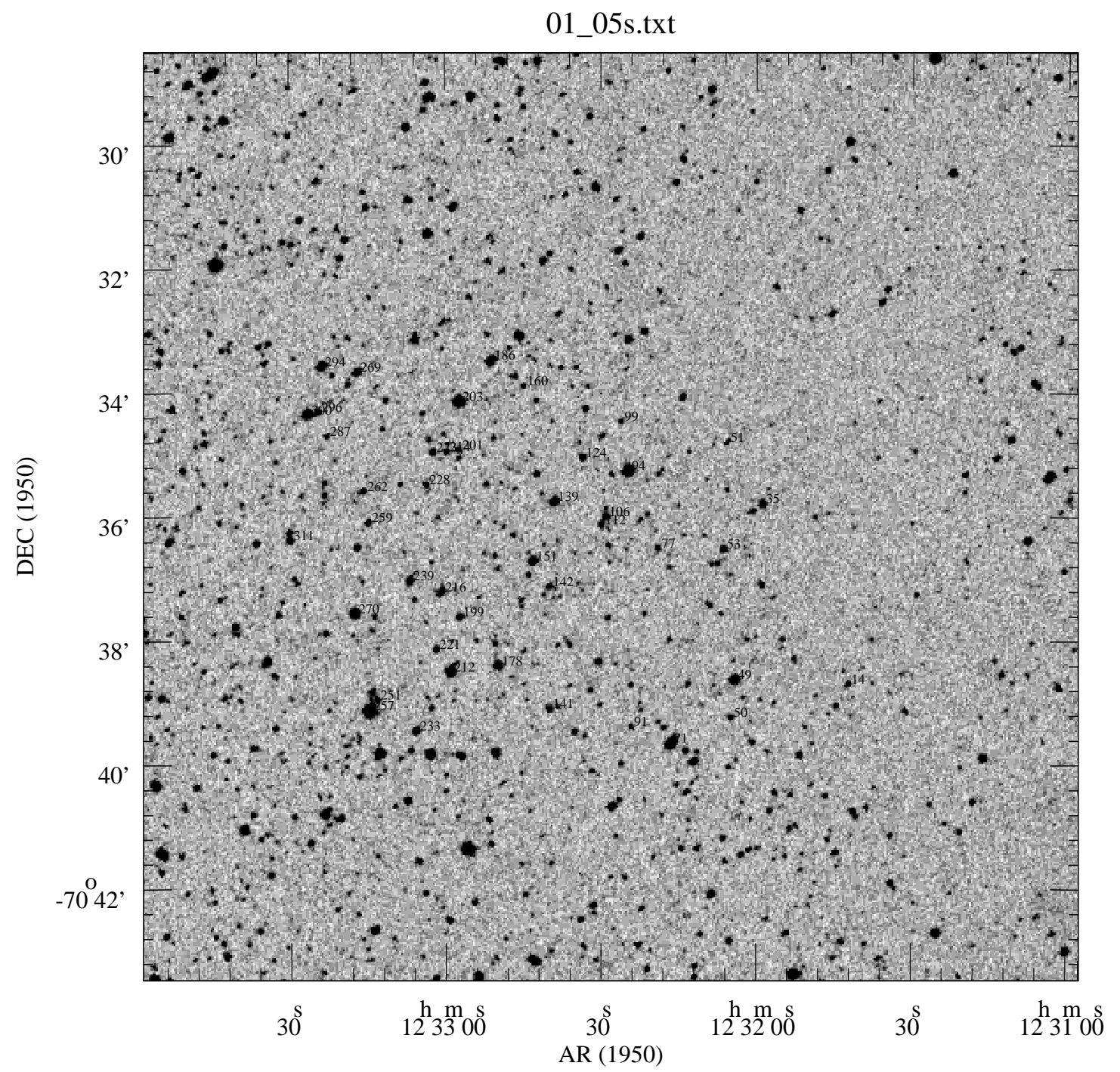

Figura C.1 Finding Chart do Campo 01 centrado em $\mathrm{AR}_{1950}=12^{\mathrm{h}} 32^{\mathrm{m}} 28^{\mathrm{s}}, \mathrm{DEC}_{1950}=-70^{\circ} 36^{\prime}$ 
Tabela C.2 Dados polarimétricos do Campo 02

\begin{tabular}{|c|c|c|c|c|c|c|c|}
\hline ID & $\begin{array}{c}\text { AR }(1950.00) \\
(\mathrm{h}: \mathrm{m}: \mathrm{s})\end{array}$ & $\begin{array}{l}\operatorname{DEC}(1950.00) \\
\left({ }^{\circ}: \mathbf{x}^{\prime}\right)\end{array}$ & $\begin{array}{l}P_{\mathrm{V}} \\
(\%)\end{array}$ & $\begin{array}{l}\sigma P_{\mathrm{V}} \\
(\%)\end{array}$ & $\begin{array}{c}\theta \\
\left({ }^{\circ}\right)\end{array}$ & $\begin{array}{c}\mathrm{V} \\
\text { (mag) }\end{array}$ & $\begin{array}{c}\sigma_{\mathrm{v}} \\
(\mathrm{mag})\end{array}$ \\
\hline 2 & $12: 29: 06.45$ & $-70: 37: 46.42$ & 4.949 & 0.227 & 103.7 & 13.9756 & 0.4 \\
\hline 4 & $12: 29: 11.74$ & $-70: 36: 07.10$ & 2.917 & 0.338 & 109.2 & 15.2158 & 0.4 \\
\hline 7 & $12: 29: 23.01$ & $-70: 33: 34.59$ & 5.221 & 0.491 & 103.4 & 15.1793 & 0.4 \\
\hline 8 & $12: 29: 23.14$ & $-70: 35: 22.63$ & 5.19 & 0.191 & 101.6 & 14.8053 & 0.4 \\
\hline 12 & $12: 29: 34.18$ & $-70: 37: 02.56$ & 5.099 & 0.876 & 99.2 & 15.1994 & 0.4 \\
\hline 13 & $12: 29: 34.90$ & $-70: 36: 09.32$ & 4.353 & 0.444 & 100.9 & 14.7223 & 0.4 \\
\hline 15 & $12: 29: 36.65$ & $-70: 33: 43.30$ & 3.885 & 0.641 & 100.6 & 15.1933 & 0.4 \\
\hline 17 & $12: 29: 39.07$ & $-70: 34: 05.07$ & 4.03 & 0.447 & 104.5 & 14.4924 & 0.4 \\
\hline 18 & $12: 29: 40.04$ & $-70: 33: 33.92$ & 5.407 & 0.375 & 94.7 & 14.79 & 0.4 \\
\hline 19 & $12: 29: 53.16$ & $-70: 33: 55.74$ & 6.836 & 0.953 & 105.6 & 15.4522 & 0.4 \\
\hline 20 & $12: 29: 59.96$ & $-70: 38: 37.69$ & 4.803 & 0.26 & 113.4 & 15.2494 & 0.4 \\
\hline 24 & $12: 30: 08.30$ & $-70: 38: 19.11$ & 4.656 & 0.275 & 105.9 & 15.2502 & 0.4 \\
\hline 25 & $12: 30: 08.95$ & $-70: 36: 10.03$ & 4.517 & 0.855 & 105.2 & 15.7648 & 0.4 \\
\hline 26 & $12: 30: 09.94$ & $-70: 39: 01.95$ & 4.185 & 0.198 & 99.9 & 15.0863 & 0.4 \\
\hline 27 & $12: 30: 13.73$ & $-70: 37: 11.14$ & 4.229 & 0.673 & 104.8 & 15.9398 & 0.4001 \\
\hline 29 & $12: 30: 21.35$ & $-70: 35: 59.70$ & 4.578 & 0.632 & 102.4 & 16.0726 & 0.4001 \\
\hline 30 & $12: 30: 24.45$ & $-70: 35: 39.95$ & 3.866 & 0.217 & 104.8 & 15.2768 & 0.4 \\
\hline 31 & $12: 30: 24.57$ & $-70: 37: 29.49$ & 4.17 & 0.104 & 104.6 & 13.5499 & 0.4 \\
\hline 34 & $12: 30: 28.42$ & $-70: 39: 14.24$ & 4.709 & 0.197 & 107.9 & 13.8301 & 0.4 \\
\hline 35 & $12: 30: 29.41$ & $-70: 36: 43.86$ & 3.365 & 0.317 & 108.4 & 14.0852 & 0.4 \\
\hline 37 & $12: 30: 32.81$ & $-70: 35: 44.84$ & 3.887 & 0.127 & 104.5 & 13.8782 & 0.4 \\
\hline 39 & $12: 30: 33.88$ & $-70: 38: 20.33$ & 4.434 & 0.117 & 105.9 & 13.4919 & 0.4 \\
\hline 41 & $12: 30: 35.50$ & $-70: 39: 26.94$ & 4.905 & 0.611 & 100.1 & 15.7678 & 0.4 \\
\hline 42 & $12: 30: 35.83$ & $-70: 35: 00.43$ & 5.061 & 0.574 & 114.2 & 16.1574 & 0.4001 \\
\hline 43 & $12: 30: 37.54$ & $-70: 38: 28.44$ & 4.173 & 0.387 & 102.4 & 13.6855 & 0.4 \\
\hline 44 & $12: 30: 37.92$ & $-70: 38: 33.97$ & 5.806 & 0.29 & 97.7 & 15.5353 & 0.4 \\
\hline 47 & $12: 30: 39.54$ & $-70: 35: 52.00$ & 4.301 & 0.471 & 101.6 & 15.7644 & 0.4 \\
\hline 50 & $12: 30: 45.27$ & $-70: 39: 15.22$ & 3.566 & 0.601 & 101.2 & 15.3592 & 0.4 \\
\hline 51 & $12: 30: 46.41$ & $-70: 35: 53.43$ & 4.391 & 0.286 & 97.9 & 14.2982 & 0.4 \\
\hline 52 & $12: 30: 48.17$ & $-70: 33: 42.21$ & 4.359 & 0.256 & 102.2 & 14.4397 & 0.4 \\
\hline 53 & $12: 30: 48.70$ & $-70: 38: 27.78$ & 5.061 & 0.318 & 98.5 & 15.8504 & 0.4 \\
\hline 55 & $12: 30: 51.61$ & $-70: 36: 34.99$ & 4.133 & 0.589 & 95.4 & 15.2428 & 0.4 \\
\hline 60 & $12: 30: 56.47$ & $-70: 36: 19.48$ & 4.897 & 0.476 & 93.4 & 15.0915 & 0.4 \\
\hline 61 & $12: 30: 57.66$ & $-70: 33: 56.13$ & 4.71 & 0.665 & 105.3 & 15.5763 & 0.4 \\
\hline 66 & $12: 31: 01.32$ & $-70: 38: 45.95$ & 4.457 & 0.431 & 98.7 & 14.3898 & 0.4 \\
\hline 68 & $12: 31: 01.30$ & $-70: 34: 36.77$ & 4.629 & 0.537 & 94.2 & 14.932 & 0.4 \\
\hline 69 & $12: 31: 03.18$ & $-70: 35: 21.11$ & 4.123 & 0.119 & 95.9 & 12.41 & 0.4 \\
\hline 89 & $12: 30: 31.81$ & $-70: 34: 12.16$ & 4.033 & 0.461 & 92.7 & 15.4022 & 0.4 \\
\hline 95 & $12: 30: 47.82$ & $-70: 35: 57.95$ & 6.436 & 0.777 & 102.9 & 15.9998 & 0.4001 \\
\hline 98 & $12: 31: 07.51$ & $-70: 36: 23.07$ & 4.212 & 0.14 & 94.7 & 13.8776 & 0.4 \\
\hline
\end{tabular}




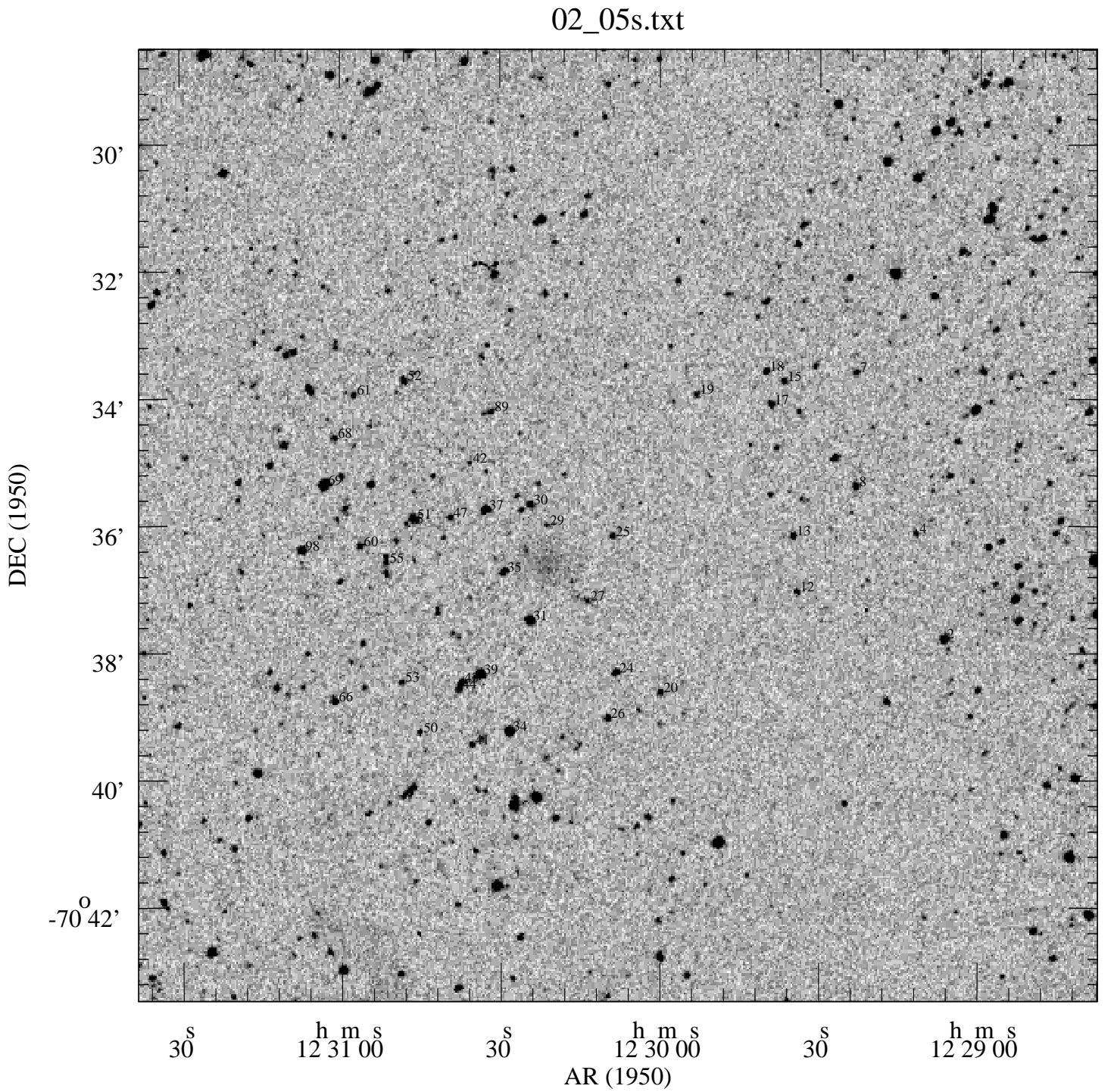

Figura C.2 Finding Chart do Campo 02 centrado em $\mathrm{AR}_{1950}=12^{\mathrm{h}} 30^{\mathrm{m}} 08^{\mathrm{s}}, \mathrm{DEC}_{1950}=-70^{\circ} 36^{\prime}$ 
Tabela C.3 Dados polarimétricos do Campo 03

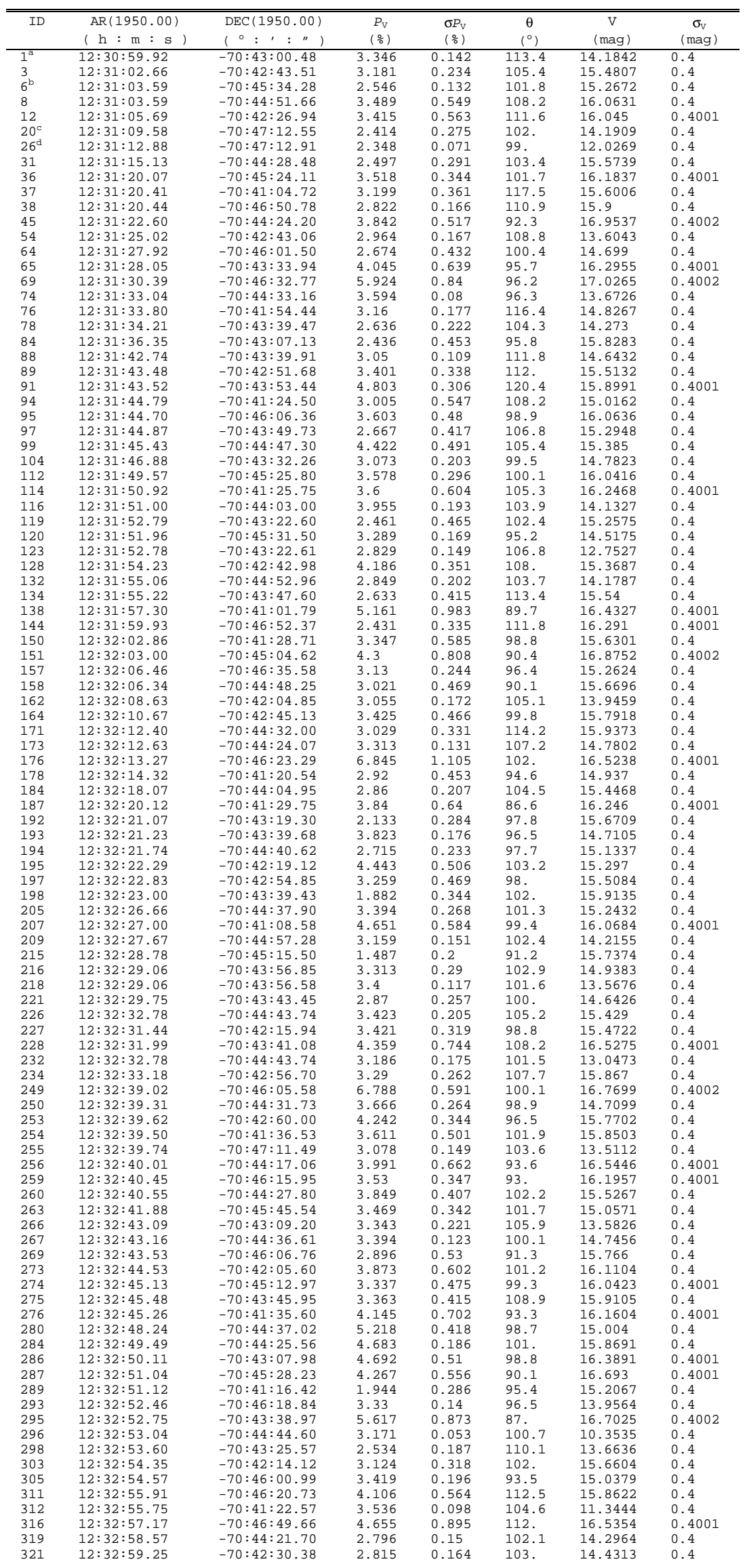


Tabela C.3 - Continuação

\begin{tabular}{|c|c|c|c|c|c|c|c|}
\hline ID & $\begin{array}{l}\operatorname{AR}(1950.00) \\
(\mathrm{h}: \mathrm{m}: \mathrm{s})\end{array}$ & $\begin{array}{l}\operatorname{DEC}(1950.00) \\
\left({ }^{\circ}::^{\prime}: "\right)\end{array}$ & $\begin{array}{l}P_{\mathrm{V}} \\
(\%) \\
\end{array}$ & $\begin{array}{l}\sigma P_{\mathrm{V}} \\
\left(\frac{\circ}{0}\right)\end{array}$ & $\begin{array}{c}\theta \\
\left({ }^{\circ}\right)\end{array}$ & $\begin{array}{c}\mathrm{V} \\
(\mathrm{mag})\end{array}$ & $\begin{array}{c}\sigma_{\mathrm{v}} \\
(\mathrm{mag})\end{array}$ \\
\hline 324 & $12: 33: 00.01$ & $-70: 44: 26.82$ & 2.334 & 0.357 & 100.6 & 15.0018 & 0.4 \\
\hline 325 & $12: 33: 00.08$ & $-70: 44: 13.24$ & 3.921 & 0.227 & 100.9 & 14.5397 & 0.4 \\
\hline 327 & $12: 33: 01.37$ & $-70: 45: 10.42$ & 3.593 & 0.09 & 101.7 & 14.705 & 0.4 \\
\hline 330 & $12: 33: 01.99$ & $-70: 43: 27.20$ & 3.517 & 0.363 & 97.6 & 14.7397 & 0.4 \\
\hline 336 & $12: 33: 03.77$ & $-70: 47: 07.75$ & 3.337 & 0.476 & 103.7 & 15.3722 & 0.4 \\
\hline 338 & $12: 33: 03.95$ & $-70: 42: 05.10$ & 2.603 & 0.238 & 102.4 & 15.4963 & 0.4 \\
\hline
\end{tabular}

a mesmo objeto na Tabela B. 4 com ID $=43$

mesmo objeto na Tabela B.4 com ID $=46$

mesmo objeto na Tabela B. 4 com ID $=53$

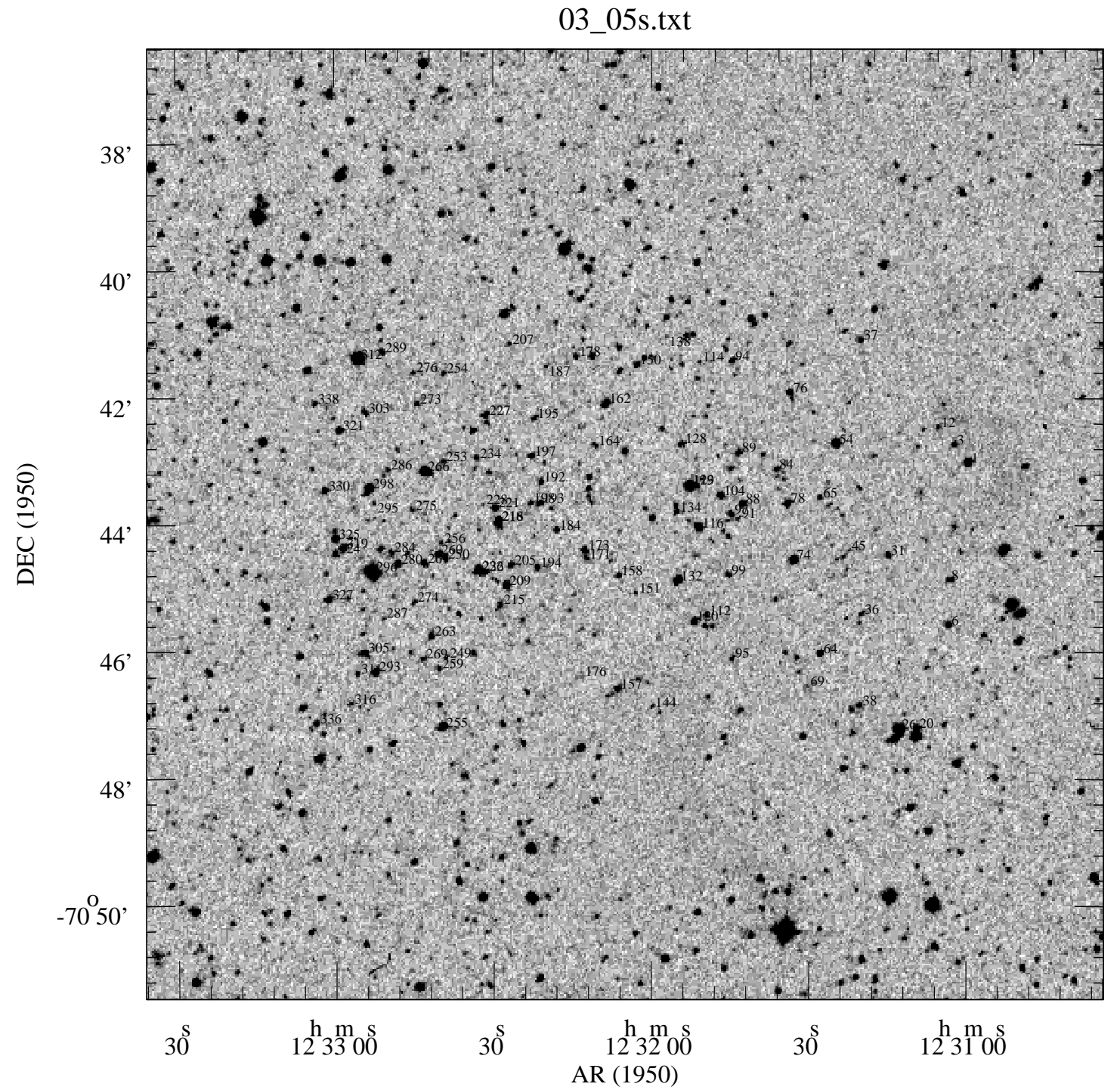

Figura C.3 Finding Chart do Campo 03 centrado em $\mathrm{AR}_{1950}=12^{\mathrm{h}} 32^{\mathrm{m}} 05^{\mathrm{s}}, \mathrm{DEC}_{1950}=-70^{\circ} 44^{\prime}$ 
Apêndice C

Tabela C.4 Dados polarimétricos do Campo 04

\begin{tabular}{|c|c|c|c|c|c|c|c|}
\hline ID & $\begin{array}{c}\operatorname{AR}(1950.00) \\
(\mathrm{h}: \mathrm{m}: \mathrm{s})\end{array}$ & $\begin{array}{l}\operatorname{DEC}(1950.00) \\
\left(0^{\circ}::^{\prime \prime}\right)\end{array}$ & $\begin{array}{l}P_{\mathrm{V}} \\
(\%)\end{array}$ & $\begin{array}{l}\sigma P_{\mathrm{v}} \\
(\%)\end{array}$ & $\begin{array}{c}\theta \\
\left({ }^{\circ}\right)\end{array}$ & $\begin{array}{c}\mathrm{V} \\
(\mathrm{mag})\end{array}$ & $\underset{(\mathrm{mag})}{\sigma_{\mathrm{v}}}$ \\
\hline 2 & $12: 29: 27.08$ & $-70: 46: 00.10$ & 3.983 & 0.081 & 100.4 & 12.6788 & 0.4 \\
\hline 3 & $12: 29: 30.41$ & $-70: 44: 55.52$ & 6.191 & 0.593 & 106.9 & 16.0186 & 0.4001 \\
\hline 7 & $12: 29: 43.38$ & $-70: 46: 59.35$ & 4.368 & 0.323 & 104.1 & 14.5263 & 0.4 \\
\hline 9 & $12: 29: 55.06$ & $-70: 43: 04.27$ & 4.006 & 0.655 & 103.1 & 15.5492 & 0.4001 \\
\hline 11 & $12: 30: 00.23$ & $-70: 42: 48.27$ & 4.271 & 0.173 & 103.8 & 13.6961 & 0.4 \\
\hline 12 & $12: 30: 01.54$ & $-70: 45: 13.63$ & 3.826 & 0.563 & 107. & 15.5849 & 0.4001 \\
\hline 13 & $12: 30: 07.41$ & $-70: 43: 54.88$ & 3.07 & 0.122 & 96.6 & 14.1159 & 0.4 \\
\hline 15 & $12: 30: 12.19$ & $-70: 46: 58.68$ & 3.607 & 0.495 & 109.1 & 15.8167 & 0.4001 \\
\hline 20 & $12: 30: 26.39$ & $-70: 42: 29.12$ & 4.492 & 0.849 & 95.9 & 15.9289 & 0.4001 \\
\hline 24 & $12: 30: 30.73$ & $-70: 41: 39.93$ & 3.989 & 0.152 & 104.2 & 13.202 & 0.4 \\
\hline 26 & $12: 30: 34.55$ & $-70: 44: 10.77$ & 2.525 & 0.268 & 102.3 & 12.9848 & 0.4 \\
\hline 28 & $12: 30: 38.29$ & $-70: 43: 16.78$ & 3.255 & 0.365 & 104.8 & 14.4527 & 0.4 \\
\hline 29 & $12: 30: 39.80$ & $-70: 44: 25.63$ & 3.362 & 0.494 & 98.4 & 14.6506 & 0.4 \\
\hline 33 & $12: 30: 46.47$ & $-70: 44: 28.11$ & 2.979 & 0.492 & 110.4 & 15.4515 & 0.4001 \\
\hline 35 & $12: 30: 49.47$ & $-70: 45: 23.39$ & 2.744 & 0.219 & 108.2 & 13.0272 & 0.4 \\
\hline 37 & $12: 30: 51.50$ & $-70: 45: 14.28$ & 2.737 & 0.052 & 110.4 & 11.901 & 0.4 \\
\hline 38 & $12: 30: 53.11$ & $-70: 44: 23.22$ & 3.088 & 0.209 & 105.4 & 13.215 & 0.4 \\
\hline 40 & $12: 30: 56.75$ & $-70: 45: 44.73$ & 2.861 & 0.56 & 115.6 & 15.5246 & 0.4001 \\
\hline $43^{\mathrm{a}}$ & $12: 30: 59.69$ & $-70: 42: 59.89$ & 3.232 & 0.242 & 114.5 & 14.5583 & 0.4 \\
\hline $46^{\mathrm{b}}$ & $12: 31: 03.48$ & $-70: 45: 34.42$ & 3.595 & 0.339 & 103.7 & 15.4609 & 0.4001 \\
\hline 48 & $12: 31: 04.18$ & $-70: 47: 08.30$ & 4.297 & 0.726 & 105.4 & 14.7638 & 0.4 \\
\hline $53^{\mathrm{c}}$ & $12: 31: 09.36$ & $-70: 47: 12.39$ & 3.156 & 0.189 & 106.2 & 13.7402 & 0.4 \\
\hline 55 & $12: 31: 09.71$ & $-70: 47: 20.26$ & 2.601 & 0.158 & 104.8 & 12.6234 & 0.4 \\
\hline $56^{d}$ & $12: 31: 12.86$ & $-70: 47: 12.63$ & 2.403 & 0.1 & 103. & 12.0881 & 0.4 \\
\hline 58 & $12: 29: 09.78$ & $-70: 47: 17.26$ & 5.058 & 0.484 & 105.8 & 14.5368 & 0.4 \\
\hline 62 & $12: 29: 53.50$ & $-70: 45: 54.08$ & 4.773 & 0.481 & 104.8 & 15.1585 & 0.4 \\
\hline 65 & $12: 30: 02.83$ & $-70: 47: 11.58$ & 3.885 & 0.561 & 109.1 & 16.1863 & 0.4002 \\
\hline 66 & $12: 30: 38.28$ & $-70: 41: 57.51$ & 3.626 & 0.685 & 107.8 & 15.59 & 0.4001 \\
\hline
\end{tabular}

a mesmo objeto na Tabela B.3 com ID $=1$

mesmo objeto na Tabela B.3 com ID $=6$

${ }^{d}$ mesmo objeto na Tabela B. $3 \mathrm{com}$ ID $=26$

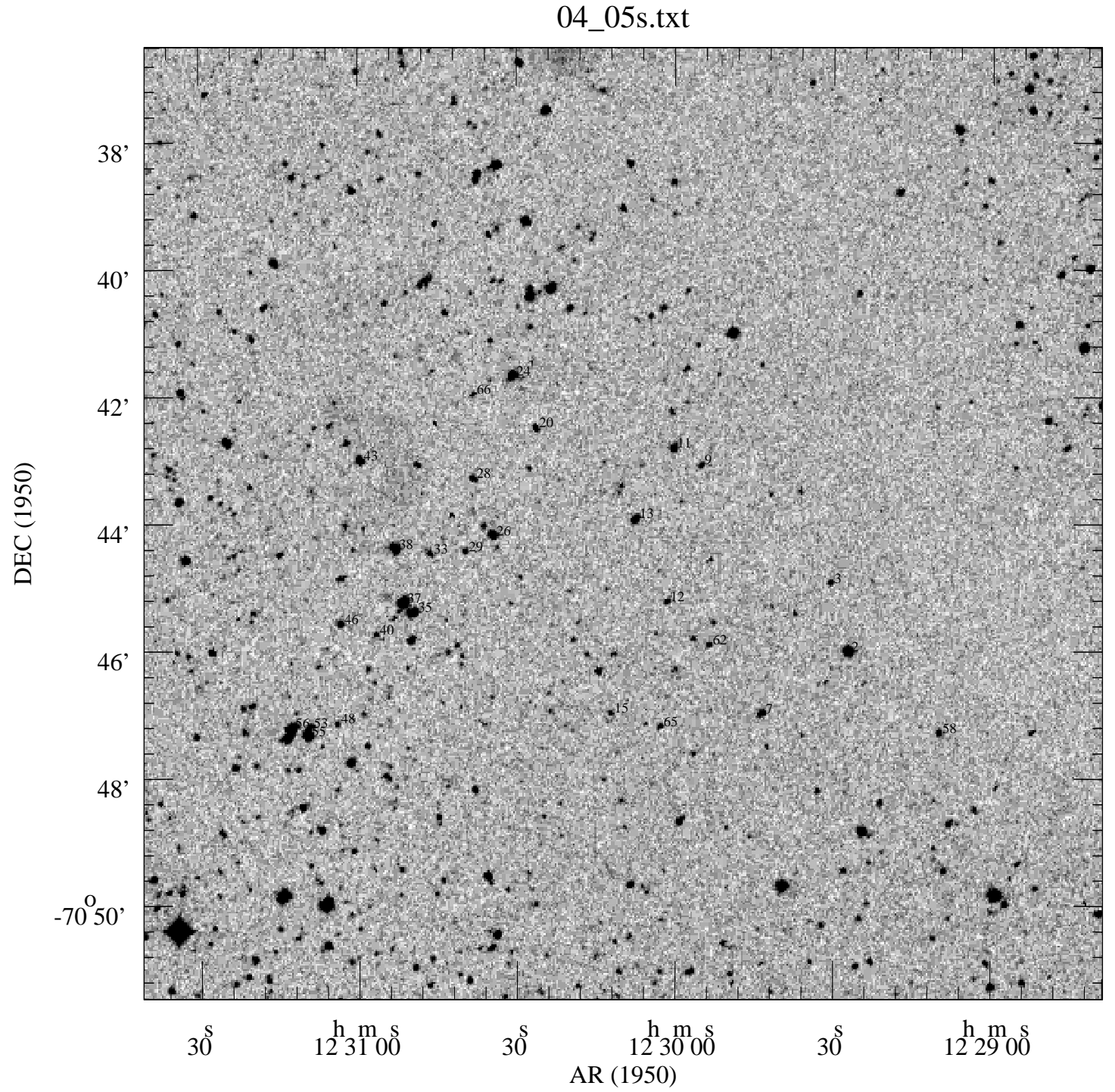

Figura C.4 Finding Chart do Campo 04 centrado em $\mathrm{AR}_{1950}=12^{\mathrm{h}} 30^{\mathrm{m}} 09.9^{\mathrm{s}}, \mathrm{DEC}_{1950}=-70^{\circ} 44^{\prime}$ 
Tabela C.5 Dados polarimétricos do Campo 05

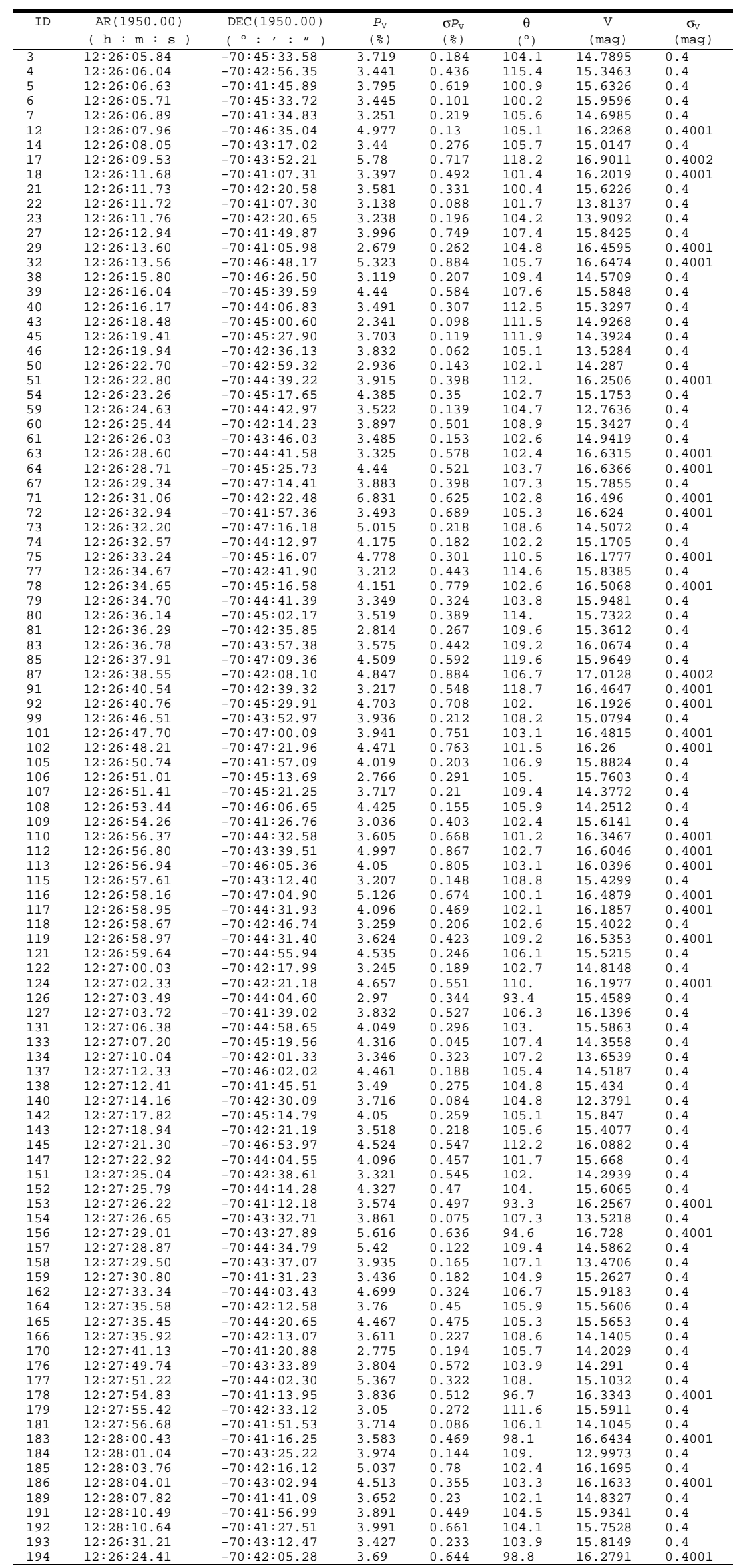




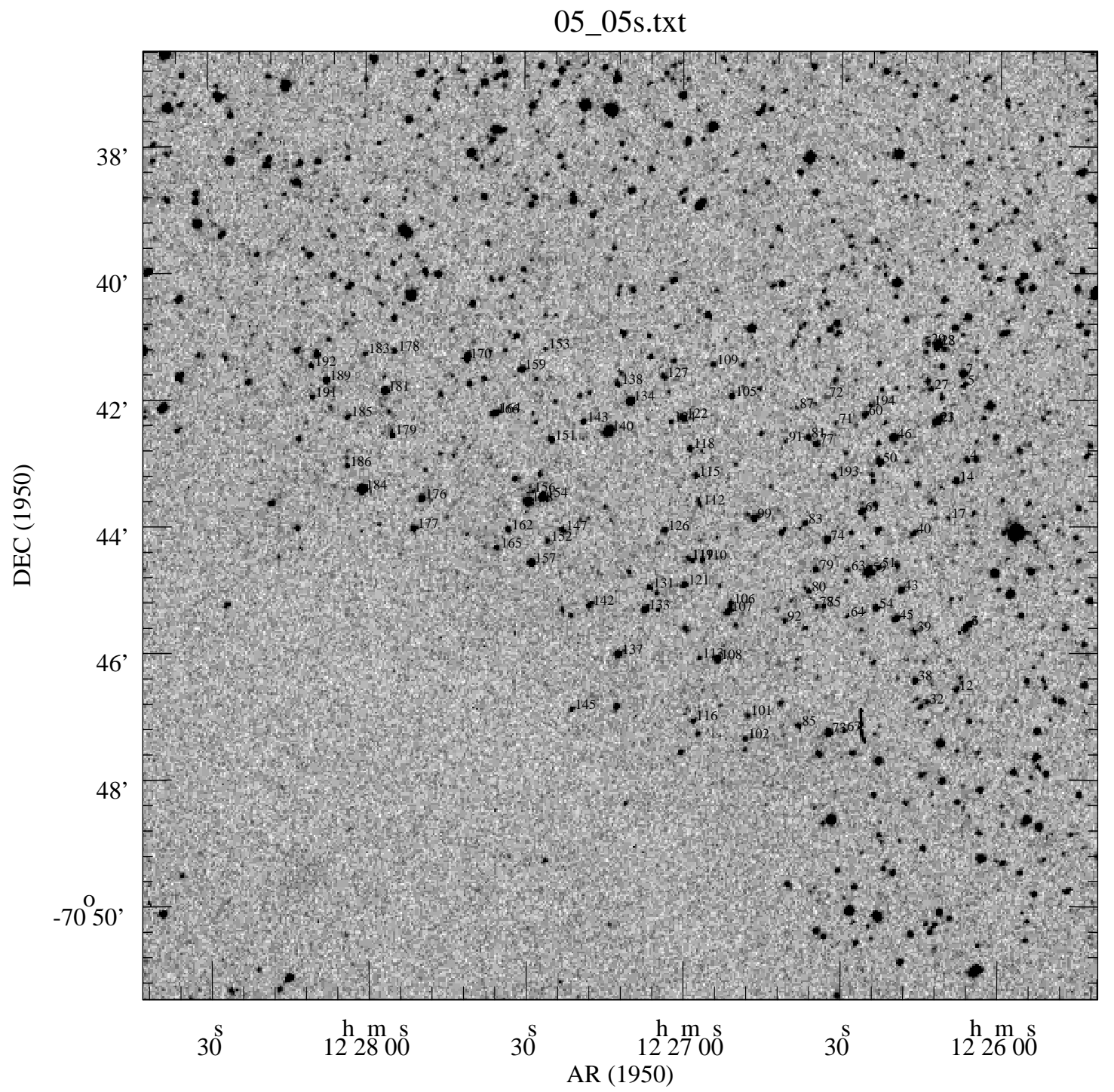

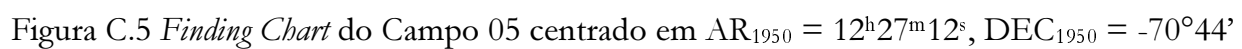


Tabela C.6 Dados polarimétricos do Campo 06

\begin{tabular}{|c|c|c|c|c|c|c|c|}
\hline ID & $\operatorname{AR}(1950.00)$ & $\operatorname{DEC}(1950.00)$ & $P_{\mathrm{V}}$ & $\sigma P_{\mathrm{V}}$ & $\theta$ & $\mathrm{V}$ & $\sigma_{\mathrm{v}}$ \\
\hline & $(\mathrm{h}: \mathrm{m}: \mathrm{s})$ & $\left({ }^{\circ}::^{\prime}: "{ }^{\prime \prime}\right)$ & $\left(\frac{\circ}{0}\right)$ & $\left(\frac{\circ}{6}\right)$ & $\left({ }^{\circ}\right)$ & (mag) & (mag) \\
\hline 2 & $12: 29: 20.63$ & $-70: 54: 33.61$ & 2.784 & 0.356 & 99.2 & 14.6659 & 0.4 \\
\hline 6 & $12: 29: 22.93$ & $-70: 50: 53.84$ & 4.115 & 0.567 & 99.3 & 15.3724 & 0.4 \\
\hline 7 & $12: 29: 23.71$ & $-70: 55: 24.60$ & 3.016 & 0.247 & 103.8 & 14.4162 & 0.4 \\
\hline 8 & $12: 29: 24.90$ & $-70: 50: 12.45$ & 5.675 & 0.948 & 110.3 & 15.6337 & 0.4 \\
\hline 10 & $12: 29: 25.39$ & $-70: 52: 17.86$ & 3.139 & 0.342 & 104 & 13.9044 & 0.4 \\
\hline 11 & $12: 29: 25.70$ & $-70: 50: 56.90$ & 6.364 & 0.656 & 95.3 & 15.5452 & 0.4 \\
\hline 13 & $12: 29: 25.82$ & $-70: 55: 03.05$ & 2.555 & 0.257 & 115.9 & 15.557 & 0.4 \\
\hline 15 & $12: 29: 27.70$ & $-70: 52: 36.90$ & 3.117 & 0.585 & 106 & 14.7855 & 0.4 \\
\hline 16 & $12: 29: 27.86$ & $-70: 53: 22.58$ & 5.691 & 1.121 & 102.9 & 16.3467 & 0.4001 \\
\hline 19 & $12: 29: 30.76$ & $-70: 53: 48.73$ & 3.842 & 0.681 & 105.1 & 15.2322 & 0.4 \\
\hline 22 & $12: 29: 32.30$ & $-70: 50: 19.29$ & 5.424 & 0.845 & 116.2 & 16.0754 & 0.4001 \\
\hline 25 & $12: 29: 39.22$ & $-70: 54: 02.31$ & 3.037 & 0.225 & 111.8 & 14.5575 & 0.4 \\
\hline 26 & $12: 29: 39.55$ & $-70: 54: 56.96$ & 3.043 & 0.398 & 105.1 & 14.5734 & 0.4 \\
\hline 27 & $12: 29: 39.59$ & $-70: 49: 42.23$ & 3.944 & 0.085 & 106.8 & 12.5323 & 0.4 \\
\hline 28 & $12: 29: 40.50$ & $-70: 54: 02.28$ & 3.488 & 0.114 & 103.3 & 14.2459 & 0.4 \\
\hline 35 & $12: 29: 49.60$ & $-70: 51: 06.71$ & 4.183 & 0.377 & 112.6 & 15.9869 & 0.4001 \\
\hline 36 & $12: 29: 49.80$ & $-70: 51: 49.81$ & 3.798 & 0.435 & 90.4 & 15.2183 & 0.4 \\
\hline 43 & $12: 29: 55.49$ & $-70: 54: 33.92$ & 3.206 & 0.277 & 102.3 & 14.8378 & 0.4 \\
\hline 46 & $12: 29: 57.48$ & $-70: 53: 47.06$ & 2.208 & 0.307 & 100.9 & 14.6464 & 0.4 \\
\hline 47 & $12: 29: 59.00$ & $-70: 55: 06.98$ & 2.876 & 0.546 & 116.7 & 15.7257 & 0.4 \\
\hline 48 & $12: 30: 00.50$ & $-70: 55: 33.29$ & 2.336 & 0.241 & 109.9 & 15.1657 & 0.4 \\
\hline 51 & $12: 30: 02.93$ & $-70: 54: 39.16$ & 2.298 & 0.116 & 96.1 & 14.0929 & 0.4 \\
\hline 55 & $12: 30: 03.95$ & $-70: 51: 15.47$ & 5.525 & 1.044 & 88.9 & 16.46 & 0.4002 \\
\hline 56 & $12: 30: 04.83$ & $-70: 55: 02.15$ & 2.345 & 0.154 & 105.2 & 12.8454 & 0.4 \\
\hline 57 & $12: 30: 05.78$ & $-70: 51: 58.60$ & 3.703 & 0.399 & 109 & 15.1149 & 0.4 \\
\hline 66 & $12: 30: 08.64$ & $-70: 50: 29.77$ & 4.209 & 0.78 & 110.6 & 15.3786 & 0.4 \\
\hline 67 & $12: 30: 09.40$ & $-70: 54: 45.59$ & 2.961 & 0.52 & 119.3 & 15.6392 & 0.4 \\
\hline 70 & $12: 30: 10.15$ & $-70: 52: 12.37$ & 4.354 & 0.771 & 101.1 & 15.7376 & 0.4 \\
\hline 76 & $12: 30: 12.64$ & $-70: 54: 43.00$ & 3.237 & 0.536 & 94.3 & 15.6505 & 0.4 \\
\hline 81 & $12: 30: 17.03$ & $-70: 52: 43.02$ & 5.964 & 0.573 & 95.4 & 16.3356 & 0.4001 \\
\hline 82 & $12: 30: 18.31$ & $-70: 55: 38.05$ & 2.357 & 0.127 & 106.1 & 12.2915 & 0.4 \\
\hline 83 & $12: 30: 18.45$ & $-70: 51: 17.76$ & 5.648 & 1.099 & 107.1 & 15.7356 & 0.4 \\
\hline 86 & $12: 30: 23.24$ & $-70: 51: 54.69$ & 6.147 & 1.139 & 104.5 & 15.7879 & 0.4001 \\
\hline 98 & $12: 30: 29.25$ & $-70: 54: 10.06$ & 2.156 & 0.19 & 108.5 & 13.6965 & 0.4 \\
\hline 105 & $12: 30: 33.55$ & $-70: 52: 42.48$ & 2.518 & 0.087 & 108.9 & 12.3864 & 0.4 \\
\hline 106 & $12: 30: 33.72$ & $-70: 55: 15.13$ & 2.107 & 0.386 & 104.8 & 14.336 & 0.4 \\
\hline 107 & $12: 30: 33.70$ & $-70: 50: 28.45$ & 2.786 & 0.347 & 110.6 & 14.2471 & 0.4 \\
\hline 109 & $12: 30: 34.71$ & $-70: 50: 39.99$ & 3.308 & 0.534 & 102.2 & 14.8791 & 0.4 \\
\hline 110 & $12: 30: 35.34$ & $-70: 53: 30.45$ & 2.453 & 0.415 & 88.8 & 15.1615 & 0.4 \\
\hline 111 & $12: 30: 35.69$ & $-70: 54: 40.37$ & 3.15 & 0.623 & 108.4 & 15.4827 & 0.4 \\
\hline 112 & $12: 30: 35.43$ & $-70: 49: 33.78$ & 3.274 & 0.075 & 105. & 13.9761 & 0.4 \\
\hline 118 & $12: 30: 39.18$ & $-70: 51: 11.02$ & 3.752 & 0.342 & 108. & 15.0414 & 0.4 \\
\hline 127 & $12: 30: 46.35$ & $-70: 51: 15.52$ & 3.337 & 0.502 & 104.7 & 15.525 & 0.4 \\
\hline 129 & $12: 30: 48.26$ & $-70: 52: 39.42$ & 3.81 & 0.578 & 86.9 & 16.4497 & 0.4001 \\
\hline 130 & $12: 30: 48.91$ & $-70: 55: 12.81$ & 4.011 & 0.663 & 105.6 & 15.6799 & 0.4 \\
\hline 131 & $12: 30: 49.08$ & $-70: 50: 59.08$ & 3.252 & 0.543 & 96.7 & 15.3117 & 0.4 \\
\hline 133 & $12: 30: 50.58$ & $-70: 52: 37.08$ & 2.521 & 0.158 & 104.5 & 15.1809 & 0.4 \\
\hline 139 & $12: 30: 54.53$ & $-70: 52: 12.58$ & 5.366 & 0.756 & 108.3 & 16.0296 & 0.4001 \\
\hline 140 & $12: 30: 55.26$ & $-70: 55: 19.52$ & 2.727 & 0.323 & 96.2 & 14.5611 & 0.4 \\
\hline 147 & $12: 30: 58.94$ & $-70: 54: 51.95$ & 3.581 & 0.503 & 116.6 & 15.4531 & 0.4 \\
\hline 154 & $12: 31: 01.78$ & $-70: 53: 54.66$ & 2.985 & 0.39 & 101 & 15.2845 & 0.4 \\
\hline 155 & $12: 31: 03.44$ & $-70: 53: 40.01$ & 3.869 & 0.53 & 106.9 & 15.0972 & 0.4 \\
\hline 157 & $12: 31: 03.61$ & $-70: 54: 13.84$ & 3.375 & 0.236 & 103.1 & 14.289 & 0.4 \\
\hline 159 & $12: 31: 03.44$ & $-70: 53: 40.01$ & 4.503 & 0.874 & 101. & 16.2842 & 0.4001 \\
\hline 161 & $12: 31: 06.02$ & $-70: 50: 39.69$ & 2.654 & 0.352 & 109. & 14.4628 & 0.4 \\
\hline 162 & $12: 31: 06.19$ & $-70: 49: 59.47$ & 2.464 & 0.081 & 104.2 & 11.1838 & 0.4 \\
\hline 163 & $12: 31: 06.95$ & $-70: 54: 10.24$ & 3.711 & 0.232 & 103.6 & 14.7634 & 0.4 \\
\hline 165 & $12: 31: 08.07$ & $-70: 51: 51.30$ & 2.505 & 0.178 & 104 & 13.1097 & 0.4 \\
\hline 166 & $12: 31: 09.40$ & $-70: 55: 29.94$ & 3.151 & 0.462 & 110.1 & 15.4771 & 0.4 \\
\hline 169 & $12: 31: 10.72$ & $-70: 51: 36.12$ & 3.719 & 0.655 & 100.9 & 15.4623 & 0.4 \\
\hline 172 & $12: 31: 14.24$ & $-70: 52: 37.28$ & 3.478 & 0.27 & 95.3 & 15.2828 & 0.4 \\
\hline 173 & $12: 31: 14.40$ & $-70: 49: 51.80$ & 2.647 & 0.082 & 100.2 & 11.2408 & 0.4 \\
\hline 175 & $12: 31: 15.22$ & $-70: 51: 39.11$ & 3.114 & 0.355 & 105.5 & 14.9265 & 0.4 \\
\hline 177 & $12: 31: 15.80$ & $-70: 53: 51.94$ & 3.844 & 0.141 & 101 & 13.334 & 0.4 \\
\hline 180 & $12: 31: 17.02$ & $-70: 53: 20.74$ & 3.265 & 0.557 & 88.2 & 15.298 & 0.4 \\
\hline 187 & $12: 31: 18.82$ & $-70: 53: 42.94$ & 3.837 & 0.381 & 106.2 & 15.089 & 0.4 \\
\hline 188 & $12: 31: 20.18$ & $-70: 54: 07.25$ & 4.6 & 0.862 & 114.2 & 15.7767 & 0.4001 \\
\hline 192 & $12: 31: 21.06$ & $-70: 51: 08.39$ & 2.715 & 0.416 & 105.2 & 15.0008 & 0.4 \\
\hline 196 & $12: 31: 21.42$ & $-70: 52: 43.07$ & 3.902 & 0.461 & 99.2 & 15.4423 & 0.4 \\
\hline 197 & $12: 31: 21.78$ & $-70: 53: 21.61$ & 3.866 & 0.154 & 104.8 & 14.5019 & 0.4 \\
\hline 198 & $12: 31: 22.20$ & $-70: 54: 35.82$ & 2.688 & 0.457 & 108.2 & 15.2047 & 0.4 \\
\hline 201 & $12: 31: 23.52$ & $-70: 51: 58.49$ & 2.651 & 0.491 & 90.3 & 14.8922 & 0.4 \\
\hline 205 & $12: 31: 24.70$ & $-70: 55: 03.18$ & 3.146 & 0.445 & 102.8 & 15.3194 & 0.4 \\
\hline
\end{tabular}




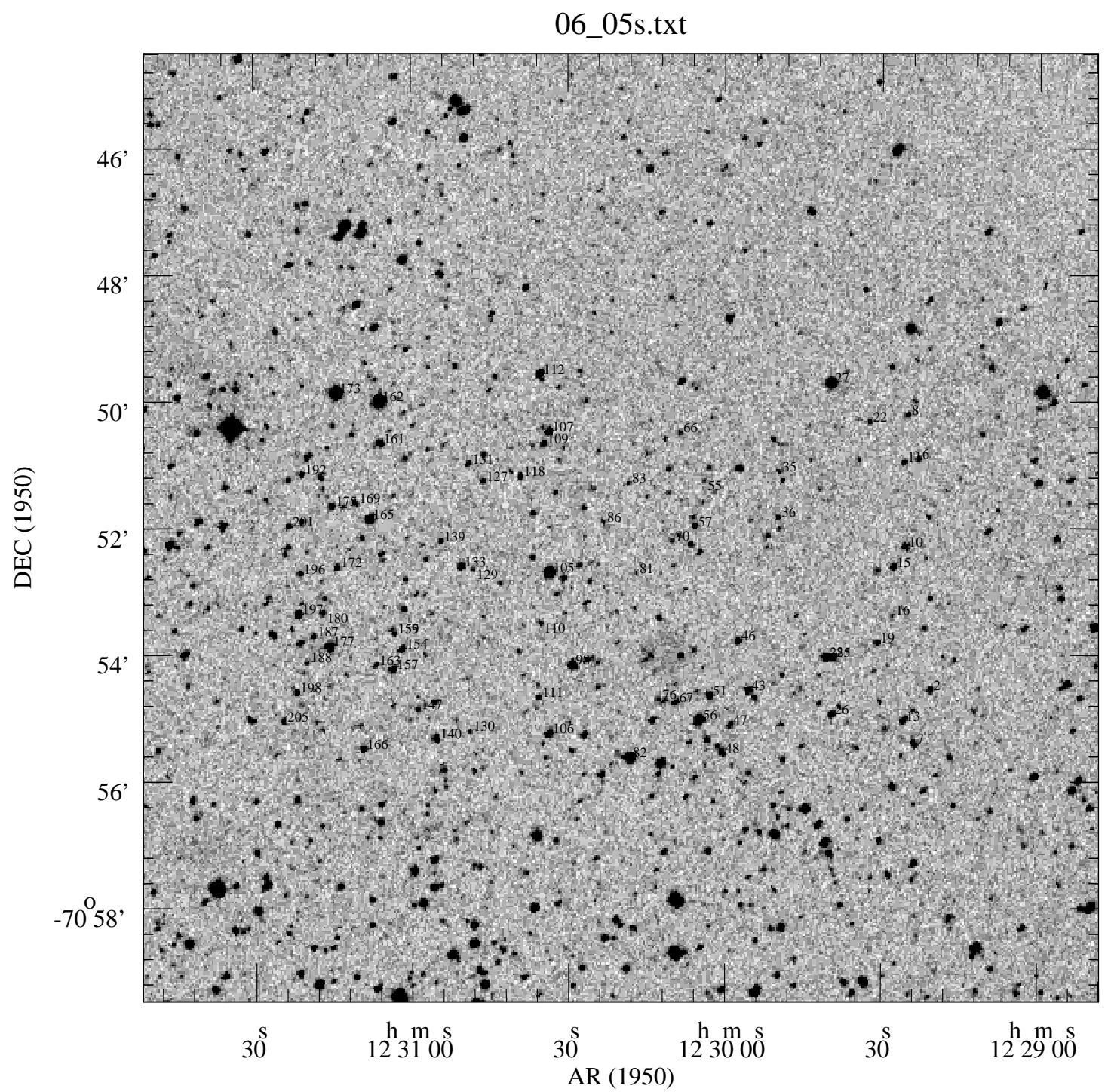

Figura C.6 Finding Chart do Campo 06 centrado em $\mathrm{AR}_{1950}=12^{\mathrm{h}} 30^{\mathrm{m}} 20^{\mathrm{s}}, \mathrm{DEC}_{1950}=-70^{\circ} 52^{\prime}$ 
Tabela C.7 Dados polarimétricos do Campo 07

\begin{tabular}{|c|c|c|c|c|c|c|c|}
\hline \multirow[t]{2}{*}{ ID } & \multirow{2}{*}{$\operatorname{AR}(1950.00)$} & DEEC (1950.00) & \multirow{2}{*}{$\begin{array}{l}P_{\mathrm{V}} \\
\left(\frac{\mathrm{o}}{\mathrm{g}}\right)\end{array}$} & \multirow{2}{*}{$\begin{array}{l}\sigma P_{\mathrm{V}} \\
\left(\frac{\circ}{6}\right)\end{array}$} & \multirow{2}{*}{$\begin{array}{c}\theta \\
\left({ }^{\circ}\right)\end{array}$} & \multirow{2}{*}{$\begin{array}{c}\mathrm{V} \\
\text { (mag) }\end{array}$} & \multirow{2}{*}{$\begin{array}{c}\sigma_{\mathrm{v}} \\
(\mathrm{mag})\end{array}$} \\
\hline & & $(\circ:,: ")$ & & & & & \\
\hline 1 & $12: 26: 39.86$ & $-70: 49: 40.29$ & 7.253 & 0.595 & 115.5 & 15.5992 & 0.4001 \\
\hline 2 & $12: 26: 57.80$ & $-70: 52: 13.59$ & 4.963 & 0.251 & 103.3 & 15.69 & 0.4001 \\
\hline 5 & $12: 27: 20.21$ & $-70: 55: 03.52$ & 4.6 & 0.699 & 124. & 14.8692 & 0.4 \\
\hline 6 & $12: 27: 20.59$ & $-70: 53: 34.06$ & 3.91 & 0.133 & 120.2 & 14.4943 & 0.4 \\
\hline 8 & $12: 27: 28.54$ & $-70: 53: 45.76$ & 5.379 & 0.552 & 96.1 & 16.2146 & 0.4001 \\
\hline 9 & $12: 27: 30.76$ & $-70: 53: 43.43$ & 3.234 & 0.052 & 113. & 14.5064 & 0.4 \\
\hline 11 & $12: 27: 35.29$ & $-70: 51: 56.39$ & $\begin{array}{l}5.234 \\
5.876\end{array}$ & 0.081 & 116.5 & 13.9833 & 0.4 \\
\hline 12 & $12: 27: 42.09$ & $-70: 52: 08.90$ & 5.86 & 0.209 & 115 & 15.5409 & 0.4 \\
\hline 13 & $12: 28: 13.85$ & $-70: 52: 37.65$ & 4.636 & 0.155 & 110 & 15.8782 & 0.4001 \\
\hline 14 & $12: 28: 15.43$ & $-70: 51: 08.67$ & 3.646 & 0.412 & 107.6 & 14.8314 & 0.4 \\
\hline 15 & $12: 28: 17.05$ & $-70: 51: 19.22$ & 4.446 & 0.187 & 132.9 & 16.4982 & 0.4002 \\
\hline 17 & $12: 28: 24.89$ & $-70: 55: 06.20$ & 3.26 & 0.402 & 91. & 16.0129 & 0.4001 \\
\hline 18 & $12: 28: 30.18$ & $-70: 51: 32.05$ & 4.635 & 0.577 & 108.8 & 15.4034 & 0.4001 \\
\hline 22 & $12: 28: 32.83$ & $-70: 54: 22.76$ & 4.083 & 0.057 & 106.5 & 12.2113 & 0.4 \\
\hline 23 & $12: 28: 32.81$ & $-70: 51: 47.29$ & 4.372 & 0.084 & 109.2 & 12.9087 & 0.4 \\
\hline 25 & $12: 28: 37.31$ & $-70: 54: 03.37$ & $\begin{array}{l}7.712 \\
7.704\end{array}$ & 0.724 & 110.5 & 16.3257 & 0.4002 \\
\hline 26 & $12: 28: 38.05$ & $-70: 54: 52.40$ & 3.566 & 0.122 & 112.4 & 15.422 & 0.4 \\
\hline 29 & $12: 28: 43.19$ & $-70: 53: 58.15$ & 6.392 & 0.13 & 97.8 & 15.8935 & 0.4001 \\
\hline 33 & $12: 28: 08.94$ & $-70: 55: 24.05$ & 4.19 & 0.199 & 115.7 & 14.8077 & 0.4 \\
\hline 35 & $12: 28: 26.24$ & $-70: 51: 20.60$ & 6.107 & 0.5 & 117.3 & 15.9219 & 0.4001 \\
\hline 36 & $12: 28: 35.66$ & $-70: 49: 31.53$ & 4.688 & 0.308 & 105.7 & 16.0677 & 0.4001 \\
\hline
\end{tabular}

\section{7_05s.txt}

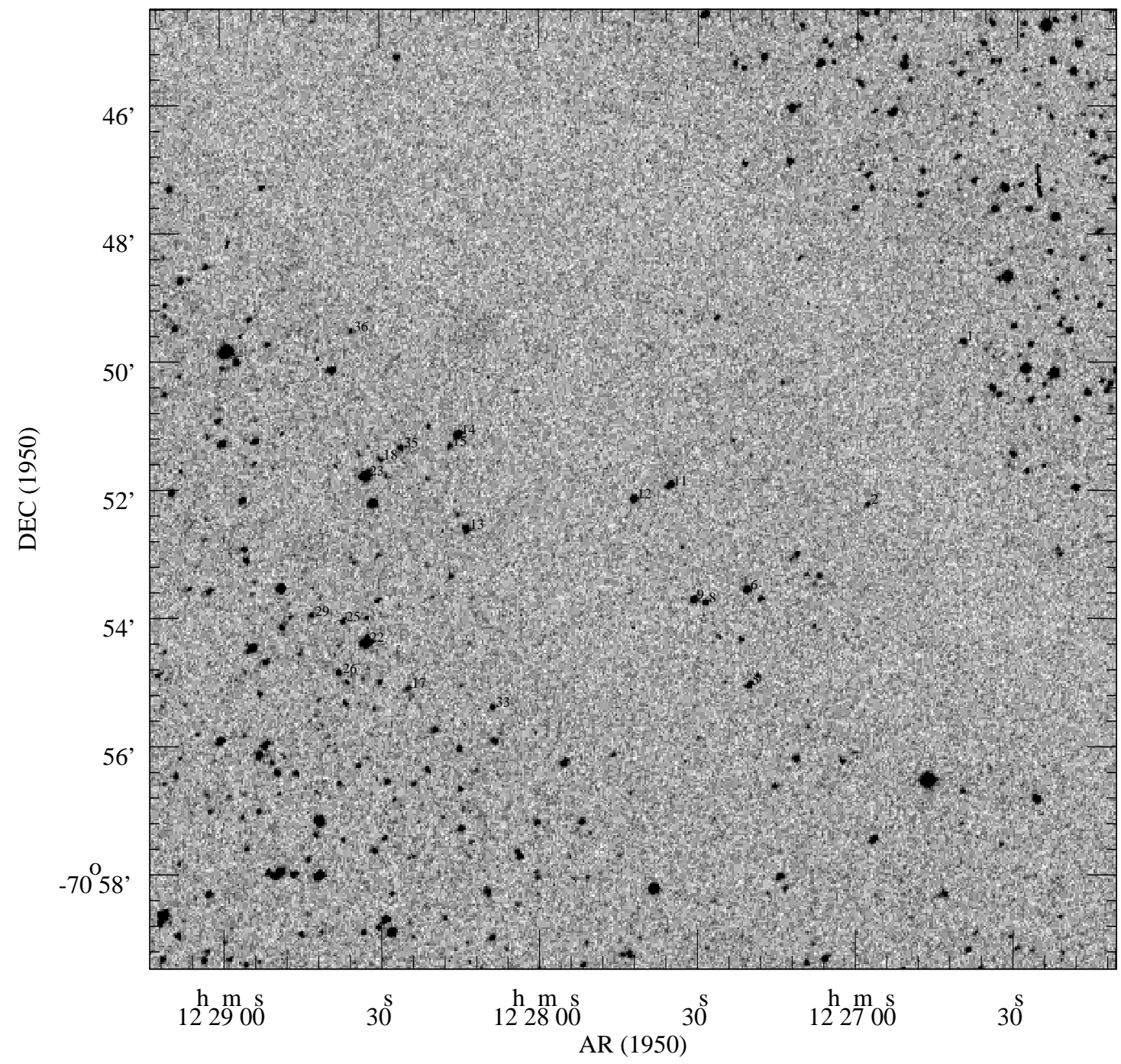

Figura C.7 Finding Chart do Campo 07 centrado em $\mathrm{AR}_{1950}=12^{\mathrm{h}} 27^{\mathrm{m}} 42.3^{\mathrm{s}}, \mathrm{DEC}_{1950}=-70^{\circ} 52^{\prime}$ 
Tabela C.8 Dados polarimétricos do Campo 08

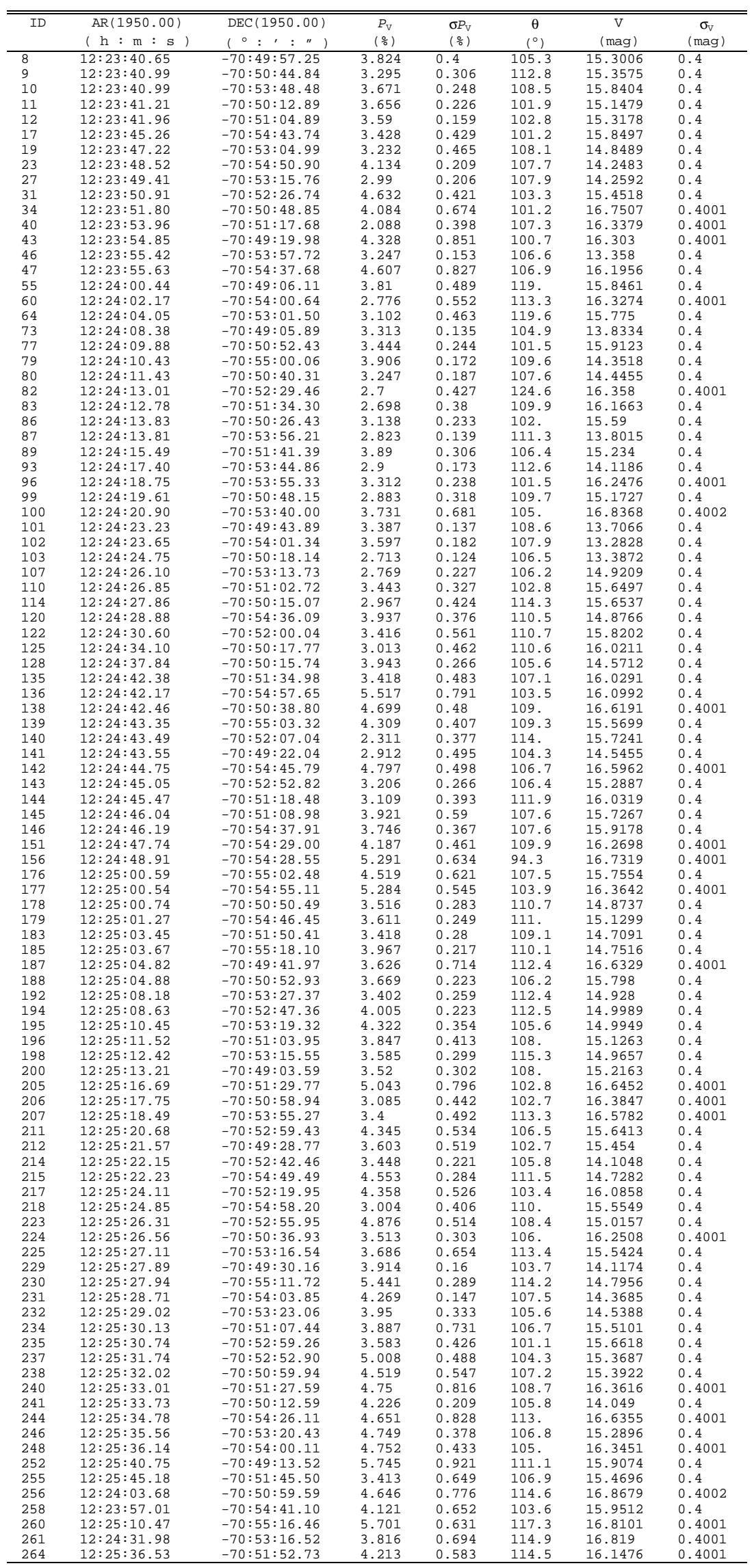




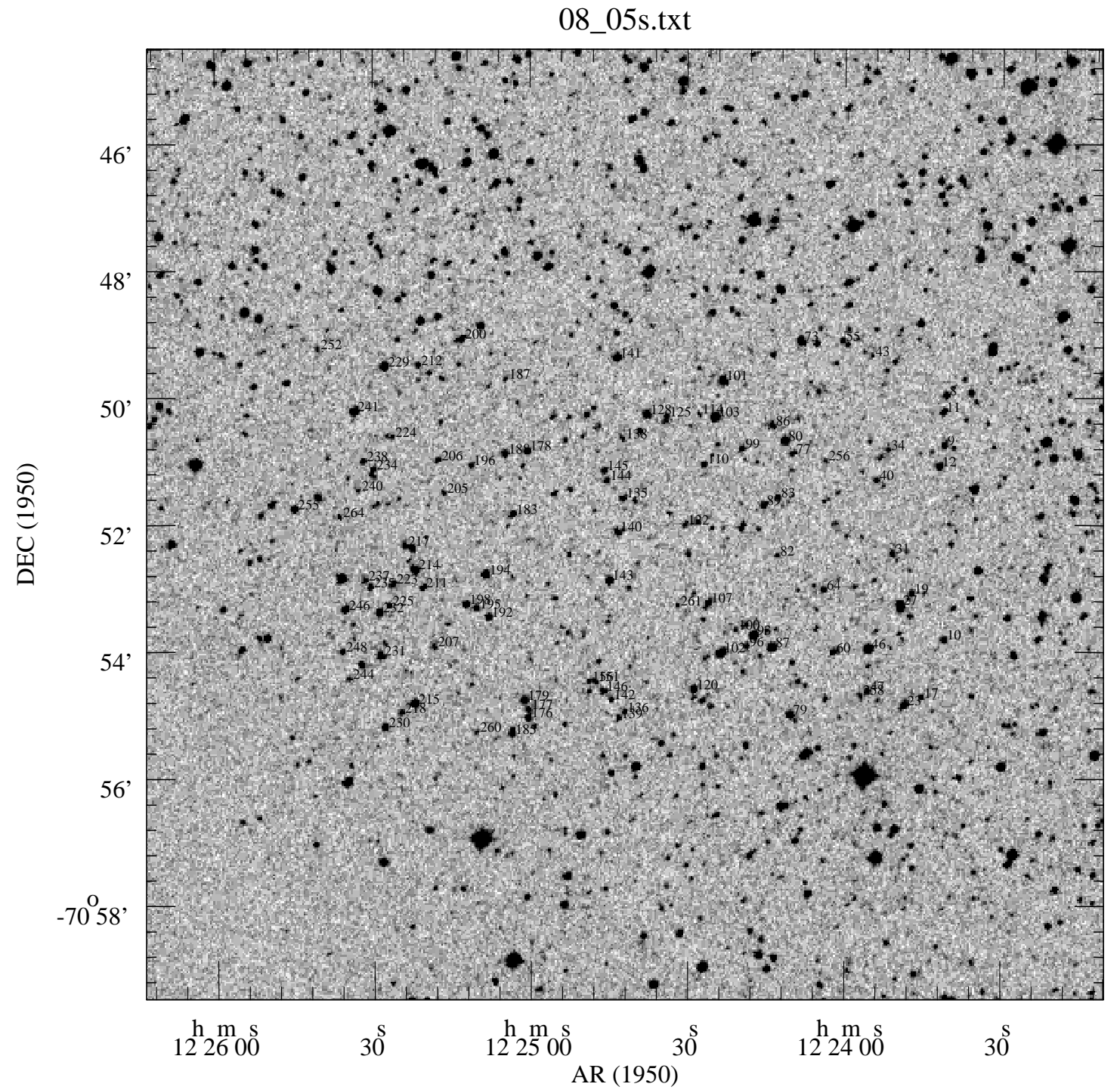

Figura C.8 Finding Chart do Campo 08 centrado em $\mathrm{AR}_{1950}=12^{\mathrm{h}} 24^{\mathrm{m}} 42^{\mathrm{s}}, \mathrm{DEC}_{1950}=-70^{\circ} 52^{\prime}$ 
Tabela C.9 Dados polarimétricos do Campo 09

\begin{tabular}{|c|c|c|c|c|c|c|c|}
\hline \multirow[t]{2}{*}{ ID } & AR (1950.00) & DEE (1950.00) & \multirow{2}{*}{$\begin{array}{l}P_{\mathrm{V}} \\
\left(\frac{\mathrm{o}}{\mathrm{O}}\right)\end{array}$} & \multirow{2}{*}{$\begin{array}{l}\sigma P_{\mathrm{V}} \\
\left(\frac{\%}{\delta}\right)\end{array}$} & \multirow{2}{*}{$\begin{array}{c}\theta \\
\left({ }^{\circ}\right)\end{array}$} & \multirow{2}{*}{$\begin{array}{c}\mathrm{V} \\
\text { (mag) }\end{array}$} & \multirow{2}{*}{$\begin{array}{c}\sigma_{\mathrm{v}} \\
(\mathrm{mag})\end{array}$} \\
\hline & $(\mathrm{h}: \mathrm{m}: \mathrm{s})$ & $(\circ:,: ")$ & & & & & \\
\hline 2 & $12: 26: 37.41$ & $-71: 02: 53.25$ & 8.541 & 1.16 & 106.6 & 15.2109 & 0.4 \\
\hline 3 & $12: 26: 38.52$ & $-70: 59: 10.62$ & $\begin{array}{l}0.011 \\
7.118\end{array}$ & 0.406 & 116.8 & 16.1552 & 0.4001 \\
\hline 5 & $12: 26: 43.02$ & $-70: 58: 18.75$ & 2.628 & 0.074 & 117.8 & 15.4097 & 0.4 \\
\hline 6 & $12: 26: 52.80$ & $-71: 01: 14.66$ & 5.504 & 0.986 & 116.9 & 15.353 & 0.4 \\
\hline 7 & $12: 26: 56.79$ & $-70: 57: 27.42$ & 5.007 & 0.14 & 117.7 & 14.3798 & 0.4 \\
\hline 9 & $12: 26: 59.82$ & $-71: 03: 25.32$ & 5.55 & 0.146 & 113. & 13.5626 & 0.4 \\
\hline 10 & $12: 27: 02.88$ & $-71: 00: 49.95$ & 6.544 & 0.145 & 112.5 & 15.4303 & 0.4 \\
\hline 11 & $12: 27: 05.76$ & $-70: 59: 21.04$ & 5.172 & 0.187 & 114.9 & 15.5095 & 0.4 \\
\hline 12 & $12: 27: 06.14$ & $-71: 01: 35.13$ & 7.03 & 0.644 & 115.7 & 15.645 & 0.4 \\
\hline 13 & $12: 27: 07.11$ & $-71: 02: 14.11$ & 6.236 & 0.311 & 115.3 & 14.5749 & 0.4 \\
\hline 17 & $12: 27: 14.50$ & $-70: 58: 02.23$ & 6.725 & 0.224 & 114.1 & 15.2323 & 0.4 \\
\hline 19 & $12: 27: 16.64$ & $-71: 03: 05.65$ & 5.202 & 0.143 & 107.5 & 14.6912 & 0.4 \\
\hline 20 & $12: 27: 25.75$ & $-71: 02: 38.99$ & 5.761 & 0.165 & 109.2 & 14.5055 & 0.4 \\
\hline 21 & $12: 27: 27.65$ & $-71: 00: 19.85$ & 6.608 & 0.087 & 109.5 & 16.0521 & 0.4001 \\
\hline 22 & $12: 27: 29.15$ & $-71: 01: 01.93$ & 5.259 & 0.114 & 112.2 & 12.9324 & 0.4 \\
\hline 23 & $12: 27: 33.58$ & $-71: 02: 22.26$ & 5.456 & 0.262 & 117.7 & 14.8329 & 0.4 \\
\hline 24 & $12: 27: 34.39$ & $-71: 00: 45.89$ & 5.067 & 0.27 & 121.6 & 16.4338 & 0.4002 \\
\hline 25 & $12: 27: 38.38$ & $-70: 58: 14.71$ & 5.156 & 0.064 & 111.7 & 12.8275 & 0.4 \\
\hline 26 & $12: 27: 38.82$ & $-71: 01: 58.61$ & 5.61 & 0.025 & 103.4 & 14.8403 & 0.4 \\
\hline 29 & $12: 27: 42.99$ & $-70: 59: 15.49$ & 6.471 & 0.338 & 113.6 & 16.2798 & 0.4001 \\
\hline 32 & $12: 27: 46.37$ & $-71: 01: 56.92$ & $\begin{array}{l}4.744 \\
4.74\end{array}$ & 0.275 & 113.6 & 14.7208 & 0.4 \\
\hline 34 & $12: 27: 52.50$ & $-71: 03: 24.97$ & 4.452 & 0.442 & 126 & 15.5695 & 0.4 \\
\hline 36 & $12: 27: 53.72$ & $-71: 01: 35.21$ & 4.431 & 0.18 & 104.8 & 14.9251 & 0.4 \\
\hline 37 & $12: 27: 56.21$ & $-71: 01: 17.84$ & 4.269 & 0.701 & 109.3 & 15.0058 & 0.4 \\
\hline 39 & $12: 28: 00.48$ & $-70: 58: 03.38$ & 3.944 & 0.284 & 119.3 & 14.802 & 0.4 \\
\hline 42 & $12: 28: 02.12$ & $-71: 01: 48.55$ & 4.149 & 0.139 & 104.9 & 14.1866 & 0.4 \\
\hline 43 & $12: 28: 03.85$ & $-70: 57: 43.83$ & 4.676 & 0.121 & 104.9 & 15.5612 & 0.4 \\
\hline 45 & $12: 28: 05.12$ & $-71: 00: 47.21$ & 5.225 & 0.821 & 106.9 & 16.2549 & 0.4001 \\
\hline 46 & $12: 28: 05.28$ & $-71: 01: 23.28$ & 3.111 & 0.021 & 107.9 & 15.4564 & 0.4 \\
\hline 47 & $12: 28: 06.97$ & $-71: 02: 48.16$ & 6.062 & 0.286 & 108.1 & 16.0969 & 0.4001 \\
\hline 49 & $12: 28: 08.69$ & $-71: 02: 59.71$ & 4.234 & 0.53 & 110.1 & 14.9344 & 0.4 \\
\hline 50 & $12: 28: 08.77$ & $-71: 00: 55.27$ & 3.976 & 0.704 & 110.2 & 15.7495 & 0.4001 \\
\hline 51 & $12: 28: 09.55$ & $-71: 02: 51.06$ & 5.033 & 0.263 & 109.3 & 15.694 & 0.4001 \\
\hline 52 & $12: 28: 12.24$ & $-70: 59: 39.68$ & 4.909 & 0.103 & 109. & 15.2857 & 0.4 \\
\hline 55 & $12: 28: 14.66$ & $-71: 02: 48.17$ & 3.767 & 0.128 & 108.3 & 14.5751 & 0.4 \\
\hline 56 & $12: 28: 14.93$ & $-70: 57: 18.72$ & 3.93 & 0.748 & 111 & 15.5664 & 0.4 \\
\hline 60 & $12: 28: 18.83$ & $-71: 02: 32.88$ & 3.366 & 0.085 & 109.7 & 13.2081 & 0.4 \\
\hline 68 & $12: 28: 28.13$ & $-70: 58: 55.95$ & 3.606 & 0.121 & 109.8 & 13.8724 & 0.4 \\
\hline 69 & $12: 28: 28.05$ & $-70: 58: 19.38$ & 4.534 & 0.168 & 114. & 16.0582 & 0.4001 \\
\hline 71 & $12: 28: 29.44$ & $-70: 59: 52.62$ & 3.695 & 0.045 & 116.1 & 14.2523 & 0.4 \\
\hline 72 & $12: 28: 29.45$ & $-70: 58: 42.87$ & 3.322 & 0.116 & 111 & 14.3038 & 0.4 \\
\hline 73 & $12: 28: 29.72$ & $-70: 57: 26.50$ & 5.442 & 0.07 & 114.5 & 15.5456 & 0.4 \\
\hline 74 & $12: 28: 31.51$ & $-70: 57: 39.50$ & 2.773 & 0.112 & 107.8 & 15.2132 & 0.4 \\
\hline 75 & $12: 28: 33.55$ & $-70: 58: 54.77$ & 4.855 & 0.926 & 104.7 & 15.7035 & 0.4001 \\
\hline 79 & $12: 28: 39.21$ & $-71: 03: 08.41$ & 5.935 & 0.558 & 100.7 & 16.1306 & 0.4001 \\
\hline 82 & $12: 28: 42.03$ & $-71: 00: 02.88$ & 5.737 & 0.452 & 101. & 15.5759 & 0.4 \\
\hline 83 & $12: 28: 42.15$ & $-70: 58: 01.46$ & 3.9 & 0.139 & 110. & 13.7791 & 0.4 \\
\hline 84 & $12: 28: 42.84$ & $-71: 03: 28.49$ & 3.573 & 0.064 & 108. & 13.4252 & 0.4 \\
\hline $\begin{array}{l}84 \\
85\end{array}$ & $12: 28: 42.95$ & $-71: 01: 21.61$ & 2.824 & 0.077 & 116.2 & 15.0291 & 0.4 \\
\hline 90 & $12: 28: 44.59$ & $-71: 01: 10.34$ & 2.657 & 0.167 & 109.3 & 14.1546 & 0.4 \\
\hline 95 & $12: 28: 09.07$ & $-70: 59: 00.29$ & 4.334 & 0.536 & 112.5 & 15.7212 & 0.4001 \\
\hline 96 & $12: 28: 13.26$ & $-71: 01: 35.10$ & 2.72 & 0.48 & 98.7 & 16.242 & 0.4001 \\
\hline
\end{tabular}




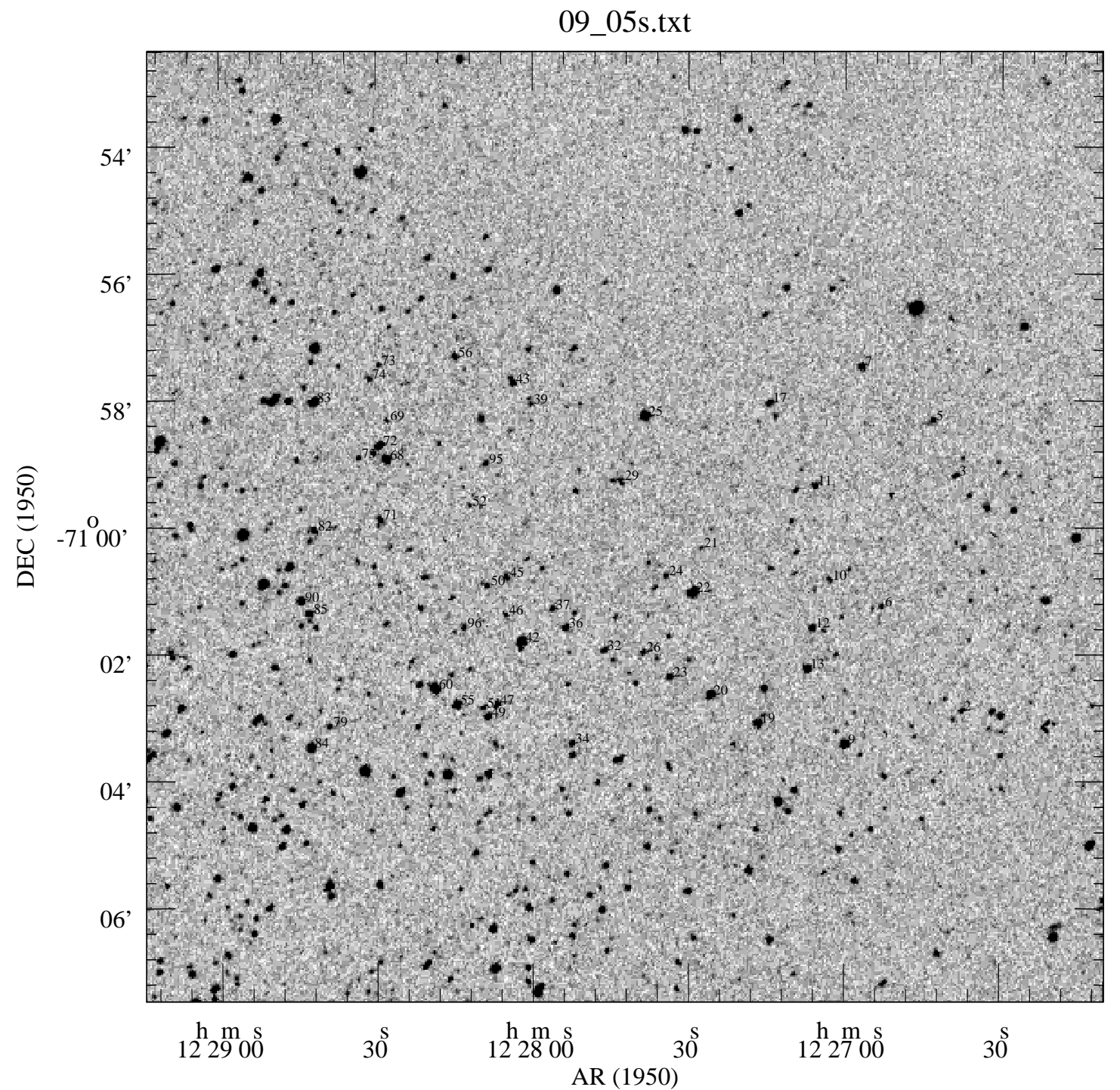

Figura C.9 Finding Chart do Campo 09 centrado em $\mathrm{AR}_{1950}=12^{\mathrm{h}} 27^{\mathrm{m}} 42.24^{\mathrm{s}}, \mathrm{DEC}_{1950}=-71^{\circ} 00^{\prime}$ 
Tabela C.10 Dados polarimétricos do Campo 10

\begin{tabular}{|c|c|c|c|c|c|c|c|}
\hline \multirow[t]{2}{*}{ ID } & $\operatorname{AR}(1950.00)$ & $\operatorname{DEC}(1950.00)$ & \multirow{2}{*}{$\begin{array}{l}P_{\mathrm{V}} \\
\left(\frac{0}{6}\right)\end{array}$} & \multirow{2}{*}{$\begin{array}{l}\sigma \sigma P_{\mathrm{V}} \\
(\%)\end{array}$} & \multirow{2}{*}{$\begin{array}{c}\theta \\
\left({ }^{\circ}\right)\end{array}$} & \multirow{2}{*}{$\begin{array}{c}\mathrm{V} \\
(\mathrm{mag})\end{array}$} & \multirow{2}{*}{$\begin{array}{c}\sigma_{\mathrm{V}} \\
(\mathrm{mag})\end{array}$} \\
\hline & $(\mathrm{h}: \mathrm{m}: \mathrm{s})$ & $\left({ }^{\circ}:{ }^{\prime}:\right.$ : ") & & & & & \\
\hline 1 & $12: 24: 09.71$ & $-70: 59: 46.60$ & 4.115 & 0.218 & 111.6 & 14.5487 & 0.4 \\
\hline 2 & $12: 24: 10.99$ & $-71: 00: 12.71$ & 5.336 & 0.427 & 113.8 & 14.0905 & 0.4 \\
\hline 3 & $12: 24: 12.67$ & $-71: 01: 35.49$ & 4.884 & 0.261 & 116.9 & 14.9876 & 0.4 \\
\hline 5 & $12: 24: 13.46$ & $-70: 58: 49.67$ & 5.407 & 0.254 & 115.4 & 14.8305 & 0.4 \\
\hline 6 & $12: 24: 13.51$ & $-71: 02: 06.61$ & 6.883 & 0.433 & 110.5 & 15.804 & 0.4001 \\
\hline 8 & $12: 24: 14.67$ & $-71: 01: 51.92$ & 4.3 & 0.54 & 107.4 & 16.0363 & 0.4001 \\
\hline 10 & $12: 24: 14.83$ & $-70: 59: 01.31$ & 4.913 & 0.697 & 114.8 & 15.326 & 0.4 \\
\hline 13 & $12: 24: 16.30$ & $-70: 58: 47.95$ & 4.312 & 0.438 & 112.5 & 14.0322 & 0.4 \\
\hline 16 & $12: 24: 17.04$ & $-71: 03: 10.88$ & 5.503 & 0.826 & 114.9 & 15.1894 & 0.4 \\
\hline 23 & $12: 24: 21.42$ & $-71: 01: 52.54$ & 3.314 & 0.544 & 113.4 & 15.1274 & 0.4 \\
\hline 24 & $12: 24: 22.26$ & $-71: 03: 00.97$ & 6.107 & 0.646 & 123.4 & 15.7568 & 0.4001 \\
\hline 27 & $12: 24: 27.13$ & $-70: 58: 58.21$ & 4.452 & 0.079 & 111.9 & 12.5138 & 0.4 \\
\hline 28 & $12: 24: 27.47$ & $-71: 03: 11.46$ & 5.2 & 0.077 & 114.4 & 12.5382 & 0.4 \\
\hline 32 & $12: 24: 34.19$ & $-71: 02: 59.21$ & 4.724 & 0.261 & 101.9 & 14.9053 & 0.4 \\
\hline 34 & $12: 24: 36.52$ & $-70: 59: 14.47$ & 4.609 & 0.217 & 113.2 & 13.9658 & 0.4 \\
\hline 35 & $12: 24: 37.01$ & $-71: 03: 20.00$ & 6.744 & 1.214 & 116.5 & 15.6115 & 0.4001 \\
\hline 36 & $12: 24: 41.13$ & $-71: 00: 24.08$ & 6.834 & 0.997 & 106.8 & 15.2746 & 0.4 \\
\hline 37 & $12: 24: 45.51$ & $-71: 00: 38.78$ & 5.054 & 0.109 & 112.9 & 13.9692 & 0.4 \\
\hline 38 & $12: 24: 48.04$ & $-71: 00: 52.55$ & 5.311 & 0.08 & 115.3 & 12.3046 & 0.4 \\
\hline 40 & $12: 24: 52.04$ & $-70: 59: 46.00$ & 5.146 & 0.51 & 108.8 & 16.1677 & 0.4001 \\
\hline 41 & $12: 24: 53.05$ & $-70: 57: 33.87$ & 4.302 & 0.443 & 112.5 & 14.7354 & 0.4 \\
\hline 42 & $12: 24: 53.71$ & $-70: 58: 00.34$ & 6.016 & 0.168 & 116.9 & 14.6688 & 0.4 \\
\hline 45 & $12: 25: 00.79$ & $-70: 57: 52.31$ & 4.213 & 0.556 & 122 & 15.9679 & 0.4001 \\
\hline 46 & $12: 25: 03.34$ & $-70: 58: 53.21$ & 5.552 & 0.084 & 113.7 & 11.2467 & 0.4 \\
\hline 47 & $12: 25: 03.52$ & $-71: 00: 27.48$ & 5.199 & 0.122 & 115.5 & 14.6994 & 0.4 \\
\hline 48 & $12: 25: 07.00$ & $-70: 59: 12.18$ & 3.917 & 0.129 & 116.9 & 15.3014 & 0.4 \\
\hline 49 & $12: 25: 07.28$ & $-71: 01: 26.99$ & 8.107 & 0.913 & 116.9 & 16.0492 & 0.4001 \\
\hline 50 & $12: 25: 12.78$ & $-70: 57: 44.30$ & 4.714 & 0.542 & 106.3 & 16.1648 & 0.4001 \\
\hline 51 & $12: 25: 20.12$ & $-70: 59: 30.73$ & 5.633 & 0.766 & 117.8 & 15.3919 & 0.4 \\
\hline 52 & $12: 25: 22.94$ & $-70: 59: 34.92$ & 6.187 & 0.11 & 115.8 & 12.2733 & 0.4 \\
\hline 53 & $12: 25: 27.94$ & $-70: 57: 19.20$ & 5.36 & 0.321 & 113 & 15.2024 & 0.4 \\
\hline 54 & $12: 26: 04.88$ & $-71: 03: 18.59$ & 9.282 & 0.48 & 107.6 & 15.9878 & 0.4001 \\
\hline 55 & $12: 26: 04.80$ & $-71: 02: 19.51$ & 5.996 & 1.169 & 119.1 & 16.4961 & 0.4002 \\
\hline 56 & $12: 26: 15.34$ & $-71: 00: 08.90$ & 6.354 & 0.292 & 119.5 & 13.3598 & 0.4 \\
\hline 58 & $12: 24: 23.49$ & $-70: 59: 53.19$ & 4.572 & 0.419 & 110.9 & 14.8786 & 0.4 \\
\hline 60 & $12: 24: 38.49$ & $-70: 58: 30.08$ & 4.368 & 0.414 & 114 & 14.9464 & 0.4 \\
\hline 62 & $12: 24: 52.93$ & $-71: 02: 25.47$ & 7.552 & 0.822 & 119.4 & 15.8417 & 0.4001 \\
\hline 63 & $12: 24: 56.09$ & $-71: 01: 36.25$ & 6.058 & 1.14 & 113.9 & 16.194 & 0.4002 \\
\hline
\end{tabular}




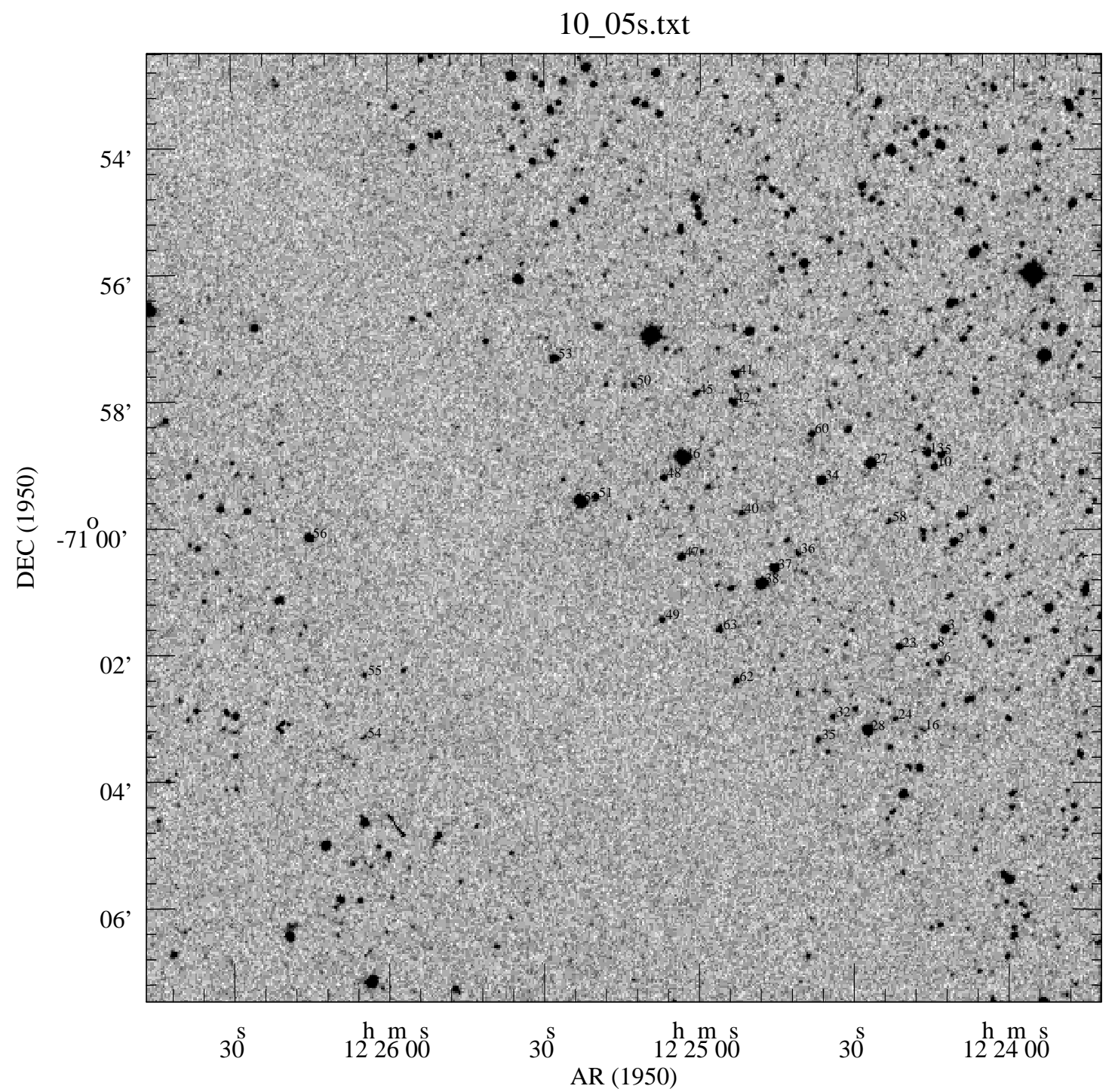

Figura C.10 Finding Chart do Campo 10 centrado em $\mathrm{AR}_{1950}=12^{\mathrm{h}} 25^{\mathrm{m}} 14.7^{\mathrm{s}}, \mathrm{DEC}_{1950}=-71^{\circ} 00^{\prime}$ 
Tabela C.11 Dados polarimétricos do Campo 11

\begin{tabular}{|c|c|c|c|c|c|c|c|}
\hline ID & $\operatorname{AR}(1950.00)$ & $\operatorname{DEC}(1950.00)$ & $P_{\mathrm{V}}$ & $\sigma P_{\mathrm{V}}$ & $\theta$ & $\mathrm{V}$ & \\
\hline & $(\mathrm{h}: \mathrm{m}: \mathrm{s})$ & $\left({ }^{\circ}:{ }^{\prime}: "\right)$ & (음) & $\left(\frac{\circ}{0}\right)$ & $\left({ }^{\circ}\right)$ & (mag) & (mag) \\
\hline 1 & $12: 26: 07.27$ & $-71: 05: 17.68$ & 4.427 & 0.359 & 123.8 & 15.2022 & 0.4 \\
\hline $2^{a}$ & $12: 26: 09.63$ & $-71: 05: 52.07$ & 4.975 & 0.281 & 108.9 & 15.0992 & 0.4 \\
\hline 3 & $12: 26: 09.82$ & $-71: 09: 09.23$ & 4.29 & 0.762 & 114.4 & 15.9073 & 0.4001 \\
\hline 4 & $12: 26: 09.98$ & $-71: 07: 47.39$ & 3.022 & 0.543 & 91.2 & 16.1593 & 0.4001 \\
\hline 5 & $12: 26: 10.53$ & $-71: 06: 00.23$ & 3.103 & 0.573 & 106.9 & 16.4436 & 0.4002 \\
\hline 7 & $12: 26: 13.08$ & $-71: 09: 14.02$ & 4.556 & 0.352 & 102.8 & 15.9832 & 0.4001 \\
\hline 9 & $12: 26: 19.43$ & $-71: 06: 27.73$ & 4.94 & 0.171 & 106.8 & 13.794 & 0.4 \\
\hline 12 & $12: 26: 23.34$ & $-71: 08: 01.00$ & 4.682 & 0.765 & 108. & 16.5539 & 0.4002 \\
\hline 14 & $12: 26: 25.82$ & $-71: 08: 38.34$ & 5.428 & 0.205 & 102.1 & 15.2915 & 0.4 \\
\hline 15 & $12: 26: 26.27$ & $-71: 10: 04.19$ & 3.651 & 0.512 & 102.8 & 14.783 & 0.4 \\
\hline 16 & $12: 26: 28.19$ & $-71: 10: 39.40$ & 3.466 & 0.681 & 116.7 & 15.2747 & 0.4 \\
\hline 18 & $12: 26: 30.46$ & $-71: 09: 16.70$ & 4.647 & 0.91 & 107.1 & 16.5064 & 0.4002 \\
\hline 22 & $12: 26: 32.97$ & $-71: 09: 12.67$ & 4.872 & 0.889 & 99.6 & 15.51 & 0.4 \\
\hline 25 & $12: 26: 35.70$ & $-71: 11: 00.24$ & 3.524 & 0.197 & 96.6 & 14.3381 & 0.4 \\
\hline 28 & $12: 26: 43.71$ & $-71: 09: 55.31$ & 2.811 & 0.189 & 104.4 & 14.6193 & 0.4 \\
\hline 29 & $12: 26: 44.12$ & $-71: 10: 39.62$ & 2.758 & 0.489 & 95.1 & 16.0931 & 0.4001 \\
\hline 32 & $12: 26: 46.17$ & $-71: 09: 10.94$ & 4.817 & 0.386 & 104.6 & 15.641 & 0.4 \\
\hline 33 & $12: 26: 49.75$ & $-71: 09: 40.10$ & 2.778 & 0.481 & 94.7 & 15.6132 & 0.4 \\
\hline 34 & $12: 26: 52.56$ & $-71: 07: 11.74$ & 4.499 & 0.213 & 110.4 & 14.8352 & 0.4 \\
\hline 35 & $12: 26: 53.70$ & $-71: 09: 24.81$ & 3.934 & 0.734 & 121.1 & 16.2844 & 0.4001 \\
\hline 36 & $12: 26: 55.08$ & $-71: 07: 36.35$ & 4.268 & 0.247 & 108.1 & 15.4066 & 0.4 \\
\hline 40 & $12: 26: 57.85$ & $-71: 05: 35.70$ & 6.915 & 0.364 & 104.7 & 15.7001 & 0.4 \\
\hline 42 & $12: 27: 01.33$ & $-71: 05: 04.62$ & 7.272 & 0.182 & 109 & 15.9669 & 0.4001 \\
\hline 43 & $12: 27: 04.11$ & $-71: 05: 27.12$ & 5.794 & 0.855 & 108. & 16.5847 & 0.4002 \\
\hline 44 & $12: 27: 05.59$ & $-71: 10: 58.26$ & 4.8 & 0.469 & 101.5 & 15.8916 & 0.4001 \\
\hline 45 & $12: 27: 07.38$ & $-71: 09: 07.80$ & 4.676 & 0.22 & 103.6 & 15.23 & 0.4 \\
\hline 48 & $12: 27: 09.15$ & $-71: 09: 59.45$ & $\begin{array}{l}4.42 \\
4.42\end{array}$ & 0.4 & 105.8 & 14.9169 & 0.4 \\
\hline 49 & $12: 27: 09.43$ & $-71: 11: 00.24$ & 3.474 & 0.197 & 100.4 & 14.4835 & 0.4 \\
\hline 55 & $12: 27: 14.34$ & $-71: 06: 30.24$ & 4.427 & 0.389 & 110.3 & 15.522 & 0.4 \\
\hline 57 & $12: 27: 17.34$ & $-71: 09: 03.88$ & 4.841 & 0.406 & 103.5 & 15.5993 & 0.4 \\
\hline 58 & $12: 27: 17.57$ & $-71: 08: 33.24$ & 4.458 & 0.703 & 99.4 & 15.9387 & 0.4001 \\
\hline 59 & $12: 27: 18.49$ & $-71: 05: 25.31$ & 4.543 & 0.172 & 108.4 & 14.3402 & 0.4 \\
\hline 60 & $12: 27: 19.23$ & $-71: 10: 20.62$ & 4.189 & 0.783 & 107.2 & 15.8626 & 0.4001 \\
\hline 63 & $12: 27: 22.64$ & $-71: 10: 21.78$ & 3.538 & 0.458 & 97.4 & 14.6423 & 0.4 \\
\hline 66 & $12: 27: 23.73$ & $-71: 09: 46.93$ & 3.787 & 0.734 & 99.4 & 15.0344 & 0.4 \\
\hline 68 & $12: 27: 26.70$ & $-71: 08: 21.88$ & 3.291 & 0.103 & 104.4 & 12.9323 & 0.4 \\
\hline 71 & $12: 27: 29.11$ & $-71: 06: 29.19$ & 4.422 & 0.257 & 106.1 & 15.7511 & 0.4001 \\
\hline 72 & $12: 27: 30.05$ & $-71: 05: 44.11$ & 6.173 & 0.641 & 109. & 15.4515 & 0.4 \\
\hline 75 & $12: 27: 32.10$ & $-71: 06: 52.39$ & 5.745 & 0.646 & 118.5 & 15.5205 & 0.4 \\
\hline 78 & $12: 27: 32.42$ & $-71: 08: 16.55$ & 3.088 & 0.11 & 106.1 & 15.0984 & 0.4 \\
\hline 84 & $12: 27: 39.50$ & $-71: 10: 47.94$ & 3.573 & 0.654 & 111. & 16.4532 & 0.4002 \\
\hline 86 & $12: 27: 42.34$ & $-71: 08: 14.96$ & 3.62 & 0.065 & 106.9 & 10.6031 & 0.4 \\
\hline 87 & $12: 27: 42.29$ & $-71: 10: 58.94$ & 4.48 & 0.607 & 109.6 & 15.8797 & 0.4001 \\
\hline 88 & $12: 27: 42.35$ & $-71: 10: 19.41$ & 4.342 & 0.657 & 99.5 & 15.2909 & 0.4 \\
\hline 92 & $12: 27: 46.00$ & $-71: 05: 19.97$ & 4.793 & 0.628 & 108. & 15.7982 & 0.4 \\
\hline 94 & $12: 27: 46.44$ & $-71: 09: 04.37$ & 4.723 & 0.689 & 102. & 15.2872 & 0.4 \\
\hline 95 & $12: 27: 46.73$ & $-71: 06: 02.09$ & 2.762 & 0.279 & 103.6 & 14.3075 & 0.4 \\
\hline 97 & $12: 27: 47.92$ & $-71: 08: 06.28$ & 3.51 & 0.578 & 103.7 & 15.3084 & 0.4 \\
\hline 99 & $12: 27: 49.16$ & $-71: 05: 49.14$ & 4.039 & 0.484 & 104.4 & 15.972 & 0.4001 \\
\hline 100 & $12: 27: 50.05$ & $-71: 07: 34.56$ & 3.679 & 0.145 & 111.6 & 14.6678 & 0.4 \\
\hline 101 & $12: 27: 50.24$ & $-71: 09: 21.44$ & 3.71 & 0.079 & 102.4 & 12.3168 & 0.4 \\
\hline 104 & $12: 27: 51.95$ & $-71: 08: 51.87$ & 4.365 & 0.538 & 106.1 & 15.8141 & 0.4001 \\
\hline 105 & $12: 27: 52.42$ & $-71: 06: 27.73$ & 4.295 & 0.255 & 109.3 & 15.2045 & 0.4 \\
\hline 106 & $12: 27: 52.87$ & $-71: 09: 14.35$ & 3.462 & 0.211 & 104.8 & 15.1628 & 0.4 \\
\hline 108 & $12: 27: 54.61$ & $-71: 08: 40.22$ & 3.647 & 0.422 & 103.4 & 14.9967 & 0.4 \\
\hline 111 & $12: 27: 58.15$ & $-71: 10: 22.63$ & 4.246 & 0.257 & 99.9 & 14.835 & 0.4 \\
\hline 112 & $12: 27: 58.89$ & $-71: 07: 17.18$ & 3.696 & 0.137 & 110.4 & 14.4027 & 0.4 \\
\hline 113 & $12: 27: 59.10$ & $-71: 07: 19.69$ & 4.031 & 0.161 & 108.1 & 13.9321 & 0.4 \\
\hline 114 & $12: 28: 00.03$ & $-71: 09: 47.37$ & 3.615 & 0.696 & 118.1 & 16.0847 & 0.4001 \\
\hline 118 & $12: 28: 00.82$ & $-71: 06: 00.62$ & 2.996 & 0.33 & 100.7 & 14.6414 & 0.4 \\
\hline 119 & $12: 28: 01.17$ & $-71: 07: 10.11$ & 3.934 & 0.431 & 108.6 & 16.0248 & 0.4001 \\
\hline 121 & $12: 28: 02.69$ & $-71: 09: 30.93$ & 4.179 & 0.294 & 107. & 14.9162 & 0.4 \\
\hline 122 & $12: 28: 03.20$ & $-71: 08: 37.93$ & 4.615 & 0.858 & 103.2 & 16.5485 & 0.4002 \\
\hline 124 & $12: 28: 03.39$ & $-71: 05: 43.56$ & 3.097 & 0.372 & 120.9 & 14.9212 & 0.4 \\
\hline 126 & $12: 28: 06.18$ & $-71: 11: 19.86$ & 4.381 & 0.573 & 103.2 & 15.8125 & 0.4 \\
\hline 127 & $12: 28: 07.11$ & $-71: 08: 49.19$ & 3.366 & 0.472 & 109.8 & 14.9794 & 0.4 \\
\hline 128 & $12: 28: 07.41$ & $-71: 06: 58.30$ & 3.527 & 0.098 & 105.7 & 14.058 & 0.4 \\
\hline 129 & $12: 28: 07.76$ & $-71: 06: 20.05$ & 3.466 & 0.2 & 107.7 & 14.1629 & 0.4 \\
\hline 133 & $12: 28: 11.42$ & $-71: 05: 07.84$ & 3.627 & 0.382 & 111. & 15.4791 & 0.4 \\
\hline 135 & $12: 28: 14.08$ & $-71: 05: 43.41$ & 3.396 & 0.625 & 98.7 & 16.432 & 0.4001 \\
\hline 141 & $12: 26: 24.94$ & $-71: 10: 06.21$ & 4.836 & 0.843 & 114.9 & 16.5183 & 0.4002 \\
\hline 149 & $12: 27: 21.30$ & $-71: 06: 07.13$ & 7.185 & 0.296 & 101.3 & 15.7007 & 0.4001 \\
\hline 151 & $12: 27: 53.87$ & $-71: 10: 50.89$ & 5.239 & 0.538 & 103.2 & 15.4611 & 0.4 \\
\hline
\end{tabular}

a mesmo objeto na Tabela B.12 com ID $=61$ 


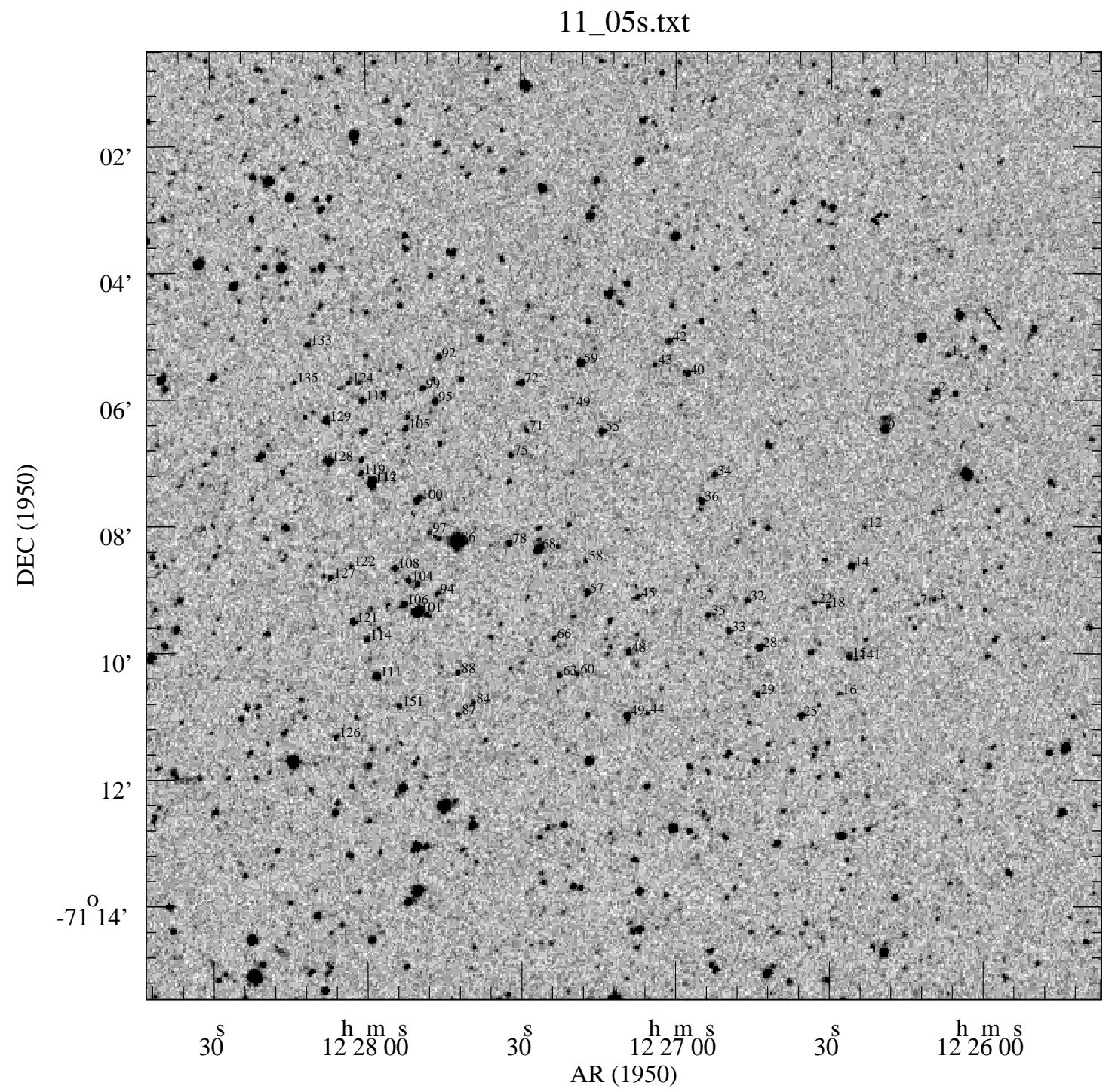

Figura C.11 Finding Chart do Campo 11 centrado em $\mathrm{AR}_{1950}=12^{\mathrm{h}} 27^{\mathrm{m}} 10^{\mathrm{s}}, \mathrm{DEC}_{1950}=-71^{\circ} 08^{\prime}$ 
Apêndice C

Tabela C.12 Dados polarimétricos do Campo 12

\begin{tabular}{|c|c|c|c|c|c|c|c|}
\hline ID & $\operatorname{AR}(1950.00)$ & $\operatorname{DEC}(1950.00)$ & $P_{\mathrm{V}}$ & $\sigma P_{\mathrm{V}}$ & $\theta$ & $\mathrm{V}$ & $\sigma_{\mathrm{v}}$ \\
\hline & & $\left({ }^{\circ}:{ }^{\prime}: "\right)$ & & & $\left({ }^{\circ}\right)$ & & (mag) \\
\hline 2 & $12: 24: 13.53$ & $-71: 06: 15.72$ & 5.791 & 0.522 & 128.1 & 16.3062 & 0.4001 \\
\hline 5 & $12: 24: 23.33$ & $-71: 09: 02.51$ & 8.127 & 0.473 & 120.9 & 15.6204 & 0.4 \\
\hline 9 & $12: 24: 46.49$ & $-71: 08: 55.46$ & 6.433 & 0.738 & 136 & 16.1027 & 0.4001 \\
\hline 10 & $12: 24: 47.34$ & $-71: 11: 35.09$ & 6.523 & 0.299 & 123.4 & 14.0712 & 0.4 \\
\hline 13 & $12: 24: 50.61$ & $-71: 10: 17.91$ & 6.758 & 0.322 & 129.5 & 15.593 & 0.4 \\
\hline 15 & $12: 24: 56.04$ & $-71: 08: 47.11$ & 6.792 & 0.378 & 121.8 & 14.4734 & 0.4 \\
\hline 16 & $12: 24: 58.42$ & $-71: 09: 34.36$ & 5.996 & 0.233 & 123.4 & 10.8343 & 0.4 \\
\hline 17 & $12: 24: 58.72$ & $-71: 10: 09.20$ & 5.369 & 0.389 & 124.8 & 15.0582 & 0.4 \\
\hline 18 & $12: 25: 02.61$ & $-71: 08: 40.38$ & 5.519 & 0.771 & 126.8 & 15.9964 & 0.4 \\
\hline 20 & $12: 25: 04.22$ & $-71: 09: 38.35$ & 5.67 & 0.697 & 128.9 & 16.9808 & 0.4002 \\
\hline 24 & $12: 25: 14.06$ & $-71: 08: 16.81$ & 6.647 & 0.641 & 122.5 & 15.2497 & 0.4 \\
\hline 26 & $12: 25: 19.54$ & $-71: 10: 26.03$ & 5.691 & 1.02 & 116 & 17.2578 & 0.4003 \\
\hline 29 & $12: 25: 27.09$ & $-71: 09: 01.91$ & 5.116 & 0.57 & 126.3 & 16.4983 & 0.4001 \\
\hline 31 & $12: 25: 33.08$ & $-71: 10: 59.76$ & 4.53 & 0.459 & 119.8 & 14.9718 & 0.4 \\
\hline 33 & $12: 25: 36.95$ & $-71: 08: 10.91$ & 6.356 & 0.362 & 120.1 & 13.5328 & 0.4 \\
\hline 41 & $12: 25: 47.51$ & $-71: 08: 08.21$ & 6.523 & 0.692 & 123.9 & 16.6714 & 0.4001 \\
\hline 42 & $12: 25: 48.79$ & $-71: 09: 46.75$ & 7.972 & 0.595 & 127.6 & 17.1284 & 0.4002 \\
\hline 48 & $12: 25: 59.64$ & $-71: 10: 03.50$ & 5.252 & 0.68 & 114.9 & 15.7283 & 0.4 \\
\hline 53 & $12: 26: 03.38$ & $-71: 07: 09.90$ & 4.491 & 0.254 & 115.7 & 12.2956 & 0.4 \\
\hline 55 & $12: 26: 04.71$ & $-71: 09: 15.83$ & 5.903 & 1.134 & 118. & 16.9549 & 0.4002 \\
\hline $61^{\mathrm{a}}$ & $12: 26: 09.67$ & $-71: 05: 52.12$ & 5.534 & 0.474 & 113. & 14.955 & 0.4 \\
\hline 77 & $12: 25: 57.78$ & $-71: 09: 47.70$ & 6.296 & 0.532 & 117.9 & 16.0788 & 0.4001 \\
\hline
\end{tabular}

a mesmo objeto na Tabela B.11 com ID $=2$

\section{5 s.txt}

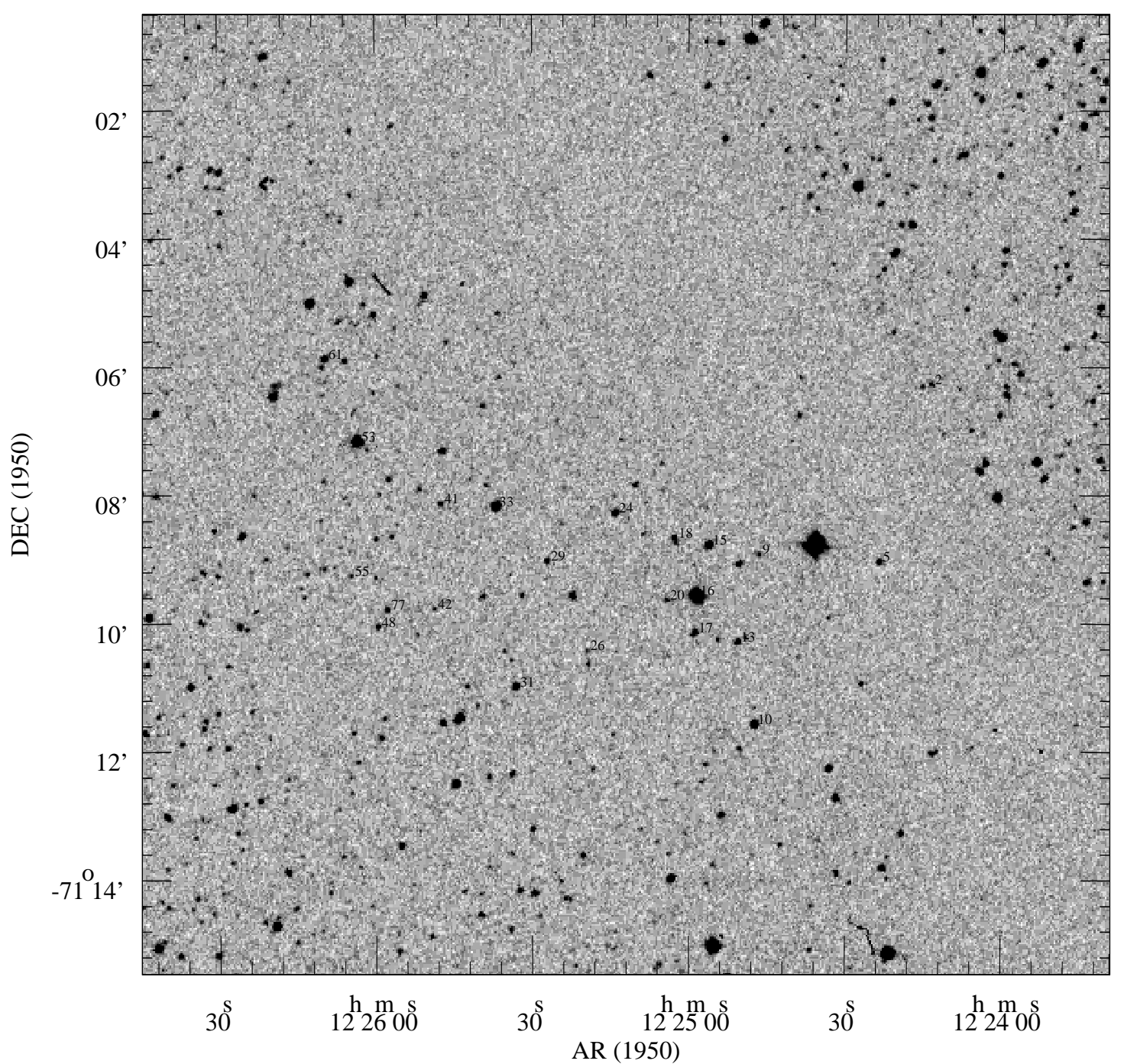

Figura C.12 Finding Chart do Campo 12 centrado em $\mathrm{AR}_{1950}=12^{\mathrm{h}} 25^{\mathrm{m}} 12^{\mathrm{s}}, \mathrm{DEC}_{1950}=-71^{\circ} 08^{\prime}$ 
Tabela C.13 Dados polarimétricos do Campo 13

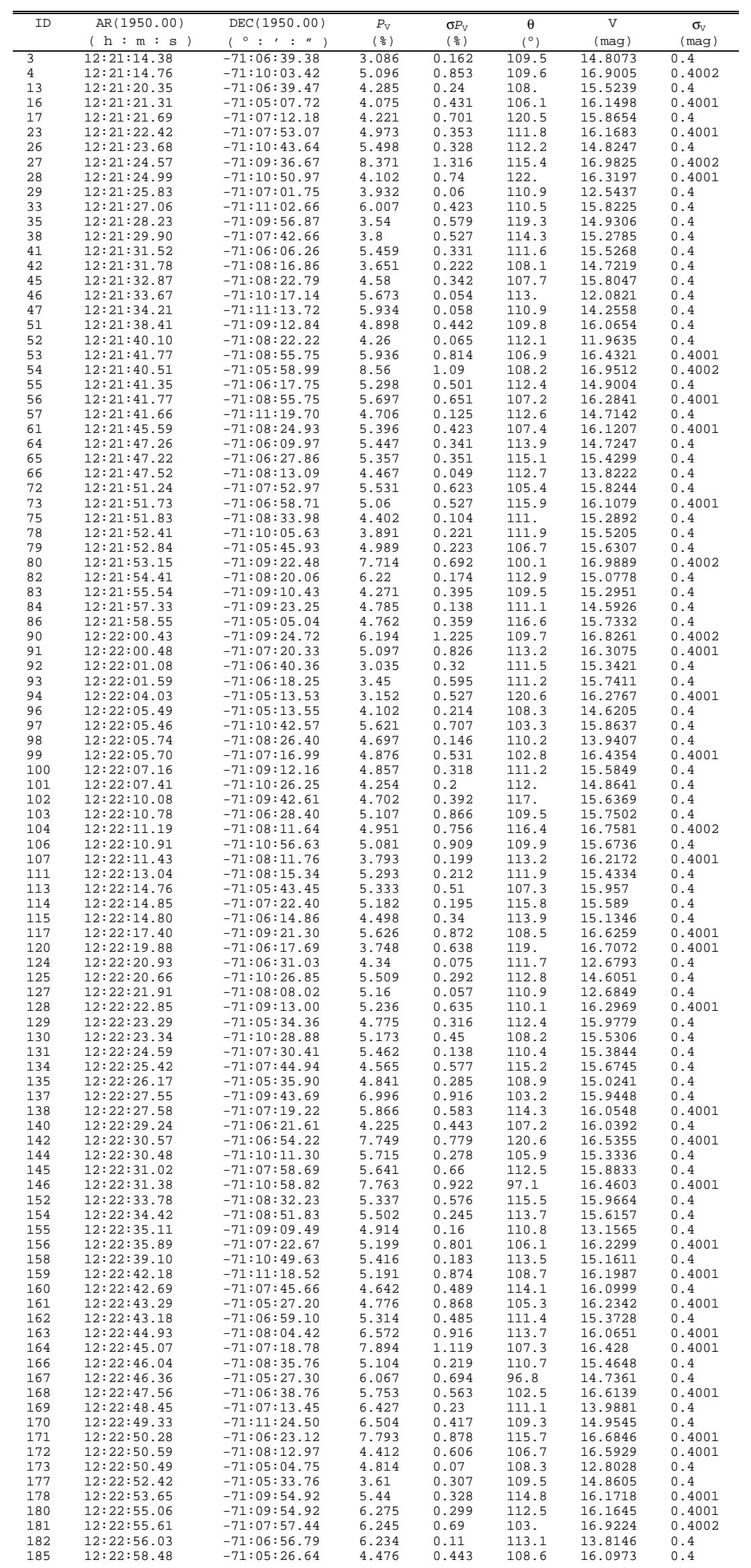


Apêndice C

Tabela C.13 - Continuação

\begin{tabular}{|c|c|c|c|c|c|c|c|}
\hline ID & $\begin{array}{l}\operatorname{AR}(1950.00) \\
(\mathrm{h}: \mathrm{m}: \mathrm{s})\end{array}$ & $\begin{array}{l}\operatorname{DEC}(1950.00) \\
\left(0^{\circ}::^{\prime}\right)\end{array}$ & $\begin{array}{c}P_{\mathrm{V}} \\
\left(\frac{0}{0}\right)\end{array}$ & $\begin{array}{l}\sigma P_{\mathrm{V}} \\
\left(\frac{\circ}{0}\right)\end{array}$ & $\begin{array}{c}\theta \\
\left({ }^{\circ}\right)\end{array}$ & $\begin{array}{c}\mathrm{V} \\
\text { (mag) }\end{array}$ & $\begin{array}{c}\sigma_{\mathrm{V}} \\
(\mathrm{mag})\end{array}$ \\
\hline 187 & $12: 22: 59.35$ & $-71: 06: 05.46$ & 4.714 & 0.563 & 115.6 & 15.7134 & 0.4 \\
\hline 190 & $12: 23: 01.07$ & $-71: 08: 21.08$ & 5.703 & 0.088 & 112.6 & 13.3721 & 0.4 \\
\hline 194 & $12: 23: 05.33$ & $-71: 07: 32.17$ & 7.998 & 1.089 & 109.9 & 16.4842 & 0.4001 \\
\hline 197 & $12: 23: 08.38$ & $-71: 06: 21.56$ & 5.126 & 0.275 & 110.5 & 15.366 & 0.4 \\
\hline 200 & $12: 23: 10.20$ & $-71: 09: 19.53$ & 6.4 & 0.207 & 113. & 14.4864 & 0.4 \\
\hline 201 & $12: 23: 13.04$ & $-71: 09: 46.46$ & 6.035 & 0.691 & 113.5 & 16.4619 & 0.4001 \\
\hline 202 & $12: 23: 14.25$ & $-71: 05: 23.04$ & 4.529 & 0.345 & 109.3 & 14.8431 & 0.4 \\
\hline 203 & $12: 23: 14.75$ & $-71: 07: 12.46$ & 6.428 & 1.199 & 111.5 & 14.7984 & 0.4 \\
\hline 204 & $12: 23: 16.59$ & $-71: 10: 31.63$ & 5.328 & 0.797 & 107.8 & 16.6728 & 0.4001 \\
\hline 207 & $12: 23: 18.81$ & $-71: 05: 38.52$ & 4.451 & 0.466 & 113.5 & 16.1424 & 0.4 \\
\hline 210 & $12: 23: 20.78$ & $-71: 06: 49.27$ & 5.349 & 0.273 & 111.2 & 14.7626 & 0.4 \\
\hline 221 & $12: 22: 13.06$ & $-71: 08: 21.86$ & 5.592 & 0.896 & 113.2 & 14.4969 & 0.4 \\
\hline 222 & $12: 21: 49.66$ & $-71: 10: 18.69$ & 5.45 & 0.806 & 114.3 & 16.5245 & 0.4001 \\
\hline
\end{tabular}

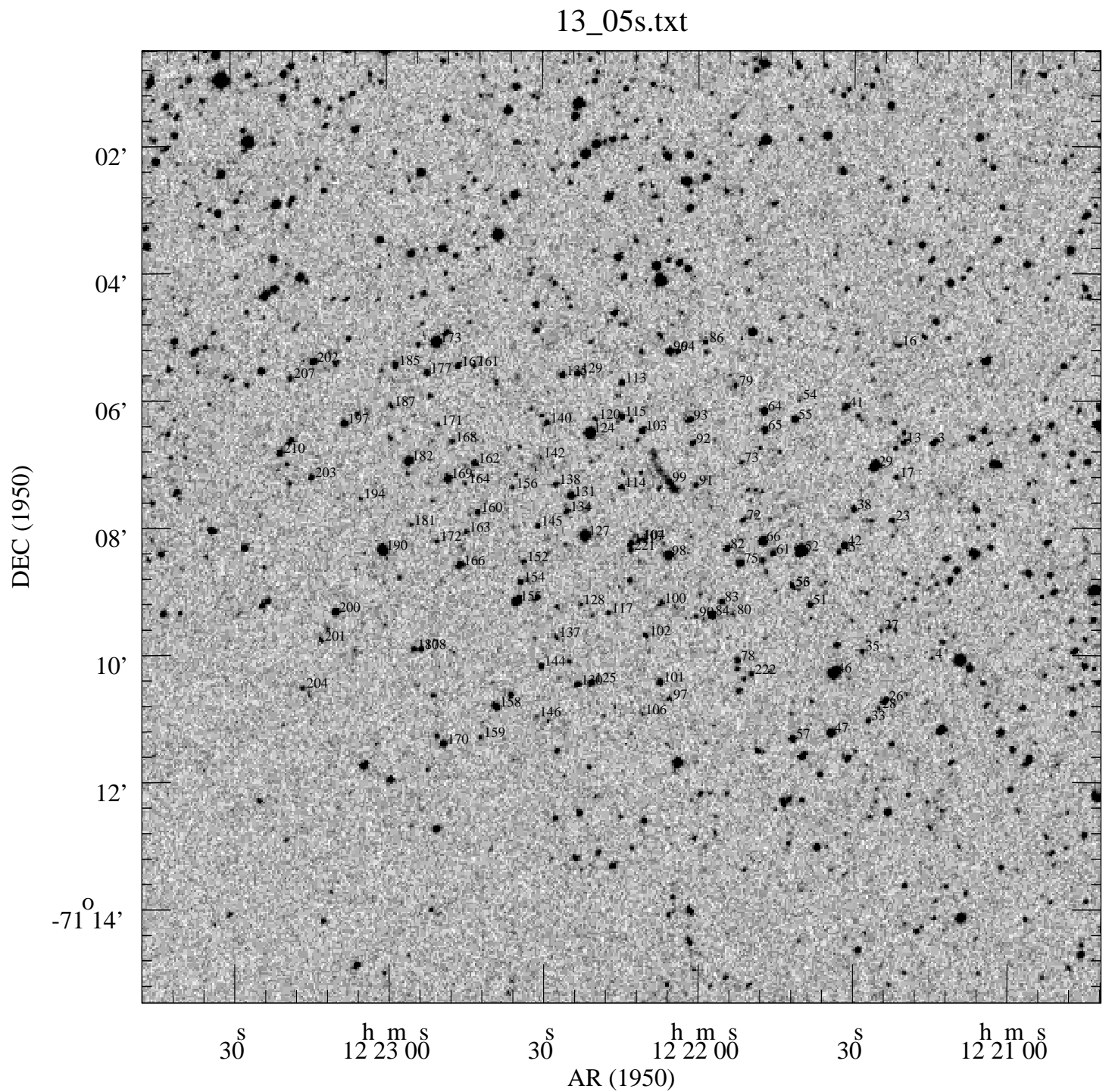

Figura C.13 Finding Chart do Campo 13 centrado em $\mathrm{AR}_{1950}=12^{\mathrm{h}} 22^{\mathrm{m}} 15^{\mathrm{s}}, \mathrm{DEC}_{1950}=-71^{\circ} 08^{\prime}$ 
Tabela C.14 Dados polarimétricos do Campo 14

\begin{tabular}{|c|c|c|c|c|c|c|c|}
\hline ID & $\begin{array}{c}\operatorname{AR}(1950.00) \\
(\mathrm{h}: \mathrm{m}: \mathrm{s})\end{array}$ & $\begin{array}{l}\operatorname{DEC}(1950.00) \\
\left({ }^{\circ}::^{\prime} \prime\right)\end{array}$ & $\begin{array}{l}P_{\mathrm{V}} \\
(\%)\end{array}$ & $\begin{array}{l}\sigma P_{\mathrm{V}} \\
(\%)\end{array}$ & $\begin{array}{c}\theta \\
\left({ }^{\circ}\right)\end{array}$ & $\begin{array}{c}\mathrm{V} \\
(\mathrm{mag})\end{array}$ & $\begin{array}{c}\sigma_{\mathrm{V}} \\
(\mathrm{mag})\end{array}$ \\
\hline 1 & $12: 23: 51.64$ & $-71: 17: 08.55$ & 6.251 & 0.856 & 116.9 & 16.4791 & 0.4001 \\
\hline 3 & $12: 24: 00.82$ & $-71: 15: 50.15$ & 7.368 & 0.505 & 114.8 & 15.0376 & 0.4 \\
\hline 6 & $12: 24: 16.60$ & $-71: 16: 10.90$ & 7.001 & 1.001 & 114.1 & 15.9453 & 0.4001 \\
\hline 9 & $12: 24: 19.25$ & $-71: 13: 16.94$ & 6.909 & 0.228 & 117.3 & 15.5548 & 0.4 \\
\hline 11 & $12: 24: 20.84$ & $-71: 17: 09.60$ & 6.658 & 1.012 & 123.4 & 16.132 & 0.4001 \\
\hline 12 & $12: 24: 21.13$ & $-71: 19: 15.33$ & 7.588 & 0.955 & 104.1 & 16.1272 & 0.4001 \\
\hline 13 & $12: 24: 21.49$ & $-71: 15: 09.46$ & 0.465 & 0.038 & 134.5 & 11.5225 & 0.4 \\
\hline 15 & $12: 24: 22.69$ & $-71: 13: 50.87$ & 7.512 & 0.373 & 113.7 & 15.561 & 0.4 \\
\hline 16 & $12: 24: 25.49$ & $-71: 17: 10.92$ & 6.206 & 0.694 & 111.9 & 15.3278 & 0.4 \\
\hline 19 & $12: 24: 31.48$ & $-71: 13: 54.37$ & 7.026 & 0.745 & 111.4 & 15.3246 & 0.4 \\
\hline 20 & $12: 24: 32.10$ & $-71: 17: 38.20$ & 5.385 & 0.713 & 110.3 & 16.0323 & 0.4001 \\
\hline 22 & $12: 24: 34.65$ & $-71: 18: 54.77$ & 5.921 & 1.085 & 113.2 & 16.1754 & 0.4001 \\
\hline 24 & $12: 24: 36.15$ & $-71: 18: 30.33$ & 5.248 & 0.347 & 112.2 & 15.8632 & 0.4 \\
\hline 26 & $12: 24: 36.71$ & $-71: 15: 05.97$ & 6.127 & 0.383 & 119.2 & 16.4048 & 0.4001 \\
\hline 29 & $12: 24: 38.51$ & $-71: 16: 00.23$ & 5.697 & 0.856 & 111.9 & 16.1269 & 0.4001 \\
\hline 33 & $12: 24: 42.50$ & $-71: 19: 14.64$ & 5.496 & 0.119 & 108.1 & 14.1555 & 0.4 \\
\hline 35 & $12: 24: 46.28$ & $-71: 16: 38.26$ & 5.361 & 0.525 & 106.6 & 16.1408 & 0.4001 \\
\hline 36 & $12: 24: 46.65$ & $-71: 18: 58.21$ & 5.266 & 0.322 & 108.2 & 16.126 & 0.4001 \\
\hline 37 & $12: 24: 47.11$ & $-71: 18: 42.85$ & 5.789 & 0.383 & 107.1 & 14.9608 & 0.4 \\
\hline 43 & $12: 24: 53.33$ & $-71: 18: 45.26$ & 4.656 & 0.195 & 104 & 14.2896 & 0.4 \\
\hline 44 & $12: 24: 53.59$ & $-71: 12: 59.85$ & 6.04 & 0.39 & 117.4 & 15.3992 & 0.4 \\
\hline 45 & $12: 24: 54.33$ & $-71: 16: 49.29$ & 7.812 & 0.567 & 113. & 15.4922 & 0.4 \\
\hline 46 & $12: 24: 55.21$ & $-71: 15: 02.71$ & 5.199 & 0.097 & 106.9 & 11.2775 & 0.4 \\
\hline 48 & $12: 24: 56.16$ & $-71: 16: 37.41$ & 4.602 & 0.639 & 111.6 & 15.9704 & 0.4 \\
\hline 50 & $12: 24: 56.27$ & $-71: 19: 15.50$ & 5.305 & 0.053 & 107.9 & 14.6539 & 0.4 \\
\hline 54 & $12: 25: 03.44$ & $-71: 13: 59.32$ & 5.285 & 0.311 & 110 . & 14.793 & 0.4 \\
\hline 55 & $12: 25: 03.60$ & $-71: 17: 11.81$ & 5.211 & 0.455 & 103.4 & 15.7425 & 0.4 \\
\hline 56 & $12: 25: 03.77$ & $-71: 19: 04.80$ & 6.507 & 0.578 & 106.3 & 15.6071 & 0.4 \\
\hline 57 & $12: 25: 05.28$ & $-71: 17: 58.29$ & 4.132 & 0.273 & 103.7 & 15.3894 & 0.4 \\
\hline 58 & $12: 25: 05.54$ & $-71: 15: 19.83$ & 5.111 & 0.646 & 98.1 & 16.337 & 0.4001 \\
\hline 59 & $12: 25: 05.67$ & $-71: 17: 21.00$ & 5.497 & 0.322 & 105.9 & 14.1982 & 0.4 \\
\hline 60 & $12: 25: 05.95$ & $-71: 13: 26.82$ & 5.162 & 0.72 & 121.9 & 16.3165 & 0.4001 \\
\hline 62 & $12: 25: 07.09$ & $-71: 16: 24.19$ & 6.686 & 1.152 & 108.4 & 16.7827 & 0.4002 \\
\hline 63 & $12: 25: 07.44$ & $-71: 16: 12.68$ & 4.263 & 0.269 & 104.9 & 15.9296 & 0.4001 \\
\hline 64 & $12: 25: 08.04$ & $-71: 17: 33.57$ & 6.243 & 1.073 & 111.7 & 16.3493 & 0.4001 \\
\hline 67 & $12: 25: 13.07$ & $-71: 16: 31.78$ & 4.754 & 0.32 & 107.5 & 14.8641 & 0.4 \\
\hline 69 & $12: 25: 16.23$ & $-71: 17: 41.54$ & 4.836 & 0.319 & 95.6 & 15.9885 & 0.4 \\
\hline 70 & $12: 25: 16.40$ & $-71: 18: 27.83$ & 2.902 & 0.467 & 112 . & 15.3764 & 0.4 \\
\hline 71 & $12: 25: 17.78$ & $-71: 17: 24.69$ & 5.124 & 0.243 & 104.2 & 14.2742 & 0.4 \\
\hline 74 & $12: 25: 20.30$ & $-71: 13: 39.13$ & 5.03 & 0.521 & 109. & 16.1596 & 0.4001 \\
\hline 79 & $12: 25: 23.38$ & $-71: 14: 17.94$ & 4.84 & 0.819 & 110.1 & 15.8895 & 0.4 \\
\hline 80 & $12: 25: 23.50$ & $-71: 18: 22.74$ & 4.545 & 0.13 & 103.3 & 14.0701 & 0.4 \\
\hline 81 & $12: 25: 24.08$ & $-71: 18: 37.65$ & 4.665 & 0.373 & 101.8 & 14.6633 & 0.4 \\
\hline 83 & $12: 25: 26.18$ & $-71: 17: 26.64$ & 4.514 & 0.59 & 101.9 & 15.6498 & 0.4 \\
\hline 85 & $12: 25: 26.60$ & $-71: 18: 01.23$ & 4.748 & 0.143 & 105.6 & 13.8971 & 0.4 \\
\hline 87 & $12: 25: 28.90$ & $-71: 16: 08.99$ & 4.491 & 0.545 & 108. & 16.1922 & 0.4001 \\
\hline 89 & $12: 25: 29.73$ & $-71: 14: 13.70$ & 5.152 & 0.168 & 112.8 & 14.8314 & 0.4 \\
\hline 90 & $12: 25: 29.66$ & $-71: 19: 08.78$ & 4.064 & 0.772 & 109.5 & 15.9156 & 0.4001 \\
\hline 92 & $12: 25: 29.93$ & $-71: 16: 28.62$ & 4.952 & 0.586 & 109.5 & 16.5908 & 0.4002 \\
\hline 95 & $12: 25: 33.20$ & $-71: 15: 46.85$ & 5.022 & 0.568 & 100.9 & 15.6183 & 0.4 \\
\hline 96 & $12: 25: 34.05$ & $-71: 14: 46.43$ & 5.676 & 0.767 & 112.8 & 15.6409 & 0.4 \\
\hline 101 & $12: 25: 36.31$ & $-71: 18: 38.47$ & 4.63 & 0.361 & 102.1 & 14.9778 & 0.4 \\
\hline 102 & $12: 25: 36.65$ & $-71: 17: 57.42$ & 4.556 & 0.354 & 101.9 & 15.3729 & 0.4 \\
\hline 104 & $12: 25: 36.78$ & $-71: 15: 35.37$ & 4.89 & 0.385 & 109.6 & 16.3822 & 0.4001 \\
\hline 105 & $12: 25: 39.42$ & $-71: 16: 57.21$ & 7.151 & 0.615 & 114. & 16.5204 & 0.4001 \\
\hline 115 & $12: 25: 47.60$ & $-71: 17: 12.77$ & 3.952 & 0.086 & 102. & 13.7129 & 0.4 \\
\hline 117 & $12: 25: 49.44$ & $-71: 14: 54.65$ & 5.178 & 0.528 & 100.3 & 15.9751 & 0.4001 \\
\hline 118 & $12: 25: 49.30$ & $-71: 17: 30.87$ & 4.519 & 0.182 & 101.6 & 14.8736 & 0.4 \\
\hline 119 & $12: 25: 50.51$ & $-71: 19: 13.23$ & 5.454 & 0.472 & 102.4 & 16.1966 & 0.4001 \\
\hline 121 & $12: 23: 55.14$ & $-71: 17: 31.60$ & 7.038 & 1.21 & 111.1 & 16.7414 & 0.4002 \\
\hline 129 & $12: 25: 33.81$ & $-71: 13: 36.85$ & 6.024 & 0.691 & 106.5 & 16.7425 & 0.4002 \\
\hline
\end{tabular}


Apêndice C

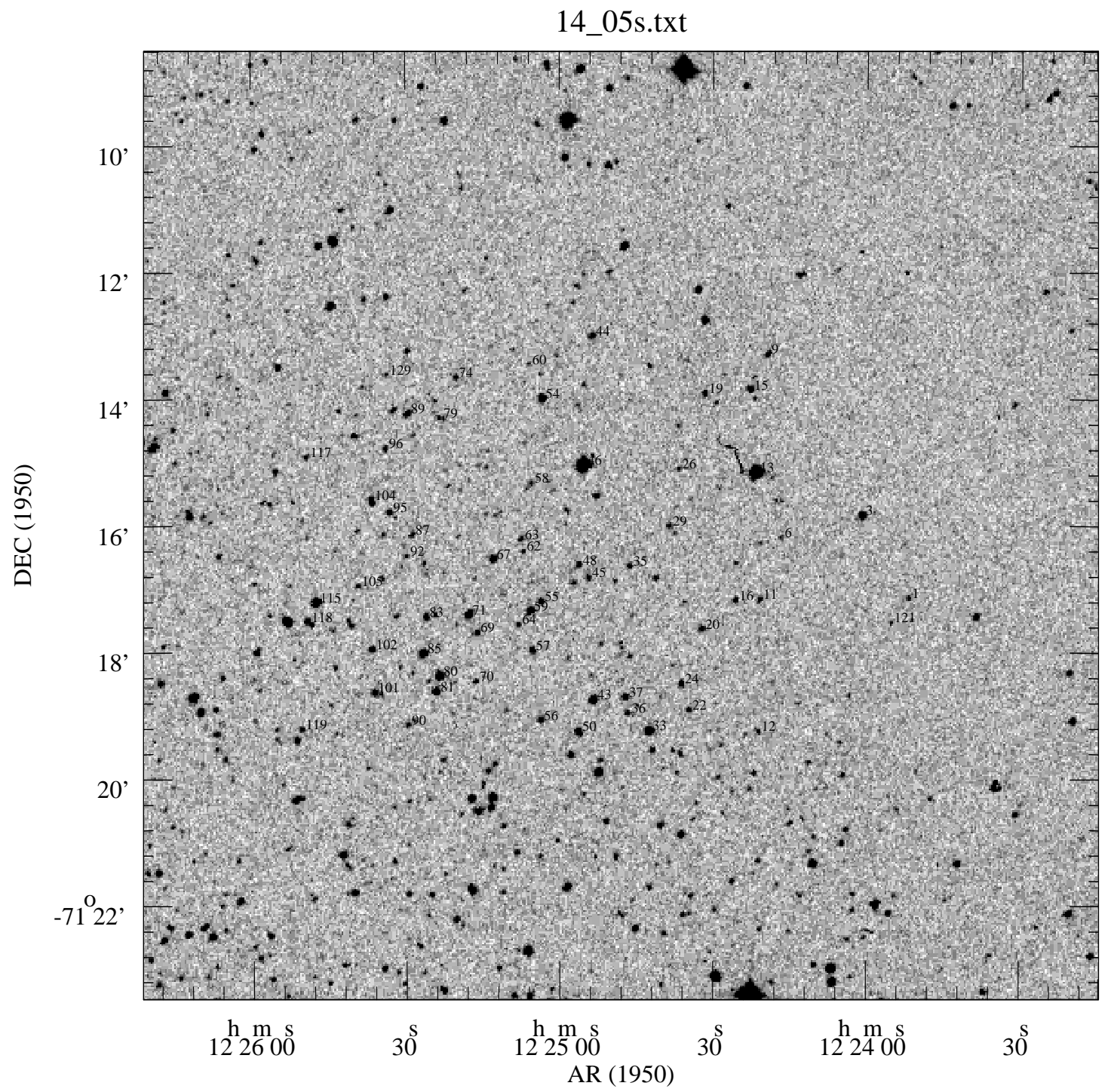

Figura C.14 Finding Chart do Campo 14 centrado em $\mathrm{AR}_{1950}=12^{\mathrm{h}} 24^{\mathrm{m}} 48^{\mathrm{s}}, \mathrm{DEC}_{1950}=-71^{\circ} 16^{\prime}$ 
Tabela C.15 Dados polarimétricos do Campo 15

\begin{tabular}{|c|c|c|c|c|c|c|c|}
\hline \multirow[t]{2}{*}{ ID } & $\operatorname{AR}(1950.00)$ & $\operatorname{DEC}(1950.00)$ & \multirow{2}{*}{$\begin{array}{c}P_{\mathrm{V}} \\
\left(\frac{\mathrm{o}}{\mathrm{o}}\right)\end{array}$} & \multirow{2}{*}{$\begin{array}{l}\sigma P_{\mathrm{V}} \\
(\%)\end{array}$} & \multirow{2}{*}{$\begin{array}{c}\theta \\
\left({ }^{\circ}\right)\end{array}$} & \multirow{2}{*}{$\begin{array}{c}\mathrm{V} \\
\text { (mag) }\end{array}$} & \multirow{2}{*}{$\begin{array}{c}\sigma_{\mathrm{V}} \\
(\mathrm{mag})\end{array}$} \\
\hline & $(\mathrm{h}: \mathrm{m}: \mathrm{s})$ & $\left({ }^{\circ}:{ }^{\prime}:\right.$ : $\left."\right)$ & & & & & \\
\hline 3 & $12: 21: 45.11$ & $-71: 17: 00.85$ & 7.938 & 1.225 & 112.4 & 15.5169 & 0.4001 \\
\hline 6 & $12: 21: 50.11$ & $-71: 18: 50.89$ & 6.586 & 0.154 & 107.9 & 12.0527 & 0.4 \\
\hline 7 & $12: 21: 50.88$ & $-71: 13: 25.02$ & 7.117 & 1.03 & 123.3 & 15.9876 & 0.4002 \\
\hline 9 & $12: 21: 51.26$ & $-71: 18: 42.17$ & 6.707 & 0.13 & 110 & 11.9 & 0.4 \\
\hline 12 & $12: 21: 55.98$ & $-71: 16: 13.55$ & 5.901 & 0.389 & 108.6 & 14.8239 & 0.4 \\
\hline 17 & $12: 22: 01.95$ & $-71: 14: 31.91$ & 6.906 & 0.654 & 117. & 14.9883 & 0.4 \\
\hline 18 & $12: 22: 01.77$ & $-71: 14: 02.96$ & 6.773 & 0.292 & 115.3 & 14.2547 & 0.4 \\
\hline 22 & $12: 22: 03.20$ & $-71: 18: 17.66$ & 6.732 & 0.633 & 117.8 & 15.1405 & 0.4 \\
\hline 27 & $12: 22: 05.89$ & $-71: 14: 05.79$ & 7.132 & 0.955 & 122.8 & 15.6413 & 0.4001 \\
\hline 32 & $12: 22: 11.79$ & $-71: 17: 53.72$ & 9.381 & 1.204 & 117.2 & 15.487 & 0.4001 \\
\hline 34 & $12: 22: 16.39$ & $-71: 13: 19.94$ & 7.14 & 0.497 & 117.8 & 14.957 & 0.4 \\
\hline 38 & $12: 22: 21.62$ & $-71: 17: 26.43$ & 7.079 & 0.585 & 108.1 & 15.174 & 0.4 \\
\hline 45 & $12: 22: 34.85$ & $-71: 16: 42.80$ & 7.694 & 1.081 & 118.3 & 15.6331 & 0.4001 \\
\hline 51 & $12: 22: 37.68$ & $-71: 19: 07.80$ & 7.364 & 0.389 & 119.3 & 14.1438 & 0.4 \\
\hline 52 & $12: 22: 40.27$ & $-71: 18: 12.30$ & 7.736 & 0.213 & 116.3 & 13.9856 & 0.4 \\
\hline 59 & $12: 22: 47.11$ & $-71: 17: 57.36$ & 8.392 & 0.216 & 115.3 & 13.2488 & 0.4 \\
\hline 60 & $12: 22: 47.77$ & $-71: 18: 57.27$ & 7.761 & 0.248 & 114.5 & 14.1426 & 0.4 \\
\hline 63 & $12: 22: 55.58$ & $-71: 16: 01.73$ & 7.968 & 0.956 & 118.3 & 15.4063 & 0.4001 \\
\hline 68 & $12: 23: 06.41$ & $-71: 14: 53.83$ & 8.405 & 0.568 & 113. & 14.3553 & 0.4 \\
\hline 70 & $12: 23: 10.97$ & $-71: 18: 01.55$ & 8.801 & 1.177 & 119.5 & 15.3509 & 0.4001 \\
\hline 72 & $12: 23: 13.01$ & $-71: 14: 11.70$ & 8.691 & 0.669 & 118.2 & 15.175 & 0.4001 \\
\hline 73 & $12: 23: 19.45$ & $-71: 19: 05.17$ & 6.1 & 0.503 & 114.4 & 14.5568 & 0.4 \\
\hline 74 & $12: 23: 20.00$ & $-71: 18: 18.86$ & 6.042 & 0.387 & 116.6 & 15.3547 & 0.4001 \\
\hline 77 & $12: 23: 38.22$ & $-71: 17: 26.26$ & 7.788 & 0.627 & 118.5 & 14.295 & 0.4 \\
\hline
\end{tabular}

\section{5_05s.txt}

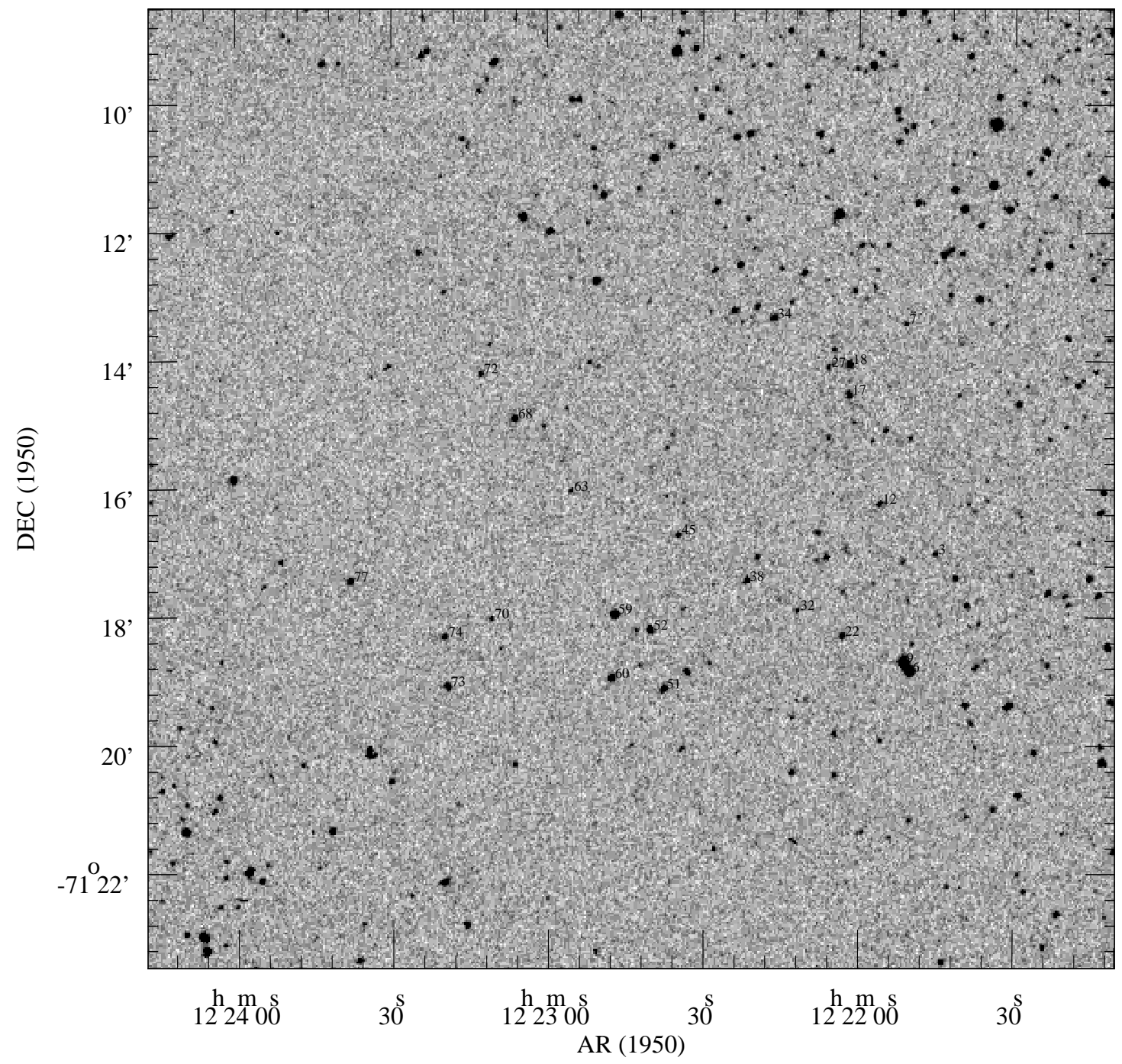

Figura C.15 Finding Chart do Campo 15 centrado em $\mathrm{AR}_{1950}=12^{\mathrm{h}} 22^{\mathrm{m}} 44^{\mathrm{s}}, \mathrm{DEC}_{1950}=-71^{\circ} 16^{\prime}$ 
Tabela C.16 Dados polarimétricos do Campo 16

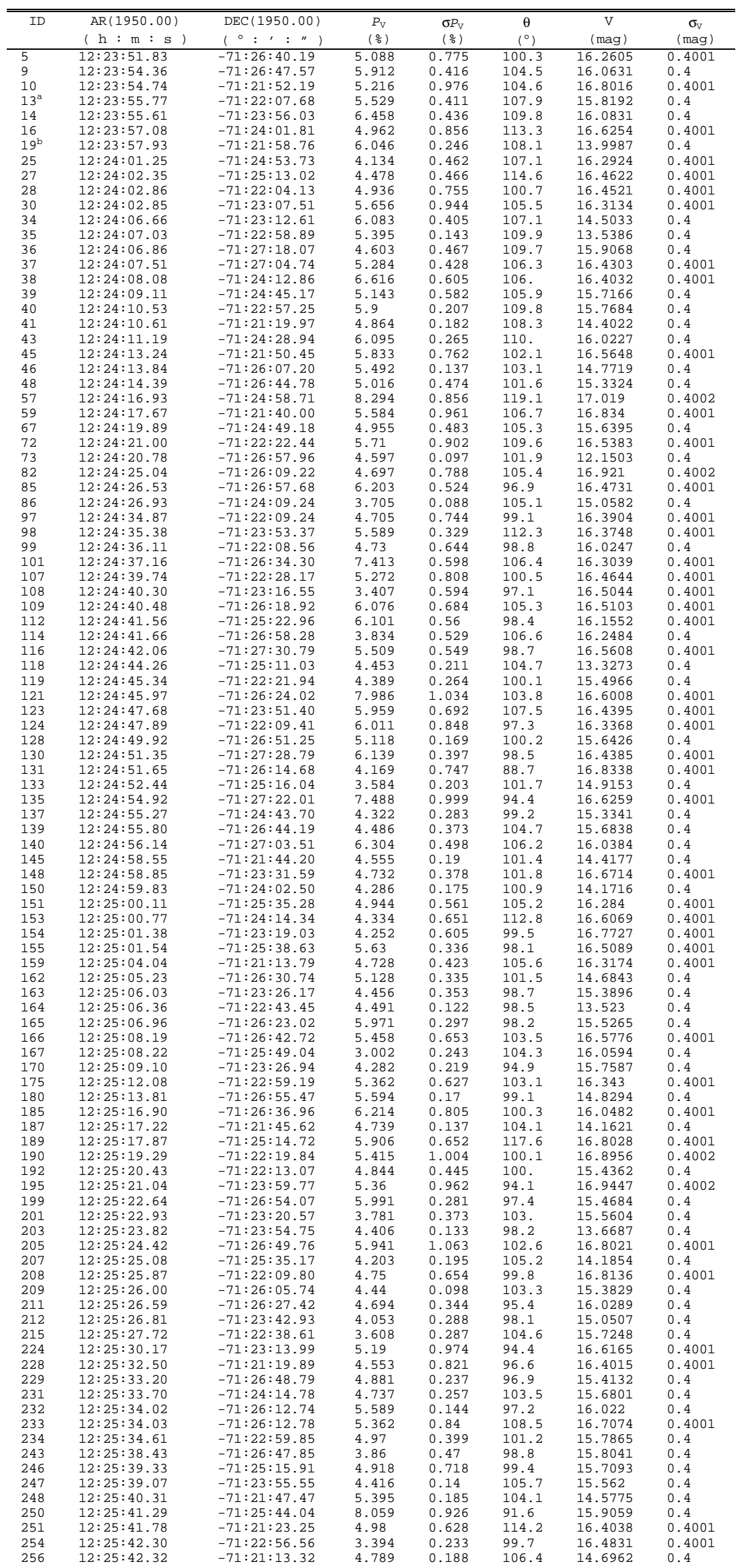


Tabela C.16 - Continuação

\begin{tabular}{|c|c|c|c|c|c|c|c|}
\hline ID & $\operatorname{AR}(1950.00)$ & $\operatorname{DEC}(1950.00)$ & $P_{\mathrm{V}}$ & $\sigma P_{\mathrm{V}}$ & $\theta$ & $\mathrm{V}$ & $\sigma_{\mathrm{v}}$ \\
\hline & $(\mathrm{h}: \mathrm{m}: \mathrm{s})$ & $\left({ }^{\circ}::^{\prime}: "{ }^{\prime \prime}\right)$ & $\left(\frac{\circ}{8}\right)$ & $\left(\frac{\circ}{\circ}\right)$ & $\left({ }^{\circ}\right)$ & (mag) & (mag) \\
\hline 257 & $12: 25: 43.93$ & $-71: 24: 41.75$ & 4.861 & 0.287 & 95.8 & 15.1678 & 0.4 \\
\hline 258 & $12: 25: 44.58$ & $-71: 25: 29.69$ & 4.574 & 0.72 & 100.1 & 15.8758 & 0.4 \\
\hline 259 & $12: 25: 45.29$ & $-71: 23: 13.19$ & 3.83 & 0.657 & 102.6 & 16.4752 & 0.4001 \\
\hline 261 & $12: 25: 46.19$ & $-71: 25: 21.11$ & 4.652 & 0.806 & 92.7 & 16.5856 & 0.4001 \\
\hline 266 & $12: 25: 48.26$ & $-71: 27: 16.44$ & 4.332 & 0.301 & 99.9 & 16.1445 & 0.4 \\
\hline 269 & $12: 25: 51.38$ & $-71: 24: 14.44$ & 6.341 & 0.883 & 98.2 & 16.5264 & 0.4001 \\
\hline 274 & $12: 25: 56.54$ & $-71: 23: 09.78$ & 3.365 & 0.48 & 108.1 & 16.1105 & 0.4 \\
\hline 276 & $12: 25: 56.98$ & $-71: 22: 28.70$ & 4.805 & 0.406 & 104. & 15.814 & 0.4 \\
\hline 277 & $12: 25: 57.39$ & $-71: 25: 04.16$ & 5.246 & 0.6 & 95.5 & 16.1643 & 0.4 \\
\hline
\end{tabular}

a mesmo objeto na Tabela B.17 com ID $=45$

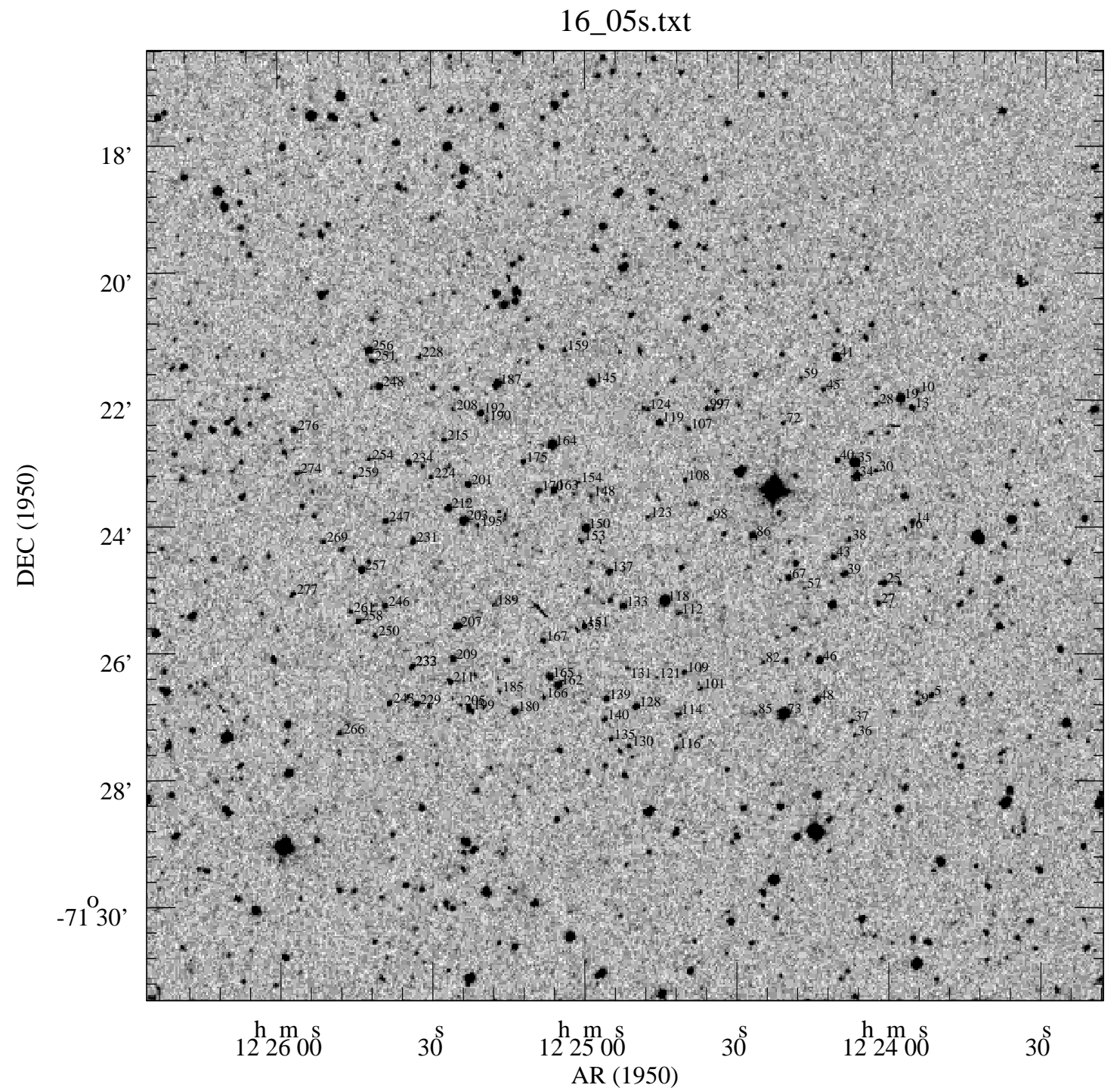

Figura C.16 Finding Chart do Campo 16 centrado em $\mathrm{AR}_{1950}=12^{\mathrm{h}} 24^{\mathrm{m}} 52^{\mathrm{s}}, \mathrm{DEC}_{1950}=-71^{\circ} 24^{\prime}$ 
Apêndice C

Tabela C.17 Dados polarimétricos do Campo 17

\begin{tabular}{|c|c|c|c|c|c|c|c|}
\hline ID & $\operatorname{AR}(1950.00)$ & $\operatorname{DEC}(1950.00)$ & $P_{P_{\mathrm{V}}}$ & $\sigma P_{\mathrm{V}}$ & $\theta$ & - & \\
\hline & $(\mathrm{h}: \mathrm{m}: \mathrm{s})$ & $\left({ }^{\circ}:{ }^{\prime}: "{ }^{\prime \prime}\right)$ & $\left(\frac{\circ}{8}\right)$ & $\left(\frac{\circ}{8}\right)$ & $\left({ }^{\circ}\right)$ & (mag) & (mag) \\
\hline 9 & $12: 23: 15.92$ & $-71: 22: 48.44$ & 5.976 & 0.792 & 115.6 & 15.2475 & 0.4 \\
\hline 11 & $12: 23: 20.00$ & $-71: 22: 08.12$ & 8.114 & 0.322 & 120.2 & 14.742 & 0.4 \\
\hline 12 & $12: 23: 21.40$ & $-71: 23: 51.13$ & 6.802 & 0.678 & 111.7 & 14.785 & 0.4 \\
\hline 14 & $12: 23: 24.89$ & $-71: 24: 33.39$ & 6.008 & 0.442 & 117.9 & 15.7738 & 0.4 \\
\hline 15 & $12: 23: 25.24$ & $-71: 27: 06.60$ & 6.095 & 0.297 & 115.5 & 13.6898 & 0.4 \\
\hline 25 & $12: 23: 36.05$ & $-71: 23: 52.13$ & 5.944 & 0.46 & 115.6 & 13.7107 & 0.4 \\
\hline 28 & $12: 23: 38.32$ & $-71: 25: 34.70$ & 5.373 & 0.407 & 112.3 & 14.4832 & 0.4 \\
\hline 29 & $12: 23: 38.61$ & $-71: 24: 50.51$ & 6.621 & 1.216 & 113.5 & 14.8942 & 0.4 \\
\hline 30 & $12: 23: 42.43$ & $-71: 24: 09.70$ & 5.769 & 0.135 & 116.1 & 11.94 & 0.4 \\
\hline $45^{\mathrm{a}}$ & $12: 23: 55.62$ & $-71: 22: 08.78$ & 7.052 & 1.091 & 123.2 & 15.7852 & 0.4001 \\
\hline $49^{b}$ & $12: 23: 57.80$ & $-71: 21: 58.46$ & 6.687 & 0.917 & 118.7 & 14.3132 & 0.4 \\
\hline
\end{tabular}

a mesmo objeto na Tabela B.16 com ID $=13$

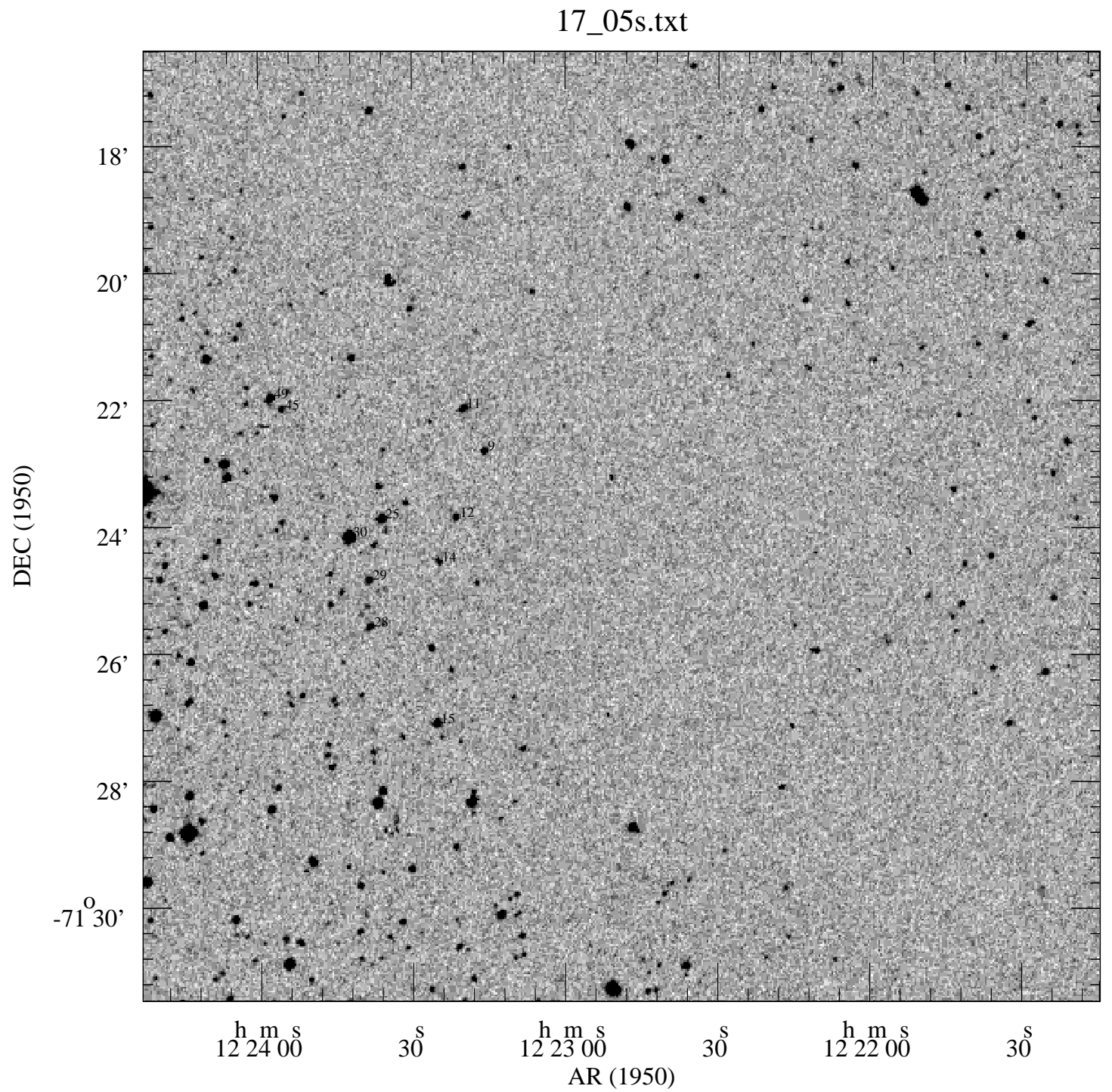

Figura C.17 Finding Chart do Campo 17 centrado em $\mathrm{AR}_{1950}=12^{\mathrm{h}} 22^{\mathrm{m}} 49^{\mathrm{s}}, \mathrm{DEC}_{1950}=-71^{\circ} 24^{\text {' }}$ 
Tabela C.18 Dados polarimétricos do Campo 18

\begin{tabular}{|c|c|c|c|c|c|c|c|}
\hline ID & $\operatorname{AR}(1950.00)$ & $\operatorname{DEC}(1950.00)$ & $P_{P_{\mathrm{V}}}$ & $\sigma P_{\mathrm{V}}$ & $\theta$ & $\mathrm{v}$ & $\overline{\sigma_{\mathrm{v}}}$ \\
\hline & $(\mathrm{h}: \mathrm{m}: \mathrm{s})$ & $\left({ }^{\circ}:{ }^{\prime}:\right.$ : $\left."\right)$ & (\%) & $\left(\frac{\circ}{0}\right)$ & $\left({ }^{\circ}\right)$ & (mag) & (mag) \\
\hline 2 & $12: 21: 44.56$ & $-71: 36: 00.51$ & 8.093 & 0.827 & 116.3 & 15.9264 & 0.4001 \\
\hline 4 & $12: 21: 52.87$ & $-71: 37: 20.72$ & 4.619 & 0.568 & 111.6 & 16.0122 & 0.4 \\
\hline 5 & $12: 21: 52.89$ & $-71: 38: 33.90$ & 4.074 & 0.116 & 106.6 & 14.3741 & 0.4 \\
\hline 6 & $12: 21: 54.24$ & $-71: 38: 02.07$ & 5. & 0.199 & 108.3 & 14.8291 & 0.4 \\
\hline 7 & $12: 21: 55.45$ & $-71: 36: 58.62$ & 5.809 & 0.644 & 112.2 & 16.1952 & 0.4001 \\
\hline 8 & $12: 21: 57.07$ & $-71: 38: 39.16$ & 5.018 & 0.151 & 105.4 & 13.9023 & 0.4 \\
\hline 12 & $12: 22: 06.87$ & $-71: 35: 36.79$ & 5.294 & 0.383 & 112.4 & 15.1387 & 0.4 \\
\hline 13 & $12: 22: 07.85$ & $-71: 36: 40.79$ & 5.328 & 0.655 & 97.2 & 15.3482 & 0.4 \\
\hline 14 & $12: 22: 08.40$ & $-71: 37: 17.99$ & 4.46 & 0.613 & 108.3 & 15.3701 & 0.4 \\
\hline 15 & $12: 22: 09.55$ & $-71: 34: 49.85$ & 5.547 & 0.387 & 113.3 & 14.7313 & 0.4 \\
\hline 17 & $12: 22: 10.61$ & $-71: 33: 30.39$ & 6.648 & 0.407 & 120.9 & 15.9015 & 0.4 \\
\hline 18 & $12: 22: 12.25$ & $-71: 36: 45.71$ & 5.81 & 0.566 & 107.1 & 16.0532 & 0.4001 \\
\hline 23 & $12: 22: 15.84$ & $-71: 37: 00.36$ & 4.221 & 0.114 & 103.9 & 15.0589 & 0.4 \\
\hline 24 & $12: 22: 16.07$ & $-71: 38: 29.33$ & 3.402 & 0.536 & 96.6 & 15.4878 & 0.4 \\
\hline 26 & $12: 22: 17.96$ & $-71: 39: 25.42$ & 5.758 & 0.751 & 104.2 & 16.4337 & 0.4001 \\
\hline 29 & $12: 22: 18.49$ & $-71: 37: 11.37$ & 4.734 & 0.515 & 109. & 15.6854 & 0.4 \\
\hline 36 & $12: 22: 23.64$ & $-71: 36: 00.83$ & 4.948 & 0.15 & 108.6 & 12.6265 & 0.4 \\
\hline 37 & $12: 22: 25.25$ & $-71: 33: 23.47$ & 4.546 & 0.207 & 115.2 & 14.7652 & 0.4 \\
\hline 38 & $12: 22: 26.14$ & $-71: 38: 17.22$ & 4.85 & 0.216 & 103.6 & 14.9085 & 0.4 \\
\hline 40 & $12: 22: 27.54$ & $-71: 38: 20.31$ & 6.379 & 0.891 & 97. & 15.9229 & 0.4001 \\
\hline 41 & $12: 22: 27.94$ & $-71: 33: 39.06$ & 4.594 & 0.33 & 112.7 & 14.7946 & 0.4 \\
\hline 43 & $12: 22: 30.13$ & $-71: 34: 23.28$ & 3.656 & 0.654 & 104.3 & 15.9523 & 0.4001 \\
\hline 44 & $12: 22: 30.52$ & $-71: 37: 47.98$ & 5.241 & 0.399 & 103.1 & 15.9448 & 0.4 \\
\hline 45 & $12: 22: 31.88$ & $-71: 39: 23.81$ & 5.034 & 0.27 & 112.2 & 15.6761 & 0.4 \\
\hline 46 & $12: 22: 32.76$ & $-71: 35: 32.35$ & 5.776 & 0.899 & 115.7 & 15.1293 & 0.4 \\
\hline 49 & $12: 22: 35.11$ & $-71: 34: 17.63$ & 6.419 & 0.422 & 113 & 16.4581 & 0.4001 \\
\hline 50 & $12: 22: 36.17$ & $-71: 37: 37.81$ & 4.731 & 0.166 & 108.1 & 14.5951 & 0.4 \\
\hline 51 & $12: 22: 36.15$ & $-71: 34: 55.17$ & 4.36 & 0.682 & 107.4 & 15.9884 & 0.4001 \\
\hline 53 & $12: 22: 38.12$ & $-71: 38: 01.81$ & 5.57 & $\begin{array}{l}0.00 \\
0.59\end{array}$ & 101. & 16.344 & 0.4001 \\
\hline 54 & $12: 22: 38.30$ & $-71: 35: 00.44$ & 4.375 & 0.162 & 110.2 & 14.1237 & 0.4 \\
\hline 55 & $12: 22: 38.32$ & $-71: 36: 59.08$ & 4.479 & 0.54 & 107.4 & 15.9953 & 0.4 \\
\hline 57 & $12: 22: 39.06$ & $-71: 39: 32.66$ & 5.286 & 0.73 & 106.6 & 16.0549 & 0.4001 \\
\hline 59 & $12: 22: 40.20$ & $-71: 39: 31.77$ & 4.454 & 0.148 & 106.5 & 12.8296 & 0.4 \\
\hline 63 & $12: 22: 41.88$ & $-71: 37: 45.22$ & 4.598 & 0.786 & 115.5 & 16.5623 & 0.4001 \\
\hline 64 & $12: 22: 41.80$ & $-71: 35: 40.58$ & 5.466 & 0.268 & 104.8 & 15.2025 & 0.4 \\
\hline 65 & $12: 22: 43.14$ & $-71: 33: 54.48$ & 4.604 & 0.293 & 107.6 & 14.8174 & 0.4 \\
\hline 67 & $12: 22: 43.90$ & $-71: 36: 16.16$ & 3.564 & 0.655 & 113.1 & 15.9931 & 0.4001 \\
\hline 70 & $12: 22: 45.90$ & $-71: 33: 48.94$ & 4.758 & 0.308 & 111.2 & 15.639 & 0.4 \\
\hline 71 & $12: 22: 46.71$ & $-71: 39: 34.64$ & 3.227 & 0.212 & 114.2 & 16.2382 & 0.4001 \\
\hline 72 & $12: 22: 46.94$ & $-71: 38: 16.30$ & 5.573 & 0.673 & 118.2 & 15.8162 & 0.4 \\
\hline 75 & $12: 22: 51.89$ & $-71: 38: 59.55$ & 4.623 & 0.455 & 109.3 & 16.1736 & 0.4001 \\
\hline 77 & $12: 22: 53.88$ & $-71: 37: 45.40$ & 5.01 & 0.195 & 102.5 & 14.6167 & 0.4 \\
\hline 79 & $12: 22: 56.17$ & $-71: 39: 19.13$ & 7.284 & 0.858 & 104.8 & 15.9454 & 0.4001 \\
\hline 81 & $12: 22: 57.20$ & $-71: 33: 29.13$ & 4.551 & 0.509 & 104.4 & 16.0461 & 0.4001 \\
\hline 82 & $12: 22: 57.90$ & $-71: 34: 50.58$ & 3.979 & 0.194 & 107.3 & 15.1272 & 0.4 \\
\hline 85 & $12: 23: 00.94$ & $-71: 36: 26.90$ & 4.17 & 0.323 & 104 & 15.3706 & 0.4 \\
\hline 89 & $12: 23: 02.55$ & $-71: 38: 01.80$ & 4.291 & 0.606 & 105.5 & 16.28 & 0.4001 \\
\hline 90 & $12: 23: 02.65$ & $-71: 37: 42.19$ & 5.159 & 0.75 & 110.1 & 16.279 & 0.4001 \\
\hline 91 & $12: 23: 02.48$ & $-71: 34: 41.74$ & 4.547 & 0.148 & 108.1 & 14.5382 & 0.4 \\
\hline 93 & $12: 23: 03.81$ & $-71: 33: 43.04$ & 4.531 & 0.484 & 103.7 & 15.2957 & 0.4 \\
\hline 97 & $12: 23: 07.08$ & $-71: 35: 46.89$ & 4.126 & 0.296 & 104.4 & 15.6248 & 0.4 \\
\hline 100 & $12: 23: 09.59$ & $-71: 35: 47.13$ & 4.879 & 0.51 & 103.3 & 16.1202 & 0.4001 \\
\hline 101 & $12: 23: 09.84$ & $-71: 36: 29.86$ & 4.813 & 0.775 & 105.1 & 15.826 & 0.4 \\
\hline 105 & $12: 23: 11.47$ & $-71: 37: 26.32$ & 3.95 & 0.192 & 107.3 & 12.7956 & 0.4 \\
\hline 109 & $12: 23: 11.93$ & $-71: 35: 11.65$ & 4.616 & 0.693 & 103.9 & 16.3386 & 0.4001 \\
\hline 119 & $12: 23: 16.49$ & $-71: 33: 50.46$ & 4.518 & 0.397 & 104.7 & 14.9858 & 0.4 \\
\hline 120 & $12: 23: 17.62$ & $-71: 39: 15.02$ & 4.451 & 0.191 & 109.3 & 16.0773 & 0.4001 \\
\hline 121 & $12: 23: 17.56$ & $-71: 37: 01.55$ & 5.787 & 0.422 & 106.6 & 15.9696 & 0.4 \\
\hline 124 & $12: 23: 20.53$ & $-71: 36: 50.66$ & 5.155 & 0.509 & 106.6 & 15.8582 & 0.4 \\
\hline 125 & $12: 23: 20.68$ & $-71: 33: 36.24$ & 4.807 & 0.937 & 108.2 & 16.0084 & 0.4 \\
\hline 128 & $12: 23: 22.51$ & $-71: 35: 17.72$ & 4.523 & 0.097 & 102.2 & 13.9908 & 0.4 \\
\hline 129 & $12: 23: 22.89$ & $-71: 37: 59.47$ & 4.072 & 0.061 & 103.3 & 12.1186 & 0.4 \\
\hline 132 & $12: 23: 24.46$ & $-71: 35: 39.33$ & 3.636 & 0.323 & 102.4 & 14.5996 & 0.4 \\
\hline 134 & $12: 23: 25.19$ & $-71: 39: 32.18$ & 5.17 & 0.175 & 105.7 & 13.2472 & 0.4 \\
\hline 137 & $12: 23: 25.45$ & $-71: 36: 20.08$ & 3.476 & 0.431 & 105. & 15.2553 & 0.4 \\
\hline 138 & $12: 23: 25.32$ & $-71: 34: 03.61$ & 4.013 & 0.114 & 105. & 11.5756 & 0.4 \\
\hline 145 & $12: 23: 27.78$ & $-71: 38: 56.17$ & 3.801 & 0.279 & 99.3 & 15.4921 & 0.4 \\
\hline 147 & $12: 23: 28.11$ & $-71: 39: 30.03$ & 6.151 & 0.649 & 103.3 & 15.6725 & 0.4 \\
\hline 149 & $12: 23: 28.57$ & $-71: 37: 33.09$ & 5.598 & 0.848 & 107.2 & 15.9635 & 0.4 \\
\hline 151 & $12: 23: 30.76$ & $-71: 38: 46.30$ & 4.082 & 0.191 & 97.4 & 13.8194 & 0.4 \\
\hline 153 & $12: 23: 32.05$ & $-71: 37: 29.30$ & 3.804 & 0.714 & 96.1 & 16.0423 & 0.4001 \\
\hline 154 & $12: 23: 32.41$ & $-71: 36: 33.48$ & 6.282 & 0.986 & 108.2 & 16.1239 & 0.4001 \\
\hline 161 & $12: 23: 35.58$ & $-71: 37: 04.82$ & 4.516 & 0.779 & 105.6 & 16.4498 & 0.4001 \\
\hline 163 & $12: 23: 36.34$ & $-71: 34: 55.56$ & 4.916 & 0.81 & 100.8 & 16.3769 & 0.4001 \\
\hline 166 & $12: 23: 37.41$ & $-71: 37: 27.68$ & 4.225 & 0.518 & 104.2 & 15.3334 & 0.4 \\
\hline 169 & $12: 23: 39.83$ & $-71: 37: 27.16$ & 4.815 & 0.186 & 104.2 & 14.1395 & 0.4 \\
\hline 171 & $12: 23: 42.51$ & $-71: 38: 00.33$ & 5.47 & 0.728 & 104.5 & 15.4083 & 0.4 \\
\hline 173 & $12: 23: 42.52$ & $-71: 38: 39.80$ & 4.303 & 0.306 & 101.3 & 15.5668 & 0.4 \\
\hline 177 & $12: 23: 48.07$ & $-71: 37: 32.35$ & 5.303 & 0.135 & 102.3 & 14.9575 & 0.4 \\
\hline 180 & $12: 23: 48.87$ & $-71: 33: 59.36$ & 5.282 & 0.843 & 114.1 & 16.367 & 0.4001 \\
\hline 183 & $12: 23: 51.49$ & $-71: 39: 05.41$ & 4.437 & 0.088 & 102.6 & 10.7889 & 0.4 \\
\hline 188 & $12: 22: 26.60$ & $-71: 34: 45.67$ & 6.223 & 0.894 & 113.7 & 15.3037 & 0.4 \\
\hline
\end{tabular}


Apêndice C

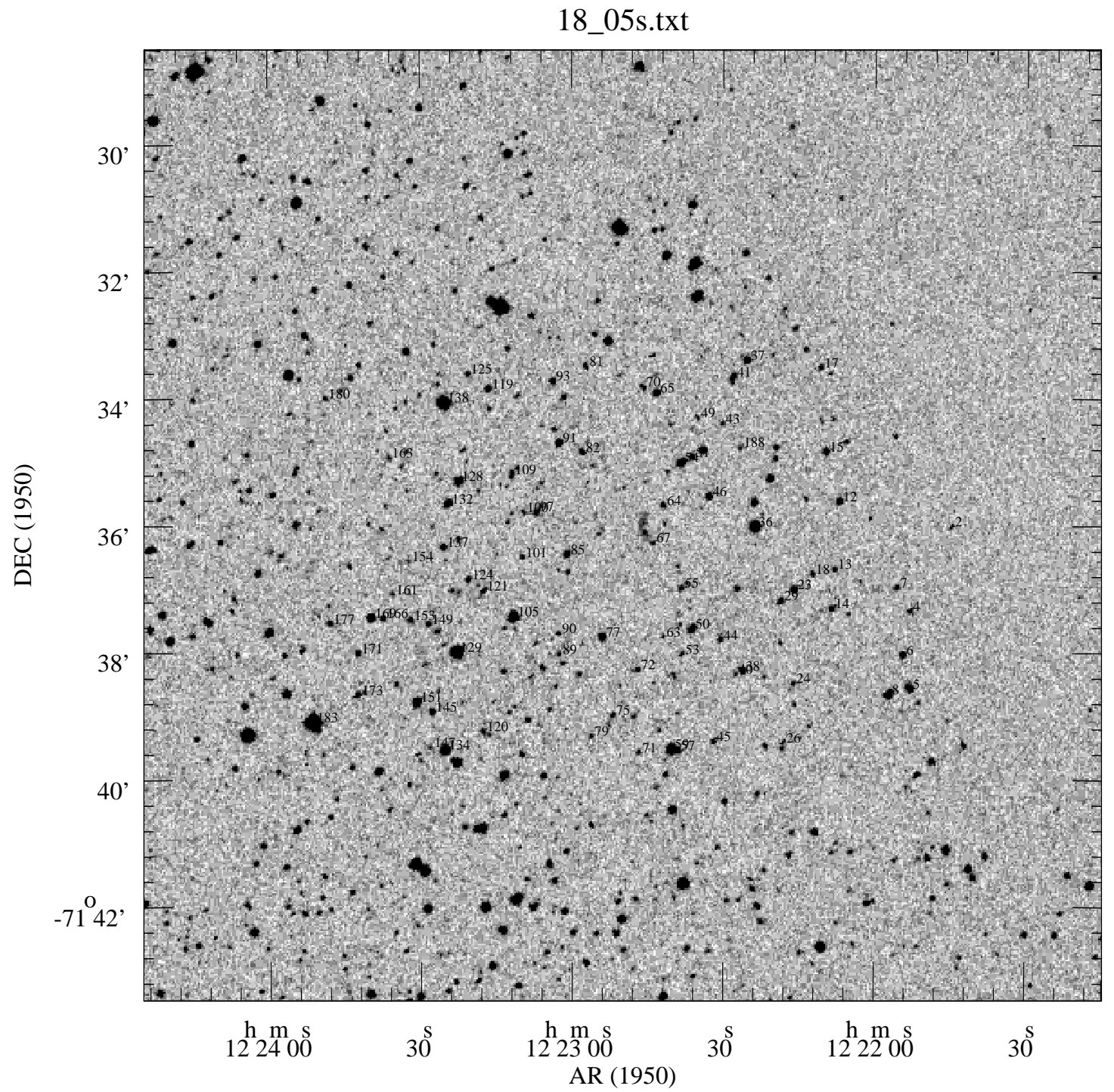

Figura C.18 Finding Chart do Campo 18 centrado em $\mathrm{AR}_{1950}=12^{\mathrm{h}} 22^{\mathrm{m}} 50^{\mathrm{s}}, \mathrm{DEC}_{1950}=-71^{\circ} 36^{\prime}$ 
Tabela C.19 Dados polarimétricos do Campo 19

\begin{tabular}{|c|c|c|c|c|c|c|c|}
\hline \multirow[t]{2}{*}{ 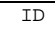 } & $\overline{A R}(1950.00)$ & 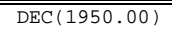 & \multirow{2}{*}{$\begin{array}{l}P_{\mathrm{V}} \\
\left(\frac{0}{0}\right)\end{array}$} & \multirow{2}{*}{$\begin{array}{l}\sigma P_{\mathrm{V}} \\
(\%)\end{array}$} & \multirow{2}{*}{$\begin{array}{c}\theta \\
\left(^{\circ}\right)\end{array}$} & \multirow{2}{*}{$\begin{array}{c}\mathrm{V} \\
\text { (mag) }\end{array}$} & \multirow{2}{*}{$\begin{array}{c}\sigma_{\mathrm{v}} \\
(\mathrm{mag})\end{array}$} \\
\hline & $(\mathrm{h}: \mathrm{m}: \mathrm{s})$ & $\left({ }^{\circ}:{ }^{\prime}: ",\right)$ & & & & & \\
\hline 5 & $12: 18: 47.99$ & $-71: 33: 41.39$ & 4.027 & 0.314 & 100.5 & 15.9062 & 0.4 \\
\hline 8 & $12: 18: 48.74$ & $-71: 37: 42.97$ & 6.227 & 0.698 & 86.4 & 16.8115 & 0.4001 \\
\hline 10 & $12: 18: 51.17$ & $-71: 35: 34.54$ & 4.965 & 0.217 & 100.3 & 15.1465 & 0.4 \\
\hline 11 & $12: 18: 51.81$ & $-71: 34: 11.43$ & 4.455 & 0.089 & 102.5 & 11.5873 & 0.4 \\
\hline 12 & $12: 18: 51.67$ & $-71: 35: 03.11$ & 5.032 & 0.075 & 101.3 & 14.527 & 0.4 \\
\hline 13 & $12: 18: 52.47$ & $-71: 39: 07.41$ & 4.71 & 0.127 & 97.2 & 12.3893 & 0.4 \\
\hline 14 & $12: 18: 53.98$ & $-71: 35: 26.53$ & 5.351 & 0.162 & 102.5 & 16.1397 & 0.4 \\
\hline 15 & $12: 18: 54.43$ & $-71: 34: 25.19$ & 5.322 & 0.508 & 100.8 & 16.5622 & 0.4001 \\
\hline 20 & $12: 18: 56.95$ & $-71: 37: 16.81$ & 7.34 & 0.874 & 107.4 & 15.9308 & 0.4 \\
\hline 22 & $12: 18: 57.85$ & $-71: 34: 56.44$ & 5.546 & 0.576 & 101.2 & 16.5731 & 0.4001 \\
\hline 23 & $12: 18: 57.99$ & $-71: 35: 37.10$ & 3.044 & 0.279 & 101.9 & 15.0477 & 0.4 \\
\hline 27 & $12: 19: 00.02$ & $-71: 36: 50.40$ & 4.916 & 0.968 & 104.9 & 16.7042 & 0.4001 \\
\hline 29 & $12: 19: 02.22$ & $-71: 33: 51.87$ & 5.526 & 0.606 & 98.8 & 16.4223 & 0.4001 \\
\hline 30 & $12: 19: 02.73$ & $-71: 34: 17.44$ & 5.944 & 0.86 & 111.3 & 16.9088 & 0.4001 \\
\hline 31 & $12: 19: 03.12$ & $-71: 38: 12.88$ & 7.285 & 0.79 & 107.1 & 16.5572 & 0.4001 \\
\hline 32 & $12: 19: 04.07$ & $-71: 35: 15.05$ & 4.665 & 0.153 & 103.6 & 13.875 & 0.4 \\
\hline 34 & $12: 19: 04.55$ & $-71: 36: 55.77$ & 6.197 & 0.946 & 114.8 & 16.5179 & 0.4001 \\
\hline 35 & $12: 19: 04.87$ & $-71: 38: 08.75$ & 4.269 & 0.405 & 98.7 & 16.0456 & 0.4 \\
\hline 43 & $12: 19: 10.56$ & $-71: 35: 38.11$ & 4.791 & 0.432 & 102.3 & 16.2667 & 0.4 \\
\hline 45 & $12: 19: 11.21$ & $-71: 36: 43.91$ & 5.601 & 0.984 & 90.9 & 16.4239 & 0.4001 \\
\hline 46 & $12: 19: 11.61$ & $-71: 36: 27.27$ & 5.124 & 0.238 & 106.8 & 15.7944 & 0.4 \\
\hline 47 & $12: 19: 11.85$ & $-71: 34: 22.36$ & 8.569 & 1.111 & 103.1 & 17.0843 & 0.4002 \\
\hline 48 & $12: 19: 13.81$ & $-71: 33: 55.74$ & 5.158 & 0.163 & 99.5 & 15.6196 & 0.4 \\
\hline 51 & $12: 19: 14.67$ & $-71: 36: 30.37$ & 4.423 & 0.142 & 104.2 & 13.9011 & 0.4 \\
\hline 52 & $12: 19: 15.08$ & $-71: 36: 36.82$ & 4.525 & 0.134 & 102.8 & 14.617 & 0.4 \\
\hline 54 & $12: 19: 15.82$ & $-71: 36: 47.34$ & 3.789 & 0.144 & 101.2 & 14.2892 & 0.4 \\
\hline 56 & $12: 19: 17.87$ & $-71: 36: 47.30$ & 4.79 & 0.308 & 103.5 & 15.0883 & 0.4 \\
\hline 57 & $12: 19: 18.27$ & $-71: 37: 21.90$ & 4.277 & 0.736 & 103.7 & 16.5852 & 0.4001 \\
\hline 58 & $12: 19: 19.70$ & $-71: 38: 32.35$ & 5.543 & 0.272 & 102.5 & 15.8849 & 0.4 \\
\hline 60 & $12: 19: 21.65$ & $-71: 33: 33.65$ & 3.827 & 0.366 & 104.1 & 14.7291 & 0.4 \\
\hline 62 & $12: 19: 23.66$ & $-71: 35: 27.92$ & 3.718 & 0.197 & 104.1 & 15.0653 & 0.4 \\
\hline 66 & $12: 19: 26.10$ & $-71: 33: 52.93$ & 3.814 & 0.72 & 103.9 & 15.9603 & 0.4 \\
\hline 71 & $12: 19: 27.96$ & $-71: 33: 52.25$ & 5.753 & 0.172 & 102. & 15.8105 & 0.4 \\
\hline 74 & $12: 19: 28.47$ & $-71: 37: 21.54$ & 3.96 & 0.101 & 103.4 & 14.3822 & 0.4 \\
\hline 75 & $12: 19: 29.71$ & $-71: 38: 02.14$ & 4.695 & 0.228 & 100.5 & 15.7434 & 0.4 \\
\hline 79 & $12: 19: 32.49$ & $-71: 33: 59 \cdot 37$ & 5.482 & 0.214 & 101.7 & 15.3016 & 0.4 \\
\hline 80 & $12: 19: 32.55$ & $-71: 33: 30.62$ & 3.816 & 0.543 & 95.7 & 16.7352 & 0.4001 \\
\hline 81 & $12: 19: 32.93$ & $-71: 33: 44.26$ & 4.682 & 0.368 & 107.3 & 16.4484 & 0.4001 \\
\hline 82 & $12: 19: 33.16$ & $-71: 36: 09.50$ & 4.812 & 0.336 & 102.9 & 15.1558 & 0.4 \\
\hline 83 & $12: 19: 33.45$ & $-71: 33: 12.51$ & 6.931 & 1.231 & 104.6 & 17.1836 & 0.4002 \\
\hline 89 & $12: 19: 36.37$ & $-71: 34: 49.98$ & 5.373 & 0.535 & 109.1 & 16.6444 & 0.4001 \\
\hline 90 & $12: 19: 39.04$ & $-71: 35: 49.86$ & 3.344 & 0.25 & 98.4 & 15.6883 & 0.4 \\
\hline 92 & $12: 19: 39.25$ & $-71: 33: 48.30$ & 5.837 & 0.823 & 112.9 & 16.6781 & 0.4001 \\
\hline 96 & $12: 19: 41.90$ & $-71: 36: 19.48$ & 5.128 & 0.662 & 98.3 & 16.0674 & 0.4 \\
\hline 97 & $12: 19: 42.27$ & $-71: 36: 54.02$ & 6.394 & 1.183 & 95.9 & 16.7123 & 0.4001 \\
\hline 99 & $12: 19: 44.24$ & $-71: 34: 00.26$ & 5.461 & 0.319 & 102.6 & 15.2 & 0.4 \\
\hline 100 & $12: 19: 44.94$ & $-71: 34: 05.42$ & 5.292 & 0.263 & 104.5 & 14.7498 & 0.4 \\
\hline 103 & $12: 19: 45.49$ & $-71: 36: 58.25$ & 6.951 & 0.454 & 109.1 & 15.8559 & 0.4 \\
\hline 106 & $12: 19: 48.80$ & $-71: 33: 12.04$ & 4.298 & 0.429 & 99.6 & 15.4555 & 0.4 \\
\hline 109 & $12: 19: 49.55$ & $-71: 33: 32.30$ & 4.943 & 0.722 & 99.5 & 16.7099 & 0.4001 \\
\hline 113 & $12: 19: 54.27$ & $-71: 37: 33.02$ & 8.592 & 1.09 & 99.1 & 17.0284 & 0.4002 \\
\hline 116 & $12: 19: 58.77$ & $-71: 33: 39.54$ & 5.541 & 0.938 & 103.7 & 16.6568 & 0.4001 \\
\hline 118 & $12: 20: 05.88$ & $-71: 38: 35.05$ & 5.847 & 0.091 & 100.5 & 12.0834 & 0.4 \\
\hline 119 & $12: 20: 06.27$ & $-71: 38: 25.69$ & 5.959 & 0.196 & 100.2 & 14.3502 & 0.4 \\
\hline 121 & $12: 20: 07.49$ & $-71: 34: 01.37$ & 5.617 & 0.553 & 103.1 & 16.3912 & 0.4001 \\
\hline 122 & $12: 20: 09.76$ & $-71: 37: 55.82$ & 7.871 & 0.592 & 103.4 & 15.9057 & 0.4 \\
\hline 127 & $12: 20: 11.46$ & $-71: 34: 06.10$ & 5.647 & 0.149 & 98.6 & 14.222 & 0.4 \\
\hline 130 & $12: 20: 13.92$ & $-71: 38: 12.19$ & 6.484 & 0.936 & 103.5 & 16.6188 & 0.4001 \\
\hline 132 & $12: 20: 15.21$ & $-71: 36: 17.65$ & 6.504 & 1.073 & 106.3 & 17.131 & 0.4002 \\
\hline 134 & $12: 20: 16.84$ & $-71: 36: 19.83$ & 6.112 & 0.322 & 99.7 & 15.7733 & 0.4 \\
\hline 137 & $12: 20: 20.16$ & $-71: 33: 49.46$ & 4.66 & 0.276 & 100.3 & 15.0854 & 0.4 \\
\hline 138 & $12: 20: 21.03$ & $-71: 39: 09.47$ & 6.932 & 0.77 & 95.6 & 15.8999 & 0.4 \\
\hline 139 & $12: 20: 24.23$ & $-71: 33: 37.74$ & 6.586 & 0.801 & 92.3 & 17.0011 & 0.4002 \\
\hline 140 & $12: 20: 24.63$ & $-71: 33: 52.47$ & 6.276 & 0.231 & 102.5 & 15.5684 & 0.4 \\
\hline 141 & $12: 20: 26.59$ & $-71: 37: 00.80$ & 5.529 & 0.126 & 98.2 & 13.9051 & 0.4 \\
\hline 143 & $12: 20: 31.95$ & $-71: 37: 43.73$ & 6.435 & 0.093 & 97.2 & 13.3777 & 0.4 \\
\hline 145 & $12: 20: 34.01$ & $-71: 34: 50.70$ & 6.986 & 0.653 & 102.7 & 16.7009 & 0.4001 \\
\hline 147 & $12: 20: 34.92$ & $-71: 36: 25.32$ & 5.771 & 0.354 & 97.7 & 16.1733 & 0.4 \\
\hline 149 & $12: 20: 36.08$ & $-71: 37: 50.32$ & 5.723 & 1.133 & 99.9 & 16.7851 & 0.4001 \\
\hline 150 & $12: 20: 45.59$ & $-71: 36: 04.53$ & 6.031 & 0.512 & 97.8 & 16.7231 & 0.4001 \\
\hline 151 & $12: 20: 46.56$ & $-71: 33: 27.96$ & 5.831 & 1.065 & 100.3 & 16.2835 & 0.4001 \\
\hline 153 & $12: 20: 51.22$ & $-71: 38: 51.50$ & 7.032 & 0.884 & 108.9 & 15.7741 & 0.4 \\
\hline
\end{tabular}


Apêndice C

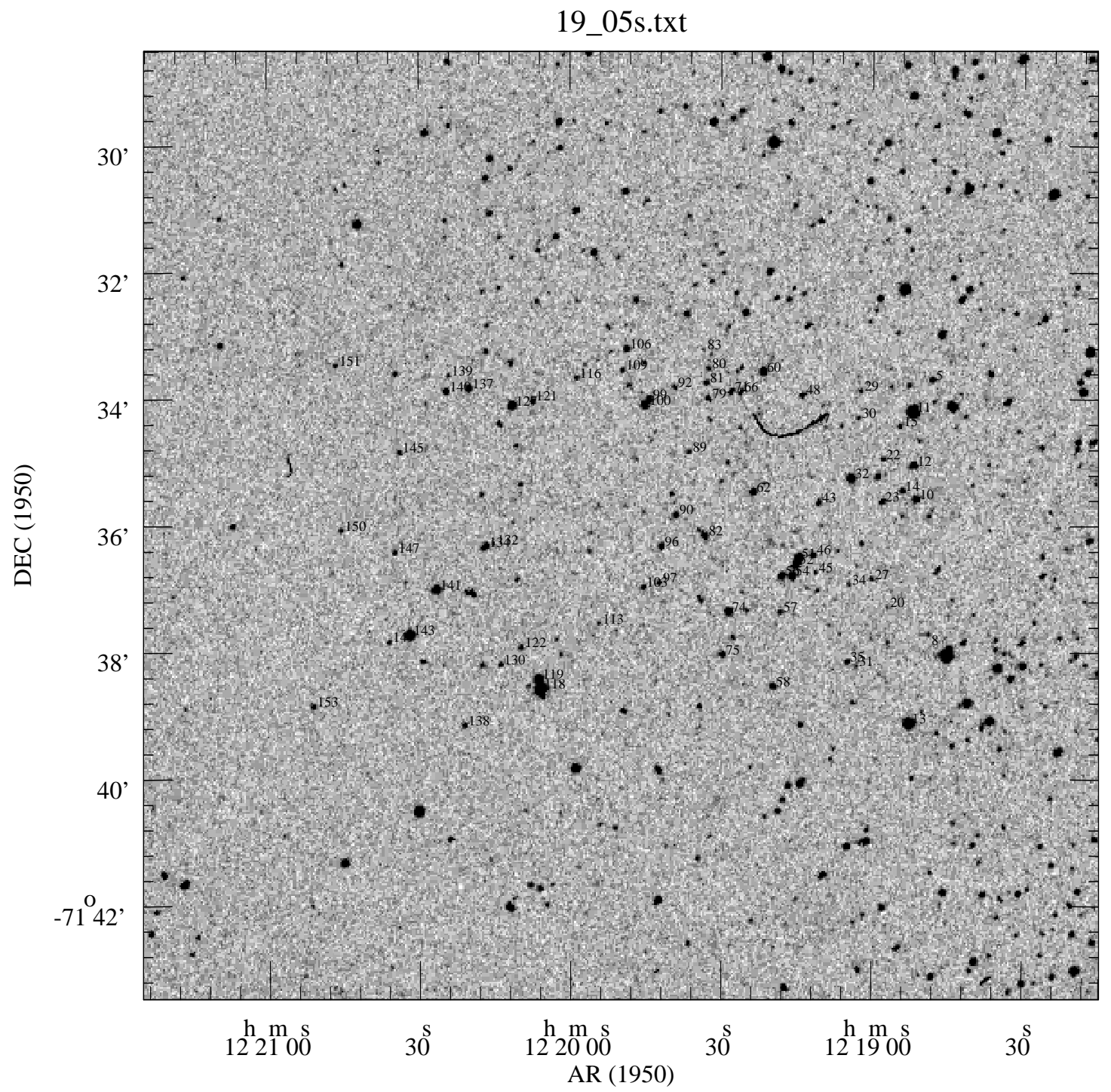

Figura C.19 Finding Chart do Campo 19 centrado em $\mathrm{AR}_{1950}=12^{\mathrm{h}} 19^{\mathrm{m}} 50^{\mathrm{s}}, \mathrm{DEC}_{1950}=-71^{\circ} 36^{\prime}$ 
Tabela C.20 Dados polarimétricos do Campo 20

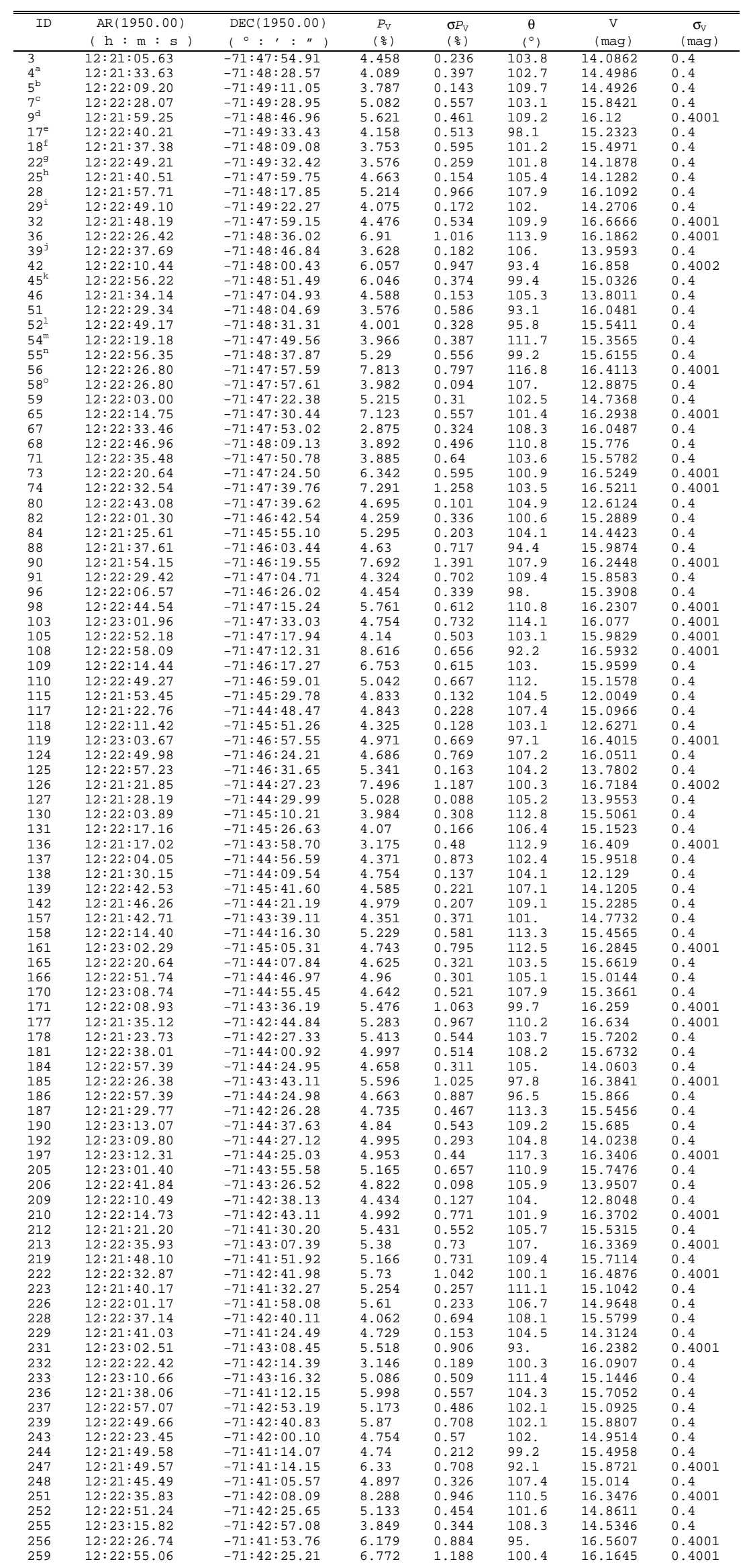


Apêndice C

Tabela C.20 - Continuação

\begin{tabular}{|c|c|c|c|c|c|c|c|}
\hline$\overline{I I D}$ & $\begin{array}{c}\operatorname{AR}(1950.00) \\
(\mathrm{h}: \mathrm{m}: \mathrm{s})\end{array}$ & $\begin{array}{l}\operatorname{DEC}(1950.00) \\
\left({ }^{\circ}::^{\prime}: "\right)\end{array}$ & $\begin{array}{l}P_{\mathrm{V}} \\
\left(\frac{\circ}{0}\right) \\
\end{array}$ & $\begin{array}{l}\sigma P_{\mathrm{V}} \\
\left(\frac{\circ}{0}\right)\end{array}$ & $\begin{array}{c}\theta \\
\left({ }^{\circ}\right) \\
\end{array}$ & $\begin{array}{c}\mathrm{V} \\
\text { (mag) }\end{array}$ & $\begin{array}{c}\sigma_{\mathrm{V}} \\
\text { (mag) }\end{array}$ \\
\hline 260 & $12: 22: 24.08$ & $-71: 41: 44 \cdot 37$ & 5.899 & 0.84 & 101.9 & 16.0247 & 0.4 \\
\hline 261 & $12: 22: 59.67$ & $-71: 42: 25.60$ & 4.739 & 0.57 & 103.9 & 15.7635 & 0.4 \\
\hline 262 & $12: 22: 50.02$ & $-71: 42: 11.34$ & 4.665 & 0.19 & 102.5 & 14.2524 & 0.4 \\
\hline 266 & $12: 22: 39.79$ & $-71: 41: 50.93$ & 6.409 & 1.079 & 90.4 & 16.2753 & 0.4001 \\
\hline 272 & $12: 22: 16.90$ & $-71: 41: 11.69$ & 4.712 & 0.45 & 106.7 & 15.3669 & 0.4 \\
\hline 273 & $12: 22: 37.84$ & $-71: 41: 38.01$ & 4.06 & 0.192 & 107.7 & 12.5291 & 0.4 \\
\hline 275 & $12: 23: 13.84$ & $-71: 42: 22.61$ & 4.233 & 0.218 & 103.3 & 14.0472 & 0.4 \\
\hline 276 & $12: 21: 49.04$ & $-71: 40: 32.12$ & 4.698 & 0.735 & 96. & 16.5304 & 0.4001 \\
\hline 278 & $12: 23: 01.39$ & $-71: 42: 03.83$ & 5.502 & 0.443 & 106.7 & 15.1496 & 0.4 \\
\hline 282 & $12: 22: 11.62$ & $-71: 40: 51.27$ & 5.643 & 0.291 & 102.7 & 14.9798 & 0.4 \\
\hline 284 & $12: 23: 07.77$ & $-71: 42: 00.64$ & 4.167 & 0.303 & 105.8 & 14.8318 & 0.4 \\
\hline 288 & $12: 23: 11.11$ & $-71: 41: 53.50$ & 5.074 & 0.21 & 105.5 & 12.7587 & 0.4 \\
\hline 289 & $12: 23: 17.16$ & $-71: 42: 00.47$ & 4.802 & 0.227 & 106.8 & 13.1296 & 0.4 \\
\hline 291 & $12: 23: 03.22$ & $-71: 41: 37.04$ & 5.067 & 0.685 & 108.9 & 15.5255 & 0.4 \\
\hline 292 & $12: 21: 51.51$ & $-71: 39: 55.24$ & 3.709 & 0.596 & 110.3 & 15.6595 & 0.4 \\
\hline 293 & $12: 23: 08.94$ & $-71: 41: 35.31$ & 4.406 & 0.859 & 109.3 & 16.4725 & 0.4001 \\
\hline 294 & $12: 21: 48.36$ & $-71: 39: 43.94$ & 4.506 & 0.337 & 101.3 & 14.7775 & 0.4 \\
\hline 296 & $12: 23: 04.64$ & $-71: 41: 20.32$ & 5.488 & 0.517 & 110.2 & 15.7626 & 0.4 \\
\hline 299 & $12: 21: 42.46$ & $-71: 39: 27.47$ & 4.603 & 0.899 & 108.5 & 15.5005 & 0.4 \\
\hline 301 & $12: 23: 01.00$ & $-71: 41: 07.17$ & 5.18 & 0.885 & 97.7 & 15.8873 & 0.4 \\
\hline 302 & $12: 22: 23.40$ & $-71: 40: 14.18$ & 4.88 & 0.82 & 99.9 & 16.3072 & 0.4001 \\
\hline 303 & $12: 22: 29.50$ & $-71: 40: 20.60$ & 4.474 & 0.314 & 106.9 & 15.7641 & 0.4 \\
\hline 306 & $12: 22: 39.94$ & $-71: 40: 29.66$ & 3.694 & 0.184 & 109.8 & 14.5143 & 0.4 \\
\hline 310 & $12: 22: 56.01$ & $-71: 40: 43.54$ & 3.599 & 0.59 & 108.1 & 15.3047 & 0.4 \\
\hline
\end{tabular}

mesmo objeto na Tabela B.22 com ID $=401$ mesmo objeto na Tabela B.22 com ID $=404$ mesmo objeto na Tabela B.22 com ID $=408$ mesmo objeto na Tabela B.22 com ID $=410$ mesmo objeto na Tabela B.22 com ID $=414$ mesmo objeto na Tabela B.22 com ID $=41$ mesmo objeto na Tabela B.22 com ID $=420$

mesmo objeto na Tabela B.22 com ID $=433$ mesmo objeto na Tabela B.22 com ID $=445$ mesmo objeto na Tabela B.22 com ID $=456$ mesmo objeto na Tabela B.22 com ID $=465$ mesmo objeto na Tabela B.22 com ID $=467$ mesmo objeto na Tabela B.22 com ID $=468$ mesmo objeto na Tabela B.22 com ID $=470$

\section{$20 \_05$ s.txt}

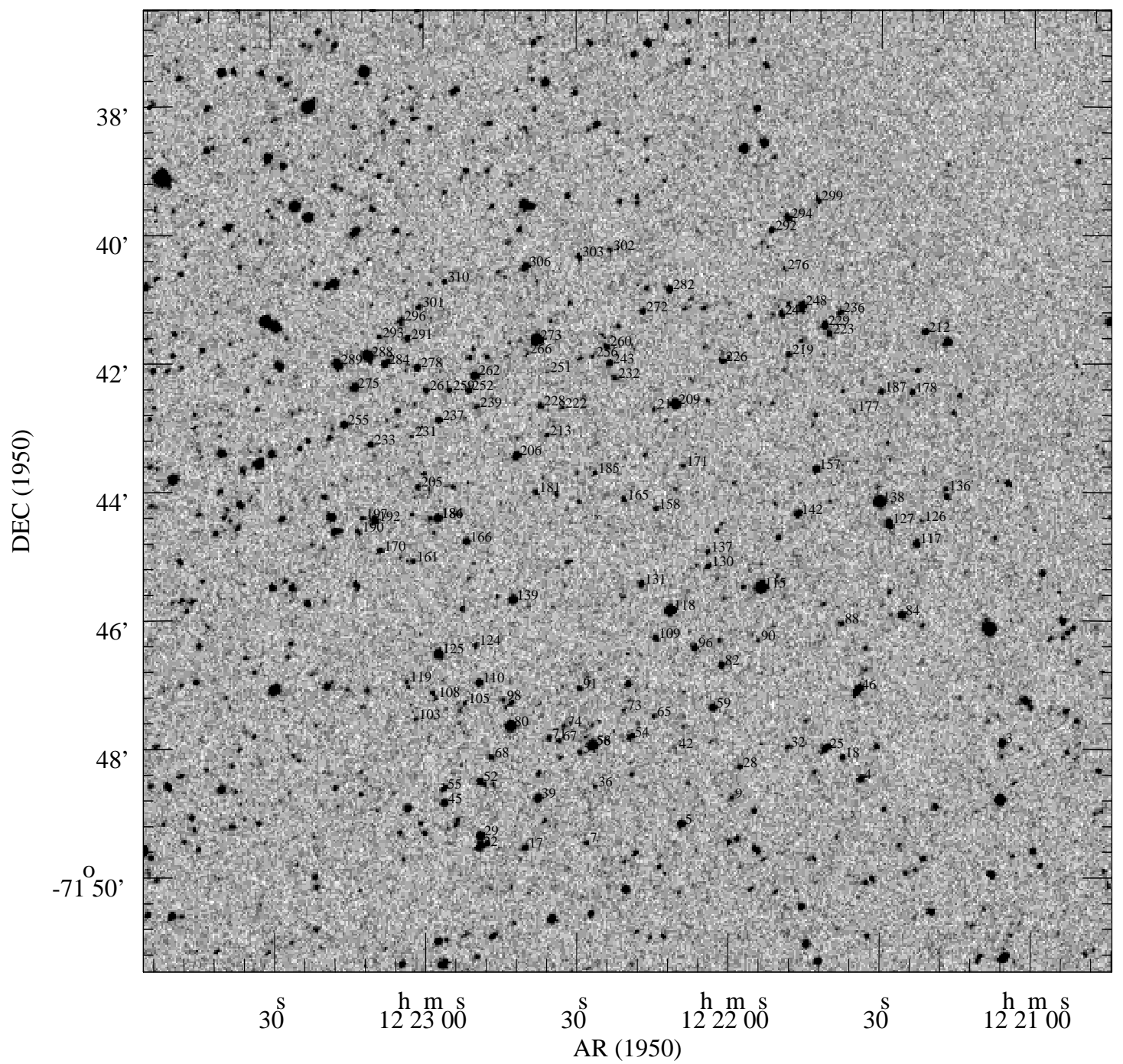

Figura C.20 Finding Chart do Campo 20 centrado em $\mathrm{AR}_{1950}=12^{\mathrm{h}} 22^{\mathrm{m}} 20^{\mathrm{s}}, \mathrm{DEC}_{1950}=-71^{\circ} 44^{\prime}$ 
Tabela C.21 Dados polarimétricos do Campo 21

\begin{tabular}{|c|c|c|c|c|c|c|c|}
\hline ID & $\begin{array}{l}\text { AR }(1950.00) \\
(\mathrm{h}: \mathrm{m}: \mathrm{s})\end{array}$ & $\begin{array}{l}\operatorname{DEC}(1950.00) \\
\left({ }^{\circ}::^{\prime}: "\right)\end{array}$ & $\begin{array}{l}P_{\mathrm{V}} \\
(\%) \\
\end{array}$ & $\begin{array}{l}\sigma P_{\mathrm{V}} \\
(\%)\end{array}$ & $\begin{array}{c}\theta \\
\left({ }^{\circ}\right) \\
\end{array}$ & $\begin{array}{c}\mathrm{V} \\
\text { (mag) }\end{array}$ & $\begin{array}{c}\sigma_{\mathrm{V}} \\
(\mathrm{mag})\end{array}$ \\
\hline 5 & $12: 19: 09.67$ & $-71: 41: 31.90$ & 6.673 & 0.229 & 97.1 & 15.1446 & 0.4 \\
\hline 9 & $12: 19: 15.18$ & $-71: 41: 53.44$ & 6.638 & 1.059 & 103. & 16.5737 & 0.4001 \\
\hline 11 & $12: 19: 17 \cdot 34$ & $-71: 43: 18.57$ & 7.711 & 0.447 & 99.1 & 15.5881 & 0.4 \\
\hline 15 & $12: 19: 20.85$ & $-71: 45: 36.26$ & 8.02 & 0.856 & 98.3 & 16.5271 & 0.4001 \\
\hline 22 & $12: 19: 34.74$ & $-71: 41: 14.80$ & 5.658 & 0.936 & 99.3 & 16.5846 & 0.4001 \\
\hline 26 & $12: 19: 42.64$ & $-71: 41: 54.91$ & 6.174 & 0.239 & 100.2 & 14.7926 & 0.4 \\
\hline 30 & $12: 20: 04.37$ & $-71: 41: 58.83$ & 7.541 & 0.871 & 103.6 & 16.7598 & 0.4001 \\
\hline 31 & $12: 20: 06.19$ & $-71: 41: 45.58$ & 5.97 & 0.562 & 102.8 & 16.2999 & 0.4001 \\
\hline 32 & $12: 20: 07.98$ & $-71: 41: 40.38$ & 5.116 & 0.604 & 105.4 & 16.4786 & 0.4001 \\
\hline 33 & $12: 20: 10.94$ & $-71: 41: 52.85$ & 9.943 & 0.822 & 111.9 & 17.0338 & 0.4002 \\
\hline 34 & $12: 20: 11.60$ & $-71: 47: 24.63$ & 5.522 & 0.45 & 106.8 & 16.0658 & 0.4 \\
\hline 35 & $12: 20: 11.97$ & $-71: 42: 02.70$ & 6.723 & 0.627 & 106.6 & 14.1082 & 0.4 \\
\hline 36 & $12: 20: 13.82$ & $-71: 44: 45.37$ & 6.155 & 0.489 & 103.4 & 16.14 & 0.4 \\
\hline 42 & $12: 20: 27.57$ & $-71: 45: 34.14$ & 7.436 & 0.544 & 111. & 15.9162 & 0.4 \\
\hline 44 & $12: 20: 29.07$ & $-71: 46: 01.24$ & 5.156 & 0.222 & 108.8 & 14.7676 & 0.4 \\
\hline 52 & $12: 20: 37.58$ & $-71: 46: 22.37$ & 4.309 & 0.566 & 107.6 & 15.5618 & 0.4 \\
\hline 53 & $12: 20: 40.37$ & $-71: 44: 12.67$ & 5.592 & 0.257 & 110.7 & 14.2932 & 0.4 \\
\hline 55 & $12: 20: 44.80$ & $-71: 41: 19.85$ & 6.091 & 0.111 & 107.9 & 14.95 & 0.4 \\
\hline 58 & $12: 20: 50.70$ & $-71: 46: 38.37$ & 4.453 & 0.42 & 106 & 16.4511 & 0.4001 \\
\hline 59 & $12: 20: 51.53$ & $-71: 46: 05.85$ & 4.36 & 0.572 & 106. & 16.2748 & 0.4001 \\
\hline 63 & $12: 20: 53.04$ & $-71: 47: 23.73$ & 5.604 & 0.464 & 116.9 & 16.4679 & 0.4001 \\
\hline 64 & $12: 20: 53.57$ & $-71: 46: 00.10$ & 4.244 & 0.382 & 108.8 & 14.7838 & 0.4 \\
\hline 68 & $12: 20: 57.93$ & $-71: 45: 14.73$ & 3.896 & 0.478 & 108.3 & 16.1064 & 0.4 \\
\hline 73 & $12: 21: 04.68$ & $-71: 43: 51.87$ & 5.802 & 0.272 & 106.5 & 15.7457 & 0.4 \\
\hline 76 & $12: 21: 08.02$ & $-71: 47: 02.87$ & 6.697 & 0.76 & 109.2 & 16.5037 & 0.4001 \\
\hline 77 & $12: 21: 08.44$ & $-71: 46: 08.37$ & 4.834 & 0.078 & 106.4 & 11.79 & 0.4 \\
\hline 82 & $12: 21: 14.51$ & $-71: 42: 29.52$ & 6.872 & 0.688 & 106.4 & 15.9692 & 0.4 \\
\hline 83 & $12: 21: 15.26$ & $-71: 42: 45.97$ & 6.486 & 1.266 & 103.9 & 16.8305 & 0.4001 \\
\hline
\end{tabular}

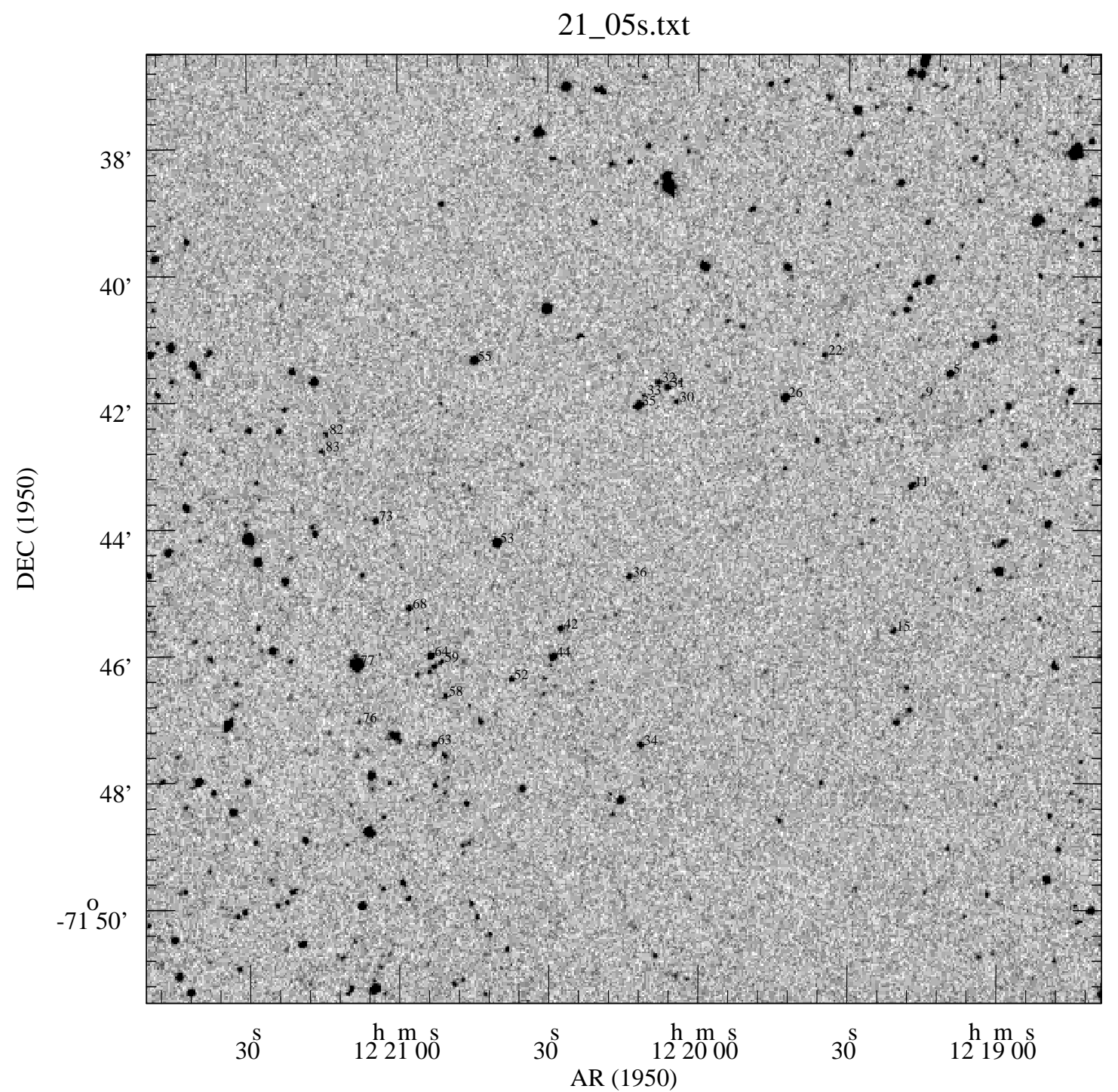

Figura C.21 Finding Chart do Campo 21 centrado em $\mathrm{AR}_{1950}=12^{\mathrm{h}} 20^{\mathrm{m}} 15^{\mathrm{s}}, \mathrm{DEC}_{1950}=-71^{\circ} 44^{\prime}$ 
Tabela C.22 Dados polarimétricos do Campo 22

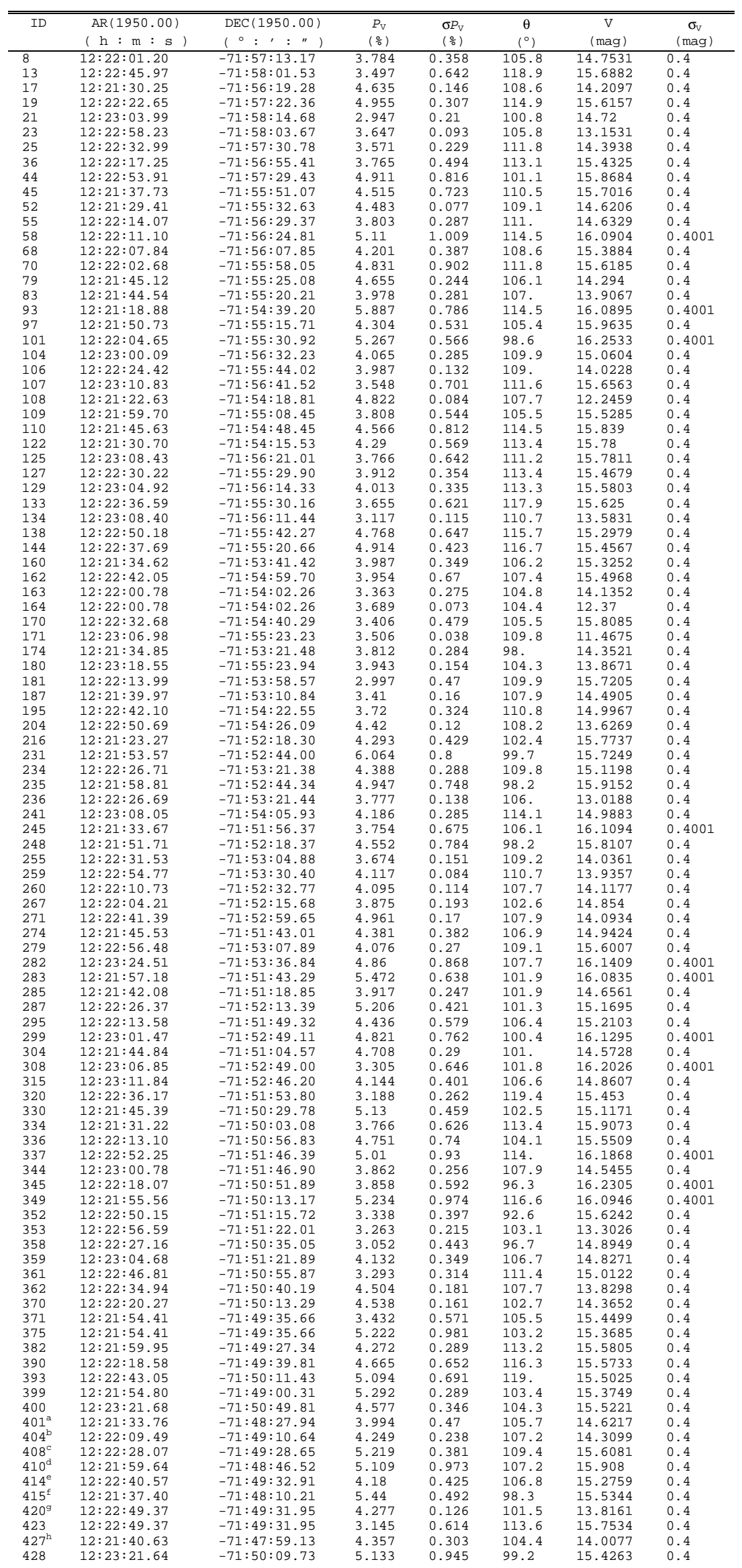


Tabela C.22 - Continuação

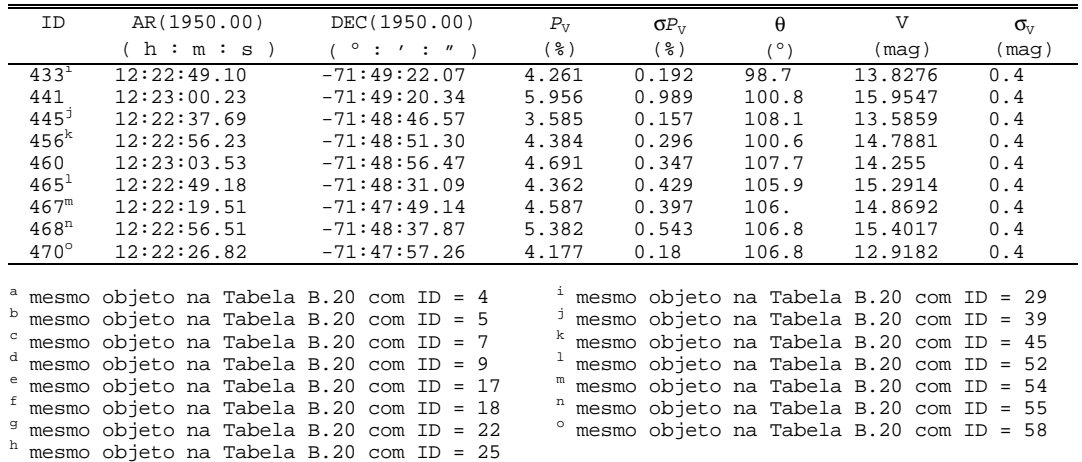

22_05s.txt

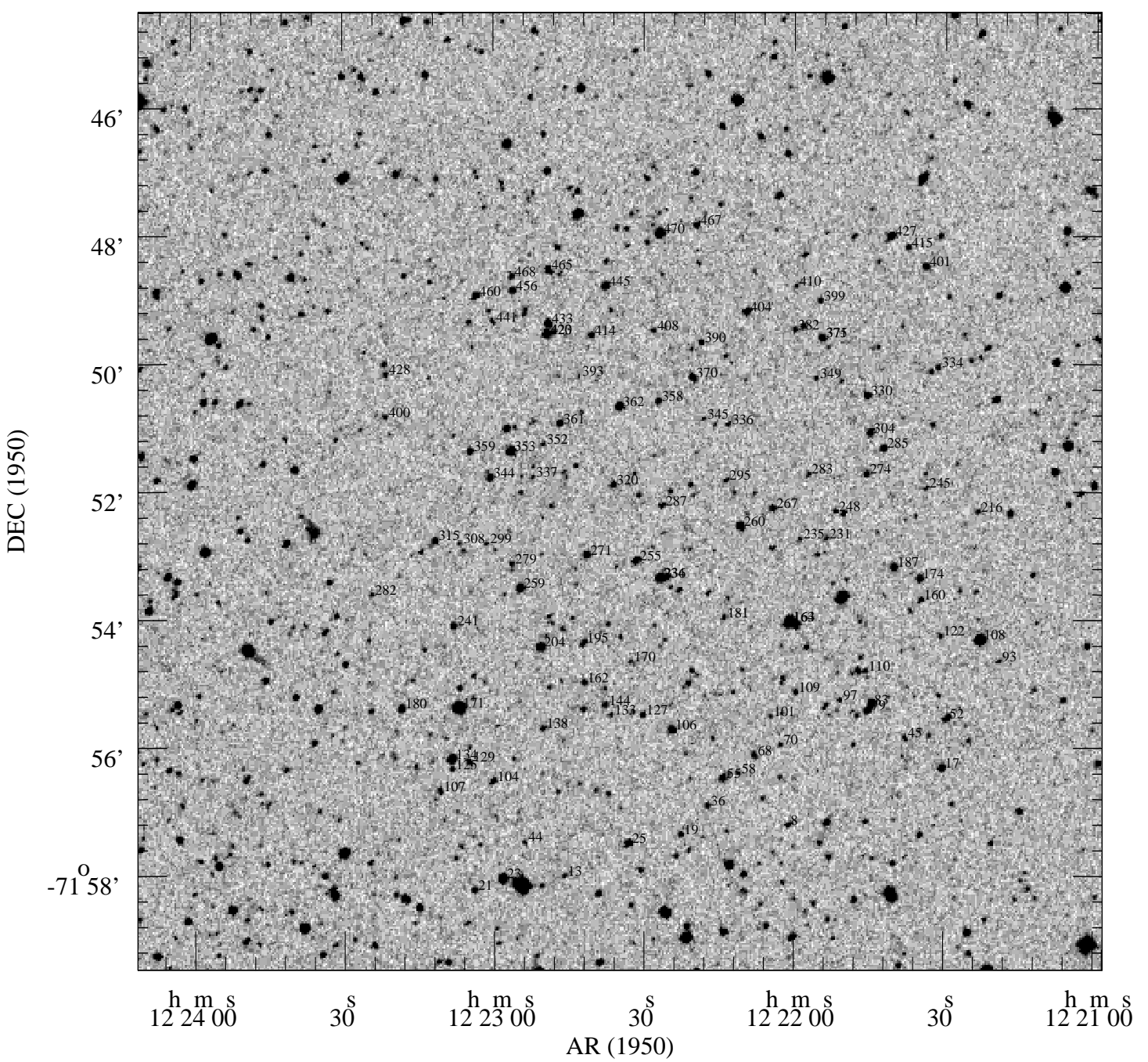

Figura C.22 Finding Chart do Campo 22 centrado em $\mathrm{AR}_{1950}=12^{\mathrm{h}} 22^{\mathrm{m}} 34.8^{\mathrm{s}}, \mathrm{DEC}_{1950}=-71^{\circ} 52^{\prime}$ 
Apêndice C

Tabela C.23 Dados polarimétricos do Campo 23

\begin{tabular}{|c|c|c|c|c|c|c|c|}
\hline \multirow[t]{2}{*}{ ID } & $\operatorname{AR}(1950.00)$ & $\operatorname{DEC}(1950.00)$ & \multirow{2}{*}{$\begin{array}{l}P_{\mathrm{V}} \\
(\%)\end{array}$} & \multirow{2}{*}{$\begin{array}{l}\sigma P_{\mathrm{V}} \\
\left(\frac{\circ}{0}\right)\end{array}$} & \multirow{2}{*}{$\begin{array}{c}\theta \\
\left({ }^{\circ}\right)\end{array}$} & \multirow{2}{*}{$\begin{array}{c}\mathrm{V} \\
\text { (mag) }\end{array}$} & \multirow{2}{*}{$\begin{array}{c}\sigma_{\mathrm{V}} \\
(\mathrm{mag})\end{array}$} \\
\hline & $(\mathrm{h}: \mathrm{m}: \mathrm{s})$ & $\left.\left({ }^{\circ}::^{\prime}: "\right)^{\prime \prime}\right)$ & & & & & \\
\hline 7 & $12: 19: 39.54$ & $-71: 54: 41.61$ & 5.799 & 0.37 & 114.6 & 14.4335 & 0.4 \\
\hline 8 & $12: 19: 44.69$ & $-71: 52: 27.21$ & 6.772 & 0.514 & 119.4 & 15.9517 & 0.4 \\
\hline 13 & $12: 20: 00.00$ & $-71: 52: 09.02$ & 4.629 & 0.923 & 111.7 & 15.8858 & 0.4 \\
\hline 17 & $12: 20: 04.91$ & $-71: 53: 51.62$ & 6.204 & 0.714 & 109.8 & 16.1176 & 0.4001 \\
\hline 20 & $12: 20: 09.83$ & $-71: 54: 56.57$ & 5.244 & 0.747 & 116.9 & 15.469 & 0.4 \\
\hline 25 & $12: 20: 17.96$ & $-71: 52: 47.16$ & 4.747 & 0.344 & 111.9 & 14.4056 & 0.4 \\
\hline 29 & $12: 20: 21.01$ & $-71: 53: 18.51$ & 5.511 & 0.846 & 108 & 15.829 & 0.4001 \\
\hline 32 & $12: 20: 22.43$ & $-71: 53: 29.97$ & 7.363 & 0.657 & 111.8 & 16.1816 & 0.4001 \\
\hline 34 & $12: 20: 26.20$ & $-71: 51: 44.24$ & 5.488 & 0.369 & 118.6 & 14.5578 & 0.4 \\
\hline 35 & $12: 20: 26.57$ & $-71: 54: 58.18$ & 5.565 & 0.575 & 109.8 & 14.2667 & 0.4 \\
\hline 42 & $12: 20: 37.48$ & $-71: 53: 46.64$ & 5.002 & 0.268 & 113.5 & 13.3213 & 0.4 \\
\hline 45 & $12: 20: 38.40$ & $-71: 51: 56.44$ & 4.127 & 0.631 & 114.5 & 16.0877 & 0.4001 \\
\hline 48 & $12: 20: 41.35$ & $-71: 54: 11.55$ & 4.561 & 0.274 & 116.3 & 13.8352 & 0.4 \\
\hline 49 & $12: 20: 41.90$ & $-71: 50: 24.83$ & 5.534 & 1.078 & 117.6 & 16.7935 & 0.4002 \\
\hline 51 & $12: 20: 44.42$ & $-71: 50: 08.27$ & 5.363 & 0.598 & 111.7 & 16.6572 & 0.4002 \\
\hline 59 & $12: 20: 49.41$ & $-71: 54: 44.62$ & 5.893 & 0.451 & 111.3 & 16.1548 & 0.4001 \\
\hline 61 & $12: 20: 49.66$ & $-71: 52: 21.02$ & 4.023 & 0.251 & 112.7 & 12.8 & 0.4 \\
\hline 69 & $12: 20: 59.27$ & $-71: 49: 36.02$ & 4.607 & 0.503 & 100.7 & 15.5489 & 0.4 \\
\hline 70 & $12: 21: 00.02$ & $-71: 51: 53.46$ & 4.273 & 0.325 & 112.4 & 14.9656 & 0.4 \\
\hline 71 & $12: 21: 01.08$ & $-71: 54: 23.85$ & 4.696 & 0.376 & 106.2 & 15.3365 & 0.4 \\
\hline 73 & $12: 21: 02.88$ & $-71: 52: 01.65$ & 4.677 & 0.743 & 107.7 & 16.1125 & 0.4001 \\
\hline 77 & $12: 21: 04.79$ & $-71: 52: 10.70$ & 4.847 & 0.521 & 110.5 & 15.9613 & 0.4001 \\
\hline 78 & $12: 21: 05.02$ & $-71: 51: 15.68$ & 3.848 & 0.248 & 109.1 & 13.6382 & 0.4 \\
\hline 79 & $12: 21: 05.82$ & $-71: 55: 14.77$ & 4.47 & 0.719 & 110.8 & 16.0396 & 0.4001 \\
\hline 82 & $12: 21: 07.56$ & $-71: 49: 58.77$ & 4.162 & 0.445 & 104.7 & 14.8694 & 0.4 \\
\hline 84 & $12: 21: 09.84$ & $-71: 51: 15.69$ & 4.6 & 0.884 & 96.7 & 16.0703 & 0.4001 \\
\hline 93 & $12: 21: 16.75$ & $-71: 52: 19.82$ & 4.025 & 0.396 & 105.2 & 14.7122 & 0.4 \\
\hline
\end{tabular}

23_05s.txt

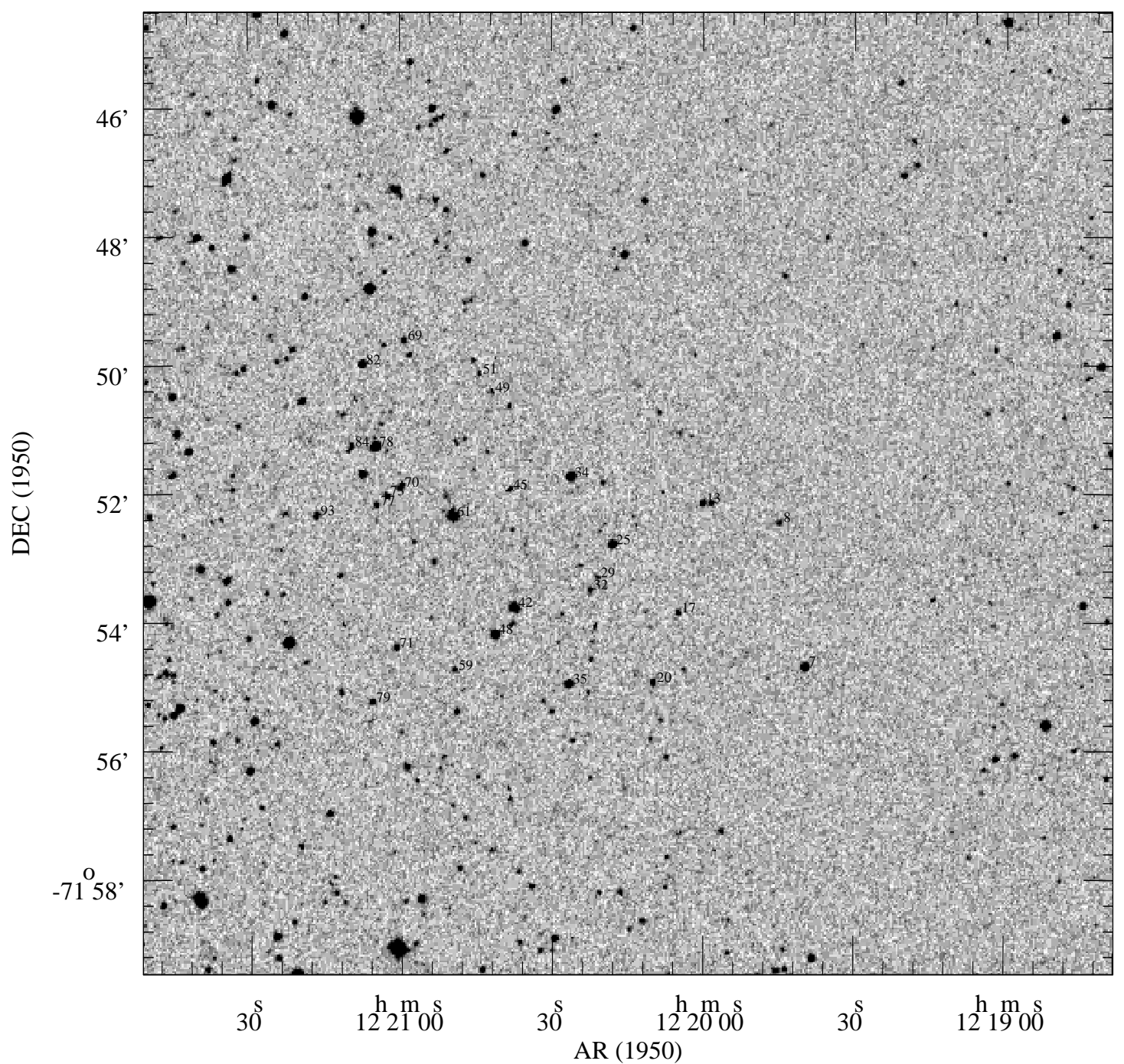

Figura C.23 Finding Chart do Campo 23 centrado em $\mathrm{AR}_{1950}=12^{\mathrm{h}} 20^{\mathrm{m}} 15^{\mathrm{s}}, \mathrm{DEC}_{1950}=-71^{\circ} 52^{\prime}$ 
Tabela C.24 Dados polarimétricos do Campo 24

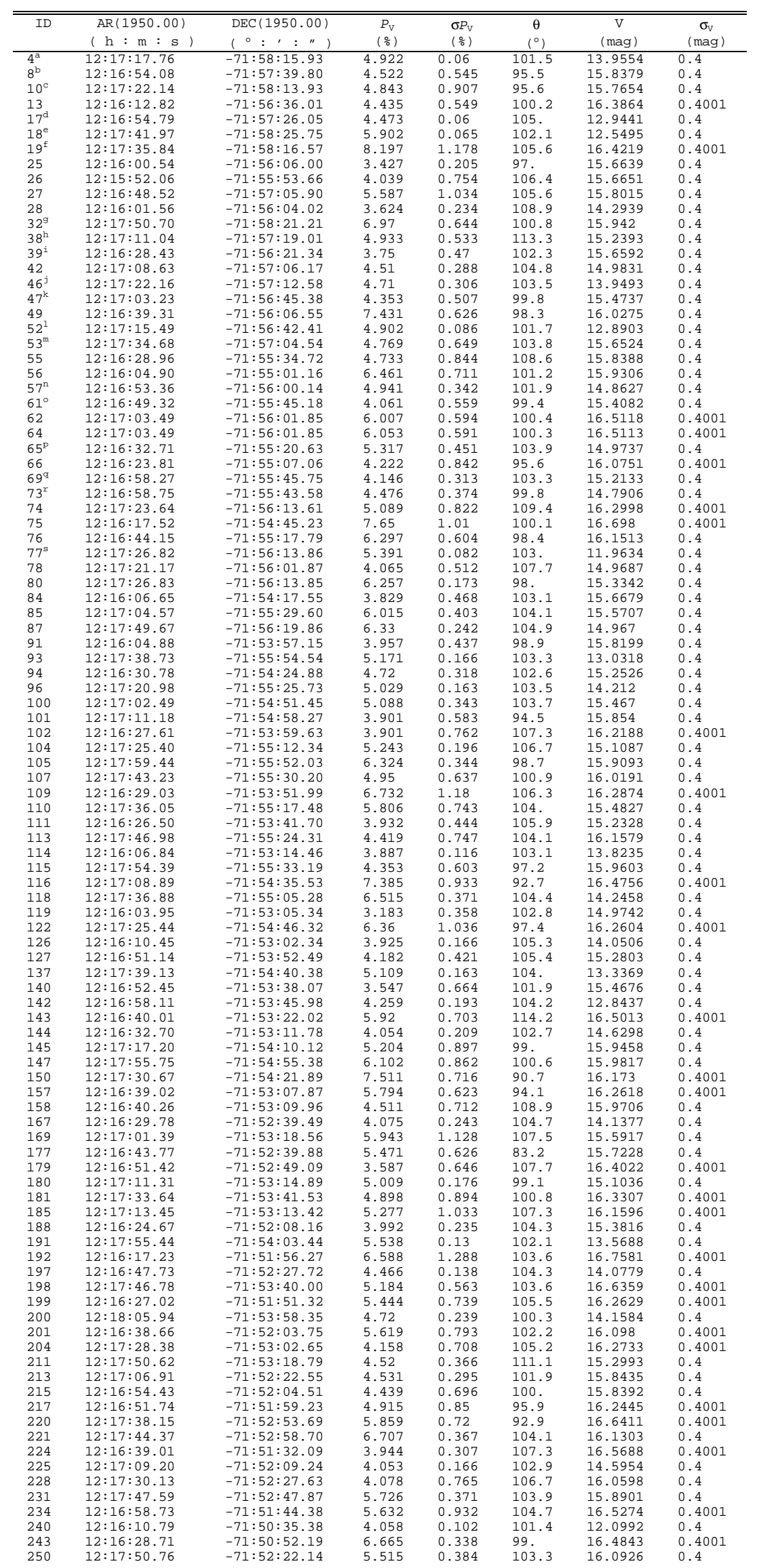


Tabela C.24 - Continuação

\begin{tabular}{|c|c|c|c|c|c|c|c|}
\hline \multirow[t]{2}{*}{ ID } & \multirow{2}{*}{$\begin{array}{l}\operatorname{AR}(1950.00) \\
(\mathrm{h}: \mathrm{m}: \mathrm{s})\end{array}$} & $\operatorname{DEC}(1950.00)$ & \multirow{2}{*}{$\begin{array}{l}P_{\mathrm{V}} \\
(\%)\end{array}$} & \multirow{2}{*}{$\begin{array}{l}\sigma P_{\mathrm{V}} \\
\left(\frac{\circ}{0}\right)\end{array}$} & \multirow{2}{*}{$\begin{array}{c}\theta \\
\left({ }^{\circ}\right)\end{array}$} & \multirow{2}{*}{$\begin{array}{c}\mathrm{V} \\
(\mathrm{mag})\end{array}$} & \multirow{2}{*}{$\begin{array}{c}\sigma_{\mathrm{v}} \\
(\mathrm{mag})\end{array}$} \\
\hline & & $\left({ }^{\circ}::^{\prime}: "\right)$ & & & & & \\
\hline 251 & $12: 16: 21.64$ & $-71: 50: 26.09$ & 3.856 & & & & \\
\hline 253 & $12: 17: 55.55$ & $-71: 52: 26.16$ & 6.476 & 0.877 & 100 & 16.7596 & 0.4001 \\
\hline 254 & $12: 16: 39.21$ & $-71: 50: 43.17$ & 3.752 & 0.589 & 101.8 & 15.7368 & 0.4 \\
\hline 255 & $12: 16: 39.14$ & $-71: 50: 43.10$ & 3.803 & 0.08 & 104.1 & 14.6184 & 0.4 \\
\hline 256 & $12: 17: 29.02$ & $-71: 51: 46.47$ & 4.115 & 0.418 & 105.6 & 14.932 & 0.4 \\
\hline 257 & $12: 18: 00.27$ & $-71: 52: 27.06$ & 4.852 & 0.686 & 105.8 & 15.4279 & 0.4 \\
\hline 260 & $12: 16: 52.69$ & $-71: 50: 45.76$ & 3.788 & 0.301 & 97.8 & 15.0929 & 0.4 \\
\hline 262 & $12: 18: 10.55$ & $-71: 52: 22.33$ & 4.416 & 0.347 & 103.9 & 16.1943 & 0.4001 \\
\hline 265 & $12: 17: 20.19$ & $-71: 51: 13.39$ & 5.978 & 0.851 & 102.2 & 16.2814 & 0.4001 \\
\hline 271 & $12: 16: 54.70$ & $-71: 50: 30.86$ & 4.568 & 0.096 & 101.4 & 14.3667 & 0.4 \\
\hline 273 & $12: 17: 35.60$ & $-71: 51: 21.41$ & 5.136 & 0.157 & 101.3 & 15.004 & 0.4 \\
\hline 274 & $12: 18: 10.15$ & $-71: 52: 04.85$ & 4.167 & 0.112 & 100.4 & 14.0032 & 0.4 \\
\hline 276 & $12: 17: 29.59$ & $-71: 51: 10.11$ & 5.515 & 0.297 & 104.5 & 14.9711 & 0.4 \\
\hline 281 & $12: 16: 27.28$ & $-71: 49: 40.57$ & 3.982 & 0.582 & 102.2 & 16.19 & 0.4 \\
\hline 282 & $12: 17: 00.75$ & $-71: 50: 18.66$ & 5.48 & 0.318 & 102.4 & 16.1044 & 0.4001 \\
\hline 294 & $12: 16: 20.09$ & $-71: 49: 03.76$ & 4.549 & 0.31 & 101.8 & 14.5294 & 0.4 \\
\hline 295 & $12: 17: 22.85$ & $-71: 50: 22.51$ & 5.66 & 0.57 & 102.5 & 15.992 & 0.4 \\
\hline 296 & $12: 16: 32.04$ & $-71: 49: 17.17$ & 4.811 & 0.187 & 100.9 & 14.5418 & 0.4 \\
\hline 297 & $12: 16: 38.41$ & $-71: 49: 26.83$ & 5.476 & 0.899 & 100.3 & 16.537 & 0.4001 \\
\hline 299 & $12: 16: 36.44$ & $-71: 49: 15.15$ & 5.099 & 0.27 & 101.7 & 14.7793 & 0.4 \\
\hline 301 & $12: 17: 22.75$ & $-71: 50: 14.48$ & 5.146 & 0.109 & 101.8 & 12.6669 & 0.4 \\
\hline 302 & $12: 16: 48.03$ & $-71: 49: 28.78$ & 4.657 & 0.086 & 100.4 & 13.1349 & 0.4 \\
\hline 305 & $12: 17: 02.15$ & $-71: 49: 42.35$ & 5.852 & 0.569 & 96.9 & 16.0708 & 0.4 \\
\hline 309 & $12: 17: 07.78$ & $-71: 49: 44.56$ & 4.99 & 0.407 & 100.4 & 15.3735 & 0.4 \\
\hline 310 & $12: 17: 12.00$ & $-71: 49: 50.14$ & 6.022 & 0.413 & 107.6 & 15.7687 & 0.4 \\
\hline 317 & $12: 17: 17.30$ & $-71: 49: 41.80$ & 5.221 & 0.855 & 110.2 & 16.6108 & 0.4001 \\
\hline 323 & $12: 17: 30.76$ & $-71: 49: 53.55$ & 5.331 & 0.982 & 96.7 & 16.2099 & 0.4001 \\
\hline 328 & $12: 17: 38.35$ & $-71: 49: 55.03$ & 6.015 & 0.175 & 99.7 & 13.7038 & 0.4 \\
\hline 330 & $12: 16: 37.12$ & $-71: 48: 32.97$ & 5.201 & 0.503 & 94.9 & 15.7677 & 0.4 \\
\hline 333 & $12: 16: 33.98$ & $-71: 48: 14.77$ & 5.22 & 0.842 & 103. & 15.6984 & 0.4 \\
\hline 337 & $12: 16: 45.88$ & $-71: 48: 28.02$ & 4.412 & 0.652 & 98.7 & 14.217 & 0.4 \\
\hline 338 & $12: 17: 09.38$ & $-71: 48: 56.34$ & 4.393 & 0.613 & 94.7 & 15.8985 & 0.4 \\
\hline 339 & $12: 16: 21.81$ & $-71: 47: 48.98$ & 5.062 & 0.996 & 103.1 & 16.4247 & 0.4001 \\
\hline 340 & $12: 17: 45.66$ & $-71: 49: 36.95$ & 4.934 & 0.287 & 101.8 & 14.6343 & 0.4 \\
\hline 341 & $12: 16: 26.36$ & $-71: 47: 53.51$ & 4.15 & 0.642 & 104.8 & 15.9207 & 0.4 \\
\hline 342 & $12: 16: 45.88$ & $-71: 48: 28.02$ & 5.58 & 0.376 & 102.6 & 15.9173 & 0.4 \\
\hline 354 & $12: 18: 11.10$ & $-71: 49: 55.54$ & 5.872 & 0.386 & 102 . & 15.4209 & 0.4 \\
\hline 355 & $12: 17: 19.83$ & $-71: 48: 49.95$ & 5.438 & 0.537 & 108.5 & 16.1833 & 0.4 \\
\hline 356 & $12: 16: 55.50$ & $-71: 48: 17.98$ & 4.6 & 0.331 & 104.8 & 14.6721 & 0.4 \\
\hline 358 & $12: 17: 36.27$ & $-71: 49: 07.86$ & 5.024 & 0.224 & 101.2 & 14.4854 & 0.4 \\
\hline 362 & $12: 16: 47.31$ & $-71: 48: 04.20$ & 3.675 & 0.565 & 107.6 & 16.1145 & 0.4 \\
\hline 363 & $12: 17: 14.20$ & $-71: 48: 38.01$ & 4.879 & 0.246 & 99.3 & 15.0764 & 0.4 \\
\hline 369 & $12: 17: 09.66$ & $-71: 48: 24.62$ & 5.445 & 0.892 & 99.2 & 16.1127 & 0.4 \\
\hline 372 & $12: 17: 56.35$ & $-71: 49: 21.97$ & 5.204 & 0.839 & 99.6 & 16.2672 & 0.4001 \\
\hline 377 & $12: 16: 53.88$ & $-71: 47: 54.27$ & 5.466 & 0.433 & 87.7 & 16.595 & 0.4001 \\
\hline 379 & $12: 18: 04.91$ & $-71: 49: 23.26$ & 4.592 & 0.826 & 105.4 & 16.0364 & 0.4 \\
\hline 382 & $12: 17: 01.93$ & $-71: 48: 00.57$ & 4.845 & 0.24 & 99.6 & 15.4334 & 0.4 \\
\hline 385 & $12: 17: 01.93$ & $-71: 48: 00.57$ & 4.756 & 0.241 & 99.4 & 15.4337 & 0.4 \\
\hline 386 & $12: 16: 24.99$ & $-71: 47: 11.06$ & 4.576 & 0.51 & 97.9 & 15.3229 & 0.4 \\
\hline
\end{tabular}

a mesmo objeto na Tabela B. $26 \mathrm{com}$ ID $=273$
b mesmo objeto na Tabela B.26 com ID $=276$

${ }^{k}$ mesmo objeto na Tabela B. $26 \mathrm{com}$ ID $=317$
${ }_{1}$ mesmo objeto na Tabela B.26 com ID $=326$ mesmo objeto na Tabela B.26 com ID $=278$ mesmo objeto na Tabela B. 26 com ID $=283$
mesmo objeto na Tabela B.26 com ID $=284$ mesmo objeto na Tabela B.26 com ID $=286$ mesmo objeto na Tabela B.26 com ID $=299$ mesmo objeto na Tabela B.26 com ID $=303$

mesmo objeto na labela B.26 com ID $=304$

mesmo objeto na Tabela B.26 com ID $=314$

mesmo objeto na Tabela B.26 com ID $=327$

mesmo objeto na Tabela B.26 com ID $=331$ mesmo objeto na Tabela B.26 com ID $=337$ mesmo objeto na Tabela B.26 com ID $=340$ mesmo objeto na Tabela B.26 com ID $=344$ mesmo objeto na Tabela B.26 com ID $=347$ mesmo objeto na Tabela B.26 com ID $=350$ 


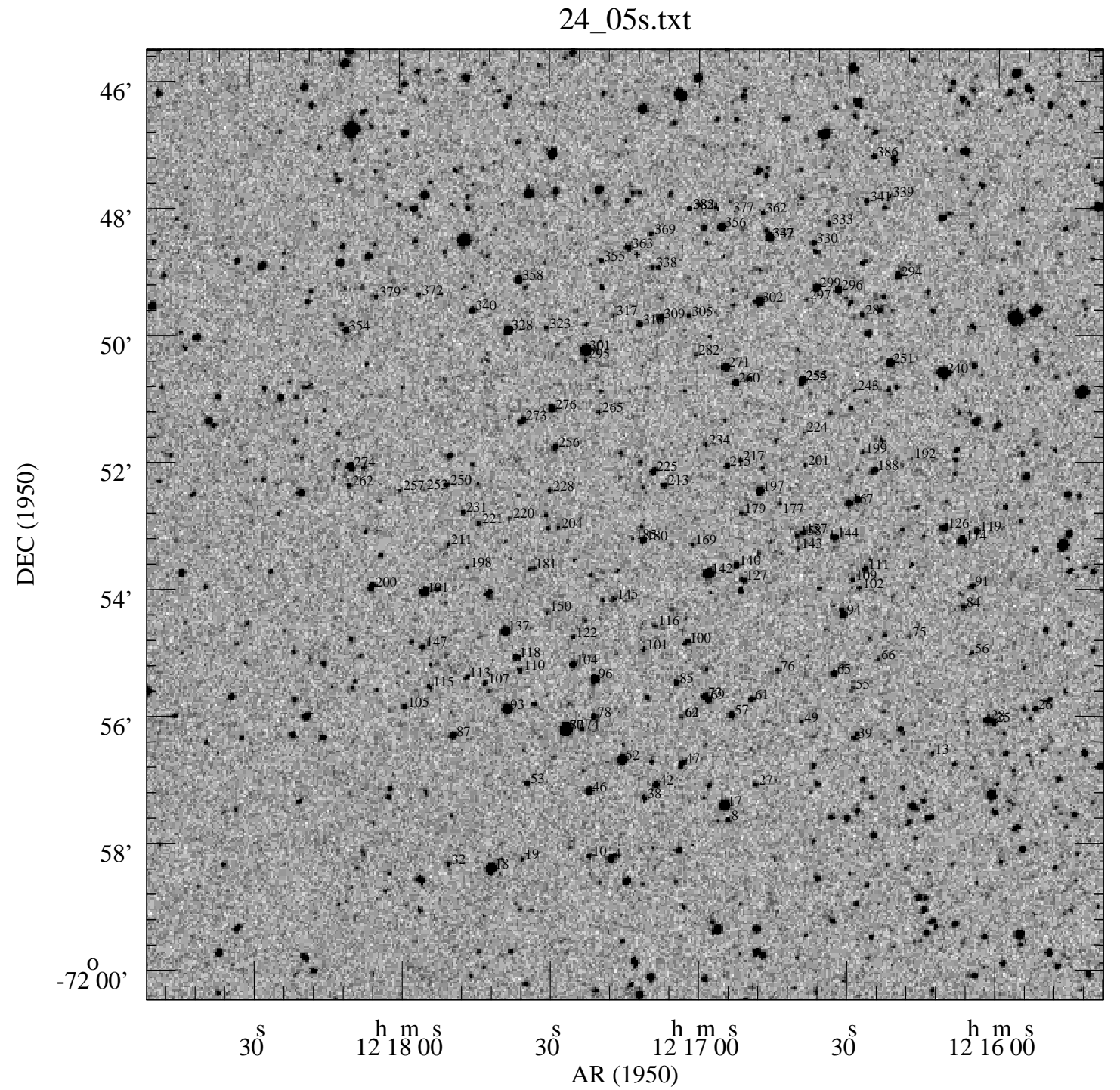

Figura C.24 Finding Chart do Campo 24 centrado em $\mathrm{AR}_{1950}=12^{\mathrm{h}} 17^{\mathrm{m}} 15^{\mathrm{s}}, \mathrm{DEC}_{1950}=-71^{\circ} 53^{\prime}$ 
Tabela C.25 Dados polarimétricos do Campo 25

\begin{tabular}{|c|c|c|c|c|c|c|c|}
\hline ID & $\operatorname{AR}(1950.00)$ & $\operatorname{DEC}(1950.00)$ & $P_{\mathrm{V}}$ & $\sigma P_{\mathrm{V}}$ & $\theta$ & $\overline{\mathrm{V}}$ & $\overline{\sigma_{\mathrm{V}}}$ \\
\hline & $(\mathrm{h}: \mathrm{m}: \mathrm{s})$ & $\left({ }^{\circ}:{ }^{\prime}: "\right)$ & (\%) & $\left(\frac{\circ}{0}\right)$ & $\left({ }^{\circ}\right)$ & (mag) & (mag) \\
\hline 3 & $12: 19: 26.14$ & $-71: 59: 42.49$ & 7.37 & 0.365 & 124.7 & 15.3533 & 0.4 \\
\hline 4 & $12: 19: 26.31$ & $-71: 59: 34.21$ & 6.339 & 0.34 & 117.3 & 15.2799 & 0.4 \\
\hline 6 & $12: 19: 30.43$ & $-72: 01: 15.95$ & 5.825 & 0.616 & 114.9 & 15.814 & 0.4001 \\
\hline 7 & $12: 19: 32.68$ & $-72: 01: 45.00$ & 5.384 & 0.154 & 116.5 & 14.2915 & 0.4 \\
\hline 8 & $12: 19: 32.87$ & $-72: 01: 34.74$ & 6.446 & 0.716 & 114.8 & 16.525 & 0.4002 \\
\hline 9 & $12: 19: 38.25$ & $-71: 59: 13.68$ & 5.478 & 0.492 & 112.6 & 14.7908 & 0.4 \\
\hline 11 & $12: 19: 41.41$ & $-72: 02: 56.56$ & 5.168 & 0.28 & 118.5 & 14.9684 & 0.4 \\
\hline 14 & $12: 19: 43.66$ & $-71: 59: 24.18$ & 6.051 & 0.5 & 119.1 & 15.6858 & 0.4001 \\
\hline 19 & $12: 19: 48.88$ & $-72: 00: 39.35$ & 4.782 & 0.691 & 124.1 & 16.3981 & 0.4001 \\
\hline 23 & $12: 19: 51.79$ & $-71: 59: 53.31$ & 4.602 & 0.784 & 117.5 & 16.4064 & 0.4002 \\
\hline 29 & $12: 19: 56.28$ & $-71: 57: 15.03$ & 5.193 & 0.649 & 122.3 & 16.1322 & 0.4001 \\
\hline 30 & $12: 19: 59.06$ & $-72: 00: 40.84$ & 5.626 & 0.391 & 117.7 & 15.7397 & 0.4 \\
\hline 33 & $12: 20: 02.01$ & $-71: 59: 38.79$ & 6.939 & 0.482 & 119.8 & 16.1008 & 0.4001 \\
\hline 34 & $12: 20: 02.43$ & $-72: 00: 33.39$ & 5.21 & 0.288 & 116.4 & 14.2283 & 0.4 \\
\hline 36 & $12: 20: 02.61$ & $-72: 02: 33.65$ & 6.253 & 0.348 & 112.3 & 14.6921 & 0.4 \\
\hline 39 & $12: 20: 05.42$ & $-72: 02: 34.67$ & 5.789 & 0.952 & 119.3 & 16.3305 & 0.4001 \\
\hline 43 & $12: 20: 07.61$ & $-72: 00: 30.67$ & 5.31 & 0.121 & 115.3 & 14.9796 & 0.4 \\
\hline 44 & $12: 20: 07.49$ & $-71: 58: 08.84$ & 5.289 & 0.802 & 118.4 & 16.5149 & 0.4002 \\
\hline 45 & $12: 20: 08.39$ & $-71: 59: 54.83$ & 5.558 & 0.185 & 118.2 & 13.894 & 0.4 \\
\hline 46 & $12: 20: 09.32$ & $-71: 59: 40.08$ & 5.794 & 0.807 & 120. & 16.393 & 0.4002 \\
\hline 48 & $12: 20: 12.00$ & $-71: 58: 38.59$ & 5.35 & 0.462 & 122.1 & 16.0701 & 0.4001 \\
\hline 53 & $12: 20: 16.40$ & $-71: 58: 12.53$ & 4.015 & 0.429 & 116.6 & 16.1487 & 0.4001 \\
\hline 59 & $12: 20: 22.63$ & $-72: 00: 49.42$ & 5.378 & 0.8 & 114 & 15.7753 & 0.4001 \\
\hline 60 & $12: 20: 24.04$ & $-72: 00: 16.40$ & 5.843 & 0.22 & 116. & 12.6673 & 0.4 \\
\hline 64 & $12: 20: 29.51$ & $-71: 58: 55.35$ & 4.805 & 0.322 & 114.2 & 15.758 & 0.4 \\
\hline 67 & $12: 20: 31.70$ & $-72: 01: 50.10$ & 4.774 & 0.852 & 118.9 & 16.1577 & 0.4001 \\
\hline 72 & $12: 20: 34.16$ & $-71: 58: 07.91$ & 5.685 & 0.679 & 109.9 & 15.8147 & 0.4001 \\
\hline 76 & $12: 20: 36.49$ & $-71: 58: 59.03$ & 6.744 & 0.755 & 108.2 & 16.2264 & 0.4001 \\
\hline 77 & $12: 20: 36.64$ & $-71: 57: 52.82$ & $\begin{array}{l}0.144 \\
4.734\end{array}$ & 0.756 & 114. & 15.991 & 0.4001 \\
\hline 79 & $12: 20: 38.75$ & $-72: 02: 51.42$ & 5.376 & 0.172 & 113. & 13.8681 & 0.4 \\
\hline 83 & $12: 20: 42.39$ & $-72: 03: 09.22$ & 5.516 & 0.649 & 104.2 & 15.4713 & 0.4 \\
\hline 85 & $12: 20: 43.91$ & $-71: 59: 24.36$ & 3.942 & 0.242 & 111.7 & 15.5163 & 0.4 \\
\hline 86 & $12: 20: 44.79$ & $-72: 03: 08.09$ & 6.757 & 0.725 & 111.8 & 16.3199 & 0.4001 \\
\hline 88 & $12: 20: 46.62$ & $-72: 03: 06.61$ & 6.341 & 0.281 & 111.7 & 15.0718 & 0.4 \\
\hline 95 & $12: 20: 53.74$ & $-71: 59: 41.12$ & 4.23 & 0.484 & 102.2 & 15.9726 & 0.4001 \\
\hline 97 & $12: 20: 56.15$ & $-71: 58: 18.37$ & 4.73 & 0.262 & 114.2 & 14.7479 & 0.4 \\
\hline 104 & $12: 21: 01.07$ & $-72: 01: 02.27$ & 4.941 & 0.214 & 109.6 & 13.6298 & 0.4 \\
\hline $\begin{array}{l}105 \\
105\end{array}$ & $12: 21: 00.74$ & $-71: 59: 05.42$ & 4.431 & 0.106 & 110.7 & 10.1726 & 0.4 \\
\hline 106 & $12: 21: 01.88$ & $-72: 02: 53.29$ & 5.779 & 1.009 & 105.9 & 16.3656 & 0.4001 \\
\hline 135 & $12: 21: 13.39$ & $-71: 57: 57.33$ & 4.945 & 0.482 & 125.2 & 16.6295 & 0.4002 \\
\hline
\end{tabular}




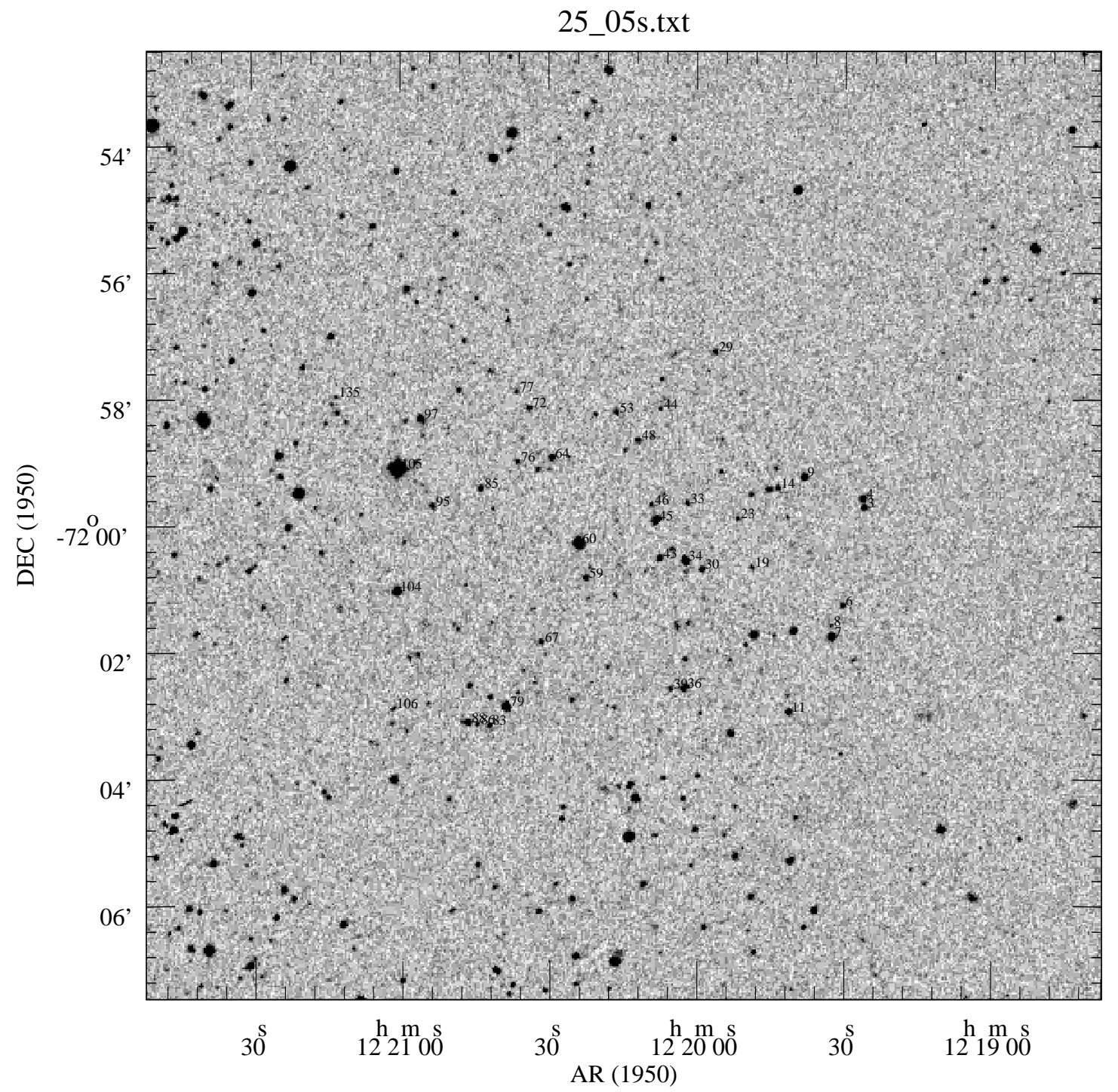

Figura C.25 Finding Chart do Campo 25 centrado em $\mathrm{AR}_{1950}=12^{\mathrm{h}} 20^{\mathrm{m}} 15^{\mathrm{s}}, \mathrm{DEC}_{1950}=-72^{\circ} 00^{\prime}$ 
Tabela C.26 Dados polarimétricos do Campo 26

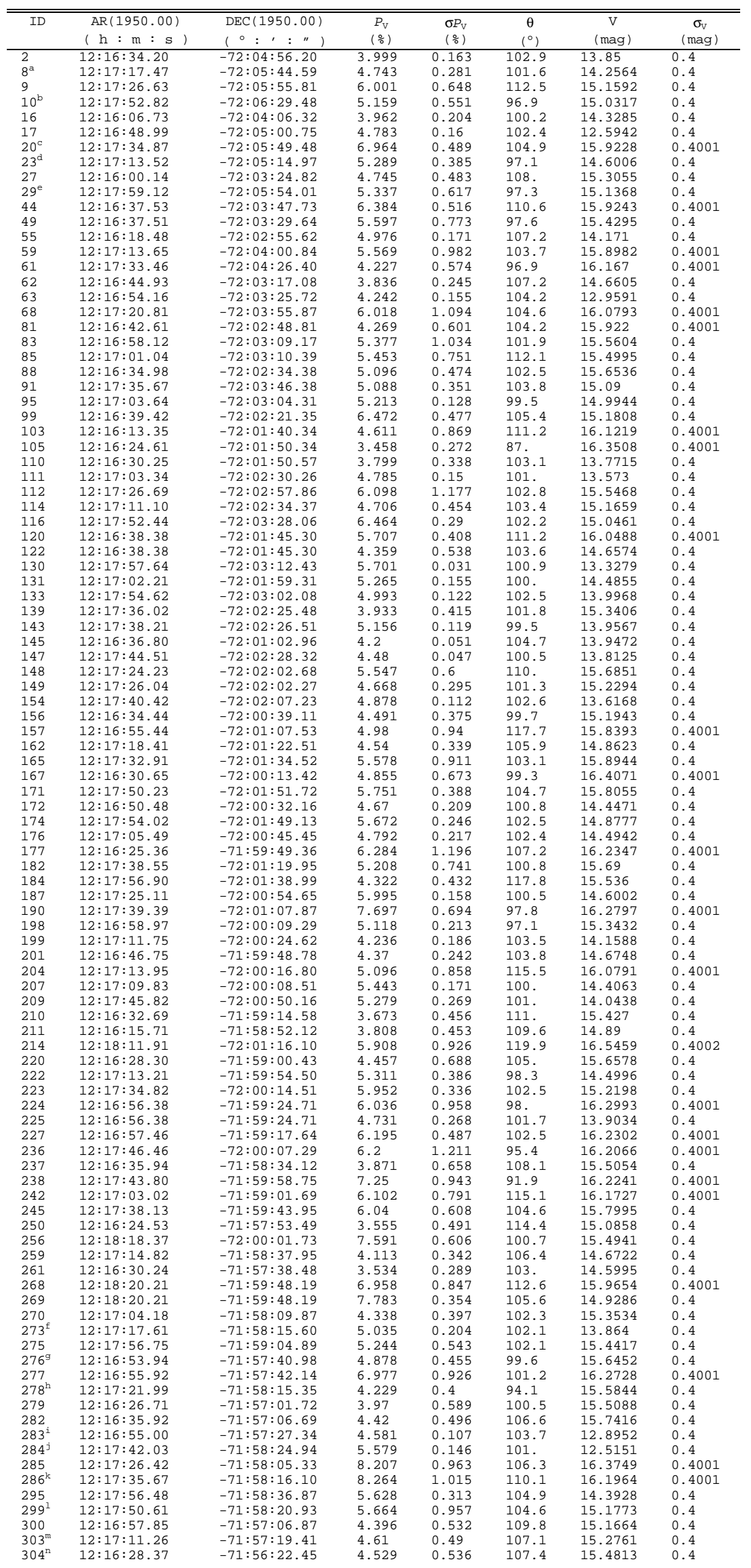


Tabela C.26 - Continuação

\begin{tabular}{|c|c|c|c|c|c|c|c|}
\hline \multirow[t]{2}{*}{ ID } & $\mathrm{AR}(1950.00)$ & DEC (1950.00) & \multirow{2}{*}{$\begin{array}{c}P_{\mathrm{V}} \\
\left(\frac{\circ}{\circ}\right)\end{array}$} & \multirow{2}{*}{$\begin{array}{l}\sigma P_{\mathrm{V}} \\
\left(\frac{\circ}{8}\right)\end{array}$} & \multirow{2}{*}{$\begin{array}{c}\theta \\
\left({ }^{\circ}\right)\end{array}$} & \multirow{2}{*}{$\begin{array}{c}\mathrm{V} \\
(\mathrm{mag})\end{array}$} & \multirow{2}{*}{$\begin{array}{c}\sigma_{\mathrm{V}} \\
(\mathrm{mag})\end{array}$} \\
\hline & $(\mathrm{h}: \mathrm{m}: \mathrm{s})$ & $\left({ }^{\circ}:,: "\right)$ & & & & & \\
\hline $314^{\circ}$ & $12: 17: 22.37$ & $-71: 57: 13.83$ & 4.811 & 0.121 & 103.2 & 13.731 & 0.4 \\
\hline $317^{p}$ & $12: 17: 03.44$ & $-71: 56: 46.70$ & 4.893 & 0.345 & 103.6 & 15.017 & 0.4 \\
\hline $326^{\mathrm{q}}$ & $12: 17: 15.71$ & $-71: 56: 42.07$ & 4.991 & 0.084 & 102.4 & 12.9906 & 0.4 \\
\hline $327^{r}$ & $12: 17: 34.81$ & $-71: 57: 04.27$ & 5.663 & 0.961 & 111. & 15.7404 & 0.4 \\
\hline $331^{s}$ & $12: 16: 53.58$ & $-71: 56: 01.46$ & 4.839 & 0.223 & 102.6 & 14.887 & 0.4 \\
\hline 334 & $12: 17: 29.53$ & $-71: 56: 41.45$ & 6.795 & 1.34 & 98.1 & 16.4011 & 0.4001 \\
\hline $337^{t}$ & $12: 16: 49.19$ & $-71: 55: 44.64$ & 4.421 & 0.291 & 101.3 & 14.9561 & 0.4 \\
\hline 339 & $12: 18: 02.61$ & $-71: 57: 09.50$ & 6.787 & 0.425 & 107.8 & 15.7185 & 0.4 \\
\hline $340^{\mathrm{u}}$ & $12: 16: 32.96$ & $-71: 55: 20.15$ & 3.937 & 0.393 & 95.3 & 14.9531 & 0.4 \\
\hline 342 & $12: 17: 21.07$ & $-71: 56: 16.74$ & 7.62 & 0.704 & 118.5 & 16.5002 & 0.4002 \\
\hline 343 & $12: 18: 02.61$ & $-71: 57: 09.59$ & 5.391 & 0.932 & 106.3 & 15.4022 & 0.4 \\
\hline $344^{\mathrm{v}}$ & $12: 16: 58.36$ & $-71: 55: 43.73$ & 4.033 & 0.263 & 102.5 & 14.8047 & 0.4 \\
\hline $347^{\mathrm{w}}$ & $12: 16: 58.36$ & $-71: 55: 43.11$ & 5.057 & 0.281 & 102.3 & 14.8184 & 0.4 \\
\hline $350^{z}$ & $12: 17: 26.69$ & $-71: 56: 13.54$ & 5.508 & 0.084 & 103.5 & 12.0093 & 0.4 \\
\hline 353 & $12: 18: 20.76$ & $-71: 57: 21.49$ & 5.868 & 1.127 & 113.7 & 16.0659 & 0.4001 \\
\hline
\end{tabular}

a mesmo objeto na Tabela B.28 com ID $=84$ m mesmo objeto na Tabela B.24 com ID $=38$ mesmo objeto na Tabela B. 28 com ID $=132$ mesmo objeto na Tabela B.28 com ID $=108$ mesmo objeto na Tabela B.24 com ID $=39$ mesmo objeto na Tabela B.24 Com ID $=46$ ${ }^{q}$ mesmo objeto na Tabela B. $24 \mathrm{com}$ ID $=52$ mesmo objeto na Tabela B. $24 \mathrm{com}$ ID $=53$ mesmo objeto na Tabela B.28 com ID $=141$ mesmo objeto na Tabela B.24 Com ID $=4$ mesmo objeto na Tabela B.24 com ID $=57$ mesmo objeto na Tabela B.24 Com ID $=8 \quad{ }^{\mathrm{t}}$ mesmo objeto na Tabela B.24 com ID $=61$ mesmo objeto na Tabela B.24 com ID $=17$ "mesmo objeto na Tabela B.24 com ID $=65$ mesmo objeto na Tabela B.24 com ID $=18$ mesmo objeto na Tabela B.24 com ID $=69$ mesmo objeto na Tabela B.24 com ID $=19$ "mesmo objeto na Tabela B.24 com ID $=73$ mesmo objeto na Tabela B.24 com ID $=32 \quad z$ mesmo objeto na Tabela B.24 com ID $=77$

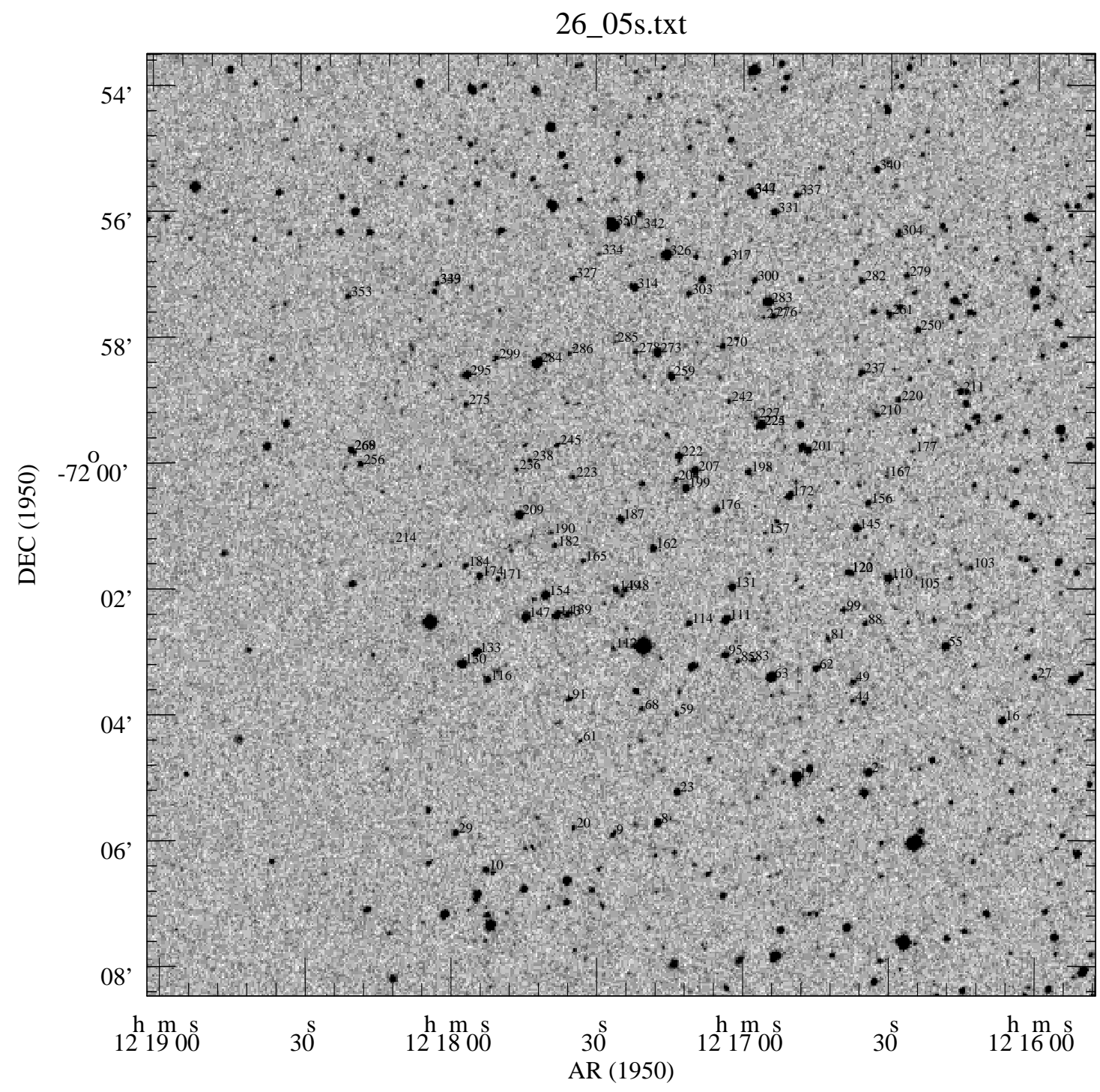

Figura C.26 Finding Chart do Campo 26 centrado em $\mathrm{AR}_{1950}=12^{\mathrm{h}} 17^{\mathrm{m}} 25^{\mathrm{s}}, \mathrm{DEC}_{1950}=-72^{\circ} 01^{\text {' }}$ 
Tabela C.27 Dados polarimétricos do Campo 27

\begin{tabular}{|c|c|c|c|c|c|c|c|}
\hline ID & $\operatorname{AR}(1950.00)$ & $\operatorname{DEC}(1950.00)$ & $P_{\mathrm{V}}$ & $\sigma P_{\mathrm{V}}$ & $\theta$ & $\mathrm{V}$ & $\sigma^{\sigma}$ \\
\hline & $(\mathrm{h}: \mathrm{m}: \mathrm{s})$ & $\left({ }^{\circ}:{ }^{\prime}:\right.$ : ") & (\%) & (\%) & $\left({ }^{\circ}\right)$ & (mag) & (mag) \\
\hline 1 & $12: 19: 12.14$ & $-72: 13: 15.41$ & 7.158 & 0.339 & 109. & 15.5893 & 0.4 \\
\hline 2 & $12: 19: 09.94$ & $-72: 13: 08.14$ & 7.254 & 0.508 & 108.1 & 15.8056 & 0.4 \\
\hline 3 & $12: 18: 58.46$ & $-72: 12: 48.91$ & 6.851 & 0.115 & 109.7 & 13.1082 & 0.4 \\
\hline 4 & $12: 19: 16.56$ & $-72: 13: 09.34$ & 4.325 & 0.361 & 103.2 & 15.9821 & 0.4 \\
\hline 7 & $12: 18: 53.20$ & $-72: 12: 28.42$ & 7.356 & 1.119 & 118.1 & 15.7919 & 0.4 \\
\hline 12 & $12: 18: 46.23$ & $-72: 11: 59.60$ & 6.518 & 0.996 & 110.7 & 16.32 & 0.4001 \\
\hline 13 & $12: 19: 40.32$ & $-72: 13: 09.69$ & 5.939 & 0.588 & 107.7 & 14.9841 & 0.4 \\
\hline 14 & $12: 20: 18.48$ & $-72: 13: 46.54$ & 6.074 & 0.164 & 112.8 & 13.5471 & 0.4 \\
\hline 18 & $12: 18: 43.83$ & $-72: 11: 36.96$ & 5.085 & 0.649 & 118.6 & 15.7256 & 0.4 \\
\hline 19 & $12: 19: 54.87$ & $-72: 13: 07.12$ & 5.534 & 0.1 & 114.1 & 11.7 & 0.4 \\
\hline 21 & $12: 19: 28.61$ & $-72: 12: 31.78$ & 4.515 & 0.345 & 108.6 & 14.5341 & 0.4 \\
\hline 22 & $12: 20: 24.24$ & $-72: 13: 34.69$ & 6.95 & 0.202 & 110.2 & 14.9113 & 0.4 \\
\hline 25 & $12: 18: 47.81$ & $-72: 11: 27.68$ & 7.319 & 0.637 & 108.4 & 16.5257 & 0.4001 \\
\hline 27 & $12: 18: 34.81$ & $-72: 11: 02.96$ & 6.772 & 1.339 & 101.3 & 16.5786 & 0.4001 \\
\hline 30 & $12: 19: 44.51$ & $-72: 12: 20.60$ & 5.618 & 0.907 & 113.1 & 15.9607 & 0.4 \\
\hline 31 & $12: 18: 41.83$ & $-72: 11: 01.33$ & 8.019 & 0.434 & 118.4 & 15.2426 & 0.4 \\
\hline 35 & $12: 19: 39.51$ & $-72: 11: 58.46$ & 5.4 & 0.274 & 109.5 & 14.8218 & 0.4 \\
\hline 36 & $12: 20: 20.71$ & $-72: 12: 47.64$ & 6.388 & 0.26 & 111.2 & 14.0296 & 0.4 \\
\hline 37 & $12: 19: 34.74$ & $-72: 11: 46.22$ & 5.597 & 0.341 & 113.2 & 15.1313 & 0.4 \\
\hline 40 & $12: 20: 16.59$ & $-72: 12: 22.38$ & 5.888 & 0.337 & 111.6 & 14.5176 & 0.4 \\
\hline 50 & $12: 19: 09.08$ & $-72: 10: 36.15$ & 7.399 & 0.796 & 110.7 & 16.0882 & 0.4 \\
\hline 51 & $12: 19: 21.35$ & $-72: 10: 38.40$ & 5.542 & 0.297 & 113.6 & 15.2818 & 0.4 \\
\hline 52 & $12: 18: 48.22$ & $-72: 09: 55.49$ & 5.81 & 0.433 & 112.3 & 15.6681 & 0.4 \\
\hline 53 & $12: 19: 46.22$ & $-72: 11: 08.52$ & 6.961 & 0.55 & 107.1 & 16.0131 & 0.4 \\
\hline 55 & $12: 19: 30.78$ & $-72: 10: 38.10$ & 6.777 & 0.346 & 114.4 & 14.9583 & 0.4 \\
\hline 56 & $12: 19: 02.11$ & $-72: 10: 00.75$ & 6.052 & 0.186 & 108.7 & 13.3347 & 0.4 \\
\hline 58 & $12: 19: 49.52$ & $-72: 10: 46.94$ & 4.587 & 0.452 & 114.6 & 14.3786 & 0.4 \\
\hline 60 & $12: 19: 42.47$ & $-72: 10: 34.47$ & 6.16 & 0.624 & 117.8 & 15.0606 & 0.4 \\
\hline 62 & $12: 18: 58.24$ & $-72: 09: 36.58$ & 4.871 & $\begin{array}{l}0.709 \\
0.709\end{array}$ & 118.6 & 16.3096 & 0.4001 \\
\hline 64 & $12: 19: 47.00$ & $-72: 10: 35.16$ & 4.571 & 0.234 & 114.5 & 13.8668 & 0.4 \\
\hline 65 & $12: 19: 57.55$ & $-72: 10: 38.73$ & 4.301 & 0.48 & 114.4 & 15.3468 & 0.4 \\
\hline 66 & $12: 20: 00.61$ & $-72: 10: 29.54$ & 4.294 & 0.111 & 111.8 & 14.4085 & 0.4 \\
\hline 67 & $12: 20: 11.62$ & $-72: 10: 37.59$ & 3.85 & 0.089 & 113.1 & 12.77 & 0.4 \\
\hline 73 & $12: 20: 01.88$ & $-72: 10: 17.14$ & 4.602 & 0.258 & 127. & 15.9772 & 0.4 \\
\hline 74 & $12: 19: 23.38$ & $-72: 09: 27.78$ & 6.911 & 0.93 & 116.3 & 16.5582 & 0.4001 \\
\hline 75 & $12: 19: 17.80$ & $-72: 09: 19.09$ & 5.714 & 0.134 & 120 & 14.303 & 0.4 \\
\hline 77 & $12: 20: 24.44$ & $-72: 10: 33.80$ & 5.165 & 0.655 & 108.1 & 15.9387 & 0.4 \\
\hline 79 & $12: 19: 19.60$ & $-72: 09: 00.06$ & 4.997 & 0.191 & 117.6 & 14.0593 & 0.4 \\
\hline 82 & $12: 19: 29.33$ & $-72: 08: 48.42$ & 5.009 & 0.317 & 114.9 & 15.1822 & 0.4 \\
\hline 83 & $12: 19: 54.32$ & $-72: 09: 19.01$ & 4.984 & 0.245 & 118.3 & 15.284 & 0.4 \\
\hline 86 & $12: 20: 11.02$ & $-72: 09: 37.75$ & 5.949 & 0.408 & 117 & 15.6517 & 0.4 \\
\hline 91 & $12: 20: 20.33$ & $-72: 09: 29.56$ & 4.871 & 0.507 & 118.6 & 13.3747 & 0.4 \\
\hline 92 & $12: 20: 30.54$ & $-72: 09: 37.18$ & 4.138 & 0.533 & 113.9 & 15.5251 & 0.4 \\
\hline 93 & $12: 20: 30.68$ & $-72: 09: 37.09$ & 4.66 & 0.306 & 105.4 & 15.2413 & 0.4 \\
\hline 94 & $12: 19: 46.67$ & $-72: 08: 37.18$ & 6.457 & 0.756 & 109.5 & 16.2957 & 0.4001 \\
\hline 95 & $12: 20: 19.22$ & $-72: 09: 12.37$ & 8.372 & 0.995 & 115.3 & 16.4101 & 0.4001 \\
\hline 96 & $12: 20: 02.77$ & $-72: 08: 46.39$ & 4.85 & 0.503 & 117.6 & 15.3207 & 0.4 \\
\hline 99 & $12: 20: 31.32$ & $-72: 09: 00.08$ & 4.833 & 0.196 & 113.7 & 14.2111 & 0.4 \\
\hline 102 & $12: 20: 27.53$ & $-72: 08: 54.59$ & 6.234 & 0.586 & 112. & 16.1477 & 0.4 \\
\hline 106 & $12: 20: 22.60$ & $-72: 08: 16.75$ & 4.802 & 0.241 & 112.8 & 14.3363 & 0.4 \\
\hline 107 & $12: 20: 18.38$ & $-72: 08: 05.71$ & 4.456 & 0.172 & 112 & 15.0246 & 0.4 \\
\hline 115 & $12: 20: 31.23$ & $-72: 07: 36.06$ & 4.445 & 0.191 & 113.9 & 15.0095 & 0.4 \\
\hline 120 & $12: 19: 36.21$ & $-72: 06: 05.22$ & 4.804 & 0.324 & 123.5 & 14.9677 & 0.4 \\
\hline 122 & $12: 20: 16.84$ & $-72: 06: 53.49$ & 4.188 & 0.154 & 113.9 & 13.2463 & 0.4 \\
\hline 124 & $12: 19: 58.69$ & $-72: 06: 20.66$ & 5.309 & 1.058 & 120.4 & 16.11 & 0.4 \\
\hline 126 & $12: 20: 24.75$ & $-72: 06: 48.43$ & 4.586 & 0.3 & 114.3 & 15.196 & 0.4 \\
\hline 127 & $12: 20: 41.10$ & $-72: 07: 02.46$ & 4.237 & 0.241 & 109 & 14.5651 & 0.4 \\
\hline 128 & $12: 19: 49.18$ & $-72: 05: 52.59$ & 6.146 & 0.462 & 116.5 & 15.7285 & 0.4 \\
\hline 129 & $12: 19: 10.20$ & $-72: 04: 47.00$ & 7.126 & 0.197 & 123.2 & 14.2688 & 0.4 \\
\hline 130 & $12: 19: 41.07$ & $-72: 05: 17.85$ & 4.776 & 0.446 & 121.6 & 15.1707 & 0.4 \\
\hline 131 & $12: 20: 32.36$ & $-72: 06: 05.56$ & 6.265 & 0.481 & 114.7 & 15.5969 & 0.4 \\
\hline 132 & $12: 19: 52.09$ & $-72: 05: 13.49$ & 5.316 & 0.502 & 109.4 & 14.6367 & 0.4 \\
\hline 134 & $12: 20: 25.60$ & $-72: 05: 54.15$ & 5.274 & 0.322 & 107.1 & 15.4942 & 0.4 \\
\hline 136 & $12: 19: 40.00$ & $-72: 04: 37.04$ & 7.528 & 1.143 & 123.5 & 15.8317 & 0.4 \\
\hline 137 & $12: 20: 49.89$ & $-72: 06: 04.87$ & 4.868 & 0.459 & 103.8 & 16.1362 & 0.4 \\
\hline 141 & $12: 20: 13.93$ & $-72: 04: 55.24$ & 5.228 & 0.206 & 111.7 & 12.7187 & 0.4 \\
\hline 152 & $12: 20: 00.44$ & $-72: 04: 48.17$ & 4.338 & 0.494 & 105. & 16.0437 & 0.4 \\
\hline 153 & $12: 19: 54.61$ & $-72: 07: 15.90$ & 7.494 & 1.138 & 110.6 & 16.6161 & 0.4001 \\
\hline 154 & $12: 20: 17.35$ & $-72: 12: 53.60$ & 6.628 & 0.629 & 108.9 & 15.5827 & 0.4 \\
\hline
\end{tabular}




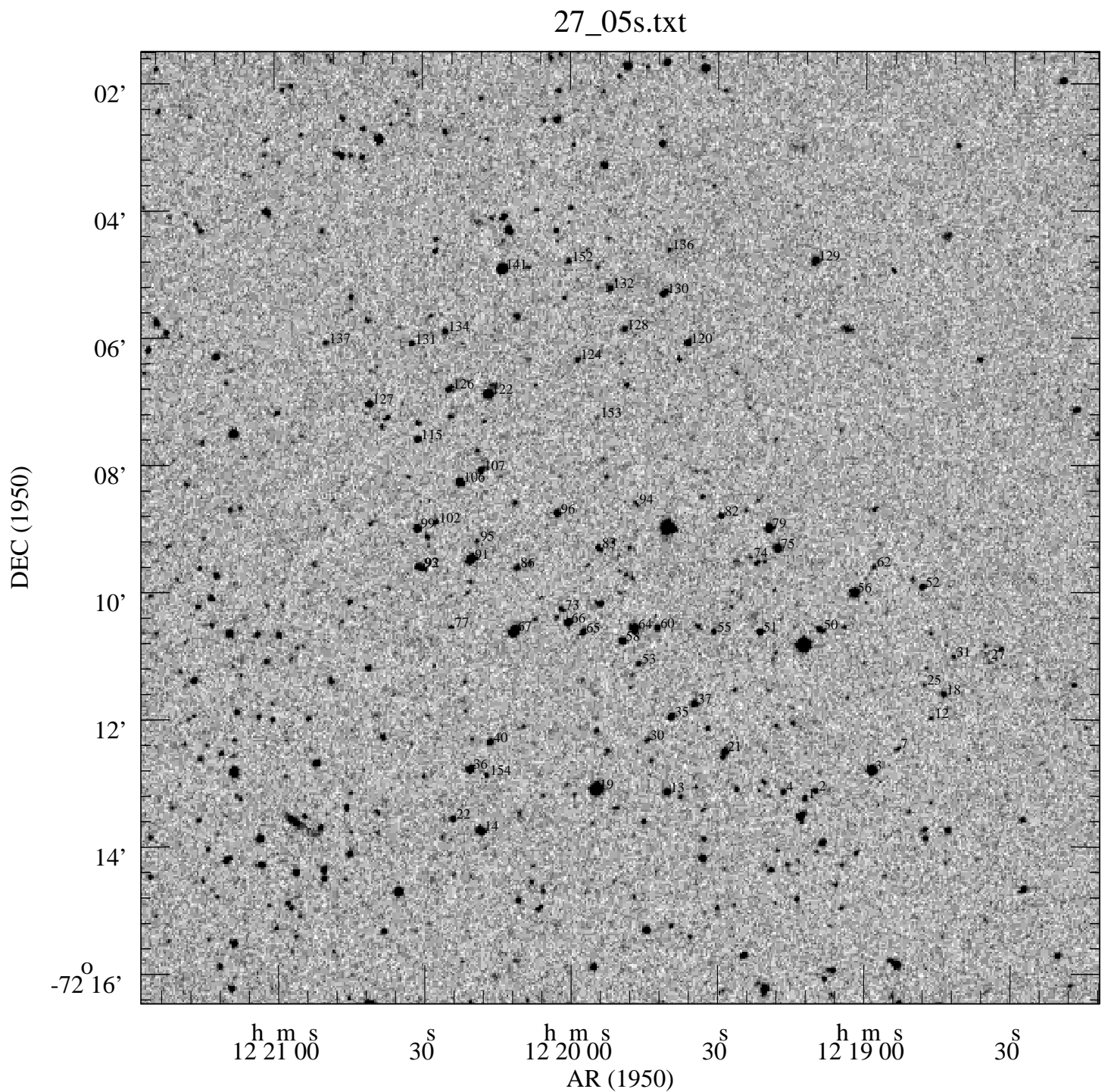

Figura C.27 Finding Chart do Campo 27 centrado em $\mathrm{AR}_{1950}=12^{\mathrm{h}} 19^{\mathrm{m}} 50^{\mathrm{s}}, \mathrm{DEC}_{1950}=-72^{\circ} 09^{\prime}$ 
Tabela C.28 Dados polarimétricos do Campo 28

\begin{tabular}{|c|c|c|c|c|c|c|c|}
\hline \multirow{2}{*}{ 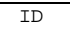 } & $\operatorname{AR}(1950.00)$ & $\operatorname{DEC}(1950.00)$ & \multirow{2}{*}{$\begin{array}{l}P_{\mathrm{V}} \\
\left(\frac{\mathrm{v}}{\mathrm{o}}\right)\end{array}$} & \multirow{2}{*}{$\begin{array}{l}\sigma P_{\mathrm{V}} \\
\left(\frac{\mathrm{o}}{6}\right)\end{array}$} & \multirow{2}{*}{$\begin{array}{c}\theta \\
\left({ }^{\circ}\right)\end{array}$} & \multirow{2}{*}{$\begin{array}{c}\mathrm{V} \\
(\mathrm{mag})\end{array}$} & \multirow{2}{*}{$\begin{array}{c}\begin{array}{c}\sigma_{\mathrm{v}} \\
(\mathrm{mag})\end{array} \\
\end{array}$} \\
\hline & $(\mathrm{h}: \mathrm{m}: \mathrm{s})$ & $\left({ }^{\circ}:{ }^{\prime}:\right.$ : ") & & & & & \\
\hline 5 & $12: 16: 32.89$ & $-72: 08: 16.17$ & 3.667 & 0.463 & 102.3 & 14.6787 & 0.4 \\
\hline 6 & $12: 16: 33.11$ & $-72: 09: 37.35$ & 4.105 & 0.218 & 101.8 & 14.6626 & 0.4 \\
\hline 11 & $12: 16: 35.32$ & $-72: 05: 14.86$ & 3.949 & 0.193 & 103.3 & 14.0802 & 0.4 \\
\hline 19 & $12: 16: 38.37$ & $-72: 08: 53.04$ & 4.741 & 0.215 & 95.8 & 15.3747 & 0.4 \\
\hline 20 & $12: 16: 38.51$ & $-72: 07: 24.34$ & 4.469 & 0.1 & 105. & 13.5041 & 0.4 \\
\hline 23 & $12: 16: 41.88$ & $-72: 07: 50.96$ & 3.465 & 0.371 & 106.8 & 15.5728 & 0.4 \\
\hline 27 & $12: 16: 44.11$ & $-72: 05: 40.93$ & 3.902 & 0.444 & 104.8 & 14.9717 & 0.4 \\
\hline 29 & $12: 16: 45.37$ & $-72: 10: 06.61$ & 3.711 & 0.213 & 102.2 & 14.6815 & 0.4 \\
\hline 31 & $12: 16: 47.65$ & $-72: 08: 47.36$ & 4.049 & 0.712 & 102.3 & 15.9184 & 0.4001 \\
\hline 33 & $12: 16: 48.89$ & $-72: 09: 57.01$ & 3.881 & 0.601 & 95.5 & 15.9335 & 0.4001 \\
\hline 35 & $12: 16: 49.01$ & $-72: 05: 00.93$ & 3.051 & 0.299 & 104.4 & 16.2155 & 0.4001 \\
\hline 41 & $12: 16: 52.19$ & $-72: 07: 25.97$ & 4.588 & 0.27 & 101.4 & 15.1112 & 0.4 \\
\hline 47 & $12: 16: 53.60$ & $-72: 07: 50.76$ & 4.672 & 0.074 & 101.1 & 12.56 & 0.4 \\
\hline 52 & $12: 16: 54.97$ & $-72: 11: 21.36$ & 4.814 & 0.534 & 101.7 & 15.4701 & 0.4 \\
\hline 64 & $12: 17: 03.76$ & $-72: 08: 21.51$ & 5.007 & 0.73 & 104. & 15.4572 & 0.4 \\
\hline 67 & $12: 17: 04.03$ & $-72: 06: 54.68$ & 4.882 & 0.354 & 107. & 15.09 & 0.4 \\
\hline 68 & $12: 17: 05.71$ & $-72: 10: 47.81$ & 3.917 & 0.704 & 106.6 & 16.066 & 0.4001 \\
\hline 69 & $12: 17: 06.39$ & $-72: 11: 09.66$ & 4.707 & 0.703 & 102.1 & 15.2719 & 0.4 \\
\hline 70 & $12: 17: 07.22$ & $-72: 06: 33.71$ & 5.884 & 0.492 & 104.3 & 16.0418 & 0.4001 \\
\hline 77 & $12: 17: 12.69$ & $-72: 10: 26.79$ & 6.07 & 0.885 & 97.2 & 16.8137 & 0.4003 \\
\hline 78 & $12: 17: 13.19$ & $-72: 10: 08.85$ & 4.144 & 0.554 & 99. & 14.813 & 0.4 \\
\hline $80^{\mathrm{a}}$ & $12: 17: 13.54$ & $-72: 05: 15.18$ & 4.525 & 0.262 & 99.8 & 14.7203 & 0.4 \\
\hline 81 & $12: 17: 14.08$ & $-72: 06: 13.13$ & 5.611 & 0.989 & 103.1 & 16.2077 & 0.4001 \\
\hline 83 & $12: 17: 15.74$ & $-72: 09: 28.31$ & 5.121 & 0.48 & 101.5 & 14.916 & 0.4 \\
\hline $84^{\mathrm{b}}$ & $12: 17: 17.87$ & $-72: 05: 43.12$ & 4.054 & 0.195 & 103.7 & 14.3712 & 0.4 \\
\hline 86 & $12: 17: 18.00$ & $-72: 06: 14.72$ & 5.879 & 0.726 & 103. & 15.6102 & 0.4001 \\
\hline 87 & $12: 17: 18.43$ & $-72: 06: 07.36$ & 5.4 & 0.86 & 103.2 & 16.7345 & 0.4003 \\
\hline 88 & $12: 17: 18.96$ & $-72: 10: 59.79$ & 4.079 & 0.129 & 99.4 & 13.5099 & 0.4 \\
\hline 95 & $12: 17: 22.59$ & $-72: 11: 03.88$ & 5.941 & 1.104 & 99.3 & 15.9812 & 0.4001 \\
\hline 102 & $12: 17: 27.60$ & $-72: 10: 50.98$ & 4.78 & 0.077 & 96.3 & 13.9417 & 0.4 \\
\hline 104 & $12: 17: 29.67$ & $-72: 06: 28.48$ & 6.277 & 0.427 & 104.3 & 16.313 & 0.4001 \\
\hline 105 & $12: 17: 31.06$ & $-72: 06: 49.68$ & 4.958 & 0.486 & 103.3 & 15.6859 & 0.4 \\
\hline 106 & $12: 17: 34.24$ & $-72: 11: 19.65$ & 4.685 & 0.216 & 94.9 & 15.5875 & 0.4 \\
\hline 107 & $12: 17: 34.46$ & $-72: 09: 26.12$ & 4.555 & 0.309 & 99.3 & 15.477 & 0.4 \\
\hline $108^{\circ}$ & $12: 17: 34.91$ & $-72: 05: 48.11$ & 4.244 & 0.631 & 103.6 & 16.1267 & 0.4001 \\
\hline 111 & $12: 17: 36.12$ & $-72: 06: 38.55$ & 4.916 & 0.179 & 102.2 & 13.9595 & 0.4 \\
\hline 114 & $12: 17: 39.69$ & $-72: 11: 06.31$ & 6.144 & 0.173 & 107.4 & 14.7857 & 0.4 \\
\hline 120 & $12: 17: 45.02$ & $-72: 06: 46.95$ & 5.794 & 0.321 & 101.5 & 14.8584 & 0.4 \\
\hline 122 & $12: 17: 47.82$ & $-72: 08: 45.92$ & 5.441 & 0.838 & 98.3 & 16.0269 & 0.4001 \\
\hline 123 & $12: 17: 48.27$ & $-72: 11: 10.12$ & 5.86 & 0.715 & 114.9 & 15.4531 & 0.4 \\
\hline 125 & $12: 17: 51.48$ & $-72: 06: 32.14$ & 7.952 & 0.631 & 102.6 & 16.3297 & 0.4001 \\
\hline 126 & $12: 17: 51.95$ & $-72: 07: 22.52$ & 5.769 & 0.206 & 99.2 & 12.5181 & 0.4 \\
\hline 128 & $12: 17: 52.58$ & $-72: 07: 12.06$ & 5.684 & 0.396 & 96.4 & 15.2408 & 0.4 \\
\hline 129 & $12: 17: 52.63$ & $-72: 10: 04.11$ & 5.546 & 0.224 & 104.6 & 14.284 & 0.4 \\
\hline $132^{\mathrm{d}}$ & $12: 17: 52.83$ & $-72: 06: 28.21$ & 5.936 & 0.261 & 102.4 & 15.5256 & 0.4 \\
\hline 134 & $12: 17: 54.88$ & $-72: 06: 51.38$ & 6.267 & 0.167 & 101.1 & 14.2239 & 0.4 \\
\hline 135 & $12: 17: 55.23$ & $-72: 06: 55.94$ & 7.267 & 0.362 & 100.2 & 15.8494 & 0.4001 \\
\hline $141^{\mathrm{e}}$ & $12: 17: 59.14$ & $-72: 05: 54.47$ & 6.719 & 0.412 & 99.3 & 14.9453 & 0.4 \\
\hline 142 & $12: 18: 01.43$ & $-72: 07: 10.74$ & 5.85 & 0.112 & 99.1 & 13.5974 & 0.4 \\
\hline 144 & $12: 18: 04.67$ & $-72: 06: 23.26$ & 5.464 & 0.731 & 95.3 & 15.5274 & 0.4 \\
\hline 145 & $12: 18: 05.10$ & $-72: 05: 32.67$ & 6.405 & 0.444 & 95.6 & 15.5876 & 0.4 \\
\hline 149 & $12: 18: 12.37$ & $-72: 08: 12.44$ & 6.481 & 0.22 & 104.9 & 14.7398 & 0.4 \\
\hline 153 & $12: 18: 17.32$ & $-72: 07: 07.87$ & 5.154 & 0.304 & 101.6 & 15.2694 & 0.4 \\
\hline 155 & $12: 18: 25.27$ & $-72: 11: 21.10$ & 8.911 & 0.786 & 107.1 & 16.1069 & 0.4001 \\
\hline 158 & $12: 18: 32.45$ & $-72: 10: 53.24$ & 5.595 & 0.42 & 114.5 & 16.0256 & 0.4001 \\
\hline 162 & $12: 18: 36.87$ & $-72: 06: 19.85$ & 4.123 & 0.432 & 101.7 & 15.8443 & 0.4001 \\
\hline & & & & & & & \\
\hline & & $26 \mathrm{com} \mathrm{ID}=$ & & & & & \\
\hline D & to na Tabela & $26 \mathrm{com} \mathrm{ID}=20$ & & & & & \\
\hline & to na Tabel & $26 \mathrm{com} \mathrm{ID}$ & & & & & \\
\hline mesmo & objeto na Tabela & B. $26 \mathrm{com} \mathrm{ID}=$ & & & & & \\
\hline
\end{tabular}




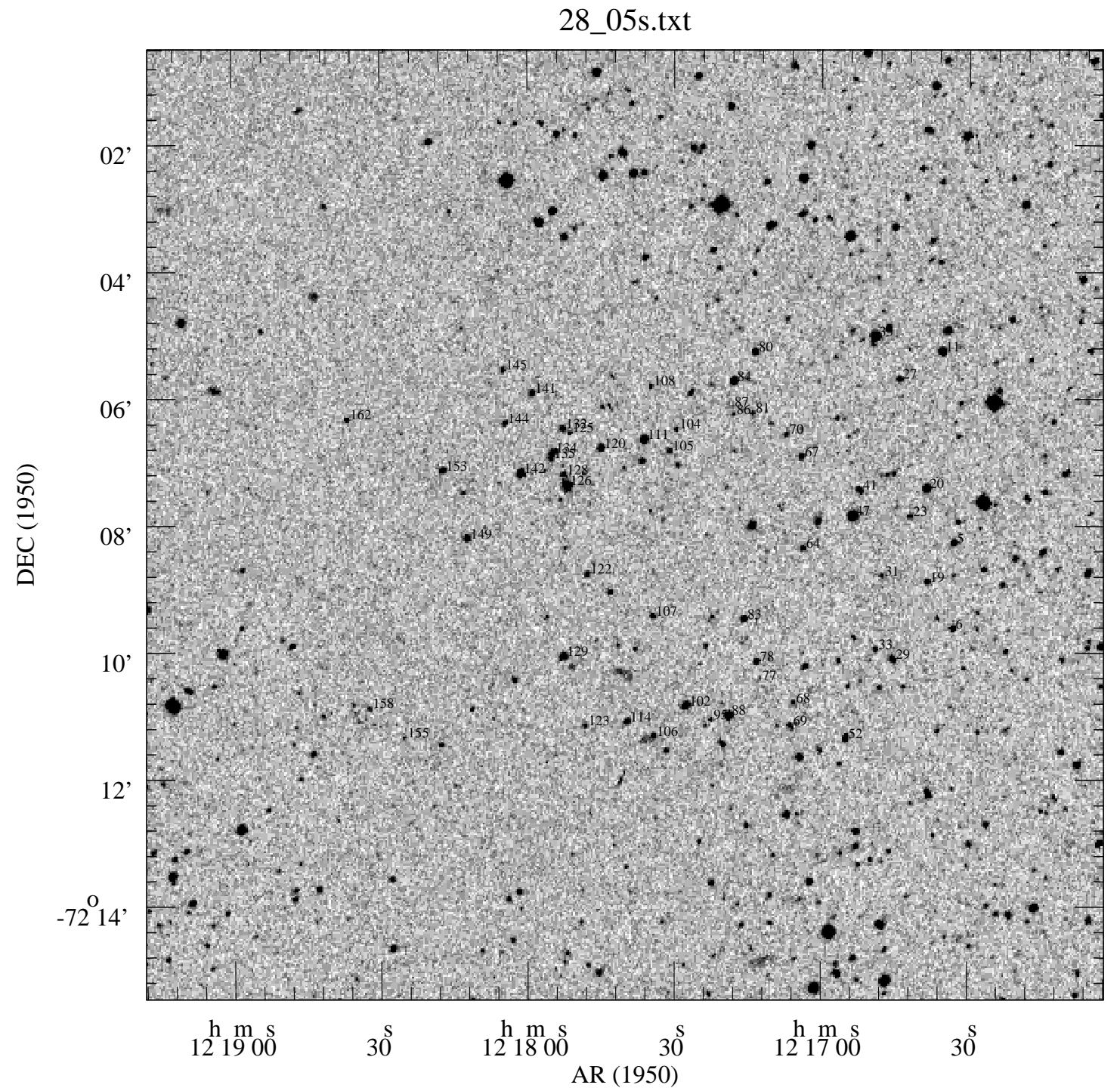

Figura C.28 Finding Chart do Campo 28 centrado em $\mathrm{AR}_{1950}=12^{\mathrm{h}} 17^{\mathrm{m}} 40^{\mathrm{s}}, \mathrm{DEC}_{1950}=-72^{\circ} 08^{\prime}$ 
Tabela C.29 Dados polarimétricos do Campo 29

\begin{tabular}{|c|c|c|c|c|c|c|}
\hline ID & $\operatorname{AR}(1950.00)$ & $\operatorname{DEC}(1950.00)$ & $P_{\mathrm{V}}$ & $\sigma P_{\mathrm{V}}$ & $\theta$ & $\mathrm{V}$ \\
\hline & $(\mathrm{h}: \mathrm{m}: \mathrm{s})$ & $\left({ }^{\circ}:{ }^{\prime}: "{ }^{\prime}\right)$ & (\%) & $(\%)$ & $\left({ }^{\circ}\right)$ & (mag) \\
\hline 4 & $12: 16: 08.73$ & $-72: 20: 42.64$ & 3.94 & 0.313 & 97.3 & 15.1373 \\
\hline 5 & $12: 16: 47.68$ & $-72: 21: 24.86$ & 4.282 & 0.472 & 91.5 & 15.0611 \\
\hline $7^{a}$ & $12: 15: 47.26$ & $-72: 20: 00.91$ & 4.182 & 0.518 & 112.9 & 15.4225 \\
\hline 8 & $12: 17: 49.70$ & $-72: 22: 34.88$ & 6.255 & 0.618 & 97. & 15.2056 \\
\hline $11^{\mathrm{b}}$ & $12: 15: 54.66$ & $-72: 19: 55.35$ & 3.264 & 0.089 & 102.4 & 13.3799 \\
\hline $14^{\mathrm{c}}$ & $12: 15: 54.66$ & $-72: 19: 55.19$ & 4.13 & 0.324 & 105.7 & 14.6229 \\
\hline 16 & $12: 16: 22.63$ & $-72: 20: 15.90$ & 4.885 & 0.301 & 100.4 & 14.7674 \\
\hline 17 & $12: 16: 40.92$ & $-72: 20: 37.23$ & 5.23 & 0.246 & 96.8 & 14.4686 \\
\hline 19 & $12: 16: 11.44$ & $-72: 19: 52.45$ & 4.175 & 0.183 & 104.2 & 13.9881 \\
\hline $31^{d}$ & $12: 15: 55.68$ & $-72: 18: 54.96$ & 3.407 & 0.492 & 104.1 & 15.6149 \\
\hline 32 & $12: 16: 09.56$ & $-72: 19: 13.56$ & 6.228 & 0.594 & 120.9 & 16.0938 \\
\hline 33 & $12: 16: 38.01$ & $-72: 19: 50.64$ & 6.448 & 0.407 & 97. & 15.5163 \\
\hline 34 & $12: 17: 53.12$ & $-72: 21: 23.59$ & 5.951 & 0.072 & 98.1 & 11.99 \\
\hline 36 & $12: 17: 47.44$ & $-72: 21: 13.80$ & 6.826 & 0.453 & 96.3 & 16.1395 \\
\hline 37 & $12: 17: 08.94$ & $-72: 20: 24.77$ & 5.351 & 0.589 & 101.7 & 15.7117 \\
\hline 38 & $12: 17: 40.58$ & $-72: 21: 04 \cdot 30$ & 6.944 & 0.499 & 94.9 & 14.6324 \\
\hline 41 & $12: 17: 23.47$ & $-72: 20: 42.26$ & 5.253 & 0.587 & 90.2 & 14.9902 \\
\hline 42 & $12: 16: 20.08$ & $-72: 19: 20.35$ & 3.669 & 0.275 & 103.7 & 14.1891 \\
\hline 51 & $12: 17: 28.80$ & $-72: 20: 25.66$ & 6.877 & 0.457 & 98.2 & 15.4253 \\
\hline 53 & $12: 15: 57.11$ & $-72: 18: 23.84$ & 3.871 & 0.39 & 100.2 & 16.153 \\
\hline 58 & $12: 17: 17.90$ & $-72: 20: 04.36$ & 5.924 & 0.777 & 92.7 & 16.0459 \\
\hline 59 & $12: 17: 09.18$ & $-72: 19: 51.33$ & 8.541 & 0.725 & 98.4 & 14.6164 \\
\hline 62 & $12: 16: 25.39$ & $-72: 18: 45.46$ & 4.177 & 0.468 & 99. & 15.393 \\
\hline 64 & $12: 17: 47.32$ & $-72: 20: 27.18$ & 6.549 & 0.329 & 97.8 & 15.2006 \\
\hline 66 & $12: 16: 46.89$ & $-72: 19: 07.21$ & 5.309 & 0.95 & 94. & 15.3402 \\
\hline 67 & $12: 16: 46.89$ & $-72: 19: 07.21$ & 4.216 & 0.285 & 95.5 & 14.4643 \\
\hline 70 & $12: 17: 24.29$ & $-72: 19: 42.48$ & 5.892 & 0.772 & 101.4 & 16.0314 \\
\hline 75 & $12: 17: 32.70$ & $-72: 19: 45.87$ & 3.759 & 0.434 & 105.4 & 15.3459 \\
\hline $76^{\mathrm{e}}$ & $12: 16: 06.01$ & $-72: 17: 52.38$ & 3.098 & 0.507 & 97.5 & 15.8406 \\
\hline 83 & $12: 17: 34.63$ & $-72: 19: 36.97$ & 6.074 & 0.917 & 97.3 & 15.9996 \\
\hline 85 & $12: 16: 44.47$ & $-72: 18: 34.17$ & 4.173 & 0.07 & 101.7 & 12.5902 \\
\hline 87 & $12: 17: 04.78$ & $-72: 19: 00.25$ & 4.979 & 0.286 & 102.9 & 13.5334 \\
\hline 89 & $12: 16: 59.10$ & $-72: 18: 47.34$ & 4.434 & 0.863 & 91.8 & 15.6229 \\
\hline 90 & $12: 17: 35.36$ & $-72: 19: 32.77$ & 4.892 & 0.573 & 98.3 & 15.2423 \\
\hline 98 & $12: 17: 17.61$ & $-72: 18: 49.41$ & 4.321 & 0.692 & 90.2 & 15.9146 \\
\hline $102^{\mathrm{f}}$ & $12: 16: 13.21$ & $-72: 17: 17.88$ & 4.231 & 0.202 & 103.2 & 13.3456 \\
\hline 103 & $12: 16: 36.47$ & $-72: 17: 43.71$ & 5.094 & 0.41 & 103.1 & 16.0475 \\
\hline 104 & $12: 17: 12.65$ & $-72: 18: 29.86$ & 4.572 & 0.174 & 98.1 & 14.112 \\
\hline 106 & $12: 16: 51.04$ & $-72: 18: 01.03$ & 4.353 & 0.21 & 102.1 & 13.3148 \\
\hline 108 & $12: 17: 09.07$ & $-72: 18: 17.04$ & 3.873 & 0.581 & 98.6 & 15.5643 \\
\hline 110 & $12: 17: 54.59$ & $-72: 19: 12.08$ & 6.649 & 0.389 & 96.9 & 15.8985 \\
\hline 112 & $12: 16: 12.79$ & $-72: 17: 00.25$ & 4.284 & 0.789 & 98.6 & 15.78 \\
\hline 113 & $12: 16: 30.66$ & $-72: 17: 13.84$ & 4.697 & 0.395 & 102.4 & 15.3198 \\
\hline 116 & $12: 17: 38.63$ & $-72: 18: 28.09$ & 6.577 & 0.513 & 106.4 & 16.189 \\
\hline 118 & $12: 17: 47.24$ & $-72: 18: 31.60$ & 5.765 & 0.784 & 105.8 & 15.7859 \\
\hline 120 & $12: 17: 27.65$ & $-72: 17: 55.89$ & 6.032 & 0.402 & 94.8 & 15.6369 \\
\hline 123 & $12: 16: 40.34$ & $-72: 16: 52.62$ & 4.41 & 0.307 & 97.4 & 15.3104 \\
\hline 124 & $12: 17: 06.39$ & $-72: 17: 23.97$ & 5.651 & 0.381 & 100.7 & 15.5867 \\
\hline 125 & $12: 17: 55.18$ & $-72: 18: 24.94$ & 6.196 & 0.204 & 98.2 & 15.0701 \\
\hline 127 & $12: 16: 29.38$ & $-72: 16: 26.53$ & 4.654 & 0.836 & 94.6 & 16.1923 \\
\hline 128 & $12: 16: 24.66$ & $-72: 16: 18.63$ & 4.62 & 0.217 & 97.8 & 14.2588 \\
\hline 131 & $12: 17: 54.96$ & $-72: 17: 59.11$ & 5.069 & 0.469 & 102.9 & 15.5274 \\
\hline 133 & $12: 17: 37.59$ & $-72: 17: 30.19$ & 6.121 & 0.421 & 106.2 & 15.2088 \\
\hline 135 & $12: 17: 20.38$ & $-72: 17: 01.07$ & 6.681 & 0.617 & 97.7 & 15.9754 \\
\hline 137 & $12: 16: 41.59$ & $-72: 16: 06.89$ & 4.778 & 0.108 & 98.8 & 13.3025 \\
\hline 142 & $12: 17: 02.42$ & $-72: 16: 21.82$ & 5.682 & 0.312 & 95.7 & 15.5576 \\
\hline $143^{9}$ & $12: 16: 22.46$ & $-72: 15: 29.07$ & 3.184 & 0.566 & 99.6 & 15.8933 \\
\hline 146 & $12: 18: 05.44$ & $-72: 17: 27.26$ & 6.439 & 0.449 & 109. & 15.2362 \\
\hline 147 & $12: 17: 31.63$ & $-72: 16: 43.02$ & 7.935 & 0.993 & 94. & 16.1577 \\
\hline 151 & $12: 16: 46.95$ & $-72: 15: 22.12$ & 6.643 & 0.953 & 106.8 & 16.2547 \\
\hline 154 & $12: 17: 15.24$ & $-72: 15: 54.79$ & 6.07 & 1.003 & 94.7 & 16.1675 \\
\hline 157 & $12: 16: 46.50$ & $-72: 15: 10.89$ & 4.051 & 0.147 & 98.7 & 13.0732 \\
\hline 160 & $12: 17: 01.15$ & $-72: 15: 18.11$ & 4.945 & 0.132 & 98.1 & 12.6328 \\
\hline 161 & $12: 17: 46.01$ & $-72: 16: 13.49$ & 6.518 & 0.081 & 99.9 & 13.2025 \\
\hline 162 & $12: 17: 53.16$ & $-72: 16: 18.98$ & 4.535 & 0.228 & 100.4 & 14.4816 \\
\hline 164 & $12: 16: 56.31$ & $-72: 15: 03.19$ & 4.571 & 0.115 & 99.1 & 14.0428 \\
\hline 170 & $12: 16: 21.47$ & $-72: 14: 08.20$ & 3.366 & 0.527 & 104. & 15.51 \\
\hline 171 & $12: 16: 53.38$ & $-72: 14: 50.51$ & 4.158 & 0.363 & 90.6 & 15.179 \\
\hline $172^{\mathrm{h}}$ & $12: 16: 15.91$ & $-72: 14: 02.22$ & 3.366 & 0.088 & 103.3 & 14.3267 \\
\hline 178 & $12: 17: 48.58$ & $-72: 15: 52.96$ & 6.574 & 1.212 & 104.8 & 16.0107 \\
\hline 180 & $12: 17: 05.32$ & $-72: 14: 49.67$ & 4.385 & 0.82 & 94.2 & 16.1951 \\
\hline 182 & $12: 16: 47.45$ & $-72: 14: 17.42$ & 3.539 & 0.112 & 97.4 & 13.8071 \\
\hline 185 & $12: 16: 57.95$ & $-72: 14: 25.29$ & 4.031 & 0.04 & 99.3 & 11.6369 \\
\hline 194 & $12: 18: 08.70$ & $-72: 15: 39.47$ & 6.162 & 0.527 & 108.4 & 15.1052 \\
\hline 196 & $12: 17: 45.02$ & $-72: 15: 04.04$ & 5.197 & 0.828 & 106.6 & 15.451 \\
\hline 197 & $12: 17: 09.95$ & $-72: 14: 16.89$ & 3.999 & 0.558 & 108.8 & 15.5709 \\
\hline 207 & $12: 17: 03.98$ & $-72: 13: 53.19$ & 4.991 & 0.937 & 96.2 & 15.7916 \\
\hline 209 & $12: 17: 51.59$ & $-72: 14: 45.43$ & 6.019 & 0.639 & 104. & 16.0885 \\
\hline 214 & $12: 17: 01.96$ & $-72: 13: 37.58$ & 3.769 & 0.236 & 96.5 & 15.062 \\
\hline 215 & $12: 17: 32.20$ & $-72: 14: 15.72$ & 8.704 & 0.852 & 87.6 & 16.367 \\
\hline 217 & $12: 16: 49.65$ & $-72: 13: 16.62$ & 4.615 & 0.757 & 95.2 & 16.0207 \\
\hline 224 & $12: 16: 55.69$ & $-72: 13: 10.89$ & 6.005 & 0.568 & 83.6 & 15.2894 \\
\hline 225 & $12: 18: 09.04$ & $-72: 14: 43.09$ & 6.249 & 1.155 & 104.7 & 15.7654 \\
\hline 226 & $12: 16: 52.45$ & $-72: 13: 03.97$ & 4.782 & 0.479 & 100.9 & 15.4738 \\
\hline 227 & $12: 17: 22.03$ & $-72: 13: 39.25$ & 5.614 & 0.724 & 93.2 & 15.9077 \\
\hline 234 & $12: 16: 37.98$ & $-72: 12: 14.70$ & 3.557 & 0.366 & 104.2 & 14.665 \\
\hline 236 & $12: 17: 39.84$ & $-72: 13: 23.47$ & 5.536 & 0.459 & 108.1 & 15.7202 \\
\hline 240 & $12: 17: 24.61$ & $-72: 12: 59.45$ & 4.148 & 0.699 & 112.8 & 16.2012 \\
\hline 241 & $12: 17: 15.25$ & $-72: 12: 44.40$ & 4.496 & 0.489 & 109.6 & 15.538 \\
\hline 242 & $12: 17: 06.85$ & $-72: 12: 33.80$ & 3.856 & 0.277 & 104.2 & 14.8755 \\
\hline
\end{tabular}

mesmo objeto na Tabela B.30 com ID $=114$

mesmo objeto na Tabela B.30 com ID $=123$

mesmo objeto na Tabela B.30 com ID $=127$

mesmo objeto na Tabela B.30 com ID $=213$

mesmo objeto na Tabla B. $30 \mathrm{com}$ ID $=213$
mesmo objeto na Tabela B.30 com ID $=243$

mesmo objeto na Tabela B.30 com ID $=323$

$\mathrm{h}$ mesmo objeto na Tabela B. $30 \mathrm{com}$ ID $=323$
mesmo objeto na Tabela B.30 com ID $=369$ 


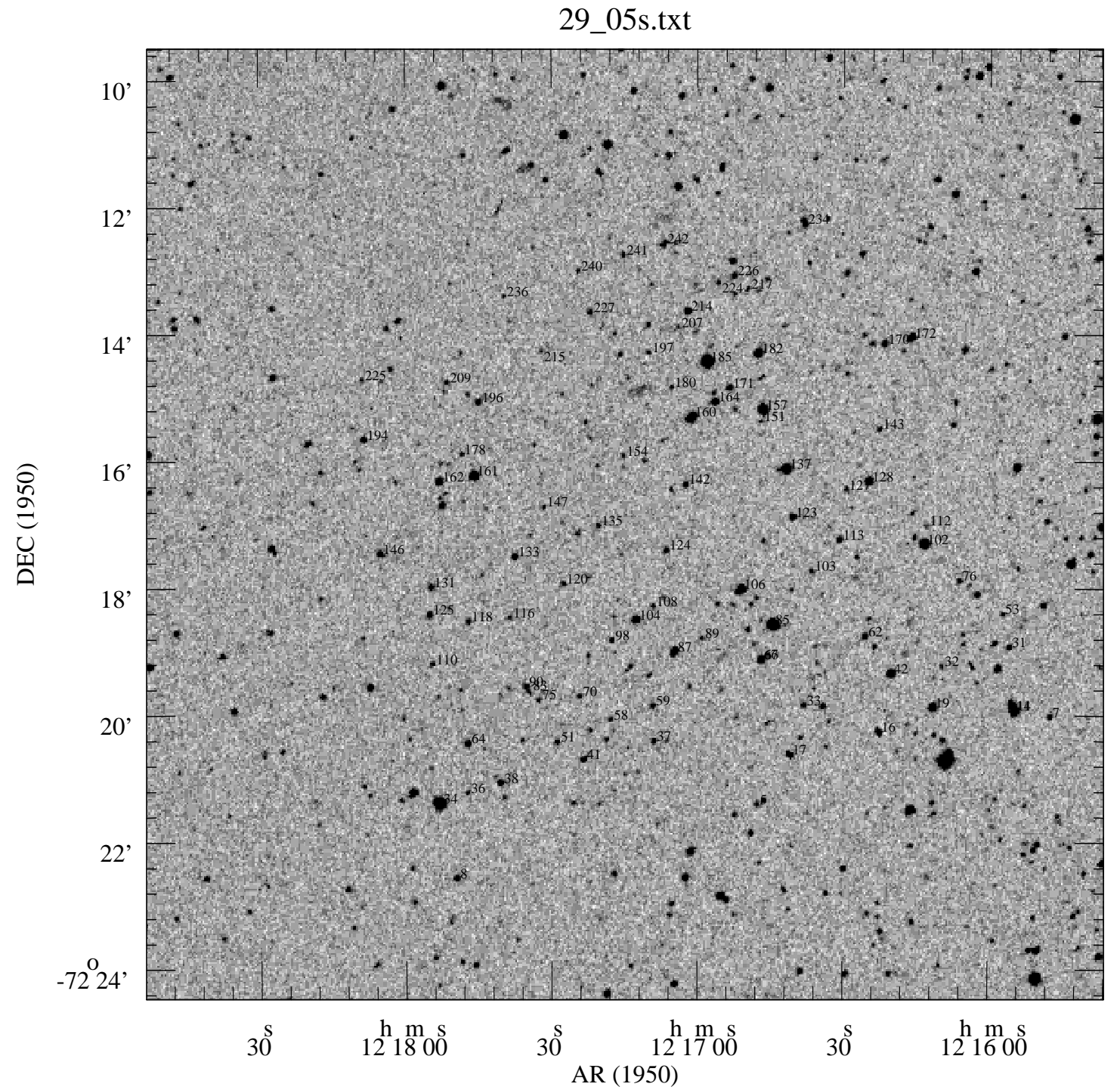

Figura C.29 Finding Chart do Campo 29 centrado em $\mathrm{AR}_{1950}=12^{\mathrm{h}} 17^{\mathrm{m}} 15^{\mathrm{s}}, \mathrm{DEC}_{1950}=-72^{\circ} 17^{\prime}$ 
Tabela C.30 Dados polarimétricos do Campo 30

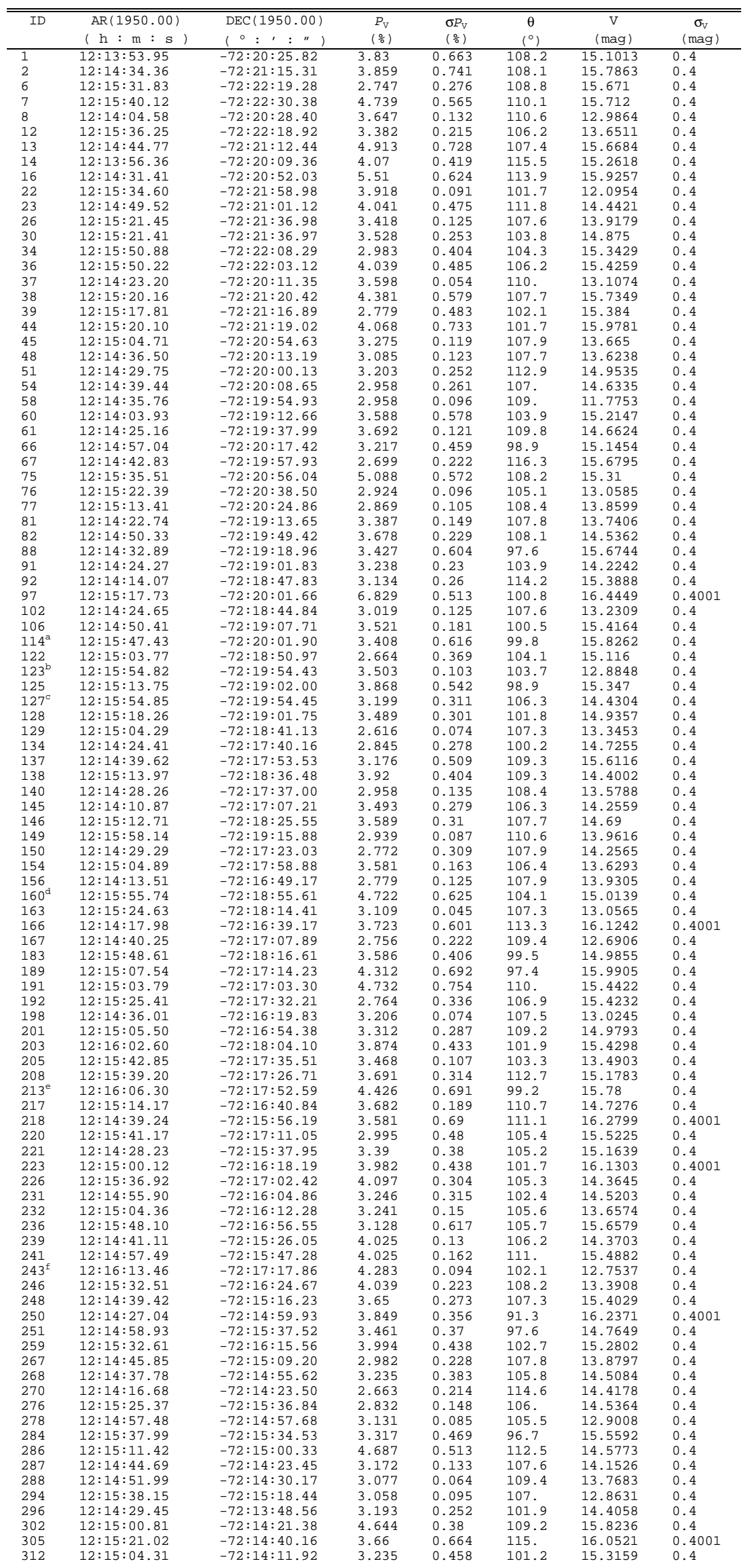


Tabela C.30 - Continuação

\begin{tabular}{|c|c|c|c|c|c|c|c|}
\hline \multirow[t]{2}{*}{ IID } & $\operatorname{AR}(1950.00)$ & "DEC (1950.00) & \multirow{2}{*}{$\begin{array}{c}P_{\mathrm{V}} \\
(\%)\end{array}$} & \multirow{2}{*}{$\begin{array}{l}\sigma P_{\mathrm{V}} \\
\left(\frac{\circ}{0}\right)\end{array}$} & \multirow{2}{*}{$\begin{array}{c}\theta \theta \\
\left({ }^{\circ}\right)\end{array}$} & \multirow{2}{*}{$\begin{array}{c}\mathrm{V} \\
(\mathrm{mag})\end{array}$} & \multirow{2}{*}{$\begin{array}{c}\sigma_{\mathrm{V}} \\
(\mathrm{mag})\end{array}$} \\
\hline & $(\mathrm{h}: \mathrm{m}: \mathrm{s})$ & $\left({ }^{\circ}:,: "\right)$ & & & & & \\
\hline 315 & $12: 14: 35.88$ & $-72: 13: 30.82$ & 3.733 & 0.654 & 114.6 & 15.0688 & 0.4 \\
\hline 316 & $12: 16: 07.74$ & $-72: 15: 24.64$ & 4.636 & 0.388 & 97.9 & 15.9886 & 0.4 \\
\hline $323^{9}$ & $12: 16: 22.49$ & $-72: 15: 28.67$ & 4.548 & 0.707 & 100.6 & 14.3521 & 0.4 \\
\hline 324 & $12: 14: 32.70$ & $-72: 13: 10 \cdot 36$ & 2.156 & 0.216 & 110.4 & 14.241 & 0.4 \\
\hline 325 & $12: 15: 33.68$ & $-72: 14: 26.66$ & 4.395 & 0.209 & 106.9 & 15.2357 & 0.4 \\
\hline 326 & $12: 15: 00.07$ & $-72: 13: 43.32$ & 2.548 & 0.154 & 108.3 & 15.2784 & 0.4 \\
\hline 330 & $12: 16: 07.26$ & $-72: 15: 03.45$ & 4.498 & 0.842 & 95.6 & 16.1154 & 0.4001 \\
\hline 334 & $12: 14: 26.84$ & $-72: 12: 50.71$ & 3.185 & 0.138 & 108.4 & 15.0874 & 0.4 \\
\hline 339 & $12: 15: 12.86$ & $-72: 13: 35.88$ & 3.122 & 0.19 & 110.2 & 14.338 & 0.4 \\
\hline 340 & $12: 15: 59.78$ & $-72: 14: 31.43$ & 3.014 & 0.527 & 101.1 & 16.3473 & 0.4001 \\
\hline 342 & $12: 15: 56.89$ & $-72: 14: 27.95$ & 4.379 & 0.38 & 105.4 & 16.0712 & 0.4001 \\
\hline 348 & $12: 14: 57.52$ & $-72: 13: 00.38$ & 3.535 & 0.495 & 104.5 & 15.373 & 0.4 \\
\hline 353 & $12: 14: 42.35$ & $-72: 12: 32.85$ & 3.452 & 0.313 & 102.4 & 14.7793 & 0.4 \\
\hline 354 & $12: 14: 28.30$ & $-72: 12: 13.17$ & 2.345 & 0.319 & 107.2 & 15.6066 & 0.4 \\
\hline 355 & $12: 16: 05.33$ & $-72: 14: 14.58$ & 6.891 & 0.785 & 97.6 & 16.3124 & 0.4001 \\
\hline 362 & $12: 14: 40.25$ & $-72: 12: 14.44$ & 2.984 & 0.263 & 108.5 & 14.2536 & 0.4 \\
\hline 367 & $12: 15: 04.85$ & $-72: 12: 37.09$ & 2.925 & 0.426 & 105.2 & 15.8778 & 0.4 \\
\hline $369^{\mathrm{h}}$ & $12: 16: 16.13$ & $-72: 14: 02.06$ & 3.275 & 0.193 & 100.3 & 13.6678 & 0.4 \\
\hline 371 & $12: 15: 01.64$ & $-72: 12: 25.14$ & 2.964 & 0.24 & 108.6 & 14.7836 & 0.4 \\
\hline 373 & $12: 14: 27.12$ & $-72: 11: 38.91$ & 2.879 & 0.149 & 106. & 13.5048 & 0.4 \\
\hline 382 & $12: 14: 39.35$ & $-72: 11: 33.91$ & 4.578 & 0.841 & 113 & 16.2158 & 0.4001 \\
\hline 385 & $12: 15: 37.93$ & $-72: 12: 46.22$ & 3.988 & 0.407 & 113.6 & 14.5418 & 0.4 \\
\hline
\end{tabular}

a mesmo objeto na Tabela B.29 com ID $=7$

mesmo objeto na Tabela B.29 com ID $=1$

mesmo objeto na Tabela B.29 com ID $=14$

mesmo objeto na Tabela B.29 com ID $=31$

mesmo objeto na Tabela B.29 com ID $=76$

mesmo objeto na Tabela B.29 com ID $=102$

hesmo objeto na Tabela B.29 com ID $=143$
mesmo objeto na Tabela B.29 com ID $=172$

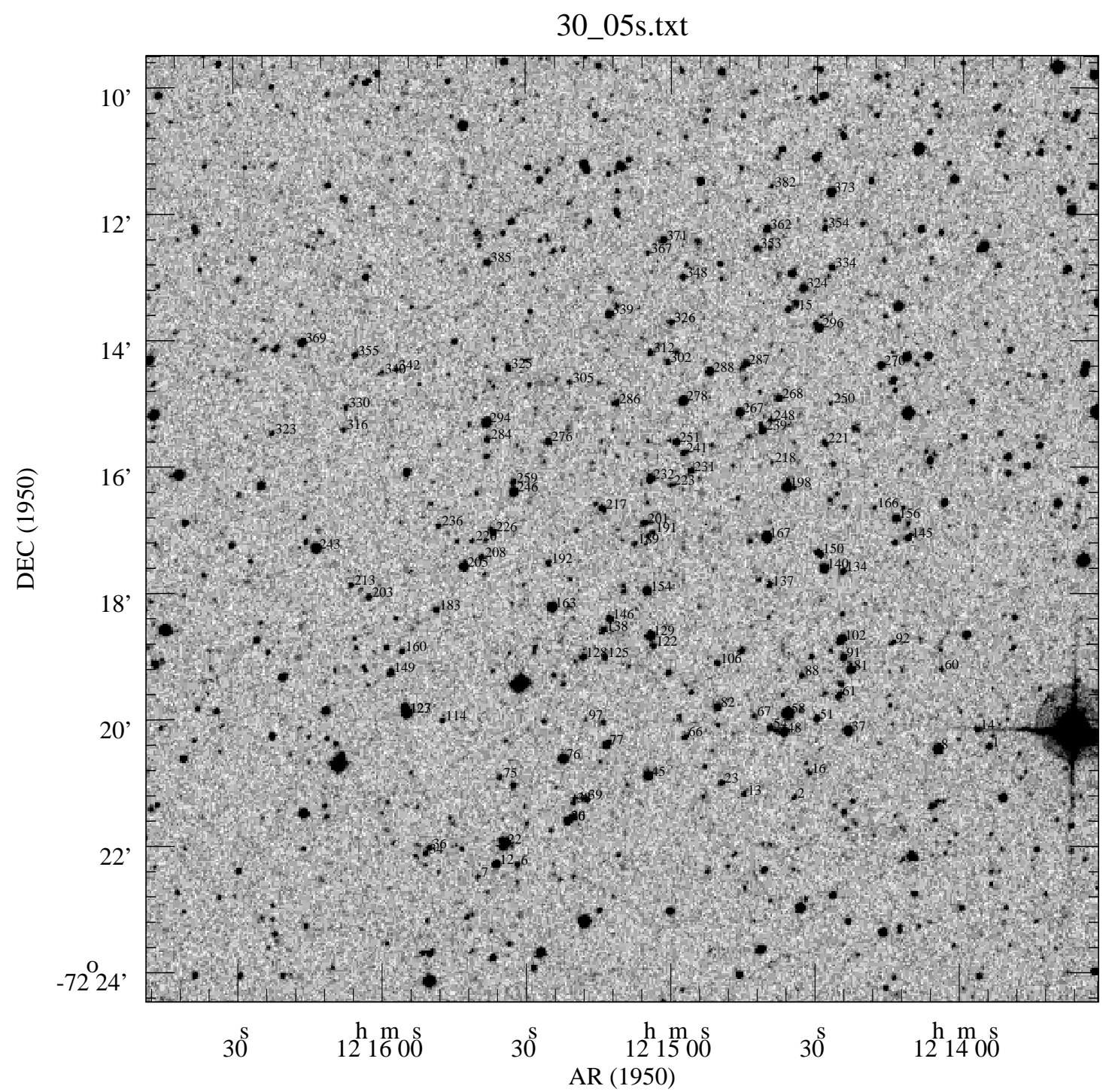

Figura C.30 Finding Chart do Campo 30 centrado em $\mathrm{AR}_{1950}=12^{\mathrm{h}} 15^{\mathrm{m}} 10^{\mathrm{s}}, \mathrm{DEC}_{1950}=-72^{\circ} 17^{\prime}$ 
Tabela C.31 Dados polarimétricos do Campo 31

\begin{tabular}{|c|c|c|}
\hline ID & $\operatorname{AR}(1950.00)$ & $\operatorname{DEC}(1950.00)$ \\
\hline & $(\mathrm{h}: \mathrm{m}: \mathrm{s})$ & $\left({ }^{\circ}:{ }^{\prime}: "\right)$ \\
\hline 1 & $12: 34: 17.51$ & $-70: 11: 00.57$ \\
\hline 12 & $12: 34: 19.24$ & $-70: 10: 11.90$ \\
\hline 30 & $12: 34: 21.62$ & $-70: 09: 34.86$ \\
\hline 32 & $12: 34: 22.10$ & $-70: 06: 05.59$ \\
\hline 35 & $12: 34: 23.45$ & $-70: 06: 42.89$ \\
\hline 42 & $12: 34: 24.37$ & $-70: 06: 14.10$ \\
\hline 44 & $12: 34: 24.62$ & $-70: 09: 20.75$ \\
\hline 51 & $12: 34: 26.11$ & $-70: 10: 59.16$ \\
\hline 52 & $12: 34: 26.29$ & $-70: 06: 49.96$ \\
\hline 56 & $12: 34: 28.30$ & $-70: 09: 12.67$ \\
\hline 57 & $12: 34: 28.55$ & $-70: 05: 14.64$ \\
\hline 60 & $12: 34: 29.70$ & $-70: 08: 04.09$ \\
\hline 65 & $12: 34: 30.95$ & $-70: 10: 54.61$ \\
\hline 81 & $12: 34: 35.43$ & $-70: 07: 51.27$ \\
\hline 88 & $12: 34: 36.36$ & $-70: 11: 04.77$ \\
\hline 96 & $12: 34: 37.22$ & $-70: 06: 28.00$ \\
\hline 99 & $12: 34: 37.64$ & $-70: 11: 22.34$ \\
\hline 101 & $12: 34: 38.57$ & $-70: 07: 04.00$ \\
\hline 104 & $12: 34: 39.61$ & $-70: 08: 08.17$ \\
\hline 106 & $12: 34: 40.34$ & $-70: 11: 15.37$ \\
\hline 108 & $12: 34: 40.48$ & $-70: 08: 03.36$ \\
\hline 110 & $12: 34: 41.39$ & $-70: 08: 36.69$ \\
\hline 121 & $12: 34: 43.78$ & $-70: 08: 48.92$ \\
\hline 124 & $12: 34: 44.46$ & $-70: 09: 46.47$ \\
\hline 129 & $12: 34: 44.96$ & $-70: 05: 31.96$ \\
\hline 132 & $12: 34: 46.09$ & $-70: 05: 16.81$ \\
\hline 136 & $12: 34: 47.68$ & $-70: 11: 25.67$ \\
\hline 142 & $12: 34: 49.35$ & $-70: 09: 01.20$ \\
\hline 143 & $12: 34: 49.43$ & $-70: 10: 28.71$ \\
\hline 144 & $12: 34: 49.44$ & $-70: 07: 21.56$ \\
\hline 160 & $12: 34: 54.63$ & $-70: 06: 50.66$ \\
\hline 168 & $12: 34: 59.84$ & $-70: 10: 46.26$ \\
\hline 174 & $12: 34: 59.50$ & $-70: 06: 53.47$ \\
\hline 175 & $12: 34: 59.84$ & $-70: 10: 46.26$ \\
\hline 184 & $12: 35: 01.31$ & $-70: 05: 13.29$ \\
\hline 190 & $12: 35: 03.07$ & $-70: 05: 53.92$ \\
\hline 191 & $12: 35: 03.60$ & $-70: 10: 27.74$ \\
\hline 192 & $12: 35: 04.44$ & $-70: 05: 46.09$ \\
\hline 198 & $12: 35: 05.66$ & $-70: 08: 30.78$ \\
\hline 200 & $12: 35: 06.50$ & $-70: 10: 19.83$ \\
\hline 210 & $12: 35: 08.81$ & $-70: 11: 00.11$ \\
\hline 212 & $12: 35: 08.97$ & $-70: 06: 17.90$ \\
\hline 219 & $12: 35: 10.32$ & $-70: 06: 55.55$ \\
\hline 233 & $12: 35: 13.02$ & $-70: 05: 21.66$ \\
\hline 234 & $12: 35: 13.16$ & $-70: 05: 21.52$ \\
\hline 236 & $12: 35: 14.07$ & $-70: 09: 14.68$ \\
\hline 243 & $12: 35: 15.38$ & $-70: 05: 30.90$ \\
\hline 244 & $12: 35: 15.42$ & $-70: 05: 15.80$ \\
\hline 245 & $12: 35: 16.04$ & $-70: 09: 14.09$ \\
\hline 248 & $12: 35: 16.70$ & $-70: 09: 31.82$ \\
\hline 256 & $12: 35: 18.91$ & $-70: 05: 13.02$ \\
\hline 259 & $12: 35: 19.71$ & $-70: 08: 33.99$ \\
\hline 260 & $12: 35: 20.03$ & $-70: 07: 12.22$ \\
\hline 267 & $12: 35: 21.87$ & $-70: 06: 37.98$ \\
\hline 269 & $12: 35: 22.56$ & $-70: 05: 31.35$ \\
\hline 271 & $12: 35: 23.45$ & $-70: 08: 26.42$ \\
\hline 275 & $12: 35: 24.05$ & $-70: 07: 07.57$ \\
\hline 281 & $12: 35: 24.73$ & $-70: 10: 29.33$ \\
\hline 286 & $12: 35: 25.45$ & $-70: 10: 21.09$ \\
\hline 290 & $12: 35: 26.39$ & $-70: 09: 09.43$ \\
\hline 297 & $12: 35: 30.00$ & $-70: 05: 50.85$ \\
\hline 314 & $12: 35: 34.90$ & $-70: 06: 06.99$ \\
\hline 321 & $12: 35: 37.43$ & $-70: 10: 29.68$ \\
\hline 322 & $12: 35: 37.46$ & $-70: 05: 15.25$ \\
\hline 324 & $12: 35: 38.38$ & $-70: 09: 55.72$ \\
\hline 329 & $12: 35: 39.65$ & $-70: 05: 49.06$ \\
\hline 331 & $12: 35: 40.82$ & $-70: 10: 10.01$ \\
\hline 332 & $12: 35: 41.38$ & $-70: 08: 54.56$ \\
\hline 333 & $12: 35: 41.48$ & $-70: 10: 17.31$ \\
\hline 339 & $12: 35: 42.54$ & $-70: 06: 08.95$ \\
\hline 351 & $12: 35: 45.34$ & $-70: 05: 55.48$ \\
\hline 355 & $12: 35: 46.87$ & $-70: 05: 21.91$ \\
\hline 356 & $12: 35: 47.15$ & $-70: 09: 47.94$ \\
\hline 363 & $12: 35: 48.61$ & $-70: 07: 59.83$ \\
\hline 366 & $12: 35: 51.40$ & $-70: 09: 24.77$ \\
\hline 387 & $12: 35: 57.50$ & $-70: 06: 24.61$ \\
\hline 399 & $12: 36: 00.21$ & $-70: 05: 16.70$ \\
\hline 403 & $12: 36: 00.68$ & $-70: 08: 16.52$ \\
\hline 409 & $12: 36: 03.06$ & $-70: 11: 08.27$ \\
\hline 413 & $12: 36: 03.90$ & $-70: 05: 39.12$ \\
\hline 421 & $12: 36: 06.80$ & $-70: 09: 20.76$ \\
\hline 423 & $12: 36: 07.61$ & $-70: 09: 55.43$ \\
\hline 427 & $12: 36: 09.46$ & $-70: 11: 16.51$ \\
\hline 428 & $12: 36: 09.34$ & $-70: 10: 41.85$ \\
\hline 435 & $12: 36: 11.35$ & $-70: 08: 37.30$ \\
\hline 436 & $12: 36: 11.75$ & $-70: 11: 06.90$ \\
\hline 441 & $12: 36: 12.17$ & $-70: 06: 03.35$ \\
\hline 448 & $12: 36: 14.23$ & $-70: 09: 16.26$ \\
\hline 449 & $12: 36: 14.01$ & $-70: 08: 15.44$ \\
\hline 460 & $12: 36: 17.33$ & $-70: 10: 58.73$ \\
\hline 464 & $12: 36: 17.64$ & $-70: 07: 19.26$ \\
\hline 468 & $12: 36: 18.56$ & $-70: 08: 24.39$ \\
\hline 470 & $12: 36: 18.72$ & $-70: 07: 54.07$ \\
\hline 486 & $12: 35: 32.42$ & $-70: 07: 15.41$ \\
\hline
\end{tabular}




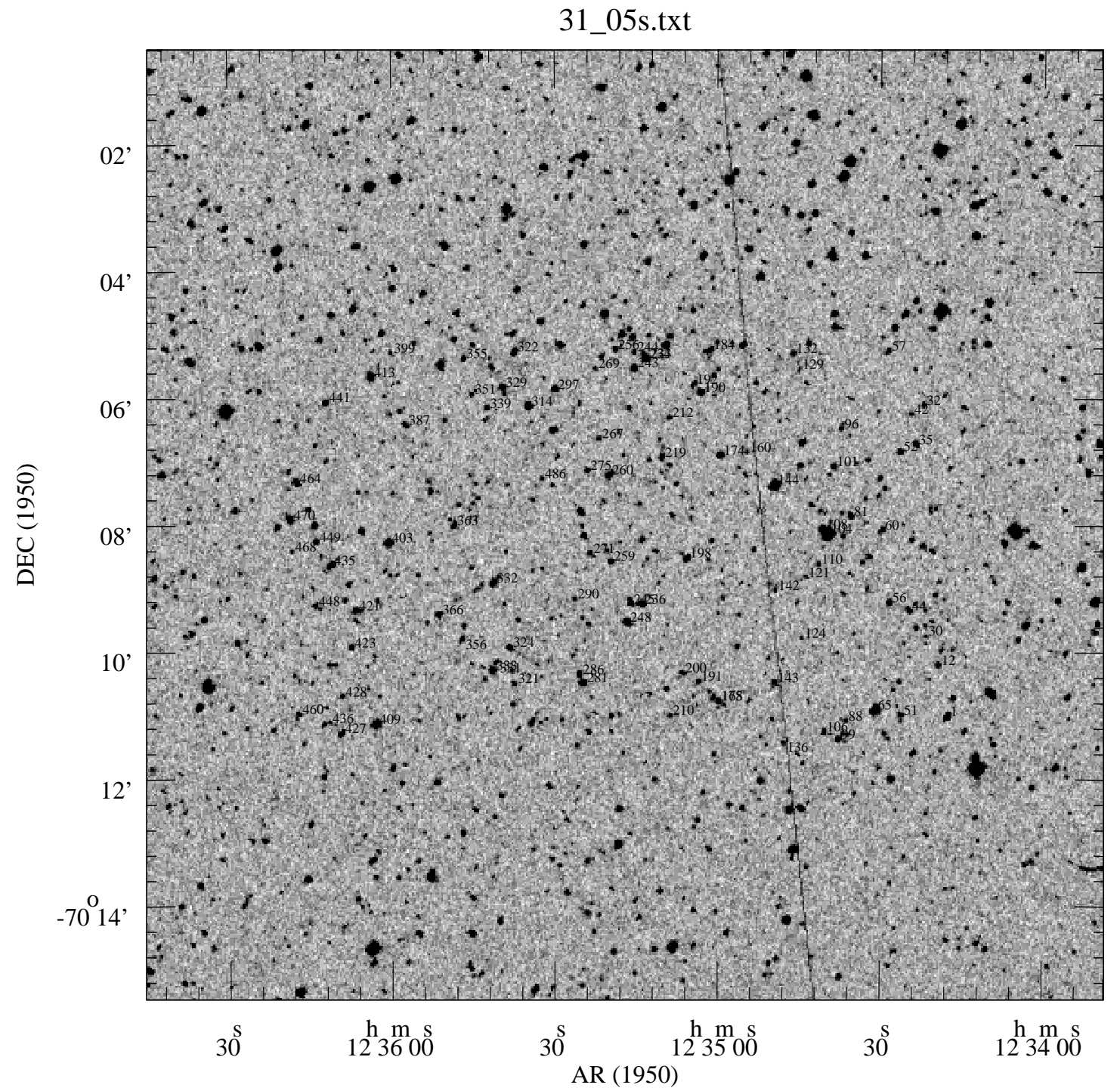

Figura C.31 Finding Chart do Campo 31 centrado em $\mathrm{AR}_{1950}=12^{\mathrm{h}} 35^{\mathrm{m}} 17^{\mathrm{s}}, \mathrm{DEC}_{1950}=-70^{\circ} 08^{\prime}$ 
Tabela C.32 Dados polarimétricos do Campo 32

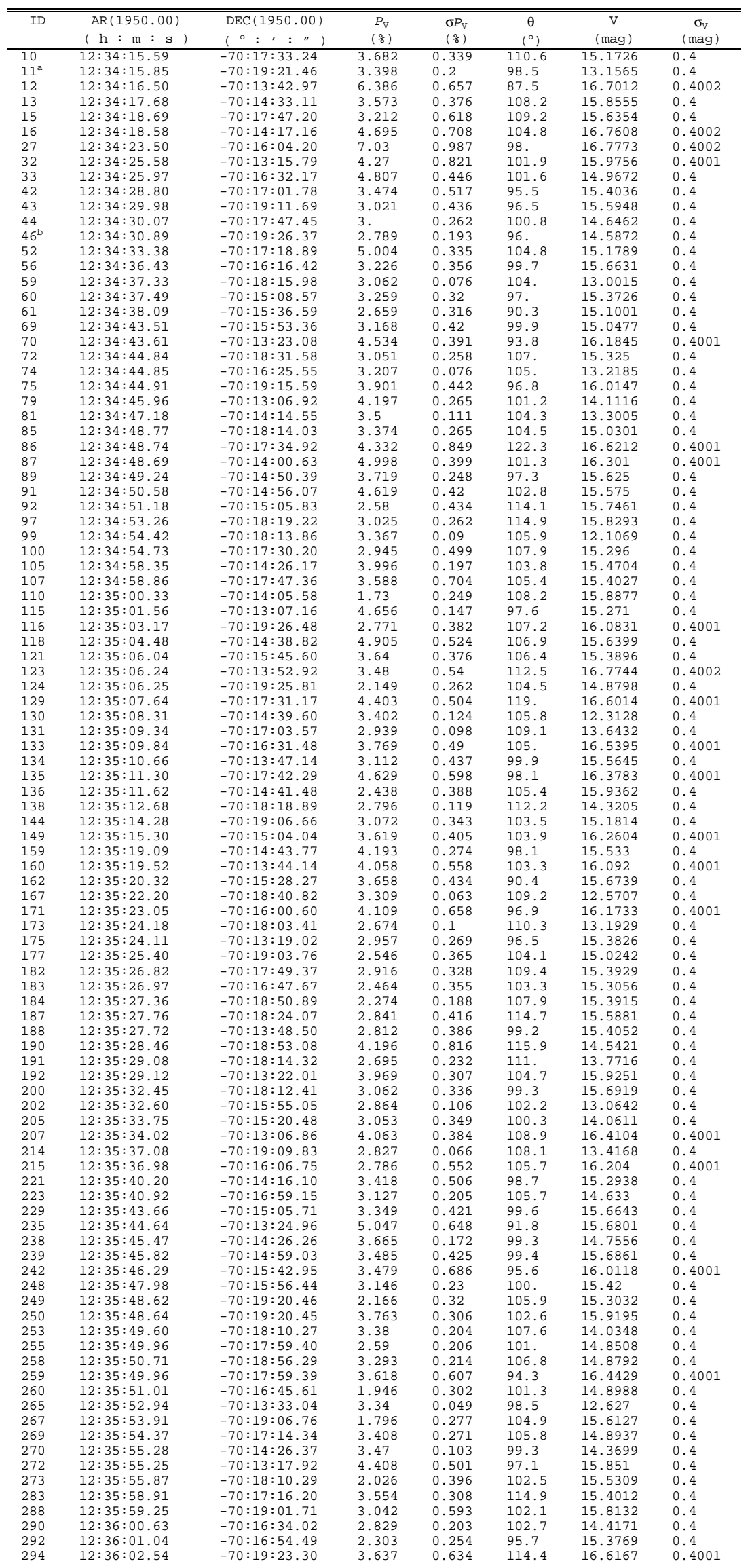


Tabela C.32 - Continuação

\begin{tabular}{|c|c|c|c|c|c|c|c|}
\hline ID & $\begin{array}{l}\text { AR }(1950.00) \\
(\mathrm{h}: \mathrm{m}: \mathrm{s})\end{array}$ & $\begin{array}{l}\operatorname{DEC}(1950.00) \\
\left({ }^{\circ}::^{\prime}: "\right)\end{array}$ & $\begin{array}{l}P_{\mathrm{V}} \\
\left(\frac{\mathrm{o}}{\circ}\right) \\
\end{array}$ & $\begin{array}{l}\sigma P_{\mathrm{V}} \\
\left(\frac{\circ}{0}\right)\end{array}$ & $\begin{array}{c}\theta \\
\left({ }^{\circ}\right)\end{array}$ & $\begin{array}{c}\mathrm{V} \\
(\mathrm{mag})\end{array}$ & $\begin{array}{c}\sigma_{\mathrm{v}} \\
(\mathrm{mag})\end{array}$ \\
\hline 296 & $12: 36: 03.42$ & $-70: 19: 14.86$ & 3.142 & 0.132 & 107.1 & 13.8574 & 0.4 \\
\hline 297 & $12: 36: 03.12$ & $-70: 13: 32.81$ & 3.481 & 0.494 & 110.8 & 15.9223 & 0.4 \\
\hline 298 & $12: 36: 03.84$ & $-70: 13: 17.84$ & 4.14 & 0.643 & 101.5 & 15.9753 & 0.4 \\
\hline 299 & $12: 36: 03.62$ & $-70: 14: 55.11$ & 3.101 & 0.143 & 98.6 & 14.6291 & 0.4 \\
\hline 300 & $12: 36: 03.66$ & $-70: 14: 41.60$ & 3.336 & 0.062 & 101.9 & 10.7038 & 0.4 \\
\hline 302 & $12: 36: 03.95$ & $-70: 13: 18.74$ & 3.038 & 0.15 & 97.5 & 14.8329 & 0.4 \\
\hline 308 & $12: 36: 05.67$ & $-70: 17: 26.77$ & 2.032 & 0.216 & 111.9 & 15.0588 & 0.4 \\
\hline 311 & $12: 36: 06.38$ & $-70: 13: 54.10$ & 3.341 & 0.147 & 97.5 & 14.8167 & 0.4 \\
\hline 312 & $12: 36: 06.95$ & $-70: 17: 30.37$ & 2.467 & 0.22 & 109.2 & 14.772 & 0.4 \\
\hline 314 & $12: 36: 07.47$ & $-70: 15: 21.06$ & 5.428 & 0.989 & 83.2 & 16.6826 & 0.4002 \\
\hline 316 & $12: 36: 08.50$ & $-70: 18: 56.45$ & 2.764 & 0.335 & 107.3 & 15.5775 & 0.4 \\
\hline 317 & $12: 36: 08.56$ & $-70: 18: 14.91$ & 2.096 & 0.367 & 113.4 & 15.6174 & 0.4 \\
\hline 321 & $12: 36: 09.18$ & $-70: 14: 19.91$ & 3.896 & 0.404 & 107.6 & 16.5483 & 0.4001 \\
\hline 323 & $12: 36: 10.75$ & $-70: 18: 57.20$ & 3.317 & 0.226 & 107.3 & 14.8418 & 0.4 \\
\hline 328 & $12: 36: 11.45$ & $-70: 17: 57.19$ & 3.534 & 0.502 & 108.2 & 15.8431 & 0.4 \\
\hline 335 & $12: 36: 15.14$ & $-70: 15: 35.67$ & 3.471 & 0.411 & 109.4 & 15.6262 & 0.4 \\
\hline 338 & $12: 36: 16.23$ & $-70: 19: 15.90$ & 2.806 & 0.184 & 110.9 & 14.5223 & 0.4 \\
\hline 339 & $12: 36: 15.72$ & $-70: 13: 35.13$ & 3.474 & 0.094 & 102.2 & 14.211 & 0.4 \\
\hline
\end{tabular}

a mesmo objeto na Tabela B.34 com ID $=447$

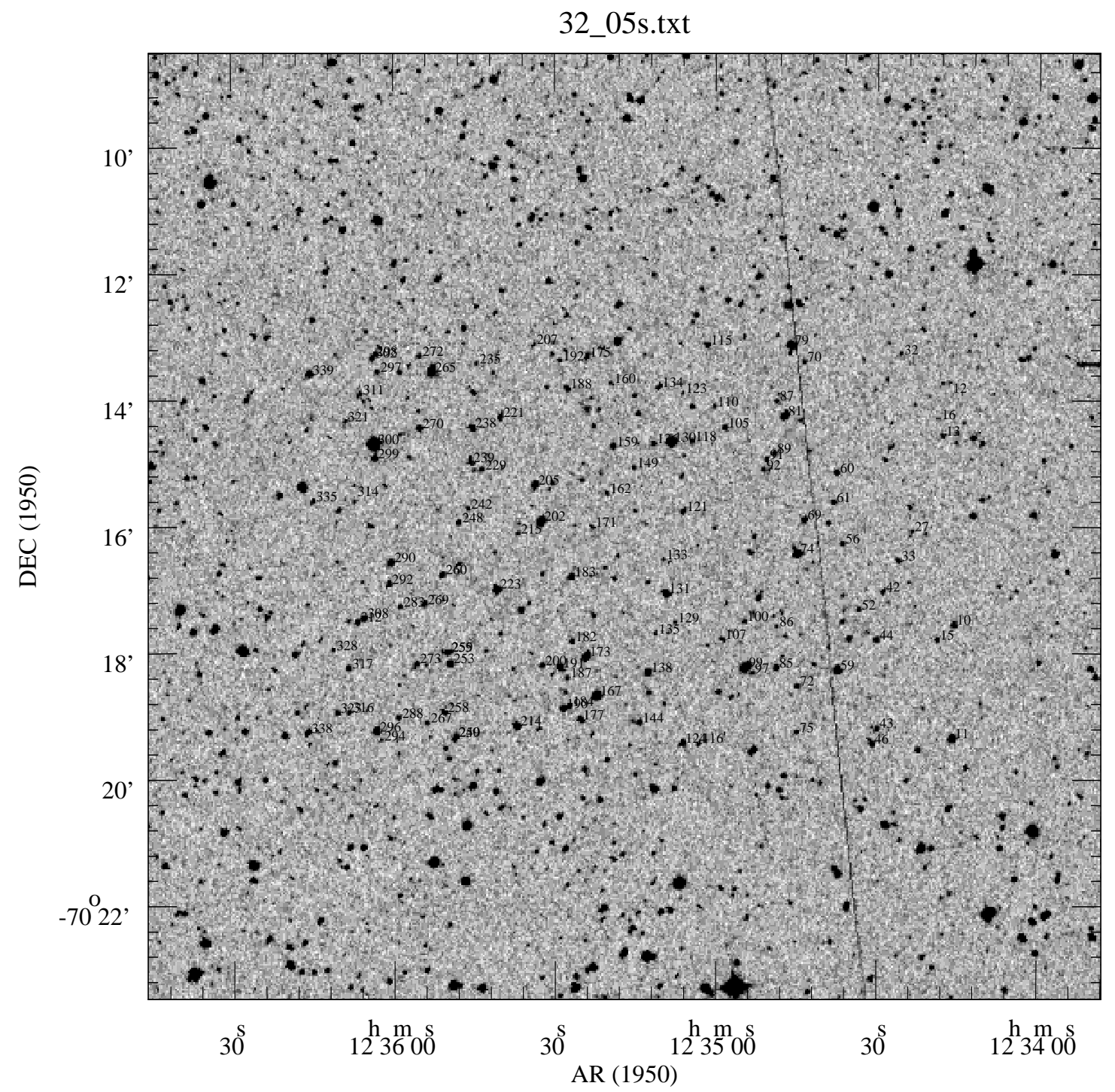

Figura C.32 Finding Chart do Campo 32 centrado em $\mathrm{AR}_{1950}=12^{\mathrm{h}} 35^{\mathrm{m}} 17^{\mathrm{s}}, \mathrm{DEC}_{1950}=-70^{\circ} 16^{\prime}$ 
Tabela C.33 Dados polarimétricos do Campo 33

\begin{tabular}{|c|c|c|c|c|c|c|c|}
\hline ID & $\operatorname{AR}(1950.00)$ & $\operatorname{DEC}(1950.00)$ & $P_{\mathrm{V}}$ & $\sigma P_{\mathrm{V}}$ & $\theta$ & $\mathrm{V}$ & \\
\hline & $(\mathrm{h}: \mathrm{m}: \mathrm{s})$ & $\left({ }^{\circ}:{ }^{\prime}: "\right)$ & (음) & $\left(\frac{\circ}{0}\right)$ & $\left({ }^{\circ}\right)$ & (mag) & (mag) \\
\hline 1 & $12: 31: 55.32$ & $-70: 14: 18.59$ & 2.268 & 0.11 & 93.3 & 12.8237 & 0.4 \\
\hline 8 & $12: 31: 57.01$ & $-70: 14: 18.36$ & 2.412 & 0.175 & 91.7 & 14.396 & 0.4 \\
\hline 10 & $12: 31: 58.24$ & $-70: 19: 10.90$ & 3.881 & 0.448 & 73.7 & 15.4287 & 0.4 \\
\hline 12 & $12: 31: 58.22$ & $-70: 19: 10.99$ & 3.339 & 0.1 & 90.1 & 12.4834 & 0.4 \\
\hline 13 & $12: 31: 58.61$ & $-70: 15: 24.53$ & 2.664 & 0.414 & 89.9 & 15.542 & 0.4 \\
\hline 14 & $12: 31: 58.90$ & $-70: 16: 55.04$ & 3.063 & 0.166 & 88.2 & 13.022 & 0.4 \\
\hline 25 & $12: 32: 02.74$ & $-70: 13: 54.08$ & 2.676 & 0.429 & 92.8 & 15.0243 & 0.4 \\
\hline 29 & $12: 32: 03.80$ & $-70: 16: 42.70$ & 2.404 & 0.184 & 85.7 & 13.9592 & 0.4 \\
\hline 32 & $12: 32: 04.50$ & $-70: 17: 48.18$ & 3.968 & 0.405 & 92.3 & 15.5183 & 0.4 \\
\hline 34 & $12: 32: 04.81$ & $-70: 13: 29.95$ & 2.367 & 0.266 & 97.2 & 14.7119 & 0.4 \\
\hline 36 & $12: 32: 04.78$ & $-70: 14: 25.28$ & 3.222 & 0.28 & 93.3 & 14.3605 & 0.4 \\
\hline 47 & $12: 32: 08.06$ & $-70: 17: 57.23$ & 4.533 & 0.211 & 89. & 14.8396 & 0.4 \\
\hline 49 & $12: 32: 08.43$ & $-70: 14: 07.80$ & 1.591 & 0.261 & 111.2 & 15.4896 & 0.4 \\
\hline 55 & $12: 32: 12.06$ & $-70: 14: 54.06$ & 5.311 & 0.961 & 78.6 & 16.3957 & 0.4001 \\
\hline 57 & $12: 32: 12.52$ & $-70: 15: 15.44$ & 2.544 & 0.45 & 98.3 & 15.7565 & 0.4 \\
\hline 59 & $12: 32: 12.61$ & $-70: 14: 14.60$ & 2.529 & 0.369 & 95. & 15.2047 & 0.4 \\
\hline 61 & $12: 32: 12.68$ & $-70: 18: 29.21$ & 2.751 & 0.15 & 88. & 12.4982 & 0.4 \\
\hline 63 & $12: 32: 13.63$ & $-70: 16: 53.00$ & 5.536 & 1.075 & 76.2 & 16.4746 & 0.4001 \\
\hline 65 & $12: 32: 14.04$ & $-70: 16: 25.39$ & 3.503 & 0.37 & 86.5 & 15.9244 & 0.4 \\
\hline 70 & $12: 32: 14.55$ & $-70: 16: 41.34$ & 5.9 & 0.55 & 73.8 & 16.0206 & 0.4001 \\
\hline 71 & $12: 32: 14.42$ & $-70: 14: 55.66$ & 2.476 & 0.404 & 95.2 & 14.9961 & 0.4 \\
\hline 78 & $12: 32: 18.15$ & $-70: 17: 11.49$ & 3.365 & 0.254 & 83.6 & 15.0902 & 0.4 \\
\hline 81 & $12: 32: 18.15$ & $-70: 17: 11.49$ & 5.161 & 1.013 & 89.5 & 15.7039 & 0.4 \\
\hline 87 & $12: 32: 19.65$ & $-70: 17: 10.49$ & 4.087 & 0.255 & 87. & 14.9479 & 0.4 \\
\hline 89 & $12: 32: 19.70$ & $-70: 17: 02.98$ & 4.58 & 0.565 & 92.2 & 16.4466 & 0.4001 \\
\hline 92 & $12: 32: 20.20$ & $-70: 17: 12.31$ & 3.67 & 0.346 & 80.1 & 15.0976 & 0.4 \\
\hline 94 & $12: 32: 21.67$ & $-70: 15: 14.93$ & 2.968 & 0.265 & 96.4 & 15.1566 & 0.4 \\
\hline 95 & $12: 32: 21.68$ & $-70: 15: 14.99$ & 3.161 & 0.502 & 91.3 & 15.1859 & 0.4 \\
\hline 102 & $12: 32: 24.05$ & $-70: 16: 00.16$ & 3.529 & 0.55 & 96.9 & 15.4737 & 0.4 \\
\hline 107 & $12: 32: 25.14$ & $-70: 13: 52.72$ & 2.774 & 0.551 & 94.5 & 15.6995 & 0.4 \\
\hline 115 & $12: 32: 29.07$ & $-70: 18: 56.89$ & 3.165 & 0.221 & 94.4 & 13.9644 & 0.4 \\
\hline 117 & $12: 32: 29.54$ & $-70: 15: 44.67$ & 3.36 & 0.274 & 91.8 & 14.9369 & 0.4 \\
\hline 121 & $12: 32: 34.17$ & $-70: 17: 09.56$ & 3.776 & 0.229 & 86.7 & 13.9993 & 0.4 \\
\hline 122 & $12: 32: 34.85$ & $-70: 16: 14.29$ & 4.908 & 0.679 & 84.3 & 16.5608 & 0.4001 \\
\hline 124 & $12: 32: 35.76$ & $-70: 14: 36.83$ & 3.722 & 0.576 & 97.2 & 15.2257 & 0.4 \\
\hline 128 & $12: 32: 35.76$ & $-70: 14: 36.83$ & 2.678 & 0.085 & 91.8 & 13.7653 & 0.4 \\
\hline 130 & $12: 32: 36.07$ & $-70: 14: 22.62$ & 2.776 & 0.109 & 93.7 & 12.6577 & 0.4 \\
\hline 136 & $12: 32: 37.84$ & $-70: 14: 16.53$ & 2.095 & 0.228 & 94.1 & 14.051 & 0.4 \\
\hline 137 & $12: 32: 37.91$ & $-70: 17: 13.10$ & 4.26 & 0.263 & 83.8 & 14.715 & 0.4 \\
\hline 138 & $12: 32: 38.38$ & $-70: 14: 31.36$ & 2.522 & 0.121 & 98.4 & 11.1634 & 0.4 \\
\hline 141 & $12: 32: 38.97$ & $-70: 16: 56.88$ & 5.653 & 0.87 & 86.4 & 16.2819 & 0.4001 \\
\hline 145 & $12: 32: 43.61$ & $-70: 17: 11.52$ & 3.33 & 0.371 & 84.4 & 15.2949 & 0.4 \\
\hline 147 & $12: 32: 44.71$ & $-70: 14: 30.57$ & 2.689 & 0.475 & 84.3 & 15.3777 & 0.4 \\
\hline 154 & $12: 32: 47.49$ & $-70: 14: 57.07$ & 3.416 & 0.651 & 92.9 & 16.3866 & 0.4001 \\
\hline 155 & $12: 32: 49.38$ & $-70: 17: 35.31$ & 3.908 & 0.577 & 89.3 & 16.0199 & 0.4 \\
\hline 156 & $12: 32: 49.38$ & $-70: 17: 35.31$ & 3.454 & 0.112 & 89.1 & 13.5411 & 0.4 \\
\hline 159 & $12: 32: 49.89$ & $-70: 16: 50.57$ & 3.793 & 0.679 & 79.4 & 16.1298 & 0.4001 \\
\hline 164 & $12: 32: 50.87$ & $-70: 15: 28.09$ & 3.895 & 0.597 & 97.9 & 15.8609 & 0.4 \\
\hline 168 & $12: 32: 51.93$ & $-70: 15: 22.50$ & 4.897 & 0.934 & 77.1 & 16.0725 & 0.4001 \\
\hline 170 & $12: 32: 54.51$ & $-70: 15: 07.01$ & 4.969 & 0.315 & 80.7 & 16.2509 & 0.4001 \\
\hline 177 & $12: 32: 59.25$ & $-70: 16: 46.17$ & 4.205 & 0.421 & 97.9 & 15.3902 & 0.4 \\
\hline 180 & $12: 32: 59.65$ & $-70: 15: 39.78$ & 4.901 & 0.406 & 102. & 15.4665 & 0.4 \\
\hline 184 & $12: 33: 03.21$ & $-70: 16: 39.19$ & 4.638 & 0.814 & 97.6 & 15.5759 & 0.4 \\
\hline 187 & $12: 33: 05.29$ & $-70: 14: 35.42$ & 3.951 & 0.485 & 90.9 & 15.5092 & 0.4 \\
\hline 190 & $12: 33: 08.74$ & $-70: 14: 21.47$ & 4.684 & 0.455 & 90.2 & 15.6568 & 0.4 \\
\hline 192 & $12: 33: 16.24$ & $-70: 14: 50.44$ & 3.631 & 0.465 & 96.4 & 15.7365 & 0.4 \\
\hline 193 & $12: 33: 17.19$ & $-70: 16: 40.37$ & 4.692 & 0.575 & 91.9 & 15.7716 & 0.4 \\
\hline 194 & $12: 33: 22.70$ & $-70: 15: 29.63$ & 4.627 & 0.667 & 93.9 & 15.994 & 0.4001 \\
\hline 198 & $12: 33: 28.92$ & $-70: 14: 21.55$ & 4.187 & 0.09 & 92.9 & 13.8884 & 0.4 \\
\hline 201 & $12: 33: 31.22$ & $-70: 18: 56.65$ & 4.198 & 0.425 & 105.1 & 15.754 & 0.4 \\
\hline 208 & $12: 33: 36.44$ & $-70: 14: 08.75$ & 4.85 & 0.562 & 100.7 & 15.95 & 0.4 \\
\hline 211 & $12: 33: 40.21$ & $-70: 18: 29.72$ & 6.114 & 0.84 & 91.7 & 16.6497 & 0.4001 \\
\hline 212 & $12: 33: 41.21$ & $-70: 18: 12.27$ & 3.481 & 0.309 & 95.4 & 14.9309 & 0.4 \\
\hline 215 & $12: 33: 42.42$ & $-70: 18: 43.60$ & 4.051 & 0.224 & 94.8 & 15.164 & 0.4 \\
\hline 219 & $12: 33: 45.25$ & $-70: 14: 06.82$ & 4.783 & 0.587 & 101. & 15.9202 & 0.4 \\
\hline 223 & $12: 33: 46.54$ & $-70: 13: 25.16$ & 3.315 & 0.306 & 103.7 & 15.932 & 0.4 \\
\hline 227 & $12: 33: 49.09$ & $-70: 18: 21.59$ & 2.801 & 0.283 & 98.2 & 15.549 & 0.4 \\
\hline 228 & $12: 33: 49.71$ & $-70: 18: 14.28$ & 3.332 & 0.431 & 98.6 & 14.8371 & 0.4 \\
\hline 229 & $12: 33: 49.93$ & $-70: 14: 15.77$ & 5.844 & 1.1 & 92.7 & 16.2797 & 0.4001 \\
\hline 233 & $12: 33: 53.83$ & $-70: 14: 43.40$ & 4.527 & 0.598 & 109.5 & 15.6791 & 0.4 \\
\hline 234 & $12: 33: 54.36$ & $-70: 16: 42.77$ & 4.21 & 0.563 & 102.1 & 15.7903 & 0.4 \\
\hline 235 & $12: 33: 54.53$ & $-70: 13: 18.19$ & 4.577 & 0.791 & 88.5 & 16.4885 & 0.4001 \\
\hline 238 & $12: 33: 56.81$ & $-70: 16: 24.78$ & 4.023 & 0.148 & 100.5 & 13.6688 & 0.4 \\
\hline
\end{tabular}




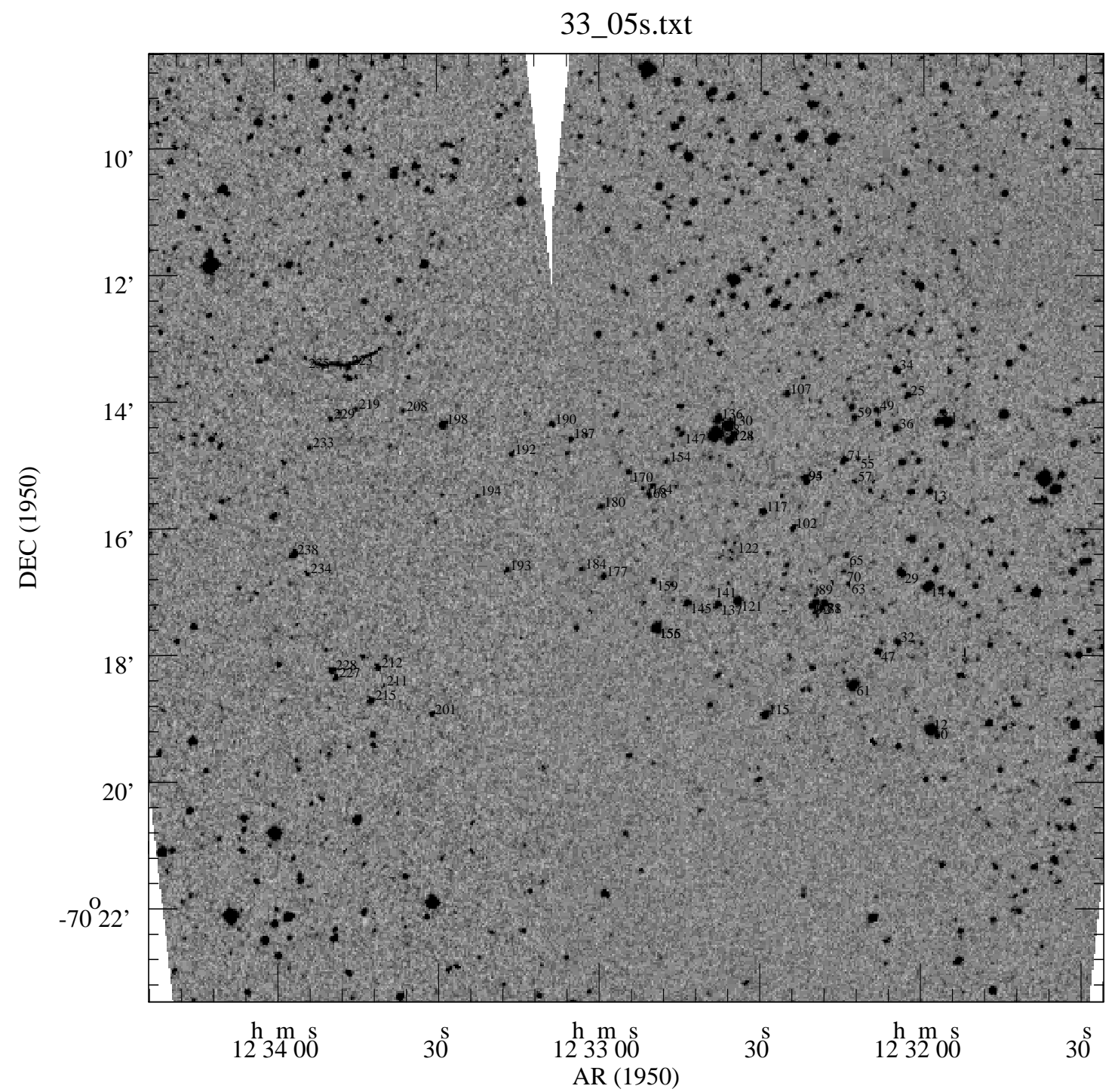

Figura C.33 Finding Chart do Campo 33 centrado em $\mathrm{AR}_{1950}=12^{\mathrm{h}} 32^{\mathrm{m}} 55^{\mathrm{s}}, \mathrm{DEC}_{1950}=-70^{\circ} 16^{\prime}$ 
Tabela C.34 Dados polarimétricos do Campo 34

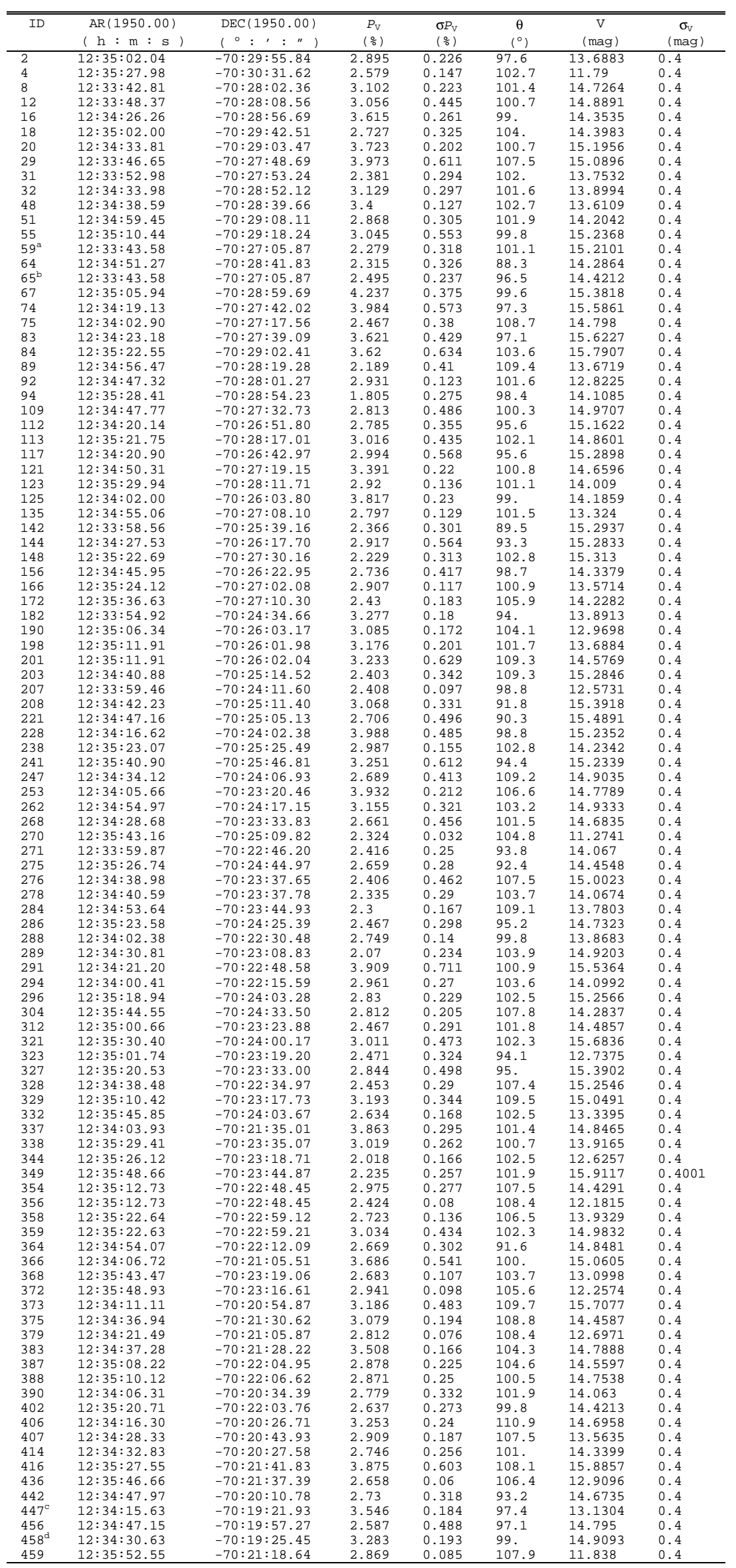


a mesmo objeto na Tabela B.35 com ID $=156$

mesmo objeto na Tabela B.35 com ID $=157$

c mesmo objeto na Tabela B. $32 \mathrm{com}$ ID $=11$
d mesmo objeto na Tabela $\mathrm{B} .32 \mathrm{com}$ ID $=46$

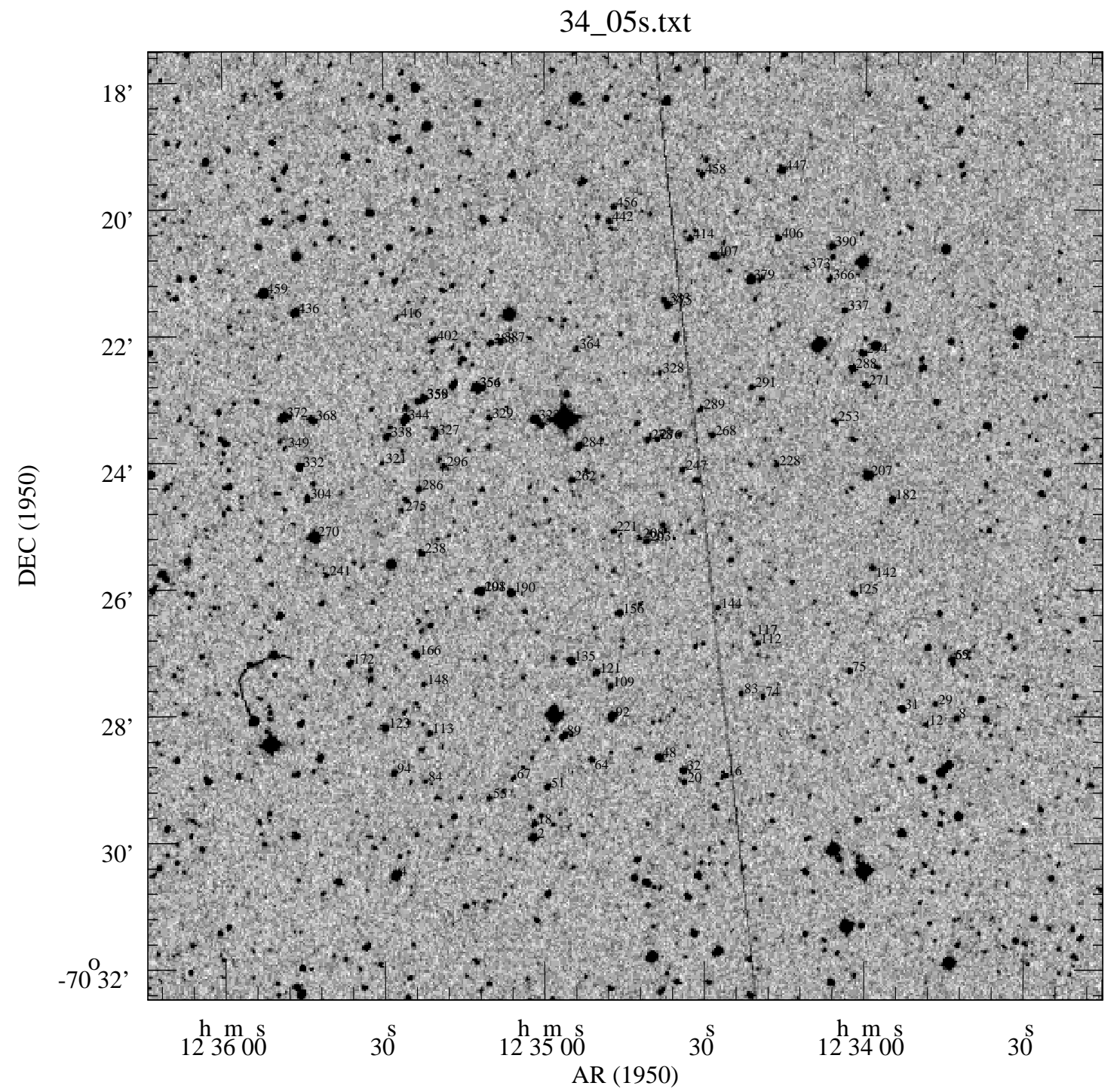

Figura C.34 Finding Chart do Campo 34 centrado em $\mathrm{AR}_{1950}=12^{\mathrm{h}} 34^{\mathrm{m}} 45^{\mathrm{s}}, \mathrm{DEC}_{1950}=-70^{\circ} 25^{\prime}$ 
Tabela C.35 Dados polarimétricos do Campo 35

\begin{tabular}{|c|c|c|c|c|c|c|c|}
\hline ID & AR (1950.00) & $\operatorname{DEC}(1950.00)$ & $P_{\mathrm{V}}$ & $\sigma P_{\mathrm{V}}$ & $\theta$ & $\overline{\mathrm{V}}$ & $\overline{\sigma_{\mathrm{v}}}$ \\
\hline & $(\mathrm{h}: \mathrm{m}: \mathrm{s})$ & $\left({ }^{\circ}:{ }^{\prime}: "{ }^{\prime \prime}\right)$ & $(\%)$ & $\left(\frac{\circ}{0}\right)$ & $\left({ }^{\circ}\right)$ & (mag) & (mag) \\
\hline 1 & $12: 31: 52.53$ & $-70: 22: 22.82$ & 3.554 & 0.634 & 84.7 & 15.6274 & 0.4 \\
\hline 2 & $12: 31: 52.89$ & $-70: 22: 51.20$ & 3.821 & 0.238 & 86.1 & 13.8811 & 0.4 \\
\hline 4 & $12: 31: 54.64$ & $-70: 25: 16.64$ & 6.347 & 0.958 & 98.8 & 16.1953 & 0.4002 \\
\hline 5 & $12: 31: 56.00$ & $-70: 21: 18.46$ & 4.308 & 0.47 & 88.3 & 15.0369 & 0.4 \\
\hline 10 & $12: 32: 08.98$ & $-70: 22: 10.03$ & 3.303 & 0.174 & 90.2 & 13.6436 & 0.4 \\
\hline 12 & $12: 32: 20.74$ & $-70: 27: 25.45$ & 4.121 & 0.392 & 104.6 & 15.5708 & 0.4 \\
\hline 16 & $12: 32: 23.43$ & $-70: 25: 07.96$ & 4.797 & 0.934 & 85. & 15.8196 & 0.4001 \\
\hline 20 & $12: 32: 38.05$ & $-70: 25: 42.12$ & 4.749 & 0.368 & 85.4 & 15.1109 & 0.4 \\
\hline 22 & $12: 32: 39.29$ & $-70: 27: 03.55$ & 3.617 & 0.37 & 91.3 & 15.4523 & 0.4 \\
\hline 27 & $12: 32: 44.47$ & $-70: 25: 39.72$ & 2.589 & 0.499 & 94.8 & 15.1312 & 0.4 \\
\hline 28 & $12: 32: 44.47$ & $-70: 26: 51.50$ & 2.774 & 0.091 & 101.1 & 13.0448 & 0.4 \\
\hline 29 & $12: 32: 44.73$ & $-70: 27: 02.48$ & 3.315 & 0.484 & 102.3 & 15.51 & 0.4 \\
\hline 36 & $12: 32: 52.17$ & $-70: 21: 25.98$ & 3.649 & 0.539 & 100.9 & 15.8832 & 0.4001 \\
\hline 37 & $12: 32: 52.86$ & $-70: 27: 13.71$ & 3.333 & 0.507 & 100.1 & 16.1787 & 0.4001 \\
\hline 38 & $12: 32: 53.56$ & $-70: 26: 36.33$ & 3.822 & 0.674 & 111. & 16.0093 & 0.4001 \\
\hline 48 & $12: 32: 58.96$ & $-70: 21: 47.75$ & 2.345 & 0.115 & $90 . \dot{9}$ & 14.1829 & 0.4 \\
\hline 52 & $12: 33: 00.37$ & $-70: 25: 12.78$ & 3.288 & 0.094 & 102.5 & 14.2538 & 0.4 \\
\hline 53 & $12: 33: 00.93$ & $-70: 26: 58.21$ & 2.249 & 0.144 & 97.2 & 13.1296 & 0.4 \\
\hline 55 & $12: 33: 01.75$ & $-70: 24: 38.25$ & 5.402 & 0.885 & 83.2 & 16.0826 & 0.4001 \\
\hline 57 & $12: 33: 02.90$ & $-70: 23: 36.43$ & 2.284 & 0.163 & 92.7 & 15.3675 & 0.4 \\
\hline 60 & $12: 33: 05.05$ & $-70: 23: 31.04$ & $\begin{array}{l}2.294 \\
2.294\end{array}$ & 0.351 & 109.6 & 14.8338 & 0.4 \\
\hline 61 & $12: 33: 05.51$ & $-70: 24: 25.58$ & 3.085 & 0.341 & 103. & 14.7323 & 0.4 \\
\hline 64 & $12: 33: 06.15$ & $-70: 24: 20.01$ & 3.436 & 0.076 & 108.3 & 11.5706 & 0.4 \\
\hline 73 & $12: 33: 10.80$ & $-70: 26: 15.92$ & 5.39 & 1.028 & 93.3 & 16.3856 & 0.4002 \\
\hline 77 & $12: 33: 11.76$ & $-70: 27: 11.96$ & 3.306 & 0.303 & 92.9 & 14.8332 & 0.4 \\
\hline 84 & $12: 33: 14.26$ & $-70: 22: 22.00$ & 2.851 & 0.305 & 104.2 & 15.4343 & 0.4 \\
\hline 88 & $12: 33: 17.89$ & $-70: 23: 14.43$ & 2.685 & 0.515 & 101.1 & 15.7576 & 0.4001 \\
\hline 90 & $12: 33: 18.96$ & $-70: 23: 44.47$ & 2.744 & 0.481 & 92.8 & 14.9417 & 0.4 \\
\hline 91 & $12: 33: 19.23$ & $-70: 25: 11.42$ & $\begin{array}{l}2.144 \\
2.977\end{array}$ & $\begin{array}{l}0.401 \\
0.117\end{array}$ & 107.4 & 14.4107 & 0.4 \\
\hline 92 & $12: 33: 19.20$ & $-70: 26: 28.02$ & 2.316 & 0.197 & 94.6 & 14.9004 & 0.4 \\
\hline 94 & $12: 33: 22.04$ & $-70: 26: 39.44$ & 3.377 & 0.648 & 111.5 & 16.0555 & 0.4001 \\
\hline 100 & $12: 33: 23.99$ & $-70: 21: 06.11$ & 3.236 & 0.402 & 100.2 & 16.0085 & 0.4001 \\
\hline 102 & $12: 33: 26.00$ & $-70: 24: 08.35$ & 2.536 & 0.216 & 95.2 & 14.0152 & 0.4 \\
\hline 103 & $12: 33: 26.15$ & $-70: 25: 00.66$ & 3.781 & 0.553 & 79.8 & 15.8482 & 0.4001 \\
\hline 104 & $12: 33: 26.60$ & $-70: 22: 55.65$ & 2.222 & 0.282 & 93. & 15.2673 & 0.4 \\
\hline 105 & $12: 33: 26.84$ & $-70: 24: 28.75$ & 2.993 & 0.228 & 101.6 & 14.2749 & 0.4 \\
\hline 114 & $12: 33: 28.76$ & $-70: 26: 11.95$ & 5.067 & 0.492 & 94.2 & 16.1479 & 0.4001 \\
\hline 117 & $12: 33: 29.42$ & $-70: 21: 13.04$ & 7.274 & 0.961 & 108.8 & 16.4167 & 0.4002 \\
\hline 118 & $12: 33: 31.23$ & $-70: 21: 55.44$ & 2.454 & 0.038 & 108.2 & 10.742 & 0.4 \\
\hline 121 & $12: 33: 33.01$ & $-70: 26: 44.33$ & 2.53 & 0.228 & 100.9 & 14.9122 & 0.4 \\
\hline 134 & $12: 33: 36.21$ & $-70: 21: 29.67$ & 2.994 & 0.57 & 96.2 & 15.3678 & 0.4 \\
\hline 135 & $12: 33: 36.58$ & $-70: 25: 03.77$ & 3.435 & 0.235 & 92.1 & 15.4318 & 0.4 \\
\hline 140 & $12: 33: 37.20$ & $-70: 23: 24.16$ & 2.57 & 0.094 & 97. & 14.0437 & 0.4 \\
\hline 141 & $12: 33: 37.44$ & $-70: 24: 20.07$ & 4.679 & 0.454 & 92.3 & 15.3922 & 0.4 \\
\hline 154 & $12: 33: 42.17$ & $-70: 22: 04.99$ & 5.154 & 0.762 & 86.5 & 16.1678 & 0.4001 \\
\hline $156^{a}$ & $12: 33: 43.54$ & $-70: 27: 08.64$ & 3.685 & 0.612 & 103.7 & 15.3846 & 0.4 \\
\hline $157^{\mathrm{b}}$ & $12: 33: 43.66$ & $-70: 27: 05.59$ & 2.126 & 0.295 & 98.8 & 14.6788 & 0.4 \\
\hline 160 & $12: 33: 43.96$ & $-70: 22: 04.11$ & 3.39 & 0.311 & 101.7 & 14.9121 & 0.4 \\
\hline 162 & $12: 33: 45.98$ & $-70: 26: 23.59$ & 2.683 & 0.183 & 97.6 & 15.023 & 0.4 \\
\hline 164 & $12: 33: 46.86$ & $-70: 23: 01.73$ & 2.503 & 0.291 & 89.4 & 14.8203 & 0.4 \\
\hline $\begin{array}{l}168 \\
168\end{array}$ & $12: 33: 49.54$ & $-70: 22: 29.44$ & 3.135 & 0.189 & 98.4 & 14.0429 & 0.4 \\
\hline 169 & $12: 33: 49.45$ & $-70: 22: 21.33$ & 3.546 & 0.534 & 89.7 & 15.4509 & 0.4 \\
\hline 170 & $12: 33: 50.49$ & $-70: 24: 56.85$ & 3.891 & 0.405 & 100.5 & 16.367 & 0.4002 \\
\hline 171 & $12: 33: 52.33$ & $-70: 26: 45.50$ & 3.24 & 0.648 & 96.3 & 15.8724 & 0.4001 \\
\hline
\end{tabular}

a mesmo objeto na Tabela B. 34 com ID $=59$

mesmo objeto na Tabela B. 34 Com ID $=59$
mesmo objeto na Tabela B.34 com ID $=65$ 


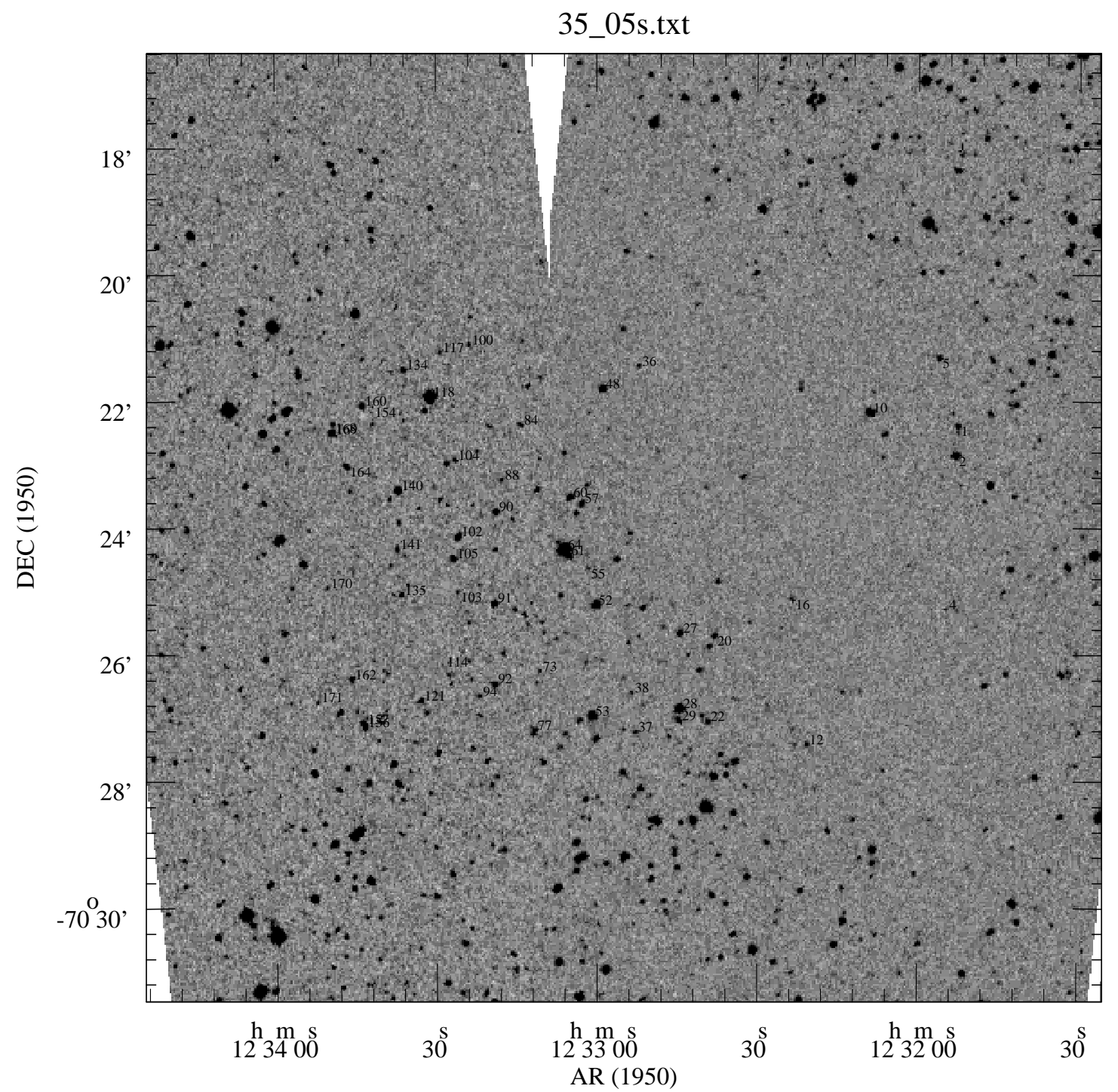

Figura C.35 Finding Chart do Campo 35 centrado em $\mathrm{AR}_{1950}=12^{\mathrm{h}} 32^{\mathrm{m}} 55^{\mathrm{s}}, \mathrm{DEC}_{1950}=-70^{\circ} 24^{\prime}$ 



\section{Apêndice D. Análise da polarimetria na Nuvem Escura de Musca}

Este apêndice apresenta em detalhe uma análise do catálogo polarimétrico da região da Nuvem Escura de Musca (Apêndice C). Basicamente, mostramos a saída da rotina SELECT do pacote PCCDPACK (ver seção 2.4.6) aplicada sobre cada campo que forma parte do catálogo. O total de 35 campos foi analisado.

Cada figura (D.1 a D.35) apresenta quatro seções. $\mathrm{Na}$ seção (a) mostramos a distribuição dos parâmetros de Stokes $Q=P \cdot \cos (2 \theta)$ e $U=P \cdot \sin (2 \theta)$ para todos os objetos do campo filtrados para uma sinal-ruído de polarização maior ou igual que 10. À direita está mostrado o cálculo dos valores médios do $Q$ e $U$ ponderados pelos erros individuais respectivos, assim como o erro médio da amostra $(\sigma)$. Com eles pode-se calcular os valores representativos médios do $P$ e $\theta$ (também mostrados) para o campo analisado. Na seção (b) mostramos os vetores de polarização distribuídos espacialmente sobre a área coberta pelo CCD. O Norte fica para cima e o Leste para a esquerda. A escala de polarização é mostrada no canto superior direito. Para distinguir com precisão alguma tendência preferencial de orientação dos vetores de polarização, na seção (c) mostramos os histogramas do ângulo de polarização. A largura do bin corresponde a $5^{\circ}$. O Norte fica em $\theta=0^{\circ}$ e o Leste em $\theta=$ $90^{\circ}$. Um ajuste de gaussianas (optativo) é utilizado para calcular a dispersão dos vetores de polarização e pode ser utilizado para obter informação sobre a intensidade do campo magnético e razões de densidades de energia. Finalmente na seção (d) mostramos os histogramas da amostra para os valores de polarização. A largura do bin corresponde a $0.5 \%$. 
$01 \rightarrow 10$ s.sel $0 .<\mathrm{p}<0.05 \mathrm{p} / \operatorname{sigma}(\mathrm{p})>10 . \quad \mathrm{cQ} 0 . \quad$ cU 0. nstars 23

a)
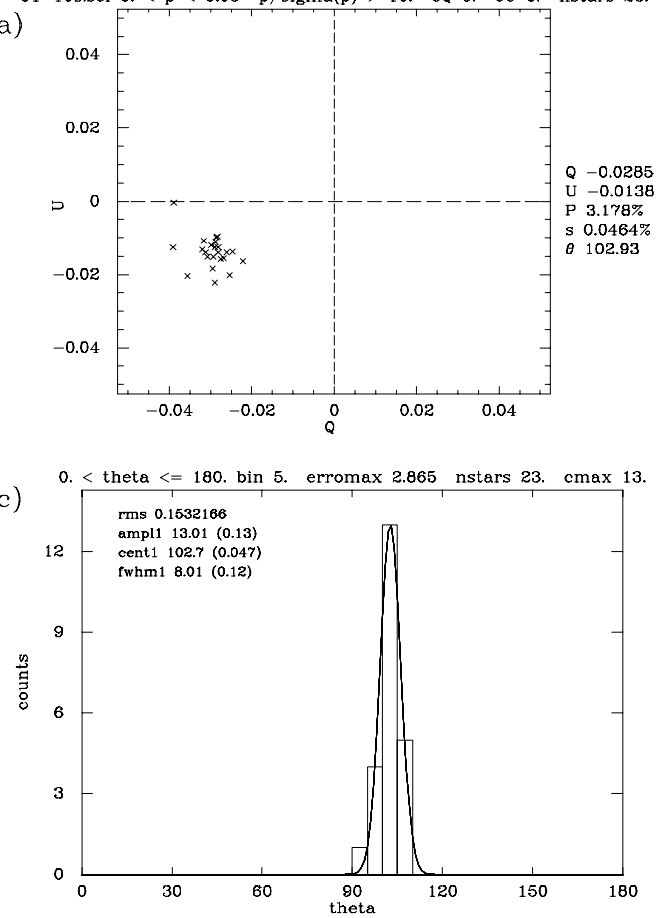

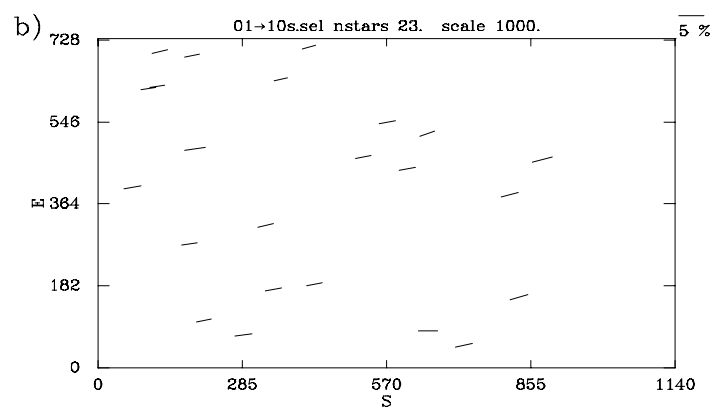

d)

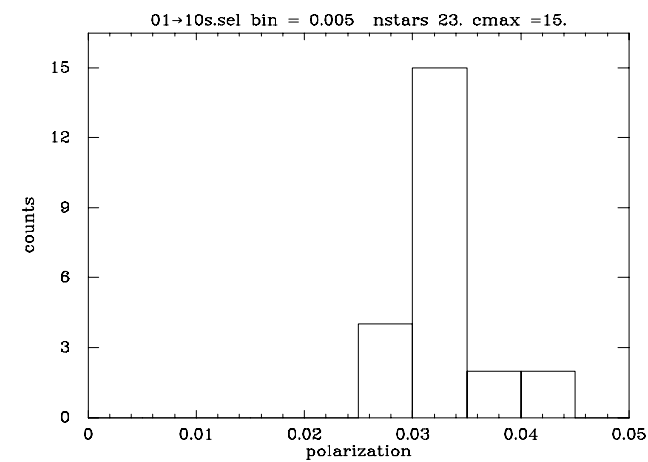

Figura D.1 Análise do Campo 01.

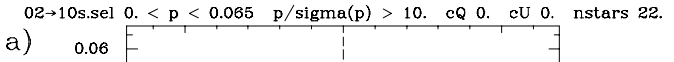

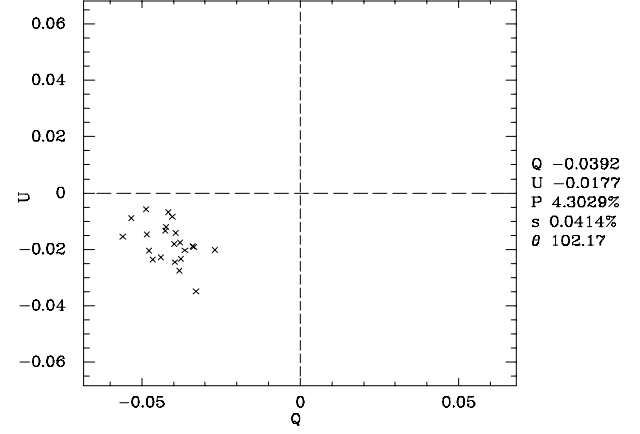

0. $<$ theta $<=180$. bin 5. erromax 2.865 nstars $22 . \quad$ max 8 .

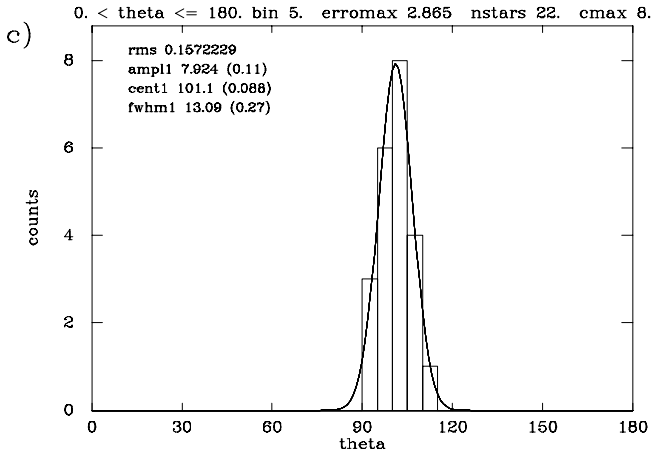

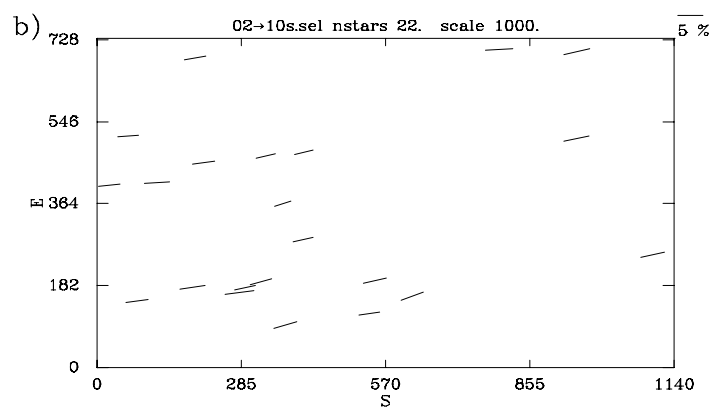

d)

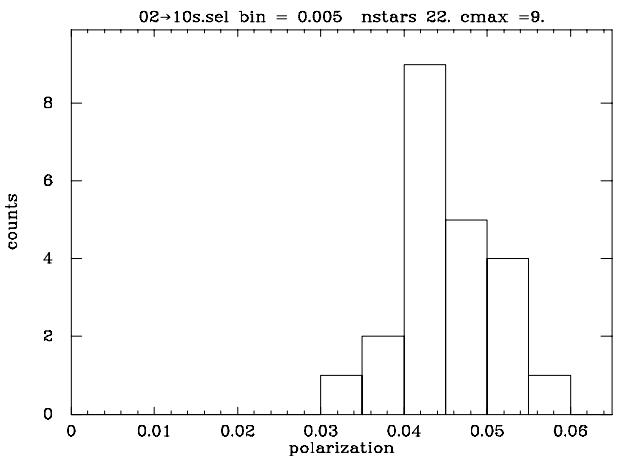

Figura D.2 Análise do Campo 02. 
a)

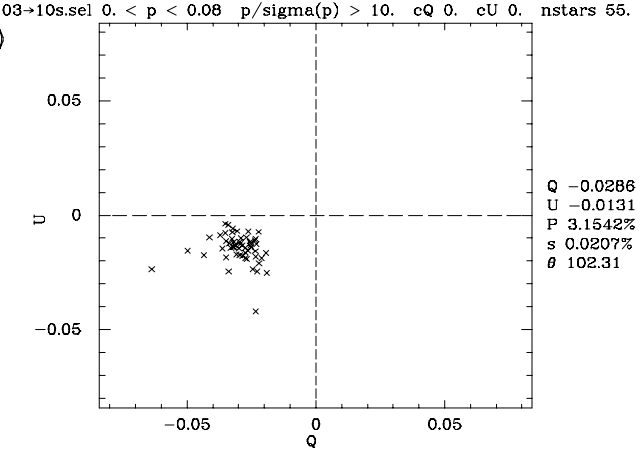

$0 .<$ theta $<=180$. bin 5 . erromax 2.865 nstars 55 amax 25.

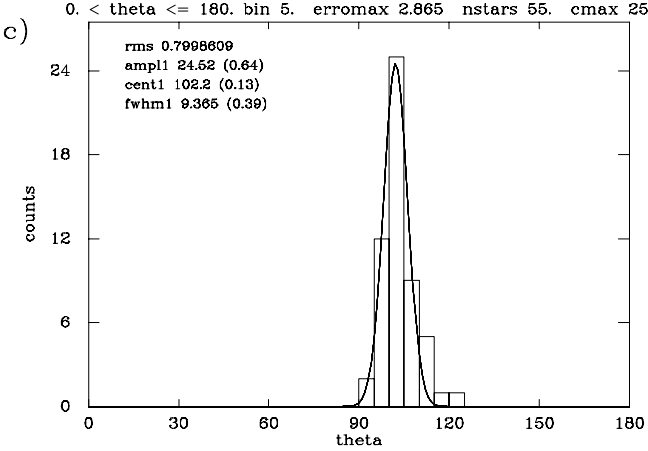

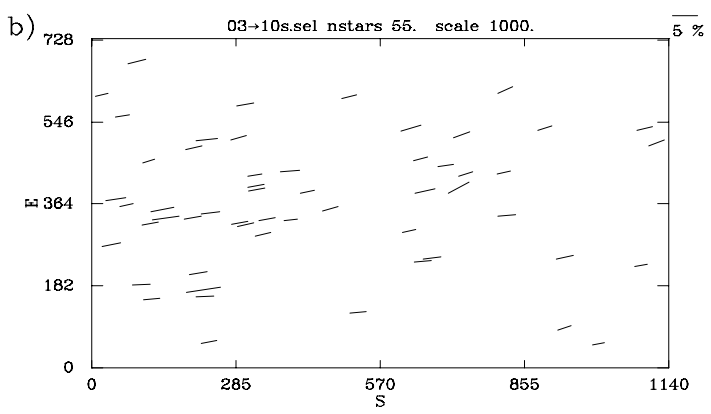

d)

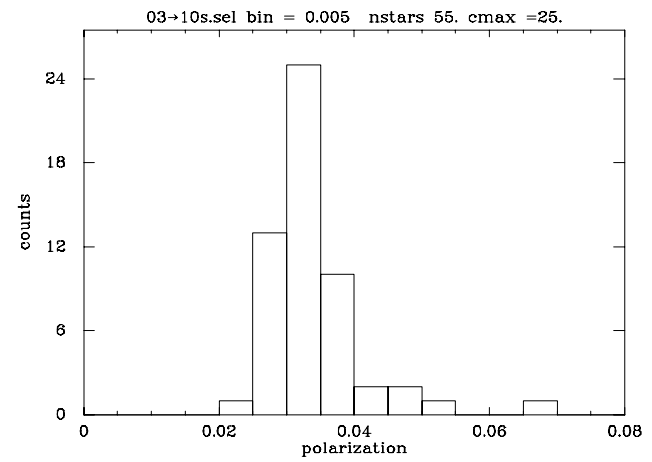

Figura D.3 Análise do Campo 03

04 $\rightarrow 10$ s.sel $0 .<p<0.1 \quad \mathrm{p} / \operatorname{sigma}(\mathrm{p})>10 . \quad \mathrm{cQ} 0 . \quad \mathrm{cU} 0$. nstars 15.
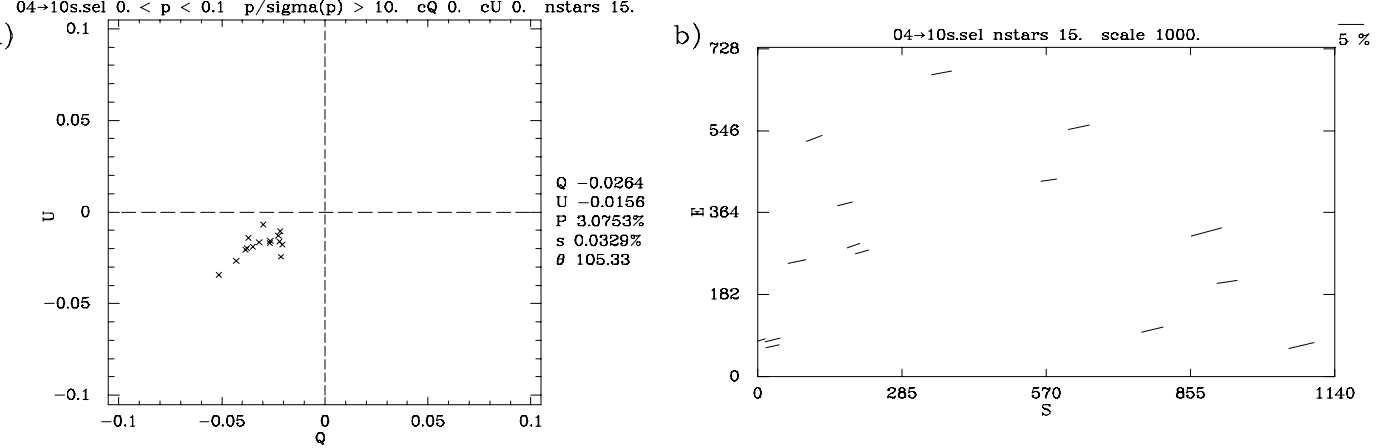

0. $<$ theta $<=180$. bin 5. erromax 2.865 nstars 15. cmax 7

d)

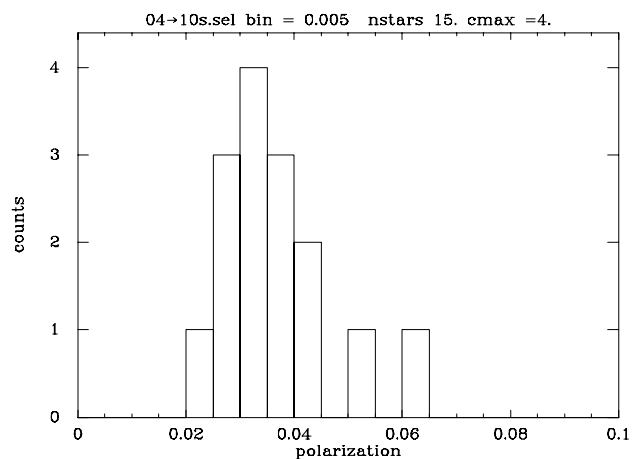

Figura D.4 Análise do Campo 04 
$05 \rightarrow 10$ s.sel $0 .<p<0.08 \quad \mathrm{p} / \operatorname{sigma}(\mathrm{p})>10 . \quad \mathrm{cQ} 0 . \quad$ cU $0 . \quad$ nstars 54

a)

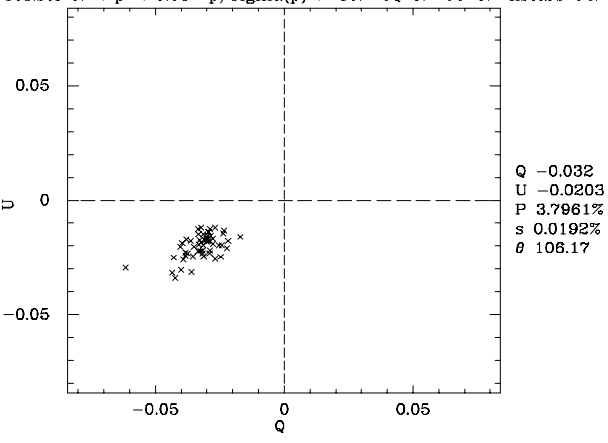

$0 .<$ theta $<=180$. bin 5. erromax 2.865 nstars 54. $\operatorname{cmax} 27$

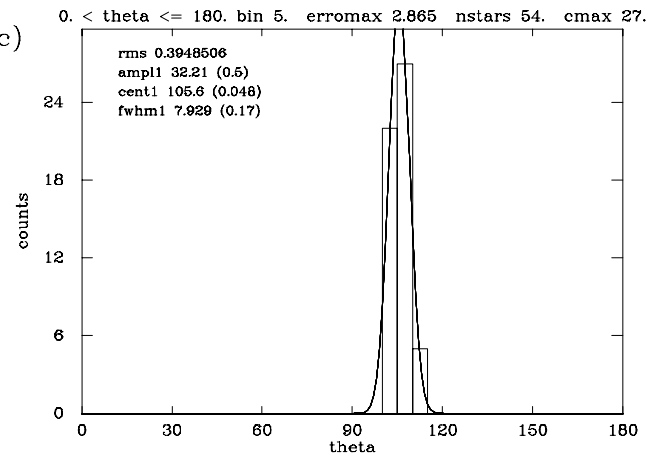

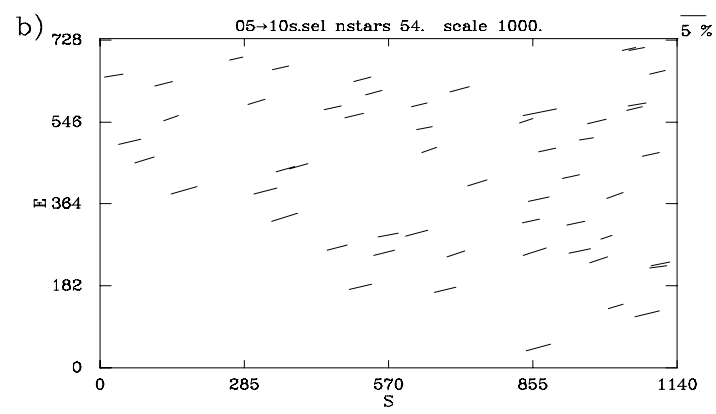

d)

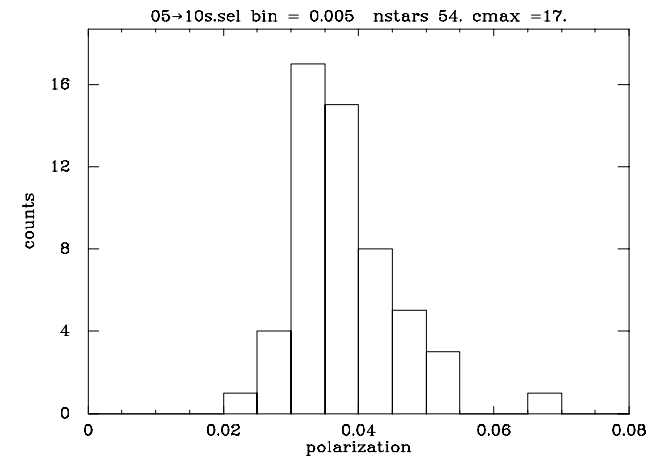

Figura D.5 Análise do Campo 05

$06 \rightarrow 10$ s.sel $0 .<p<0.1 \quad \mathrm{p} /$ sigma $(\mathrm{p})>10 . \quad \mathrm{cQ} 0 . \quad \mathrm{cU} 0$. nstars 24.

a)

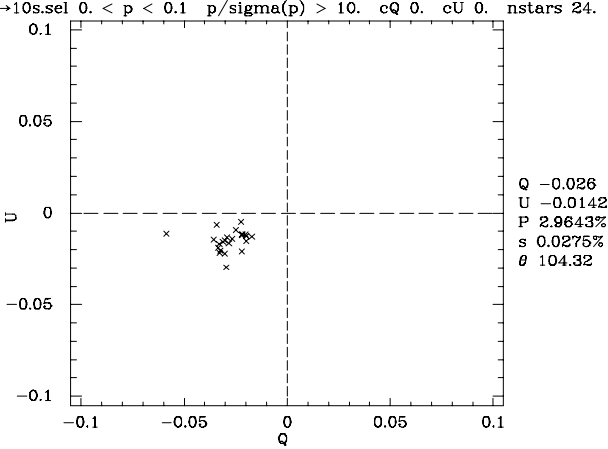

0. $<$ theta $<=180$. bin 5. erromax 2.865 nstars 24. $\quad \operatorname{cmax} 11$

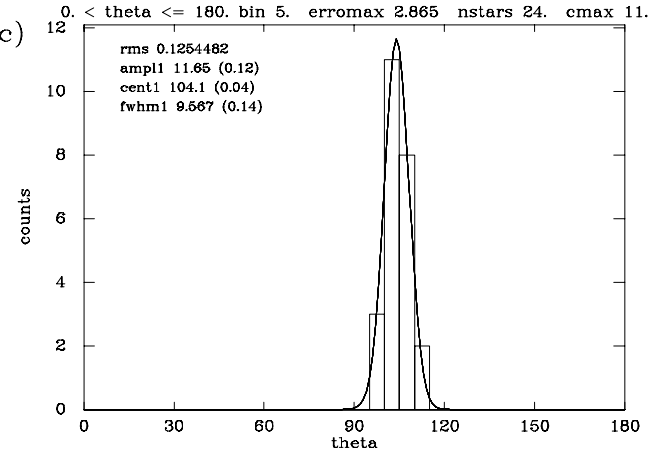

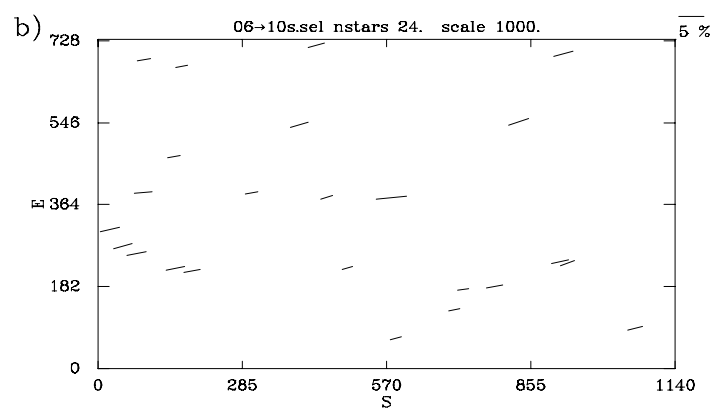

d)

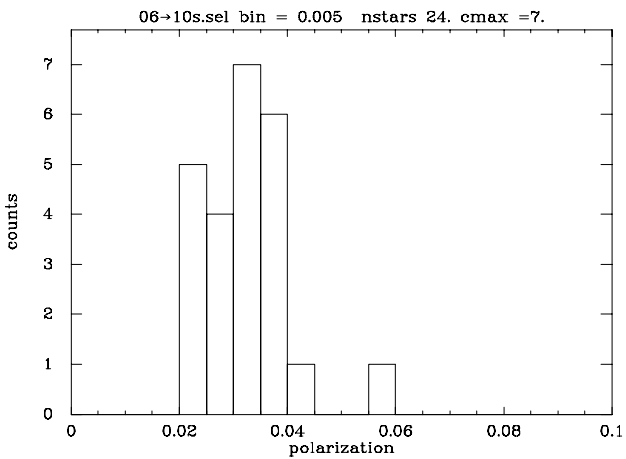

Figura D.6 Análise do Campo 06 
07 $\rightarrow 10$ s.sel $0 .<p<0.1 \quad \mathrm{p} /$ sigma $(\mathrm{p})>10$. cQ $0 . \quad$ cU 0. nstars 16 .

a) 0.1 .
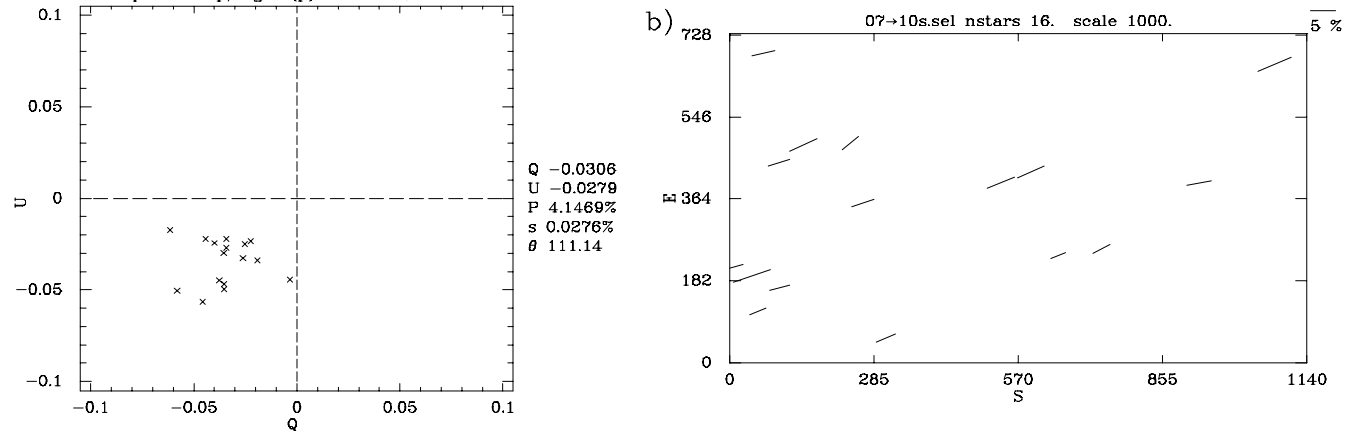

$0 .<$ theta $<=180$. bin 5. erromax 2.865 nstars 16. cmax 5 .

d)

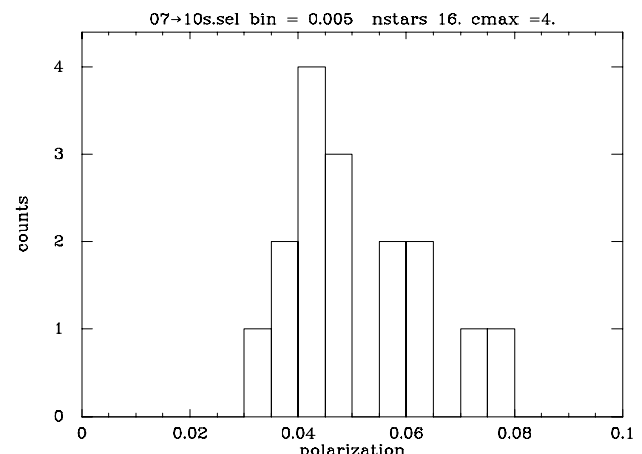

Figura D.7 Análise do Campo 07

$08 \rightarrow 10$ s.sel $0 .<\mathrm{p}<0.06 \mathrm{p} / \operatorname{sigma}(\mathrm{p})>10 . \mathrm{CQ} 0 . \quad \mathrm{cU} 0$. nstars 48
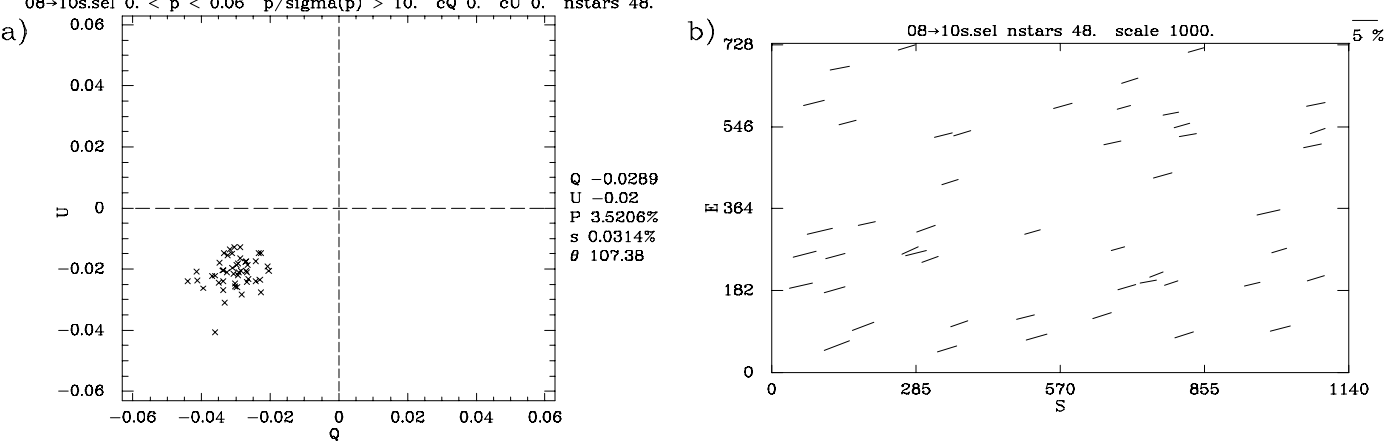

0. $<$ theta $<=180$. bin 5. erromax 2.865 nstars 48. cmax 26 .

d)

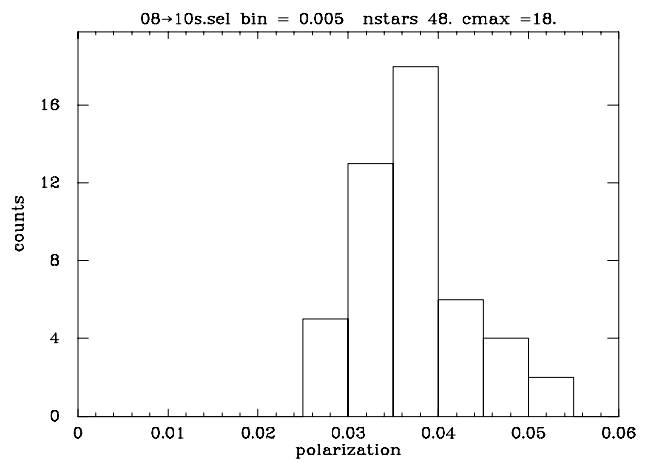

Figura D.8 Análise do Campo 08 
$09 \rightarrow 10$ s.sel $0 .<p<0.08 \quad \mathrm{p} /$ sigma(p) $>10 . \quad \mathrm{cQ} \quad 0 . \quad \mathrm{cU} 0$. nstars 41

a)

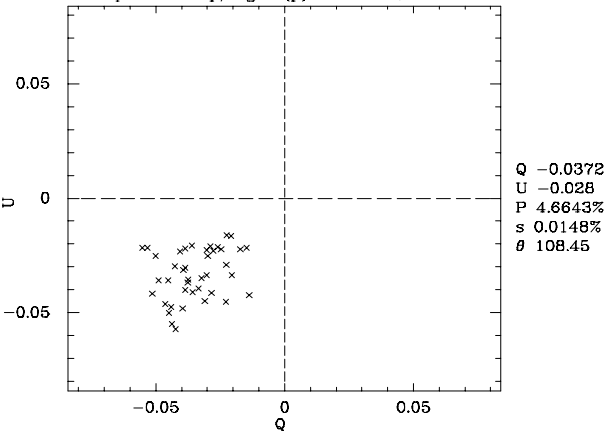

$0<$ theta $<=180$. bin 5 erromax 2865 nstars 41 amax 12

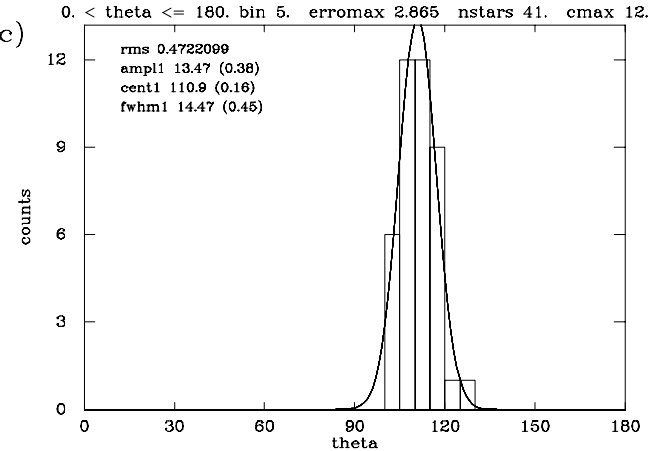

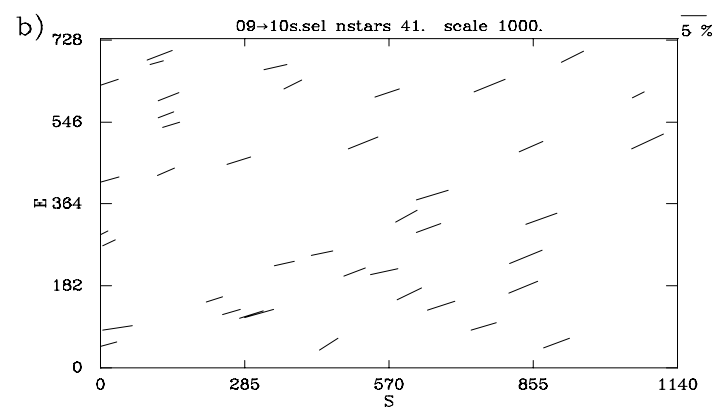

d)

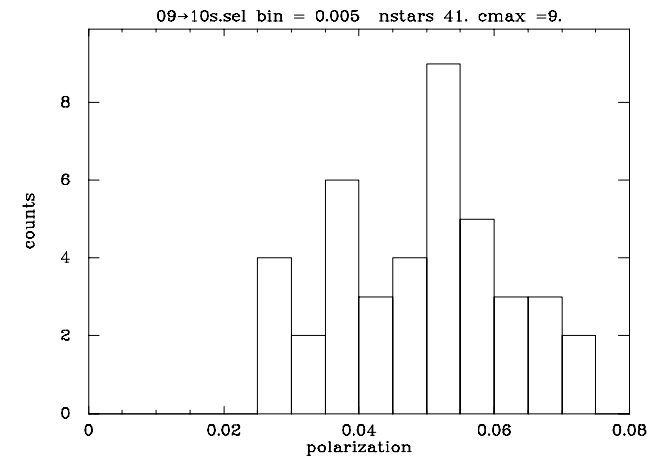

Figura D.9 Análise do Campo 09

$10 \rightarrow 10$ s.sel $0 .<p<0.1 \quad \mathrm{p} /$ sigma $(\mathrm{p})>10 . \quad \mathrm{cQ} 0 . \quad \mathrm{cU} 0$. nstars 22.

a)

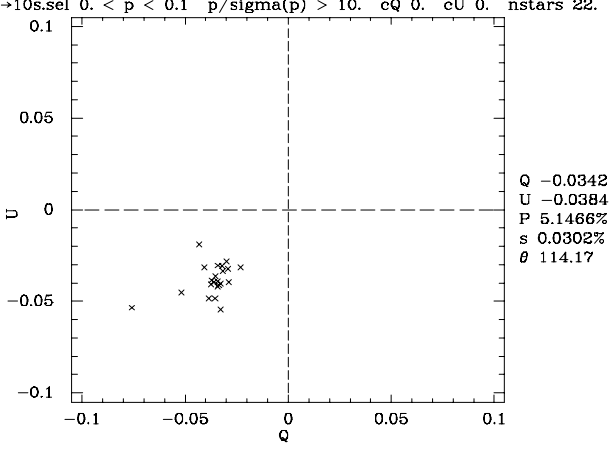

0. $<$ theta $<=180$. bin 5. erromax 2.865 nstars 22. $\operatorname{cmax} 11$.

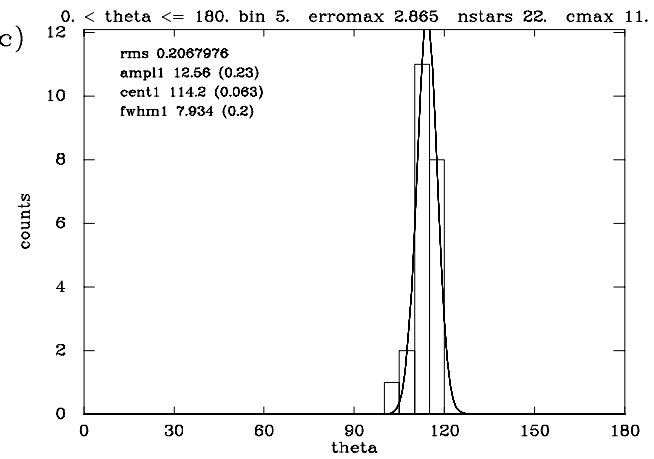

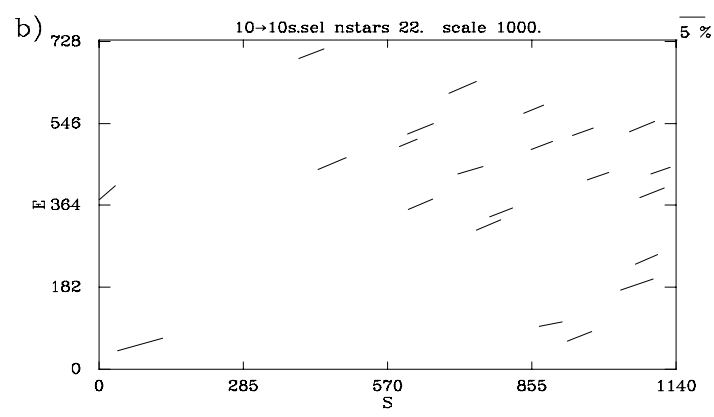

d)

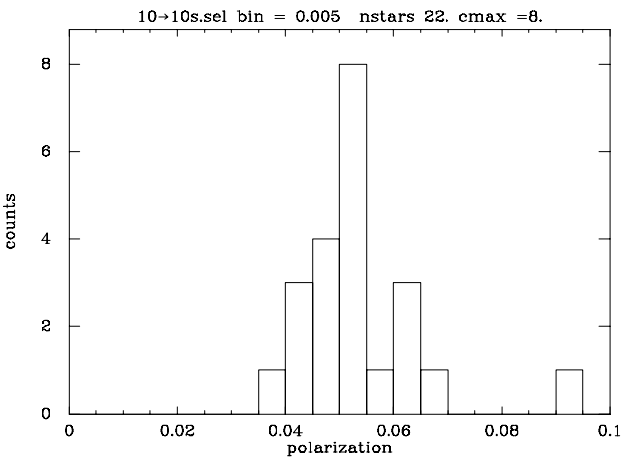

Figura D.10 Análise do Campo 10 
$11 \rightarrow 10$ s.sel $0 .<p<0.1 \quad \mathrm{p} / \operatorname{sigma}(\mathrm{p})>10 . \quad \mathrm{cQ} 0 . \quad \mathrm{cU} 0$. nstars 34 .
a)
0.1
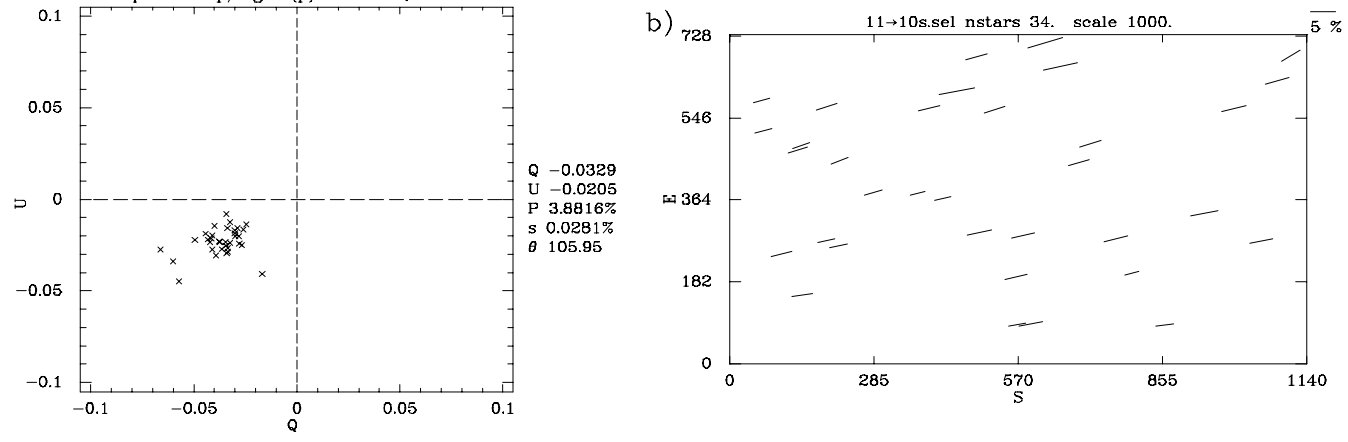

c. $<$ theta $<=180$. bin 5. erromax 2.865 nstars 34. cmax 14.

d)

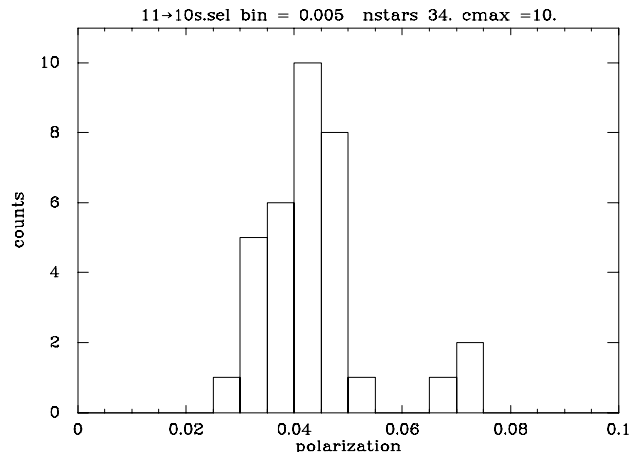

Figura D.11 Análise do Campo 11

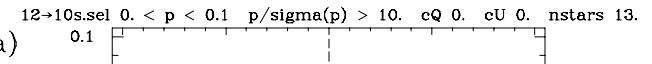

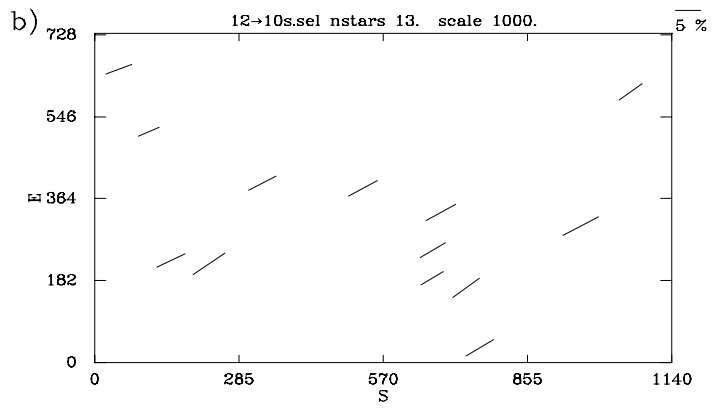

$0 .<$ theta $<=180$. bin 5. erromax 2.865 nstars 13. $\operatorname{cmax} 7$

d)

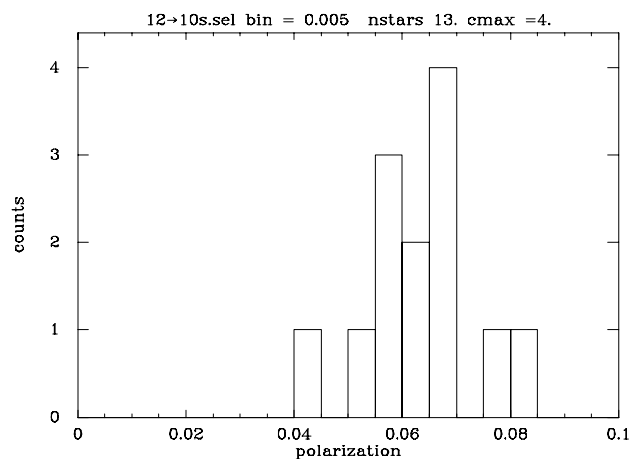

Figura D.12 Análise do Campo 12 
$13 \rightarrow 10$ s.sel $0 .<\mathrm{p}<0.09 \mathrm{p} / \operatorname{sigma}(\mathrm{p})>10 . \quad \mathrm{cQ} 0 . \quad \mathrm{cU} 0$. nstars 65 .

a)

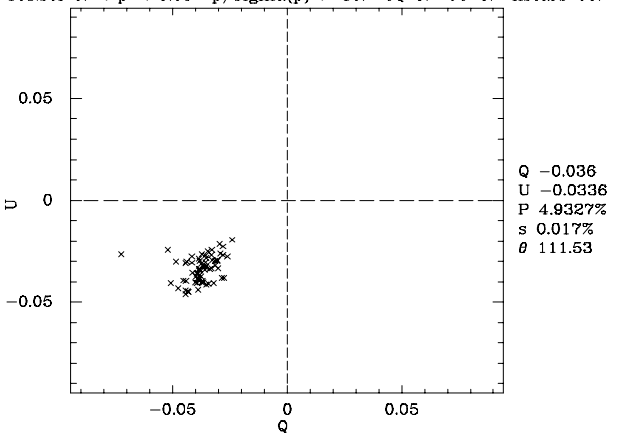

$0 .<$ theta $<=180$. bin 5 . erromax 2865 nstars 65. max 41

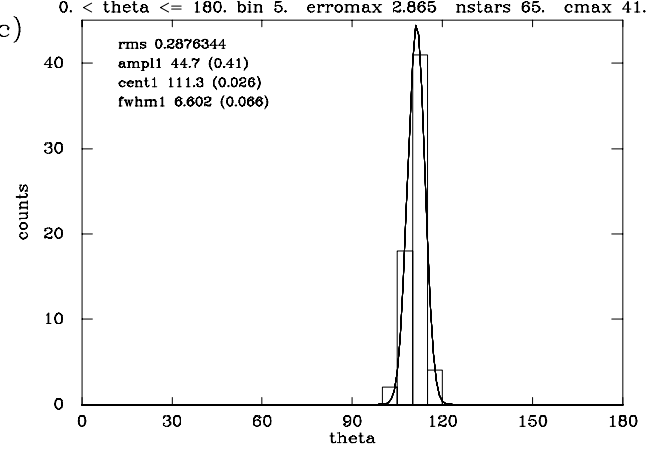

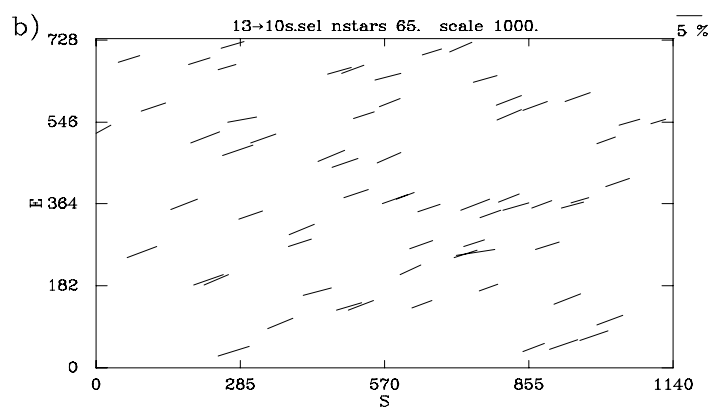

d)

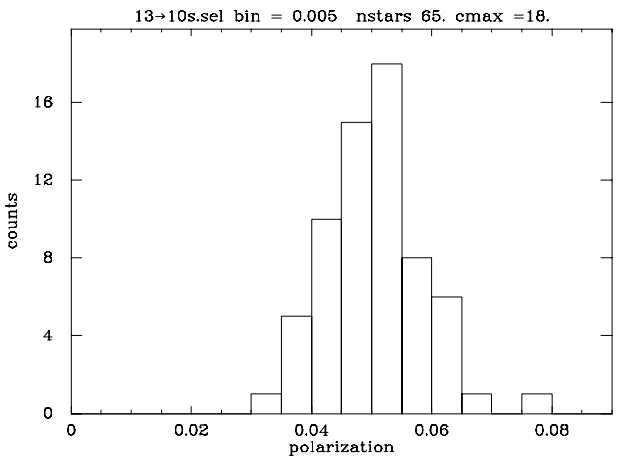

Figura D.13 Análise do Campo 13

a)
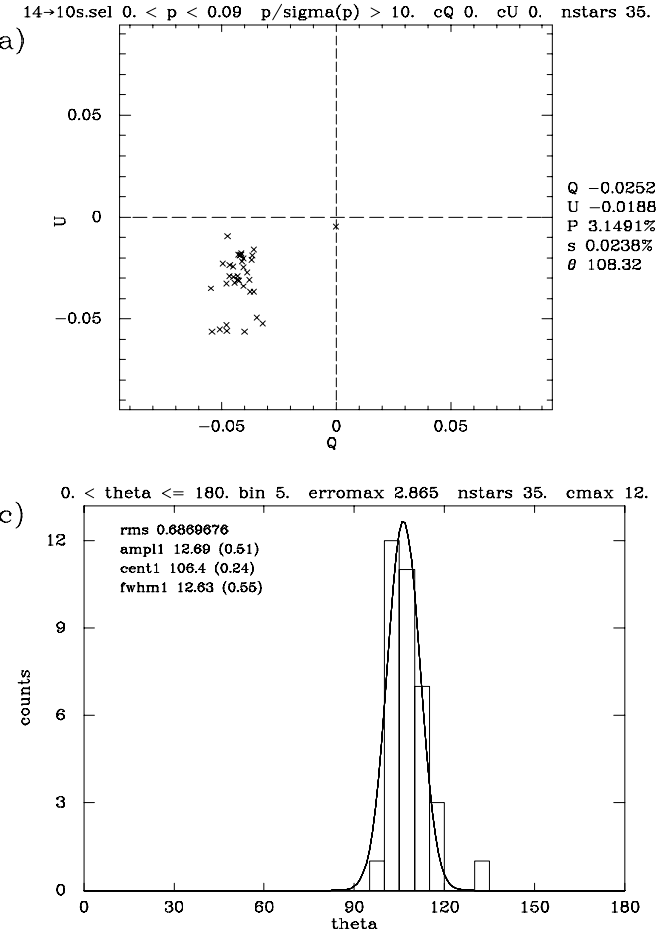

b)

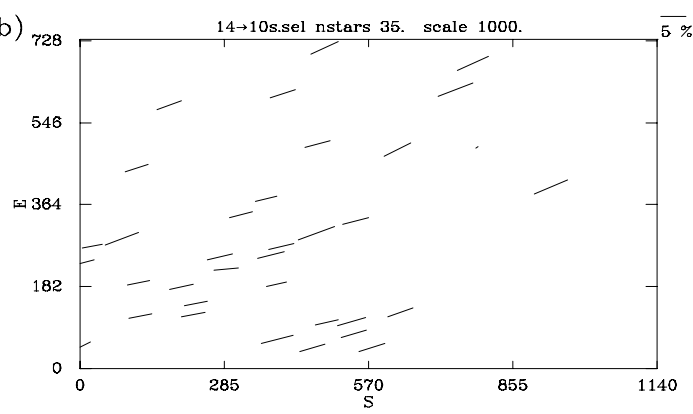

d)

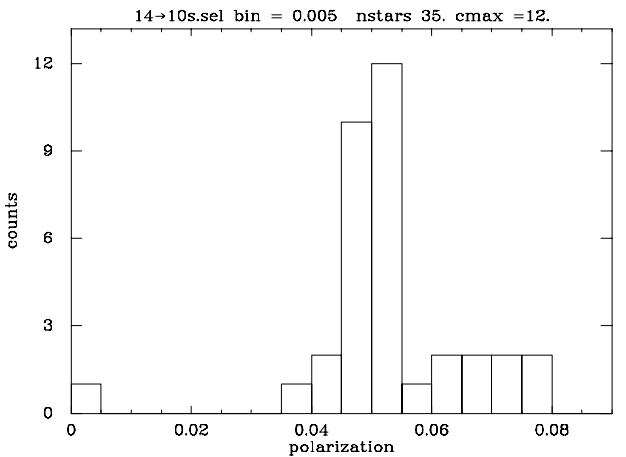

Figura D.14 Análise do Campo 14 
$15 \rightarrow 10$ s.sel $0 .<p<0.1 \quad \mathrm{p} / \operatorname{sigma}(\mathrm{p})>10 . \quad \mathrm{cQ} 0 . \quad \mathrm{cU} 0$. nstars 17 .
a) $0.1 \mathrm{P}$
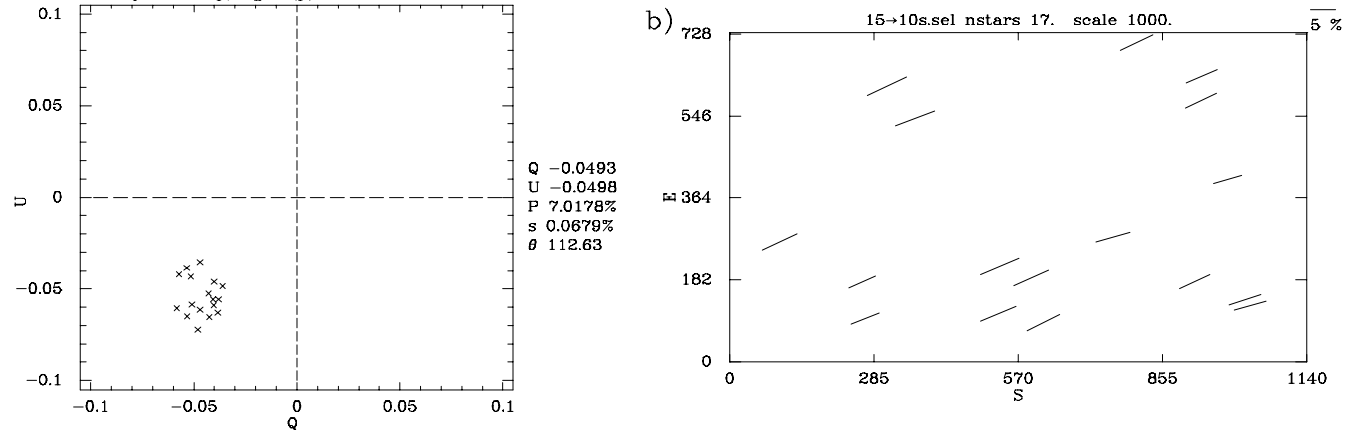

0. $<$ theta $<=180$. bin 5. erromax 2.865 nstars 17. cmax 10.

d)

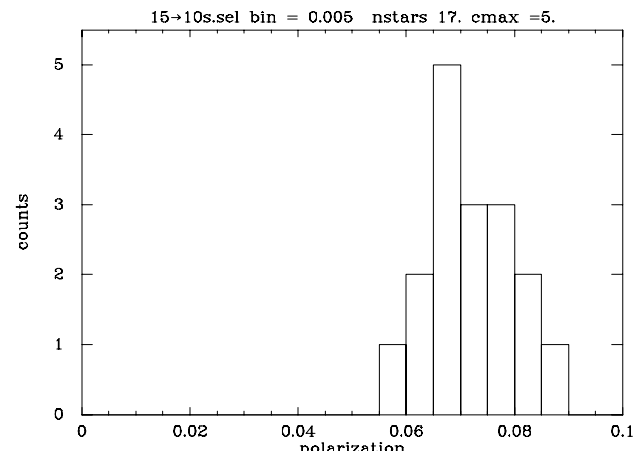

Figura D.15 Análise do Campo 15

a)

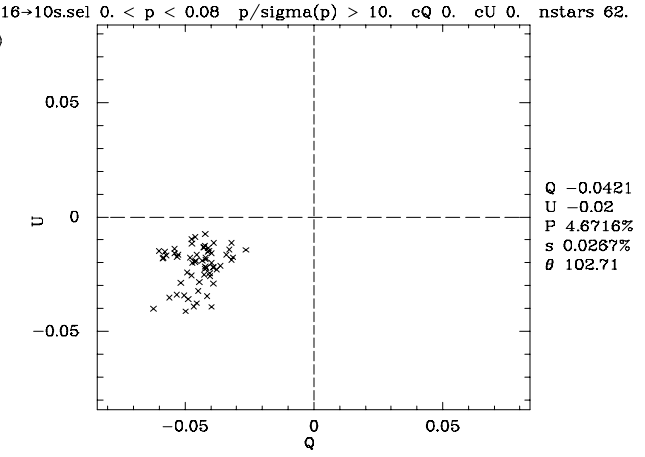

0. $<$ theta $<=180$. bin 5. erromax 2.865 nstars 62. cmax 23 .

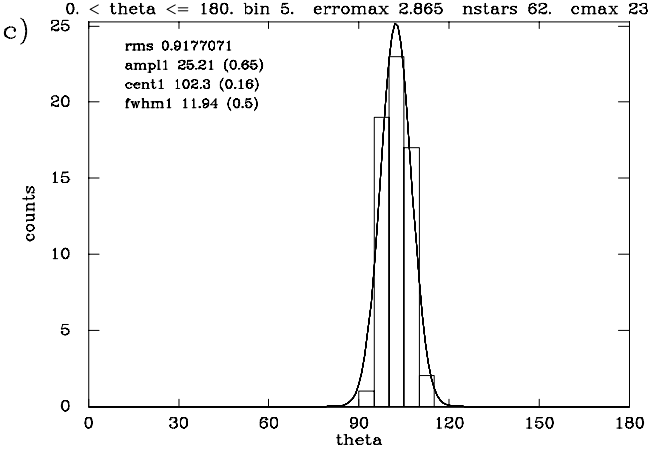

b)

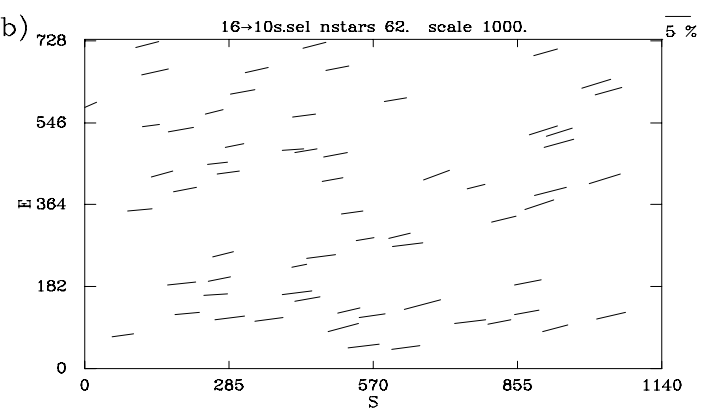

d)

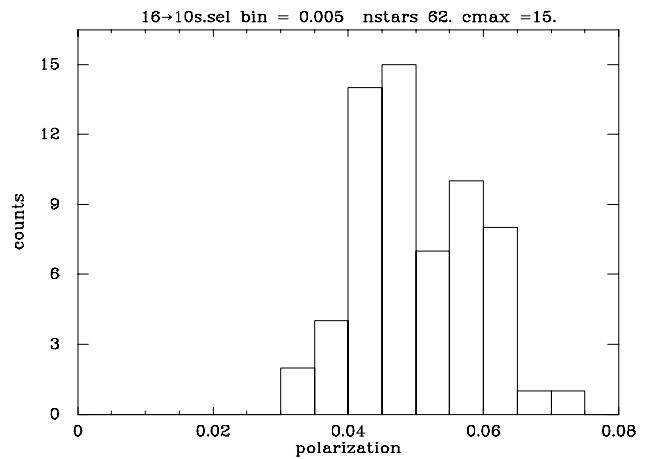

Figura D.16 Análise do Campo 16 
$17 \rightarrow 10$ s.sel $0 .<p<0.1 \quad \mathrm{p} / \operatorname{sigma}(\mathrm{p})>10 . \quad \mathrm{cQ} 0 . \quad \mathrm{cU} 0$. nstars 7

a)

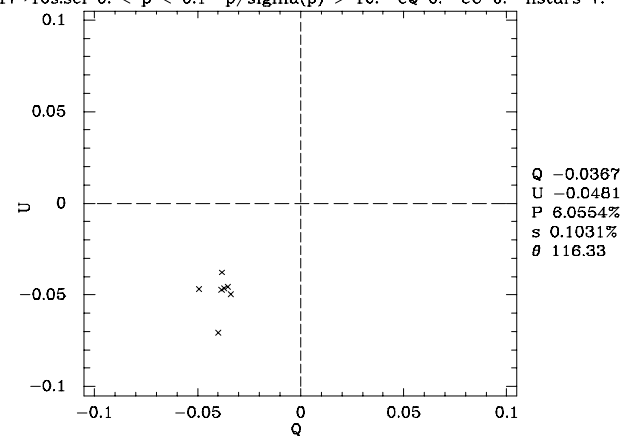

$0 .<$ theta $<=180$. bin 5. erromax 2.865 nstars 7. $\operatorname{cmax} 4$.

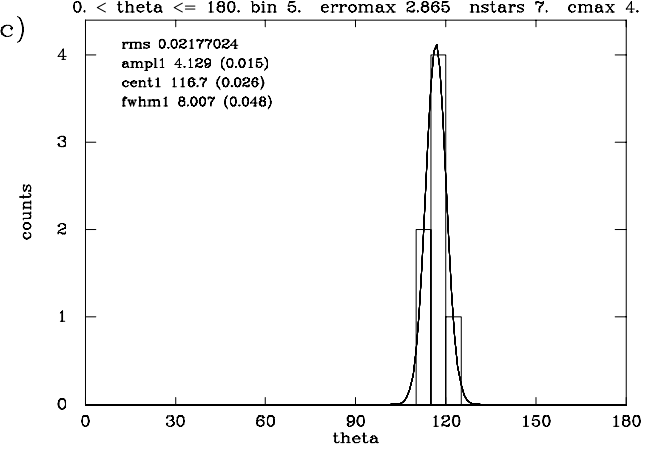

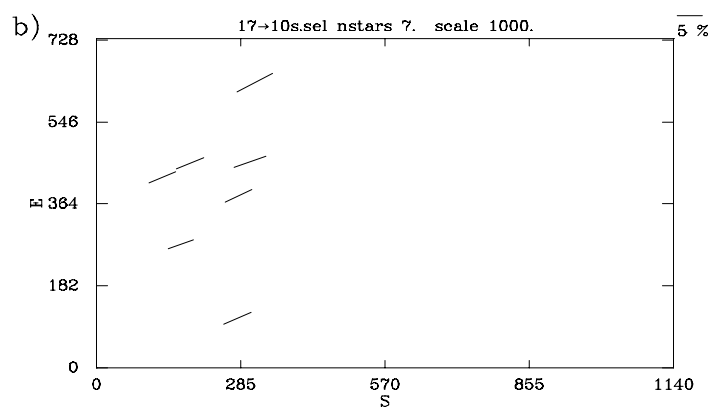

d)

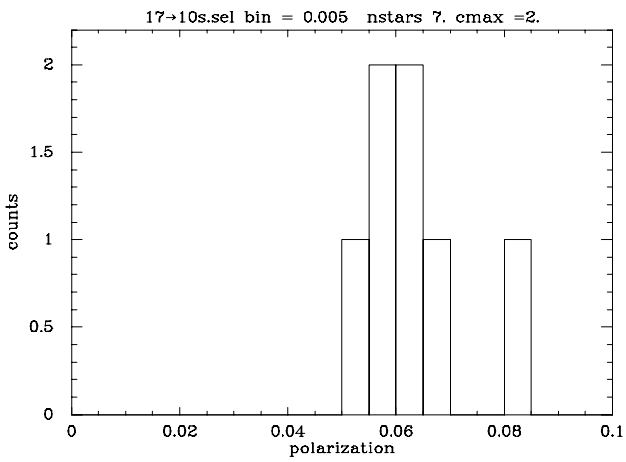

Figura D.17 Análise do Campo 17

a)

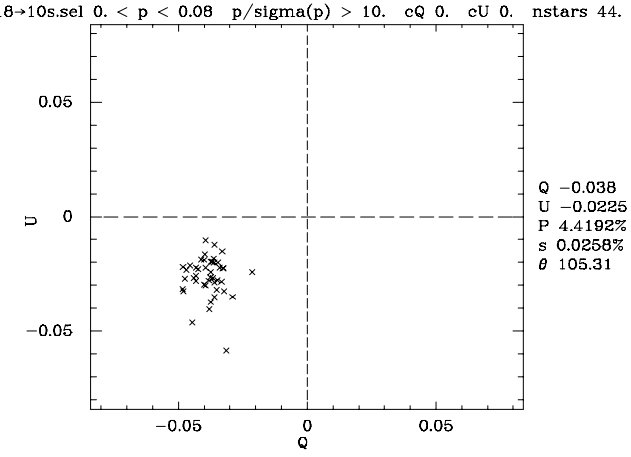

$0 .<$ theta $<=180$. bin 5. erromax 2.865 nstars 44 cmax 17

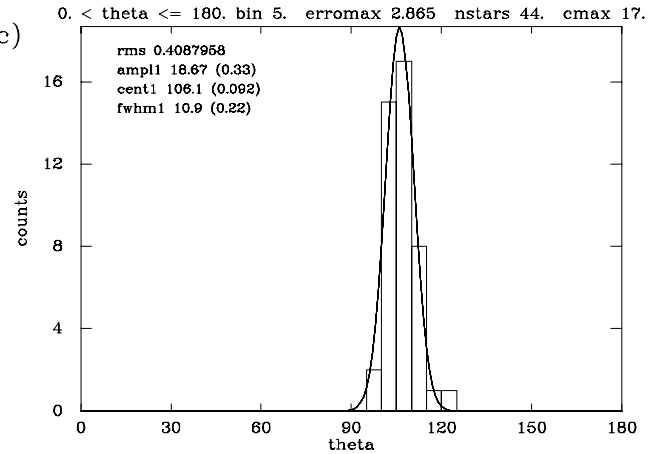

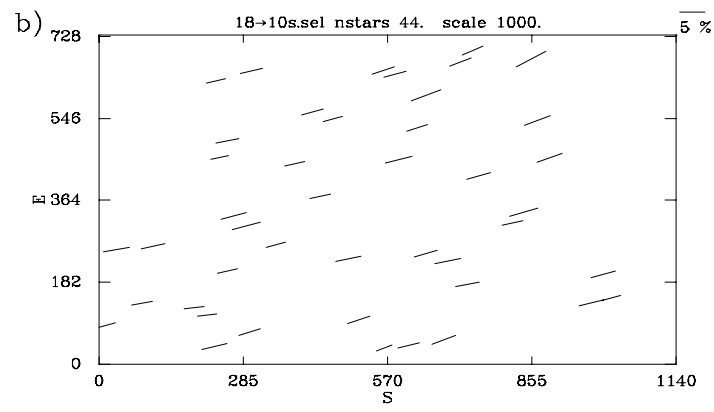

d)

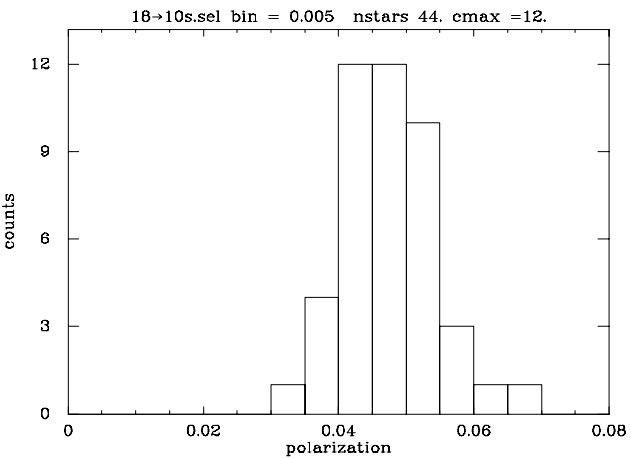

Figura D.18 Análise do Campo 18 
$19 \rightarrow 10$ s.sel $0 .<p<0.1 \quad \mathrm{p} / \operatorname{sigma}(\mathrm{p})>10$. cQ 0. cU 0. nstars 45 .
a) 0.1,
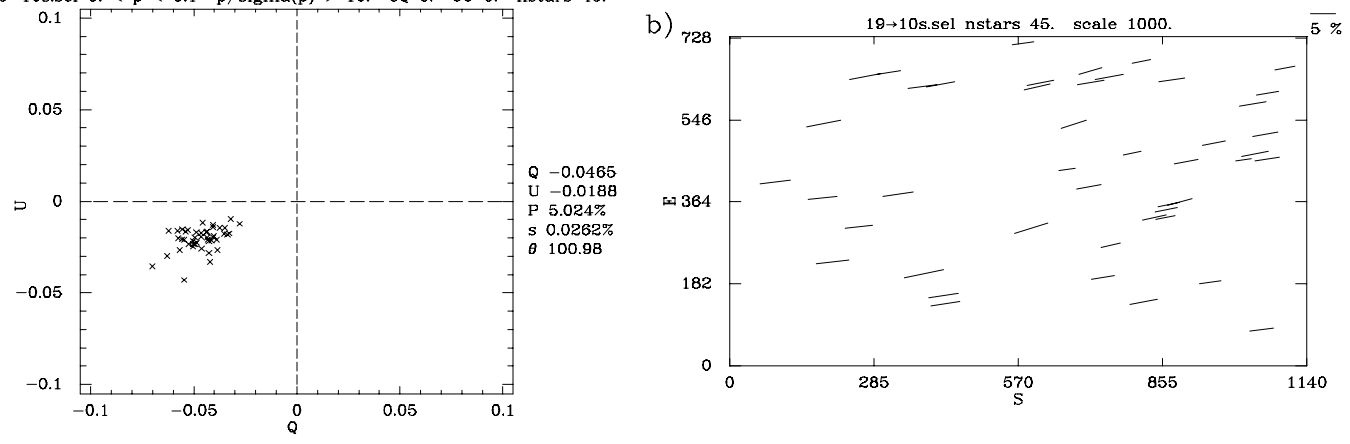

0. $<$ theta $<=180$. bin 5. erromax 2.865 nstars 45. $\operatorname{cmax} 30$.

d)

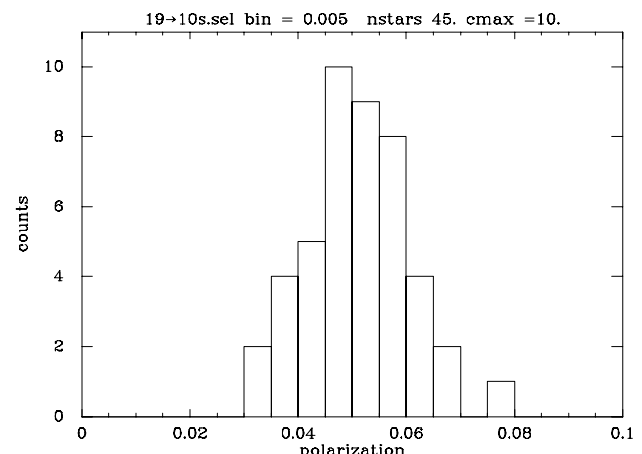

Figura D.19 Análise do Campo 19

$20 \rightarrow 10$ s.sel $0 .<p<0.1 \quad \mathrm{p} / \operatorname{sigma}(\mathrm{p})>10 . \quad \mathrm{cQ} 0 . \quad \mathrm{cU} 0$. nstars 64

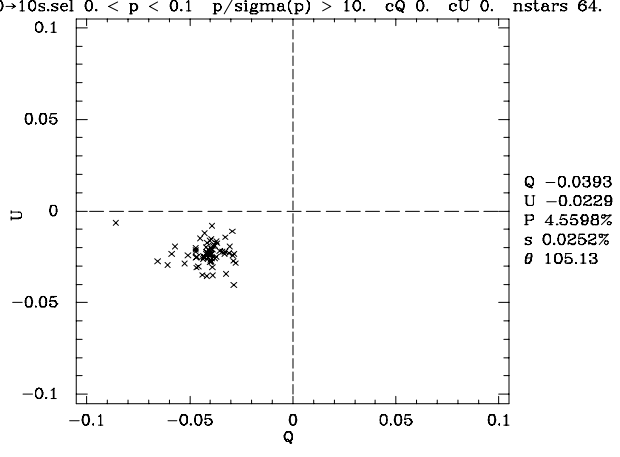

0. $<$ theta $<=180$. bin 5. erromax 2.865 nstars 64. $\operatorname{cmax} 28$

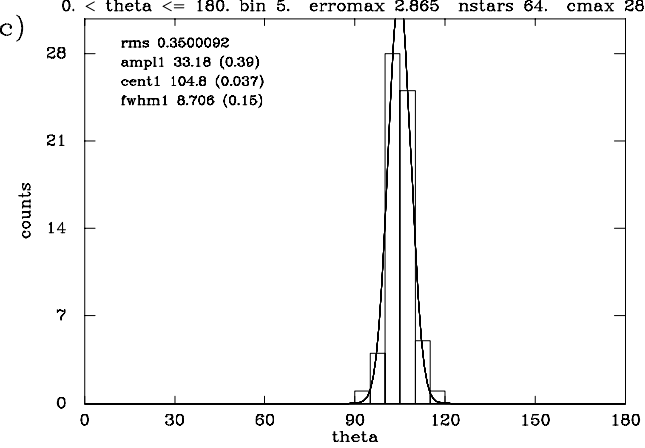

b)

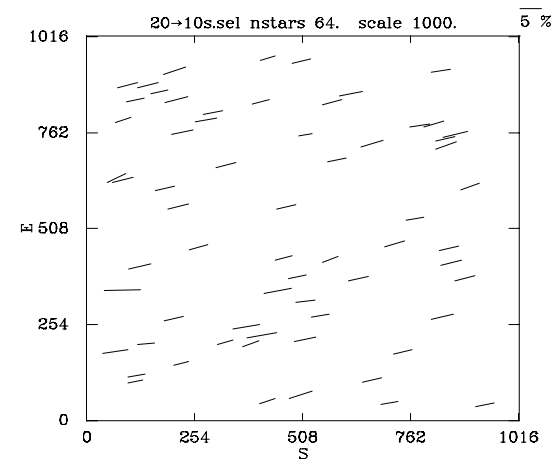

d)

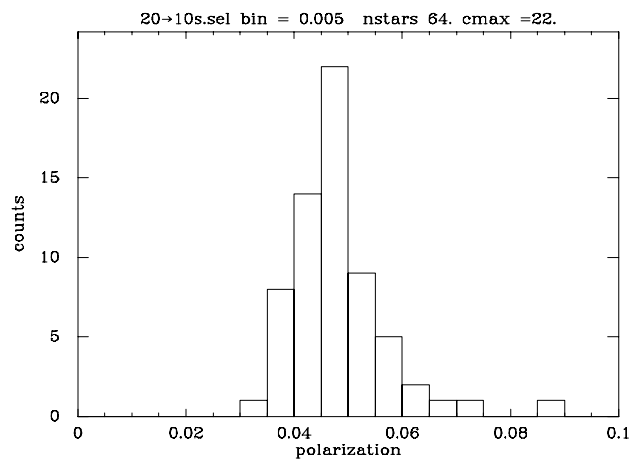

Figura D.20 Análise do Campo 20 
$21 \rightarrow 10$ s.sel $0 .<\mathrm{p}<0.11 \mathrm{p} / \operatorname{sigma}(\mathrm{p})>10 . \quad \mathrm{cQ} 0 . \quad$ cU 0. nstars 17
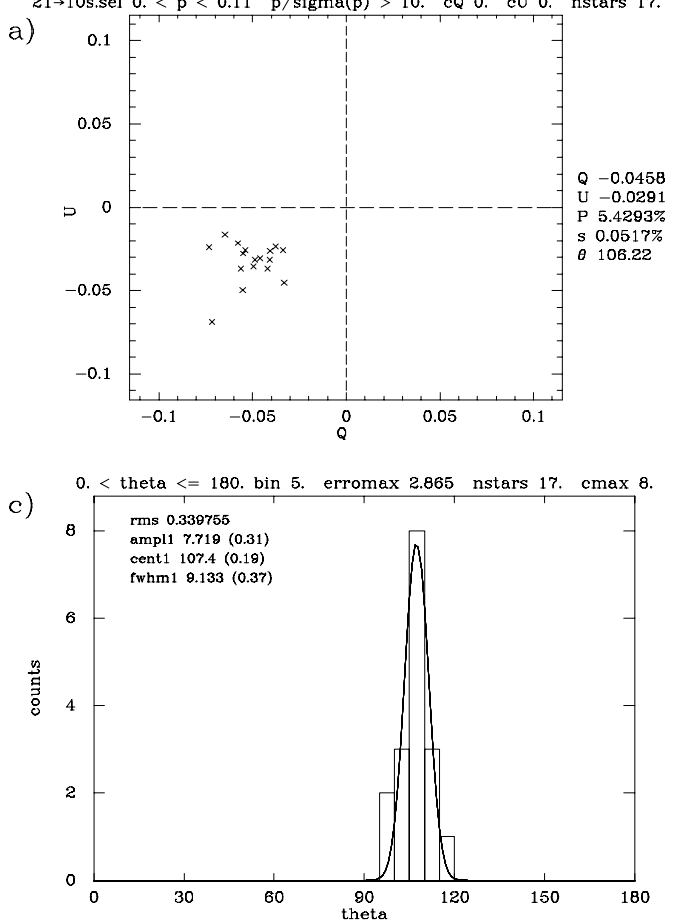

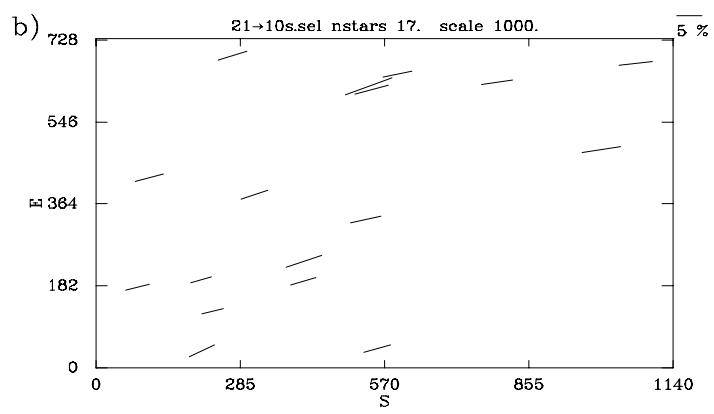

d)

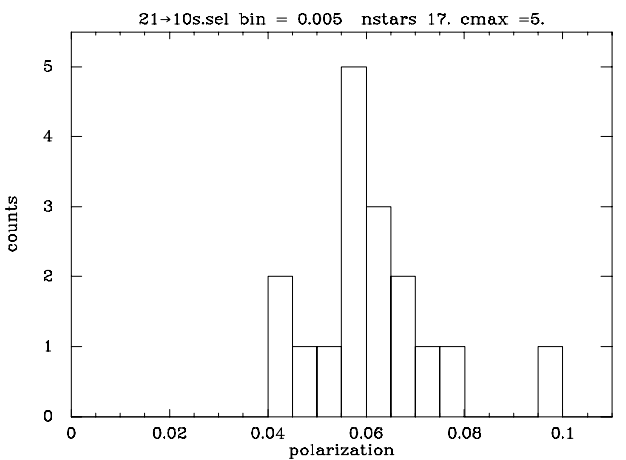

Figura D.21 Análise do Campo 21

$22 \rightarrow 10$ s.sel $0 .<\mathrm{p}<0.06 \mathrm{p} / \operatorname{sigma}(\mathrm{p})>10 . \quad \mathrm{cQ} 0 . \quad \mathrm{cU} 0$. nstars 65.

a)

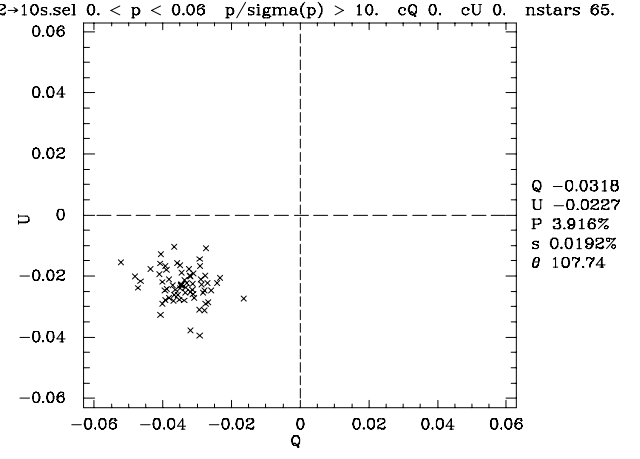

b)

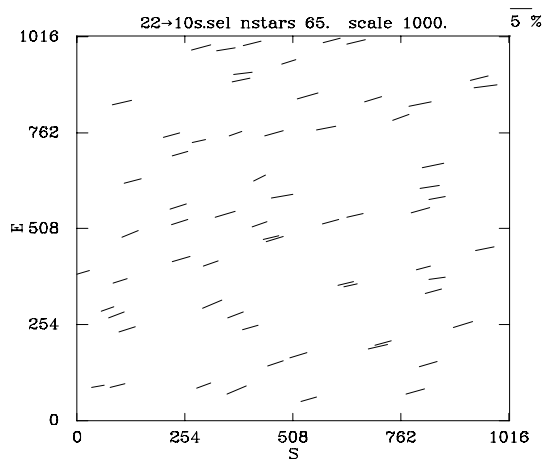

d)

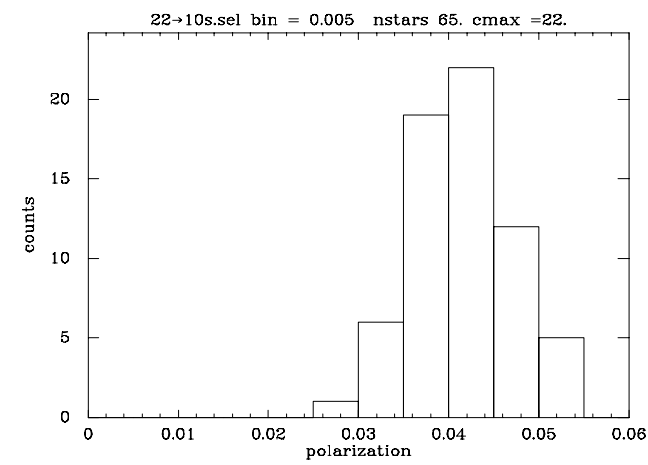

Figura D.22 Análise do Campo 22 


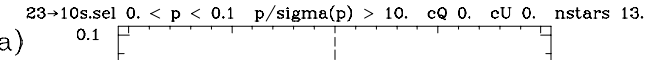
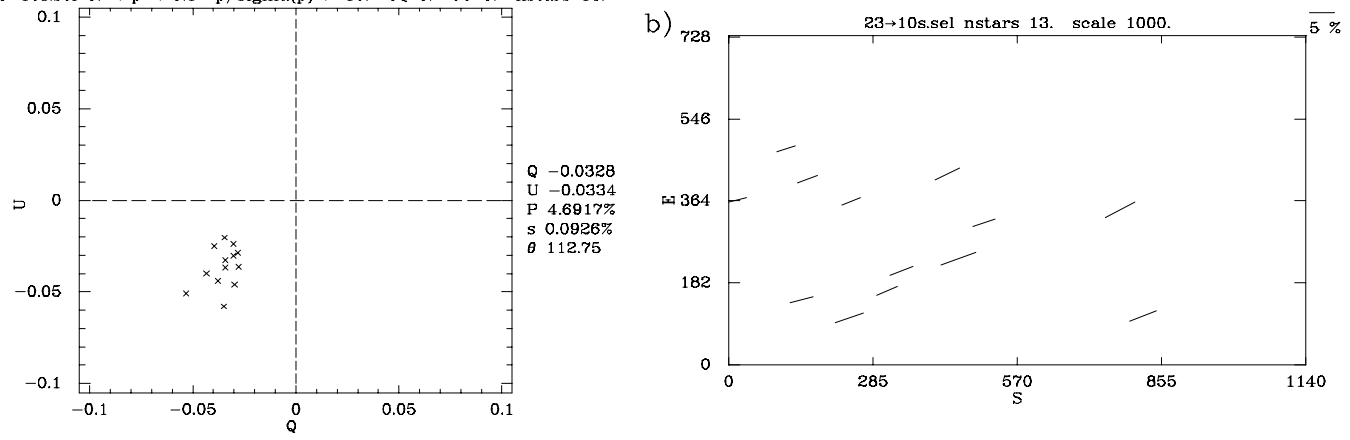

0. $<$ theta $<=180$. bin 5. erromax 2.865 nstars 13. cmax ?

d)

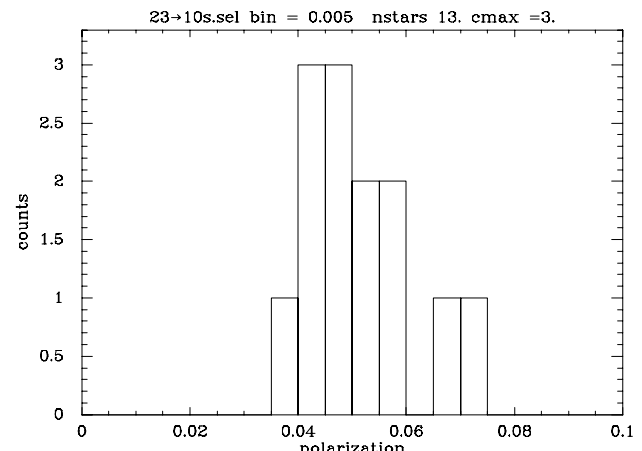

Figura D.23 Análise do Campo 23

a)

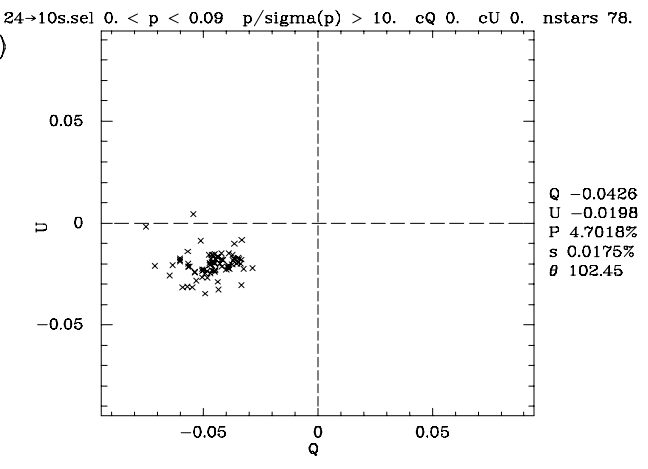

$0 .<$ theta $<=180$. bin 5. erromax 2.865 nstars 78. cmax 53.

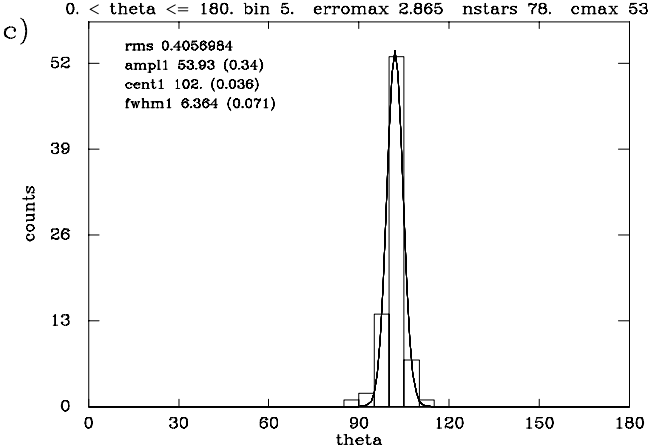

b)

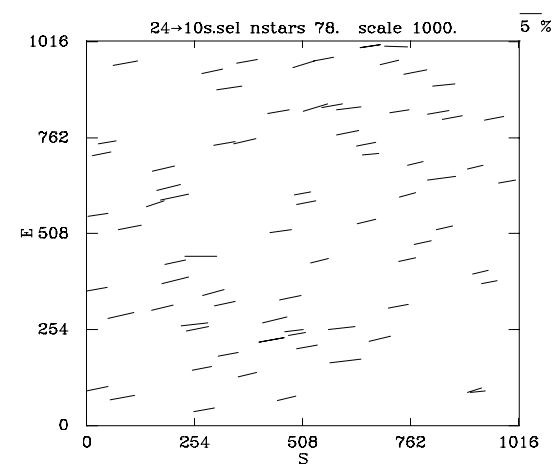

d)

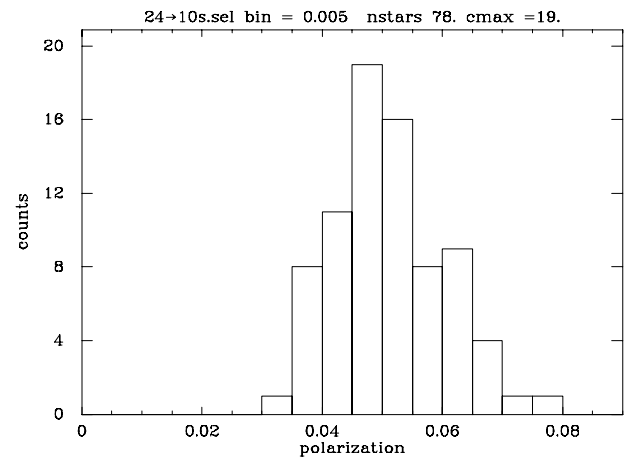

Figura D.24 Análise do Campo 24 
$25 \rightarrow 10$ s.sel $0 .<\mathrm{p}<0.08 \quad \mathrm{p} / \operatorname{sigma}(\mathrm{p})>10 . \quad \mathrm{cQ} 0 . \quad \mathrm{cU} 0 . \quad$ nstars 22

a)
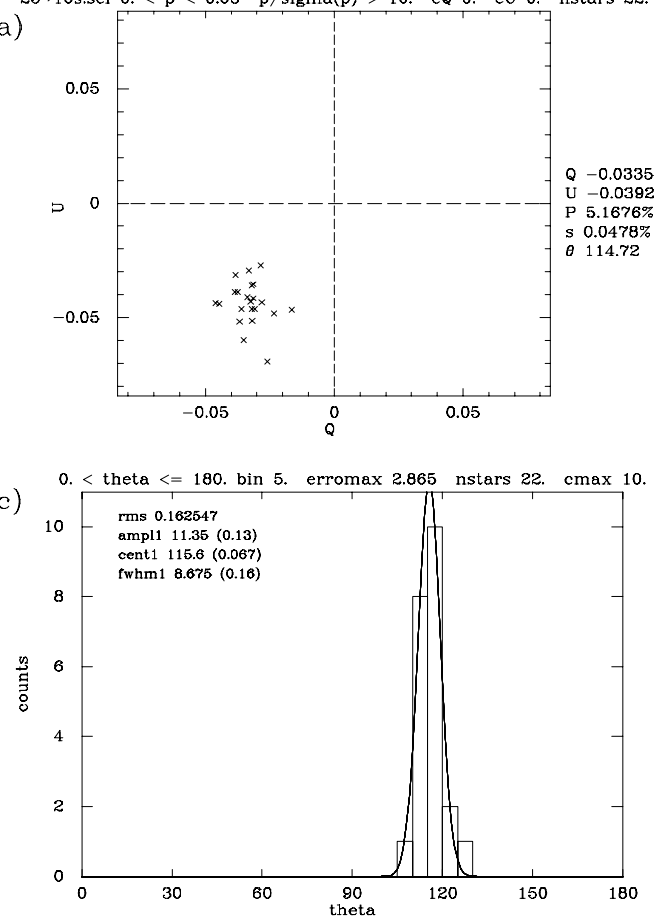

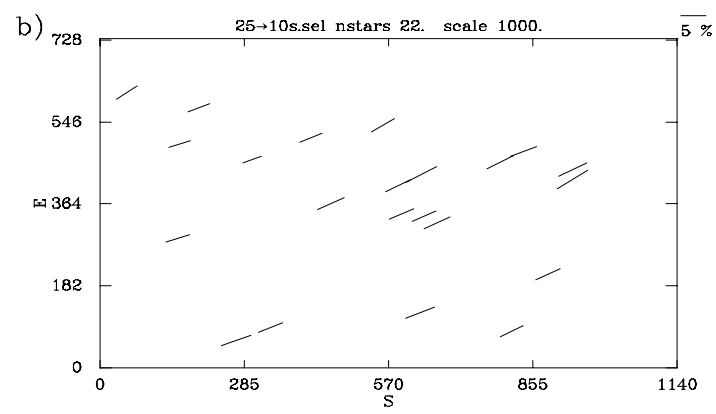

d)

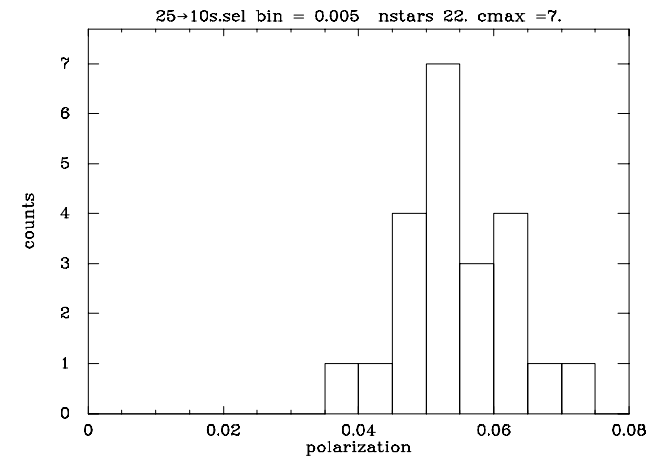

Figura D.25 Análise do Campo 25

a)

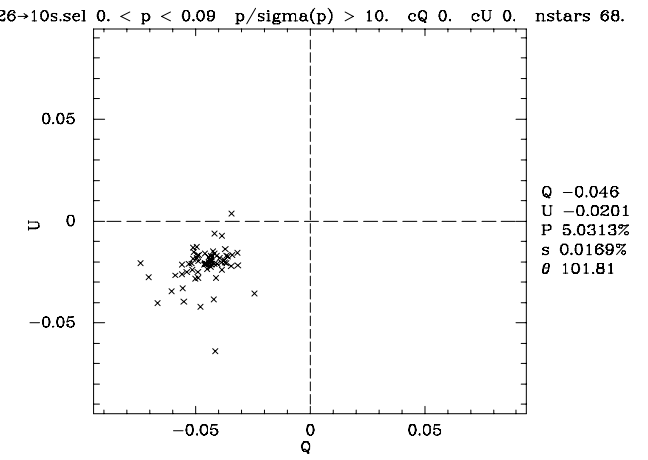

$0 .<$ theta $<=180$. bin 5. erromax 2865 nstars 68 . omax 46 .

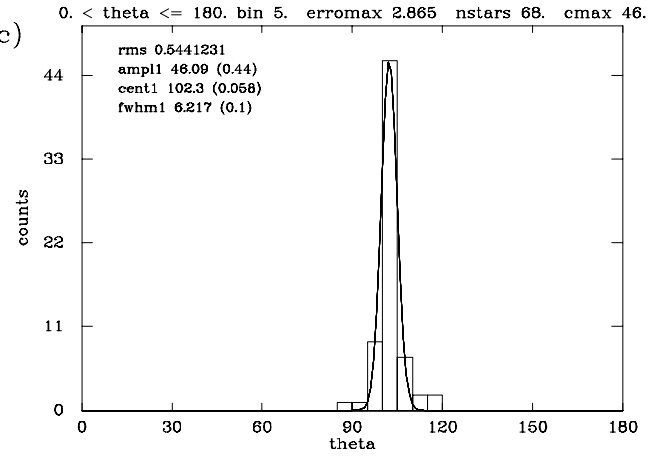

b)

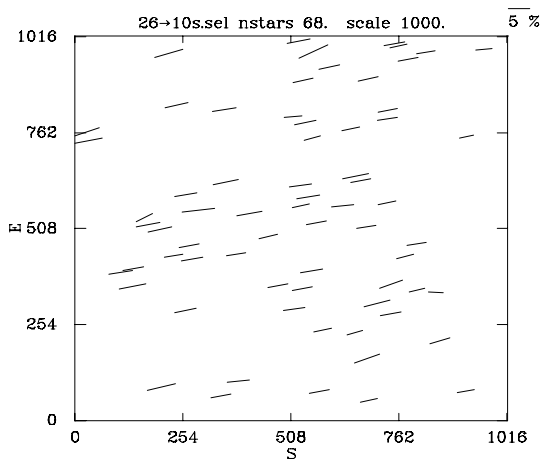

d)

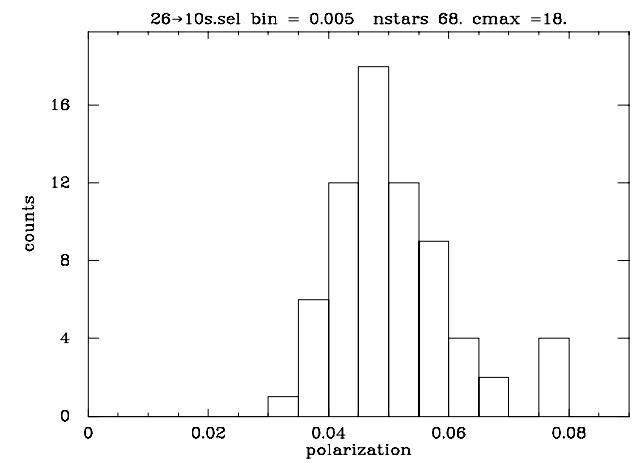

Figura D.26 Análise do Campo 26 
$27 \rightarrow 10$ s.sel $0 .<p<0.1 \quad \mathrm{p} / \operatorname{sigma}(\mathrm{p})>10 . \quad \mathrm{cQ} 0 . \quad$ cU 0. nstars 49 a)

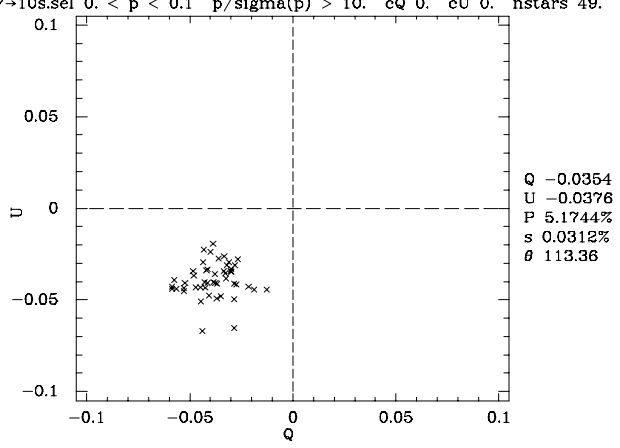

0. $<$ theta $<=180$. bin 5. erromax 2.865 nstars 49. $\quad \operatorname{cmax} 23$.

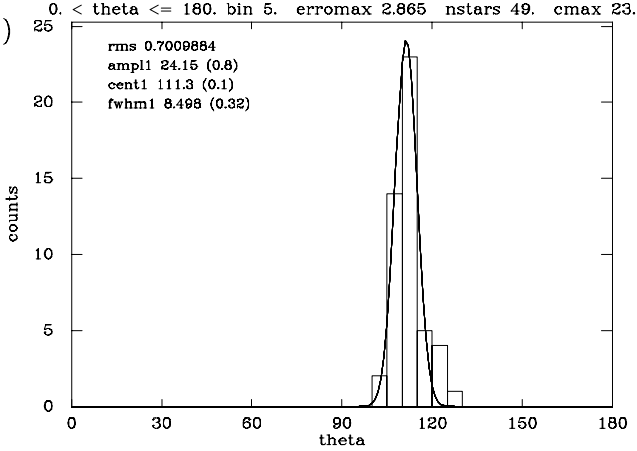

b)

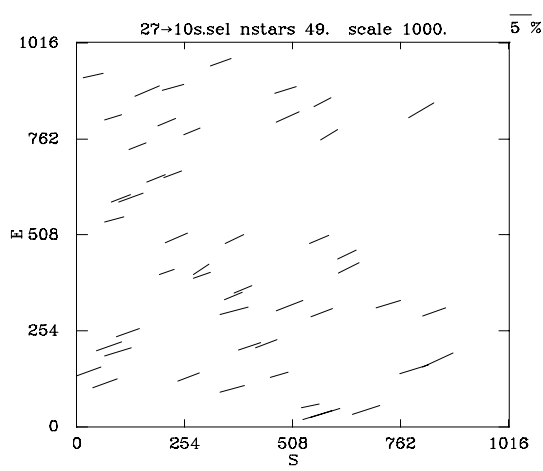

d)

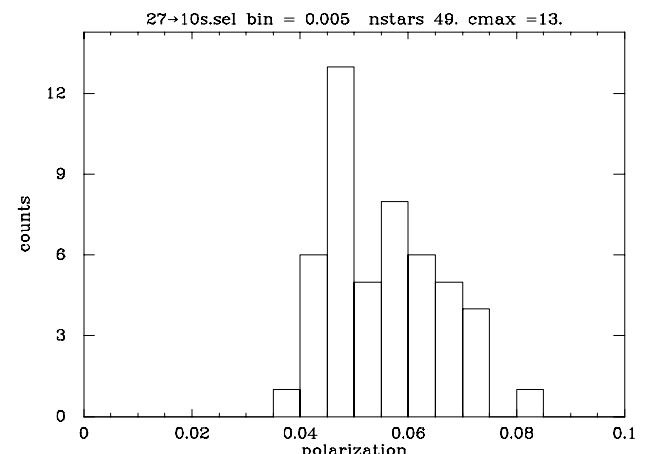

Figura D.27 Análise do Campo 27

$28 \rightarrow 10$ s.sel $0 .<p<0.1 \quad \mathrm{p} / \operatorname{sigma}(\mathrm{p})>10 . \quad \mathrm{cQ} 0 . \quad$ cU 0. nstars 36 .
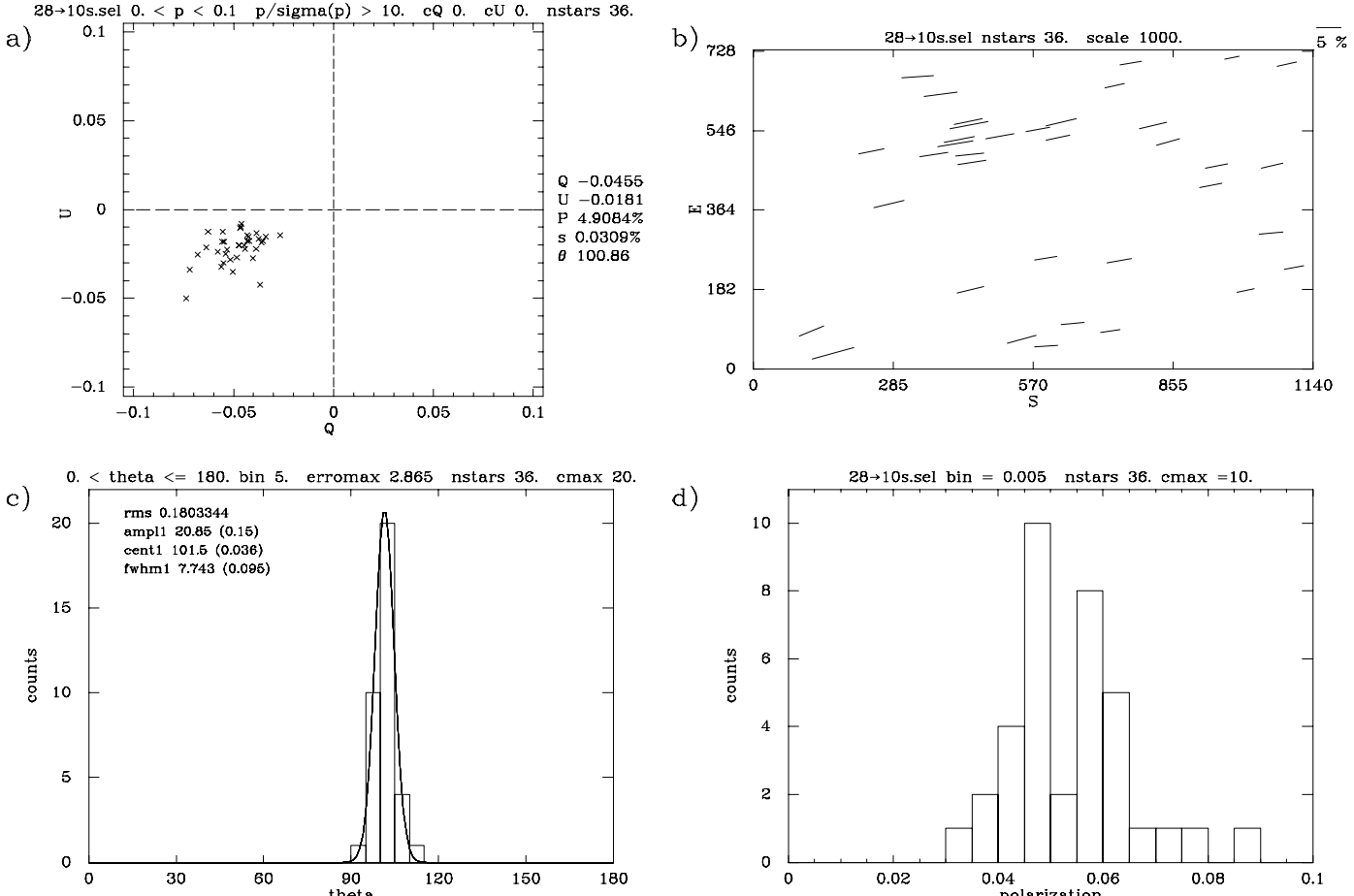

d)

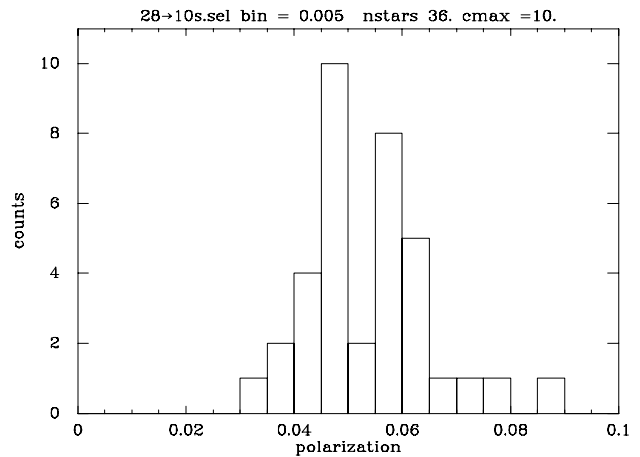

Figura D.28 Análise do Campo 28 
$29 \rightarrow 10$ s.sel $0 .<p<0.1 \quad p /$ sigma(p) $>10 . \quad c Q 0 . \quad$ cU 0. nstars 52

a)

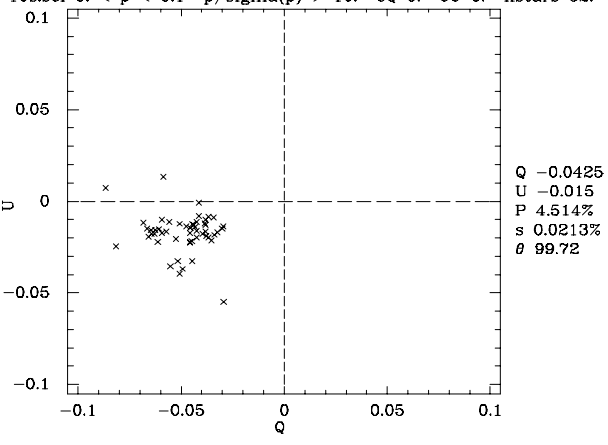

$0 .<$ theta $<=180$. bin 5 . erromax 2.865 nstars 52 omax 25

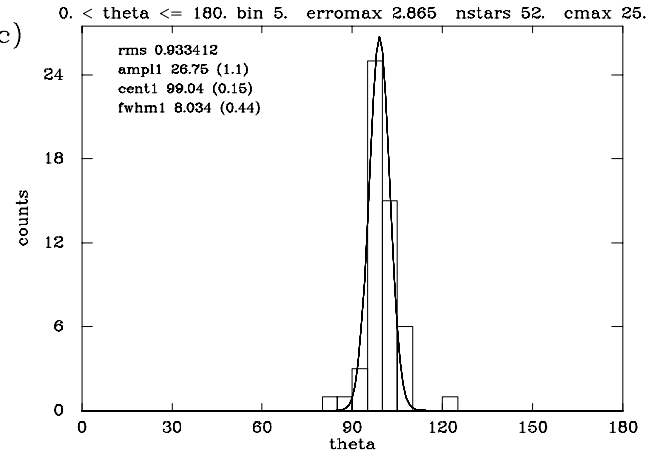

b)

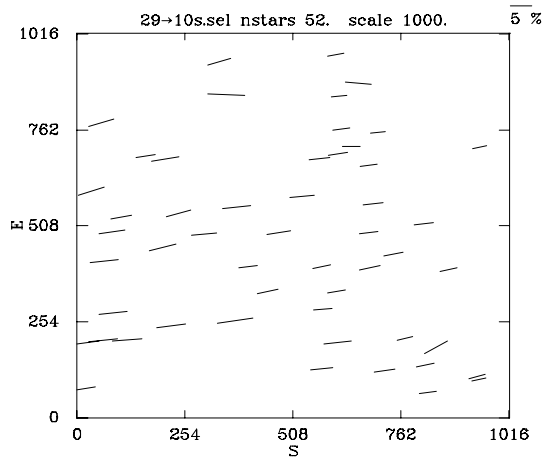

d)

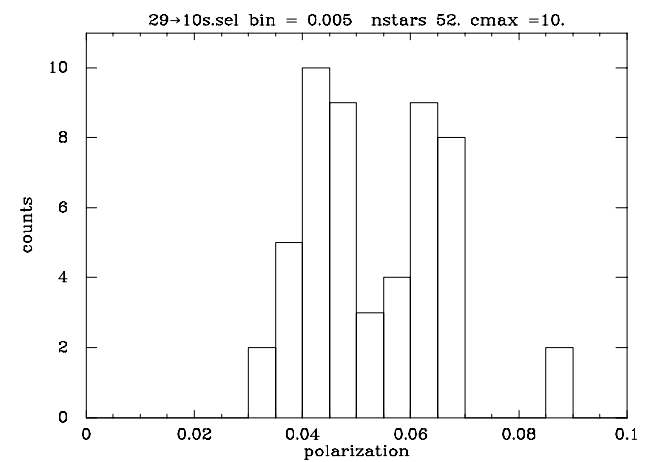

Figura D.29 Análise do Campo 29

a)

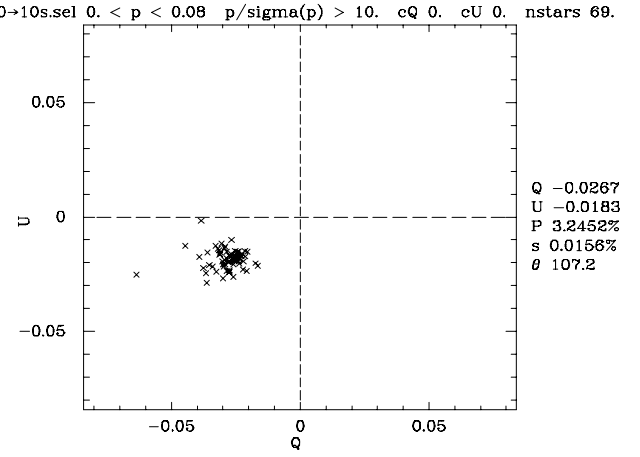

$0 .<$ theta $<=180$. bin 5. erromax 2.865 nstars 69. $\quad$ max 42

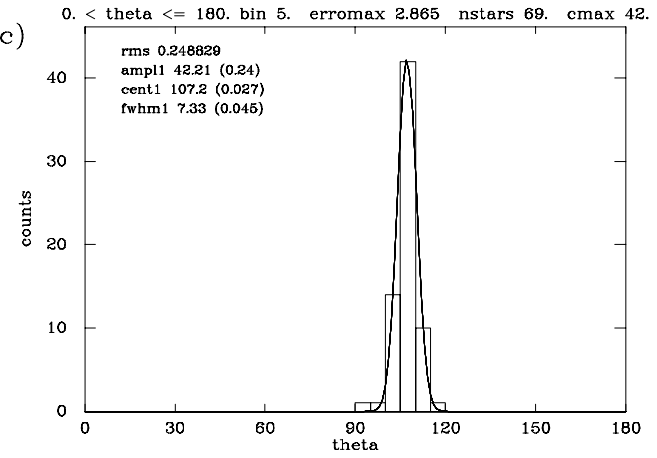

b)

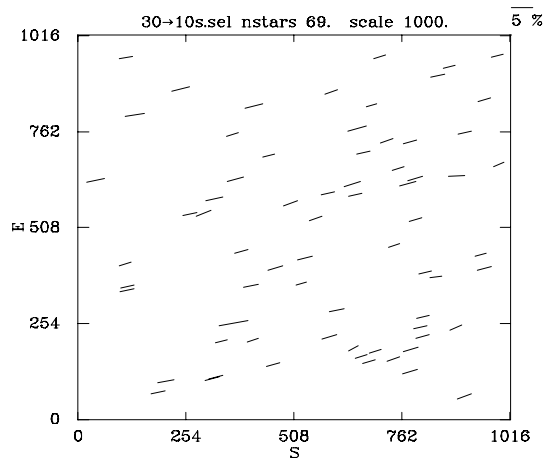

d)

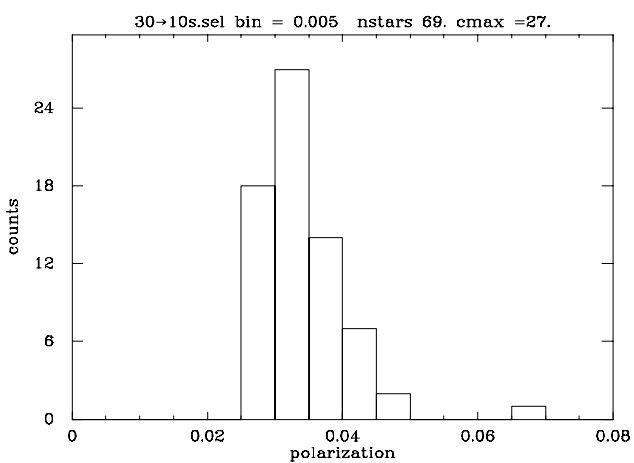

Figura D.30 Análise do Campo 30 
a)

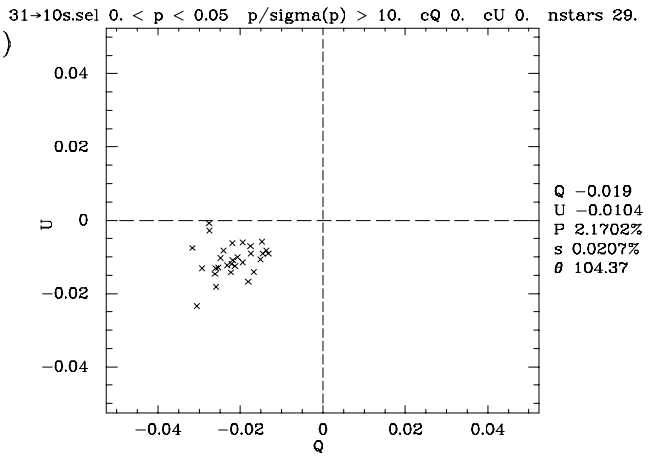

$0 .<$ theta $<=180$. bin 5. erromax 2.865 nstars 29. $\operatorname{cmax} 12$.

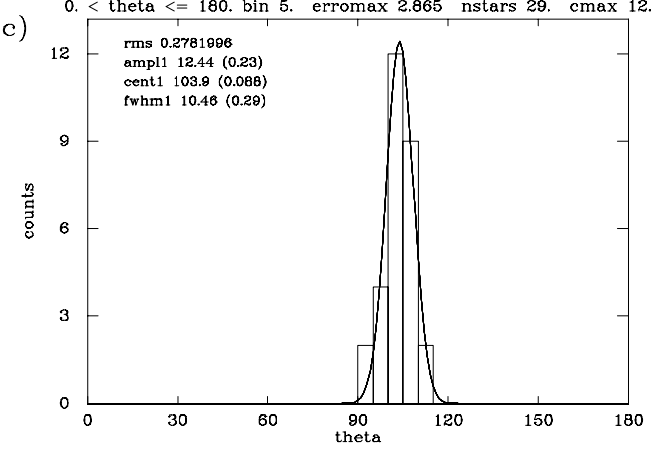

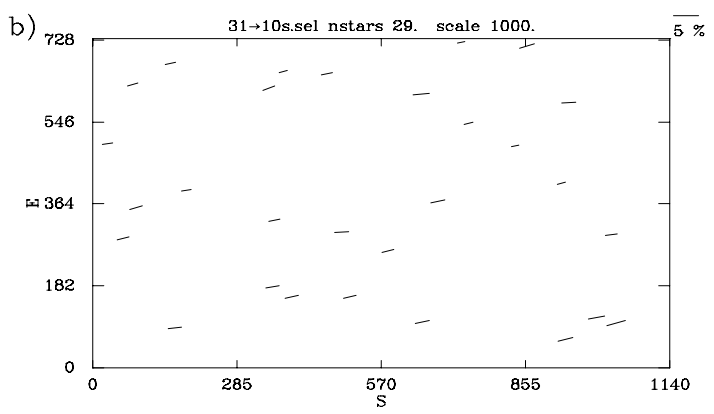

d)

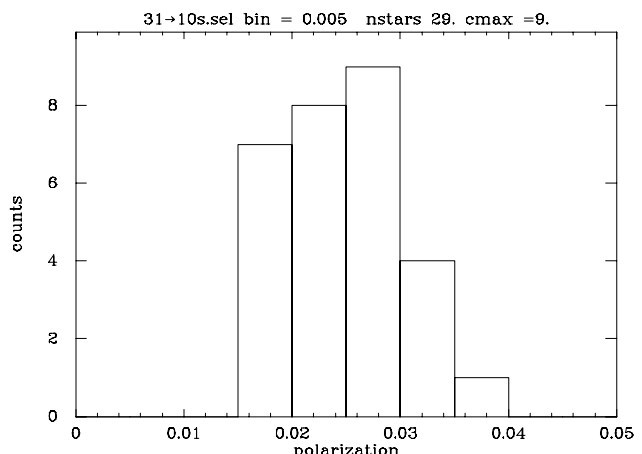

Figura D.31 Análise do Campo 31

a) 0.06 a $0 .<p<0.06 \mathrm{p} / \mathrm{sigma}(\mathrm{p})>10 . \mathrm{cQ} 0 . \mathrm{cU} 0$. nstars 55.
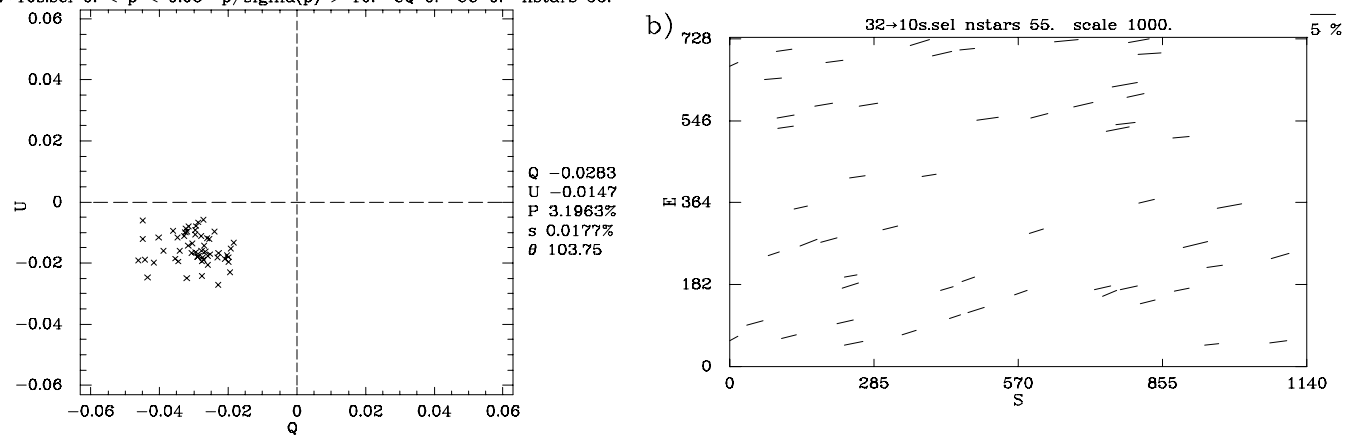

c)

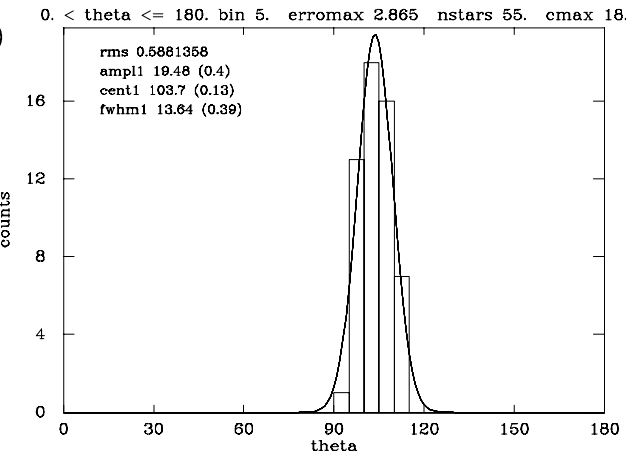

d)

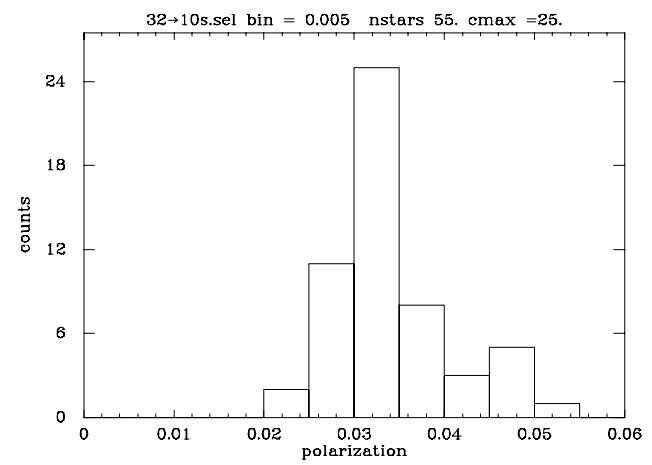

Figura D.32 Análise do Campo 32 
$33 \rightarrow 10$ s.sel $0 .<\mathrm{p}<0.07 \quad \mathrm{p} / \operatorname{sigma}(\mathrm{p})>10 . \quad \mathrm{cQ} 0 . \quad \mathrm{cU} 0$. nstars 29

a)

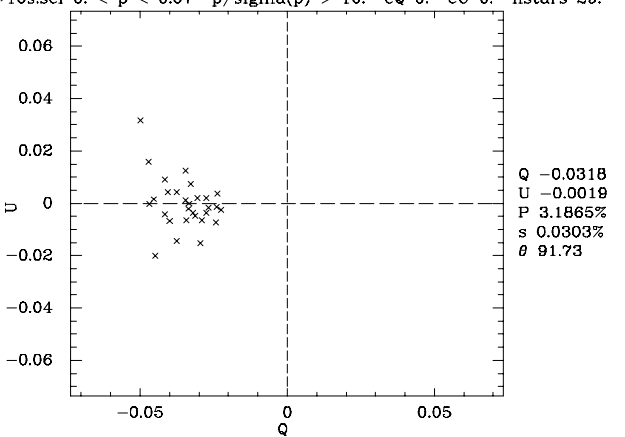

$0 .<$ theta $<=180$. bin 5. erromax 2.865 nstars 29. $\quad \operatorname{cmax} 11$

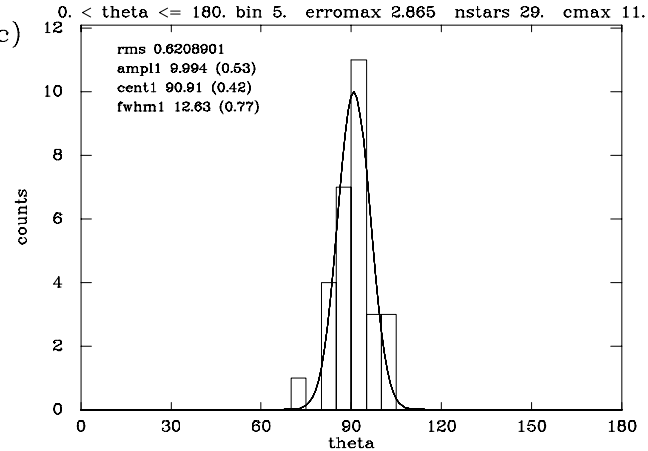

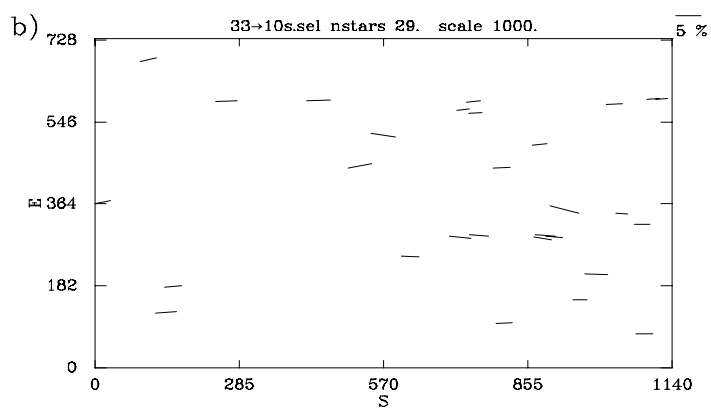

d)

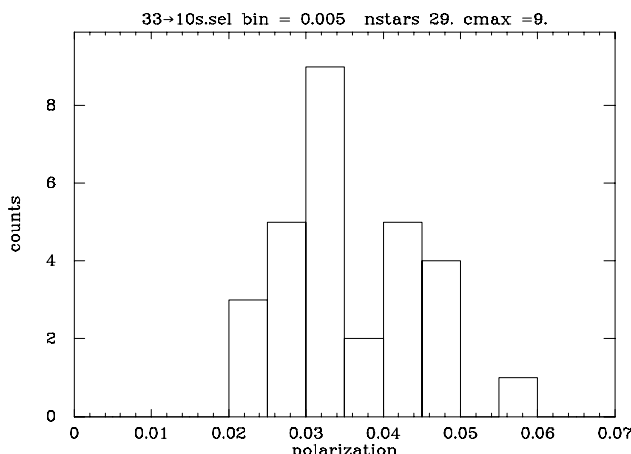

Figura D.33 Análise do Campo 33

$34 \rightarrow 10$ s.sel $0 .<\mathrm{p}<0.05 \mathrm{p} / \operatorname{sigma}(\mathrm{p})>10 . \quad \mathrm{cQ} 0 . \quad \mathrm{cU} 0$. nstars 49

a)

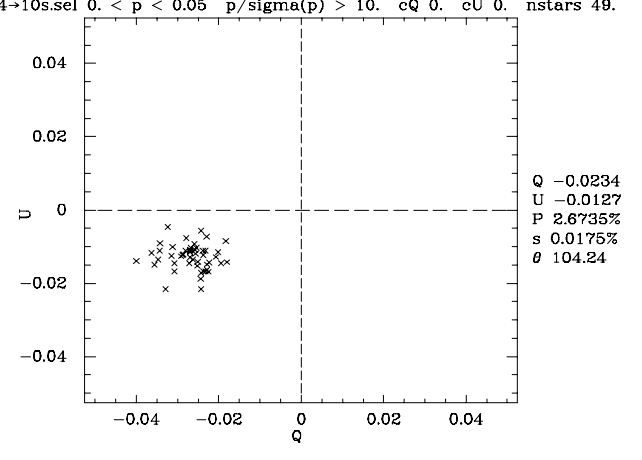

b)

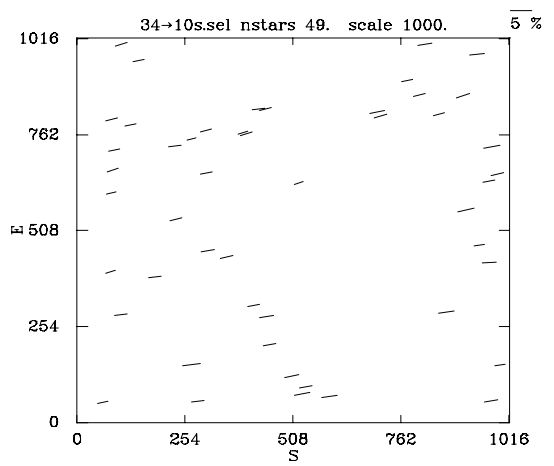

d)

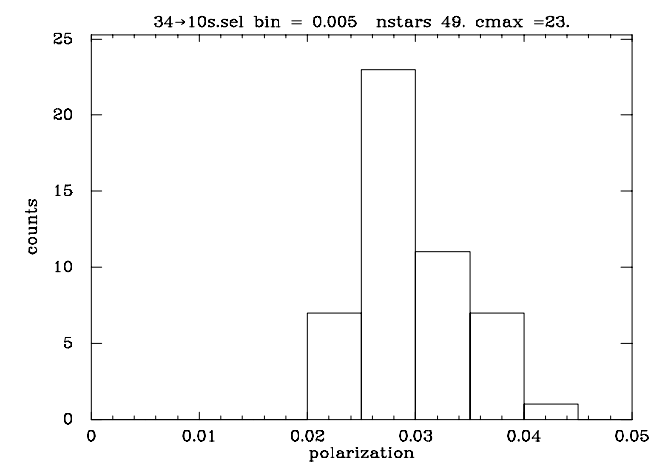

Figura D.34 Análise do Campo 34 
$35 \rightarrow 10$ s.sel $0 .<p<0.1 \quad \mathrm{p} / \operatorname{sigma}(\mathrm{p})>10$. cQ 0. cU 0. nstars 24 .
a) 0.1 .
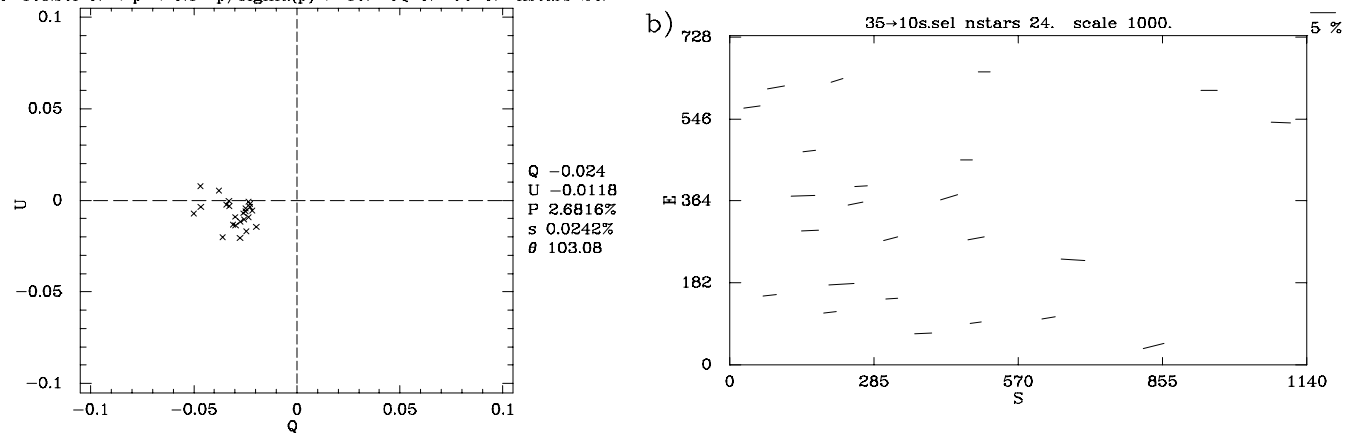

c) $<$ theta $<=180$. bin 5. erromax 2.865 nstars $24 . \quad \operatorname{cmax} 8$.

d)

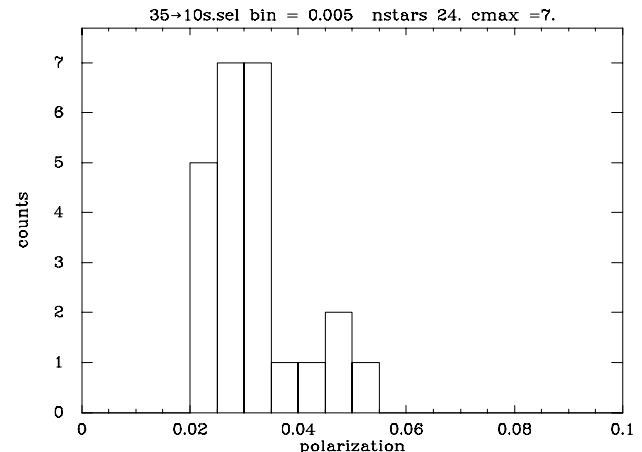

Figura D.35 Análise do Campo 35 



\section{Apêndice E. Catálogo polarimétrico da região IRAS Vela Shell/Gum}

Este apêndice contém um catálogo polarimétrico da região IRAS Vela Shell/Nebulosa de Gum da direção de HD62542. Está composto de 16 tabelas e igual número de findings charts, um por cada campo onde medidas foram feitas (ver Figura 4.5). Todos os objetos deste catálogo apresentam uma sinal-ruído de polarização maior ou igual que 10. O número total de objetos é 856, dos quais 19 apresentam duas medidas polarimétricas independentes e estão indicados nos pé de pagina respectivos.

Em cada tabela, a primeira coluna é o número de identificação (ID) de cada objeto em cada campo. Este número indica a posição do objeto nos findings charts. A segunda e terceira colunas são as coordenadas equatoriais (1950). O erro estimado na posição é menor que 1 segundo de arco. A quarta e quinta coluna são os valores da polarização observada no filtro $\mathrm{V}\left(P_{\mathrm{V}}\right)$ e seu erro respectivo $\left(\sigma P_{\mathrm{V}}\right)$. O ângulo de polarização $(\theta)$ está na última coluna. 
Tabela E.1Dados polarimétricos do Campo 01

\begin{tabular}{cccccc}
\hline \hline ID & $\begin{array}{c}\text { AR }(1950.00) \\
(\mathrm{h}: \mathrm{m}: \mathrm{s})\end{array}$ & $\begin{array}{c}\text { DEC }(1950.00) \\
\left({ }^{\circ}: \boldsymbol{~}^{\prime \prime}\right)\end{array}$ & $\begin{array}{c}P_{\mathrm{V}} \\
\left(\frac{\circ}{0}\right)\end{array}$ & $\begin{array}{c}\sigma P_{\mathrm{V}} \\
\left(\frac{\circ}{\circ}\right)\end{array}$ & $\begin{array}{c}\theta \\
\left({ }^{\circ}\right)\end{array}$ \\
\hline 9 & $7: 40: 37.11$ & $-42: 04: 34.01$ & 0.309 & 0.019 & 81.9 \\
23 & $7: 40: 41.14$ & $-42: 04: 07.88$ & 0.344 & 0.029 & 29.5 \\
24 & $7: 40: 42.98$ & $-42: 08: 33.40$ & 2.088 & 0.127 & 122.4 \\
30 & $7: 40: 44.69$ & $-42: 02: 58.32$ & 0.981 & 0.013 & 45. \\
32 & $7: 40: 45.43$ & $-42: 04: 14.50$ & 1.948 & 0.066 & 62.6 \\
42 & $7: 40: 50.82$ & $-42: 05: 03.17$ & 1.823 & 0.052 & 65.4 \\
54 & $7: 40: 55.08$ & $-42: 06: 27.34$ & 1.723 & 0.164 & 70.9 \\
70 & $7: 41: 01.93$ & $-42: 09: 43.22$ & 3.11 & 0.231 & 98.8 \\
73 & $7: 41: 03.25$ & $-42: 05: 26.66$ & 1.394 & 0.007 & 29.8 \\
76 & $7: 41: 04.35$ & $-42: 05: 03.96$ & 1.611 & 0.054 & 25.5 \\
77 & $7: 41: 05.13$ & $-42: 07: 21.40$ & 2.571 & 0.051 & 10.1 \\
83 & $7: 41: 09.55$ & $-42: 07: 30.86$ & 2.377 & 0.054 & 172.1 \\
85 & $7: 41: 10.55$ & $-42: 09: 17.96$ & 1.962 & 0.052 & 64.7 \\
88 & $7: 41: 11.19$ & $-42: 06: 06.69$ & 1.103 & 0.038 & 24.2 \\
\hline
\end{tabular}

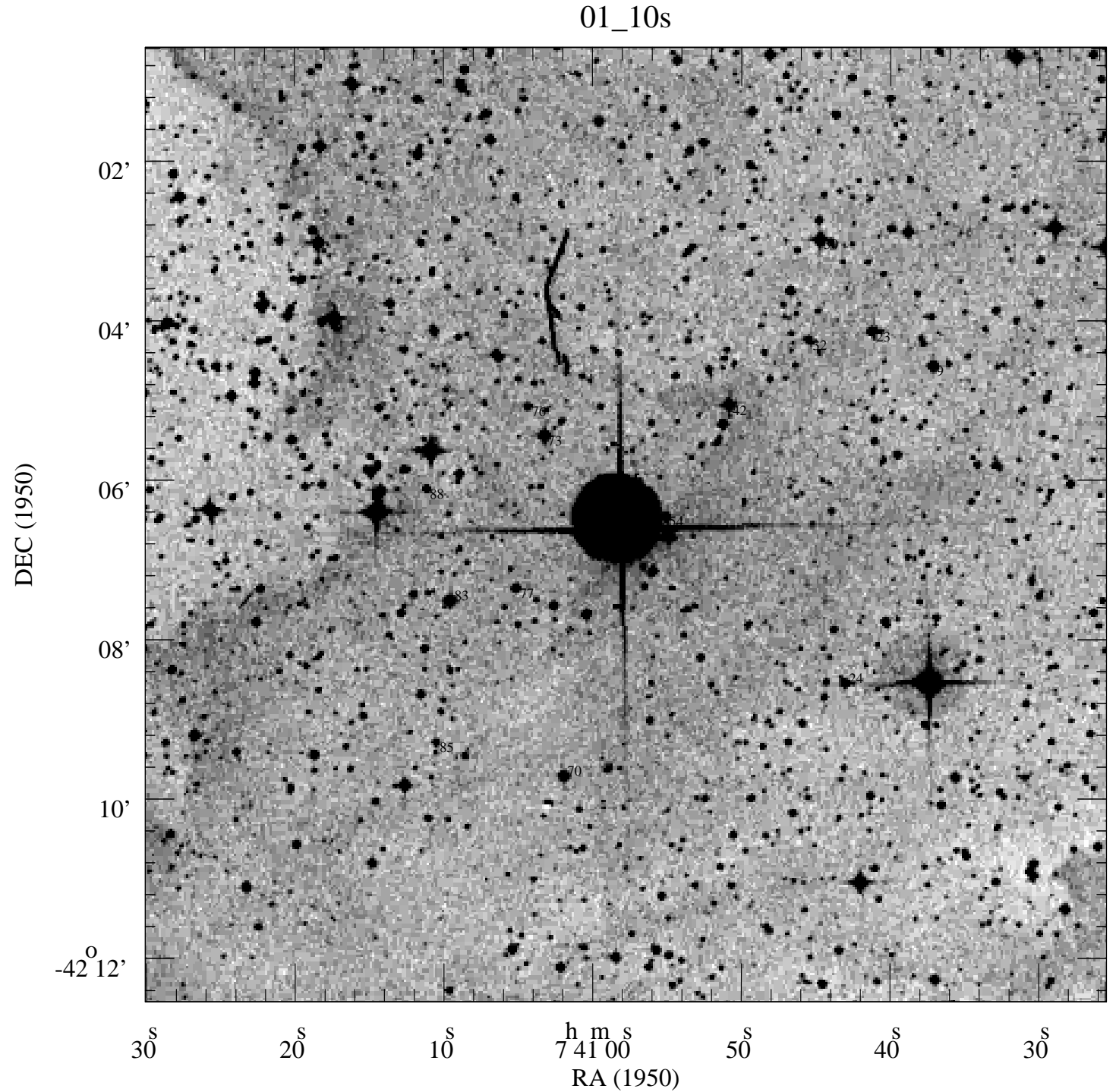

Figura E.1 Finding Chart do Campo 01 centrado em $\mathrm{AR}_{1950}=07^{\mathrm{h}} 40^{\mathrm{m}} 57.8^{\mathrm{s}}, \mathrm{DEC}_{1950}=-42^{\circ} 06^{\prime} 34^{\prime \prime}$ 
Tabela E.2 Dados polarimétricos do Campo 02

\begin{tabular}{|c|c|c|c|c|c|}
\hline ID & $\begin{array}{l}\text { AR }(1950.00) \\
(\mathrm{h}: \mathrm{m}: \mathrm{s})\end{array}$ & $\begin{array}{l}\operatorname{DEC}(1950.00) \\
\left(0^{\circ}::^{\prime}\right)\end{array}$ & $\begin{array}{l}P_{\mathrm{V}} \\
(\%)\end{array}$ & $\begin{array}{l}\sigma P_{\mathrm{V}} \\
(\%)\end{array}$ & $\begin{array}{c}\theta \\
\left({ }^{\circ}\right)\end{array}$ \\
\hline 9 & $7: 39: 58.93$ & $-41: 57: 56.70$ & 1.465 & 0.019 & 60.4 \\
\hline $10^{\mathrm{a}}$ & $7: 39: 58.97$ & $-41: 56: 20.65$ & 1.479 & 0.136 & 46.9 \\
\hline 14 & $7: 39: 59.34$ & $-41: 59: 47.96$ & 0.456 & 0.016 & 58.7 \\
\hline $16^{\mathrm{b}}$ & $7: 39: 59.51$ & $-41: 58: 27.01$ & 0.389 & 0.004 & 44.1 \\
\hline 26 & $7: 40: 00.03$ & $-41: 57: 17.30$ & 1.804 & 0.176 & 50.3 \\
\hline $27^{\circ}$ & $7: 40: 00.22$ & $-41: 56: 29.11$ & 1.501 & 0.093 & 41.9 \\
\hline 40 & $7: 40: 01.32$ & $-42: 00: 43.47$ & 1.413 & 0.114 & 79.2 \\
\hline 42 & $7: 40: 01.81$ & $-42: 02: 48.88$ & 1.924 & 0.065 & 28.8 \\
\hline 45 & $7: 40: 01.90$ & $-42: 00: 51.30$ & 1.346 & 0.01 & 80.6 \\
\hline 48 & $7: 40: 02.30$ & $-42: 03: 00.40$ & 0.928 & 0.01 & 88.7 \\
\hline 52 & $7: 40: 02.44$ & $-42: 01: 49.77$ & 1.533 & 0.011 & 81.4 \\
\hline 56 & $7: 40: 02.72$ & $-41: 58: 50.61$ & 1.774 & 0.12 & 52.8 \\
\hline 58 & $7: 40: 02.80$ & $-41: 58: 07.22$ & 0.787 & 0.025 & 64. \\
\hline 60 & $7: 40: 02.44$ & $-42: 01: 49.58$ & 1.897 & 0.055 & 76.8 \\
\hline 63 & $7: 40: 03.52$ & $-42: 01: 07.27$ & 1.748 & 0.1 & 47.8 \\
\hline 64 & $7: 40: 03.57$ & $-41: 57: 45.88$ & 2.158 & 0.029 & 62.8 \\
\hline 75 & $7: 40: 04.87$ & $-41: 59: 22.86$ & 2.524 & 0.132 & 58.1 \\
\hline 80 & $7: 40: 05.37$ & $-41: 58: 59.35$ & 1.472 & 0.016 & 53.8 \\
\hline 90 & $7: 40: 06.26$ & $-41: 59: 33.18$ & 1.666 & 0.015 & 65. \\
\hline 109 & $7: 40: 07.73$ & $-41: 57: 02.46$ & 0.721 & 0.013 & 66.4 \\
\hline 119 & $7: 40: 09.16$ & $-41: 57: 01.43$ & 1.345 & 0.068 & 48.1 \\
\hline 135 & $7: 40: 10.46$ & $-42: 01: 58.46$ & 0.776 & 0.011 & 65.8 \\
\hline 138 & $7: 40: 10.52$ & $-42: 02: 07.86$ & 2.472 & 0.04 & 66.8 \\
\hline 144 & $7: 40: 11.70$ & $-41: 57: 21.83$ & 1.314 & 0.024 & 31.4 \\
\hline 146 & $7: 40: 11.94$ & $-42: 00: 37.93$ & 1.723 & 0.124 & 66.8 \\
\hline 152 & $7: 40: 12.29$ & $-42: 00: 34.46$ & 2.901 & 0.106 & 57.7 \\
\hline 157 & $7: 40: 12.69$ & $-41: 58: 56.93$ & 0.528 & 0.028 & 70. \\
\hline 159 & $7: 40: 12.67$ & $-41: 57: 48.14$ & 0.473 & 0.015 & 93.2 \\
\hline 165 & $7: 40: 13.14$ & $-41: 57: 54.79$ & 2.803 & 0.275 & 82.1 \\
\hline 166 & $7: 40: 13.59$ & $-41: 58: 52.45$ & 2.133 & 0.131 & 54.4 \\
\hline 169 & $7: 40: 13.71$ & $-41: 56: 31.41$ & 2.386 & 0.026 & 63.2 \\
\hline 171 & $7: 40: 13.91$ & $-41: 57: 26.09$ & 1.973 & 0.16 & 62.9 \\
\hline $177^{\mathrm{d}}$ & $7: 40: 14.35$ & $-41: 56: 52.91$ & 0.513 & 0.035 & 53. \\
\hline 179 & $7: 40: 14.44$ & $-41: 59: 34.60$ & 1.58 & 0.043 & 62.1 \\
\hline 182 & $7: 40: 14.66$ & $-41: 59: 57.10$ & 1.372 & 0.005 & 61. \\
\hline 184 & $7: 40: 14.78$ & $-41: 59: 13.10$ & 1.157 & 0.043 & 78.9 \\
\hline 196 & $7: 40: 16.62$ & $-42: 01: 17.08$ & 1.218 & 0.007 & 51.7 \\
\hline 201 & $7: 40: 17.17$ & $-42: 01: 27.62$ & 1.08 & 0.05 & 65.2 \\
\hline 202 & $7: 40: 17.22$ & $-41: 56: 42.25$ & 0.305 & 0.017 & 136.5 \\
\hline 209 & $7: 40: 17.99$ & $-41: 58: 08.16$ & 2.306 & 0.161 & 10.1 \\
\hline 210 & $7: 40: 17.99$ & $-42: 03: 00.55$ & 1.023 & 0.023 & 81. \\
\hline 212 & $7: 40: 18.13$ & $-41: 57: 00.38$ & 4.542 & 0.061 & 57.7 \\
\hline 213 & $7: 40: 18.11$ & $-42: 02: 35.16$ & 0.6 & 0.004 & 63.9 \\
\hline 219 & $7: 40: 18.65$ & $-42: 02: 49.13$ & 0.772 & 0.041 & 30.3 \\
\hline 225 & $7: 40: 19.00$ & $-41: 58: 20.65$ & 0.249 & 0.009 & 48.4 \\
\hline 228 & $7: 40: 19.20$ & $-41: 59: 45.05$ & 1.572 & 0.033 & 55. \\
\hline 235 & $7: 40: 19.75$ & $-42: 00: 19.95$ & 1.24 & 0.003 & 30. \\
\hline 243 & $7: 40: 20.38$ & $-41: 59: 55.12$ & 0.133 & 0.01 & 90.4 \\
\hline 248 & $7: 40: 20.90$ & $-41: 58: 38.80$ & 2.117 & 0.033 & 65.5 \\
\hline 250 & $7: 40: 21.00$ & $-42: 00: 15.49$ & 1.292 & 0.05 & 78.6 \\
\hline 254 & $7: 40: 21.50$ & $-42: 02: 31.36$ & 1.12 & 0.035 & 65.7 \\
\hline $255^{\mathrm{e}}$ & $7: 40: 21.64$ & $-41: 57: 21.14$ & 1.48 & 0.029 & 83.3 \\
\hline 258 & $7: 40: 21.97$ & $-41: 57: 45.01$ & 0.52 & 0.03 & 77.3 \\
\hline 277 & $7: 40: 24.13$ & $-42: 01: 37.91$ & 1.488 & 0.084 & 53.9 \\
\hline 278 & $7: 40: 24.54$ & $-41: 59: 43.50$ & 1.425 & 0.028 & 71.6 \\
\hline 287 & $7: 40: 25.33$ & $-42: 03: 03.14$ & 0.432 & 0.029 & 31.1 \\
\hline 288 & $7: 40: 25.46$ & $-42: 00: 32.87$ & 1.066 & 0.057 & 52.7 \\
\hline 292 & $7: 40: 25.79$ & $-42: 00: 56.82$ & 0.984 & 0.029 & 44.3 \\
\hline $305^{f}$ & $7: 40: 27.13$ & $-41: 56: 45.33$ & 1.06 & 0.015 & 60. \\
\hline 315 & $7: 40: 28.92$ & $-42: 02: 51.12$ & 0.645 & 0.016 & 53.9 \\
\hline 316 & $7: 40: 29.23$ & $-41: 58: 23.92$ & 1.132 & 0.042 & 94.1 \\
\hline 322 & $7: 40: 29.78$ & $-41: 58: 33.37$ & 1.286 & 0.062 & 85.5 \\
\hline 333 & $7: 40: 31.10$ & $-41: 58: 10.65$ & 1.282 & 0.09 & 80. \\
\hline 335 & $7: 40: 31.55$ & $-42: 00: 41.25$ & 0.212 & 0.003 & 67.4 \\
\hline 345 & $7: 40: 32.10$ & $-42: 02: 34.54$ & 1.711 & 0.047 & 52.7 \\
\hline 346 & $7: 40: 32.75$ & $-41: 59: 06.53$ & 2.122 & 0.023 & 120.2 \\
\hline 349 & $7: 40: 33.21$ & $-41: 57: 46.17$ & 0.759 & 0.018 & 105.3 \\
\hline 357 & $7: 40: 33.92$ & $-41: 58: 32.72$ & 0.478 & 0.029 & 175.5 \\
\hline $364^{9}$ & $7: 40: 34.99$ & $-41: 57: 17.51$ & 1.354 & 0.003 & 83.9 \\
\hline 366 & $7: 40: 35.19$ & $-41: 58: 44.53$ & 0.79 & 0.043 & 95. \\
\hline $370^{\mathrm{h}}$ & $7: 40: 35.35$ & $-41: 56: 30.68$ & 2.732 & 0.233 & 83.5 \\
\hline
\end{tabular}

a mesmo objeto na Tabela D.3 com ID $=489$

mesmo objeto na Tabela D.3 com ID $=496$

mesmo objeto na Tabela D.3 com ID $=510$

mesmo objeto na Tabela D.10 com ID $=9$

mesmo objeto na Tabela D.10 com ID $=94$

g mesmo objeto na Tabela D.10 com ID $=145$

mesmo objeto na Tabela D.10 com ID $=225$ 


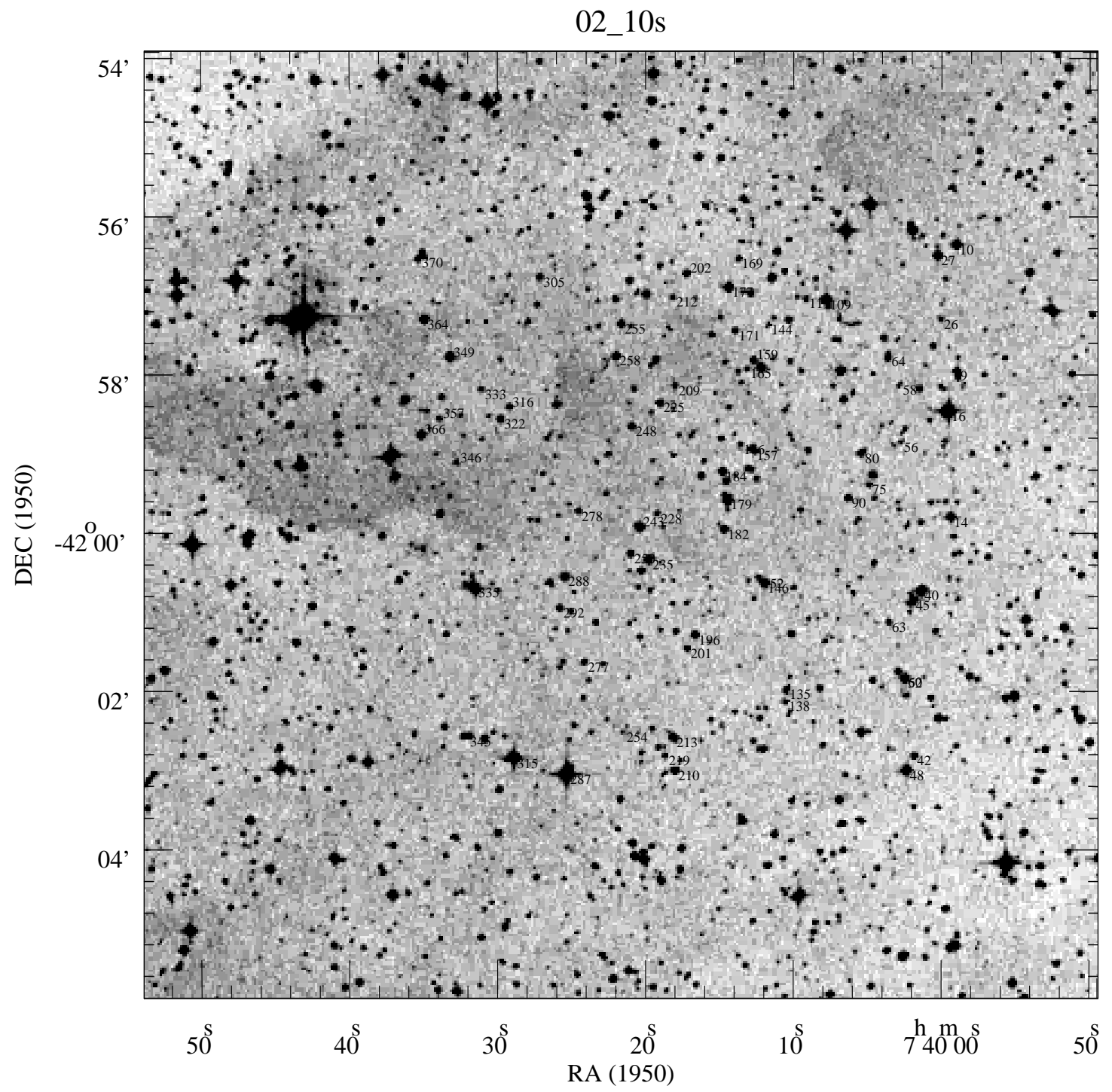

Figura E.2 Finding Chart do Campo 02 centrado em $\mathrm{AR}_{1950}=07^{\mathrm{h}} 40^{\mathrm{m}} 21.7^{\mathrm{s}}, \mathrm{DEC}_{1950}=-41^{\circ} 59^{\prime} 54^{\prime \prime}$ 
Tabela E.3 Dados polarimétricos do Campo 03

\begin{tabular}{|c|c|c|c|c|c|}
\hline ID & $\begin{array}{l}\text { AR }(1950.00) \\
(\mathrm{h}: \mathrm{m}: \mathrm{s})\end{array}$ & $\begin{array}{l}\operatorname{DEC}(1950.00) \\
\left(0^{\circ}::^{\prime}\right)\end{array}$ & $\begin{array}{l}P_{\mathrm{V}} \\
(\%)\end{array}$ & $\begin{array}{l}\sigma P_{\mathrm{V}} \\
\left(\frac{0}{0}\right)\end{array}$ & $\begin{array}{c}\theta \\
\left({ }^{\circ}\right)\end{array}$ \\
\hline 31 & $7: 39: 24.35$ & $-41: 57: 56.45$ & 0.629 & 0.017 & 133.4 \\
\hline 39 & $7: 39: 25.02$ & $-41: 58: 10.31$ & 1.246 & 0.017 & 141.3 \\
\hline 54 & $7: 39: 25.79$ & $-41: 57: 14.68$ & 1.116 & 0.042 & 151.8 \\
\hline 59 & $7: 39: 26.24$ & $-41: 58: 03.69$ & 1.071 & 0.069 & 158.1 \\
\hline 61 & $7: 39: 26.29$ & $-41: 54: 50.18$ & 0.629 & 0.056 & 7.7 \\
\hline 66 & $7: 39: 26.56$ & $-41: 53: 58.94$ & 0.502 & 0.046 & 77.2 \\
\hline 72 & $7: 39: 27.12$ & $-41: 53: 35.72$ & 0.765 & 0.028 & 61.5 \\
\hline 75 & $7: 39: 27.31$ & $-41: 57: 16.33$ & 1.372 & 0.078 & 25.7 \\
\hline 82 & $7: 39: 27.75$ & $-41: 57: 50.31$ & 1.821 & 0.091 & 69.2 \\
\hline 98 & $7: 39: 28.83$ & $-41: 52: 20.23$ & 0.66 & 0.053 & 69.3 \\
\hline 101 & $7: 39: 28.91$ & $-41: 55: 27.46$ & 0.458 & 0.03 & 22.3 \\
\hline 109 & $7: 39: 29.74$ & $-41: 51: 47.78$ & 0.768 & 0.052 & 100.8 \\
\hline 117 & $7: 39: 30.37$ & $-41: 52: 42.79$ & 1.039 & 0.032 & 57.2 \\
\hline 126 & $7: 39: 31.07$ & $-41: 51: 50.15$ & 1.244 & 0.079 & 104.9 \\
\hline 127 & $7: 39: 31.19$ & $-41: 51: 42.85$ & 1.167 & 0.111 & 99. \\
\hline 130 & $7: 39: 31.47$ & $-41: 53: 49.25$ & 0.681 & 0.045 & 75.1 \\
\hline 141 & $7: 39: 32.50$ & $-41: 53: 21.60$ & 0.994 & 0.098 & 76.1 \\
\hline 160 & $7: 39: 34.01$ & $-41: 52: 22.36$ & 1.283 & 0.108 & 17.7 \\
\hline 166 & $7: 39: 34.20$ & $-41: 53: 07.75$ & 2.248 & 0.058 & 58.2 \\
\hline 172 & $7: 39: 34.87$ & $-41: 54: 19.67$ & 0.326 & 0.032 & 54.9 \\
\hline 178 & $7: 39: 35.15$ & $-41: 54: 58.69$ & 0.669 & 0.052 & 172.2 \\
\hline 182 & $7: 39: 35.20$ & $-41: 51: 32.31$ & 1.624 & 0.146 & 105. \\
\hline 196 & $7: 39: 36.15$ & $-41: 56: 04.19$ & 1.925 & 0.149 & 51.4 \\
\hline 199 & $7: 39: 36.22$ & $-41: 57: 24.32$ & 0.725 & 0.043 & 17.4 \\
\hline 201 & $7: 39: 36.31$ & $-41: 52: 00.01$ & 2.447 & 0.103 & 63.9 \\
\hline 202 & $7: 39: 36.33$ & $-41: 54: 20.67$ & 0.707 & 0.044 & 39.3 \\
\hline 203 & $7: 39: 36.59$ & $-41: 58: 19.00$ & 1.043 & 0.086 & 27.8 \\
\hline 207 & $7: 39: 36.90$ & $-41: 57: 48.80$ & 1.209 & 0.115 & 96.3 \\
\hline 208 & $7: 39: 37.08$ & $-41: 54: 21.14$ & 0.442 & 0.02 & 66.4 \\
\hline 221 & $7: 39: 38.07$ & $-41: 57: 38.78$ & 0.683 & 0.048 & 19.8 \\
\hline 235 & $7: 39: 38.88$ & $-41: 52: 48.88$ & 1.354 & 0.118 & 77. \\
\hline 236 & $7: 39: 39.08$ & $-41: 52: 19.07$ & 0.288 & 0.019 & 76.1 \\
\hline 240 & $7: 39: 39.19$ & $-41: 57: 36.08$ & 0.338 & 0.021 & 23.6 \\
\hline 248 & $7: 39: 39.91$ & $-41: 53: 53.98$ & 2.174 & 0.195 & 64.3 \\
\hline 255 & $7: 39: 40.66$ & $-41: 53: 29.58$ & 1.362 & 0.075 & 71.1 \\
\hline 262 & $7: 39: 41.32$ & $-41: 55: 14.19$ & 0.544 & 0.039 & 103.7 \\
\hline 270 & $7: 39: 41.95$ & $-41: 53: 50.11$ & 0.874 & 0.052 & 74.5 \\
\hline 280 & $7: 39: 42.70$ & $-41: 52: 40.42$ & 2.043 & 0.142 & 79.7 \\
\hline 287 & $7: 39: 42.86$ & $-41: 57: 08.12$ & 2.079 & 0.13 & 29.7 \\
\hline 289 & $7: 39: 43.00$ & $-41: 57: 55.58$ & 0.552 & 0.012 & 39.7 \\
\hline 299 & $7: 39: 43.63$ & $-41: 53: 52.38$ & 0.885 & 0.078 & 78.5 \\
\hline 309 & $7: 39: 44.11$ & $-41: 52: 30.71$ & 1.217 & 0.085 & 100.2 \\
\hline 319 & $7: 39: 44.55$ & $-41: 56: 42.45$ & 1.237 & 0.114 & $67.9^{2}$ \\
\hline 324 & $7: 39: 44.96$ & $-41: 52: 08.49$ & 2.246 & 0.186 & 76. \\
\hline 328 & $7: 39: 45.25$ & $-41: 57: 33.34$ & 0.246 & 0.013 & 66.1 \\
\hline 329 & $7: 39: 45.27$ & $-41: 56: 11.91$ & 0.941 & 0.049 & 32.1 \\
\hline 330 & $7: 39: 45.28$ & $-41: 56: 04.54$ & 0.687 & 0.01 & 53.5 \\
\hline 332 & $7: 39: 45.44$ & $-41: 51: 50.63$ & 1.436 & 0.111 & 53.7 \\
\hline 337 & $7: 39: 45.62$ & $-41: 57: 57.01$ & 1.135 & 0.111 & 7.8 \\
\hline 339 & $7: 39: 45.89$ & $-41: 52: 29.14$ & 1.56 & 0.095 & 75.5 \\
\hline 355 & $7: 39: 47.85$ & $-41: 53: 34.83$ & 0.874 & 0.057 & 73.4 \\
\hline 367 & $7: 39: 48.64$ & $-41: 52: 01.76$ & 1.812 & 0.12 & 81.1 \\
\hline 374 & $7: 39: 49.07$ & $-41: 52: 24.57$ & 3.987 & 0.258 & 70.7 \\
\hline 384 & $7: 39: 49.80$ & $-41: 57: 14.66$ & 0.577 & 0.051 & 48.6 \\
\hline 402 & $7: 39: 51.38$ & $-41: 54: 35.51$ & 0.843 & 0.038 & 63.5 \\
\hline 403 & $7: 39: 51.51$ & $-41: 54: 06.87$ & 1.198 & 0.105 & 76.4 \\
\hline 408 & $7: 39: 52.13$ & $-41: 56: 27.24$ & 0.637 & 0.053 & 69.3 \\
\hline 411 & $7: 39: 52.20$ & $-41: 53: 52.00$ & 0.761 & 0.041 & 74.4 \\
\hline 422 & $7: 39: 52.88$ & $-41: 54: 27.68$ & 1.158 & 0.077 & 75.7 \\
\hline 428 & $7: 39: 53.89$ & $-41: 54: 53.74$ & 2.15 & 0.196 & 82.2 \\
\hline 437 & $7: 39: 54.72$ & $-41: 55: 27.68$ & 0.993 & 0.07 & 87. \\
\hline 438 & $7: 39: 54.70$ & $-41: 53: 26.67$ & 0.84 & 0.052 & 73.8 \\
\hline 451 & $7: 39: 56.12$ & $-41: 52: 28.79$ & 3.699 & 0.24 & 53.1 \\
\hline $489^{a}$ & $7: 39: 58.96$ & $-41: 56: 20.91$ & 1.547 & 0.015 & 48.7 \\
\hline 492 & $7: 39: 59.26$ & $-41: 55: 37.97$ & 1.811 & 0.13 & 79.7 \\
\hline 493 & $7: 39: 59.41$ & $-41: 52: 40.88$ & 1.846 & 0.073 & 65. \\
\hline $496^{b}$ & $7: 39: 59.53$ & $-41: 58: 27.26$ & 0.455 & 0.02 & 56.6 \\
\hline $510^{\mathrm{c}}$ & $7: 40: 00.22$ & $-41: 56: 29.35$ & 1.4 & 0.027 & 49.1 \\
\hline
\end{tabular}

a mesmo objeto na Tabela D.2 com ID $=10$

mesmo objeto na Tabela D.2 com ID $=16$ 


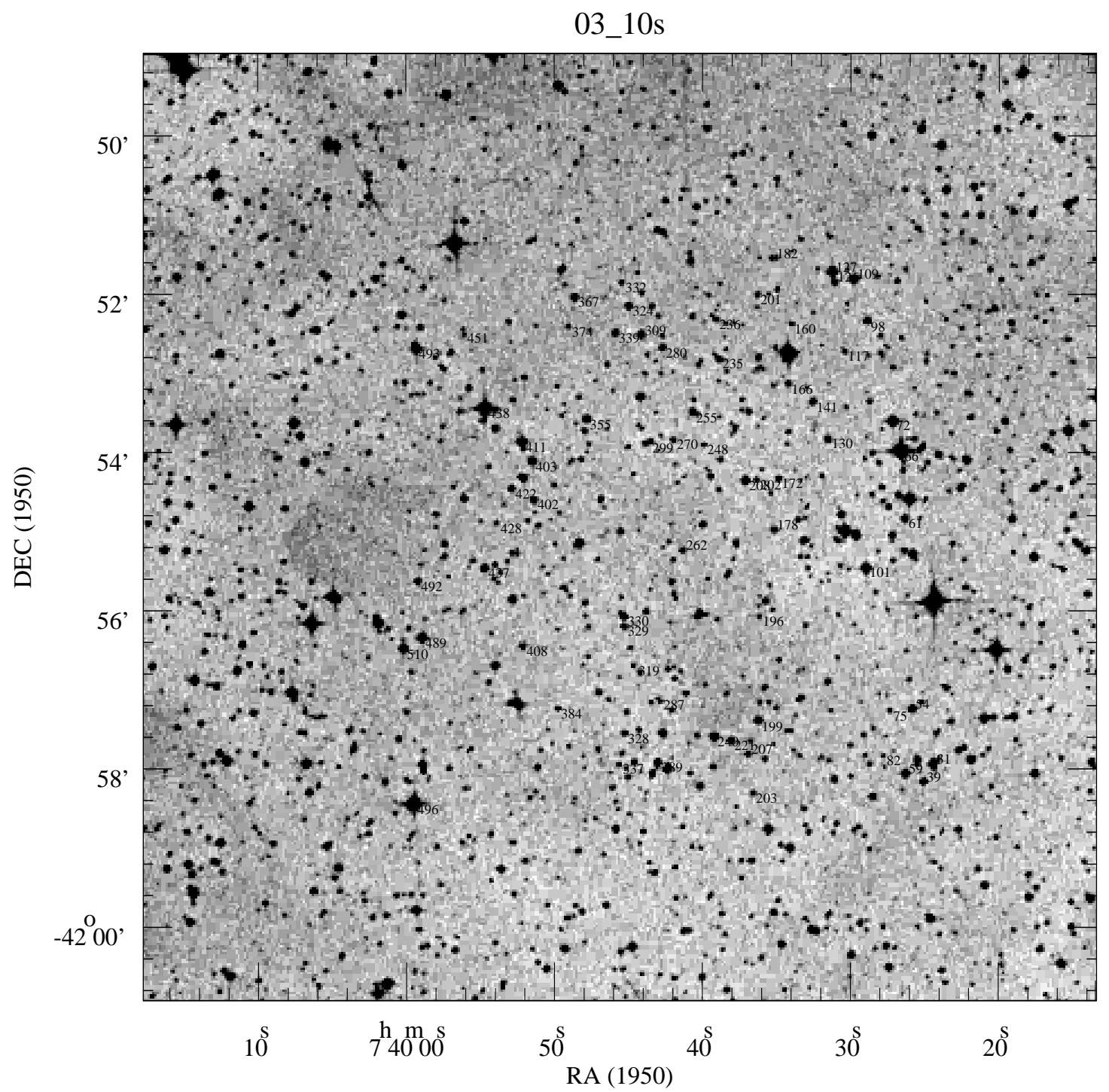

Figura E.3 Finding Chart do Campo 03 centrado em $\mathrm{AR}_{1950}=07 \mathrm{~h} 39^{\mathrm{m}} 45.6^{\mathrm{s}}, \mathrm{DEC}_{1950}=-41^{\circ} 54^{\prime} 57^{\prime \prime}$ 
Tabela E.4 Dados polarimétricos do Campo 04

\begin{tabular}{|c|c|c|c|c|c|}
\hline \multirow[t]{2}{*}{ ID } & $\operatorname{AR}(1950.00)$ & DEC (1950.00) & \multirow{2}{*}{$\begin{array}{c}P_{\mathrm{V}} \\
\left(\frac{8}{\%}\right)\end{array}$} & \multirow{2}{*}{$\begin{array}{l}\sigma P_{\mathrm{V}} \\
\left(\frac{\circ}{6}\right)\end{array}$} & \multirow{2}{*}{$\begin{array}{c}\theta \\
\left({ }^{\circ}\right)\end{array}$} \\
\hline & $(\mathrm{h}: \mathrm{m}: \mathrm{s})$ & $\left({ }^{\circ}:{ }^{\prime}: " \prime\right)$ & & & \\
\hline 4 & $7: 41: 11.16$ & $-42: 10: 13.89$ & 3.483 & 0.034 & 100.4 \\
\hline 13 & $7: 41: 11.89$ & $-42: 14: 30.64$ & 1.036 & 0.015 & 114.2 \\
\hline 17 & $7: 41: 12.76$ & $-42: 09: 50.98$ & 2.521 & 0.024 & 87.5 \\
\hline 19 & $7: 41: 12.79$ & $-42: 12: 51.99$ & 3.458 & 0.04 & 95.5 \\
\hline $22^{\mathrm{a}}$ & $7: 41: 13.10$ & $-42: 15: 35.90$ & 0.355 & 0.015 & 154.1 \\
\hline 23 & $7: 41: 13.26$ & $-42: 15: 28.00$ & 1.113 & 0.039 & 69.4 \\
\hline 24 & $7: 41: 13.39$ & $-42: 14: 26.53$ & 1.657 & 0.018 & 100.2 \\
\hline 33 & $7: 41: 14.20$ & $-42: 10: 38.86$ & 3.583 & 0.052 & 97.4 \\
\hline 37 & $7: 41: 14.68$ & $-42: 10: 02.53$ & 2.983 & 0.044 & 98.1 \\
\hline 40 & $7: 41: 14.78$ & $-42: 10: 49.26$ & 2.905 & 0.015 & 94.3 \\
\hline $44^{b}$ & $7: 41: 15.23$ & $-42: 15: 31.13$ & 1.233 & 0.016 & 108.3 \\
\hline 45 & $7: 41: 15.23$ & $-42: 15: 31.09$ & 3.092 & 0.166 & 96.8 \\
\hline 53 & $7: 41: 16.25$ & $-42: 09: 38.58$ & 1.366 & 0.023 & 46.3 \\
\hline 56 & $7: 41: 16.60$ & $-42: 13: 42.11$ & 2.303 & 0.056 & 94.1 \\
\hline $66^{c}$ & $7: 41: 17.50$ & $-42: 15: 54.30$ & 2.238 & 0.004 & 106. \\
\hline 69 & $7: 41: 17.93$ & $-42: 14: 21.01$ & 0.648 & 0.018 & 60.5 \\
\hline 73 & $7: 41: 18.40$ & $-42: 15: 46.90$ & 0.585 & 0.041 & 144.3 \\
\hline $80^{d}$ & $7: 41: 19.37$ & $-42: 14: 49.25$ & 1.094 & 0.008 & 79.8 \\
\hline 86 & $7: 41: 20.00$ & $-42: 10: 33.95$ & 2.138 & 0.031 & 85.2 \\
\hline 97 & $7: 41: 21.51$ & $-42: 11: 19.17$ & 2.41 & 0.052 & 106.8 \\
\hline 98 & $7: 41: 21.61$ & $-42: 16: 20.50$ & 1.777 & 0.101 & 85.3 \\
\hline 102 & $7: 41: 21.95$ & $-42: 13: 44.20$ & 1.804 & 0.024 & 82.2 \\
\hline 104 & $7: 41: 22.56$ & $-42: 11: 37.97$ & 3.254 & 0.216 & 92.8 \\
\hline 106 & $7: 41: 22.89$ & $-42: 14: 01.21$ & 2.188 & 0.037 & 101.4 \\
\hline 131 & $7: 41: 26.58$ & $-42: 09: 49.74$ & 1.092 & 0.036 & 42.8 \\
\hline 145 & $7: 41: 27.86$ & $-42: 13: 10.96$ & 3.214 & 0.017 & 106.5 \\
\hline 148 & $7: 41: 28.33$ & $-42: 13: 56.56$ & 2.561 & 0.07 & 82.3 \\
\hline 150 & $7: 41: 28.53$ & $-42: 10: 26.38$ & 0.816 & 0.011 & 15.4 \\
\hline 157 & $7: 41: 29.60$ & $-42: 16: 23.03$ & 2.209 & 0.098 & 109.4 \\
\hline 164 & $7: 41: 30.80$ & $-42: 15: 04.86$ & 1.11 & 0.016 & 119.5 \\
\hline 173 & $7: 41: 31.44$ & $-42: 15: 54.84$ & 2.15 & 0.03 & 105.6 \\
\hline 174 & $7: 41: 31.48$ & $-42: 12: 07.50$ & 0.582 & 0.011 & 99.6 \\
\hline 176 & $7: 41: 31.66$ & $-42: 15: 25.60$ & 2.662 & 0.058 & 116.9 \\
\hline 184 & $7: 41: 33.13$ & $-42: 15: 41.40$ & 1.984 & 0.007 & 116.3 \\
\hline 201 & $7: 41: 35.13$ & $-42: 15: 07.10$ & 0.836 & 0.039 & 75.9 \\
\hline 220 & $7: 41: 37.24$ & $-42: 09: 50.68$ & 0.19 & 0.002 & 61.5 \\
\hline 221 & $7: 41: 37.33$ & $-42: 15: 15.97$ & 3.485 & 0.05 & 79.8 \\
\hline 223 & $7: 41: 37.69$ & $-42: 15: 20.15$ & 1.465 & 0.028 & 91.1 \\
\hline 224 & $7: 41: 37.79$ & $-42: 15: 55.93$ & 2.495 & 0.031 & 92.1 \\
\hline 225 & $7: 41: 38.28$ & $-42: 16: 39.72$ & 1.23 & 0.014 & 93.6 \\
\hline 232 & $7: 41: 38.76$ & $-42: 12: 24.30$ & 1.059 & 0.021 & 38.1 \\
\hline 243 & $7: 41: 40.13$ & $-42: 10: 19.15$ & 1.372 & 0.087 & 29.2 \\
\hline 258 & $7: 41: 41.84$ & $-42: 10: 34.20$ & 0.775 & 0.012 & 23.4 \\
\hline 265 & $7: 41: 43.03$ & $-42: 11: 58.48$ & 0.322 & 0.003 & 48.3 \\
\hline 278 & $7: 41: 44.22$ & $-42: 11: 09.56$ & 2.255 & 0.072 & 37. \\
\hline 279 & $7: 41: 44.29$ & $-42: 13: 01.79$ & 1.818 & 0.08 & 51.8 \\
\hline 285 & $7: 41: 45.03$ & $-42: 14: 15.39$ & 2.523 & 0.251 & 97.9 \\
\hline 288 & $7: 41: 45.03$ & $-42: 11: 22.93$ & 1.221 & 0.078 & 76.1 \\
\hline 292 & $7: 41: 45.48$ & $-42: 11: 07.34$ & 1.533 & 0.133 & 36.1 \\
\hline 294 & $7: 41: 45.86$ & $-42: 12: 07.38$ & 2.148 & 0.074 & 41.1 \\
\hline 302 & $7: 41: 46.74$ & $-42: 10: 24.88$ & 2.053 & 0.176 & 38. \\
\hline 305 & $7: 41: 47.03$ & $-42: 12: 05.75$ & 1.881 & 0.002 & 39.7 \\
\hline 306 & $7: 41: 47.07$ & $-42: 12: 18.93$ & 3.364 & 0.067 & 32.4 \\
\hline 309 & $7: 41: 47.41$ & $-42: 14: 06.32$ & 1.363 & 0.023 & 60.2 \\
\hline 311 & $7: 41: 47.64$ & $-42: 11: 21.42$ & 1.992 & 0.135 & 37. \\
\hline 316 & $7: 41: 47.66$ & $-42: 11: 21.59$ & 0.262 & 0.01 & 50.5 \\
\hline 322 & $7: 41: 48.15$ & $-42: 10: 30.23$ & 1.878 & 0.087 & 53.2 \\
\hline 324 & $7: 41: 48.27$ & $-42: 14: 38.44$ & 3.214 & 0.205 & 90. \\
\hline 333 & $7: 41: 48.82$ & $-42: 10: 22.33$ & 2.248 & 0.135 & 30.5 \\
\hline
\end{tabular}

a mesmo objeto na Tabela D.12 com ID $=212$

${ }^{b}$ mesmo objeto na Tabela D.12 com ID $=224$

mesmo objeto na Tabela D.12 com ID $=244$
d mesmo objeto na Tabela D.12 com ID $=253$ 


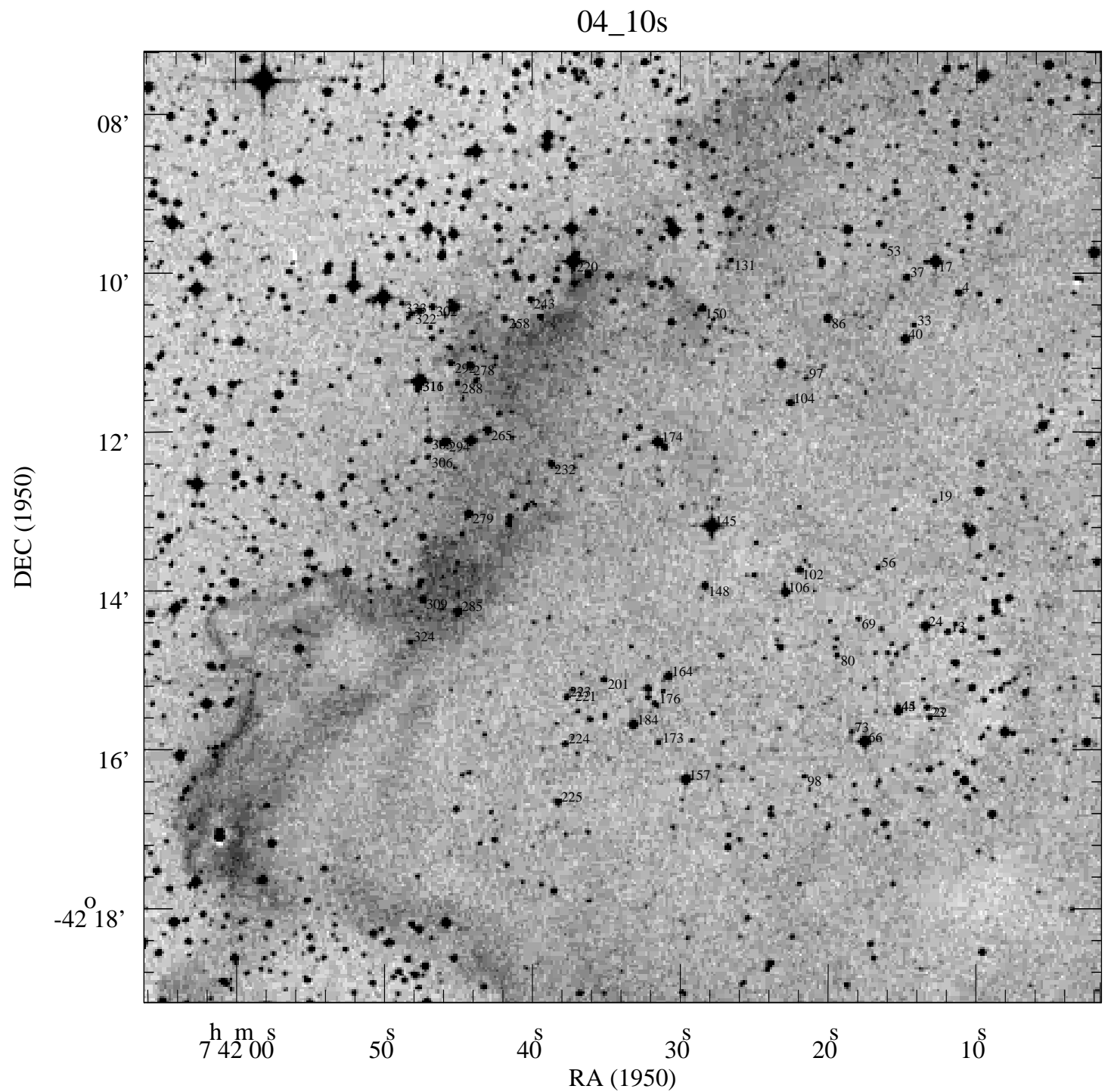

Figura E.4 Finding Chart do Campo 04 centrado em $\mathrm{AR}_{1950}=07^{\mathrm{h}} 41^{\mathrm{m}} 33.9^{\mathrm{s}}, \mathrm{DEC}_{1950}=-42^{\circ} 13^{\prime} 12^{\prime \prime}$ 
Tabela E.5 Dados polarimétricos do Campo 05

\begin{tabular}{|c|c|c|c|c|c|}
\hline ID & $\begin{array}{c}\operatorname{AR}(1950.00) \\
(\mathrm{h}: \mathrm{m}: \mathrm{s})\end{array}$ & $\operatorname{DEC}(1950.00)$ & $\begin{array}{l}P_{\mathrm{V}} \\
\left(\frac{\mathrm{o}}{0}\right)\end{array}$ & $\begin{array}{l}\sigma P_{\mathrm{V}} \\
\left(\frac{\circ}{0}\right)\end{array}$ & $\theta$ \\
\hline 8 & $7: 37: 03.01$ & $-41: 26: 29.08$ & 2.608 & 0.018 & $\frac{1}{41.5}$ \\
\hline 10 & $7: 37: 03.39$ & $-41: 30: 27.42$ & 2.999 & 0.078 & 35.4 \\
\hline 13 & $7: 37: 03.49$ & $-41: 32: 16.66$ & 1.307 & 0.017 & 23. \\
\hline 15 & $7: 37: 03.96$ & $-41: 29: 07.18$ & 3.306 & 0.164 & 34.8 \\
\hline 16 & $7: 37: 04.06$ & $-41: 29: 57.28$ & 2.998 & 0.023 & 37.2 \\
\hline 18 & $7: 37: 04.06$ & $-41: 33: 19.85$ & 0.644 & 0.02 & 60.9 \\
\hline 22 & $7: 37: 04.90$ & $-41: 31: 08.54$ & 2.393 & 0.134 & 39.1 \\
\hline 31 & $7: 37: 05.78$ & $-41: 30: 46.63$ & 2.351 & 0.071 & 37.5 \\
\hline 47 & $7: 37: 07.75$ & $-41: 28: 48.44$ & 3.055 & 0.002 & 42.8 \\
\hline 48 & $7: 37: 07.79$ & $-41: 29: 50.37$ & 3.565 & 0.239 & 36.4 \\
\hline 51 & $7: 37: 07.89$ & $-41: 32: 53.81$ & 1.257 & 0.036 & 41.6 \\
\hline 53 & $7: 37: 08.13$ & $-41: 33: 20.06$ & 1.528 & 0.068 & 39.2 \\
\hline 58 & $7: 37: 08.92$ & $-41: 26: 56.00$ & 2.464 & 0.099 & 35. \\
\hline 62 & $7: 37: 08.97$ & $-41: 31: 23.69$ & $\begin{array}{l}2.404 \\
1.44\end{array}$ & 0.041 & 31.5 \\
\hline 66 & $7: 37: 09.56$ & $-41: 29: 35.03$ & 3.061 & 0.113 & 40. \\
\hline 78 & $7: 37: 10.97$ & $-41: 28: 42.97$ & 3.358 & 0.044 & 54.1 \\
\hline 83 & $7: 37: 11.49$ & $-41: 31: 13.88$ & 2.236 & 0.169 & 43.2 \\
\hline 90 & $7: 37: 13.11$ & $-41: 29: 43.12$ & 3.123 & 0.038 & 43.4 \\
\hline 91 & $7: 37: 13.49$ & $-41: 27: 01.26$ & 3.84 & 0.039 & 41.9 \\
\hline 94 & $7: 37: 13.58$ & $-41: 31: 45.87$ & 1.813 & 0.002 & 45.8 \\
\hline 98 & $7: 37: 14.01$ & $-41: 30: 17.71$ & 2.641 & 0.083 & 46.9 \\
\hline 103 & $7: 37: 14.34$ & $-41: 30: 19.78$ & 2.463 & 0.107 & 41.6 \\
\hline 108 & $7: 37: 14.93$ & $-41: 29: 15.90$ & 3.107 & 0.075 & 46.1 \\
\hline 114 & $7: 37: 15.41$ & $-41: 30: 06.83$ & 0.809 & 0.023 & 14.4 \\
\hline 117 & $7: 37: 15.58$ & $-41: 27: 33.86$ & 3.296 & 0.035 & 43.5 \\
\hline 125 & $7: 37: 15.77$ & $-41: 32: 30.37$ & 1.724 & 0.024 & 32.8 \\
\hline 131 & $7: 37: 16.92$ & $-41: 27: 04.57$ & 3.603 & 0.338 & 44.2 \\
\hline 133 & $7: 37: 16.97$ & $-41: 32: 10.62$ & 2.389 & 0.111 & 30.7 \\
\hline 139 & $7: 37: 18.02$ & $-41: 31: 28.49$ & 2.281 & 0.145 & 25.8 \\
\hline 147 & $7: 37: 18.78$ & $-41: 33: 12.87$ & $\begin{array}{l}2.201 \\
1.004\end{array}$ & 0.091 & $\begin{array}{l}23.0 \\
37.7\end{array}$ \\
\hline 148 & $7: 37: 19.06$ & $-41: 31: 06.80$ & 1.822 & 0.014 & 28 \\
\hline 150 & $7: 37: 19.23$ & $-41: 30: 25.57$ & 2.58 & 0.006 & 43. \\
\hline 155 & $7: 37: 19.88$ & $-41: 29: 36.35$ & 2.852 & 0.01 & 38. \\
\hline 158 & $7: 37: 20.87$ & $-41: 27: 27.38$ & 4.345 & 0.143 & 42.4 \\
\hline 159 & $7: 37: 20.78$ & $-41: 31: 37.41$ & 2.81 & 0.204 & 33.3 \\
\hline 163 & $7: 37: 20.88$ & $-41: 31: 46.11$ & $\begin{array}{l}2.01 \\
1.781\end{array}$ & 0.101 & 49.6 \\
\hline 166 & $7: 37: 21.11$ & $-41: 27: 58.82$ & 3.612 & 0.008 & 43.2 \\
\hline 168 & $7: 37: 21.16$ & $-41: 32: 11.50$ & 1.593 & 0.003 & 39.9 \\
\hline 175 & $7: 37: 22.47$ & $-41: 26: 31.68$ & 3.751 & 0.032 & 42. \\
\hline 179 & $7: 37: 23.48$ & $-41: 31: 44.08$ & 1.875 & 0.15 & 45.2 \\
\hline 181 & $7: 37: 23.64$ & $-41: 30: 49.48$ & $\begin{array}{l}1.013 \\
1.448\end{array}$ & 0.035 & 47.8 \\
\hline 182 & $7: 37: 23.79$ & $-41: 28: 00.05$ & 3.086 & 0.237 & 39.8 \\
\hline 184 & $7: 37: 23.92$ & $-41: 28: 20.97$ & 4.557 & 0.012 & 41.7 \\
\hline 187 & $7: 37: 24.10$ & $-41: 26: 44.42$ & 1.943 & 0.095 & 48.1 \\
\hline 189 & $7: 37: 24.31$ & $-41: 32: 28.93$ & 1.077 & 0.017 & 36.3 \\
\hline 191 & $7: 37: 24.60$ & $-41: 30: 44.07$ & 1.585 & 0.043 & 43.7 \\
\hline 194 & $7: 37: 24.97$ & $-41: 27: 54.05$ & 2.694 & 0.024 & 22.3 \\
\hline 211 & $7: 37: 27.04$ & $-41: 26: 55.91$ & 3.409 & 0.122 & 32.5 \\
\hline 212 & $7: 37: 26.88$ & $-41: 32: 40.50$ & 1.32 & 0.017 & 35.1 \\
\hline 213 & $7: 37: 27.04$ & $-41: 26: 55.91$ & 3.388 & 0.164 & 44.9 \\
\hline 220 & $7: 37: 27.61$ & $-41: 27: 46.48$ & 3.95 & 0.092 & 43. \\
\hline 222 & $7: 37: 27.65$ & $-41: 32: 50.48$ & $\begin{array}{l}5.008 \\
1.508\end{array}$ & 0.04 & 37. \\
\hline 224 & $7: 37: 27.96$ & $-41: 32: 29.05$ & 1.52 & 0.095 & 42. \\
\hline 228 & $7: 37: 28.19$ & $-41: 32: 47.01$ & 1.522 & 0.111 & 35.6 \\
\hline 231 & $7: 37: 28.47$ & $-41: 30: 14.08$ & $\begin{array}{l}1.916 \\
1.916\end{array}$ & 0.05 & 47.5 \\
\hline 235 & $7: 37: 28.54$ & $-41: 31: 02.13$ & 2.296 & 0.023 & 46.3 \\
\hline 242 & $7: 37: 29.22$ & $-41: 29: 40.32$ & 2.196 & 0.19 & 52.6 \\
\hline 252 & $7: 37: 31.02$ & $-41: 31: 39.14$ & 1.834 & 0.032 & 35.1 \\
\hline 255 & $7: 37: 31.15$ & $-41: 30: 34.07$ & 2.849 & 0.004 & 46.7 \\
\hline 266 & $7: 37: 32.28$ & $-41: 31: 13.07$ & 1.813 & 0.116 & 36.3 \\
\hline 267 & $7: 37: 32.36$ & $-41: 28: 50.50$ & 2.513 & 0.141 & 23.6 \\
\hline 271 & $7: 37: 32.57$ & $-41: 32: 42.74$ & 1.27 & 0.058 & 42.6 \\
\hline 274 & $7: 37: 32.97$ & $-41: 31: 58.02$ & 2.621 & 0.261 & 42.8 \\
\hline 281 & $7: 37: 33.96$ & $-41: 26: 39.80$ & 3.738 & 0.008 & 32.5 \\
\hline 284 & $7: 37: 34.39$ & $-41: 27: 18.84$ & 2.7 & 0.093 & 29.8 \\
\hline 286 & $7: 37: 35.03$ & $-41: 28: 38.51$ & 2.695 & 0.033 & 35.8 \\
\hline 289 & $7: 37: 35.25$ & $-41: 26: 41.62$ & 2.86 & 0.073 & 37.5 \\
\hline 292 & $7: 37: 35.36$ & $-41: 29: 30.58$ & 3.026 & 0.014 & 39.2 \\
\hline 302 & $7: 37: 36.59$ & $-41: 28: 33.89$ & 2.966 & 0.016 & 29.4 \\
\hline 304 & $7: 37: 36.63$ & $-41: 32: 28.35$ & 1.519 & 0.003 & 37.6 \\
\hline 307 & $7: 37: 37.06$ & $-41: 28: 49.16$ & 3.541 & 0.02 & 38.9 \\
\hline 318 & $7: 37: 37.81$ & $-41: 32: 27.73$ & $\begin{array}{l}3.041 \\
1.092\end{array}$ & 0.08 & 29. \\
\hline 319 & $7: 37: 38.16$ & $-41: 30: 05.47$ & 1.553 & 0.016 & 39.8 \\
\hline 328 & $7: 37: 39.03$ & $-41: 30: 20.38$ & 2.045 & 0.099 & 40.6 \\
\hline 331 & $7: 37: 39.25$ & $-41: 28: 00.37$ & 4.956 & 0.446 & 40. \\
\hline 336 & $7: 37: 39.31$ & $-41: 32: 05.80$ & 0.731 & 0.05 & 23. \\
\hline
\end{tabular}




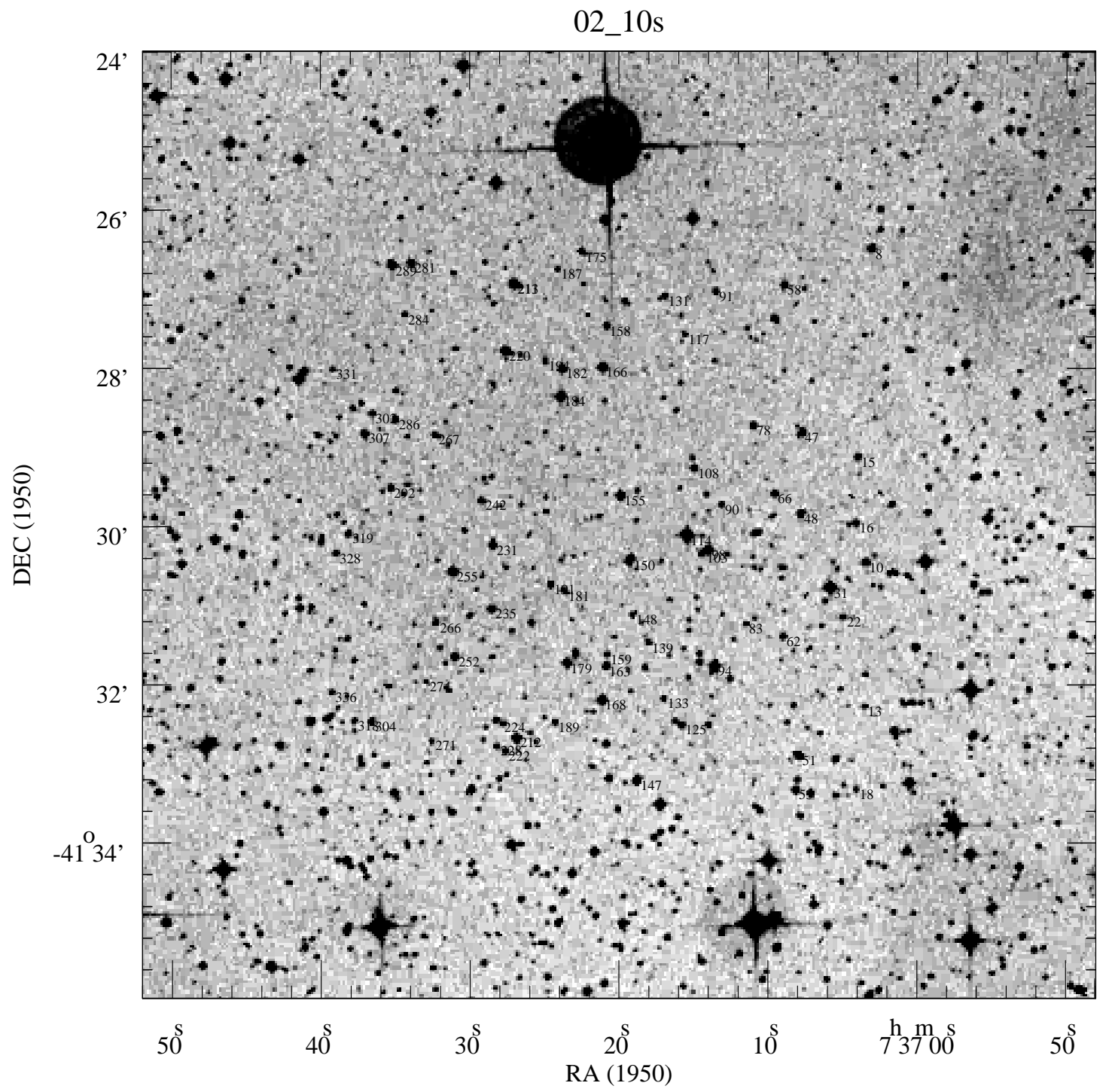

Figura E.5 Finding Chart do Campo 05 centrado em $\mathrm{AR}_{1950}=07 \mathrm{~h} 37^{\mathrm{m}} 20^{\mathrm{s}}, \mathrm{DEC}_{1950}=-41^{\circ} 29^{\prime} 59^{\prime \prime}$ 
Tabela E.6 Dados polarimétricos do Campo 06

\begin{tabular}{|c|c|c|c|c|c|}
\hline \multirow[t]{2}{*}{ ID } & $\operatorname{AR}(1950.00)$ & $\operatorname{DEC}(1950.00)$ & \multirow{2}{*}{$\begin{array}{c}P_{\mathrm{V}} \\
(\%)\end{array}$} & \multirow{2}{*}{$\begin{array}{l}\sigma P_{\mathrm{V}} \\
\left(\frac{\circ}{0}\right)\end{array}$} & \multirow{2}{*}{$\begin{array}{c}\theta \\
\left({ }^{\circ}\right)\end{array}$} \\
\hline & $(\mathrm{h}: \mathrm{m}: \mathrm{s})$ & $\left({ }^{\circ}:{ }^{\prime}: "{ }^{\prime \prime}\right)$ & & & \\
\hline 7 & $7: 37: 34.93$ & $-41: 25: 01.11$ & 2.151 & 0.187 & 20.2 \\
\hline 12 & $7: 37: 36.06$ & $-41: 20: 17.92$ & 1.646 & 0.088 & 177.2 \\
\hline 14 & $7: 37: 36.45$ & $-41: 24: 54.22$ & 2.127 & 0.022 & 21.5 \\
\hline 21 & $7: 37: 36.93$ & $-41: 20: 27.26$ & 1.76 & 0.104 & 4.6 \\
\hline 27 & $7: 37: 37.65$ & $-41: 18: 37.20$ & 2.572 & 0.085 & 22.5 \\
\hline 29 & $7: 37: 38.06$ & $-41: 20: 07.86$ & 1.002 & 0.01 & 21. \\
\hline 30 & $7: 37: 38.71$ & $-41: 19: 27.09$ & 1.548 & 0.064 & 29. \\
\hline 31 & $7: 37: 38.57$ & $-41: 24: 14.27$ & 1.642 & 0.008 & 20.8 \\
\hline 41 & $7: 37: 39.41$ & $-41: 21: 39.76$ & 2.275 & 0.024 & 1.2 \\
\hline 44 & $7: 37: 39.70$ & $-41: 23: 52.67$ & 1.316 & 0.015 & 27.9 \\
\hline 56 & $7: 37: 41.25$ & $-41: 18: 43.90$ & 1.167 & 0.036 & 13. \\
\hline 61 & $7: 37: 41.45$ & $-41: 25: 21.67$ & 2.636 & 0.052 & 32.6 \\
\hline 63 & $7: 37: 41.76$ & $-41: 20: 51.02$ & 1.574 & 0.156 & 6.3 \\
\hline 69 & $7: 37: 42.50$ & $-41: 21: 31.72$ & 1.729 & 0.002 & 8.3 \\
\hline 75 & $7: 37: 43.59$ & $-41: 18: 29.90$ & 0.726 & 0.053 & 45.1 \\
\hline 86 & $7: 37: 44.33$ & $-41: 18: 57.14$ & 1.648 & 0.021 & 25.4 \\
\hline 102 & $7: 37: 46.02$ & $-41: 21: 28.51$ & 2.212 & 0.086 & 173.2 \\
\hline 105 & $7: 37: 46.15$ & $-41: 25: 07.55$ & 2.843 & 0.009 & 25.5 \\
\hline 106 & $7: 37: 46.43$ & $-41: 24: 18.71$ & 3.05 & 0.041 & 21.5 \\
\hline 118 & $7: 37: 48.30$ & $-41: 22: 47.95$ & 3.728 & 0.026 & 172.1 \\
\hline 124 & $7: 37: 48.66$ & $-41: 24: 19.10$ & 2.148 & 0.008 & 22.7 \\
\hline 126 & $7: 37: 48.96$ & $-41: 24: 44.07$ & 1.992 & 0.1 & 22.9 \\
\hline 131 & $7: 37: 49.35$ & $-41: 23: 24.98$ & 2.523 & 0.162 & 13.6 \\
\hline 135 & $7: 37: 49.74$ & $-41: 24: 04.49$ & 2.728 & 0.203 & 18.3 \\
\hline 144 & $7: 37: 51.09$ & $-41: 24: 31.77$ & 2.364 & 0.023 & 13. \\
\hline 145 & $7: 37: 51.63$ & $-41: 19: 31.27$ & 0.979 & 0.009 & 169.2 \\
\hline 149 & $7: 37: 51.79$ & $-41: 24: 23.73$ & 2.908 & 0.153 & 9.1 \\
\hline 154 & $7: 37: 52.16$ & $-41: 22: 18.15$ & 2.262 & 0.013 & 4.7 \\
\hline 156 & $7: 37: 52.10$ & $-41: 25: 18.28$ & 1.657 & 0.108 & 10.8 \\
\hline 160 & $7: 37: 52.32$ & $-41: 21: 54.15$ & 1.766 & 0.174 & 16. \\
\hline 164 & $7: 37: 52.47$ & $-41: 22: 43.13$ & 1.75 & 0.035 & 2.9 \\
\hline 179 & $7: 37: 54.26$ & $-41: 22: 39.41$ & 1.772 & 0.17 & 5.1 \\
\hline 182 & $7: 37: 54.74$ & $-41: 21: 48.95$ & 2.047 & 0.013 & 13.1 \\
\hline 187 & $7: 37: 55.78$ & $-41: 21: 05.76$ & 1.645 & 0.011 & 2.3 \\
\hline 192 & $7: 37: 56.15$ & $-41: 25: 01.04$ & 1.555 & 0.077 & 38.7 \\
\hline 194 & $7: 37: 56.39$ & $-41: 20: 56.36$ & 2.106 & 0.009 & 174.7 \\
\hline 197 & $7: 37: 57.14$ & $-41: 22: 04.28$ & 2.761 & 0.014 & 14.3 \\
\hline 201 & $7: 37: 57.13$ & $-41: 22: 45.00$ & 1.699 & 0.078 & 12.5 \\
\hline 202 & $7: 37: 57.29$ & $-41: 19: 16.07$ & 2.082 & 0.064 & 162.7 \\
\hline 204 & $7: 37: 57.44$ & $-41: 25: 04.45$ & 1.457 & 0.017 & 37.8 \\
\hline 214 & $7: 38: 00.00$ & $-41: 22: 02.57$ & 3.687 & 0.002 & 6.6 \\
\hline 229 & $7: 38: 01.12$ & $-41: 23: 58.26$ & 1.257 & 0.059 & 19.9 \\
\hline 231 & $7: 38: 01.80$ & $-41: 20: 56.92$ & 1.856 & 0.013 & 6.5 \\
\hline 236 & $7: 38: 01.84$ & $-41: 20: 57.31$ & 1.75 & 0.031 & 6.3 \\
\hline 241 & $7: 38: 02.01$ & $-41: 22: 25.12$ & 2.096 & 0.05 & 0.8 \\
\hline 243 & $7: 38: 02.12$ & $-41: 24: 16.37$ & 1.034 & 0.09 & 173.9 \\
\hline 248 & $7: 38: 02.57$ & $-41: 21: 27.74$ & 2.44 & 0.01 & 179.5 \\
\hline 252 & $7: 38: 03.09$ & $-41: 25: 25.13$ & 0.8 & 0.003 & 12.9 \\
\hline 256 & $7: 38: 03.45$ & $-41: 22: 08.21$ & 1.6 & 0.022 & 8. \\
\hline 260 & $7: 38: 03.75$ & $-41: 21: 53.21$ & 2.769 & 0.148 & 1.3 \\
\hline 264 & $7: 38: 04.37$ & $-41: 25: 12.69$ & 0.397 & 0.007 & 91. \\
\hline 265 & $7: 38: 04.64$ & $-41: 19: 04.05$ & 1.015 & 0.065 & 50.8 \\
\hline 267 & $7: 38: 05.23$ & $-41: 18: 47.12$ & 1.231 & 0.029 & 25.2 \\
\hline 268 & $7: 38: 05.08$ & $-41: 20: 16.28$ & 0.711 & 0.007 & 19.6 \\
\hline 273 & $7: 38: 05.55$ & $-41: 23: 44.08$ & 1.567 & 0.038 & 170.9 \\
\hline 278 & $7: 38: 05.97$ & $-41: 22: 01.66$ & 1.037 & 0.01 & 13.1 \\
\hline 280 & $7: 38: 06.26$ & $-41: 20: 39.86$ & 1.323 & 0.01 & 175.9 \\
\hline 283 & $7: 38: 06.37$ & $-41: 24: 59.92$ & 0.87 & 0.072 & 179.3 \\
\hline 290 & $7: 38: 07.34$ & $-41: 22: 04.72$ & 1.13 & 0.03 & 173.7 \\
\hline 291 & $7: 38: 07.26$ & $-41: 25: 12.56$ & 0.774 & 0.003 & 14.1 \\
\hline 293 & $7: 38: 07.33$ & $-41: 25: 19.38$ & 0.642 & 0.03 & 17.4 \\
\hline 298 & $7: 38: 07.97$ & $-41: 19: 05.72$ & 0.98 & 0.002 & 16. \\
\hline 306 & $7: 38: 08.89$ & $-41: 21: 40.45$ & 1.503 & 0.034 & 170.5 \\
\hline 317 & $7: 38: 09.66$ & $-41: 20: 27.41$ & 0.417 & 0.005 & 80.4 \\
\hline 323 & $7: 38: 09.86$ & $-41: 23: 29.70$ & 2.362 & 0.226 & \\
\hline 325 & $7: 38: 10.42$ & $-41: 19: 32.65$ & 1.237 & 0.004 & 27.5 \\
\hline 328 & $7: 38: 10.44$ & $-41: 23: 21.46$ & 0.627 & 0.017 & 172.7 \\
\hline 340 & $7: 38: 12.01$ & $-41: 19: 21.21$ & 1.349 & 0.106 & 41.1 \\
\hline
\end{tabular}




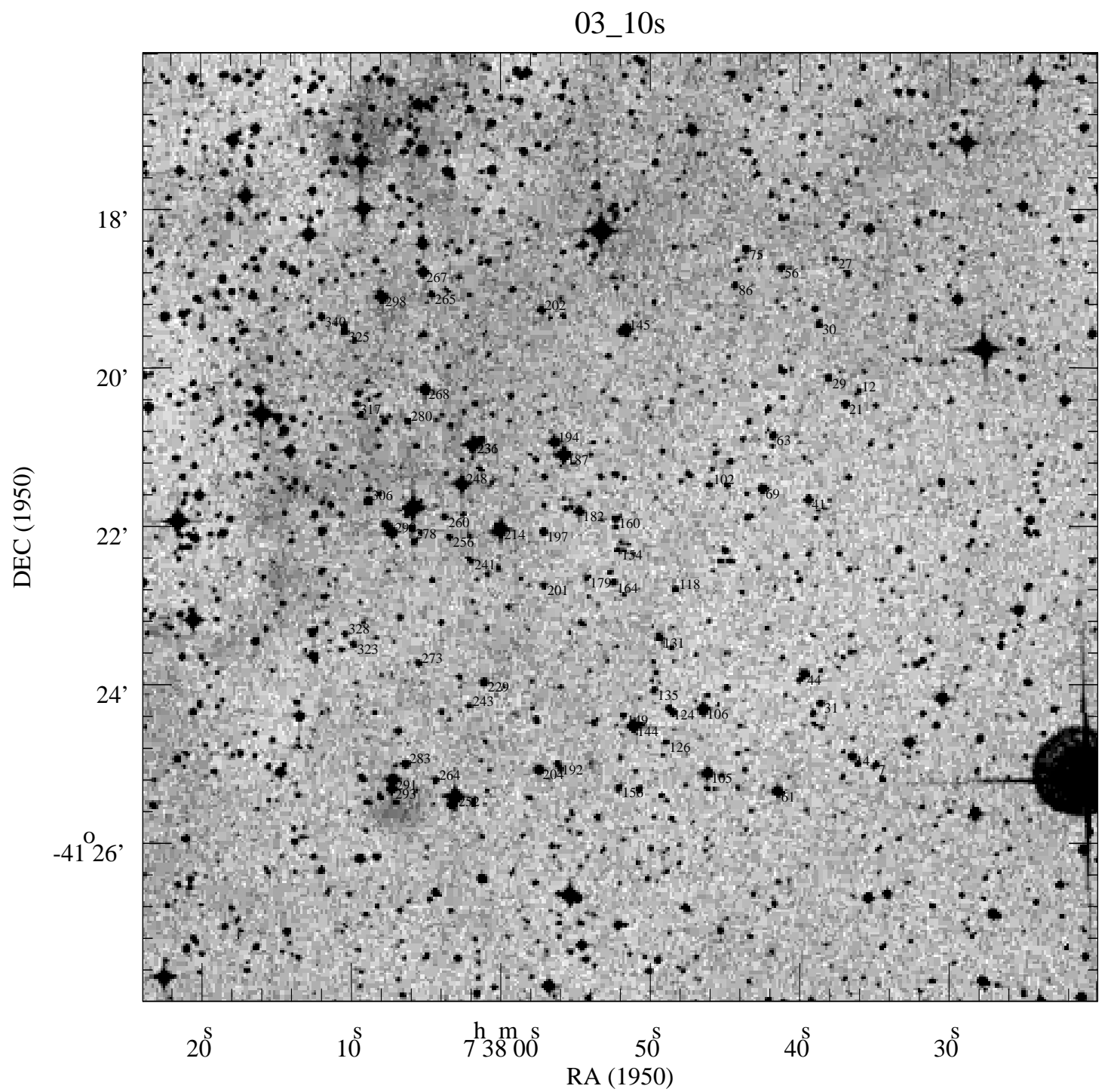

Figura E.6 Finding Chart do Campo 06 centrado em $\mathrm{AR}_{1950}=07 \mathrm{~h} 37 \mathrm{~m} 52^{\mathrm{s}}, \mathrm{DEC}_{1950}=-41^{\circ} 22^{\prime} 01^{\prime \prime}$ 
Tabela E.7 Dados polarimétricos do Campo 07

\begin{tabular}{|c|c|c|c|c|c|}
\hline \multirow[t]{2}{*}{ ID } & $\operatorname{AR}(1950.00)$ & DEC (1950.00) & \multirow{2}{*}{$\begin{array}{l}P_{\mathrm{V}} \\
(\%)\end{array}$} & \multirow{2}{*}{$\begin{array}{l}\sigma P_{\mathrm{V}} \\
\left(\frac{\%}{6}\right)\end{array}$} & \multirow{2}{*}{$\begin{array}{c}\theta \\
\left({ }^{\circ}\right)\end{array}$} \\
\hline & $(\mathrm{h}: \mathrm{m}: \mathrm{s})$ & $\left({ }^{\circ}:{ }^{\prime}: ",\right)$ & & & \\
\hline 25 & $7: 38: 08.60$ & $-41: 28: 47.71$ & 0.505 & 0.001 & \\
\hline 26 & $7: 38: 08.87$ & $-41: 28: 18.56$ & 3.153 & 0.156 & 54.6 \\
\hline 42 & $7: 38: 10.49$ & $-41: 31: 29.31$ & 2.187 & 0.072 & 17. \\
\hline 53 & $7: 38: 12.00$ & $-41: 28: 05.19$ & 1.149 & 0.086 & 10.8 \\
\hline 62 & $7: 38: 13.71$ & $-41: 29: 22.14$ & 3.41 & 0.097 & 24.1 \\
\hline 64 & $7: 38: 14.46$ & $-41: 27: 07.20$ & 2.317 & 0.053 & 22.8 \\
\hline 69 & $7: 38: 14.78$ & $-41: 33: 02.25$ & 2.562 & 0.021 & 8.1 \\
\hline 74 & $7: 38: 15.71$ & $-41: 32: 38.87$ & 2.082 & 0.034 & 9.4 \\
\hline 75 & $7: 38: 16.35$ & $-41: 27: 20.26$ & 2.183 & 0.039 & 20.4 \\
\hline 79 & $7: 38: 16.88$ & $-41: 33: 05.30$ & 2.911 & 0.039 & 25.4 \\
\hline 83 & $7: 38: 17.64$ & $-41: 26: 59.13$ & 3.804 & 0.126 & 6.5 \\
\hline 86 & $7: 38: 18.42$ & $-41: 29: 30.19$ & 4.776 & 0.038 & 25.4 \\
\hline 87 & $7: 38: 18.51$ & $-41: 27: 03.38$ & 4.765 & 0.077 & 0.4 \\
\hline 92 & $7: 38: 19.46$ & $-41: 29: 29.86$ & 4.141 & 0.257 & 22.4 \\
\hline 102 & $7: 38: 20.84$ & $-41: 26: 33.27$ & 2.936 & 0.063 & 174. \\
\hline 104 & $7: 38: 20.90$ & $-41: 28: 27.00$ & 6.373 & 0.063 & 1.3 \\
\hline 107 & $7: 38: 21.12$ & $-41: 27: 19.82$ & 5.086 & 0.195 & 174.8 \\
\hline 110 & $7: 38: 21.44$ & $-41: 28: 48.40$ & 4.946 & 0.215 & 176.5 \\
\hline 111 & $7: 38: 21.59$ & $-41: 26: 32.54$ & 4.3 & 0.344 & 176.7 \\
\hline 112 & $7: 38: 21.76$ & $-41: 30: 39.17$ & 2.947 & 0.031 & 6. \\
\hline 122 & $7: 38: 23.61$ & $-41: 30: 51.68$ & 3.653 & 0.095 & 179.6 \\
\hline 123 & $7: 38: 23.41$ & $-41: 33: 27.85$ & 1.827 & 0.016 & 22.6 \\
\hline 124 & $7: 38: 23.58$ & $-41: 31: 36.52$ & 2.744 & 0.005 & 176. \\
\hline 132 & $7: 38: 25.08$ & $-41: 31: 34.21$ & 2.351 & 0.031 & 178.7 \\
\hline 141 & $7: 38: 26.27$ & $-41: 27: 08.96$ & 5.904 & 0.059 & 172.2 \\
\hline 147 & $7: 38: 26.56$ & $-41: 32: 27.42$ & 3.855 & 0.169 & 9.4 \\
\hline 151 & $7: 38: 27.08$ & $-41: 28: 57.91$ & 5.357 & 0.22 & 165.9 \\
\hline 154 & $7: 38: 27.65$ & $-41: 29: 48.02$ & 4.089 & 0.036 & 176.4 \\
\hline 160 & $7: 38: 28.71$ & $-41: 32: 49.04$ & 2.973 & 0.105 & 1.5 \\
\hline 162 & $7: 38: 28.88$ & $-41: 33: 16.02$ & 3.461 & 0.087 & 170.7 \\
\hline 169 & $7: 38: 29.77$ & $-41: 28: 49.43$ & 6.389 & 0.159 & 165. \\
\hline 173 & $7: 38: 30.29$ & $-41: 27: 22.74$ & 3.083 & 0.044 & 167.9 \\
\hline 176 & $7: 38: 30.63$ & $-41: 31: 33.99$ & 2.243 & 0.078 & 171. \\
\hline 177 & $7: 38: 30.89$ & $-41: 29: 48.74$ & 4.049 & 0.313 & 171.6 \\
\hline 179 & $7: 38: 31.36$ & $-41: 27: 24.60$ & 2.589 & 0.049 & 172.5 \\
\hline 182 & $7: 38: 32.01$ & $-41: 26: 44.92$ & 3.363 & 0.019 & 175.5 \\
\hline 188 & $7: 38: 32.69$ & $-41: 26: 56.85$ & 2.181 & 0.028 & 169.4 \\
\hline 189 & $7: 38: 32.60$ & $-41: 33: 04.25$ & 3.307 & 0.159 & 169.5 \\
\hline 195 & $7: 38: 33.91$ & $-41: 30: 36.72$ & 2.366 & 0.055 & 161. \\
\hline 200 & $7: 38: 34.57$ & $-41: 28: 38.68$ & 2.893 & 0.005 & 151.5 \\
\hline 201 & $7: 38: 34.69$ & $-41: 27: 25.75$ & 2.987 & 0.047 & 166.3 \\
\hline 204 & $7: 38: 34.97$ & $-41: 32: 58.84$ & 3.768 & 0.028 & 164.8 \\
\hline 205 & $7: 38: 35.08$ & $-41: 31: 13.30$ & 3.211 & 0.009 & 162.3 \\
\hline 207 & $7: 38: 35.15$ & $-41: 32: 17.94$ & 4.467 & 0.395 & 166.4 \\
\hline 210 & $7: 38: 35.33$ & $-41: 27: 35.79$ & 2.197 & 0.025 & 0.8 \\
\hline 216 & $7: 38: 36.08$ & $-41: 29: 55.22$ & 2.868 & 0.068 & 160.5 \\
\hline 219 & $7: 38: 36.61$ & $-41: 29: 50.45$ & 2.566 & 0.022 & 160.3 \\
\hline 222 & $7: 38: 37.16$ & $-41: 29: 19.21$ & 3.298 & 0.196 & 164.2 \\
\hline 224 & $7: 38: 37.30$ & $-41: 27: 36.25$ & 1.551 & 0.028 & 168.6 \\
\hline 227 & $7: 38: 37.57$ & $-41: 28: 37.90$ & 1.167 & 0.015 & 175.9 \\
\hline 233 & $7: 38: 37.94$ & $-41: 33: 16.10$ & 3.939 & 0.072 & 167.1 \\
\hline 234 & $7: 38: 38.03$ & $-41: 30: 41.68$ & 3.435 & 0.053 & 161.3 \\
\hline 238 & $7: 38: 38.65$ & $-41: 29: 48.48$ & 2.424 & 0.037 & 151.6 \\
\hline 240 & $7: 38: 38.97$ & $-41: 30: 56.09$ & $\begin{array}{l}2.424 \\
4.741\end{array}$ & 0.091 & 170.7 \\
\hline 246 & $7: 38: 39.48$ & $-41: 30: 10.88$ & 1.794 & 0.065 & 151.4 \\
\hline 252 & $7: 38: 40.03$ & $-41: 28: 54.90$ & 1.237 & 0.04 & 163.6 \\
\hline 256 & $7: 38: 40.46$ & $-41: 33: 23.96$ & 4.1 & 0.075 & 171.7 \\
\hline 258 & $7: 38: 40.50$ & $-41: 31: 32.18$ & 4.198 & 0.373 & 165.2 \\
\hline 259 & $7: 38: 40.77$ & $-41: 27: 17.70$ & 0.361 & 0.021 & 155.6 \\
\hline 260 & $7: 38: 40.67$ & $-41: 32: 57.38$ & 4.385 & 0.067 & 169.9 \\
\hline 266 & $7: 38: 41.40$ & $-41: 28: 52.22$ & 2.385 & 0.037 & 1. \\
\hline
\end{tabular}




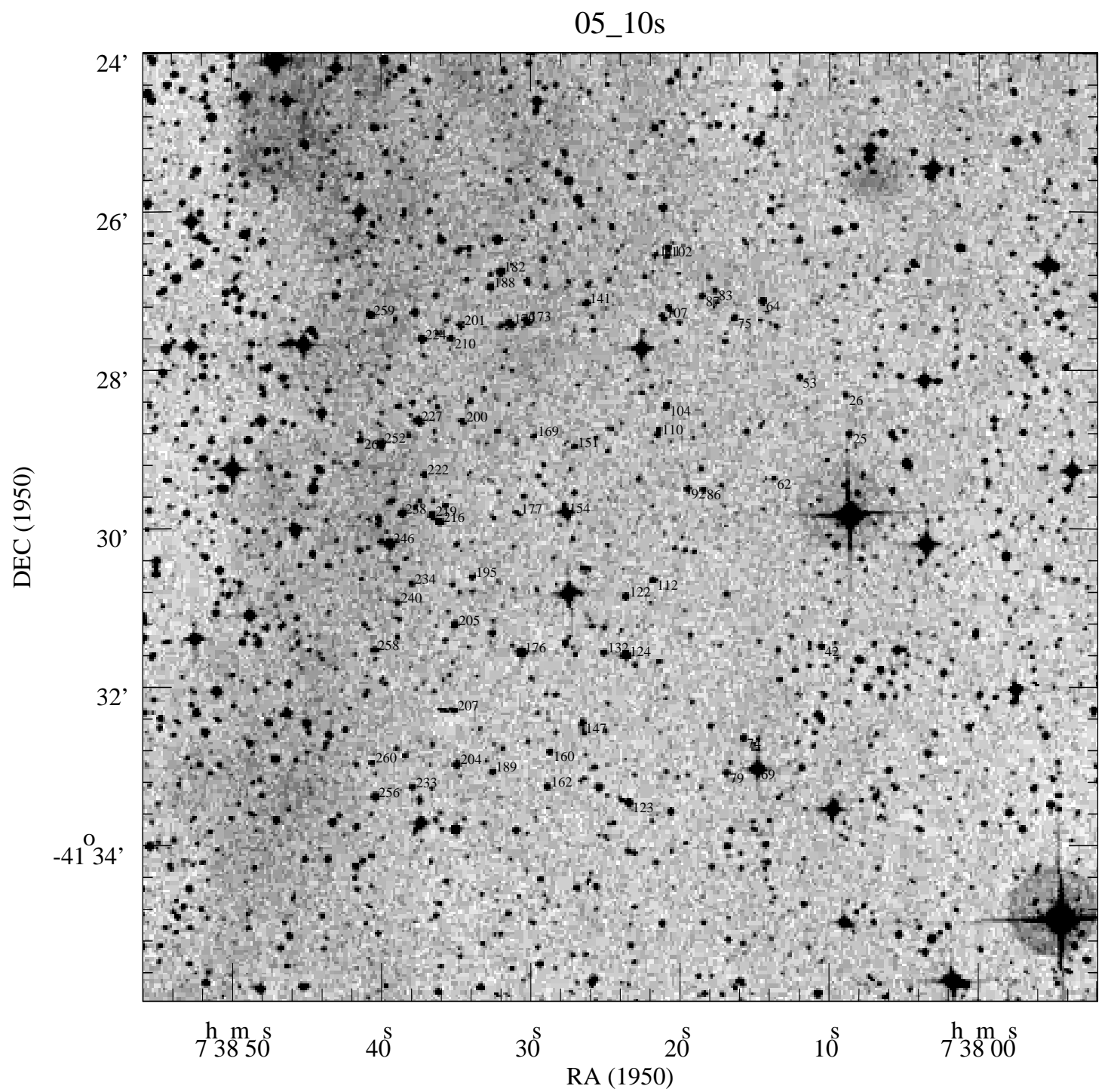

Figura E.7 Finding Chart do Campo 07 centrado em $\mathrm{AR}_{1950}=07 \mathrm{~h} 38^{\mathrm{m}} 24^{\mathrm{s}}, \mathrm{DEC}_{1950}=-41^{\circ} 29^{\prime} 59^{\prime \prime}$ 
Tabela E.8 Dados polarimétricos do Campo 08

\begin{tabular}{|c|c|c|c|c|c|}
\hline ID & $\operatorname{AR}(1950.00)$ & $\operatorname{DEC}(1950.00)$ & $P_{\mathrm{V}}$ & $\sigma P_{\mathrm{V}}$ & $\theta$ \\
\hline & $(\mathrm{h}: \mathrm{m}: \mathrm{s})$ & $\left({ }^{\circ}:,: "\right)$ & (\%) & $(\%)$ & $\left({ }^{\circ}\right)$ \\
\hline 1 & $7: 38: 06.03$ & $-41: 40: 32.53$ & 1.896 & 0.113 & 41.2 \\
\hline 10 & $7: 38: 06.66$ & $-41: 39: 16.44$ & 1.891 & 0.011 & 31.9 \\
\hline 27 & $7: 38: 08.12$ & $-41: 34: 50.52$ & 3.492 & 0.062 & 20.9 \\
\hline 31 & $7: 38: 08.22$ & $-41: 38: 42.84$ & 2.846 & 0.033 & 31.9 \\
\hline 39 & $7: 38: 08.96$ & $-41: 34: 57.99$ & 2.372 & 0.028 & 27.7 \\
\hline 53 & $7: 38: 10.69$ & $-41: 35: 53.52$ & 1.975 & 0.135 & 30.4 \\
\hline 60 & $7: 38: 11.33$ & $-41: 41: 02.44$ & 1.538 & 0.018 & 38.6 \\
\hline 61 & $7: 38: 11.40$ & $-41: 38: 29.89$ & 2.122 & 0.205 & 31.2 \\
\hline 63 & $7: 38: 11.72$ & $-41: 34: 45.53$ & 3.312 & 0.183 & 36.1 \\
\hline 66 & $7: 38: 12.02$ & $-41: 40: 11.51$ & 0.634 & 0.024 & 23.2 \\
\hline 69 & $7: 38: 12.32$ & $-41: 39: 20.38$ & 2.037 & 0.071 & 27. \\
\hline 80 & $7: 38: 13.84$ & $-41: 39: 40.66$ & 1.666 & 0.074 & 21.1 \\
\hline 89 & $7: 38: 15.22$ & $-41: 38: 58.21$ & 2.061 & 0.072 & 34.1 \\
\hline 98 & $7: 38: 15.59$ & $-41: 39: 46.05$ & 1.781 & 0.141 & 42. \\
\hline 99 & $7: 38: 15.97$ & $-41: 35: 43.08$ & 2.047 & 0.128 & 25.8 \\
\hline 107 & $7: 38: 16.42$ & $-41: 39: 41.98$ & 2.473 & 0.149 & 42.4 \\
\hline 109 & $7: 38: 16.74$ & $-41: 35: 11.20$ & 2.244 & 0.086 & 6.5 \\
\hline 111 & $7: 38: 16.75$ & $-41: 39: 17.28$ & 2.947 & 0.088 & 30.4 \\
\hline 112 & $7: 38: 16.74$ & $-41: 38: 46.19$ & 1.566 & 0.075 & 43.5 \\
\hline 122 & $7: 38: 18.35$ & $-41: 35: 54.18$ & 2.004 & 0.125 & 30.6 \\
\hline 126 & $7: 38: 18.72$ & $-41: 35: 40.64$ & 2.239 & 0.069 & 17.6 \\
\hline 130 & $7: 38: 19.25$ & $-41: 37: 33.01$ & 0.829 & 0.019 & 39.5 \\
\hline 132 & $7: 38: 19.21$ & $-41: 39: 26.35$ & 2.497 & 0.156 & 17. \\
\hline 133 & $7: 38: 19.89$ & $-41: 38: 14.20$ & 1.13 & 0.076 & 44.1 \\
\hline 136 & $7: 38: 20.24$ & $-41: 37: 30.02$ & 3.212 & 0.009 & 38.7 \\
\hline 145 & $7: 38: 21.48$ & $-41: 39: 25.35$ & 1.822 & 0.039 & 30.6 \\
\hline 154 & $7: 38: 22.13$ & $-41: 41: 00.81$ & $\begin{array}{l}1.022 \\
1.582\end{array}$ & 0.042 & 32.7 \\
\hline 157 & $7: 38: 22.33$ & $-41: 41: 37.88$ & 1.172 & 0.019 & 48.5 \\
\hline 162 & $7: 38: 23.25$ & $-41: 35: 15.35$ & $\begin{array}{l}1.112 \\
1.763\end{array}$ & 0.018 & $\begin{array}{l}40.0 \\
9.5\end{array}$ \\
\hline 174 & $7: 38: 24.47$ & $-41: 40: 19.60$ & 1.435 & 0.007 & 25.1 \\
\hline 177 & $7: 38: 24.87$ & $-41: 38: 16.59$ & 3.153 & 0.216 & 45.9 \\
\hline 180 & $7: 38: 25.08$ & $-41: 36: 33.07$ & 2.113 & 0.11 & 44. \\
\hline 181 & $7: 38: 25.21$ & $-41: 39: 06.56$ & 2.096 & 0.007 & 37. \\
\hline 186 & $7: 38: 25.53$ & $-41: 38: 31.15$ & 2.436 & 0.068 & 20. \\
\hline 188 & $7: 38: 25.85$ & $-41: 35: 43.16$ & 2.253 & 0.013 & 32.9 \\
\hline 189 & $7: 38: 25.81$ & $-41: 41: 07.79$ & 2.89 & 0.159 & 37.7 \\
\hline 190 & $7: 38: 25.83$ & $-41: 39: 55.70$ & 1.402 & 0.016 & 31.7 \\
\hline 197 & $7: 38: 26.56$ & $-41: 37: 41.91$ & 3.071 & 0.043 & 35.1 \\
\hline 198 & $7: 38: 26.59$ & $-41: 38: 10.76$ & 2.304 & 0.06 & 33.1 \\
\hline 202 & $7: 38: 26.89$ & $-41: 39: 39.49$ & 1.655 & 0.136 & 16. \\
\hline 207 & $7: 38: 27.55$ & $-41: 40: 45.30$ & 2.455 & 0.02 & 57.5 \\
\hline 208 & $7: 38: 27.70$ & $-41: 39: 35.36$ & 2.912 & 0.126 & 22.5 \\
\hline 211 & $7: 38: 29.01$ & $-41: 37: 11.14$ & 2.029 & 0.054 & 33.3 \\
\hline 216 & $7: 38: 29.26$ & $-41: 36: 36.56$ & 1.479 & 0.051 & 26.6 \\
\hline 217 & $7: 38: 29.09$ & $-41: 41: 08.72$ & 1.545 & 0.105 & 33.9 \\
\hline 218 & $7: 38: 29.28$ & $-41: 37: 48.28$ & 2.42 & 0.068 & 36.1 \\
\hline 219 & $7: 38: 29.30$ & $-41: 36: 03.48$ & 1.631 & 0.013 & 19.8 \\
\hline 224 & $7: 38: 29.45$ & $-41: 40: 07.94$ & 1.304 & 0.043 & 28.3 \\
\hline 227 & $7: 38: 29.90$ & $-41: 38: 17.95$ & 1.905 & 0.17 & 36.5 \\
\hline 228 & $7: 38: 30.03$ & $-41: 36: 38.38$ & 2.786 & 0.013 & 37.3 \\
\hline 242 & $7: 38: 31.20$ & $-41: 40: 03.21$ & 1.762 & 0.015 & 34.6 \\
\hline 246 & $7: 38: 31.85$ & $-41: 38: 50.48$ & 2.504 & 0.027 & 36.4 \\
\hline 248 & $7: 38: 31.99$ & $-41: 38: 07.23$ & 3.622 & 0.043 & 26.2 \\
\hline $\begin{array}{l}240 \\
251\end{array}$ & $7: 38: 31.88$ & $-41: 39: 44.90$ & $\begin{array}{l}3.022 \\
1.769\end{array}$ & 0.025 & 26.7 \\
\hline 257 & $7: 38: 32.45$ & $-41: 41: 06.81$ & 1.834 & 0.095 & 23.4 \\
\hline 266 & $7: 38: 33.25$ & $-41: 36: 39.41$ & 3.436 & 0.11 & 30.1 \\
\hline 267 & $7: 38: 33.23$ & $-41: 37: 29.85$ & 1.907 & 0.059 & 34.9 \\
\hline 268 & $7: 38: 33.37$ & $-41: 35: 47.82$ & 1.993 & 0.071 & 29.2 \\
\hline 282 & $7: 38: 34.70$ & $-41: 39: 21.17$ & 2.207 & 0.07 & 35.6 \\
\hline 291 & $7: 38: 36.22$ & $-41: 35: 51.24$ & 3.649 & 0.043 & $8.2^{\circ}$ \\
\hline 295 & $7: 38: 36.57$ & $-41: 37: 39.78$ & 3.185 & 0.166 & 25.8 \\
\hline 298 & $7: 38: 36.70$ & $-41: 37: 21.09$ & 3.545 & 0.212 & 14. \\
\hline 306 & $7: 38: 37.83$ & $-41: 39: 57.48$ & 0.439 & 0.007 & 41.2 \\
\hline 311 & $7: 38: 38.39$ & $-41: 37: 15.09$ & 3.558 & 0.053 & 13.2 \\
\hline 323 & $7: 38: 40.29$ & $-41: 35: 06.28$ & 2.706 & 0.11 & 11.2 \\
\hline 333 & $7: 38: 40.95$ & $-41: 38: 34.92$ & 0.401 & 0.024 & 76.1 \\
\hline 345 & $7: 38: 42.17$ & $-41: 36: 47.21$ & 2.913 & 0.17 & 29.4 \\
\hline 361 & $7: 38: 43.51$ & $-41: 40: 07.62$ & 0.404 & 0.003 & 174.6 \\
\hline
\end{tabular}




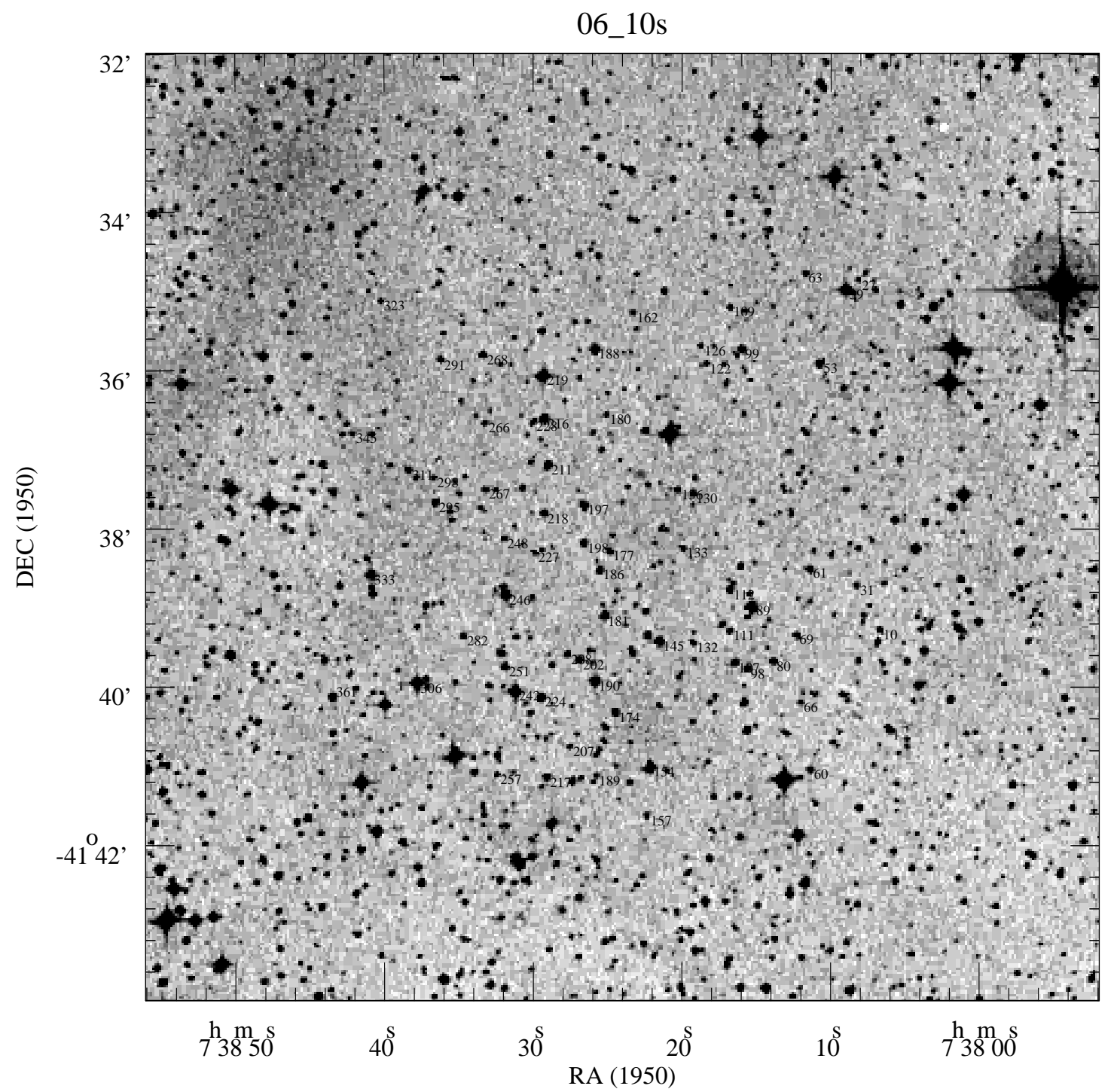

Figura E.8 Finding Chart do Campo 07 centrado em $\mathrm{AR}_{1950}=07 \mathrm{~h} 38^{\mathrm{m}} 24^{\mathrm{s}}, \mathrm{DEC}_{1950}=-41^{\circ} 37^{\prime} 59^{\prime \prime}$ 
Tabela E.9 Dados polarimétricos do Campo 09

\begin{tabular}{|c|c|c|c|c|c|}
\hline \multirow[t]{2}{*}{ ID } & AR (1950.00) & DEC $(1950.00)$ & \multirow{2}{*}{$\begin{array}{c}P_{\mathrm{V}} \\
\left(\frac{0}{\%}\right)\end{array}$} & \multirow{2}{*}{$\begin{array}{l}\sigma P_{\mathrm{V}} \\
\left(\frac{\circ}{0}\right)\end{array}$} & \multirow{2}{*}{$\begin{array}{c}\theta \\
\left({ }^{\circ}\right)\end{array}$} \\
\hline & $(\mathrm{h}: \mathrm{m}: \mathrm{s})$ & $\left({ }^{\circ}::^{\prime}: "\right)$ & & & \\
\hline 6 & $7: 38: 38.38$ & $-41: 47: 26.51$ & 0.366 & 0.01 & 92.5 \\
\hline 12 & $7: 38: 39.26$ & $-41: 44: 07.21$ & 0.94 & 0.088 & 30.6 \\
\hline 23 & $7: 38: 40.49$ & $-41: 47: 13.74$ & 0.418 & 0.018 & 104 \\
\hline 35 & $7: 38: 42.73$ & $-41: 49: 33.62$ & 0.229 & 0.022 & 30.7 \\
\hline 59 & $7: 38: 45.78$ & $-41: 47: 52.75$ & 0.419 & 0.038 & 71.3 \\
\hline 91 & $7: 38: 49.77$ & $-41: 46: 02.54$ & 0.561 & 0.046 & 118. \\
\hline 104 & $7: 38: 51.03$ & $-41: 43: 30.43$ & 0.807 & 0.053 & 111.9 \\
\hline 106 & $7: 38: 51.26$ & $-41: 46: 36.72$ & 0.167 & 0.015 & 69.5 \\
\hline 131 & $7: 38: 54.70$ & $-41: 42: 58.58$ & 0.424 & 0.036 & 77.7 \\
\hline 152 & $7: 38: 57.25$ & $-41: 44: 00.35$ & 1.096 & 0.018 & 95.6 \\
\hline 153 & $7: 38: 57.37$ & $-41: 48: 42.21$ & 0.436 & 0.015 & 179.9 \\
\hline 154 & $7: 38: 57.65$ & $-41: 49: 37.67$ & 1.059 & 0.047 & 176.2 \\
\hline 156 & $7: 38: 57.94$ & $-41: 42: 52.32$ & 0.955 & 0.019 & 96.9 \\
\hline 168 & $7: 39: 00.41$ & $-41: 49: 18.30$ & 1.081 & 0.077 & 14.6 \\
\hline 180 & $7: 39: 02.82$ & $-41: 49: 14.03$ & 0.837 & 0.063 & 113.1 \\
\hline 191 & $7: 39: 04.48$ & $-41: 47: 15.70$ & 0.691 & 0.008 & 96.8 \\
\hline 206 & $7: 39: 07.18$ & $-41: 46: 51.79$ & 1.715 & 0.047 & 100.8 \\
\hline 235 & $7: 39: 14.80$ & $-41: 44: 49.03$ & 1.82 & 0.125 & 110.8 \\
\hline
\end{tabular}

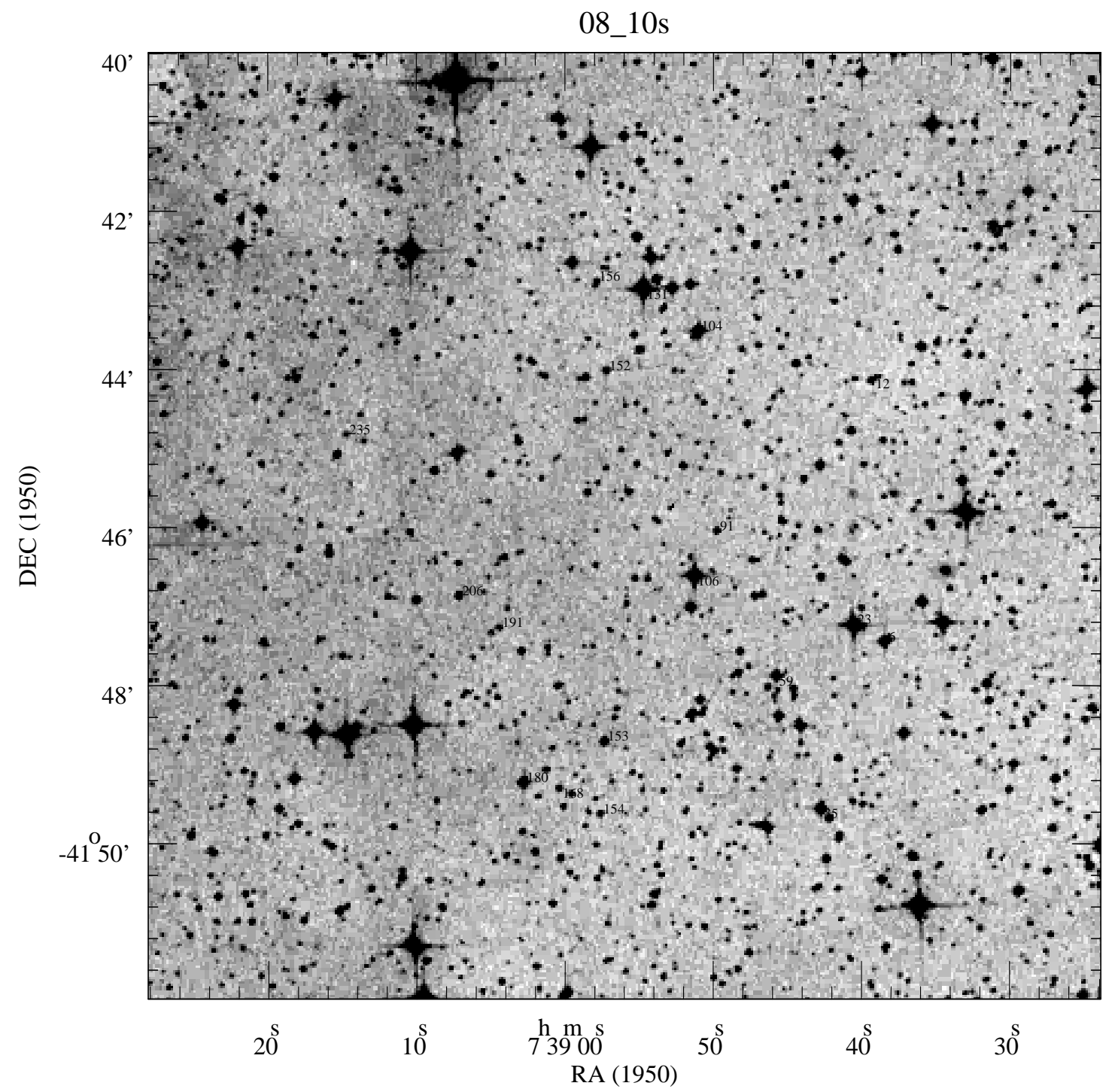

Figura E.9 Finding Chart do Campo 08 centrado em $\mathrm{AR}_{1950}=07^{\mathrm{h}} 38^{\mathrm{m}} 56^{\mathrm{s}}, \mathrm{DEC}_{1950}=-41^{\circ} 45^{\prime} 59^{\prime \prime}$ 
Tabela E.10 Dados polarimétricos do Campo 10

\begin{tabular}{|c|c|c|c|c|c|}
\hline \multirow[t]{2}{*}{ ID } & $\operatorname{AR}(1950.00)$ & "DEC (1950.00) & \multirow{2}{*}{$\begin{array}{c}P_{\mathrm{V}} \\
\left(\frac{0}{0}\right)\end{array}$} & \multirow{2}{*}{$\begin{array}{l}\sigma P_{\mathrm{V}} \\
(\%)\end{array}$} & \multirow{2}{*}{$\begin{array}{c}\theta \\
\left({ }^{\circ}\right)\end{array}$} \\
\hline & $(\mathrm{h}: \mathrm{m}: \mathrm{s})$ & $\left.\left({ }^{\circ}:,: "\right)^{\prime}\right)$ & & & \\
\hline 4 & $7: 40: 13.15$ & $-41: 50: 29.69$ & 1.24 & 0.101 & 13.5 \\
\hline $9^{a}$ & $7: 40: 14.34$ & $-41: 56: 51.83$ & 0.282 & 0.008 & \\
\hline 11 & $7: 40: 14.76$ & $-41: 54: 38.57$ & 0.226 & 0.002 & 69.6 \\
\hline 18 & $7: 40: 15.67$ & $-41: 54: 52.14$ & 0.561 & 0.003 & 120.3 \\
\hline 19 & $7: 40: 15.53$ & $-41: 57: 29.71$ & 1.482 & 0.029 & 66.5 \\
\hline 24 & $7: 40: 16.20$ & $-41: 50: 30.51$ & 0.282 & 0.005 & 18.6 \\
\hline 31 & $7: 40: 16.39$ & $-41: 55: 14.25$ & 0.408 & 0.01 & 40.8 \\
\hline 47 & $7: 40: 17.60$ & $-41: 51: 03.22$ & 0.625 & 0.02 & 11.5 \\
\hline 49 & $7: 40: 17.72$ & $-41: 54: 04.06$ & 2.04 & 0.027 & 169.9 \\
\hline 64 & $7: 40: 19.32$ & $-41: 52: 15.04$ & 0.733 & 0.048 & 154.3 \\
\hline 66 & $7: 40: 19.37$ & $-41: 54: 11.47$ & 0.43 & 0.028 & 14.9 \\
\hline 68 & $7: 40: 19.37$ & $-41: 55: 04.06$ & 0.516 & 0.007 & 43.2 \\
\hline 73 & $7: 40: 19.56$ & $-41: 54: 31.69$ & 0.174 & 0.002 & 164.1 \\
\hline 75 & $7: 40: 19.99$ & $-41: 51: 43.42$ & 0.711 & 0.006 & 18.5 \\
\hline 76 & $7: 40: 19.91$ & $-41: 56: 59.02$ & 1.152 & 0.024 & 93.8 \\
\hline 80 & $7: 40: 20.33$ & $-41: 56: 21.46$ & 1.515 & 0.028 & 32.7 \\
\hline 85 & $7: 40: 20.70$ & $-41: 52: 58.01$ & 1.288 & 0.049 & 62.6 \\
\hline $94^{b}$ & $7: 40: 21.63$ & $-41: 57: 19.97$ & 1.366 & 0.008 & 88. \\
\hline 105 & $7: 40: 22.46$ & $-41: 54: 41.79$ & 0.279 & 0.003 & 123.7 \\
\hline 111 & $7: 40: 22.86$ & $-41: 51: 59.53$ & 0.963 & 0.046 & 32.2 \\
\hline 117 & $7: 40: 23.79$ & $-41: 50: 40.92$ & 0.892 & 0.035 & 14.9 \\
\hline 129 & $7: 40: 24.55$ & $-41: 55: 11.07$ & 0.397 & 0.008 & 42.5 \\
\hline $145^{\mathrm{C}}$ & $7: 40: 27.13$ & $-41: 56: 45.91$ & 0.751 & 0.01 & 94.2 \\
\hline 148 & $7: 40: 27.41$ & $-41: 52: 55.20$ & 0.661 & 0.007 & 42.7 \\
\hline 151 & $7: 40: 27.57$ & $-41: 52: 46.61$ & 0.262 & 0.006 & 21.7 \\
\hline 154 & $7: 40: 27.89$ & $-41: 53: 08.56$ & 0.557 & 0.042 & 23.9 \\
\hline 160 & $7: 40: 28.50$ & $-41: 51: 45.33$ & 0.241 & 0.018 & 10.9 \\
\hline 171 & $7: 40: 29.84$ & $-41: 51: 37.23$ & 0.338 & 0.002 & 104.8 \\
\hline 174 & $7: 40: 30.03$ & $-41: 54: 28.04$ & 1.695 & 0.078 & $94.5^{\circ}$ \\
\hline 178 & $7: 40: 30.01$ & $-41: 54: 27.97$ & 0.518 & 0.022 & 178.1 \\
\hline 184 & $7: 40: 30.68$ & $-41: 54: 31.79$ & 0.982 & 0.073 & 166.2 \\
\hline 187 & $7: 40: 30.95$ & $-41: 51: 38.24$ & 1.568 & 0.026 & 25.7 \\
\hline 192 & $7: 40: 32.13$ & $-41: 52: 29.26$ & 0.994 & 0.023 & 23.9 \\
\hline 193 & $7: 40: 32.01$ & $-41: 53: 27.07$ & 0.707 & 0.012 & 3. \\
\hline 198 & $7: 40: 32.13$ & $-41: 54: 26.55$ & 0.553 & 0.006 & 61.5 \\
\hline 214 & $7: 40: 33.82$ & $-41: 54: 19.83$ & 0.448 & 0.02 & 12.3 \\
\hline $225^{d}$ & $7: 40: 34.98$ & $-41: 57: 18.12$ & 1.253 & 0.019 & 96.7 \\
\hline $226^{\mathrm{e}}$ & $7: 40: 35.13$ & $-41: 56: 29.70$ & 1.241 & 0.01 & 71. \\
\hline 227 & $7: 40: 35.09$ & $-41: 56: 28.18$ & 2.754 & 0.12 & 90.8 \\
\hline 230 & $7: 40: 35.32$ & $-41: 53: 03.70$ & 0.687 & 0.011 & 40.7 \\
\hline 231 & $7: 40: 35.35$ & $-41: 56: 31.29$ & 2.419 & 0.104 & 75.3 \\
\hline 249 & $7: 40: 36.72$ & $-41: 51: 15.34$ & 0.734 & 0.04 & 161.9 \\
\hline 254 & $7: 40: 37.77$ & $-41: 54: 12.50$ & 0.254 & 0.023 & 30.1 \\
\hline 257 & $7: 40: 37.92$ & $-41: 56: 03.41$ & 0.421 & 0.019 & 77.8 \\
\hline 262 & $7: 40: 38.63$ & $-41: 56: 16.80$ & 1.224 & 0.036 & 62.8 \\
\hline 293 & $7: 40: 41.42$ & $-41: 52: 55.32$ & 0.392 & 0.002 & 22.8 \\
\hline 295 & $7: 40: 41.62$ & $-41: 54: 55.64$ & 0.472 & 0.04 & 37.7 \\
\hline 300 & $7: 40: 41.87$ & $-41: 55: 54.23$ & 0.242 & 0.021 & 94.4 \\
\hline 301 & $7: 40: 41.73$ & $-41: 53: 23.12$ & 1.306 & 0.063 & 136.4 \\
\hline 302 & $7: 40: 41.97$ & $-41: 53: 05.23$ & 0.235 & 0.01 & 11.8 \\
\hline 305 & $7: 40: 42.04$ & $-41: 56: 07.15$ & 1.046 & 0.021 & 147.6 \\
\hline 306 & $7: 40: 42.33$ & $-41: 54: 15.51$ & 0.222 & 0.017 & 41.6 \\
\hline 308 & $7: 40: 42.51$ & $-41: 51: 06.39$ & 0.078 & 0.003 & 12.4 \\
\hline 309 & $7: 40: 42.61$ & $-41: 50: 49.41$ & 0.974 & 0.036 & 20.9 \\
\hline 311 & $7: 40: 42.64$ & $-41: 55: 52.20$ & 0.55 & 0.037 & 155.8 \\
\hline 337 & $7: 40: 44.31$ & $-41: 52: 41.90$ & 1.42 & 0.026 & 125. \\
\hline 342 & $7: 40: 44.33$ & $-41: 53: 36.90$ & 0.483 & 0.042 & 4.4 \\
\hline 351 & $7: 40: 44.95$ & $-41: 55: 55.51$ & 1.506 & 0.037 & 71.6 \\
\hline 352 & $7: 40: 45.27$ & $-41: 52: 34.37$ & 1.262 & 0.021 & 172.4 \\
\hline 353 & $7: 40: 45.26$ & $-41: 51: 10.35$ & 1.121 & 0.051 & $85.6^{2}$ \\
\hline 363 & $7: 40: 46.02$ & $-41: 50: 46.39$ & 0.167 & 0.005 & 37.1 \\
\hline 366 & $7: 40: 46.46$ & $-41: 52: 07.62$ & 0.162 & 0.007 & 41.6 \\
\hline 369 & $7: 40: 46.57$ & $-41: 55: 26.36$ & 0.922 & 0.036 & 127.3 \\
\hline 372 & $7: 40: 46.76$ & $-41: 51: 41.84$ & 0.125 & 0.002 & 30. \\
\hline 375 & $7: 40: 47.01$ & $-41: 53: 44.27$ & 0.797 & 0.027 & 138.8 \\
\hline 377 & $7: 40: 47.04$ & $-41: 56: 33.33$ & 1.189 & 0.073 & 49.5 \\
\hline 381 & $7: 40: 47.23$ & $-41: 57: 32.15$ & 0.422 & 0.012 & 155.6 \\
\hline 387 & $7: 40: 47.70$ & $-41: 56: 46.85$ & 0.196 & 0.005 & 36.5 \\
\hline 392 & $7: 40: 48.15$ & $-41: 55: 18.21$ & 0.295 & 0.023 & 171. \\
\hline 397 & $7: 40: 48.45$ & $-41: 52: 18.59$ & 0.106 & 0.002 & 43.5 \\
\hline 405 & $7: 40: 49.10$ & $-41: 56: 08.50$ & 0.535 & 0.039 & 88.5 \\
\hline 407 & $7: 40: 49.35$ & $-41: 53: 30.90$ & 0.281 & 0.014 & 8.4 \\
\hline 411 & $7: 40: 49.63$ & $-41: 53: 16.42$ & 0.209 & 0.006 & 34.5 \\
\hline 416 & $7: 40: 50.31$ & $-41: 54: 21.66$ & 0.814 & 0.047 & 172.7 \\
\hline 422 & $7: 40: 50.65$ & $-41: 53: 19.65$ & 0.528 & 0.013 & 45.5 \\
\hline 423 & $7: 40: 50.88$ & $-41: 57: 15.40$ & 1.418 & 0.107 & 66.9 \\
\hline 424 & $7: 40: 51.23$ & $-41: 50: 56.23$ & 0.274 & 0.021 & 44.7 \\
\hline 435 & $7: 40: 51.62$ & $-41: 55: 05.76$ & 0.509 & 0.01 & 164.1 \\
\hline
\end{tabular}

a mesmo objeto na Tabela D.2 com ID $=177$

mesmo objeto na Tabela D.2 com ID $=255$

${ }^{c}$ mesmo objeto na Tabela D.2 com ID $=305$

d mesmo objeto na Tabela D.2 com ID $=364$
e mesmo objeto na Tabela D.2 com ID $=370$ 


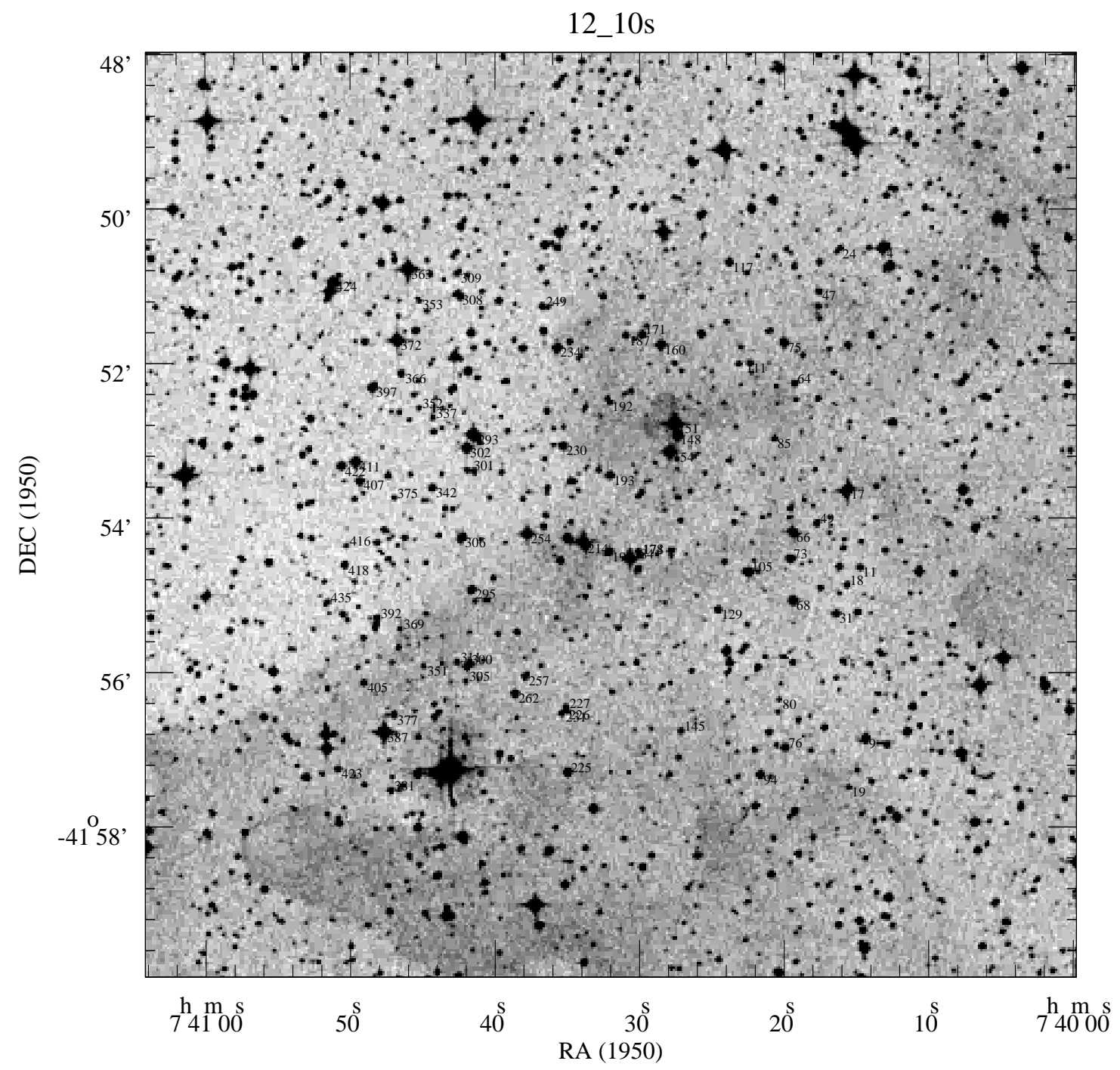

Figura E.10 Finding Chart do Campo 10 centrado em $\mathrm{AR}_{1950}=07 \mathrm{~h} 40^{\mathrm{m}} 32^{\mathrm{s}}, \mathrm{DEC}_{1950}=-41^{\circ} 53^{\prime} 58^{\prime \prime}$ 
Tabela E.11 Dados polarimétricos do Campo 11

\begin{tabular}{|c|c|c|c|c|c|}
\hline ID & $\operatorname{AR}(1950.00)$ & $\operatorname{DEC}(1950.00)$ & $P_{\mathrm{V}}$ & $\sigma P_{\mathrm{V}}$ & $\theta$ \\
\hline & $(\mathrm{h}: \mathrm{m}: \mathrm{s})$ & $\left({ }^{\circ}:{ }^{\prime}: "\right)$ & (을 & $\left(\frac{\circ}{0}\right)$ & $\left({ }^{\circ}\right)$ \\
\hline 5 & $7: 40: 13.92$ & $-42: 10: 58.32$ & 0.76 & 0.022 & 53.9 \\
\hline 15 & $7: 40: 15.18$ & $-42: 07: 52.33$ & 1.674 & 0.115 & 70.9 \\
\hline 17 & $7: 40: 15.22$ & $-42: 09: 30.10$ & 0.422 & 0.005 & 30.1 \\
\hline 26 & $7: 40: 15.88$ & $-42: 13: 08.79$ & 0.559 & 0.037 & 62.6 \\
\hline 30 & $7: 40: 16.74$ & $-42: 06: 23.98$ & 0.799 & 0.067 & 99.6 \\
\hline 39 & $7: 40: 17.53$ & $-42: 08: 36.17$ & 0.913 & 0.024 & 82.5 \\
\hline 43 & $7: 40: 17.84$ & $-42: 09: 53.34$ & 0.86 & 0.004 & 151.9 \\
\hline 52 & $7: 40: 18.75$ & $-42: 12: 05.14$ & 1.017 & 0.032 & 22.8 \\
\hline 56 & $7: 40: 19.54$ & $-42: 08: 03.55$ & 1.488 & 0.02 & 109.4 \\
\hline 61 & $7: 40: 20.10$ & $-42: 13: 06.51$ & 1.022 & 0.019 & 136.1 \\
\hline 63 & $7: 40: 20.28$ & $-42: 13: 03.47$ & 1.056 & 0.027 & 85.2 \\
\hline 69 & $7: 40: 21.04$ & $-42: 08: 57.80$ & 1.011 & 0.044 & 95.2 \\
\hline 73 & $7: 40: 21.12$ & $-42: 12: 54.84$ & 1.281 & 0.045 & 80.9 \\
\hline 74 & $7: 40: 21.21$ & $-42: 11: 07.51$ & 0.318 & 0.021 & 126.6 \\
\hline 82 & $7: 40: 21.98$ & $-42: 08: 49.53$ & 0.922 & 0.065 & 86.9 \\
\hline 117 & $7: 40: 24.68$ & $-42: 10: 01.72$ & 0.8 & 0.052 & 103.4 \\
\hline 128 & $7: 40: 26.33$ & $-42: 08: 50.19$ & 1.249 & 0.078 & 131.3 \\
\hline 131 & $7: 40: 26.36$ & $-42: 09: 11.07$ & 1.226 & 0.09 & 84.6 \\
\hline 135 & $7: 40: 26.84$ & $-42: 09: 44.22$ & 1.854 & 0.112 & 92.9 \\
\hline 147 & $7: 40: 28.65$ & $-42: 10: 07.94$ & 1.575 & 0.05 & 109.5 \\
\hline 152 & $7: 40: 28.82$ & $-42: 13: 03.78$ & 0.359 & 0.002 & 106.9 \\
\hline 155 & $7: 40: 29.03$ & $-42: 12: 17.14$ & 1.525 & 0.063 & 111.4 \\
\hline 167 & $7: 40: 29.78$ & $-42: 07: 28.58$ & 1.877 & 0.103 & 91.3 \\
\hline 173 & $7: 40: 30.21$ & $-42: 10: 48.94$ & 0.527 & 0.003 & 143.6 \\
\hline 180 & $7: 40: 30.73$ & $-42: 06: 42.70$ & 2.746 & 0.018 & 108.9 \\
\hline 191 & $7: 40: 31.59$ & $-42: 06: 45.67$ & 2.868 & 0.284 & 96.1 \\
\hline 200 & $7: 40: 32.62$ & $-42: 09: 55.91$ & 1.237 & 0.109 & 107. \\
\hline 203 & $7: 40: 32.76$ & $-42: 11: 03.07$ & 1.375 & 0.118 & 103.2 \\
\hline 204 & $7: 40: 32.91$ & $-42: 07: 41.35$ & 2.661 & 0.037 & 105.9 \\
\hline 219 & $7: 40: 34.76$ & $-42: 10: 42.48$ & 1.44 & 0.006 & 119.7 \\
\hline 220 & $7: 40: 34.78$ & $-42: 10: 42.41$ & 1.584 & 0.025 & 99.2 \\
\hline 227 & $7: 40: 35.65$ & $-42: 09: 43.87$ & 1.211 & 0.025 & 106.5 \\
\hline 233 & $7: 40: 36.57$ & $-42: 10: 04.43$ & 1.699 & 0.015 & 104.3 \\
\hline 248 & $7: 40: 37.57$ & $-42: 09: 05.43$ & 1.214 & 0.047 & 109.4 \\
\hline 252 & $7: 40: 37.84$ & $-42: 07: 32.93$ & 2.64 & 0.1 & 92.3 \\
\hline 260 & $7: 40: 39.15$ & $-42: 12: 50.93$ & 1.375 & 0.062 & 145.7 \\
\hline 269 & $7: 40: 40.26$ & $-42: 07: 46.90$ & 2.241 & 0.131 & 102.8 \\
\hline 272 & $7: 40: 40.26$ & $-42: 07: 46.90$ & 2.713 & 0.139 & 105.6 \\
\hline 279 & $7: 40: 40.74$ & $-42: 11: 15.97$ & 1.309 & 0.08 & 142.1 \\
\hline 280 & $7: 40: 40.73$ & $-42: 12: 17.88$ & 1.925 & 0.093 & 142. \\
\hline 284 & $7: 40: 41.32$ & $-42: 09: 57.74$ & 2.408 & 0.172 & 103.2 \\
\hline 290 & $7: 40: 41.87$ & $-42: 11: 03.48$ & 1.07 & 0.007 & 107.4 \\
\hline 304 & $7: 40: 43.45$ & $-42: 11: 54.71$ & 1.319 & 0.036 & 113.3 \\
\hline 310 & $7: 40: 43.61$ & $-42: 12: 41.90$ & 0.722 & 0.028 & 124.2 \\
\hline 311 & $7: 40: 43.75$ & $-42: 07: 52.49$ & 2.81 & 0.164 & 94.9 \\
\hline 316 & $7: 40: 44.32$ & $-42: 08: 32.26$ & 3.504 & 0.272 & 106.7 \\
\hline 321 & $7: 40: 44.47$ & $-42: 12: 19.50$ & 1.765 & 0.02 & 111.3 \\
\hline 332 & $7: 40: 45.59$ & $-42: 09: 58.73$ & 3.889 & 0.185 & 118.7 \\
\hline 337 & $7: 40: 45.90$ & $-42: 09: 03.25$ & 1.8 & 0.017 & 107.7 \\
\hline 349 & $7: 40: 46.85$ & $-42: 13: 22.79$ & 1.289 & 0.024 & 120.6 \\
\hline 363 & $7: 40: 48.20$ & $-42: 09: 03.09$ & 2.582 & 0.051 & 119.7 \\
\hline 365 & $7: 40: 48.23$ & $-42: 11: 40.50$ & 1.629 & 0.049 & 113.3 \\
\hline 377 & $7: 40: 49.39$ & $-42: 09: 59.38$ & 4.098 & 0.259 & 105.4 \\
\hline 379 & $7: 40: 49.55$ & $-42: 07: 49.51$ & 2.777 & 0.053 & 99.9 \\
\hline 387 & $7: 40: 50.60$ & $-42: 10: 27.56$ & 1.816 & 0.133 & 103.2 \\
\hline
\end{tabular}




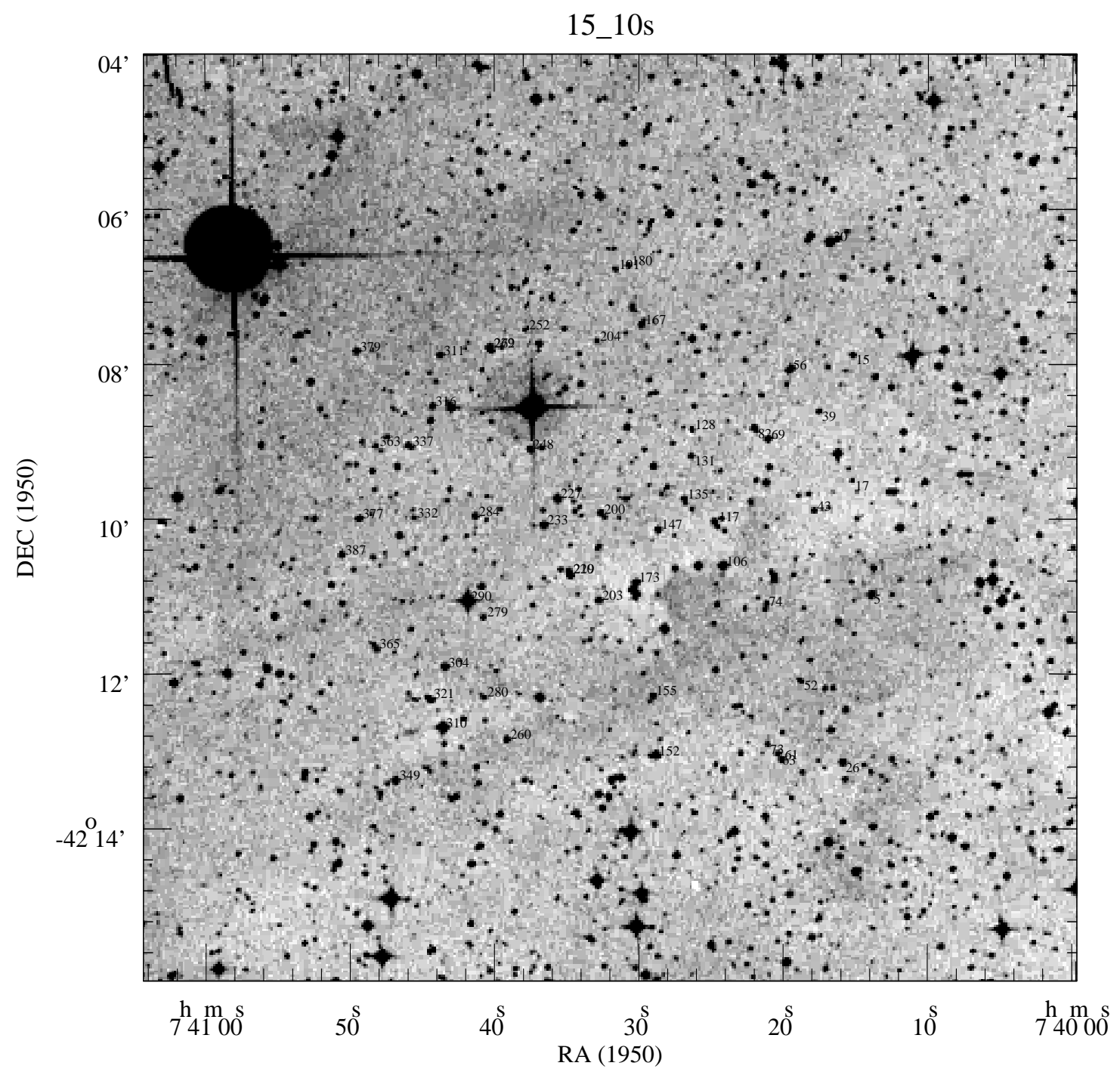

Figura E.11 Finding Chart do Campo 11 centrado em $\mathrm{AR}_{1950}=07 \mathrm{~h} 40^{\mathrm{m}} 32^{\mathrm{s}}, \mathrm{DEC}_{1950}=-42^{\circ} 09^{\prime} 59^{\prime \prime}$ 
Tabela E.12 Dados polarimétricos do Campo 12

\begin{tabular}{|c|c|c|c|c|c|}
\hline \multirow[t]{2}{*}{ ID } & $\operatorname{AR}(1950.00)$ & "DEC (1950.00) & \multirow{2}{*}{$\begin{array}{l}P_{\mathrm{V}} \\
\left(\frac{\circ}{0}\right)\end{array}$} & \multirow{2}{*}{$\begin{array}{l}\sigma P_{\mathrm{V}} \\
\left(\frac{\circ}{6}\right)\end{array}$} & \multirow{2}{*}{$\begin{array}{c}\theta \\
\left({ }^{\circ}\right)\end{array}$} \\
\hline & $(\mathrm{h}: \mathrm{m}: \mathrm{s})$ & $\left({ }^{\circ}:,: "\right)$ & & & \\
\hline $4^{\mathrm{a}}$ & $7: 40: 45.93$ & $-42: 17: 30.37$ & & & \\
\hline 6 & $7: 40: 46.24$ & $-42: 21: 03.62$ & 1.346 & 0.089 & 14.5 \\
\hline 7 & $7: 40: 46.50$ & $-42: 21: 27.73$ & 0.465 & 0.006 & 13.6 \\
\hline $8^{\mathrm{b}}$ & $7: 40: 46.42$ & $-42: 20: 39.61$ & 1.761 & 0.006 & 22.3 \\
\hline 20 & $7: 40: 47.65$ & $-42: 18: 40.51$ & 0.41 & 0.022 & 74.8 \\
\hline $21^{\mathrm{c}}$ & $7: 40: 47.77$ & $-42: 17: 55.42$ & 3.504 & 0.073 & 100.9 \\
\hline $22^{\mathrm{d}}$ & $7: 40: 47.81$ & $-42: 15: 40.15$ & 1.109 & 0.002 & 109.7 \\
\hline $24^{\mathrm{e}}$ & $7: 40: 47.94$ & $-42: 17: 40.59$ & 3.593 & 0.297 & 107.1 \\
\hline $25^{\mathrm{f}}$ & $7: 40: 48.16$ & $-42: 17: 00.09$ & 2.058 & 0.032 & 117.6 \\
\hline $28^{9}$ & $7: 40: 48.69$ & $-42: 15: 16.36$ & 1.469 & 0.001 & 103.6 \\
\hline 29 & $7: 40: 48.77$ & $-42: 18: 17.63$ & 2.168 & 0.145 & 145.1 \\
\hline 32 & $7: 40: 49.00$ & $-42: 14: 35.76$ & 1.105 & 0.009 & 139.2 \\
\hline 34 & $7: 40: 48.77$ & $-42: 15: 39.44$ & 1.391 & 0.01 & 123.1 \\
\hline 40 & $7: 40: 49.60$ & $-42: 15: 07.04$ & 1.972 & 0.184 & 123.5 \\
\hline 54 & $7: 40: 50.85$ & $-42: 20: 39.91$ & 0.857 & 0.028 & 5.5 \\
\hline 56 & $7: 40: 50.96$ & $-42: 21: 20.20$ & 1.291 & 0.077 & 20.9 \\
\hline 66 & $7: 40: 51.57$ & $-42: 21: 08.31$ & 1.98 & 0.191 & 48.3 \\
\hline 75 & $7: 40: 53.10$ & $-42: 16: 58.72$ & 1.128 & 0.021 & 120.8 \\
\hline 78 & $7: 40: 53.28$ & $-42: 16: 50.53$ & 1.616 & 0.13 & 119.4 \\
\hline 81 & $7: 40: 53.37$ & $-42: 20: 50.20$ & 2.128 & 0.099 & 10.1 \\
\hline 92 & $7: 40: 54.88$ & $-42: 20: 30.48$ & 1.932 & 0.01 & 24. \\
\hline 93 & $7: 40: 55.18$ & $-42: 16: 23.97$ & 2.242 & 0.031 & 103.6 \\
\hline 105 & $7: 40: 56.63$ & $-42: 20: 03.85$ & 1.936 & 0.016 & 28.7 \\
\hline 109 & $7: 40: 57.38$ & $-42: 16: 28.62$ & 2.482 & 0.218 & 106.5 \\
\hline 111 & $7: 40: 57.30$ & $-42: 17: 12.08$ & 2.023 & 0.009 & 116.5 \\
\hline 112 & $7: 40: 57.44$ & $-42: 21: 08.03$ & 1.094 & 0.013 & 171.6 \\
\hline 116 & $7: 40: 58.47$ & $-42: 17: 59.12$ & 2.123 & 0.03 & 119.8 \\
\hline 119 & $7: 40: 58.74$ & $-42: 19: 51.84$ & 1.221 & 0.026 & 158.9 \\
\hline 123 & $7: 40: 59.14$ & $-42: 16: 59.79$ & 1.49 & 0.106 & 108.6 \\
\hline 124 & $7: 40: 59.16$ & $-42: 15: 49.46$ & 1.779 & 0.05 & 105.1 \\
\hline 128 & $7: 41: 00.01$ & $-42: 16: 38.57$ & 1.683 & 0.061 & 108.8 \\
\hline 133 & $7: 41: 01.32$ & $-42: 21: 12.09$ & 1.736 & 0.02 & 20.6 \\
\hline 134 & $7: 41: 01.51$ & $-42: 19: 53.64$ & 1.869 & 0.002 & 15.7 \\
\hline 138 & $7: 41: 02.41$ & $-42: 15: 53.88$ & 0.257 & 0.008 & 12.9 \\
\hline 159 & $7: 41: 06.22$ & $-42: 21: 33.98$ & 2.027 & 0.151 & 25.5 \\
\hline 165 & $7: 41: 06.60$ & $-42: 20: 49.19$ & 0.91 & 0.041 & 2.9 \\
\hline 171 & $7: 41: 07.96$ & $-42: 15: 47.71$ & 0.881 & 0.004 & 135.5 \\
\hline 177 & $7: 41: 08.70$ & $-42: 14: 47.83$ & 0.553 & 0.001 & 153.9 \\
\hline 185 & $7: 41: 09.50$ & $-42: 20: 07.35$ & 2.493 & 0.006 & 13.9 \\
\hline 187 & $7: 41: 09.64$ & $-42: 18: 32.61$ & 1.597 & 0.026 & 125.3 \\
\hline 188 & $7: 41: 09.63$ & $-42: 21: 23.80$ & 2.703 & 0.14 & 30.9 \\
\hline 192 & $7: 41: 10.31$ & $-42: 15: 12.57$ & 0.747 & 0.005 & 125.5 \\
\hline 195 & $7: 41: 10.58$ & $-42: 16: 35.95$ & 1.17 & 0.07 & 173.8 \\
\hline 196 & $7: 41: 10.71$ & $-42: 16: 23.32$ & 2.824 & 0.048 & 151.8 \\
\hline 200 & $7: 41: 11.21$ & $-42: 16: 17.53$ & 1.54 & 0.093 & 165.2 \\
\hline 205 & $7: 41: 11.72$ & $-42: 19: 35.36$ & 2.652 & 0.172 & 13.5 \\
\hline 207 & $7: 41: 11.95$ & $-42: 20: 31.51$ & 1.844 & 0.006 & 7.7 \\
\hline 208 & $7: 41: 12.03$ & $-42: 20: 38.44$ & 3.743 & 0.02 & 40.3 \\
\hline 211 & $7: 41: 13.03$ & $-42: 16: 14.33$ & 1.539 & 0.019 & 128.7 \\
\hline $212^{\mathrm{h}}$ & $7: 41: 13.03$ & $-42: 15: 35.22$ & 1.51 & 0.029 & 173.2 \\
\hline & $7: 41: 13.44$ & $-42: 16: 55.56$ & 0.836 & 0.023 & 175.5 \\
\hline $224^{i}$ & $7: 41: 15.16$ & $-42: 15: 30.47$ & 1.376 & 0.035 & 112.8 \\
\hline 226 & $7: 41: 15.10$ & $-42: 21: 28.91$ & 0.721 & 0.005 & 20.7 \\
\hline 231 & $7: 41: 15.65$ & $-42: 21: 01.91$ & 1.515 & 0.072 & 18.8 \\
\hline 234 & $7: 41: 16.23$ & $-42: 16: 57.24$ & 2.263 & 0.006 & 144.5 \\
\hline 241 & $7: 41: 17.02$ & $-42: 18: 28.23$ & 1.955 & 0.187 & 43.9 \\
\hline $244^{j}$ & $7: 41: 17.42$ & $-42: 15: 55.38$ & 2.091 & 0.035 & 102.8 \\
\hline 245 & $7: 41: 17.46$ & $-42: 16: 48.58$ & 1.708 & 0.005 & 129.7 \\
\hline $253^{k}$ & $7: 41: 19.44$ & $-42: 14: 50.26$ & 1.739 & 0.116 & 74.8 \\
\hline 265 & $7: 41: 21.47$ & $-42: 21: 18.50$ & 2.357 & 0.016 & 26. \\
\hline 268 & $7: 41: 22.35$ & $-42: 18: 21.32$ & 1.333 & 0.12 & $5 . \dot{9}$ \\
\hline 271 & $7: 41: 23.29$ & $-42: 14: 41.85$ & 0.53 & 0.053 & 84.8 \\
\hline
\end{tabular}

${ }^{a}$ mesmo objeto na Tabela D.13 com ID $=308$

b mesmo objeto na Tabela D.13 com ID $=313$

mesmo objeto na Tabela D.13 com ID $=324$

mesmo objeto na Tabela D.13 com ID $=325$

mesmo objeto na Tabela D.13 com ID $=327$

mesmo objeto na Tabela D.13 com ID $=328$

mesmo objeto na Tabela D.13 com ID $=331$

mesmo objeto na Tabela D.4 com ID $=22$

mesmo objeto na Tabela D.4 com ID $=44$

mesmo objeto na Tabela D.4 com ID $=66$
$k$ mesmo objeto na Tabela D. 4 com ID $=80$ 


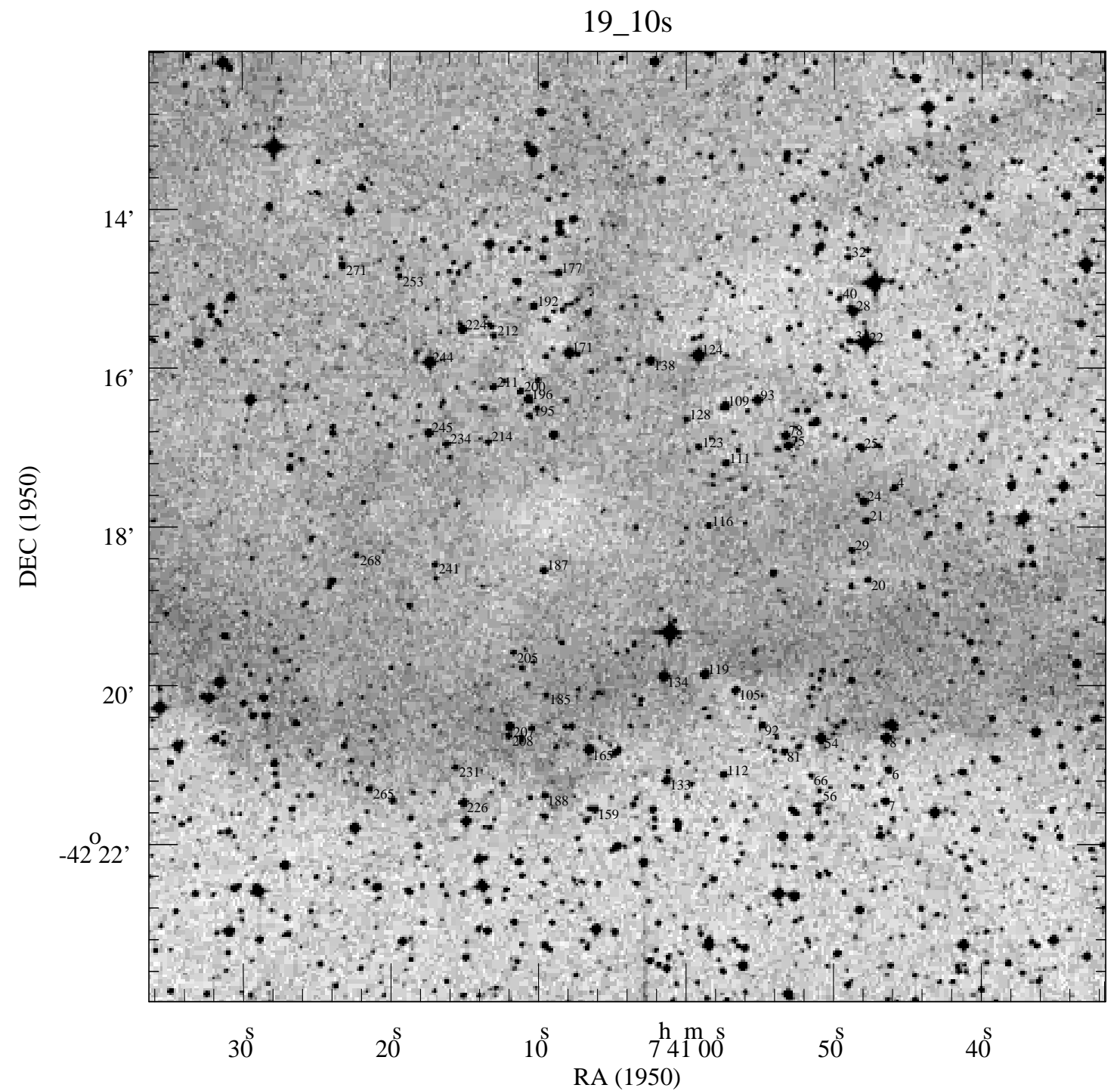

Figura E.12 Finding Chart do Campo 12 centrado em $\mathrm{AR}_{1950}=07 \mathrm{~h} 41^{\mathrm{m}} 04^{\mathrm{s}}, \mathrm{DEC}_{1950}=-42^{\circ} 18^{\prime} 00^{\prime \prime}$ 
Tabela E.13 Dados polarimétricos do Campo 13

\begin{tabular}{|c|c|c|c|c|c|}
\hline \multirow[t]{2}{*}{ ID } & AR $(1950.00)$ & DEC (1950.00) & \multirow{2}{*}{$\begin{array}{c}P_{\mathrm{V}} \\
\left(\frac{\%}{0}\right)\end{array}$} & \multirow{2}{*}{$\begin{array}{l}\sigma P_{\mathrm{V}} \\
(\%)\end{array}$} & \multirow{2}{*}{$\begin{array}{c}\theta \\
\left({ }^{\circ}\right)\end{array}$} \\
\hline & $(\mathrm{h}: \mathrm{m}: \mathrm{s})$ & $\left({ }^{\circ}:,: "\right)$ & & & \\
\hline 4 & $7: 40: 13.33$ & $-42: 18: 49.85$ & 0.885 & 0.036 & 93.6 \\
\hline 8 & $7: 40: 14.10$ & $-42: 16: 23.76$ & 1.373 & 0.053 & 103.5 \\
\hline 11 & $7: 40: 14.40$ & $-42: 16: 04.90$ & 1.053 & 0.008 & 99.5 \\
\hline 26 & $7: 40: 16.58$ & $-42: 17: 46.40$ & 1.474 & 0.032 & 98.1 \\
\hline 29 & $7: 40: 16.70$ & $-42: 18: 58.56$ & 1.911 & 0.051 & 79.7 \\
\hline 30 & $7: 40: 16.97$ & $-42: 16: 56.09$ & 1.997 & 0.015 & 107.6 \\
\hline 40 & $7: 40: 17.60$ & $-42: 19: 19.31$ & 1.659 & 0.023 & 80.4 \\
\hline 52 & $7: 40: 18.53$ & $-42: 17: 20.06$ & 0.996 & 0.041 & 123.1 \\
\hline 56 & $7: 40: 19.39$ & $-42: 19: 34.30$ & 1.58 & 0.022 & 94.7 \\
\hline 61 & $7: 40: 19.76$ & $-42: 15: 43.21$ & 3.035 & 0.252 & 94.9 \\
\hline 69 & $7: 40: 20.47$ & $-42: 19: 35.80$ & 1.632 & 0.006 & 101.6 \\
\hline 76 & $7: 40: 20.86$ & $-42: 18: 55.20$ & 0.397 & 0.004 & 141.3 \\
\hline 82 & $7: 40: 21.82$ & $-42: 16: 57.00$ & 1.89 & 0.011 & $\begin{array}{l}109.7 \\
109.7\end{array}$ \\
\hline 89 & $7: 40: 22.40$ & $-42: 18: 20.79$ & 1.597 & 0.093 & 102.4 \\
\hline 95 & $7: 40: 22.58$ & $-42: 17: 04.89$ & 3.236 & 0.067 & 115. \\
\hline 96 & $7: 40: 22.57$ & $-42: 17: 01.58$ & 1.409 & 0.008 & 113.3 \\
\hline 98 & $7: 40: 22.99$ & $-42: 17: 18.24$ & 1.484 & 0.073 & 115.8 \\
\hline 111 & $7: 40: 24.64$ & $-42: 16: 20.54$ & 2.131 & 0.188 & 123.5 \\
\hline 114 & $7: 40: 24.96$ & $-42: 15: 31.57$ & 2.208 & 0.194 & 110.5 \\
\hline 121 & $7: 40: 25.22$ & $-42: 20: 57.90$ & 2.316 & 0.026 & 5.4 \\
\hline 131 & $7: 40: 26.47$ & $-42: 18: 08.71$ & 3.027 & 0.231 & 104.2 \\
\hline 161 & $7: 40: 29.53$ & $-42: 15: 53.33$ & 3.219 & 0.023 & 104.4 \\
\hline 164 & $7: 40: 29.78$ & $-42: 14: 50.04$ & 1.13 & 0.009 & 98.6 \\
\hline 170 & $7: 40: 30.11$ & $-42: 20: 16.52$ & 1.469 & 0.005 & 155.2 \\
\hline 177 & $7: 40: 30.66$ & $-42: 17: 21.30$ & 1.758 & 0.019 & 108.7 \\
\hline 179 & $7: 40: 30.66$ & $-42: 21: 05.35$ & 1.479 & 0.147 & 119.4 \\
\hline 199 & $7: 40: 32.90$ & $-42: 14: 40.73$ & 0.763 & 0.041 & 99.2 \\
\hline 203 & $7: 40: 33.24$ & $-42: 15: 27.23$ & 1.791 & 0.019 & 96.9 \\
\hline 211 & $7: 40: 34.44$ & $-42: 17: 30.02$ & 1.436 & 0.007 & 107.2 \\
\hline 223 & $7: 40: 36.31$ & $-42: 15: 47.37$ & 1.048 & 0.052 & $95.3^{2}$ \\
\hline 226 & $7: 40: 36.46$ & $-42: 18: 27.43$ & 2.345 & 0.111 & 126.3 \\
\hline 228 & $7: 40: 36.64$ & $-42: 18: 15.72$ & 3.242 & 0.118 & 115.1 \\
\hline 231 & $7: 40: 37.13$ & $-42: 17: 52.07$ & 2.15 & 0.037 & 101.1 \\
\hline 240 & $7: 40: 37.96$ & $-42: 17: 27.45$ & 1.716 & 0.008 & 99.3 \\
\hline 249 & $7: 40: 39.03$ & $-42: 20: 55.05$ & 0.738 & 0.014 & 164.5 \\
\hline 264 & $7: 40: 40.43$ & $-42: 19: 42.06$ & 2.618 & 0.157 & 96.8 \\
\hline 272 & $7: 40: 41.49$ & $-42: 18: 00.09$ & 2.409 & 0.031 & 98.9 \\
\hline 273 & $7: 40: 41.65$ & $-42: 15: 15.23$ & $\begin{array}{l}2.798 \\
1.798\end{array}$ & 0.092 & 112.3 \\
\hline 277 & $7: 40: 41.93$ & $-42: 17: 14.90$ & 2.074 & 0.065 & 114.4 \\
\hline 296 & $7: 40: 44.17$ & $-42: 18: 46.08$ & 3.922 & 0.114 & 119.7 \\
\hline & $7: 40: 44.37$ & $-42: 15: 35.19$ & 1.199 & 0.093 & 105.2 \\
\hline $308^{a}$ & $7: 40: 45.92$ & $-42: 17: 30.75$ & 2.712 & 0.06 & 99.6 \\
\hline 309 & $7: 40: 45.94$ & $-42: 20: 29.68$ & 0.658 & 0.065 & 2.8 \\
\hline $313^{b}$ & $7: 40: 46.44$ & $-42: 20: 38.56$ & 1.343 & 0.007 & 19.1 \\
\hline $324^{c}$ & $7: 40: 47.76$ & $-42: 17: 54.34$ & 3.569 & 0.097 & 109.1 \\
\hline $325^{d}$ & $7: 40: 47.79$ & $-42: 15: 39.07$ & 1.128 & 0.011 & 110.6 \\
\hline $327^{\mathrm{e}}$ & $7: 40: 47.94$ & $-42: 17: 39.51$ & 4.097 & 0.002 & 104.3 \\
\hline $328^{\mathrm{f}}$ & $7: 40: 48.21$ & $-42: 16: 59.00$ & 1.974 & 0.128 & 111.4 \\
\hline $331^{9}$ & $7: 40: 48.81$ & $-42: 15: 15.26$ & 1.399 & 0.018 & 106. \\
\hline 361 & $7: 40: 51.18$ & $-42: 16: 40.89$ & 2.087 & 0.141 & 103.4 \\
\hline
\end{tabular}

mesmo objeto na Tabela D.12 com ID $=4$

mesmo objeto na Tabela D.12 com ID $=8$

mesmo objeto na Tabela D.12 com ID $=22$

mesmo objeto na Tabela D.12 com ID $=24$

mesmo objeto na Tabela D.12 com ID $=25$
mesmo objeto na Tabela D.12 com ID $=28$ 


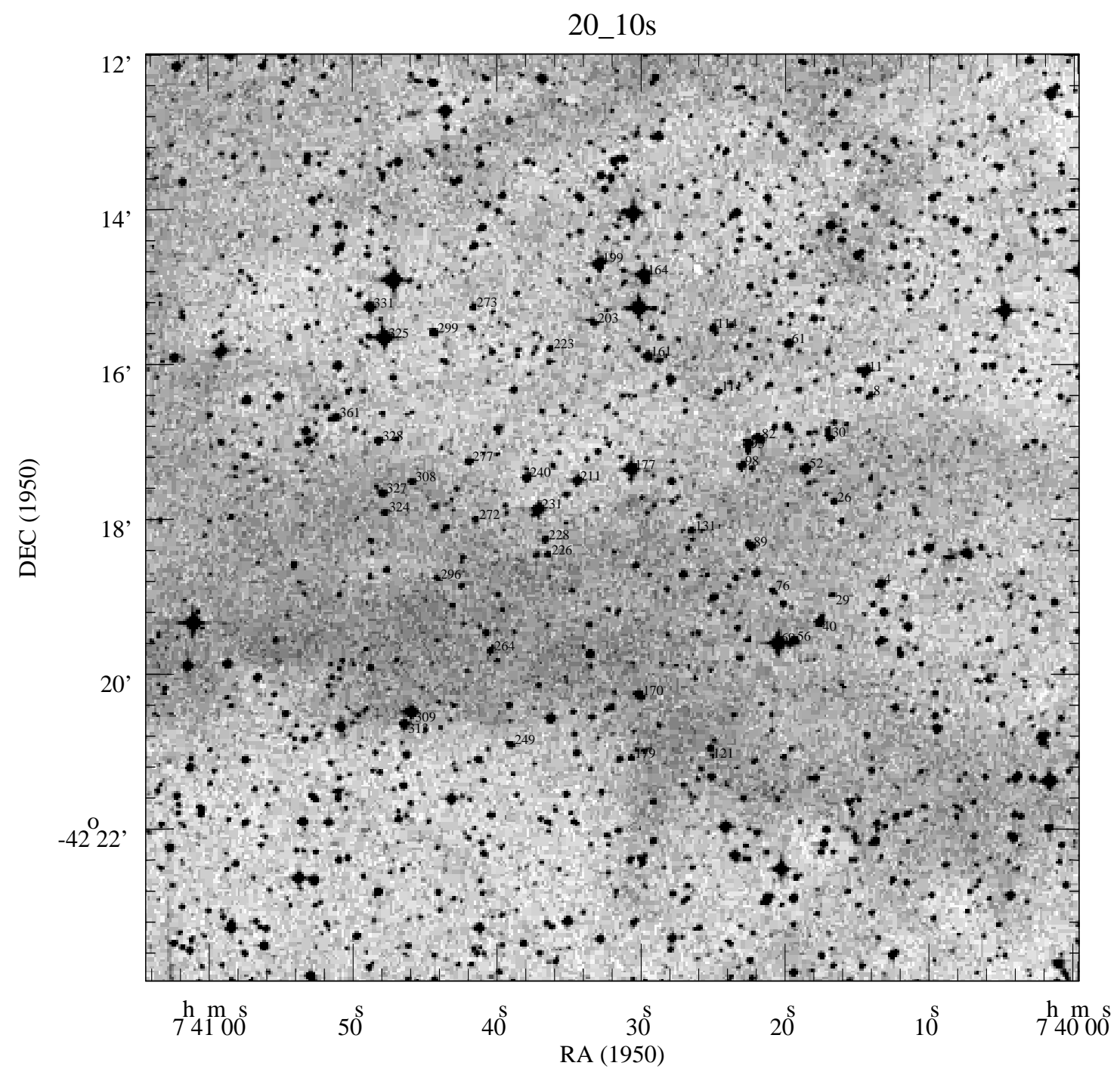

Figura E.13 Finding Chart do Campo 13 centrado em $\mathrm{AR}_{1950}=07 \mathrm{~h} 40^{\mathrm{m}} 32^{\mathrm{s}}, \mathrm{DEC}_{1950}=-42^{\circ} 17^{\prime} 59^{\prime \prime}$ 
Tabela E.14 Dados polarimétricos do Campo 14

\begin{tabular}{|c|c|c|c|c|c|}
\hline \multirow[t]{2}{*}{ ID } & $\operatorname{AR}(1950.00)$ & DEC (1950.00) & \multirow{2}{*}{$\begin{array}{l}P_{\mathrm{V}} \\
\left(\frac{0}{0}\right)\end{array}$} & \multirow{2}{*}{$\begin{array}{l}\sigma P_{\mathrm{V}} \\
(\%)\end{array}$} & \multirow{2}{*}{$\begin{array}{c}\theta \\
\left({ }^{\circ}\right)\end{array}$} \\
\hline & $(\mathrm{h}: \mathrm{m}: \mathrm{s})$ & $\left(0^{\circ}:,: "\right)$ & & & \\
\hline 4 & $7: 39: 10.11$ & $-42: 19: 02.99$ & 0.539 & 0.053 & 2.4 \\
\hline 8 & $7: 39: 10.19$ & $-42: 24: 13.09$ & 0.788 & 0.004 & 21.7 \\
\hline 23 & $7: 39: 11.29$ & $-42: 25: 15.21$ & 1.176 & 0.01 & 0.1 \\
\hline 32 & $7: 39: 12.41$ & $-42: 18: 50.58$ & 0.12 & 0.009 & 29.4 \\
\hline 39 & $7: 39: 12.90$ & $-42: 24: 15.07$ & 0.388 & 0.037 & 34.5 \\
\hline 56 & $7: 39: 15.10$ & $-42: 19: 39.73$ & 0.152 & 0.001 & 15. \\
\hline 57 & $7: 39: 15.04$ & $-42: 24: 48.97$ & 0.774 & 0.024 & $17 \dot{4} .7$ \\
\hline 58 & $7: 39: 15.40$ & $-42: 19: 09.13$ & 0.226 & 0.006 & 6.7 \\
\hline 62 & $7: 39: 15.21$ & $-42: 24: 55.52$ & 0.769 & 0.004 & 170.6 \\
\hline 63 & $7: 39: 15.47$ & $-42: 19: 34.54$ & 0.5 & 0.014 & 135.9 \\
\hline 65 & $7: 39: 15.68$ & $-42: 18: 35.16$ & 0.359 & 0.035 & 33.5 \\
\hline 77 & $7: 39: 16.63$ & $-42: 18: 53.91$ & 0.471 & 0.024 & 9.5 \\
\hline 79 & $7: 39: 16.97$ & $-42: 20: 30.77$ & 0.685 & 0.048 & 24.2 \\
\hline 101 & $7: 39: 18.47$ & $-42: 22: 53.53$ & 0.755 & 0.009 & 69.8 \\
\hline 103 & $7: 39: 18.74$ & $-42: 18: 36.60$ & 0.236 & 0.003 & 9.4 \\
\hline 106 & $7: 39: 19.12$ & $-42: 21: 59.20$ & 0.828 & 0.02 & 30.8 \\
\hline 113 & $7: 39: 19.24$ & $-42: 25: 23.99$ & 0.491 & 0.019 & 60. \\
\hline 114 & $7: 39: 19.45$ & $-42: 21: 14.83$ & 0.418 & 0.004 & 88.7 \\
\hline 122 & $7: 39: 20.77$ & $-42: 21: 45.90$ & 0.276 & 0.001 & 76.8 \\
\hline 134 & $7: 39: 22.34$ & $-42: 21: 17.92$ & 1.076 & 0.099 & 102.8 \\
\hline 149 & $7: 39: 23.61$ & $-42: 21: 14.44$ & 1.928 & 0.09 & 73.5 \\
\hline 155 & $7: 39: 24.26$ & $-42: 20: 45.38$ & 1.085 & 0.092 & 62. \\
\hline 159 & $7: 39: 24.69$ & $-42: 20: 13.64$ & 0.587 & 0.008 & 75.4 \\
\hline 168 & $7: 39: 25.27$ & $-42: 25: 18.11$ & 0.43 & 0.022 & 6.9 \\
\hline 177 & $7: 39: 26.17$ & $-42: 19: 08.03$ & 0.166 & 0.008 & 72.7 \\
\hline 178 & $7: 39: 26.04$ & $-42: 21: 08.30$ & $\begin{array}{l}1.12 \\
1.12\end{array}$ & 0.015 & 78.5 \\
\hline 182 & $7: 39: 26.36$ & $-42: 21: 43.05$ & 0.693 & 0.013 & 77.5 \\
\hline 183 & $7: 39: 26.49$ & $-42: 23: 22.84$ & 0.215 & 0.018 & 11.9 \\
\hline 187 & $7: 39: 26.64$ & $-42: 20: 54.53$ & 1.602 & 0.003 & 71.6 \\
\hline 198 & $7: 39: 28.04$ & $-42: 19: 20.82$ & 1.061 & 0.027 & 82.6 \\
\hline 202 & $7: 39: 28.37$ & $-42: 19: 40.27$ & 1.147 & 0.059 & 8.4 \\
\hline 211 & $7: 39: 29.25$ & $-42: 24: 50.74$ & 0.446 & 0.015 & 133.3 \\
\hline 227 & $7: 39: 31.56$ & $-42: 22: 50.51$ & 1.485 & 0.064 & 76.7 \\
\hline 228 & $7: 39: 31.55$ & $-42: 25: 23.17$ & 0.646 & 0.064 & 178.8 \\
\hline 233 & $7: 39: 31.91$ & $-42: 18: 54.33$ & 0.865 & 0.04 & 87.6 \\
\hline 241 & $7: 39: 32.39$ & $-42: 22: 21.02$ & 0.333 & 0.013 & 176.5 \\
\hline 251 & $7: 39: 33.54$ & $-42: 19: 34.84$ & 0.898 & 0.036 & 51.8 \\
\hline 258 & $7: 39: 34.64$ & $-42: 18: 48.18$ & 0.543 & 0.042 & 53.2 \\
\hline 263 & $7: 39: 34.97$ & $-42: 25: 00.10$ & 2.077 & 0.135 & 135.7 \\
\hline 267 & $7: 39: 35.23$ & $-42: 20: 51.41$ & 2.865 & 0.171 & 81.5 \\
\hline 281 & $7: 39: 37.08$ & $-42: 21: 16.54$ & 0.843 & 0.013 & 89.1 \\
\hline 284 & $7: 39: 37.58$ & $-42: 21: 46.69$ & 1.606 & 0.032 & 39.7 \\
\hline 288 & $7: 39: 37.98$ & $-42: 24: 42.28$ & 0.628 & 0.017 & 10.3 \\
\hline 290 & $7: 39: 38.74$ & $-42: 24: 23.43$ & 1.057 & 0.02 & 147.3 \\
\hline 299 & $7: 39: 39.55$ & $-42: 24: 43.33$ & 0.59 & 0.042 & 9.8 \\
\hline 300 & $7: 39: 39.66$ & $-42: 22: 04.84$ & 1.151 & 0.014 & 160.2 \\
\hline 303 & $7: 39: 40.55$ & $-42: 19: 38.23$ & 1.28 & 0.023 & 75.9 \\
\hline 307 & $7: 39: 40.55$ & $-42: 19: 38.23$ & $\begin{array}{l}1.20 \\
1.447\end{array}$ & 0.066 & 66.1 \\
\hline 309 & $7: 39: 40.59$ & $-42: 19: 38.04$ & 1.304 & 0.018 & 74.4 \\
\hline 314 & $7: 39: 41.33$ & $-42: 19: 03.16$ & 1.061 & 0.067 & 55. \\
\hline 318 & $7: 39: 41.50$ & $-42: 23: 52.63$ & 1.158 & 0.018 & 145.7 \\
\hline 320 & $7: 39: 41.74$ & $-42: 24: 31.84$ & 0.346 & 0.01 & 2.3 \\
\hline 322 & $7: 39: 42.00$ & $-42: 18: 49.99$ & 0.518 & 0.03 & 41.7 \\
\hline 323 & $7: 39: 41.91$ & $-42: 21: 20.97$ & 2.103 & 0.013 & 140.7 \\
\hline 324 & $7: 39: 41.97$ & $-42: 22: 47.80$ & 1.979 & 0.097 & 151.7 \\
\hline 329 & $7: 39: 42.65$ & $-42: 23: 34.17$ & 0.884 & 0.021 & 157.2 \\
\hline 335 & $7: 39: 42.93$ & $-42: 22: 14.47$ & 1.177 & 0.045 & 147.6 \\
\hline 347 & $7: 39: 44.09$ & $-42: 23: 27.39$ & 0.414 & 0.008 & 159.2 \\
\hline 348 & $7: 39: 44.13$ & $-42: 24: 46.31$ & 0.182 & 0.004 & 178.4 \\
\hline 353 & $7: 39: 45.08$ & $-42: 18: 35.26$ & 1.449 & 0.007 & $71.3^{2}$ \\
\hline 358 & $7: 39: 45.69$ & $-42: 24: 48.90$ & 0.274 & 0.007 & 174.1 \\
\hline 369 & $7: 39: 46.87$ & $-42: 23: 10.69$ & 0.584 & 0.005 & 124.6 \\
\hline 380 & $7: 39: 47.88$ & $-42: 19: 46.68$ & 0.909 & 0.011 & 104.6 \\
\hline
\end{tabular}




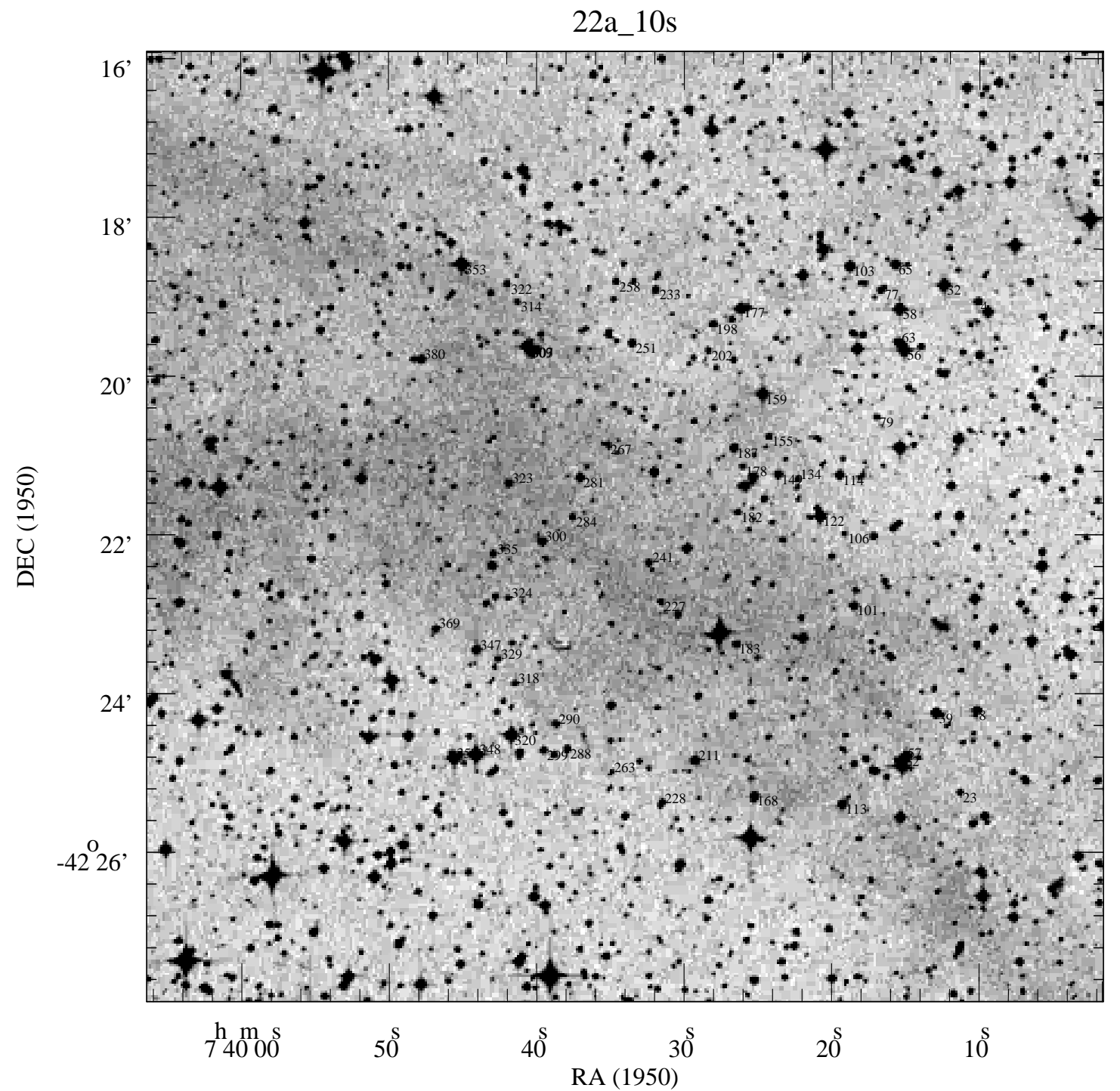

Figura E.14 Finding Chart do Campo 14 centrado em $\mathrm{AR}_{1950}=07 \mathrm{~h} 39^{\mathrm{m}} 34^{\mathrm{s}}, \mathrm{DEC}_{1950}=-42^{\circ} 21^{\prime} 54^{\prime \prime}$ 
Apêndice E

Tabela E.15 Dados polarimétricos do Campo 15

\begin{tabular}{cccccc}
\hline \hline ID & $\begin{array}{c}\text { AR }(1950.00) \\
(\mathrm{h}: \mathrm{m}: \mathrm{s})\end{array}$ & $\begin{array}{c}\mathrm{DEC}(1950.00) \\
\left({ }^{\circ}: \mathbf{l}^{\prime}\right)\end{array}$ & $\begin{array}{c}P_{\mathrm{V}} \\
\left(\frac{\circ}{0}\right)\end{array}$ & $\begin{array}{c}\sigma P_{\mathrm{V}} \\
\left(\frac{\circ}{0}\right)\end{array}$ & $\begin{array}{c}\theta \\
\left({ }^{\circ}\right)\end{array}$ \\
\hline 15 & $7: 38: 16.47$ & $-42: 49: 47.03$ & 1.719 & 0.065 & 116.1 \\
35 & $7: 38: 22.88$ & $-42: 48: 02.39$ & 1.119 & 0.037 & 165.3 \\
44 & $7: 38: 25.70$ & $-42: 49: 57.62$ & 3.552 & 0.052 & 115.7 \\
83 & $7: 38: 34.63$ & $-42: 49: 32.27$ & 3.702 & 0.195 & 143.7 \\
101 & $7: 38: 37.63$ & $-42: 47: 09.12$ & 1.664 & 0.056 & 27. \\
114 & $7: 38: 39.24$ & $-42: 46: 54.02$ & 1.074 & 0.074 & 161.1 \\
118 & $7: 38: 39.78$ & $-42: 52: 04.42$ & 2.749 & 0.061 & 166.2 \\
128 & $7: 38: 40.97$ & $-42: 52: 11.27$ & 1.539 & 0.016 & 175.1 \\
140 & $7: 38: 42.00$ & $-42: 47: 29.50$ & 1.163 & 0.024 & 64.3 \\
184 & $7: 38: 46.44$ & $-42: 47: 16.43$ & 0.117 & 0.003 & 138.9 \\
205 & $7: 38: 47.48$ & $-42: 50: 40.21$ & 1.11 & 0.056 & 170.6 \\
217 & $7: 38: 48.77$ & $-42: 50: 25.54$ & 0.965 & 0.008 & 168.6 \\
\hline
\end{tabular}

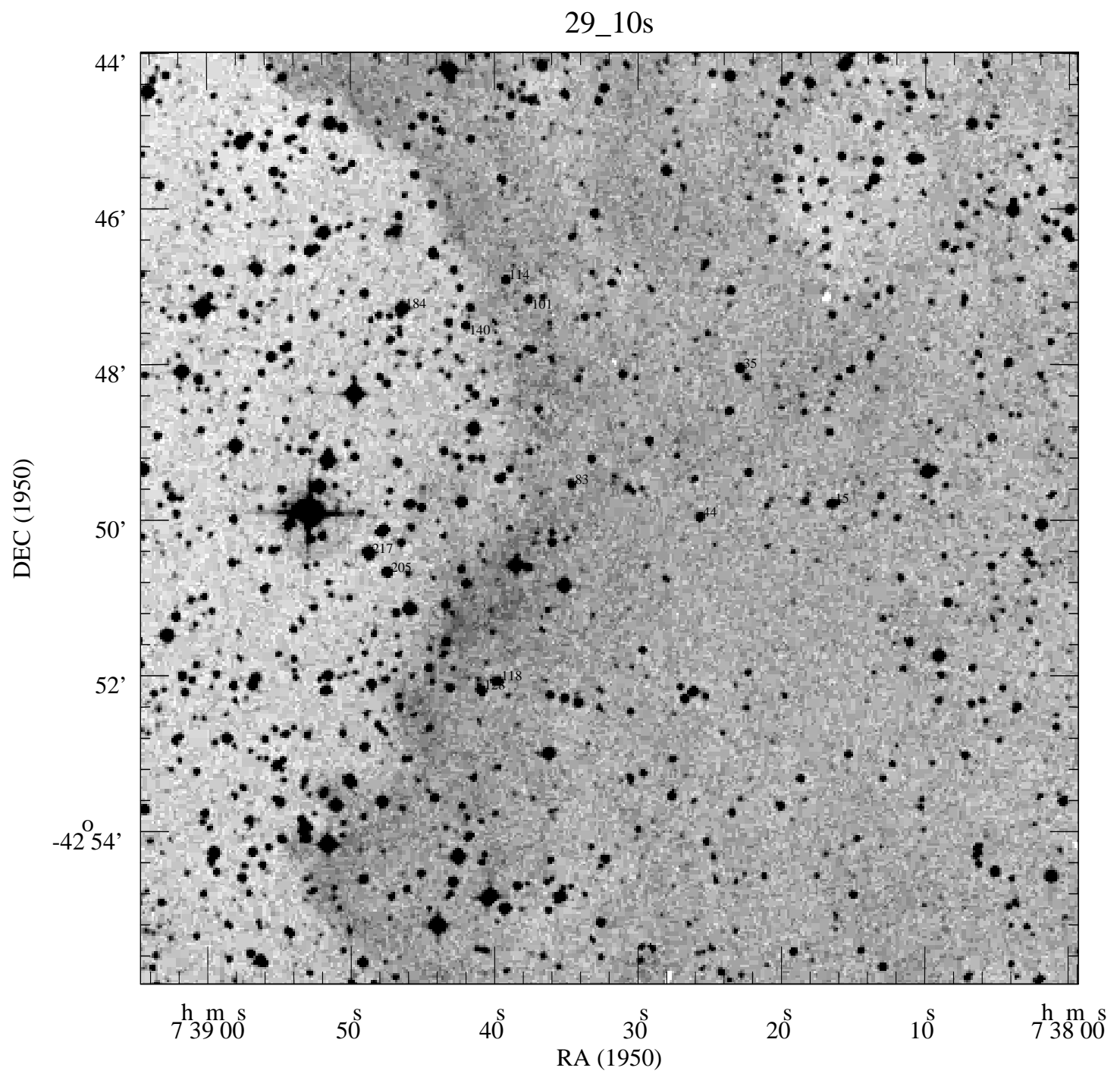

Figura E.15 Finding Chart do Campo 15 centrado em $\mathrm{AR}_{1950}=07_{\mathrm{h}} 38^{\mathrm{m}} 32^{\mathrm{s}}, \mathrm{DEC}_{1950}=-42^{\circ} 49^{\prime} 59^{\prime \prime}$ 
Tabela E.16 Dados polarimétricos do Campo 16

\begin{tabular}{|c|c|c|c|c|c|}
\hline \multirow[t]{2}{*}{ 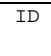 } & AR (1950.00) & DEC (1950.00) & \multirow{2}{*}{$\begin{array}{l}P_{\mathrm{V}} \\
\left(\frac{\circ}{8}\right)\end{array}$} & \multirow{2}{*}{$\begin{array}{l}\sigma P_{\mathrm{V}} \\
\left(\frac{\circ}{\circ}\right)\end{array}$} & \multirow{2}{*}{$\begin{array}{c}\theta \\
\left(^{\circ}\right)\end{array}$} \\
\hline & $(\mathrm{h}: \mathrm{m}: \mathrm{s})$ & $(\circ:,: ")$ & & & \\
\hline 7 & $7: 37: 42.53$ & $-42: 59: 06.85$ & 0.659 & 0.009 & 120.9 \\
\hline 14 & $7: 37: 43.58$ & $-42: 58: 50.53$ & 0.677 & 0.042 & 130.5 \\
\hline 23 & $7: 37: 45.14$ & $-43: 01: 10.10$ & 1.855 & 0.096 & 161.6 \\
\hline 24 & $7: 37: 45.14$ & $-43: 00: 40.29$ & $\begin{array}{l}1.055 \\
1.475\end{array}$ & 0.006 & $\begin{array}{l}109.8 \\
109.8\end{array}$ \\
\hline 26 & $7: 37: 45.14$ & $-43: 00: 40.29$ & 1.218 & 0.071 & 104.9 \\
\hline 31 & $7: 37: 46.16$ & $-43: 02: 50.81$ & 0.768 & 0.047 & 11.5 \\
\hline 45 & $7: 37: 48.91$ & $-42: 59: 59.04$ & 1.447 & 0.049 & 37.3 \\
\hline 57 & $7: 37: 51.60$ & $-43: 01: 05.31$ & 0.737 & 0.033 & 105.5 \\
\hline 59 & $7: 37: 51.76$ & $-42: 58: 52.02$ & 0.721 & 0.008 & \\
\hline 60 & $7: 37: 51.75$ & $-42: 58: 38.00$ & 2.293 & 0.174 & 178.8 \\
\hline 66 & $7: 37: 52.70$ & $-42: 59: 21.57$ & 0.424 & 0.019 & 37.1 \\
\hline 67 & $7: 37: 52.67$ & $-43: 02: 44.11$ & 0.532 & 0.029 & 102.9 \\
\hline 92 & $7: 37: 55.54$ & $-42: 59: 06.46$ & 0.893 & 0.002 & 165.5 \\
\hline 105 & $7: 37: 56.99$ & $-42: 58: 44.22$ & 0.717 & 0.008 & 42.4 \\
\hline 117 & $7: 37: 58.77$ & $-42: 58: 37.63$ & 0.594 & 0.058 & 83. \\
\hline 119 & $7: 37: 58.77$ & $-42: 58: 37.61$ & 1.308 & 0.022 & 45.5 \\
\hline 126 & $7: 38: 00.06$ & $-43: 02: 34.69$ & 0.81 & 0.024 & 19.6 \\
\hline 131 & $7: 38: 00.36$ & $-43: 02: 01.77$ & 0.522 & 0.003 & 121.7 \\
\hline 139 & $7: 38: 00.92$ & $-43: 00: 09.97$ & 0.901 & 0.059 & 159.4 \\
\hline 144 & $7: 38: 01.22$ & $-43: 01: 03.95$ & 1.474 & 0.007 & 152.4 \\
\hline $\begin{array}{l}148 \\
148\end{array}$ & $7: 38: 01.28$ & $-43: 05: 08.16$ & 1.753 & 0.051 & 136.2 \\
\hline 155 & $7: 38: 02.01$ & $-42: 59: 21.35$ & 0.6 & 0.02 & 146. \\
\hline 157 & $7: 38: 02.15$ & $-43: 04: 39.91$ & 1.039 & 0.021 & 142.6 \\
\hline 158 & $7: 38: 02.23$ & $-43: 03: 56.40$ & 0.483 & 0.025 & $62.9^{\circ}$ \\
\hline 165 & $7: 38: 02.94$ & $-43: 00: 10.82$ & 0.586 & 0.022 & 11.7 \\
\hline 166 & $7: 38: 03.09$ & $-43: 00: 26.57$ & 1.059 & 0.085 & 57. \\
\hline 170 & $7: 38: 03.57$ & $-43: 02: 37.20$ & 0.364 & 0.028 & 7.9 \\
\hline 173 & $7: 38: 03.89$ & $-43: 03: 02.80$ & 1.615 & 0.054 & 174.8 \\
\hline $\begin{array}{l}187 \\
187\end{array}$ & $7: 38: 05.72$ & $-43: 04: 09.80$ & $\begin{array}{l}1.015 \\
1.355\end{array}$ & 0.075 & $\begin{array}{l}174.0 \\
151.7\end{array}$ \\
\hline 198 & $7: 38: 07.80$ & $-43: 02: 25.41$ & 1.207 & 0.044 & 107.3 \\
\hline 210 & $7: 38: 09.06$ & $-42: 58: 57.15$ & 0.756 & 0.068 & 26.2 \\
\hline 212 & $7: 38: 09.03$ & $-42: 59: 47.82$ & 1.724 & 0.127 & 108.2 \\
\hline 216 & $7: 38: 09.50$ & $-43: 02: 07.27$ & 1.291 & 0.002 & 102.7 \\
\hline 220 & $7: 38: 10.20$ & $-43: 04: 14.96$ & 0.935 & 0.018 & 32.4 \\
\hline 221 & $7: 38: 10.23$ & $-43: 03: 53.37$ & 0.675 & 0.01 & 27.9 \\
\hline 229 & $7: 38: 10.82$ & $-43: 03: 02.18$ & 1.579 & 0.037 & 176.1 \\
\hline 236 & $7: 38: 11.88$ & $-43: 03: 42.01$ & 0.941 & 0.038 & 1.6 \\
\hline 245 & $7: 38: 12.37$ & $-43: 04: 58.01$ & 0.959 & 0.007 & 27.1 \\
\hline 254 & $7: 38: 13.78$ & $-42: 58: 36.02$ & 1.042 & 0.023 & 30.5 \\
\hline 258 & $7: 38: 14.09$ & $-43: 04: 04.46$ & 0.475 & 0.025 & 0.2 \\
\hline 268 & $7: 38: 14.92$ & $-42: 58: 53.54$ & 0.876 & 0.005 & \\
\hline 269 & $7: 38: 15.00$ & $-43: 00: 43.45$ & 0.722 & 0.041 & 67.8 \\
\hline 284 & $7: 38: 16.87$ & $-43: 01: 02.13$ & 0.361 & 0.011 & 65.8 \\
\hline 295 & $7: 38: 17.36$ & $-43: 05: 13.89$ & 0.731 & 0.016 & 29.8 \\
\hline 298 & $7: 38: 17.67$ & $-43: 05: 20.20$ & 0.524 & 0.037 & 21.3 \\
\hline 302 & $7: 38: 18.28$ & $-43: 04: 26.66$ & 0.202 & 0.002 & 52.8 \\
\hline 304 & $7: 38: 18.44$ & $-42: 59: 09.92$ & 0.845 & 0.008 & 26.8 \\
\hline 306 & $7: 38: 18.39$ & $-43: 04: 02.42$ & 1.72 & 0.048 & 120.2 \\
\hline 310 & $7: 38: 18.67$ & $-43: 00: 33.26$ & 1.04 & 0.049 & 3.6 \\
\hline 311 & $7: 38: 18.55$ & $-43: 04: 24.75$ & 0.294 & 0.012 & 24.1 \\
\hline 315 & $7: 38: 19.05$ & $-43: 00: 57.50$ & 1.536 & 0.145 & 31.2 \\
\hline 317 & $7: 38: 19.16$ & $-43: 04: 20.72$ & 1.015 & 0.017 & 81.5 \\
\hline
\end{tabular}




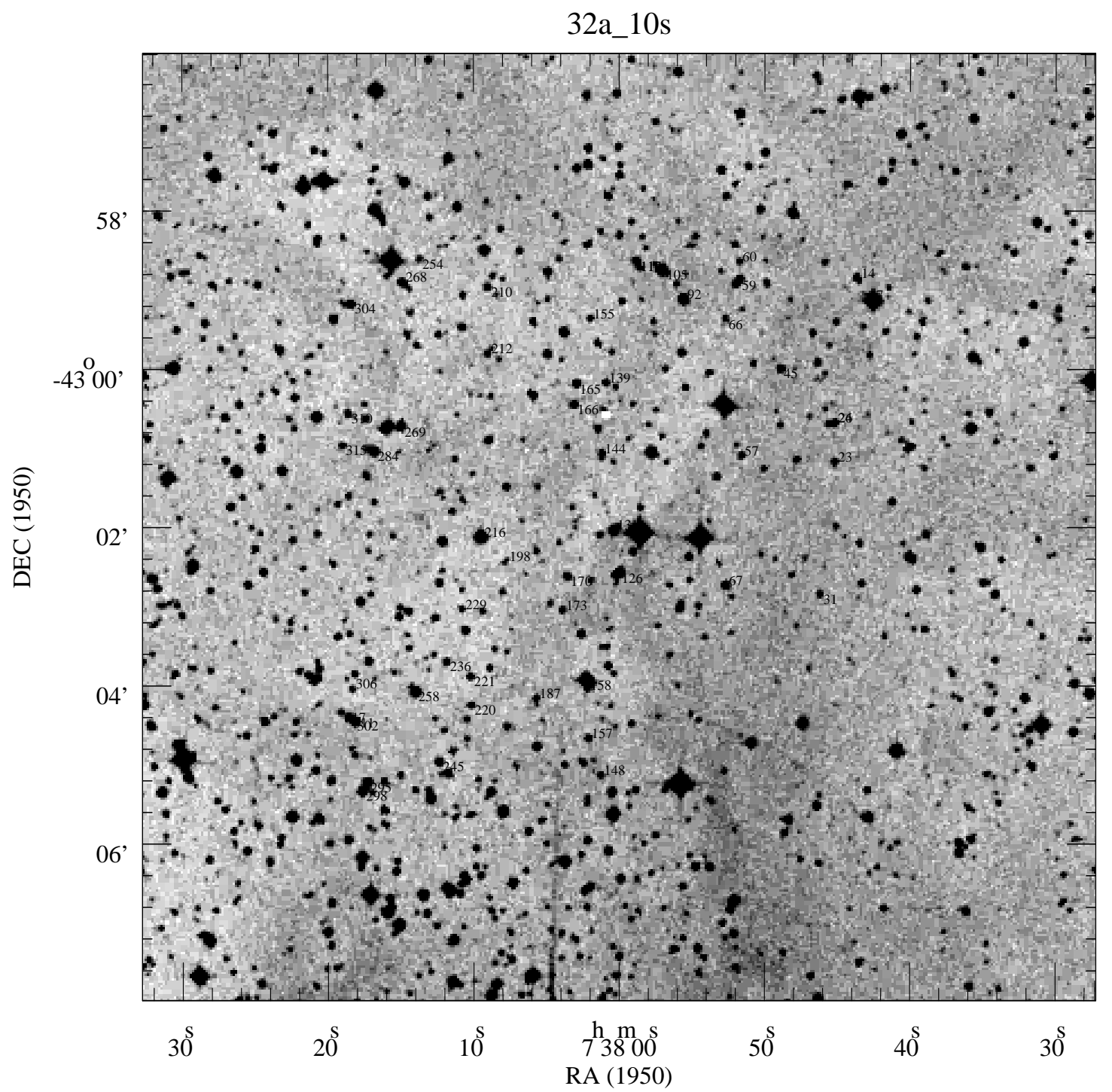

Figura E.16 Finding Chart do Campo 16 centrado em $\mathrm{AR}_{1950}=07^{\mathrm{h}} 38^{\mathrm{m}} 00^{\mathrm{s}}, \mathrm{DEC}_{1950}=-43^{\circ} 02^{\prime} 00^{\prime \prime}$ 


\section{Apêndice F. Análise da polarimetria na região IRAS Vela Shell/Gum}

Este apêndice mostra com detalhe a análise do catálogo polarimétrico da região IRAS Vela Shell/Nebulosa de Gum na direção de HD62542 (Apêndice E). Mostramos a saída da rotina SELECT do pacote PCCDPACK (ver seção 2.4.6) aplicada sobre cada um dos 16 campos que formam parte deste catálogo. A filtragem foi feita para uma sinal-ruído de polarização maior que 10. A análise (figuras F.1 a F.16) é semelhante àquele mostrado no Apêndice D. 
$01 \rightarrow 10$ s.sel $0 .<p<0.04 \quad \mathrm{p} / \operatorname{sigma}(\mathrm{p})>10 . \quad \mathrm{cQ} 0 . \quad \mathrm{cU} 0$. nstars 14

a)

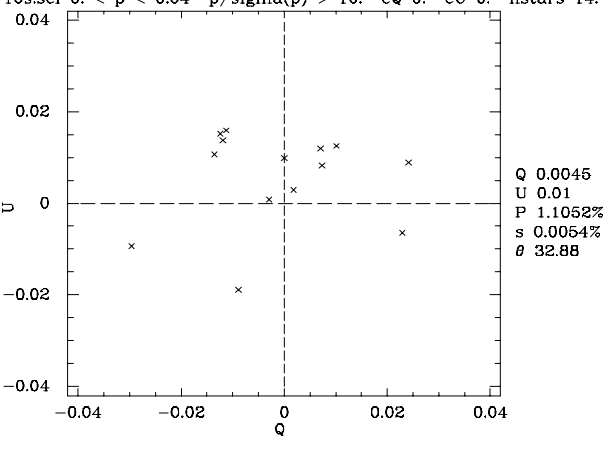

$0 .<$ theta $<=180$, bin 5 . erromax 2865 nstars 14.4 cmax 3.

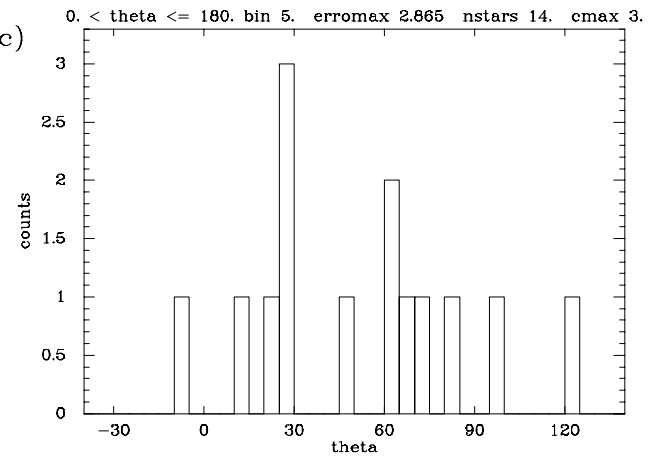

b)

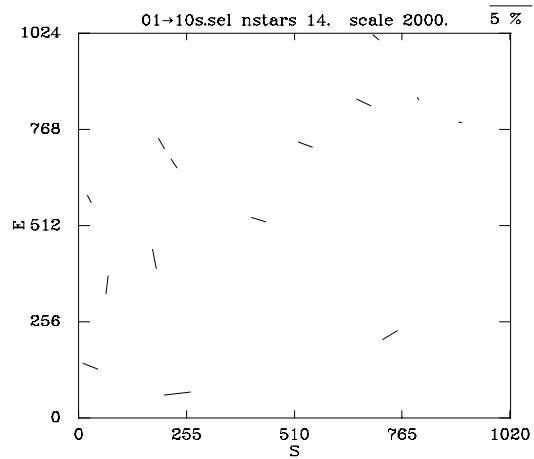

d)

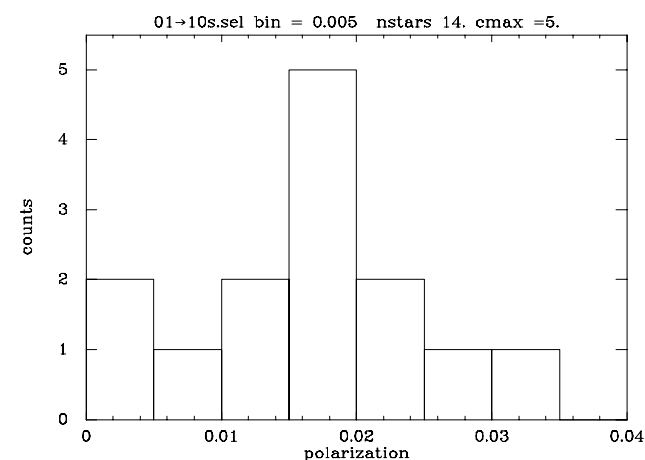

Figura F. 1 Análise do Campo 01

$02 \rightarrow 10$ s.sel $0 .<p<0.055 \mathrm{p} / \mathrm{sigma}(\mathrm{p})>10 . \quad \mathrm{cQ} 0 . \quad \mathrm{cU} 0 . \quad$ nstars 71

a)

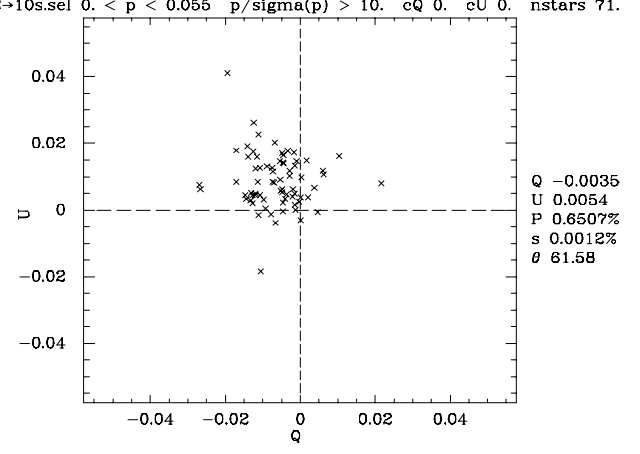

$0 .<$ theta $<=180$. bin 5. erromax 2.865 nstars 71. $\quad$ max 10.

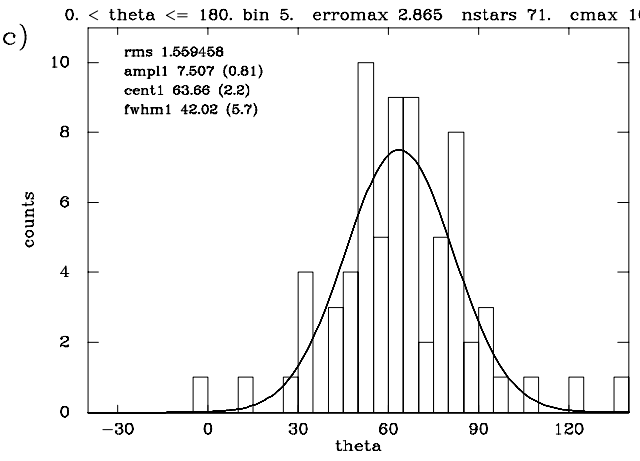

b)

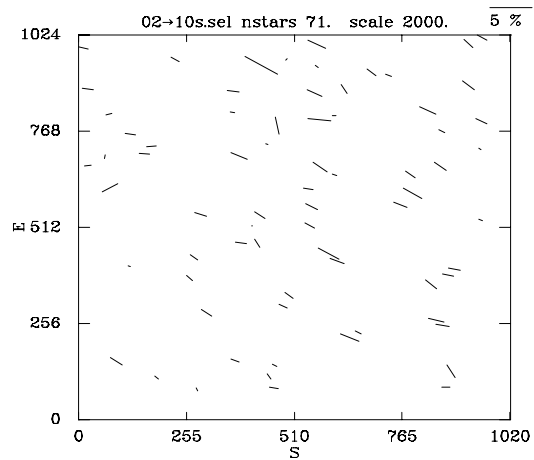

d)

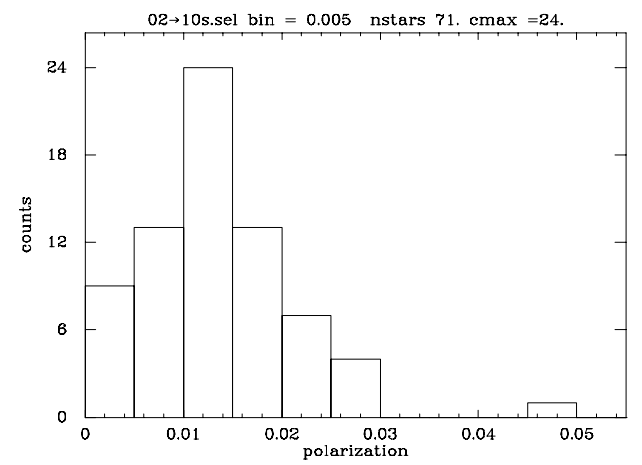

Figura F.2 Análise do Campo 02 
$03 \rightarrow 10$ s.sel $0 .<\mathrm{p}<0.045 \mathrm{p} / \operatorname{sigma}(\mathrm{p})>10 . \quad \mathrm{cQ} 0 . \quad \mathrm{cU} 0$. nstars 68

a)

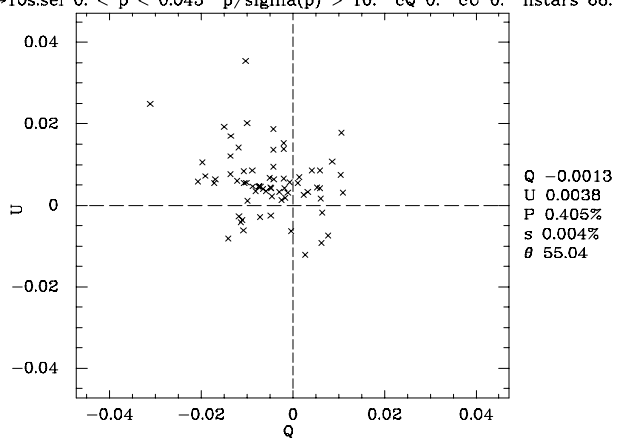

0. $<$ theta $<=180$. bin 5. erromax 2.865 nstars 68. $\quad \operatorname{cmax} 12$

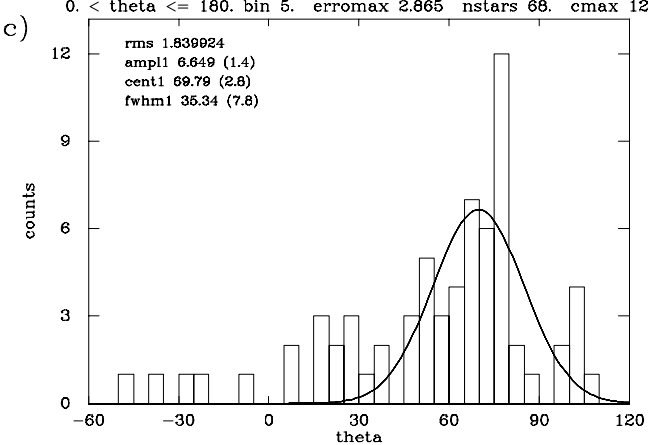

b)

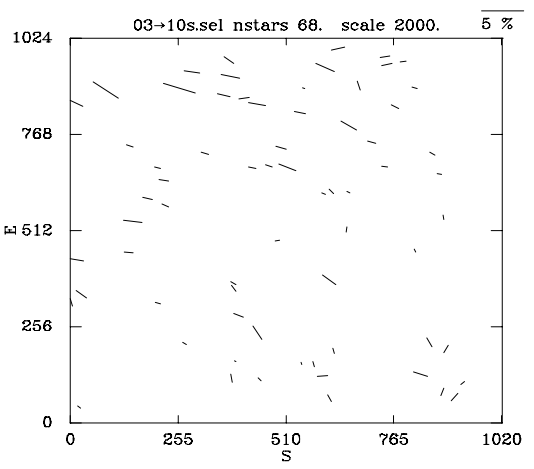

d)

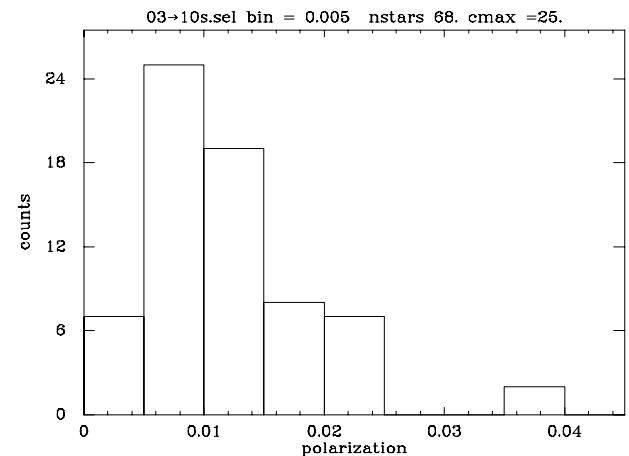

Figura F.3 Análise do Campo 03

$04 \rightarrow 10$ s.sel $0 .<\mathrm{p}<0.045 \mathrm{p} / \operatorname{sigma}(\mathrm{p})>10 . \quad \mathrm{cQ} 0 . \quad \mathrm{cU} 0$. nstars 59

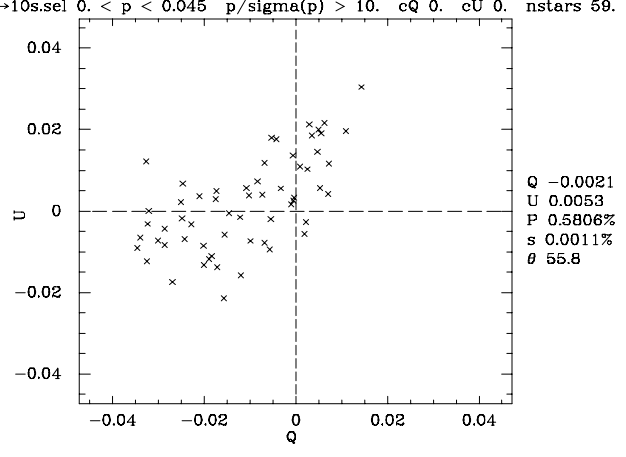

0. $<$ theta $<=180$. bin 5. erromax 2.865 nstars 59. $\operatorname{cmax} 7$.

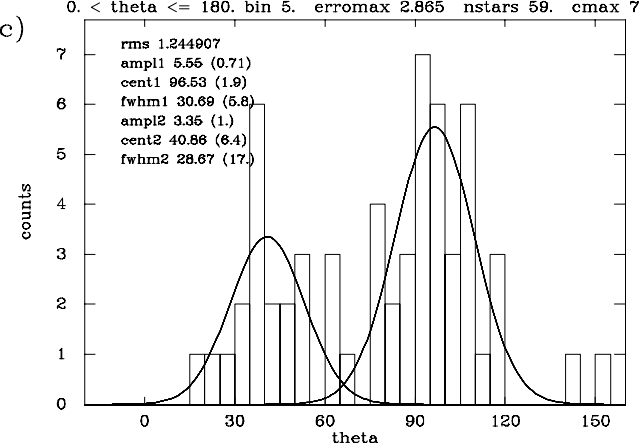

b)

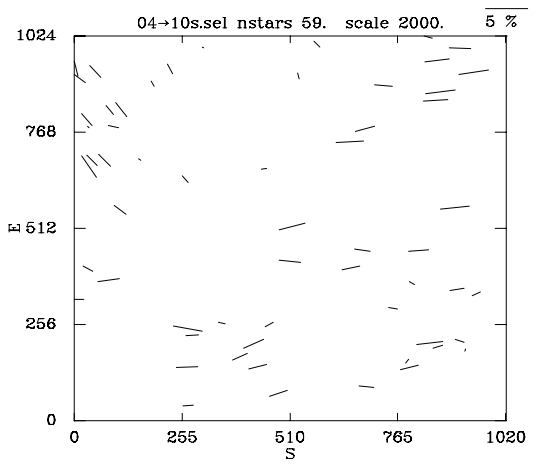

d)

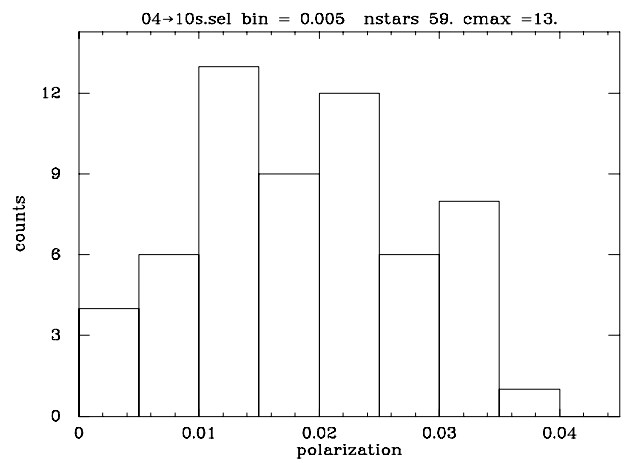

Figura F.4 Análise do Campo 04 
$02 \rightarrow 10$ s.sel $0 .<p<0.055 \mathrm{p} / \operatorname{sigma}(\mathrm{p})>10 . \quad \mathrm{cQ} 0 . \quad \mathrm{cU} 0 . \quad$ nstars 76

a)

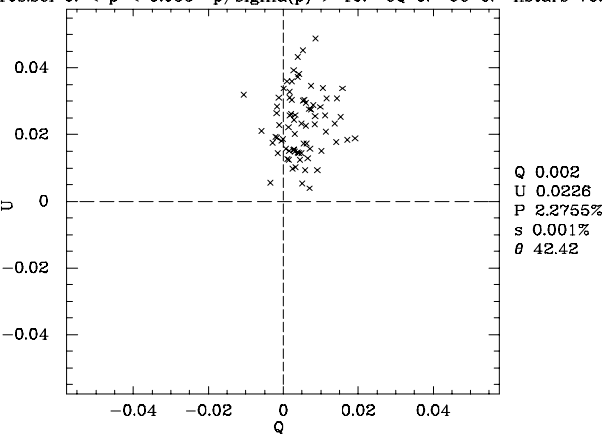

romax 2.865 nstars 76. cmax

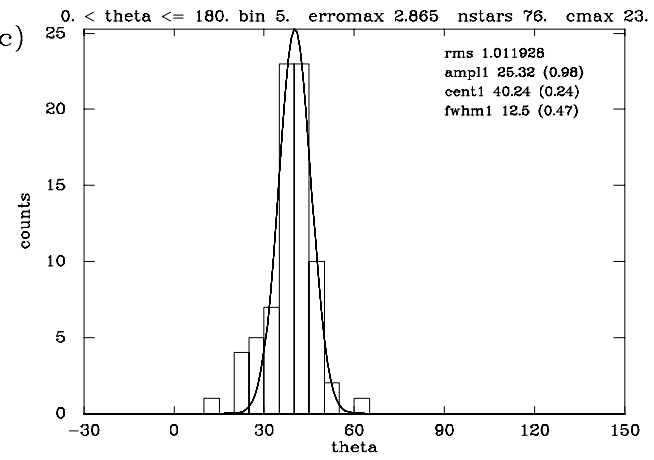

b)

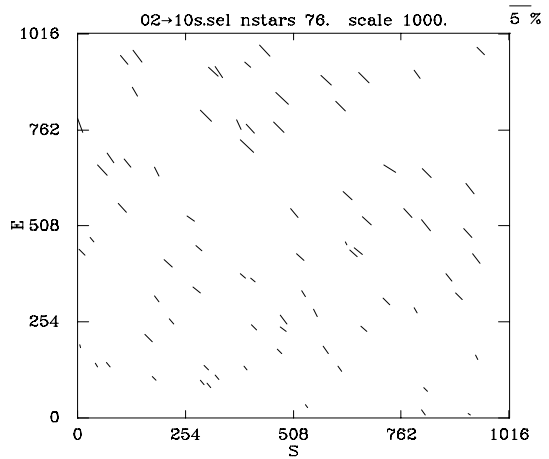

d)

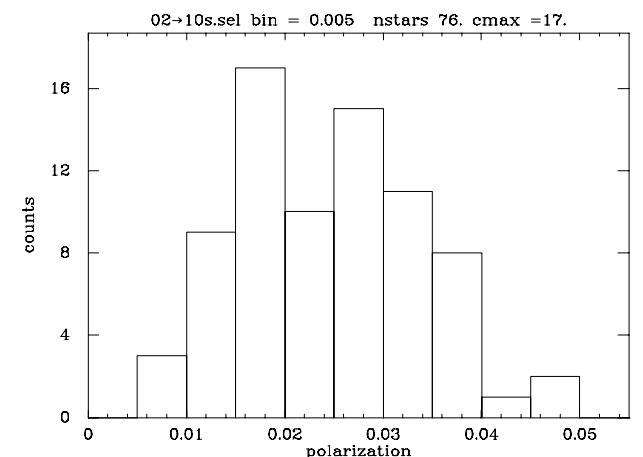

Figura F.5 Análise do Campo 05

$03 \rightarrow 10$ s.sel $0 .<p<0.045 \mathrm{p} / \operatorname{sigma}(\mathrm{p})>10 . \quad \mathrm{cQ} 0 . \quad \mathrm{cU} 0 . \quad$ nstars 68

a)

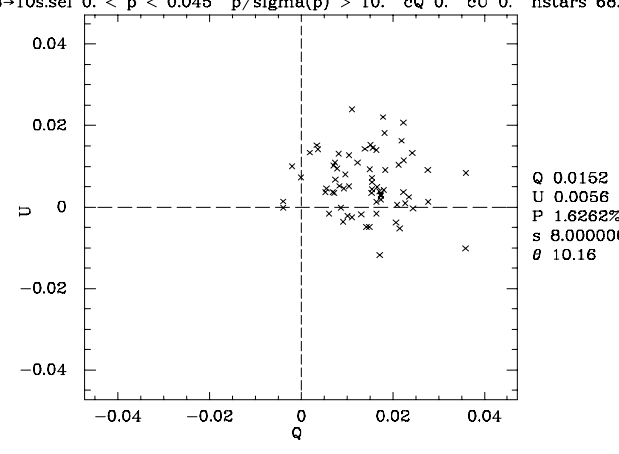

$0 .<$ theta $<=180$. bin 5. erromax 2.865 nstars 68 cmax 10.

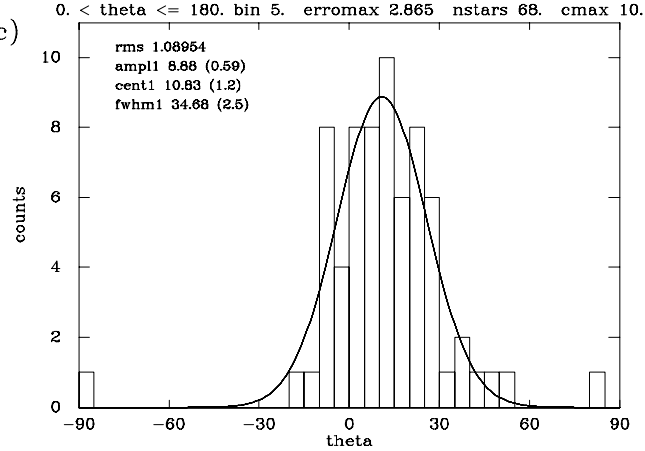

b)

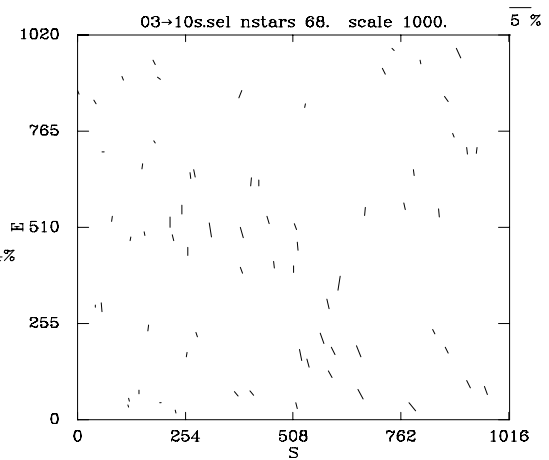

d)

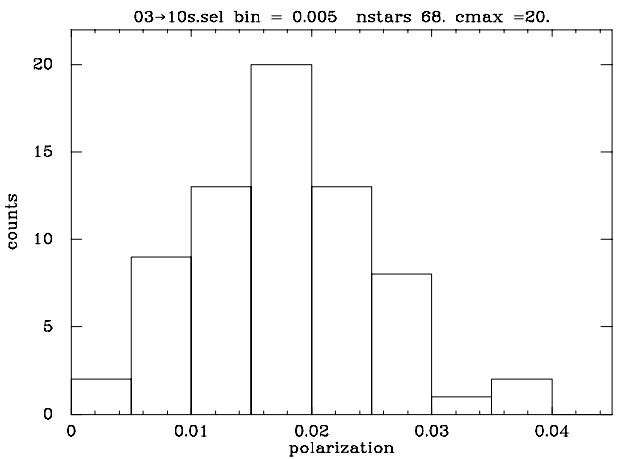

Figura F.6 Análise do Campo 06 
$05 \rightarrow 10$ s.sel $0 .<p<0.07 \quad \mathrm{p} / \operatorname{sigma}(\mathrm{p})>10 . \quad \mathrm{cQ} 0 . \quad \mathrm{cU} 0$. nstars 61.

a)

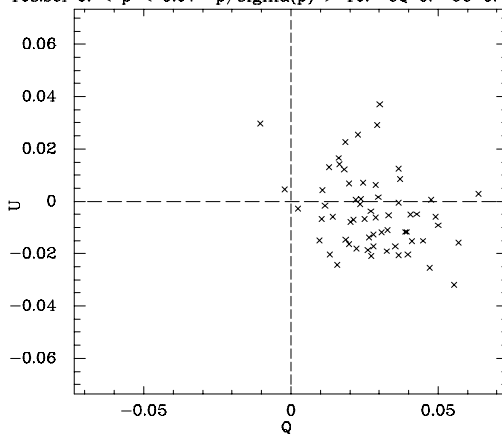

c)

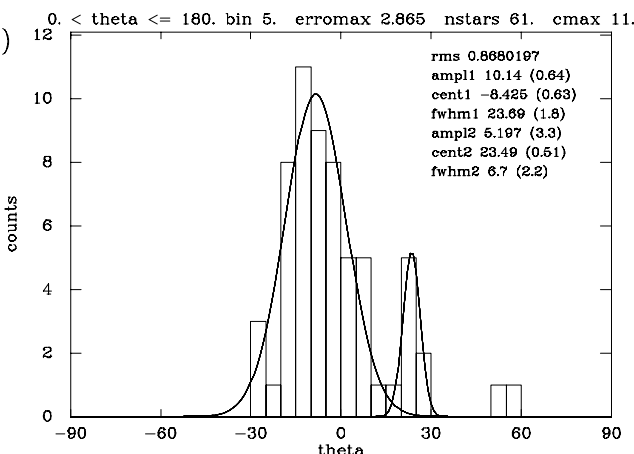

b)

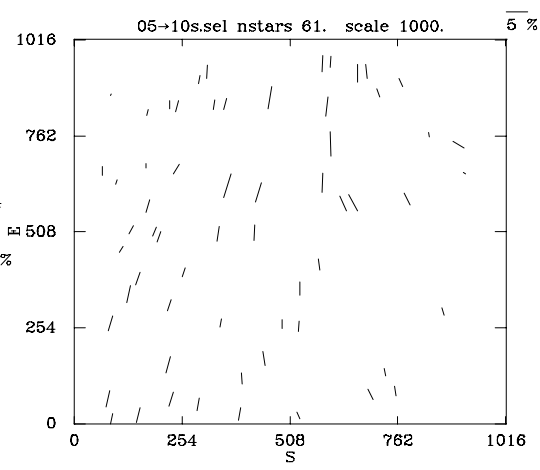

d)

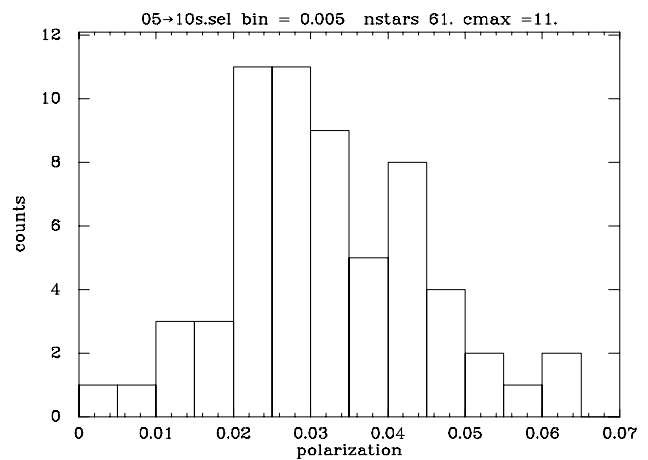

Figura F.7 Análise do Campo 07

$06 \rightarrow 10$ s.sel $0 .<\mathrm{p}<0.045 \mathrm{p} / \operatorname{sigma}(\mathrm{p})>10 . \quad \mathrm{cQ} 0 . \quad \mathrm{cU} 0 . \quad$ nstars 68

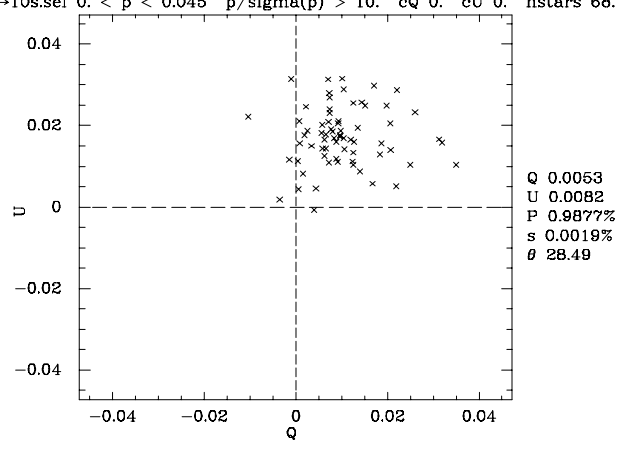

0. $<$ theta $<=180$. bin 5. erromax 2.865 nstars 68. $\operatorname{cmax} 17$

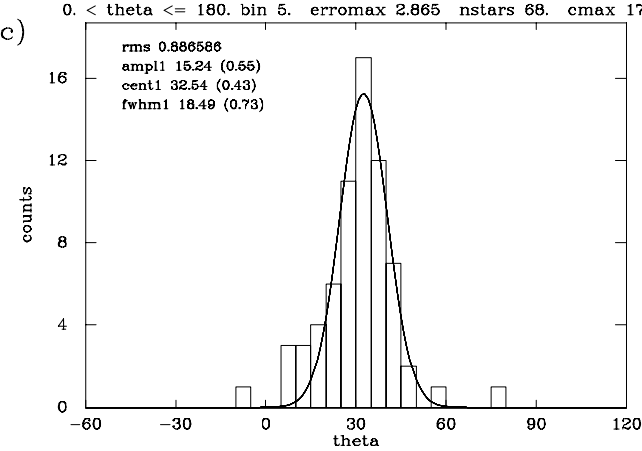

b)

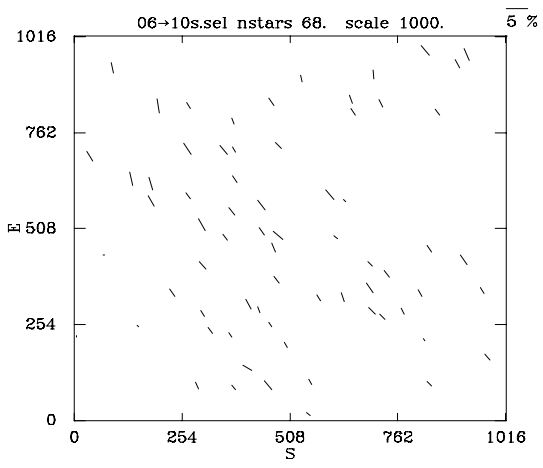

d)

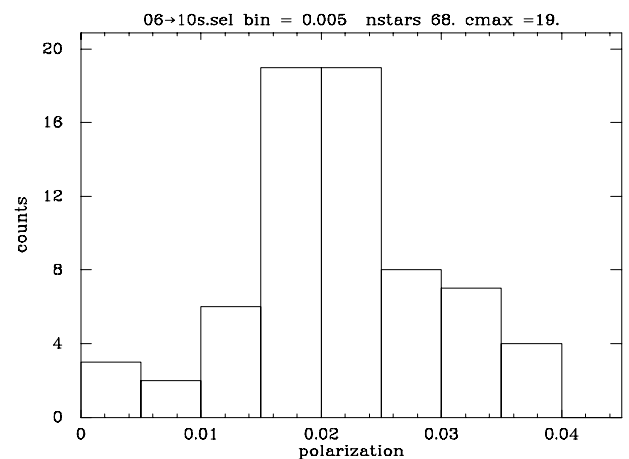

Figura F.8 Análise do Campo 08 
$08 \rightarrow 10$ s.sel $0 .<p<0.025 \mathrm{p} /$ sigma $(\mathrm{p})>10 . \quad \mathrm{cQ} 0 . \quad \mathrm{cU} 0 . \quad$ nstars 18

a)

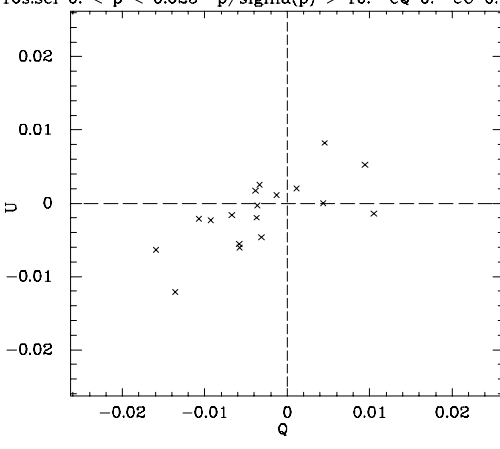

$0 .<$ theta $<=180$. bin 5. erromax 2.865 nstars 18. $\mathrm{cmax} 3$.

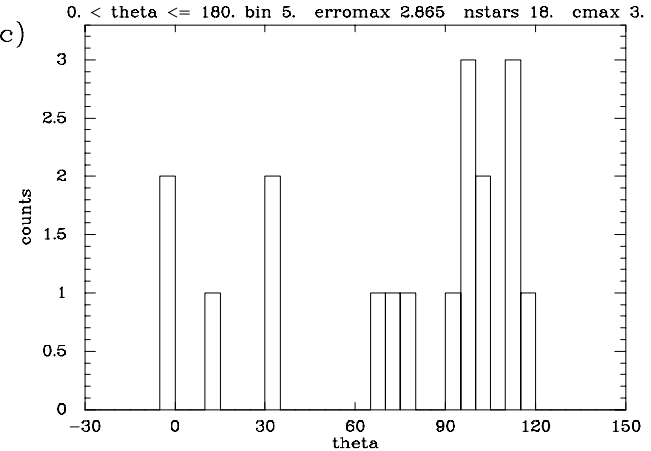

b)

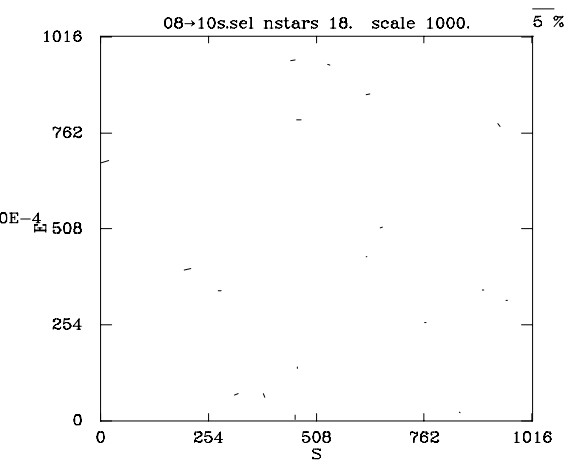

d)

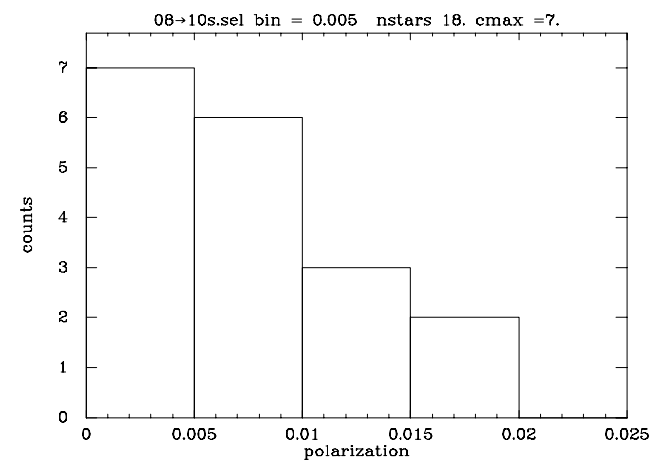

Figura F. 9 Análise do Campo 09

a)

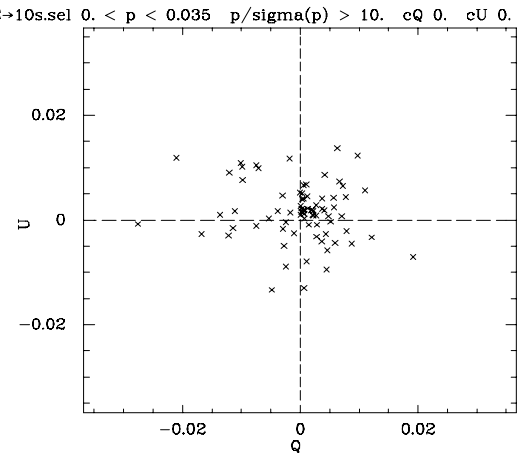

c)

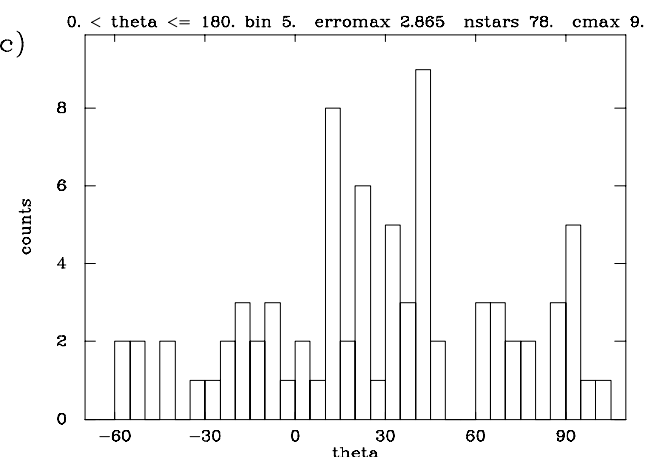

b)

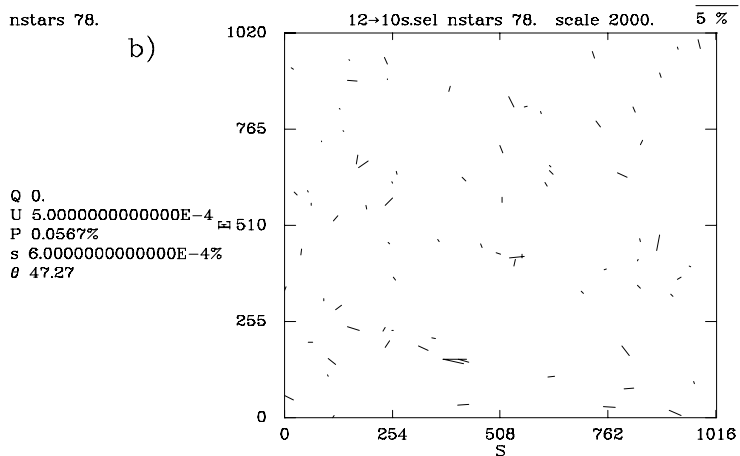

d)

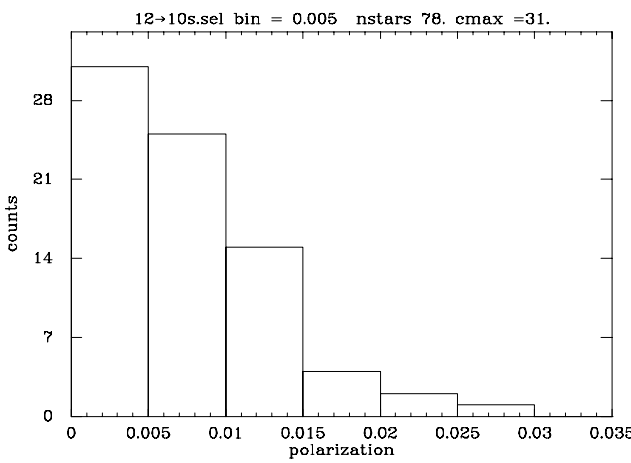

Figura F.10 Análise do Campo 10 
$15 \rightarrow 10$ s.sel $0 .<p<0.05 \mathrm{p} / \operatorname{sigma}(\mathrm{p})>10 . \quad \mathrm{cQ} 0 . \quad \mathrm{cU} 0$. nstars 55

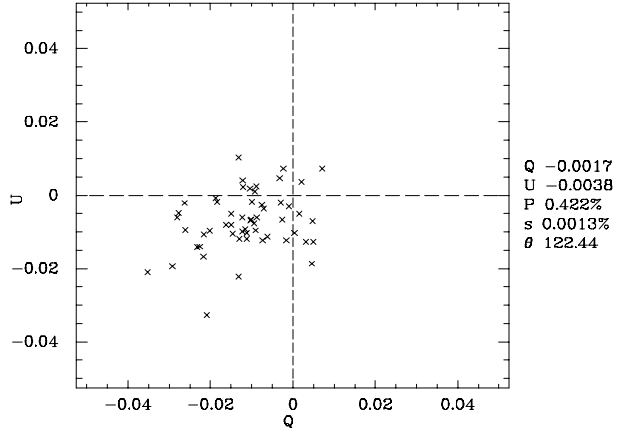

0. $<$ theta $<=180$. bin 5. erromax 2.865 nstars 55. $\operatorname{cmax} 13$.

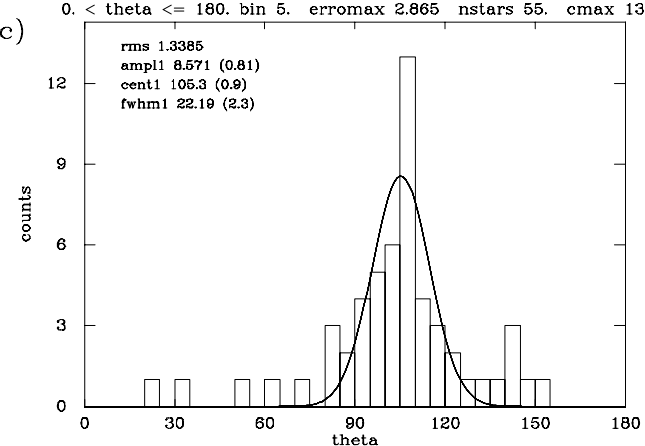

b)

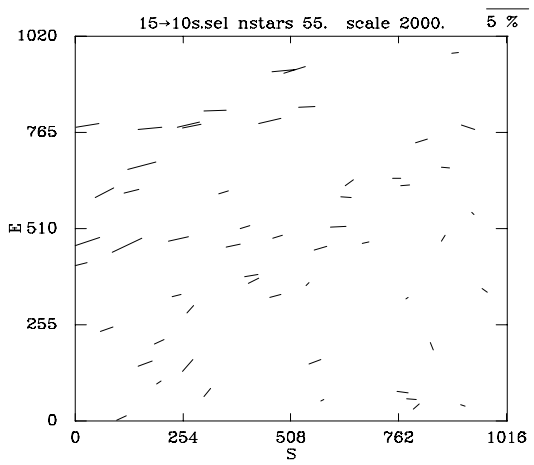

d)

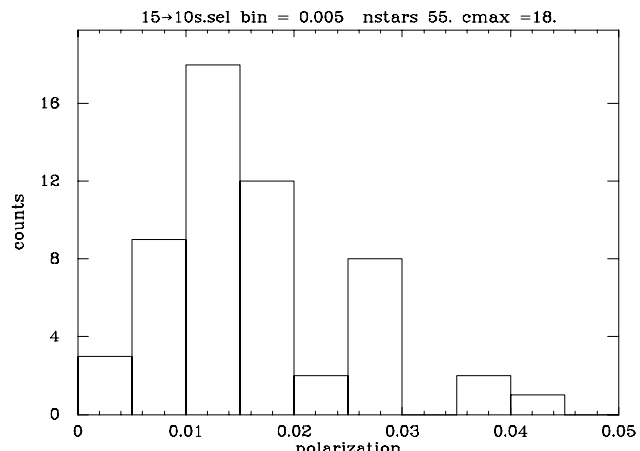

Figura F.11 Análise do Campo 11

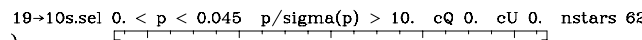

a)

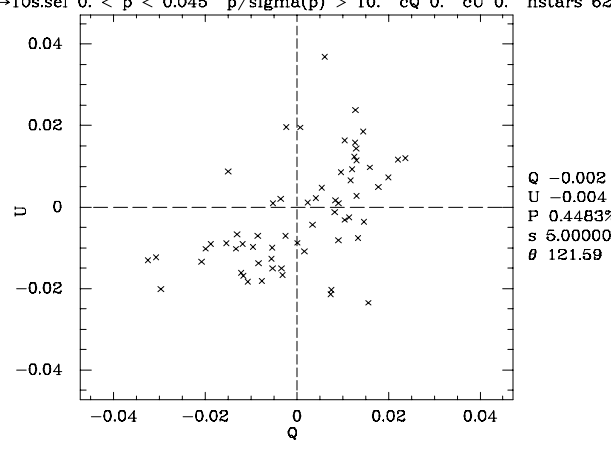

b)

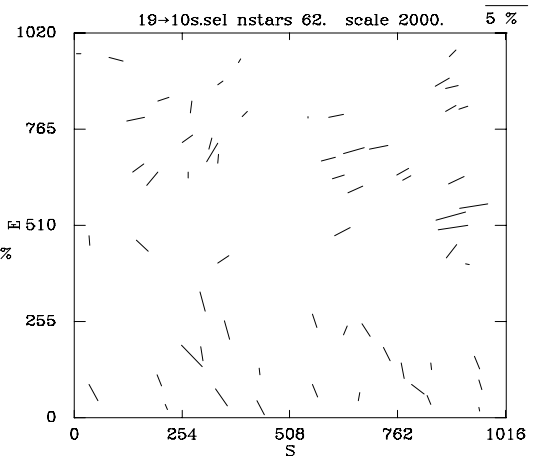

c)

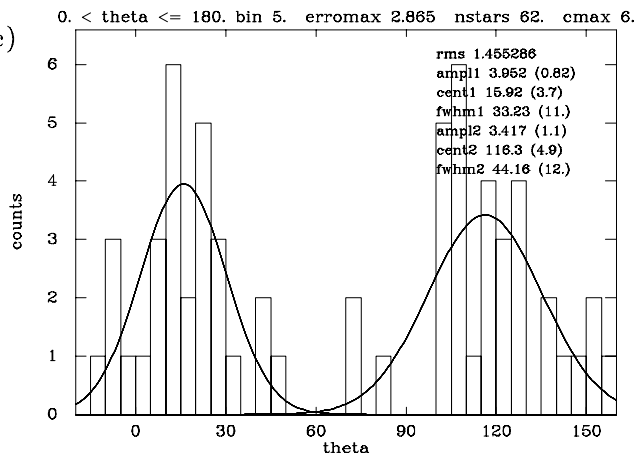

d)

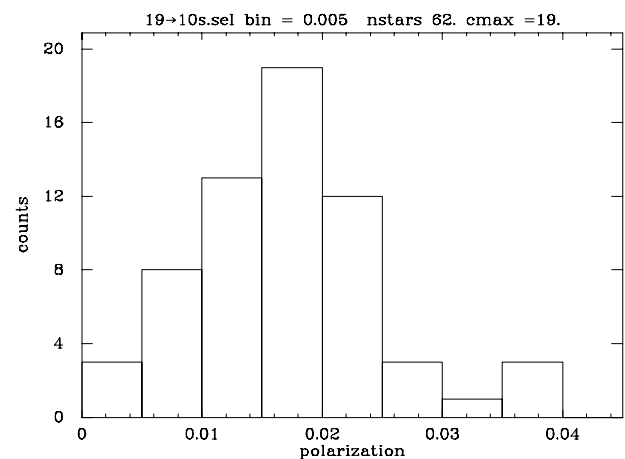

Figura F.12 Análise do Campo 12 
$20 \rightarrow 10$ s.sel $0 .<p<0.05 \quad \mathrm{p} /$ sigma(p) $>10 . \quad$ cQ $0 . \quad$ cU 0. nstars 50

a)

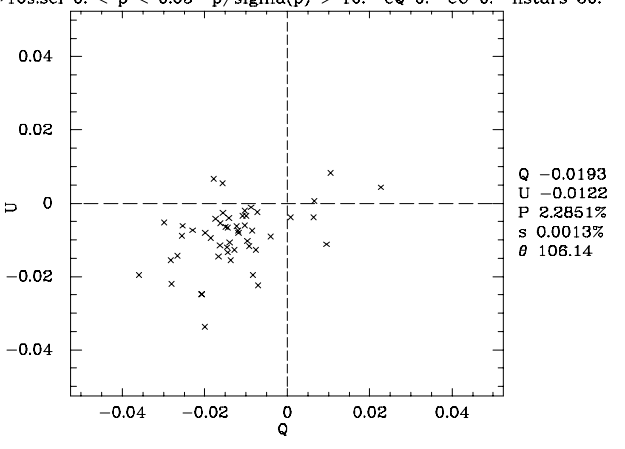

$0 .<$ theta $<=180$ bin 5 , erromax 2.865 nstars $50 . \quad$ max 10.

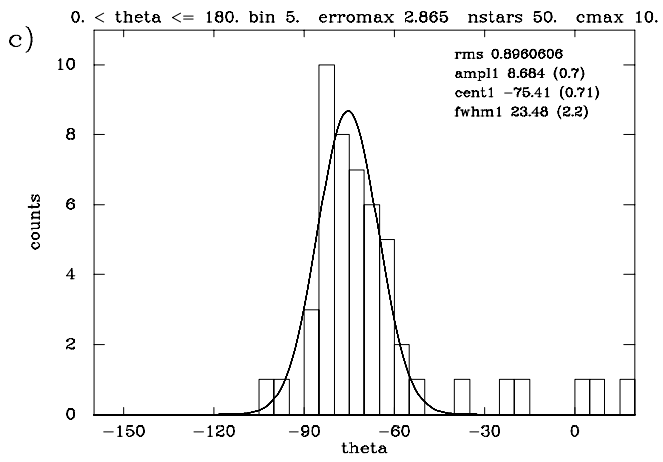

b)

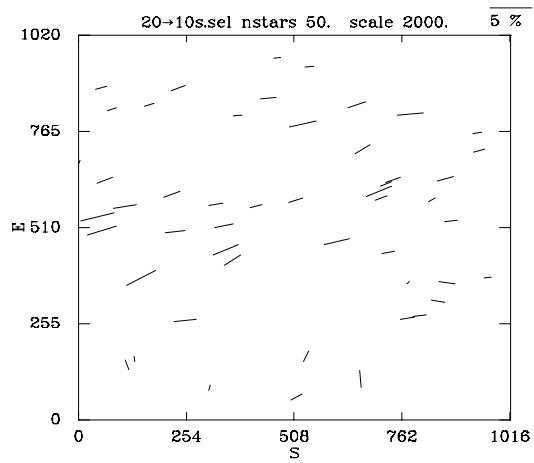

d)

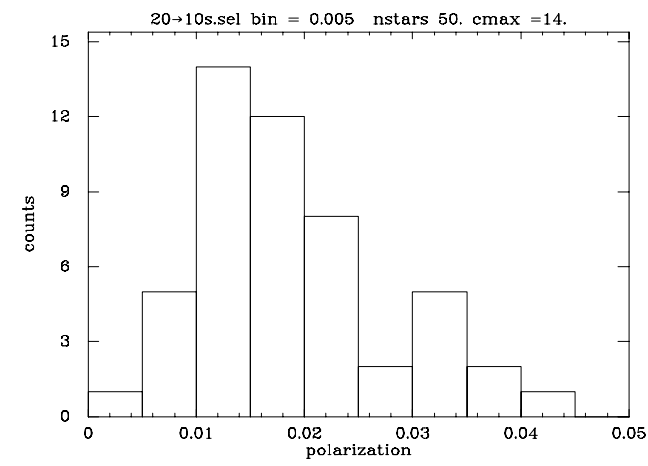

Figura F.13 Análise do Campo 13

a)

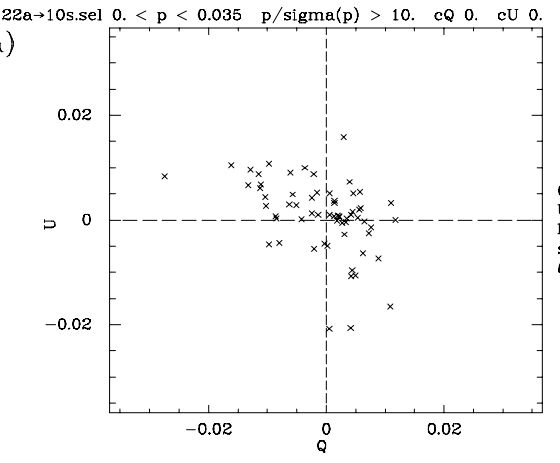

0. $<$ theta $<=180$. bin 5. erromax 2.865 nstars 63. cmax 6 .

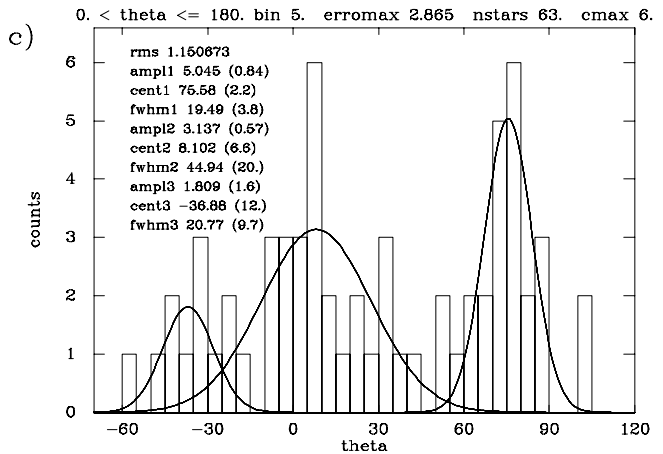

b)

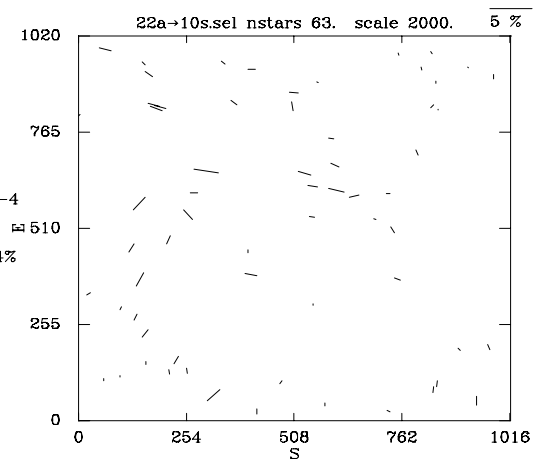

d)

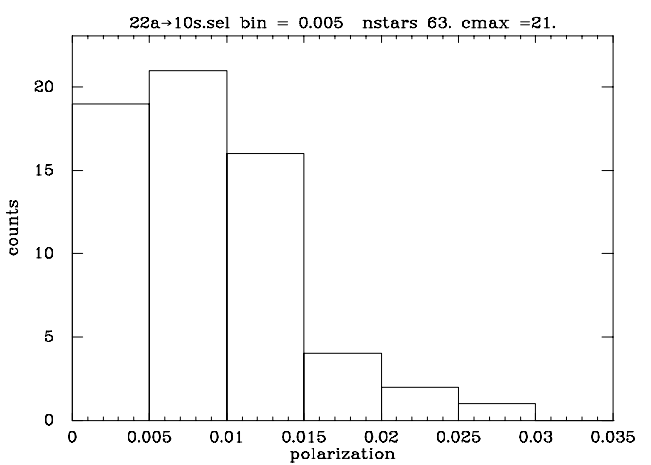

Figura F.14 Análise do Campo 14 
$29 \rightarrow 10$ s.sel $0 .<p<0.05 \mathrm{p} / \operatorname{sigma}(\mathrm{p})>10 . \quad \mathrm{cQ} 0 . \quad \mathrm{cU} 0$. nstars 12

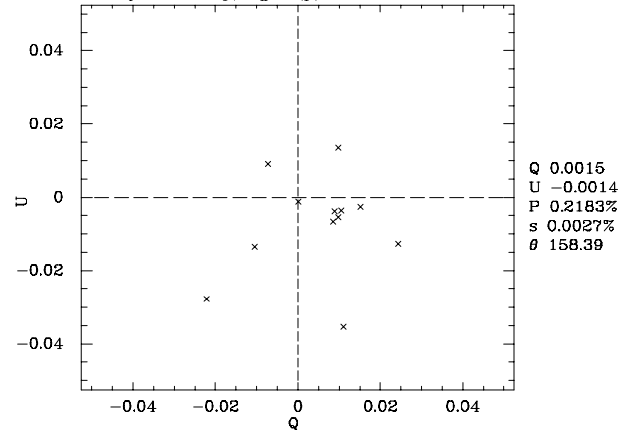

0. $<$ theta $<=180$. bin 5. erromax 2.865 nstars 12. cmax 3.

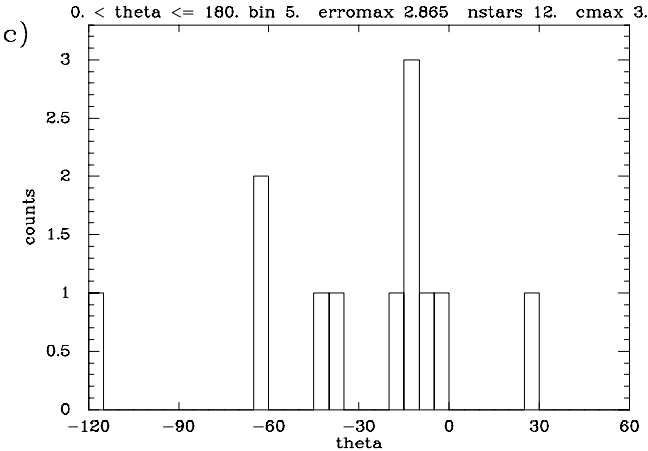

b)

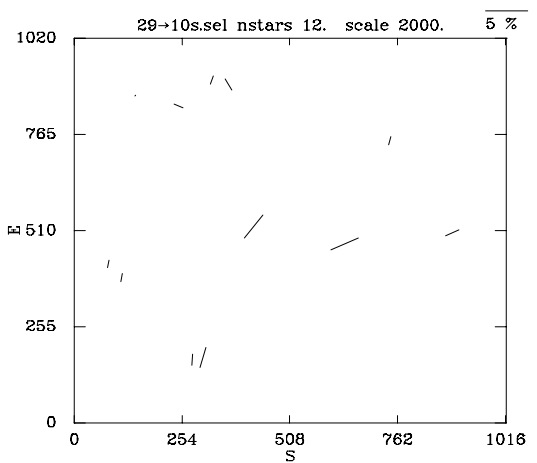

d)

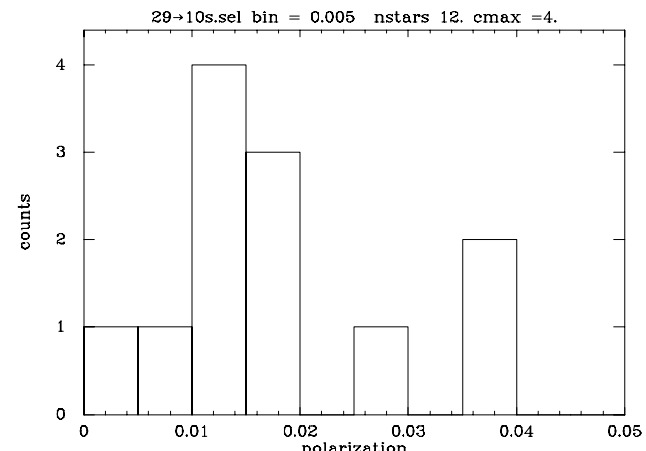

Figura F.15 Análise do Campo 15

a) $32 \mathrm{a} \rightarrow 10$ s.sel $0 .<\mathrm{p}<0.03 \mathrm{p} / \mathrm{sigma}(\mathrm{p})>10 . \quad \mathrm{cQ} 0 . \mathrm{cU} 0$. nstars 52

a)

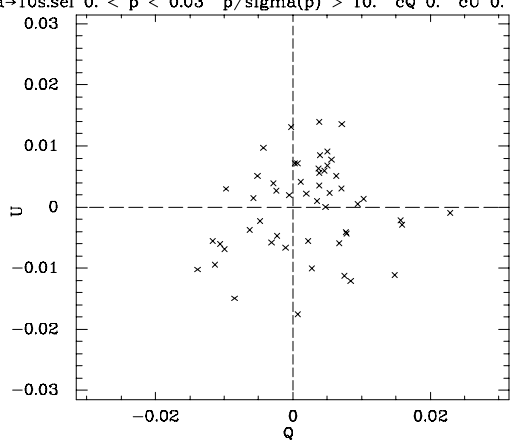

c)

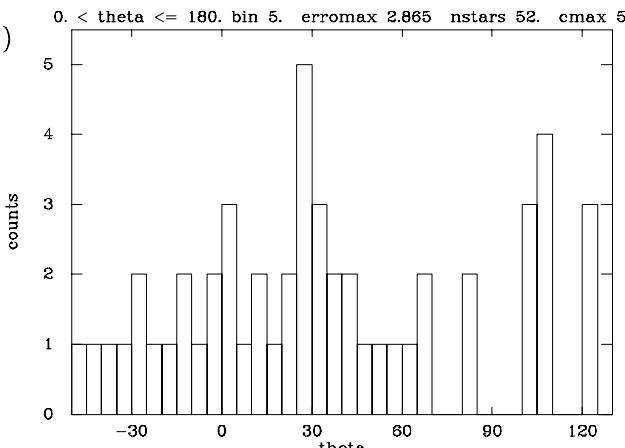

b)

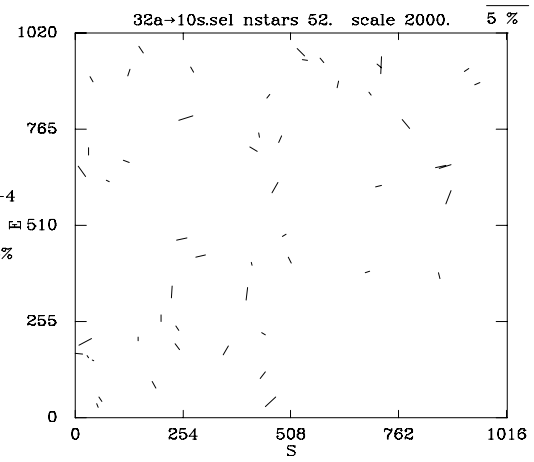

d)

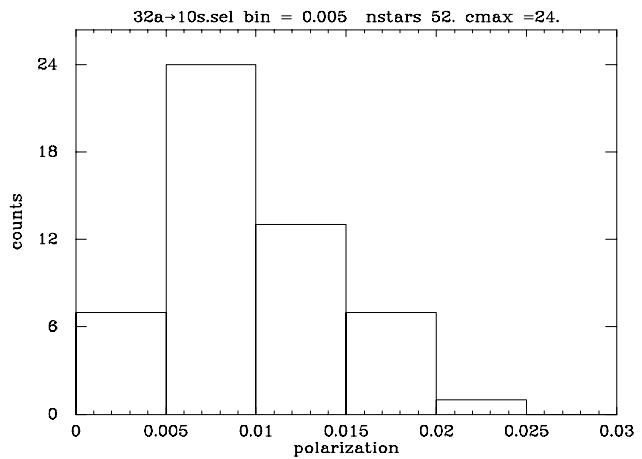

Figura F.16 Análise do Campo 16 



\section{Referências}

Abbot, D. C., Bieging, J. H., Churchwell, E., e Torres, A. V. 1986, ApJ, 303, 239

Aitken, D. K., Roche, P. F., Bailey, J. A., Briggs, G. P., Hough, J. H., e Thomas, J. A. 1986, MNRAS, 218, 363

Aitken, D. K., Roche, P. F., Smith, C. H., James, S. D., e Hough, J. H. 1988, MNRAS, 230, 629

Aitken, D. K., Smith, C. H., e Roche, P. F. 1989, MNRAS, 236, 919

Alcaino, G. 1974, A\&AS, 13, 345

Allen, C. W. 1964, Astrophysical Quantities, Athlone, London

Allen, C. W. 1973, Astrophysical Quantities, Athlone, London.

Arnal, E., Morras, R. e Rizzo, J. 1993, MNRAS 265, 1

Axon, D. J., e Ellis, R. S. 1976, MNRAS, 177, 499

Bless, R. C., Savage, B. D. 1972, ApJ, 171, 293

Bohlin, R. C., Savage, B. D., e Drake, J. F. 1978, ApJ, 224, 132

Brandt, J. C., Stetcher, T. P., Crawford, D. L., e Maran, S. P. 1971, ApJ, 163, L99

Capps, R. W., e Knacke, R. F. 1976, ApJ, 210, 76

Cardelli, J. A., e Savage, B. D. 1988, ApJ, 325, 864

Cardelli, J. A., Suntzeff, N. B., Edgar, R. J., e Savage, B. D. 1990, ApJ, 362, 551

Cardelli, J. A., e Clayton, G. C. 1991, ApJ, 101, 1021

Cambrésy, L. 1999, A\&A, 345, 965

Chandrasekhar, S. e Fermi, E. 1953, ApJ, 118, 113

Churchwell, E., Winnberg, A., Cardelli, J., Cooper, G., e Suntzeff, N. B. 1996, ApJ, 469, 209

Chrysostomou, A., Hough, J. H., Burton, M. G., e Tamura, M. 1994, MNRAS, 268, 325

Clayton, G. C., Anderson, C. M., Magalhães, A. M., Code, A. D., Nordsieck, K. H., Meade, M. R., Wolff, M. J., Babler, B., Bjorkman, K. S., Schulte-Ladbeck, R. E., Taylor, M., e Whitney, B. A. 1992, ApJ Lett., 385, L53

Codina-Landaberry, S. e Magalhães, A. M. 1976, A\&A, 49, 407

Davis, L. e Greenstein, J. L. 1951, ApJ, 114, 206

Dickman, R. L. 1978, AJ, 83, 363

Feitzinger, J.V. e Stüve, J. A. 1984, A\&AS, 58, 386

Franco, G. A. P. 1990, A\&A, 227, 499

Franco, G. A. P. 1991, A\&A, 251, 581 
Referencias

Gerakines, P. A., Whittet, D. C. B., e Lazarian, A. 1995, ApJ, 455, L171

Goodman, A. A., Jones, T. J., Lada, E. A., e Myers, P. C 1992, ApJ, 399, 108

Goodman, A. A., Jones, T. J., Lada, E. A., e Myers, P. C. 1995, ApJ, 448, 748

Goodman, A. A. 1996, em Polarimetry of the Interestellar Medium, ASP Conferences Series, 97, eds. W. G. Roberge e D. C. B. Whittet, p 325

Gonatas, D. P., Engargiola, G. A., Hildebrand, R. H., Platt, S. R., Wu, X. D., Davidson, J. A., Novak, G., Aitken, D. K., e Smith, C. 1990, ApJ, 357, 132

Gredel, R., van Dishoeck, E. F., e Black, J. H. 1993, A\&A, 269, 477

Gredel, R., van Dishoeck, E. F., e Black, J. H. 1994, A\&A, 285, 300

Greenberg, J. M. 1968, Nebulae and Interestellar Matter, eds. B. M. Middlehurst e L. H. Aller (University of Chicago Press) p 221

Gregorich, D., e Cardelli, J. A. 1992, comunicação privada

Gregorio-Hetem, J. C., Sanzovo, G. C., e Lepine, J. R. D. 1988, A\&AS, 76, 347

Hartley, M., Manchester, R. N., Smith, R. M., Tritton, S. B., e Goss, W. M. 1986, A\&AS, 63,27

Hawarden, T. G., e Brand, P. W. J. L. 1976, MNRAS, 175, 19P

Heyer, M. H., Vrba, F. J., Snell, R. L., Schloerb, F. P., Strom, S. E., Goldsmith, P. F., e Strom, K. M. 1987, ApJ, 321, 855

Heiles, C. 1987, Interestellar Processes, eds. D. J. Hollenbach e H. A. Thronson (Reidel, Dordrecht) p 171

Hiltner, W. A. 1949, ApJ, 109, 471

Hollenbach, D. e Salpeter, E. E. 1971, ApJ, 163, 155

Itoh, Y., Chrysostomou, A., Burton, M., Hough, J. H., e Tamura, M. 1999, MNRAS, 304, 406

Lasker, B. M., Sturch, C. R., McLean, B. J., Russell, J. L., Jenkner, H. e Shara, M.M. 1990, AJ, 99, 2019

Lillie, C. F., e Witt, A. N. 1976, ApJ, 208, 64

McCutcheon, W. H., Vrba, F. J., Dickman, R. L., Clemens, D. P. 1986, ApJ, 309, 619

McGregor, P. J., Harrison, T. E., \& Hough, J. H., e Bailey, J. A. 1994

Magalhães, A. M. 1979, Ph.D. Thesis, Universidade de São Paulo

Magalhães, A. M., Benedetti, E. e Roland, E. H. 1984, PASP, 96, 383

Magalhães, A. M., Rodriguez, C.V., Margoniner, V.E. e Pereyra, A. 1996, ASP Conf. Ser. 97 (W.G. Roberge and D.C.B. Whittet eds.), p 118 
Martin, P. G., Adamson, A. J., Whittet, D. C. B., Hough, J. H., Bayley, J. A., Kim, S. H., Tamura, M. e Yamasjita, Y. 1992, ApJ, 392, 691

Mathewson, D. S., e Ford, V. L. 1970, Mem. R. Astron. Soc., 74, 139

Mathis, J. S., Rumpl, W., e Nordseik, K. H. 1977, ApJ, 217, 425

Mathis, J. S. 1979, ApJ, 232, 747

Mathis, J. S. 1986, ApJ, 308, 281

Mizuno, A., Hayakawa, T., Yamaguchi, N., Kato, S., Hara, A., Mizuno, N., Yonekura, Y., Onishi, T., Kawamura, A., Tachihara, K., Obayashi, A., Xiao, K., Ogawa, H., e Fukui, Y. 1998, ApJ, 507, L83

Morris, J. A., Davidson, J. A., Werner, M., Dotson, J., Figer, D. F., Hildebrand, R., Novak, G., e Platt. S., 1992, ApJ, 399, L63

Mouschovias, T. Ch. 1978, em Protostars and Planets, ed. T. Gehrels (Tucson: Univ. Arizona Press), p 209

Nagata, T. 1990, ApJ Lett., 348, L13

Nozawa, S., Mizuno, A., Teshima, Y., Ogawa, H., e Fukui, Y. 1991, ApJS, 77, 647

O’Donnell, J. E., Cardelli, J. A., e Churchwell, E. 1992, AJ, 104, 2161

Olson, G. L., e Castor, J. I. 1981, ApJ, 244, 79

Purcell, E. M. 1975, The Dusty Universe, eds. G. B. Field e A. G. W. Cameron (Neale Watson Academic Publications, New York) p 155

Purcell, E. M. 1979, ApJ, 231, 404

Reipurth, B. 1983, A\&A, 117, 183

Reynolds, R. 1976a, ApJ, 203, 151

Reynolds, R. 1976b, ApJ, 206, 679

Rizzo, J. R., Morras, R., e Arnal, E. M. 1998, MNRAS, 300, 497

Sahu, M. S. 1992, Ph.D. thesis, Rijksuniversiteit Gröningen

Sandqvist, Aa. 1976, MNRAS, 177, 69P

Serkowsky, K. 1973, IAU Symp. No. 52, Interestellar Dust and Related Topics, eds. J. M. Greenberg e H. C. van de Hulst (Reidel, Dordrecht) p 145

Serkowsky, K. 1974a, em Gehrels T., ed., Planets, Stars and Nebulae studied with photopolarimetry, The University of Arizona Press, Tucson, p 146

Serkowsky, K. 1974b, em Carleton N., ed., Methods of Experimental Physics, 12, Part A. Academic Press, New York, p. 361

Serkowsky, K., Mathewson, D. S., e Ford, V. L. 1975, ApJ, 196, 261

Shu, F. C., Adams F. C., e Lizano, S. 1987, ARA\&A, 25, 23 
Referencias

Spitzer, L. 1978, Physical Processes in the Interestellar Medium (Jhon Wiley \& Sons, New York)

Strom, S. E., Strom, K. M., e Edwards, S. 1988, em Galactic and Extragalactic Star Formation, ed. R. E. Pudritz e M. Fich (Dordrecht: Kluwer), p 53

Tamura, M., Nagata, T., Sato, S., e Tanaka, M. 1987, MNRAS, 224, 413

Tamura, M., Yamashita, T., Sato, S., Nagata, T., e Gatley, I. 1988, MNRAS, 231, 445

Toller, G. N. 1981, Thesis (State University of New York at Stony Brook)

Upton, E. K. L. 1971, The Gum Nebula and Related Problems, eds. S. P. Maran, J. C. Brandt e T. P. Stecher

van der Hucht, K. A., Cassinelli, J. P., e Williams, P. M. 1986, A\&A, 168, 111

van der Hucht, K. A., Schrijver, H., Stenholm, B., Lundström, I., Moffat, A. F. J., Marchenko, S. V., Seggewiss W., Setia Gunawan, D. Y. A., Sutantyo, W., van den Heuvel, E. P. J., De Cuyper, J. P., e Gómez, A. E. 1997, New Astronomy, vol. 2, no. 3 , p 245

van Dishoeck, E. F., Black, J. H., Philllips, T. G., e Gredel, R. 1991, ApJ, 366, 141

van Rhijn, P. J., 1929, Publ. Astron. Lab. Groningen, No. 43

Vilas-Boas, J. W. S., Myers, P. C., e Fuller, G. A. 1994, ApJ, 433, 96

Vrba, F. J., Strom, S. E., e Strom, K. M. 1976, AJ, 81, 958

Vrba, F. J., Coyne, G. V., e Tapia, S. 1981, ApJ, 243, 489

Vrba, F. J., Strom, S. E., e Strom, K. M. 1988, AJ, 96,680

Weaver, R., McCray, C. T., Castor, J., Shapiro, P., Moore, R. 1977, ApJ, 218, 377

Whittet, D. C. B., e Blades, J. C. 1980, MNRAS, 191, 309

Whittet, D. C. B., Duley, W. W., e Martin, P. G. 1990, MNRAS, 244, 427

Whittet, D. C. B., Martin, P. G., Hough, J. H., Rouse, M. F., Bailey, J. A., e Axon, D. J. 1992a, ApJ, 386, 562

Whittet, D. C. B. 1992b, Dust in the Galactic Environment, eds. R. J. Tayler e R. E. White (Institute of Physics Publishing Ltd.)

Whittet, D. C. B., Gerakines, P. A.., Carkner, A. L., Hough, J. H., Martin, P. G., Prusti, T., e Kilkenny, D. 1994, MNRAS 268, 1

Wilking, B. A., Lebofsky, M. J., Rieke, G. H., e Kemp, J. C. 1979, AJ, 84, 199

Wilking, B. A., Lebofsky, M. J., Martin, P. G., Rieke, G. H. e Kemp J. C., 1980, ApJ, 235, 905

Wilking, B. A., Lebofsky, M. J. e Rieke, G. H. 1982, AJ, 87, 695

Zombeck, M. V. 1980, High Energy Astrophysics Habdbook, SAO special report 386

Zealey, W. J., Ninkov, Z., Rice, E., Hartley, M., e Tritton, S. B. 1983, ApL, 23, 119 
Zuckerman, B., e Palmer, P. 1974, ARA\&A, 12, 279

Zweibel, E. G., 1990, ApJ, 362, 545 